\title{
ENGINE SYSTEM ASSESSMENT STUDY USING MARTIAN PROPELLANTS
}

FINAL REPORT

June 1992

NASA CR 189188

Contract No. NAS3-25809

SAIC Report. No. 0265-079

\author{
Prepared by: \\ Dennis Pelaccio \\ Mark Jacobs \\ Christine Scheil \\ John Collins \\ Science Applications International Corporation \\ 21151 Western Avenue \\ Torrance, CA 90501
}

\author{
Prepared for: \\ NASA Lewis Research Center \\ Space Propulsion Technology Division \\ 21000 Brookpark Road \\ Cleveland, OH 44135
}





\section{FOREWORD}

This report was prepared by Science Applications International Corporation (SAIC) in Torrance, California, and contains the results of a study performed for the National Aeronautics and Space Administration (NASA) Lewis Research Center, Space Propulsion Technology Division, as part of contract NAS3-25809, "Manned Lunar and Mars Mission Propulsion System Assessment Studies." 


\section{ACKNOWLEDGEMENTS}

The Engine System Assessment Study Using Martian Propellants was performed under the direction of Mr. Michael Meyer of NASA Lewis Research Center. Science Applications International Corporation (SAIC) personnel responsible for major contributions to the study included:

Mr. Dennis Pelaccio - Study Manager, Propulsion Technologies and Assessment, Requirements, Systems Design and Development Planning

Mr. Mark Jacobs - Mission Analysis Technical Leader, Mission Analysis, Planning and Requirements

Ms. Christine Scheil - Propulsion System Analysis and Design

Mr. John Collins - Mission Analysis, Planning and Requirements

Other contributors who provided guidance to the study also included Ms. Diane Linne of NASA Lewis Research Center and Mr. Michael Stancati of SAIC. Dr. Robert Mog of SAIC also provided technical assistance associated with the tank meteoroid protection system analysis. 


\section{CONTENTS}

Section

Page

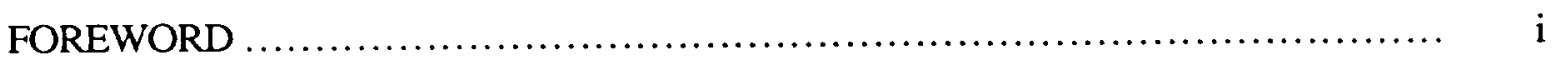

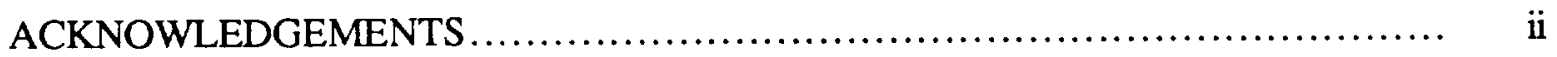

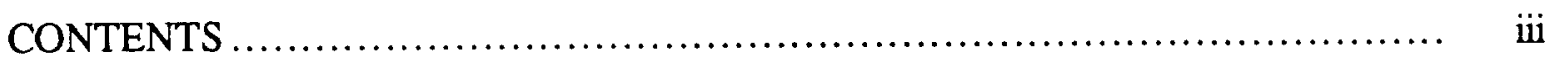

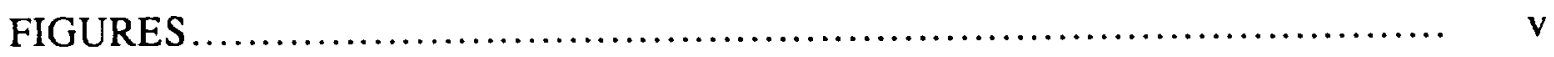

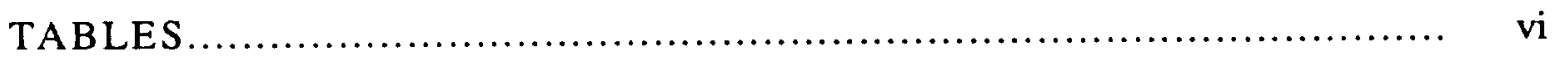

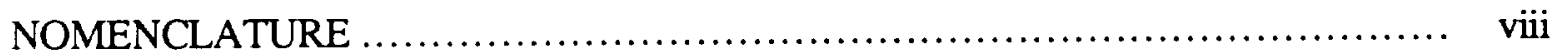

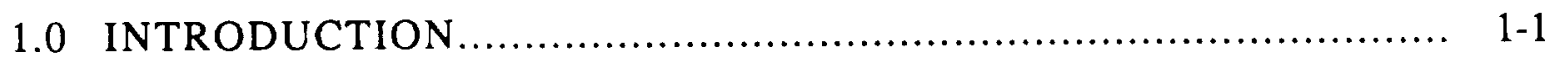

2.0 INITIAL ENGINE SYSTEM REQUIREMENTS $\ldots \ldots \ldots \ldots \ldots \ldots \ldots \ldots \ldots \ldots \ldots . \ldots \ldots$

2.1 In Situ Propellant Candidates and Production Requirements............... 2-1

2.2 Mission Description .................................................... $2-2$

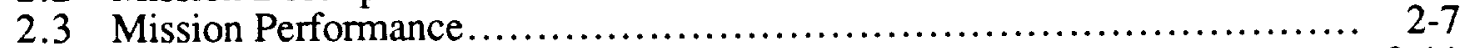

2.4 Engine System Requirements .................................... 2-11

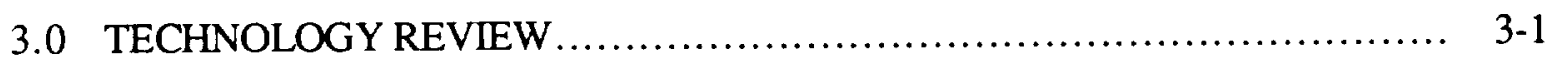

3.1 Tripropellant Engine Systems ..................................... $3-1$

3.2 Heat Transfer/Cooling................................................ $3-2$

3.3 Injection/Ignition/Combustion..................................... $3-4$

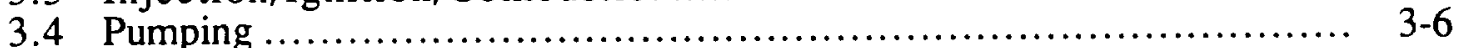

3.5 Materials Compatibility ............................................ 3-6

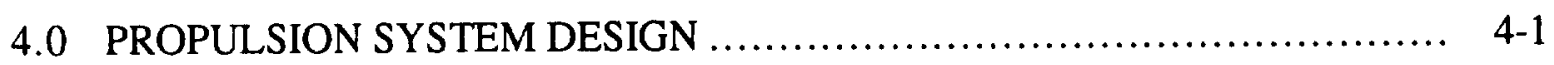

4.1 Engine System Requirements Concepts.................................. 4-2

4.1.1 Identification of Requirements ............................. 4-3

4.1.2 Engine System Cycle Considerations/Recommendations............. 4-4

4.2 Engine System Assessment.......................................... 4-13

4.2.1 Assessment Approach and Assumptions............................ 4-13

4.2.2 Design Sensitivity Trades....................................... 4-21

4.2.3 Baseline Engine Systems ...................................... 4-23

4.2.4 Other Engine Design Comparisons ............................ 4-27

4.3 Propellant Tank Design Assessment.................................... 4-29

4.3.1 Design Requirements/Considerations ........................... 4-29

4.3.2 Analysis Approach and Results ............................... 4-39 


\section{CONTENTS (Cont.)}

Section

Page

5.0 MISSION PERFORMANCE AND COMPARISON ......................... $5-1$

5.1 Expander vs. Gas Generator Cycle Engine Assessment .................... 5-3

5.2 Engine Design and Tank Reuse Trades .............................. 5-8

5.2 .1 Engine Mass ............................................... $5-10$

5.2.2 Engine Performance ...................................................... 5-10

5.2.3 Nozzle Area Ratio....................................................... 5-12

5.2.4 Tank Reuse Strategies............................................ 5-13

5.3 Mission Performance Conclusions and Recommendations..................... 5 5-15

6.0 TECHNOLOGY MATURATION PLAN ................................... $6-1$

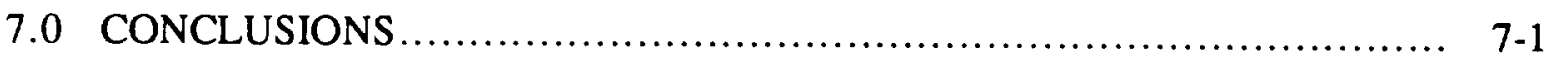

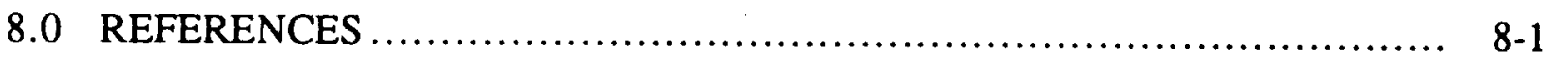




\section{FIGURES}

Figure $\quad$ Page

2-1 Infrastructure Elements ............................................ $2-3$

2-2 Mission Profiles ...........................................................

2-3 Mission Description for Scenarios Using Lunar and Mars ISPP

(Mission Profile \#1) ................................................. 2-5

2-4 Mission Description for Scenarios Using Mars ISPP (Mission Profile \#2)..... 2-6

2-5 Mission Performance Prediction Methodology ........................... 2-8

2-6 Summary of Initial Engine Masses...................................... 2-12

3-1 Typical Tri-Propellant Engine System Operation.......................... 3-3

4-1 Representative Tripropellant Engine System Common Hardware Elements ..... 4-2

4-2 Generic Engine Cycles Studied ...................................... 4-12

4-3 Definition of an Engine Family for Each Engine Concept.................... 4-14

4-4 Baseline Thrust Chamber Nozzle Design Features Assumed .................. 4-16

4-5 Throttling Engine Weight Correlation Assumed............................ 4-18

4-6 Overall Engine System Trade Space Evaluation Process ..................... 4-20

4-7 Engine Thrust-to-Weight as a Function of Thrust......................... 4-26

4-8 Tankage Requirements Are Based on a 435-Day Mars Reference Mission ...... 4-34

4-9 Growth Version of the Advanced Launch System ............................ 4-37

4-10 Inflatable Tanks May Be Attractive to Store In Situ Propellants................ 4-39

4-11 The Tank Meteoroid Shield Penetration Concept Evaluated...................... 4-40

4-12 Typical Tank Meteoroid Protection System Characteristics as a Function of

Probability for No Tank Penetration (PRF) ............................ 4-42

4-13 Typical Tank Meteoroid Protection System Characteristics as a Function of Mission Exposure ...................................................... 4-43

4-14 Common Tank Sizing Analysis Approach ................................ 4-44

5-1 ISPP Plant Mass Comparison ......................................... $5-4$

5-2 MEV Mass Comparison ............................................. $5-4$

5-3 LEV Mass Comparison.................................................. $5-5$

5-4 MTV Mass Comparison ................................................ 5

5-5 Steady-State Earth Launch Mass per Mission Comparison: Engine Cycle Assessment............................................................. 5-7

5-6 Mars Plant Mass Comparison.......................................... 5-9

5-7 MEV and MTV Mass Comparison .................................... 5-9

5-8 Steady-State Earth Launch Mass per Mission Comparison: Engine Design and Tankage Assessment............................................... 5-11

5-9 Results of Engine Mass Trade Study .................................... 5-12

5-10 Results of Engine Isp Trade Study ....................................... 5-12

5-11 Results of Engine Nozzle Area Ratio Trade Study .......................... 5-13

5-12 Alternative Tank Reuse/Staging Strategies ................................ 5-14

5-13 Results of Tank Reuse/Staging Strategy Analyses ........................ 5-15

6-1 Development of a Mars In Situ Propellant-Based Propulsion System.......... 6-1

6-2 $\begin{aligned} & \text { Overall Process to Support Development of an In Situ Mars Propellant- } \\ & \text { Based Propulsion System ........................................................... 6 }\end{aligned}$

6-3 Overall Technology Development Plan Schedule and Required Funding ........ 6-12 


\section{TABLES}

Table

Page

2-1 Initial Mission Performance Assessment Scenarios.......................... 2-3

2-2 Initial Engine Parameters .............................................. 2-9

2-3 Mission Performance/Vehicle Design Assumptions............................. 2-10

2-4 Overall Engine System Requirements Summary: Scenario 1...................... 2-13

2-5 Overall Engine System Requirements Summary: Scenario 2...................... 2-14

2-6 Overall Engine System Requirements Summary: Scenario 3..................... 2-15

2-7 Overall Engine System Requirements Summary: Scenario 4...................... 2-16

2-8 Overall Engine System Requirements Summary: Scenario 5...................... 2-17

2-9 Overall Engine System Requirements Summary: Scenario 6..................... 2-18

2-10 Overall Engine System Requirements Summary: Scenario 7...................... 2-19

3-1 Example Propellant/Material Compatibility Data - Turbopump...................... 3-7

3-2 Example Propellant/Material Compatibility Data - General Summary ........... 3-9

4-1 Top-Level Requirements for Engine System Candidates....................... 4-4

4-2 Engine System Assessment Trade Space Summary................................. 4-5

4-3 Number of Engines and Power Rating Summary ............................ 4-6

4-4 Candidate Engine Cycles .................................................... 4-7

4-5 Key Engine Cycle Assessment Factors for In Situ Propellant-Based Mars Missions and Their Impact on Engine Cycle Design............................. 4-7

4-6 Candidate Engine Cycle Top-Level Comparison ............................ 4-8

4-7 Engine Cycles Which Demonstrate Many Key Engine Features of Interest...... 4-11

4-8 Baseline Engine Systems Defined............................................ 4-13

4-9 Major Engine System Design Parameters Examined............................ 4-15

4-10 Key Screening Criteria Used......................................................... 4-15

4-11 Engine System Design Technology Level Considerations ...................... 4-16

4-12 Other Key Design Analysis Factors/Assumptions..................................... 4-17

4-13 Safety Factors Assumed ...................................................... 4-19

4-14 Major Engine Component Materials and Design Approaches Assumed ........... 4-19

4-15 In Situ Propellant Expander Cycle Engines ................................... 4-22

4-16 In Situ Propellant Gas Generator Cycle Engines ............................. 4-22

4-17 Baseline Engine Summary - Expander Cycle Engines ........................ 4-24

4-18 Baseline Engine Summary - Gas Generator Cycle Engines ................... 4-25

4-19 Translating Nozzle Effects in Terms of Packaging and Weight.................... 4-28

4-20 Turbine Blade Strength Influence on Chamber Pressure ........................ 4-28

4-21 $\mathrm{LO}_{2} / \mathrm{CH}_{4} / \mathrm{CO}$ Gas Generator Engine Common Fuel Turbopump Design

4-22 Key Space Debris Tank Design Considerations by Mission Segment ............ 4-33

4-23 General Tankage System Features/Requirements ............................. 4-35

4-24 Initial Tank System Sizing Results.......................................... 4-36

4-25 MTV Tank Configuration Strategy Options Summary............................. 4-38

4-26 Impact Shielding Materials/Options Considerations................................. 4-41

4-27 General Tank Design Features Assumed ................................... 4-44 


\section{TABLES (Cont.)}

Table $\quad$ Page

4-28 Tank Design Systems Evaluated by Mission Segment............................. 4-45

4-29 Tank Design Comparison Rationale............................................. 4-45

4-30 Tank Design Comparison Results Summary....................................... 4-47

4-31 Summary of Total Tankage System Mass Fractions ........................ 4-50

4-32 Summary of Potential Tankage System Weight Savings by Employing Common Propellant Tanks for MTV Earth-Mars-Earth Mission Segments...... 4-50

5-1 Mission Performance Assessment Scenarios ............................ 5-2

5-2 Propellant Tank Mass Allocations ......................................... 5-3

5-3 Summary of Final Mission Performance Data ............................. 5-16

6-1 Engine System Characteristics to Meet Space Basing Requirements............... 6-2

6-2 Technology Readiness Levels ......................................... 6-3

6-3 Technology Readiness of Fundamental Research Issues Associated With In Situ Mars Propellant-Based Engines.................................... 6-4

6-4 Propulsion System Subsystem/Component Evaluation............................ 6-4

6-5 Key Research and Development Issues.......................................... 6-5

6-6 Major Assumptions in Defining Technology Development Plan ............... 6-7

6-7 Key Areas to Be Addressed by the Technology Development Plan............. 6-7

6-8 Summary of Goal(s) and Activities by Development Phase........................ 6-9

6-9 Summary of Technology Development Plan Program......................... 6-10 


\section{NOMENCLATURE}

\begin{tabular}{|c|c|}
\hline$\%$ & Percent \\
\hline$\% \mathrm{Noz}$ & Nozzle Percent Length \\
\hline $\mathrm{Al}$ & Aluminum \\
\hline AR & Nozzle Area Ratio \\
\hline $\mathrm{CH}_{4}$ & Methane \\
\hline $\mathrm{cm}$ & centimeter \\
\hline $\mathrm{cm}^{3}$ & cubic centimeter \\
\hline Co & Isentropic Spouting Velocity \\
\hline $\mathrm{CO}$ & Carbon Monoxide \\
\hline $\mathrm{CO}_{2}$ & Carbon Dioxide \\
\hline const & constant \\
\hline E or $\varepsilon$ & Nozzle Area Ratio \\
\hline ELES & Expanded Liquid Engine Simulation \\
\hline ELM & Earth Launch Mass \\
\hline EOI & Earth Orbit Insertion \\
\hline ETO & Earth To Orbit \\
\hline $\mathrm{F}$ & Degree Fahrenheit or Thrust \\
\hline$F_{1}$ & Fuel No. 1 \\
\hline $\mathrm{F}_{2}$ & Fuel No. 2 \\
\hline $\mathrm{g}$ & gram or gravitational acceleration \\
\hline GG & Gas Generator \\
\hline $\mathrm{H}_{2}$ & Hydrogen \\
\hline hab & habitat \\
\hline $\mathrm{HC}$ & Head Coefficient \\
\hline in & inches \\
\hline Inj Dens & Injector Density \\
\hline Inj Type & Injector Type \\
\hline Isp & Specific Impulse \\
\hline ISPP & In Situ Propellant Production \\
\hline $\mathrm{K}$ & Degree Kelvin \\
\hline $\mathrm{kg}$ & kilogram \\
\hline lbf & pound force \\
\hline $\mathrm{lbm}$ & pound mass \\
\hline LEO & Low Earth Orbit \\
\hline
\end{tabular}




$\begin{array}{ll}\text { LeRC } & \text { Lewis Research Center } \\ \text { LEV } & \text { Lunar Excursion Vehicle } \\ \mathrm{LH}_{2} & \text { Liquid Hydrogen } \\ \text { Li } & \text { Lithium } \\ \text { LO } & \text { Low Lunar Orbit } \\ \text { LMO } & \text { Low Mars Orbit } \\ \text { LOI } & \text { Lunar Orbit Insertion } \\ \text { LOX or LO } & \text { Liquid Oxygen } \\ \text { m } & \text { meter } \\ \text { m } 2 & \text { square meter } \\ \text { mm } & \text { millimeter } \\ \text { MEV } & \text { Mars Excursion Vehicle } \\ \text { MLI } & \text { Multilayer Insulation } \\ \text { MOI } & \text { Mars Orbit Insertion } \\ \text { MR } & \text { Mixture Ratio } \\ \text { MSFC } & \text { Marshall Space Flight Center } \\ \text { msn } & \text { mission } \\ \text { MTV } & \text { Mars Transfer Vehicle } \\ \text { N } & \text { Newton } \\ \text { NASA } & \text { National Aeronautics and Space Administration } \\ \text { NASP } & \text { National AeroSpace Plane } \\ \text { OTV } & \text { Orbit Transfer Vehicle } \\ \text { Pc } & \text { Chamber Pressure } \\ \mathrm{P}_{\text {RF }} & \text { Probability of No Penetration } \\ \text { PSDOC } & \text { Protective Structures Design Optimization Code } \\ \text { psi } & \text { pounds force per square inch } \\ \text { psia } & \text { pounds force per square inch absolute } \\ \text { R } & \text { Degree Rankine } \\ \text { regen } & \text { regenerative } \\ \text { RPM } & \text { Revolutions Per Minute } \\ \mathrm{s} & \text { second } \\ \text { SAIC } & \text { Science Applications International Corporation } \\ \text { Si } & \text { Silicon } \\ \text { SOA } & \text { State-of-the-Art } \\ \text { SS } & \text { Steady-State or Pump Specific Speed } \\ \text { SSME } & \text { Space Shuttle Main Engine } \\ \text { SSTO } & \text { Single Stage to Orbit } \\ & \end{array}$




$\begin{array}{ll}\text { STBE } & \text { Space Transportation Booster Engine } \\ \text { STME } & \text { Space Transportation Main Engine } \\ \mathbf{t} & \text { metric tonnes } \\ \text { Tc } & \text { Chamber Temperature } \\ \text { TEI } & \text { Trans-Earth Injection } \\ \text { TLI } & \text { Trans-Lunar Injection } \\ \text { TMI } & \text { Trans-Mars Injection } \\ \text { TPA } & \text { Turbopump Assembly } \\ \Delta V & \text { Change in Velocity } \\ \text { vac. } & \text { vacuum } \\ \text { Wgt } & \text { Weight }\end{array}$




\subsection{INTRODUCTION}

Recent studies have shown that there can be substantial advantages in using in situ propellants for fast transfers to, and explorations of, Mars when compared to chemical systems that use Earth-based propellants, see Refs. 1-1 through 1-4. Using vehicles that have propulsion systems that use Martian resources has the potential to greatly reduce Low-Earth-Orbit (LEO) mass requirements as well as potentially increase mobility on the surface of Mars. A single propulsion system that can use two or more candidate propellant combinations, such as $\mathrm{LOX} / \mathrm{LH}_{2}, \mathrm{LOX} / \mathrm{CH}_{4}$ and LOX/CO, could best leverage this exploration option. Design of such a propulsion system is challenging due to its requirements that it be inherently compatible with numerous candidate propellants and their by-products, as well as operate efficiently over a large range of conditions.

The objective of this top-level feasibility study was to identify and characterize promising chemical propulsion system designs that use two or more of the following propellant combinations: $\mathrm{LOX} / \mathrm{LH}_{2}, \mathrm{LOX} / \mathrm{CH}_{4}$ and LOX/CO. Key results from this study were: 1) identifying the propellant combinations that are best suited for a single multipropellant engine system design, 2) identifying and characterizing promising engine cycles and concepts, 3) determining and characterizing the impact of mission performance on using multipropellant combinations in a given engine design, and 4) identifying and prioritizing enabling and enhancing technologies required to support successful development of such an engine system. The results from this study identify the major engine design and overall mission impact issues associated with the development and use of such engine systems.

The overall study approach integrated both mission and engine system design analyses to address engine system design and performance issues and to determine the impact of such systems on missions performed and In Situ Propellant Production (ISPP) requirements. Based on a recent ISPP study, Ref. 1-4, promising mission scenarios were defined and characterized. Top-level engine system requirements were then identified from these results. In parallel with this effort, a literature review was conducted that addressed key in situ engine system technology areas. These results, then, form the basis for the identification and design assessment of the promising engine system concepts that meet a majority of the mission requirements. These tripropellant, LOX-cooled engine systems for Mars transfer applications, as well appropriate bipropellant design derivatives for lunar and Mars excursion applications, which included both expander and gas generator engine cycle versions of each system, were baselined for the study and examined in detail. Propellant tankage system design considerations and concepts were also examined in a top-level manner for the propulsion systems of interest. 
At the conclusion of the study, the initial study mission analysis results were updated for a select number of promising mission scenarios based on the detailed baseline engine system data mentioned previously. For these mission scenarios and engine systems of interest, in addition to characterizing mission performance for a given scenario flight profile, top-level sensitivities of engine system mass, specific-impulse and transfer vehicle propellant staging approach, and their impact on ISPP system requirements are also examined. Additionally, a technology maturation plan was defined that addresses engine system design/ technology issues required to support development of such engine propulsion systems.

Detailed discussions of the study's approach, considerations, assumptions, results, and recommendations are presented in the following sections. 


\subsection{INITIAL ENGINE SYSTEM REQUIREMENTS}

Mission performance was assessed initially to obtain requirements for a space propulsion system that utilizes propellants produced at the Moon and/or Mars for support of manned Mars exploration. These initial requirements provide a starting point for in situ engine design efforts using lunar and/or Mars propellants. Lunar in situ propellants, produced from lunar regolith, are used to fuel the Mars Transfer Vehicle (MTV) for the outbound portion of the Mars mission. Mars in situ propellants, produced from the Martian atmosphere, are used to fuel the MTV for the return leg of the trip.

A major design objective of any space mission is to reduce Earth Launch Mass (ELM) as much as possible without compromising mission objectives. To perform a round-trip, piloted, opposition-class Mars mission (which departs from LEO), the vehicle travels to Mars with a crew and mission payload, and returns to LEO) with conventional $\mathrm{LOX} / \mathrm{H}_{2}$ chemical propulsion requires a vehicle initial mass in LEO of about 1600 metric tonnes $(t)$. This translates into a large amount of mass to be launched from the Earth to LEO for assembly. One option for reducing ELM for a piloted Mars mission that has been proposed in recent studies, see Ref. 1-1, is the use of aerocapture at Mars arrival and at Earth return. This significantly reduces the mission propellant requirements, but the total initial vehicle mass for such a mission is still on the order of $800 \mathrm{t}$, see Ref. 2-1. Another option for reducing ELM is to set up ISPP plants on extraterrestrial bodies to fuel an MTV in space. This reduces the amount of mission propellant that has to be launched from Earth. While initial plant development, set-up, and supporting infrastructure costs may be high, over the long term, launching some of the MTV propellant from the surface of the Moon up to low lunar orbit (LLO) or from the surface of Mars up to low Mars orbit (LMO) to fuel the MTV might be less costly than launching all of the fuel from the surface of Earth up to LEO at the start of each mission.

This section describes the major assumptions made in determining ISPP requirements and the methodology used for evaluating mission performance. Initial mission performance results are then used to derive top-level engine requirements to serve as a starting point in the design of a space propulsion system that can use multiple in situ propellant combinations.

\subsection{In Situ Propellant Candidates and Production Requirements}

Many studies have been performed to assess potential benefits of utilizing in situ propellants. In these studies, the ISPP requirements were based on a single processing approach. 
The approach used for this study was developed to assess the utility of various in situ propellant combinations and did not attempt to identify an optimal propellant processing scheme. In a previous study, see Ref. 1-4, many processing techniques were reviewed, and ISPP requirement ranges were parametrically characterized to approximate the requirements to obtain a given propellant combination and to encompass the range of requirements presented in the ISPP literature. Promising propellant combinations considered for this study included $\mathrm{LOX} / \mathrm{H}_{2}$, LOX $/ \mathrm{CH}_{4}$, and $\mathrm{LOX} / \mathrm{CO}$. Other propellant candidates, such as metallized monopropellants, were not considered because of lack of commonality with bipropellant systems. Although $\mathrm{CH}_{4}$ and $\mathrm{CO}$ can be obtained from the Moon through extraction of solar wind gases, lunar LOX/CO was not considered because of excessive processing requirements to obtain the needed quantities to support a LOX/CO propulsion system. LOX/CO and $\mathrm{LOX} / \mathrm{CH}_{4}$ were chosen as Mars propellant candidates because they are readily available from the Martian atmosphere. Lunar LOX and lunar $\mathrm{LOX} / \mathrm{CH}_{4}$ were chosen as the lunar candidates because they are more compatible with the Mars candidates than are other possible lunar-produced propellants (e.g., metallized monopropellants like LOX/Si or LOX/Al). Earth $\mathrm{LOX} / \mathrm{H}_{2}$ is used for the outbound leg of mission scenarios not utilizing lunar propellant and for boosting the MTV from LEO to LLO for scenarios using lunar propellant. All the candidates are compatible in that they are all used in cryogenic chemical bipropellants with LOX as the oxidizer.

\subsection{Mission Description}

As previously mentioned, the purpose of this assessment is to investigate the application of various in situ lunar and Mars propellants for fueling an MTV that transports crew and payload to Mars to perform a 30-day surface mission and then returns the crew to Earth. Three different propellant combinations ( $\mathrm{LOX} / \mathrm{CO}, \mathrm{LOX} / \mathrm{CH}_{4}$, and $\mathrm{LOX} / \mathrm{H}_{2}$ ) and three engine types were considered for analysis in different piloted Mars mission scenarios in which some or all of these propellants would be produced and used in situ at the Moon and/or Mars. One proposed engine design burns both $\mathrm{LOX} / \mathrm{H}_{2}$ and LOX/CO. Another design burns both $\mathrm{LOX} / \mathrm{H}_{2}$ and $\mathrm{LOX} / \mathrm{CH}_{4}$. The third one burns both $\mathrm{LOX} / \mathrm{CO}$ and $\mathrm{LOX} / \mathrm{CH}_{4}$. Seven different scenarios were initially considered, as shown in Table 2-1. Some of the scenarios use both lunar and Mars propellant, and some use only Mars propellant.

The basic infrastructure elements in each scenario are the lunar/Mars propellant production plants, the MTV, the Lunar Excursion Vehicle (LEV), the Mars Excursion Vehicle (MEV), and an expendable booster stage and are schematically shown in Figure 2-1. The LEV and MEV are reusable lunar and Mars-based vehicles that transfer crew, mission payload, ISPP 
support, and in situ derived propellants between the MTV and the lunar or Mars surface. The expendable booster stage uses high performance $\mathrm{LOX} / \mathrm{H}_{2}$ propulsion and is responsible for transporting the MTV to LLO from LEO in scenarios using lunar-produced propellants. This stage is jettisoned after completing this transfer. The MTV carries the crew, Mars mission payload, and ISPP support to Mars and returns the crew to Earth.

Table 2-1. Initial Mission Performance Assessment Scenarios

\begin{tabular}{|c|c|c|c|}
\hline Scenario & $\begin{array}{l}\text { Outbound } \\
\text { Propellant }\end{array}$ & $\begin{array}{c}\text { Return } \\
\text { Propellant }\end{array}$ & $\begin{array}{c}\text { Mission } \\
\text { Profile } \\
\text { No. }\end{array}$ \\
\hline 1 & Earth $\mathrm{LOX} / \mathrm{H}_{2}$ & Earth $\mathrm{LOX} / \mathrm{H}_{2}$ & Baseline \\
\hline 2 & Lunar LOX/Earth $\mathrm{H}_{2}$ * & Mars LOX/CO & 1 \\
\hline 3 & Lunar LOX/Earth $\mathrm{H}_{2}$ " & Mars $\mathrm{LOX} / \mathrm{CH}_{4}$ & 1 \\
\hline 4 & Lunar $\mathrm{LOX} \mathrm{CH}_{4}$ & Mars LOX/CO & 1 \\
\hline 5 & Lunar $\mathrm{LOX} \mathrm{CH}_{4}$ * & Mars $\mathrm{LOX} / \mathrm{CH}_{4}$ & 1 \\
\hline 6 & Earth $\mathrm{LOX} / \mathrm{H}_{2}$ & Mars LOX/CO & 2 \\
\hline 7 & Earth $\mathrm{LOX} / \mathrm{H}_{2}$ & Mars $\mathrm{LOX} / \mathrm{CH}_{4}$ & 2 \\
\hline
\end{tabular}

- Earth $\mathrm{LOX} / \mathrm{H}_{2}$ used for trans-lunar injection and lunar orbit insertion

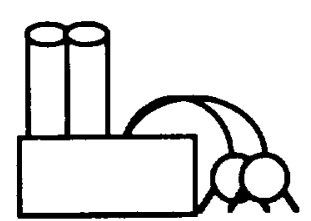

Lunar and Mars ISPP Plants (includes all systems necessary for feedstock collection through propellant storage)

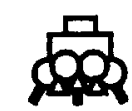

Lunar Excursion Vehicle

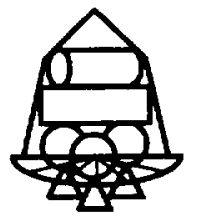

Mars Excursion Vehicle

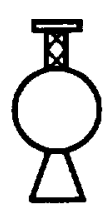

$\mathrm{LOX} / \mathrm{H}_{2}$ Expendable LEO->LLO Stage

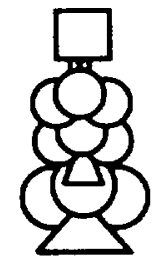

Mars Transfer Vehicle

Figure 2-1. Infrastructure Elements 
The mission profiles examined are shown in Figure 2-2. The baseline scenario, which uses only Earth supplied $\mathrm{LOX} / \mathrm{H}_{2}$, is used as a point of comparison to evaluate ISPP scenarios. Mission Profile \#1 was used for scenarios using both lunar and Mars-produced propellants. Mission Profile \#2 was used for scenarios that used Earth-supplied propellant for the outbound leg and Mars-produced propellants for the return trip.
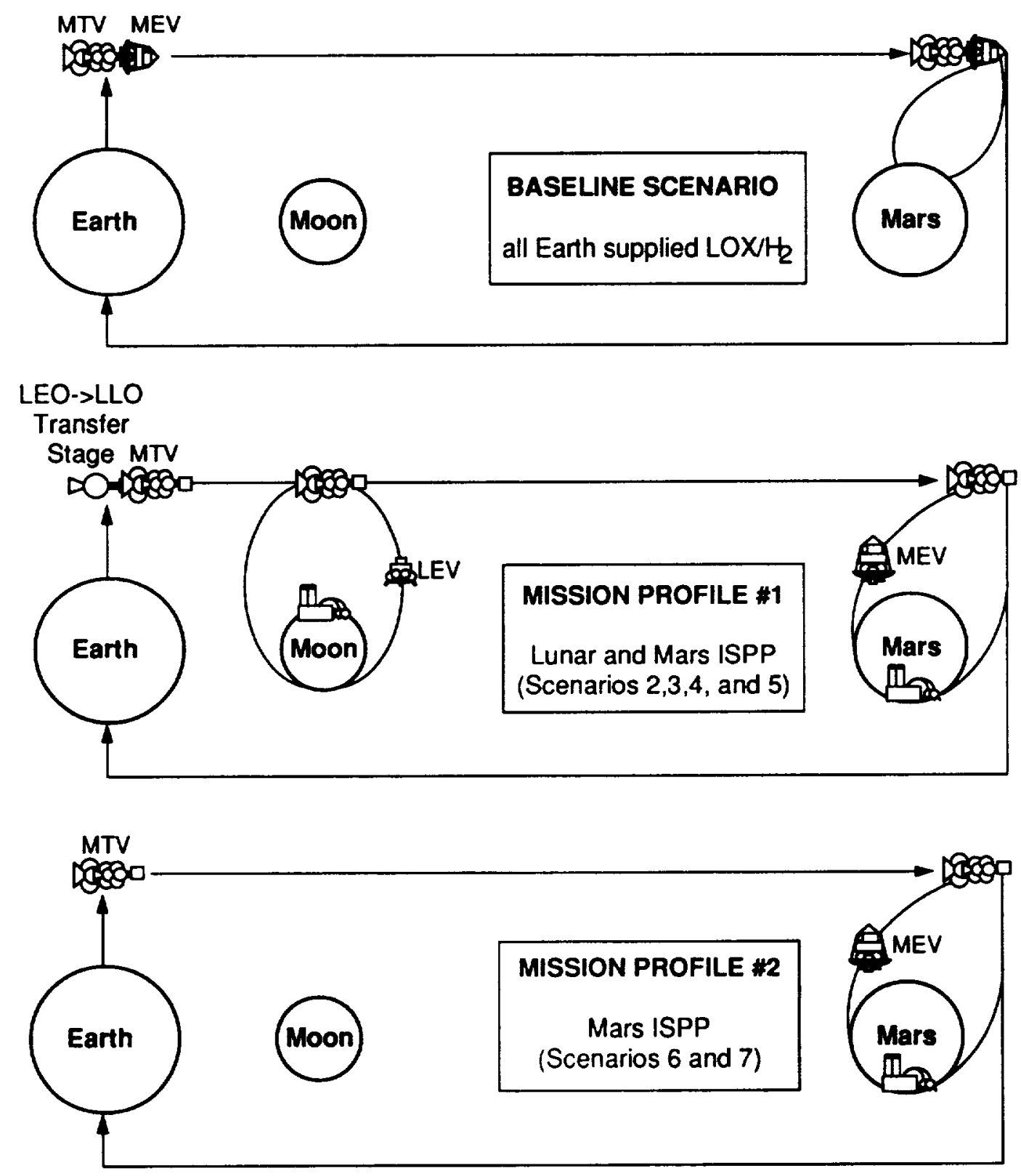

Figure 2-2. Mission Profiles 
Scenarios 2-5, where both lunar and Mars propellant are utilized, are described in Figure 2-3. In these scenarios, a plant is set up on the Moon to produce the propellant needed to send the MTV from the Moon to Mars, and the propellant needed by the LEV to transport this MTV propellant up to the MTV in LLO and to carry lunar ISPP plant support to the lunar surface. Additionally, a plant is set up on Mars to produce the propellant needed to send the MTV from Mars back to Earth, and the propellant needed for the MEV to carry the crew, Mars mission payload, and Mars ISPP plant support to the Mars surface. The propellant produced on Mars is also used by the MEV to transport the MTV return trip propellant up to the MTV in LMO. The MTV is brought out to the Moon on an expendable stage, which performs both Earth orbit departure and lunar orbit insertion and then separates from the MTV and is left in LLO. The MTV is fueled up in LLO by the LEV with lunar-produced propellant to make the trip to Mars. At Mars, after the crew performs its surface mission, the MTV is fueled up in LMO by the MEV with Mars-produced propellant for the return trip back to Earth.

LEV:

- Brings lunar in situ propellant for trans-Mars injection and Mars orbit insertion to LLO

- Brings lunar ISPP refurbishment/resupply to lunar surface from LLO

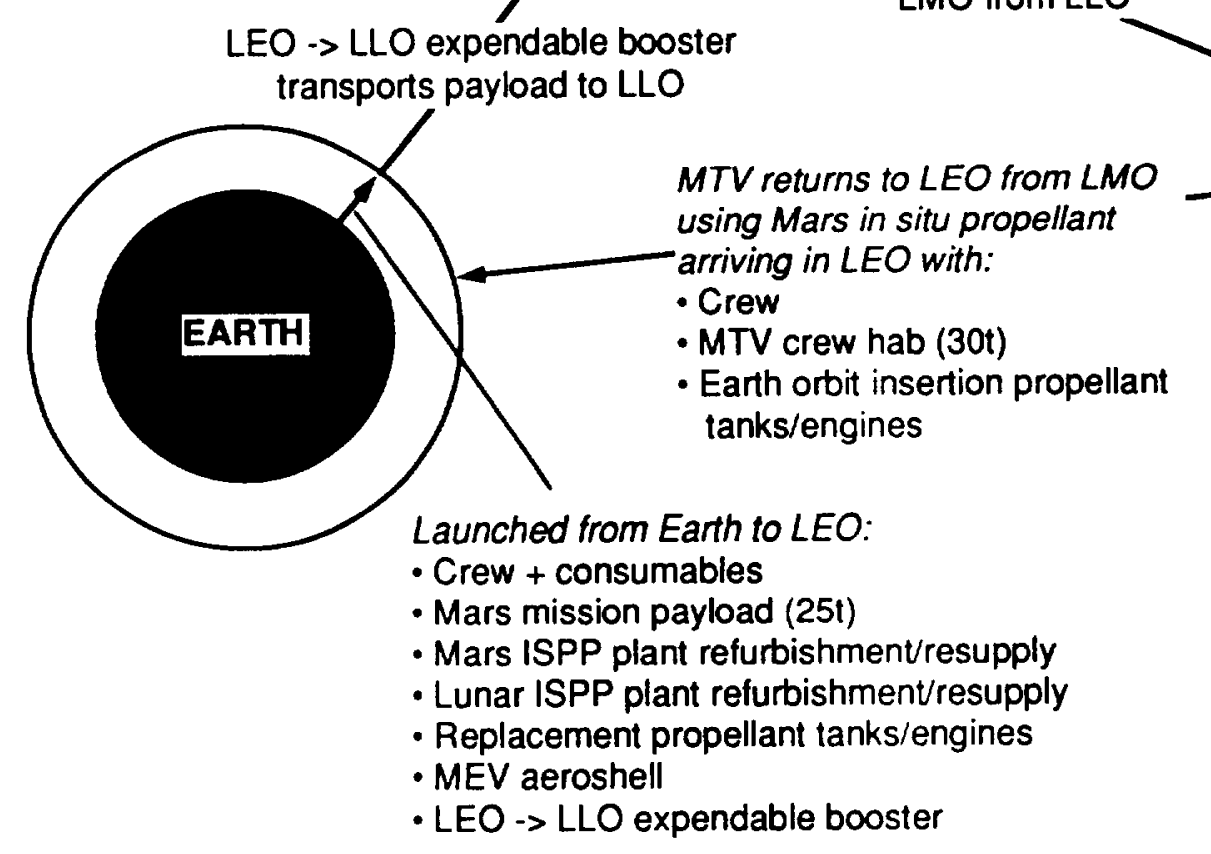

MEV:

- Brings crew, mission payload (25t), and Mars ISPP refurbishment/resupply to Mars surface

- Returns crew and Mars in situ propellant for trans-Earth injection and Earth orbit insertion to LMO

Figure 2-3. Mission Description for Scenarios Using Lunar and Mars ISPP (Mission Profile \#1) 
Scenarios 6 and 7, where only in situ Mars propellant is used, are described in Figure 2-4. In these scenarios, there is no lunar plant or LEV, and the MTV does not stop at the moon at all. It is injected from Earth orbit onto a Mars transfer trajectory by the expendable booster stage, which is jettisoned upon completion of the Earth departure burn. Several months later, the MTV captures into a Mars orbit, and the crew performs its mission after landing on the Mars surface. After the mission is complete, the MTV is fueled up by the MEV with Mars-produced propellant for the trip back to Earth.

As previously mentioned, Scenario 1 is an all propulsive, all Earth-supplied $\mathrm{LOX} / \mathrm{H}_{2}$ propellant baseline case against which all the other results should be compared. In Scenario 1, no in situ propellants are used and there are no lunar or Mars ISPP plants. All of the propellant utilized by the transfer and excursion vehicles is Earth-supplied $\mathrm{LOX} / \mathrm{H}_{2}$. This case differs from the 90-Day Study chemical propulsion/aerocapture baseline case (see Reference 1-1) in that aerobraking is not employed at Earth or Mars; all maneuvers are performed propulsively.

MEV:

- Brings crew, mission payload (25t), and Mars ISPP

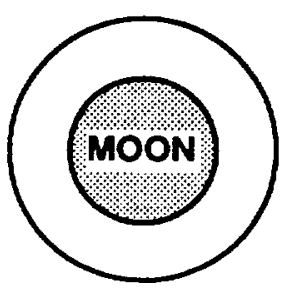
refurbishmentresupply to Mars surface

- Returns crew and Mars in situ propellant for trans-Earth injection and Earth orbit insertion to LMO

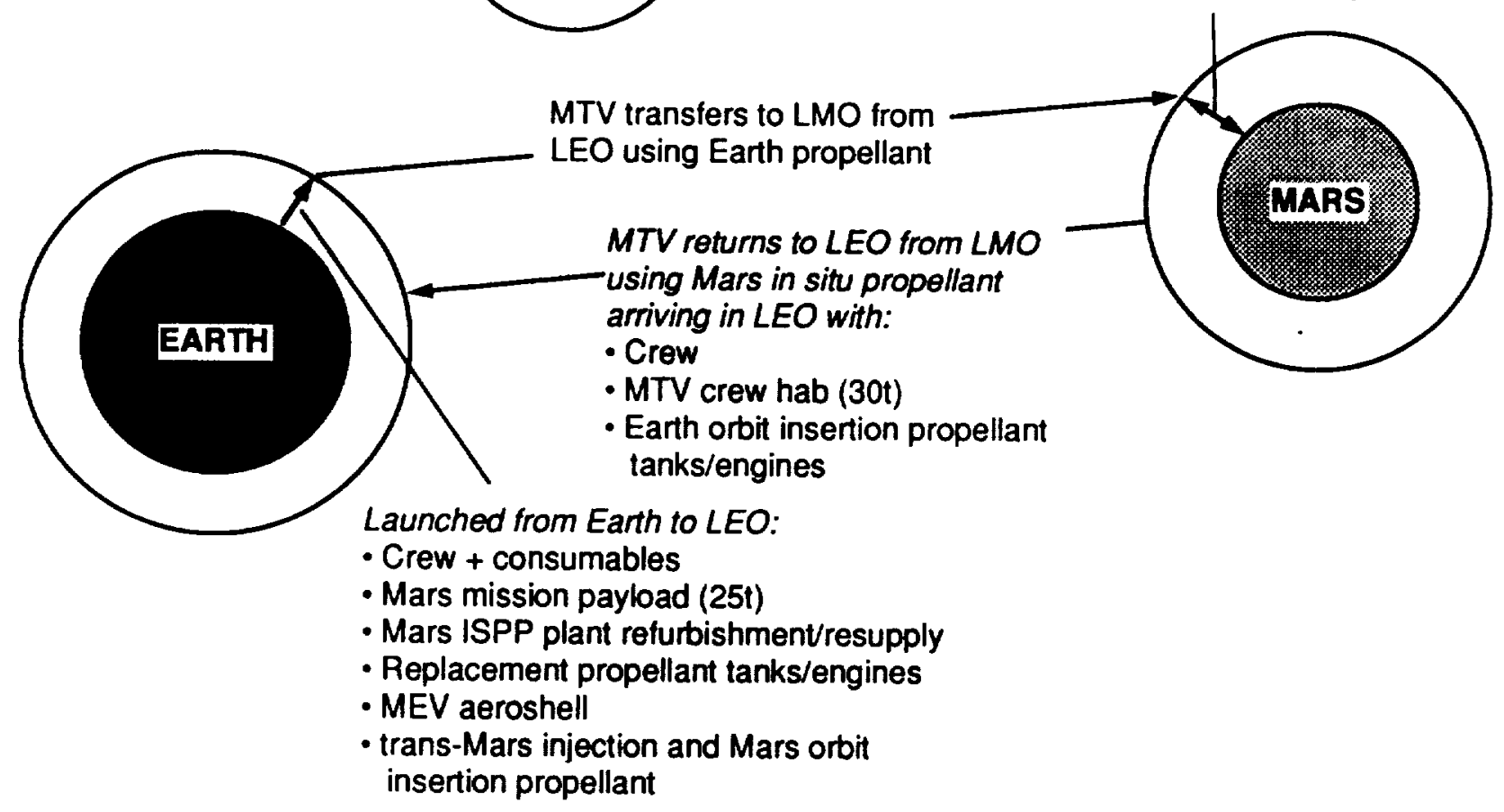

Figure 2-4. Mission Description for Scenarios Using Mars ISPP (Mission Profile \#2) 
In Scenario 2, a LOX plant is set up on the Moon and a LOX/CO plant is set up on Mars. For this case, an expendable booster using Earth-supplied LOX/ $/ \mathrm{H}_{2}$ carries the MTV from LEO to LLO. In LLO, the MTV is fueled by a LEV with lunar-produced LOX, which is used with Earth-supplied $\mathrm{H}_{2}$ to transport the MTV from LLO to LMO. The sole purpose of the LEV is to carry propellant up to the MTV in LLO and bring lunar plant resupply materials back down to the lunar surface. At Mars, the MEV meets the MTV in LMO so that the crew and mission payload can be transferred to the MEV. The MEV then descends to the surface of Mars where it fills up its tanks with propellant for the MTV, while the crew performs their surface mission. When the excursion is complete, the crew return aboard the MEV to LMO, and transfer back into the MTV. The MEV also transfers Mars-produced LOX/CO to the MTV for the return trip to Earth.

Scenario 3 is the same as Scenario 2 except that $\mathrm{LOX} / \mathrm{CH}_{4}$, not $\mathrm{LOX} / \mathrm{CO}$, is produced at Mars. In Scenario 4, $\mathrm{LOX} / \mathrm{CH}_{4}$ is produced at the Moon and $\mathrm{LOX} / \mathrm{CO}$ is produced at Mars. For this scenario, no Earth-produced $\mathrm{H}_{2}$ is needed for the LLO to LMO leg of the mission. Scenario 5 employs both lunar $\mathrm{LOX} / \mathrm{CH}_{4}$ and $\mathrm{Mars} \mathrm{LOX} / \mathrm{CH}_{4}$.

Scenarios 6 and 7 are simpler than Scenarios 2-5 in that no lunar-produced propellant is used. The MTV goes directly from LEO to LMO and back to LEO, using Earth-produced LOX $/ \mathrm{H}_{2}$ for the outbound trip and Mars-produced propellant for the return trip. In scenario 6, Mars LOX/CO is used for the return, while in Scenario 7, Mars $\mathrm{LOX} / \mathrm{CH}_{4}$ is used.

\subsection{Mission Performance}

Each mission scenario of interest was characterized using SAIC's ISPP Mission Performance Model to determine $\Delta V s$, propellant requirements, vehicle sizes and masses, and flight times for each phase of a given flight profile. From this information, overall propulsion system requirements were derived for each mission scenario.

The methodology used in the mission performance model is depicted in Figure 2-5. This

figure shows the steps used to determine steady-state mission requirements. The steady-state requirements assume all ISPP plants to be operational and other associated infrastructure to be established. First, the amount of in situ propellant required to return the MTV to LEO from LMO is determined. This propellant, along with the propellant needed by the MEV to carry the crew, Mars mission payload, and Mars ISPP plant support to the Mars surface from LMO and to carry the MTV's return propellant to LMO from the Mars surface, determine the production rate 


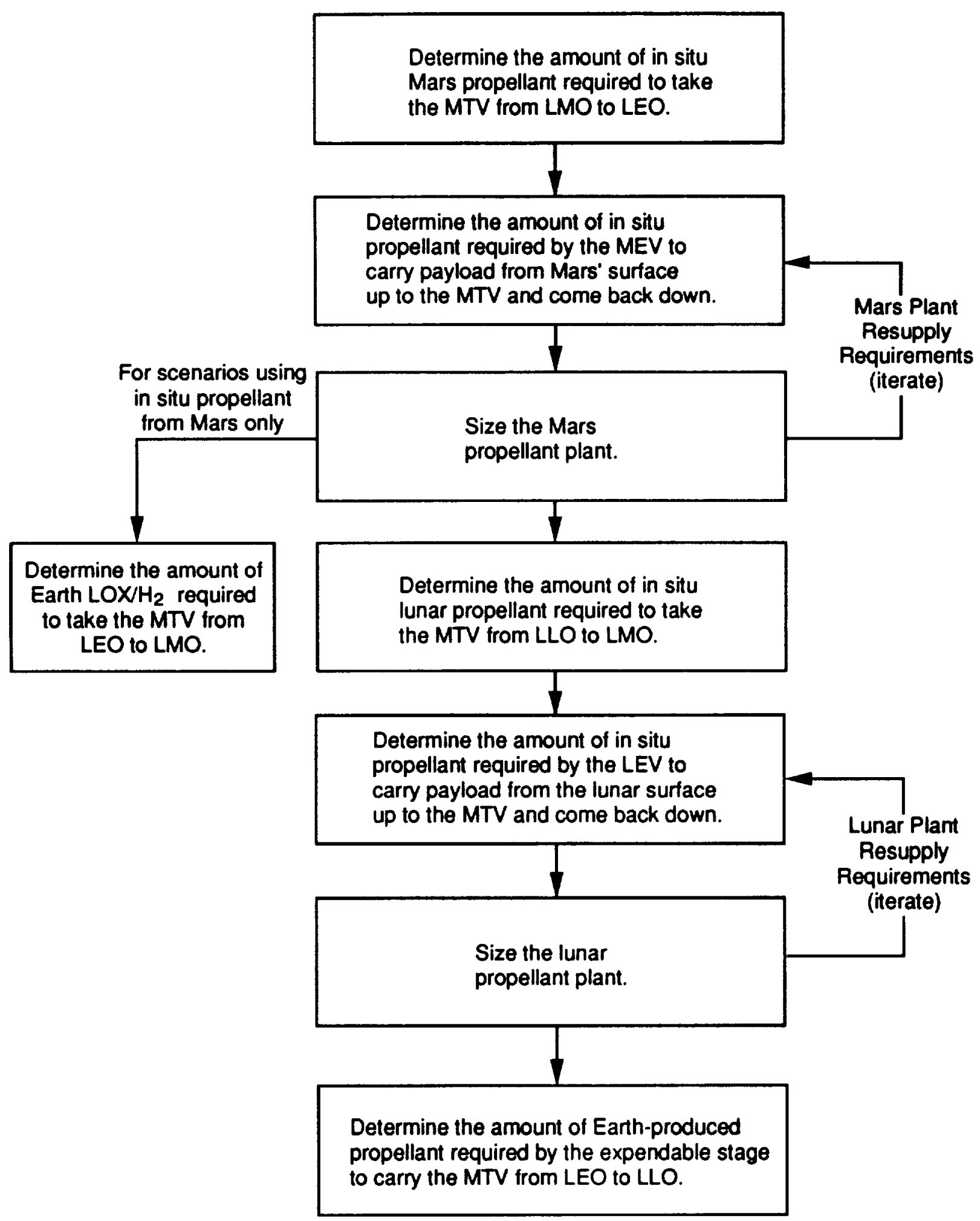

Figure 2-5. Mission Performance Prediction Methodology 
and size of the Mars ISPP plant. An iteration is required to estimate the MEV's propellant requirements because each time the MEV's propellant requirement is determined, the size and support requirements for the Mars ISPP plant change, and, therefore, the MEV's payload requirements change. When the iteration is complete, the mass needed in LMO to support a mission is known. If the mission does not use lunar propellants, the MTV is sized to carry this mass from LEO using Earth-supplied propellant. If the mission uses lunar propellant, the same approach used to determine mass needed in LMO is used to estimate the mass needed in LLO to support a mission. An expendable stage is then sized to deliver this mass from LEO to LLO. When these steps are completed, the ELM requirements to support a mission in the steady-state mode are obtained. Also, the masses of the lunar and/or Mars ISPP plants and excursion vehicles and the MTV are determined. The masses of the ISPP plants are representative of the set-up requirements to enable utilization of in situ propellants in a given scenario. The excursion and transfer vehicle masses are representative of the requirements for vehicle change-out or replacement after these vehicles have reached the end of their life cycle. More details on this approach can be found in Ref. 1-4.

Initially, all these scenarios were evaluated using the simple engine mass scaling relations shown in Table 2-2 and the mission performance/vehicle design assumptions presented in Table 2-3. This analysis approach enabled estimation of the thrust requirements for each propulsive maneuver for each of the vehicles in the infrastructure-booster stage, MTV, MEV, and LEV.

Table 2-2. Initial Engine Parameters

\begin{tabular}{|c|c|c|c|}
\hline $\begin{array}{l}\text { Propellant } \\
\text { Combination }\end{array}$ & $\begin{array}{l}\text { Specific } \\
\text { Impulse- } \\
\text { Vacuum, } \\
\text { sec. }\end{array}$ & $\begin{array}{l}\text { Thrust/Weight, } \\
\text { N/kg (lbf/lbm) }\end{array}$ & $\begin{array}{c}\text { Mixture Ratlo } \\
(\mathrm{O} / \mathrm{F}) \\
\end{array}$ \\
\hline $\mathrm{LOX} / \mathrm{H}_{2}$ & 470 & $765(78)$ & 6.0 \\
\hline $\mathrm{LOXNCH}_{4}$ & 380 & $883(90)$ & 3.6 \\
\hline LOXVOO & 290 & $961(98)$ & 0.6 \\
\hline
\end{tabular}


- All maneuvers are done propulsively (no aerobraking)

- Mission $\Delta V s$ and flight times are averaged from 6 opposition class opportunities (2015-2030 timeframe):

Scenarios 1.6 .7 (LEO->LMO->LEO)

$\Delta \mathrm{VTMI}=3982 \mathrm{~m} / \mathrm{sec}$

$\triangle \mathrm{VMOI}=2590 \mathrm{~m} / \mathrm{sec}$

$\triangle \mathrm{V} \mathrm{TEI}=2521 \mathrm{~m} / \mathrm{sec}$

$\triangle V E O I=4081 \mathrm{~m} / \mathrm{sec}$

$\Delta T$ Earth $->$ Mars $=250$ days

$\Delta T$ Mars stay $=30$ days

$\Delta \mathrm{T}$ Mars $->$ Earth $=273$ days

\section{Scenarios 2.5 (LEO->LLO->LMO->LEO)}

$\Delta V \mathrm{TLI}=3300 \mathrm{~m} / \mathrm{sec}$

$\Delta V$ LOI $=1110 \mathrm{~m} / \mathrm{sec}$

$\Delta V$ TMI $=2005 \mathrm{~m} / \mathrm{sec}$

$\triangle \mathrm{V} \mathrm{MOI}=2590 \mathrm{~m} / \mathrm{sec}$

$\triangle V \mathrm{TEI}=2521 \mathrm{~m} / \mathrm{sec}$

$\triangle \mathrm{V} \mathrm{EOI}=4081 \mathrm{~m} / \mathrm{sec}$

$\Delta \mathrm{T}$ Earth->Moon $=3.5$ days

$\Delta \mathrm{T}$ Moon stay $=3$ days

$\Delta \mathrm{T}$ Moon->Mars $=250$ days

$\Delta \mathrm{T}$ Mars stay $=30$ days

$\Delta T$ Mars $->$ Earth $=273$ days

- Earth departure/arrival orbit is $407 \mathrm{~km}$ circular

- Mars parking orbit is $250 \mathrm{~km} \times 1$ sol

- 4 crew members assumed with consumable rate of $93 \mathrm{~kg}$ per person per month

- MTV crew habitation module $=30 \mathrm{t}$

- 2 MEVs operate simultaneously to bring crew, mission payload (25t), and ISPP refurbishment/resupply down to Mars surface and return crew and Mars in situ propellant for TEI + EOI back to the MTV in LMO

- Vehicle structure mass $=15 \%$ of propellant tank dry mass

- Reserve propellant $=2.5 \%$ of propellant required

- Propellant tanks are jettisoned after each major burn except for EOI tanks (reused as part of MTV core)

- Empty propellant tanks are brought on the MTV to be filled up at the Moon and also at Mars

- Propellant tank mass $=\chi \%$ of propellant mass in the tank (assumes $2 \%$ tank ullage):

\begin{tabular}{c|r} 
Cryogen & $X \%$ \\
\hline $\mathrm{H}_{2}$ & 12 \\
$\mathrm{O}_{2}$ & 2 \\
$\mathrm{CO}$ & 2 \\
$\mathrm{CH}_{4}$ & 2
\end{tabular}




\subsection{Engine System Requirements}

Detailed mission performance and requirements data for each scenario is given in Appendix A. In Appendix A, for each mission scenario considered, tables summarizing the mission features and assumptions, performance for each mission phase, and overall engine system requirements are given. Figure 2-6 summarizes engine thrust and mass requirements for each burn in each scenario, while Tables 2-4 through 2-10 display the overall propulsion system requirements for Scenarios 1 through 7 , respectively.

It should be noted that these initial mission performance predictions are based on rough engine mass scaling relations from which initial overall propulsion system estimates were derived (e.g., thrust requirements and engine burn times). These initial estimates served as inputs to the engine system design effort. This analysis was updated in Section 5 using more accurate engine system data based on detailed engine design analysis to obtain more accurate mass performance results. Scenario 5 was included as a point of comparison to the other alternatives because it was one of the better scenarios in terms of mission performance, see Ref. 1-4. This scenario was not considered for further analysis here because it does not utilize two different propellant combinations for the MTV engine. 


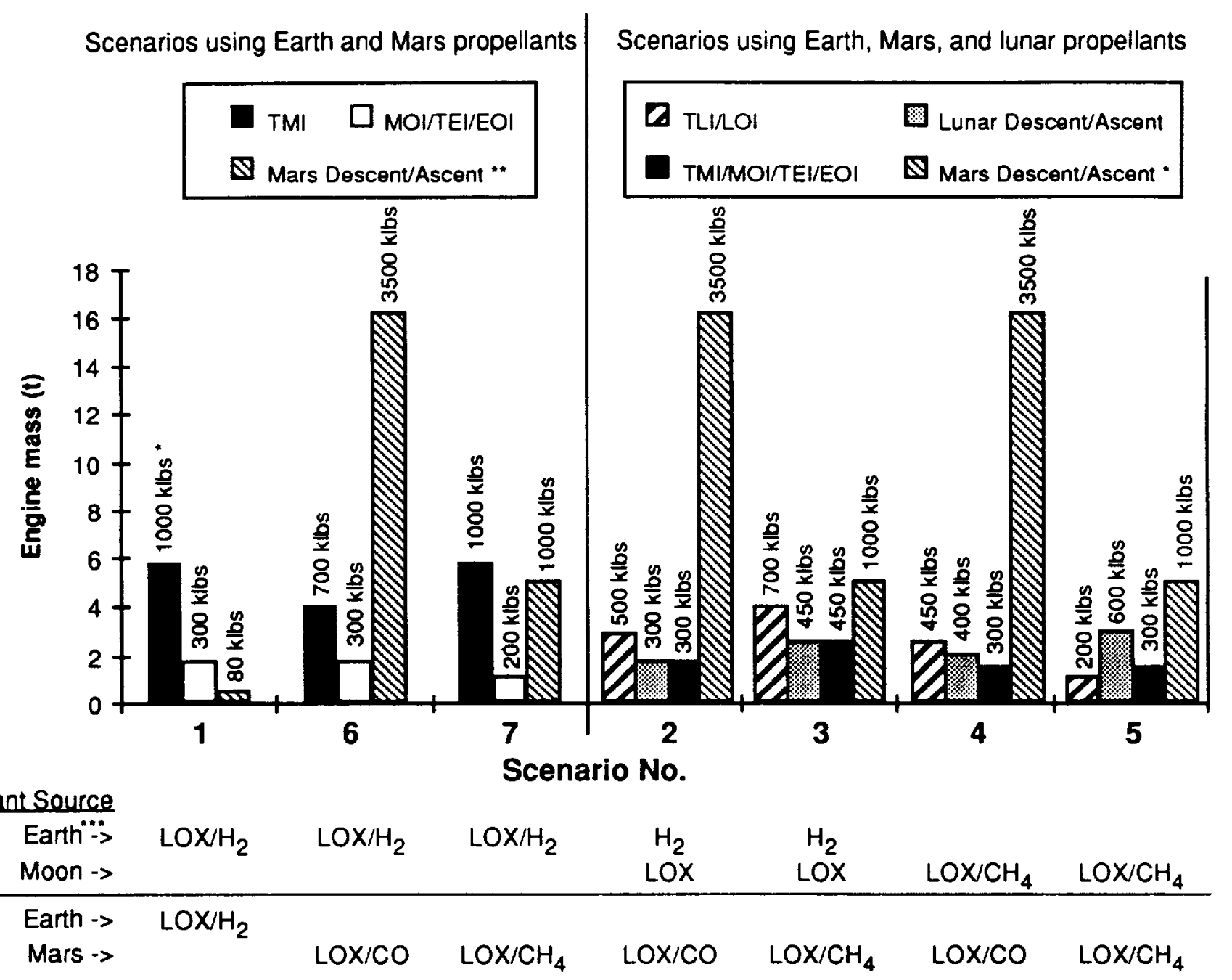

" NOTE: Engine thrust levels shown above each bar; each bar represents a single engine or set of engines which perform the indicated burn(s)

** For cases using in situ propellants, Mars Descent/Ascent requirements are shown for one of 2 vehicles required

"** For cases using lunar propellant for the outbound trip, TLI and LOI are performed with Earth $\mathrm{LOXJH}_{2}$

Figure 2-6. Summary of Initial Engine Masses 


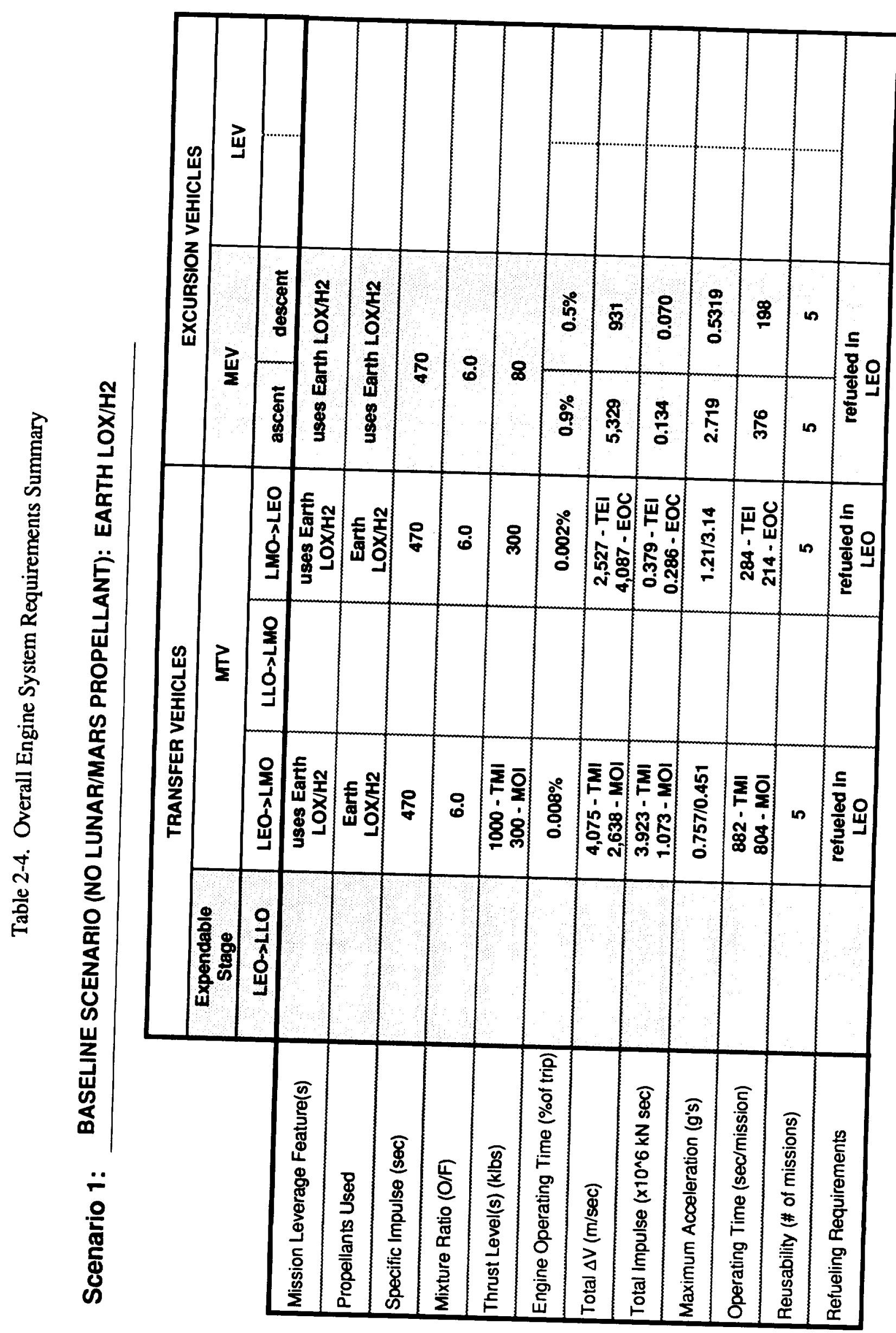




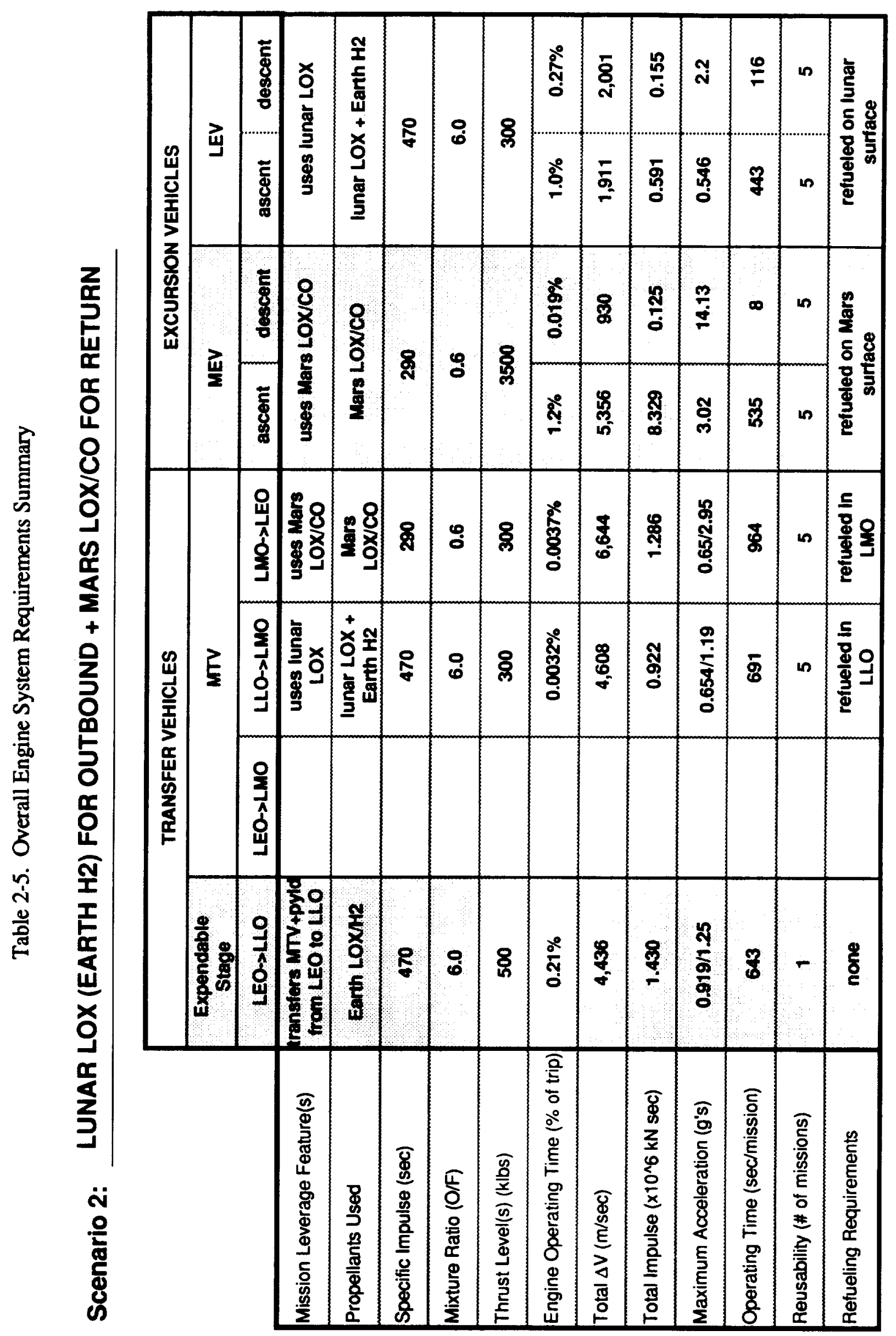




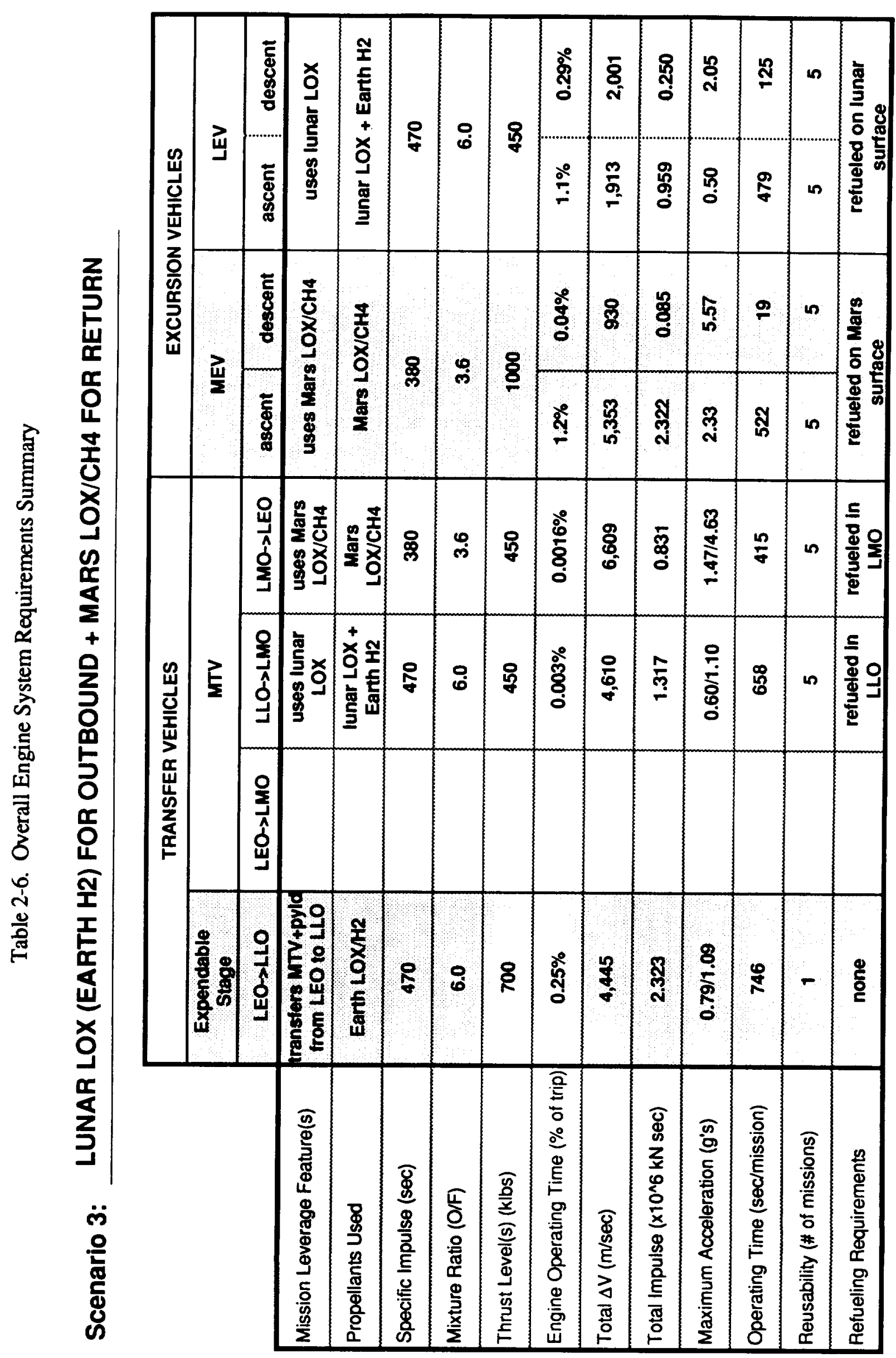




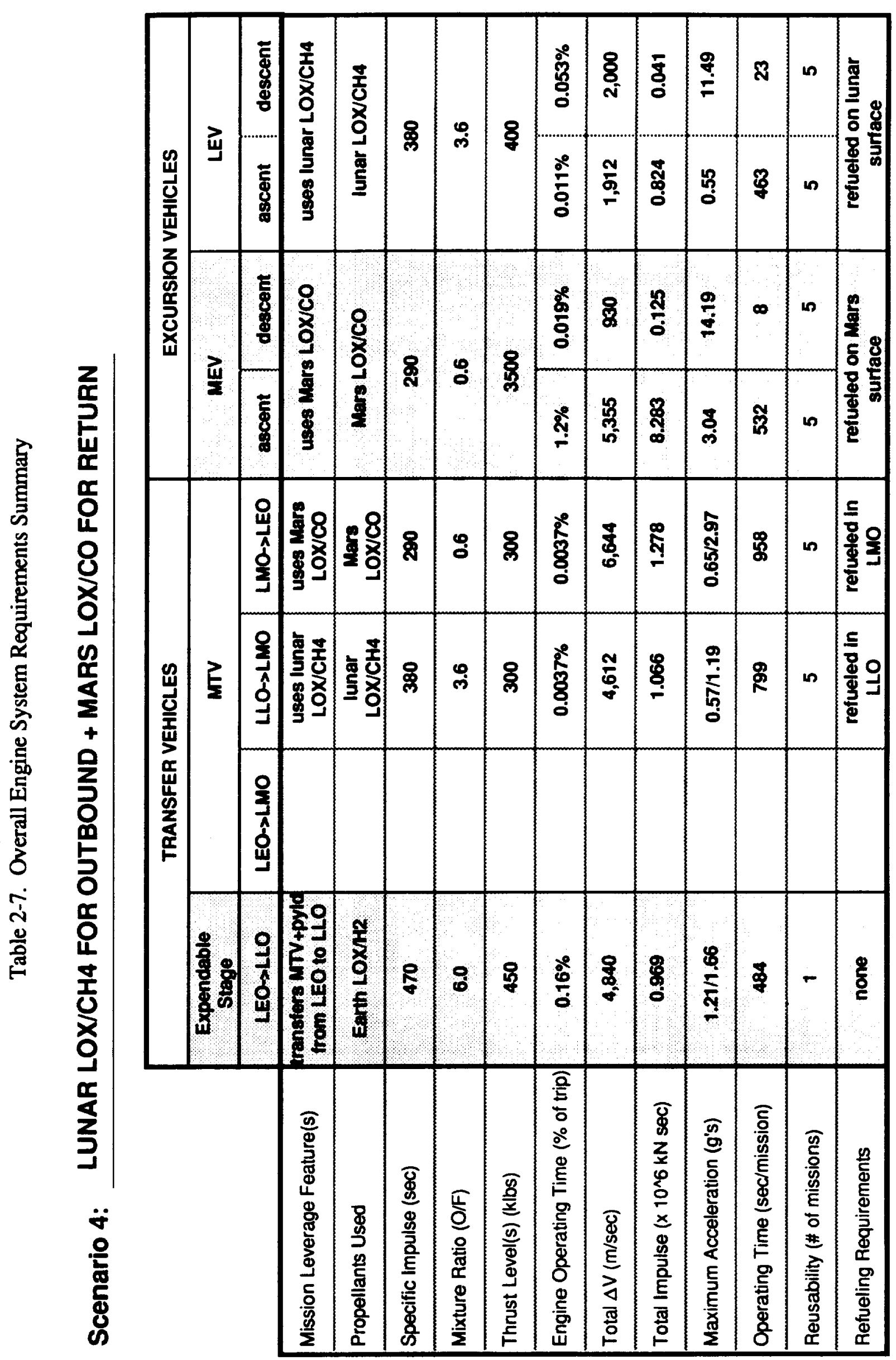




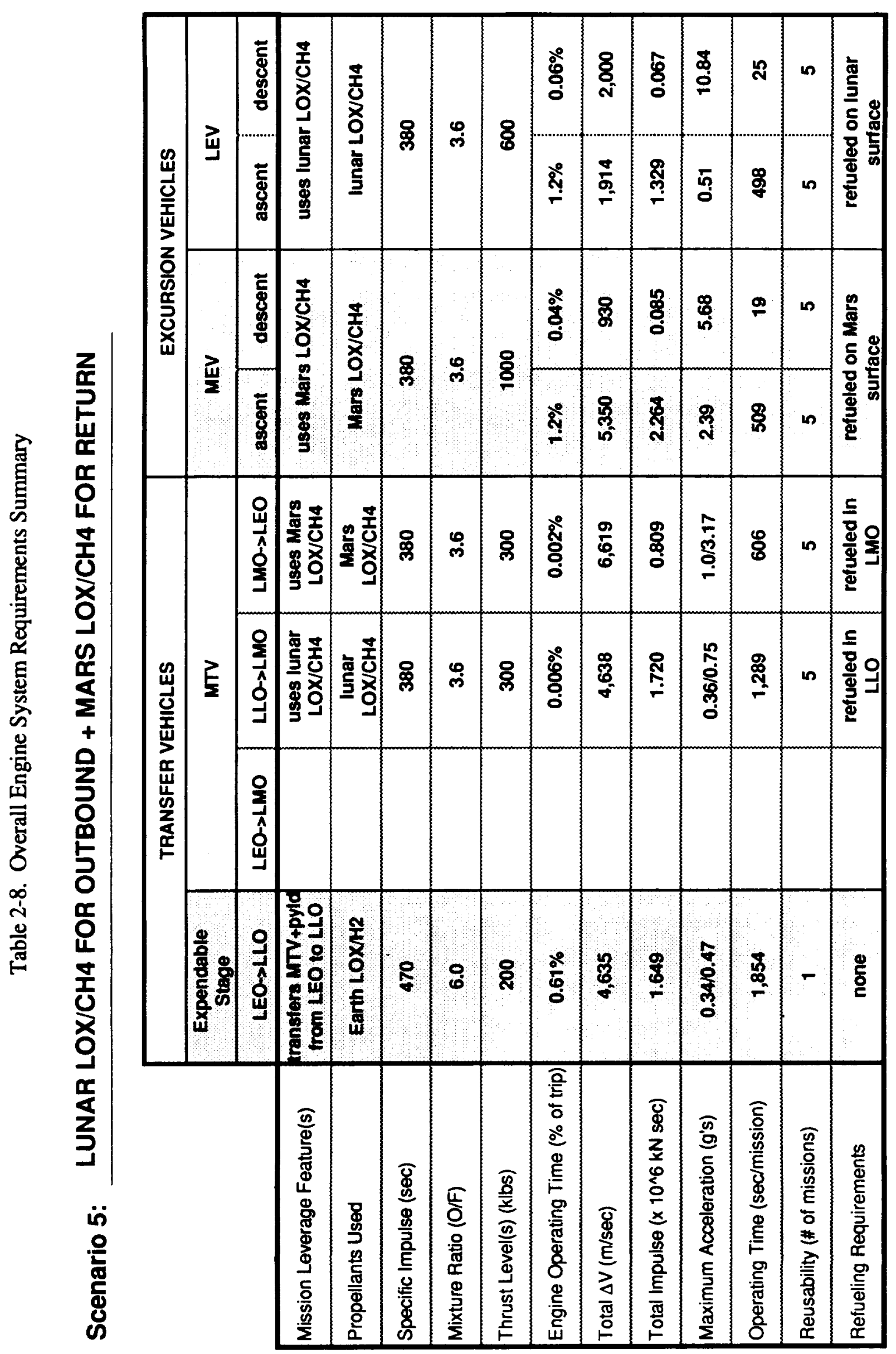




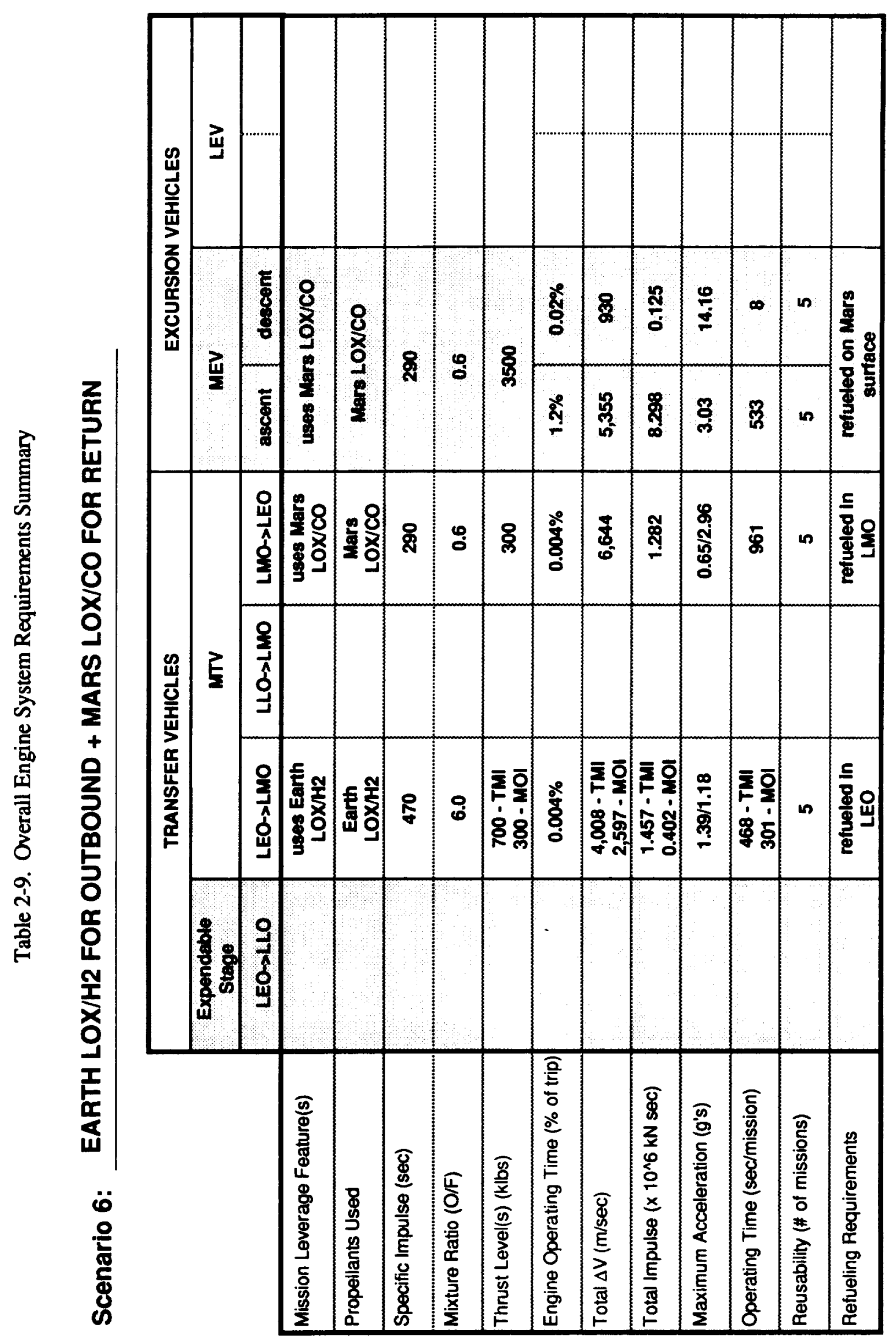




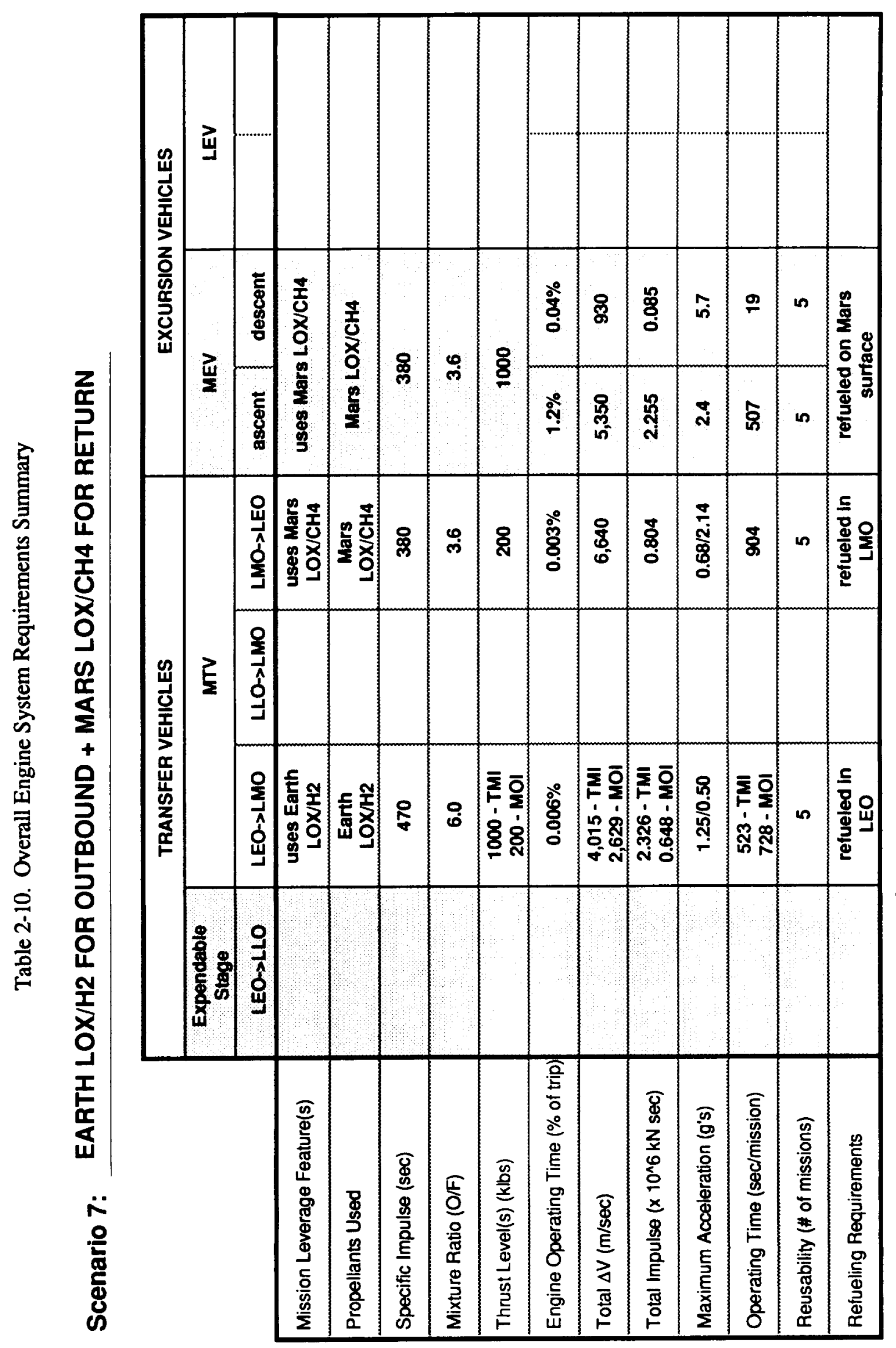





\subsection{TECHNOLOGY REVIEW}

A technology review was conducted to support identification of key technology issues associated with multi-propellant, in situ-based propulsion systems of interest to this study. Additionally, this technology review established a corresponding database that supported the assessment, design, and development of such systems. Key areas of interest in this review included heat transfer/cooling, injection/ignition/combustion characteristics, performance, pumping, materials compatibility and tankage. Technology data compiled in this effort was also used to support engine system characterization and the technology assessment of these systems which are reported in Sections 4.0 and 6.0, respectively.

To support this effort, an extensive literature search was undertaken that focused on rocket engine system technology. The NASA/RECON, Dialog and DTIC literature search database sources were surveyed in key technology/design areas, as well as in other areas such as tripropellant engine systems. Hundreds of literature abstracts were reviewed. From this listing, approximately 30 to 50 technical papers were reviewed indepth that covered the range of technology and design areas of interest. In general, it was found that little of the past work identified in the literature search was directly applicable to integrated multipropellant Mars in situ propellant-based propulsion systems. Most of the literature reviewed addressed technologies associated with $\mathrm{LOX} / \mathrm{H}_{2}$ and LOX/Hydrocarbons engine systems that have some relevance to this effort. Results and supporting rationale associated with this technology review in areas unique to Mars multipropellant, in situ-based propulsion systems are summarized in the following.

\subsection{Tripropellant Engine Systems}

Tripropellant engine systems have many unique similarities as well as differences with multipropellant Mars in situ-based propulsion systems. These similarities include use of three propellants to support engine operations and integration, design issues such as pumping (multiple fuel systems), control and thrust chamber cooling. It is these similarities that make review of past work in this area of interest to this study.

In considering the applicability of past tripropellant engine studies for this assessment, one must understand the application and operational aspects of these studies and those associated with an in situ multipropellant Mars propulsion system. Past tripropellant engine design and supporting technology investigations focused on Single-Stage-to-Orbit (SSTO) and advanced Earth-to-Orbit (ETO) applications. These engine systems designs stress optimal performance over a typical ETO 
trajectory with minimal engine system hardware to keep weight at a minimum. Typical tripropellant engine system operation for a dual-throat or dual-expander cycle engines is shown in Figure 3-1. Multimode operation of these engine systems is performed in parallel. During low altitude operation, the LOX/Hydrocarbon and/or $\mathrm{LOX} / \mathrm{H}_{2} / \mathrm{Hydrocarbon}$ engine segments are operated. In this operating mode, moderate thrust density and performance is achieved. At high altitude, only the LOX/H $\mathrm{H}_{2}$ engine segment is operated which gives low thrust density, but high performance.

These engine system design/operation features are different from those associated with multipropellant Mars in situ-based propulsion systems, where only single bipropellant combinations are operated in series, restartability is required and commonality of hardware, such as a single thrust chamber, is stressed. Though these differences exist, review of past data in this area was considered worth while due to many of the design issues and technology areas they have in common, as previously mentioned.

There is an extensive past database available associated with tripropellant engine systems. Most of the work has been accomplished by Aerojet. They initiated this work in the early 1970's and have been active at a modest level since then. This work has been both IR\&D and contract supported. Aerojet has performed numerous engine system and application studies, and supporting technology experimental investigations, see Refs. 3-1 through 3-4. Another past study of interest is one performed by Rocketdyne in 1977, see Ref. 3-5. This study examined the feasibility of modifying the Space Shuttle Main Engine (SSME) for dual mode operation. This is quite different than the other studies conducted in this area because it examined the performance and compatibility issues of a given engine design optimized for $\mathrm{LOX} / \mathrm{H}_{2}$ and operating it with a LOX/Hydrocarbon propellant combination. Such issues and design tradeoffs are typical of the Mars engine systems of interest to this study.

\subsection{Heat Transfer/Cooling}

Heat transfer and cooling of the thrust chamber was identified as a key issue associated with in situ-based multipropellant Mars engine systems. Key issues associated with this area are: 1) regeneratively cooling thrust chambers using LOX or $\mathrm{CO}$ and 2) the design of a regeneratively cooled thrust chamber that can effectively operate with different coolants during different phases of operation associated with a Mars tripropellant engine. Both issues greatly impact the cycle selection and design of this class engine. 

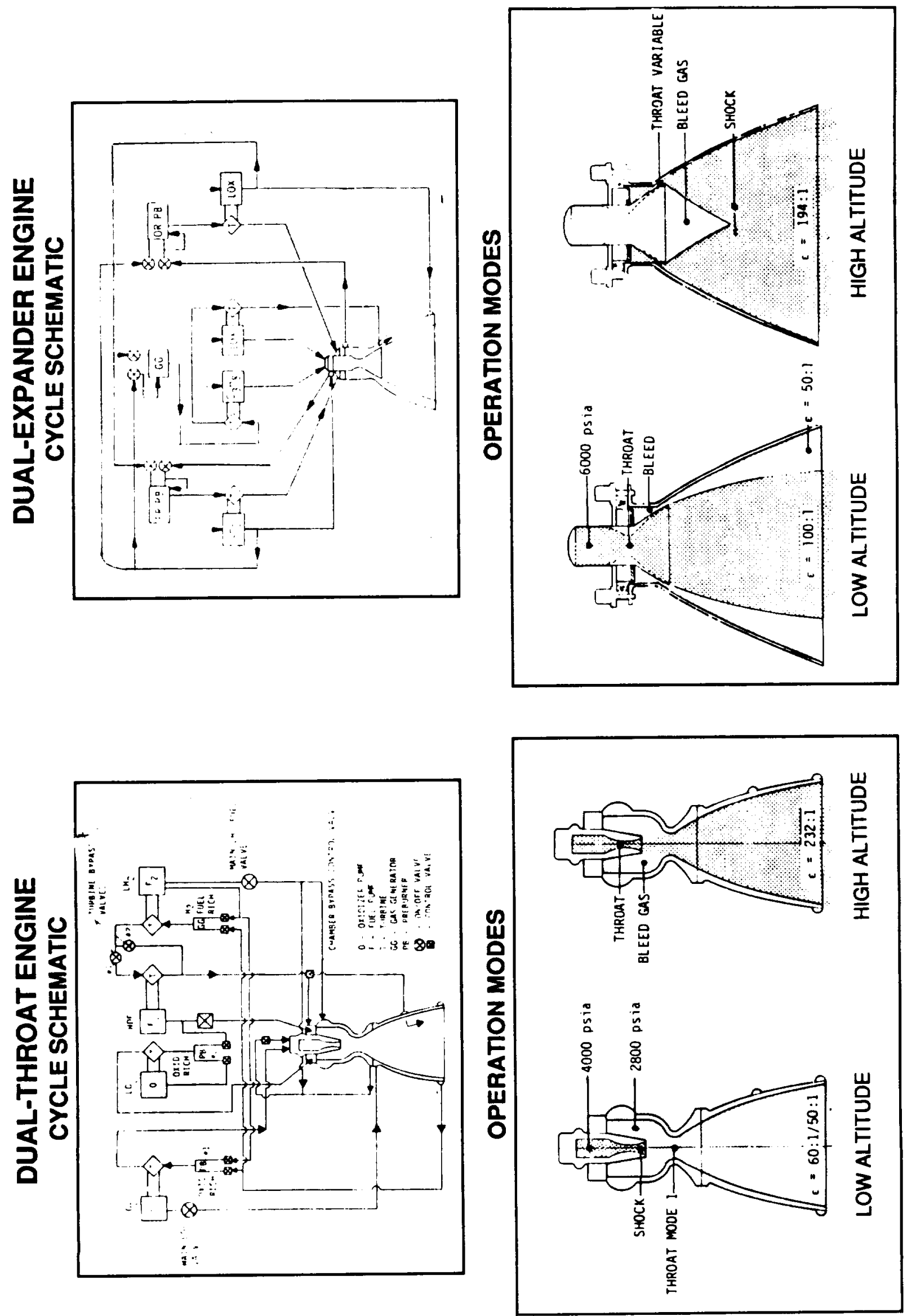

 
Thrust chamber cooling characteristics for numerous propellants of interest, such as $\mathrm{H}_{2}$, LOX, and $\mathrm{CH}_{4}$ plus others, are summarized in Ref. 3-6. Review of the literature indicated that there is extensive data available for using $\mathrm{H}_{2}$ and Hydrocarbons $\left(\mathrm{CH}_{4}\right)$ to cool engine thrust chambers. This area has been extremely active in recent years due to related interest in cooling the SSME, Space Transportation Booster Engine (STBE) and Space Transportation Main Engine (STME), see Refs. 3-7 through 3-9. Fundamental and applicable engine system design data in this area is available.

Some applicable data on the cooling of thrust chambers using LOX is also available. Aerojet's Orbit Transfer Vehicle (OTV) engine concept, see Ref. 3-10, employs a high performance LOX-cooled thrust chamber. Research and development in this area for large engine applications has been conducted for many years, see Refs. 3-11 and 3-12. Additionally, fundamental data associated with LOX cooling is available, see Ref. 3-6.

The literature survey identified no past experimental or analytical work that examined $\mathrm{CO}$ as a thrust chamber coolant or supporting fundamental data that would be applicable for such an application. Recent NASA LeRC's work which addressed the use of $\mathrm{CO}$ as an engine system coolant, Ref. 3-13, and experimental investigations in this area, Ref. 3-14, were the only relevant items found. It is important that fundamental $\mathrm{CO}$ cooling data be established.

Another key result of the technology review in this area was that no literature and/or data was found in the thrust chamber design area that used more than one propellant in series as a coolant. Such an engine system design feature would be highly desirable for Mars in situ-based multipropellant engine systems. It should be noted that past tripropellants engine designs were not required to be cooled in such a manner. They typically operate their various engine modes in parallel and/or use $\mathrm{H}_{2}$ as a thrust chamber coolant, which is well documented.

\subsection{Injection/Ignition/Combustion}

A number of issues were investigated in the injection/ignition/combustion technology area. Key technology and/or design issues include: 1) CO injection, ignition and combustion characteristics, 2) gas generator design for a multi-propellant Mars in situ-based tripropellant

engines, and 3) multipropellant injector design performance and thrust chamber cooling compatibility. 
The literature review indicated that fundamental $\mathrm{CO}$ injection, ignition and combustion data is lacking. No past relevant work was found except for the recent ongoing NASA LeRC study efforts examining this area, see Ref. 3-15. Such data is critical in the design and assessment of engine systems employing $\mathrm{CO}$ as a propellant.

Due to the multipropellant compatibility and the wide operating range that will likely be required of a Mars in situ-based tripropellant engine system, a conventional gas generator design may not be optimal. Recent work by NASA LeRC, Ref. 3-15, has shown that for ignition of LOX/CO, mixture ratios that are associated with relatively high combustion temperatures for gas generators may be required which will greatly affect the design and reliability of the propellant system's turbopump(s) drive turbine. Recent work by Aerojet on a stoichiometric gas generator concept, Ref. 3-16, addresses many of these issues. It is an attractive design option for inclusion in a candidate Mars in situ-based tripropellant engine system. This concept employs a small core flow at stoichiometric combustion (high temperature) conditions that is diluted downstream by the addition of propellant to a lower temperature, before it enters the turbine drive region.

Advanced ignition devices technologies, such as laser igniters, are other technology options that should be considered for Mars in situ-based tripropellant engine systems. They are relatively lightweight, reliable and have the potential to perform the ignition function for a number of propellant combinations over a wide range of operating conditions. This technology is maturing rapidly and is currently being developed for solid motor and National Aerospace Plane (NASP) applications.

Little literature or supporting data was found that addressed the issues and/or design of a single injector for more than one combination of propellants. Aerojet's past tripropellant engine design efforts did not address this issue because they employ separate embedded combustor(s) or outer ring combustor designs, see Figure 3-1. Rocketdyne's past tripropellant SSME study effort, Ref. 3-5, showed that using a single injector design for more than one propellant combination, $\mathrm{LOX} / \mathrm{H}_{2}$ and $\mathrm{LOX} / \mathrm{CH}_{4}$, was a major problem. In addition to performance issues, stability and thrust chamber cooling compatibility over a wide range of operating conditions are other issues that need further study. 


\subsection{Pumping}

Key technology/design areas associated with pumping technology of Mars in situ-based tripropellant engine systems are: 1) Warm $\mathrm{O}_{2}$ and oxidizer-rich driven turbopumps, 2) the pumping of $\mathrm{CO}$, and 3) multipropellant capable, single turbopumps designs.

Warm $\mathrm{O}_{2}$ and oxidizer-rich driven turbopump designs have been examined in the past that have applicability to the design and assessment of Mars in situ-based engine systems of interest to this study. Such a turbopump is incorporated in Aerojet's OTV engine design, Ref. 3-17. R\&D has been performed in this area for many years and some supporting fundamental data is available. Design issues associated with this class of turbopump are well understood.

Little data was found to be available in the literature on the pumping of $\mathrm{CO}$. It is believed that the best source for this data may reside in the petroleum/chemical industry, Ref. 3-18, but no effort was undertaken in this study to substantiate this claim. NASA LeRC has performed some recent work, Ref. 3-13, that addresses $C O$ pumping requirements and performance for applicable engine systems of interest. This work is preliminary in nature and needs to be substantiated by the development of a fundamental database in this area.

The literature survey showed that design issues associated with multipropellant capable, single turbopump designs are well understood, but little demonstrated capability or supporting data is available in this area. The Rocketdyne tripropellant study, Ref. 3-5, which examines the use of SSME turbopump hardware for multipropellant usage does address this issue. No substantial turbopump design and/or test work has been done in this area.

\subsection{Materials Compatibility}

The compatibility of a propellant and/or its by-products (after it is burned with another propellant) with which the engine material interfaces is critical for all the major subsystems/components, such as the propellant tank(s), fuel line(s), valve(s), turbopump(s), thrust chamber, and nozzle of any liquid propulsion system.

The multipropellant capability, wide operating range, and the maximum use of common hardware for engine systems of interest in this study, stress the material options and technologies available to support its development. Key design and technology issues examined in this area were: 1) Warm $\mathrm{O}_{2}$ and oxidizer-rich turbine materials that are compatible, 2) $\mathrm{O}_{2}, \mathrm{CH}_{4}$ and $\mathrm{CO}$ 
compatible materials for thrust chamber applications, and 3) materials that are all compatible with $\mathrm{CO}, \mathrm{CH}_{4}$ and $\mathrm{H}_{2}$ for common fuel propellant tank applications.

The literature survey identified some fundamental data on warm $\mathrm{O}_{2}$ and oxidizer-rich turbopump turbine materials. Aerojet has been active in this area for many years. An example of the data available, depicted in Table 3-1 and discussed in Ref. 3-19, shows compatibility data for candidate $\mathrm{O}_{2}$ driven turbopump materials. Review of the literature in this area has shown that design issues associated with this area are well understood but that more data is required to properly design such systems with a high degree of confidence.

Table 3-1. Example Propellant/Material Compatibility Data - Candidate Burn Resistant Materials for Oxygen-Driven Turbopumps* -

\begin{tabular}{|l|r|l|}
\hline \multicolumn{1}{|c|}{ Material } & $\begin{array}{c}\text { Burn } \\
\text { Factor }\end{array}$ & \multicolumn{1}{c|}{ Observations } \\
\hline Zirconium Copper & 35 & No Ignition in Any Test $\left(790 / 1800^{\circ} \mathrm{F}\right)^{* *}$ \\
Nickel 200 & 550 & Ignition Above $2200^{\circ} \mathrm{F}$ in FRT Only $\left(825 / 220^{\circ} \mathrm{F}\right)$ \\
Silicon Carbide & 1145 & No Ignition in Limited Testing $\left(850 /-{ }^{\circ} \mathrm{F}\right)$ \\
Monel 400 & 1390 & Ignition Above $1200^{\circ} \mathrm{F}$ FRT Only $\left(800 / 1200^{\circ} \mathrm{F}\right)$ \\
K Monel-500 & 2090 & Ignition Above $1500^{\circ} \mathrm{F} \mathrm{FRT}\left(750 / 1500^{\circ} \mathrm{F}\right)$ \\
Inconel 600 & 3226 & Ignition Above $1100^{\circ} \mathrm{F}\left(-11000^{\circ} \mathrm{F}\right)$ \\
316 Stainless Steel & 4515 & Ignition in All Tests $\left(450 / 800^{\circ} \mathrm{F}\right)$ \\
Invar-36 & 5444 & Ignition in All Tests $\left(675 / 340^{\circ} \mathrm{F}\right)$ \\
Hastelloy-X & 7160 & Ignition in All Tests $\left(725 / 750^{\circ} \mathrm{F}\right)$ \\
\hline
\end{tabular}

* L. Schoenman, AIAA Journal of Propulsion and Power, Volume 3, No. 1, Jan-Feb 1987, Pages 46-55.

** Temperatures from particle impingement test friction rubbing test (FRT) at $1000 \mathrm{psi}$ and $17,000 \mathrm{rpm}$.

Materials compatibility data for $\mathrm{CO}$ was found to be lacking. Little was found in the open aerospace literature. Only one document in this area was found to be relevant, Ref. 3-20, but was classified and could not be reviewed. A discussion with an expert in this field, Ref. 3-19, indicated that the petroleum/chemical industry is probably the best source for this information, but no effort in this study was undertaken to substantiate this claim. Additionally, this expert claimed that for a first approximation, to support preliminary design efforts, that materials which are compatible with $\mathrm{CH}_{4}$ would likely be compatible with $\mathrm{CO}$ except for materials that have iron content. Fundamental data needs to be established in this area. 
Little data was found to be available that addresses the common compatibility of a number of propellant of interest in this study $\left(\mathrm{O}_{2}, \mathrm{CH}_{4}, \mathrm{H}_{2}\right.$ and $\left.\mathrm{CO}\right)$, with material candidates that are used in thrust chambers, propellant tanks, lines, and valves. Some fundamental data was found to be available for many specific propellant/material combinations. Data needs to be established experimentally in this area to address the commonality issue. Based on the literature, Table 3-2 presents a "top-level" preliminary propellant/material compatibility screening summary for many of the materials and propellants of interest to Mars in situ-based propulsion systems. 


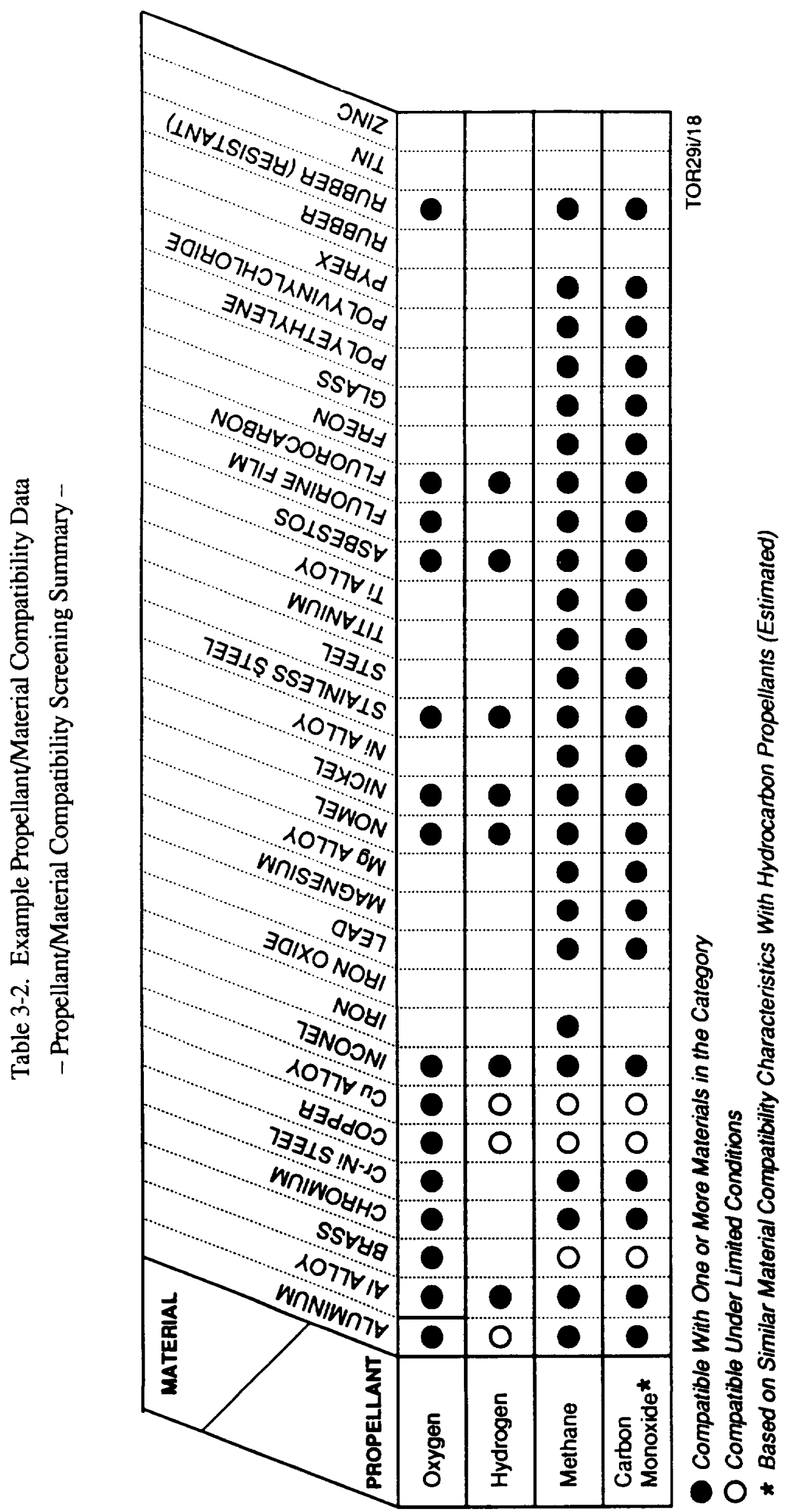





\subsection{PROPULSION SYSTEM DESIGN}

The principal goal of this study effort portion was to characterize promising systems that can efficiently use the multiple propellant combination of interest to this study, $\mathrm{LOX} / \mathrm{H}_{2} / \mathrm{CO}$, $\mathrm{LOX} / \mathrm{H}_{2} / \mathrm{CH}_{4}$ and $\mathrm{LOX} / \mathrm{CO} / \mathrm{CH}_{4}$. This effort focused on defining representative engine systems that meet the overall mission requirements such as performance, weight, thrust level, throttling and operation mode (series operations), for many of the scenario options discussed in Section 2.0. Additionally, these representative engine systems were configured to: 1) use the maximum amount of common engine system hardware, while attempting to minimize engine system mass, and 2) exhibit high performance for each engine operating mode and range of interest.

Major tripropellant engine system elements considered for commonality are shown in Figure 4-1. These engine system elements included the fuel propellant tank, oxidizer feed system, injector, thrust chamber, and nozzle. For the initial study effort, common fuel feed systems were not considered due to the inherent difference in pumping requirements for the fuels considered. Such requirements would produce a common fuel turbopump design that would operate inefficiently over the range in which it would be required to operate. This design issue was addressed in a preliminary manner in the latter portion of this study. Additionally, in a latter portion of this effort, propellant tank system sizing and commonality issues are also addressed.

To perform this effort, top-level engine system requirements were established from the initial mission analysis results discussed in Section 2.0. Promising engine system concepts were then identified for further study. A baseline technology/design database was then established for each engine system concept. The database drew on results from the initial technology review that is discussed in Section 3.0. These candidate engine system concepts were then analyzed by using SAIC's version of the Expanded Liquid Engine System (ELES) analysis code, see Refs. 4-1 and 4-2. Using ELES, numerous design sensitivity analyses were performed to determine the influence of key engine system parameters such as: mixture ratio, chamber pressure, nozzle area ratio, injector pattern density and type, turbine bypass, regenerative cooling channel bypass, turbine inlet temperature, and thrust chamber channel design geometry. From these sensitivity studies, representative engine systems were identified. Propellant tank system requirements were established, and design and sizing of representative candidate systems using the ELES analysis code was then performed at the conclusion of this study effort. 


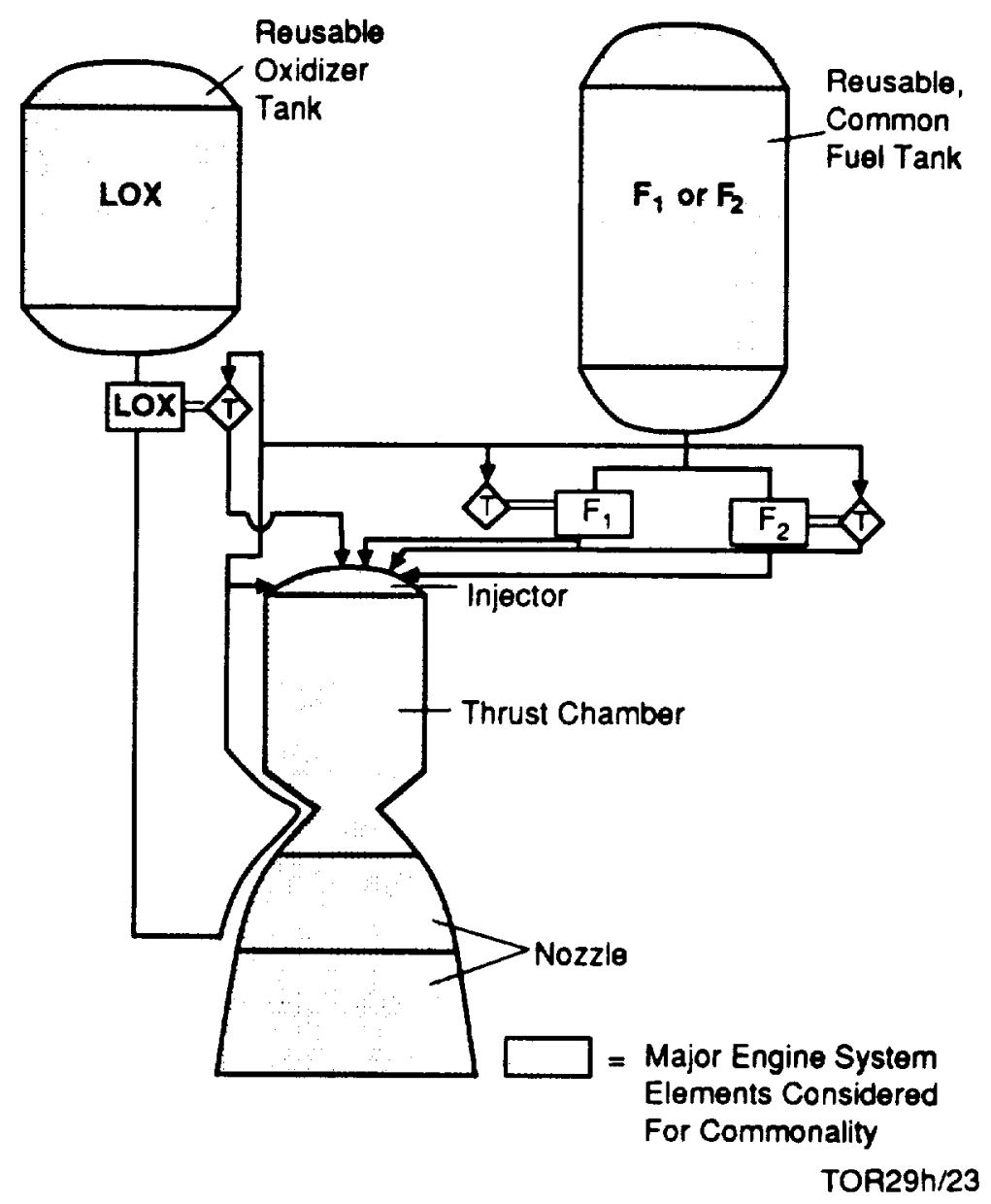

Figure 4-1. Representative Tripropellant Engine System Common Hardware Elements

The following discussion highlights the engineering assumptions and rationale and results in characterizing representative common tripropellant propulsion system candidates to support in situ propellant-based Mars missions.

\subsection{Engine System Requirements Concepts}

Engine system design requirements were derived from the initial mission analysis assessment discussed in Section 2.0. From these requirements, top-level baseline representative engine system concepts were identified that addressed a large portion of the mission scenarios considered in this study. These engine system concepts were then defined and characterized in more detail in the engine assessment portion of the study, see Section 4.2. The following sections address the development and rationale of the engine system design requirements and the identification of the baseline engine system concepts. 


\subsubsection{Identification of Requirements}

Figure 2-2 shows the two basic mission profiles that were considered for this study that use ISPP resources. Mission Profile No. 1, which corresponds to Scenarios 2, 3, and 4, uses some form of in situ propellants from both the Moon and Mars, and Mission Profile No. 2, which correspond to Scenarios 6 and 7, employs only Mars in situ-produced propellants. Review of the initial mission analysis results and their corresponding requirements indicates that the in situ engine system commonality would best be leveraged for the transfer vehicle outbound and inbound mission elements. Little differences in engine system requirements, such as for thrust level and acceleration profiles, were found for these mission elements. Likewise, it was noted that a high proportion of the overall mission delta- $\mathrm{v}$ is associated with these mission segments. Large differences in excursion vehicle engine system requirements, such as thrust levels and acceleration profiles, were also observed. From this initial assessment of requirements it was concluded for further study that: 1) the baseline engine system(s) be based on transfer vehicle requirements, and 2) that these baseline engine system(s) and/or their hardware be used only where possible to meet excursion vehicle requirements.

Other engine system design assessment requirements specified are that the baseline engine system examined should be easily scalable in terms of thrust level and address key functions, design issues, and technologies that are representative of such systems. Due to the nature of the deep space missions considered, high reliability and reusability (five missions) would be required. This was addressed in the study by employing one or both of the following approaches: 1) sizing the propulsion system with engine out capability and/or 2) operating at a derated power level for most of the mission operation profile. Because of man-rating considerations, a maximum vehicle acceleration level of $3 \mathrm{~g}$ 's was assumed which is directly related to an engine system's throttling requirements. A conservative limit of $2.8 \mathrm{~g}$ 's was used in the requirements analysis.

Considering many of the just mentioned engine system requirements and reviewing the initial mission analysis results, top-level requirements for baseline engine system candidates were derived which are displayed in Table 4-1. These candidate engine systems address a large portion of mission scenario trade space as shown in Table 4-2. At least one engine concept shown in Table 4-1 applies to all deep space transfer and excursion mission segments which employ multiple fuels to perform the mission. The LEO $\rightarrow$ LLO transfer mission phase is not addressed by any of the engine system concepts because the transfer vehicle uses an expendable $\mathrm{LOX} / \mathrm{H}_{2}$ stage that is a more conventional engine system, which is not of interest to the study. Likewise, the engine system concepts do not address Scenarios 1 and 5 because they use only conventional single- 
propellant combinations, $\mathrm{LOX} / \mathrm{H}_{2}$ and $\mathrm{LOX} / \mathrm{CH}_{4}$, respectively. Table 4-3 shows the number of engines, the percent power rating level, and engine out capability, if specified, by each mission segment for each applicable engine system concept.

Table 4-1. Top-Level Requirements for Engine System Candidates

\begin{tabular}{|l|c|c|c|}
\hline \multicolumn{1}{|c|}{ Concept No: } & 1 & 2 & $\mathbf{3}$ \\
\hline Propellants & $\mathrm{LOX} / \mathrm{H}_{2} / \mathrm{CO}$ & $\mathrm{LOX} / \mathrm{H}_{2} / \mathrm{CH}_{4}$ & $\mathrm{LOX} / \mathrm{CH}_{4} / \mathrm{CO}$ \\
Thrust Level (bf): & 175,000 & 250,000 & 175,000 \\
Throttling Range: & $5: 1$ & $2.2: 1$ & $6: 1$ \\
\hline
\end{tabular}

\subsubsection{Engine System Cycle Considerations/Recommendations}

After initial sizing of the baseline engine systems was completed, engine system options and their applicability to meet the tripropellant Mars in situ propellant engine system requirements, were then addressed. Table 4-4 lists the numerous candidate engine cycles considered. Assessment factors used in evaluating these engine cycles are given in Table 4-5. These factors are highly coupled to overall requirements unique to the missions of interest. Table 4-5 also shows how these factors impact engine cycle design characteristics. A top-level comparison of these engine cycle candidates is shown in Table 4-6. Major advantages and disadvantages of each engine cycle option are presented as well as a qualitative assessment of its applicability to meet in situ propellant-based Mars evaluation factors.

The staged combustion cycle maximizes performance for a given engine size by eliminating secondary flow losses and by maximizing the energy available to drive the turbine. The turbomachinery is subjected to high-pressure operating conditions because the turbine drive gases are injected into the main combustion chamber at its stagnation chamber pressure level. This exposes the main injector to high-temperature turbine gases. Though it exhibits good performance and thrust-to-weight traits, it has marginal reliability and multipropellant capability qualities because of its inherent complexity.

The gas generator cycle is a simplified system that maximizes the independence of the components, which is done by placing the turbine gas flow path in parallel with the thrust chamber gas flow path. It also lends itself to independent component experimental development that helps ensure high initial system reliability. The gas generator cycle, due to its simplicity and operational maturity, meets all assessment factors positively except for performance which is marginal. 


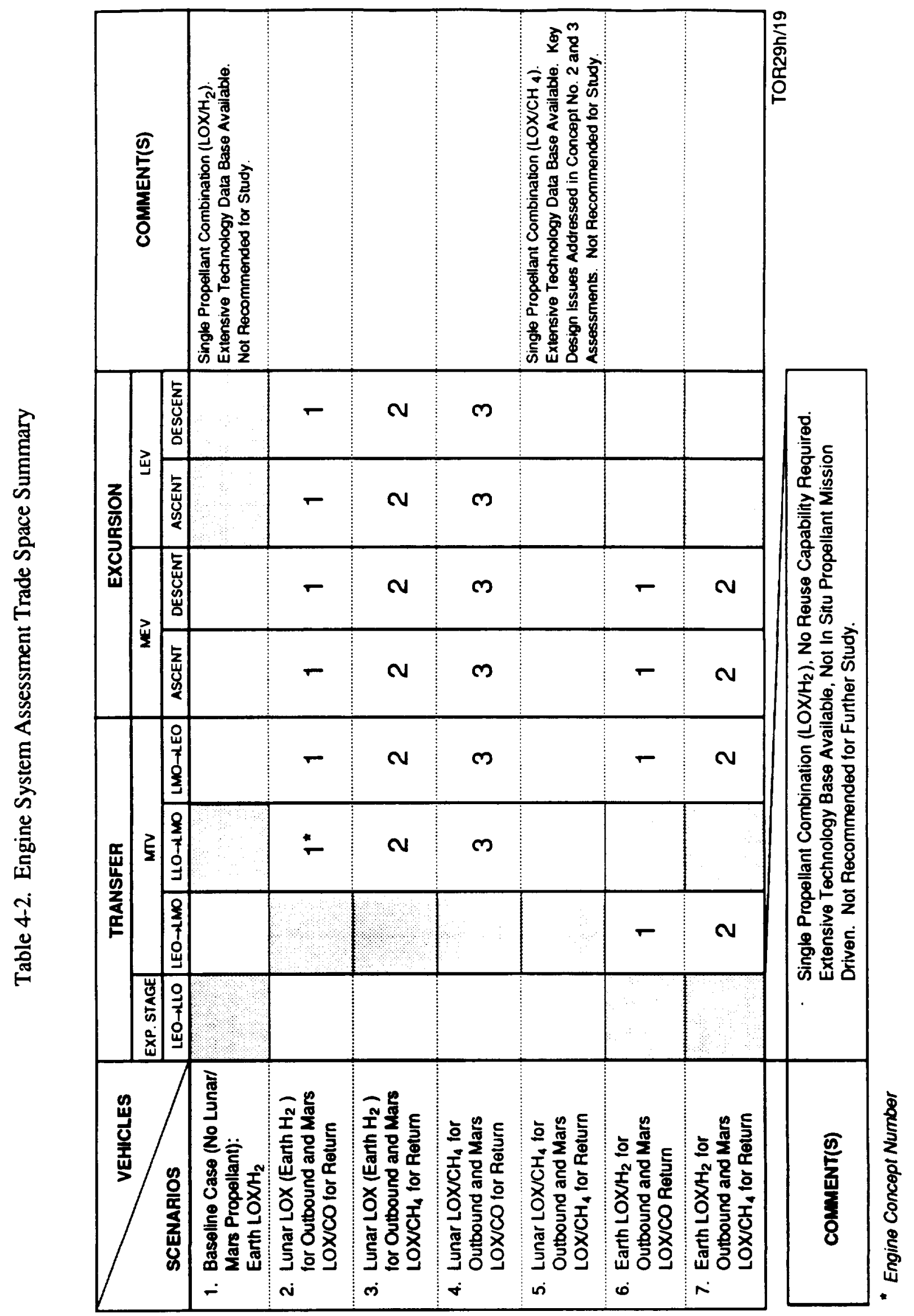




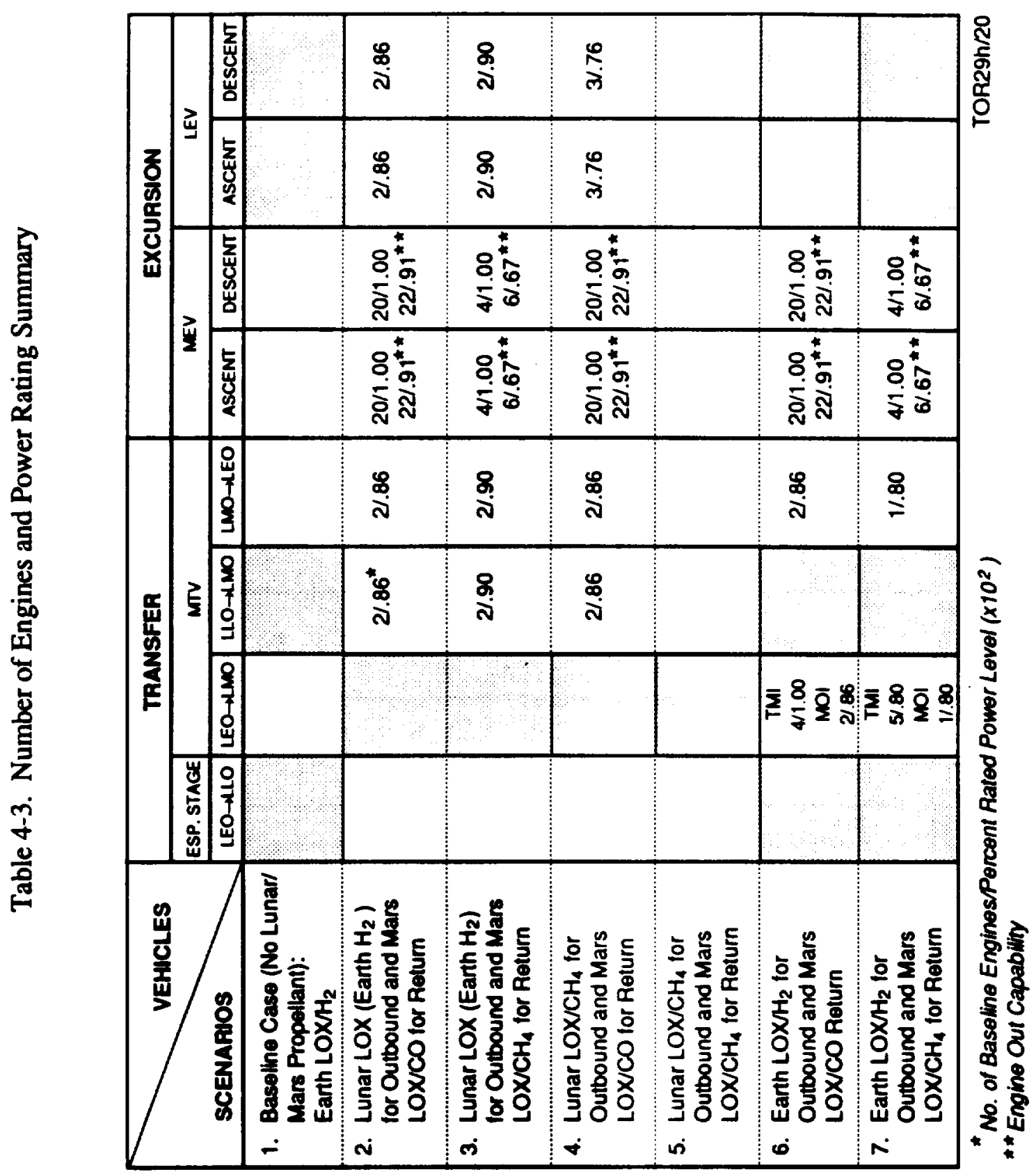


Table 4-4. Candidate Engine Cycles

- Staged Combustion

- Gas Generator

- Expander

- Hybrid Staged Combustion

- Augmented Expander

- Dual Expansion

- High Pressure, Low Pump Discharge

- Thrust Chamber Tapoff

- Full Bleed Cycle

Table 4-5. Key Engine Cycle Assessment Factors for In Situ Propellant-Based Mars Missions and Their Impact on Engine Cycle Design

- High Performance

- High Reliability $\rightarrow$ Simple Design

- High Thrust/Weight $\rightarrow$ High Pressure Operation, Compact Packaging

- Throttleability $\rightarrow$ Controllable, Simple Design

- Multi-Propellant Capability $\rightarrow$ Simple Design/Operation

- Maturity

Maximum performance can be obtained by employing an expander cycle for a given engine complexity by eliminating both the secondary flow losses and the need for a hot-gas preburner. It is the most benign system for the turbomachinery, but is limited to maximum chamber pressure operation by the available energy to drive the turbines. This results in a relatively low chamber pressure that translates into low thrust-to-weight and large engine systems. Like the staged combustion cycle, it is a high coupled, complex system. Its applicability is for low-thrust and high-altitude (orbit transfer) engines. Though rating high on performance, reliability, and operational maturity, it exhibits low thrust-to-weight and marginal throttleability and propellant compatibility characteristics.

The remaining engine cycles considered in Table 4-6 are derivatives and/or combinations of the basic three-cycle types just mentioned. These remaining engine cycle options exhibit little in terms of positive features to meet the engine assessment requirements. 


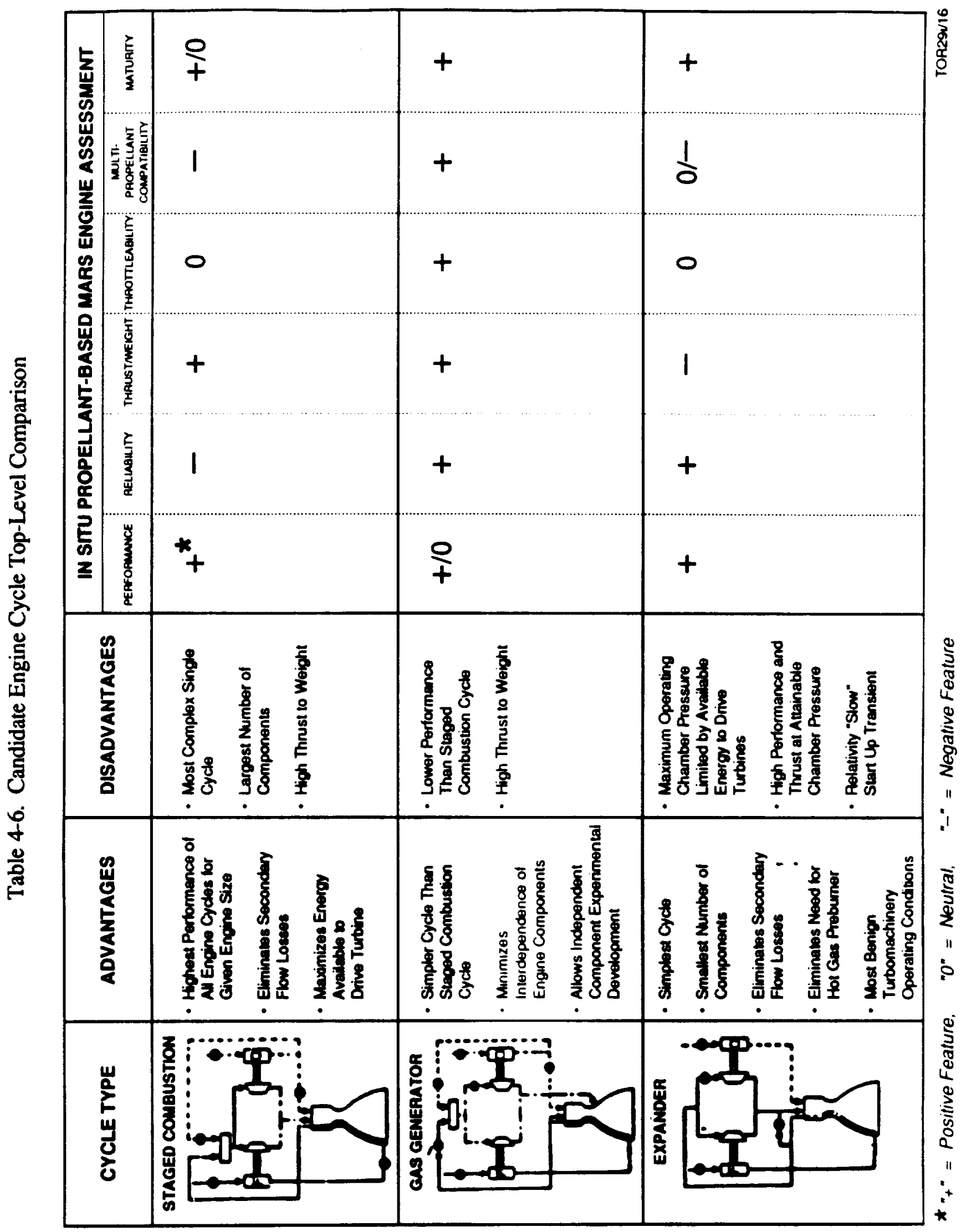




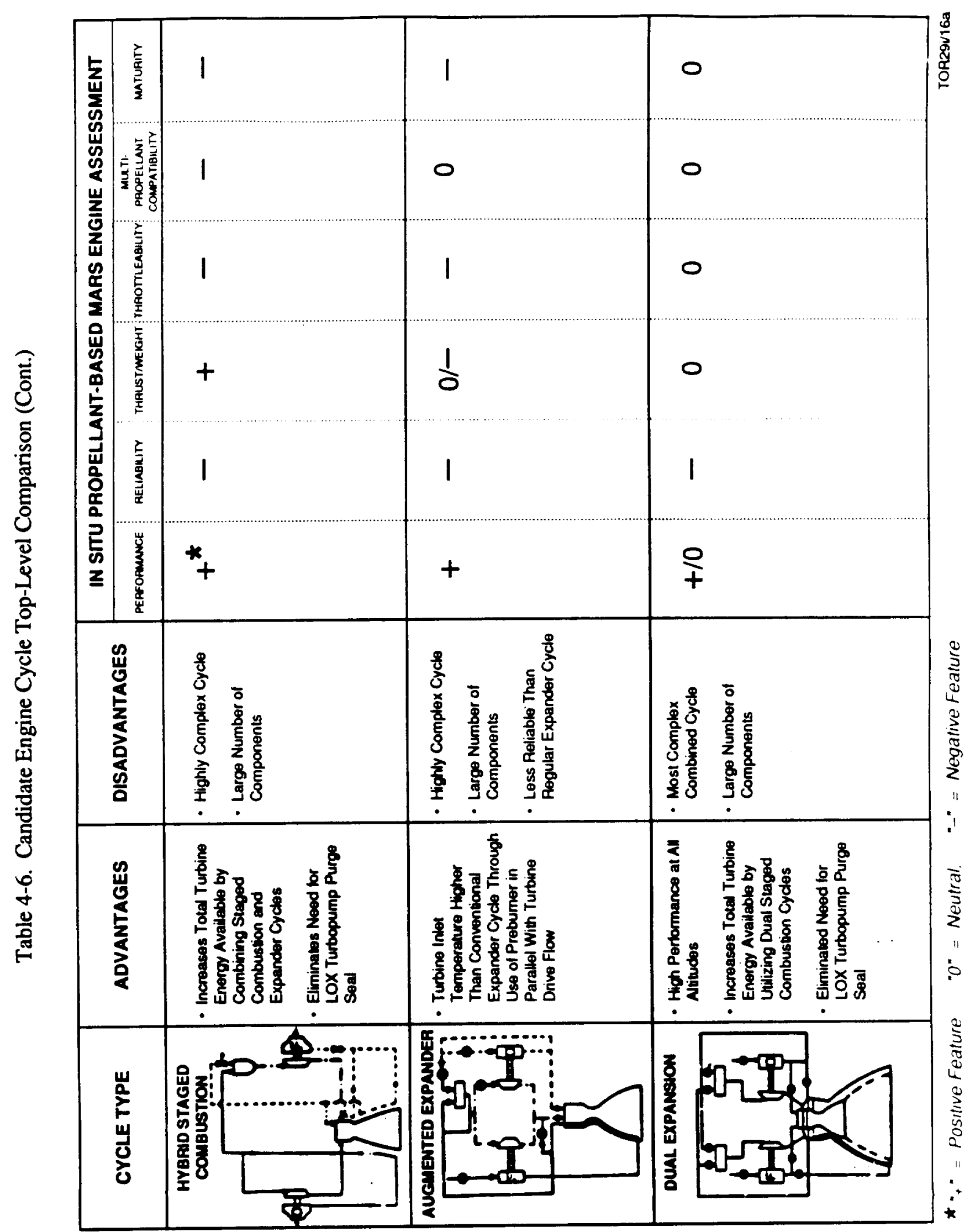




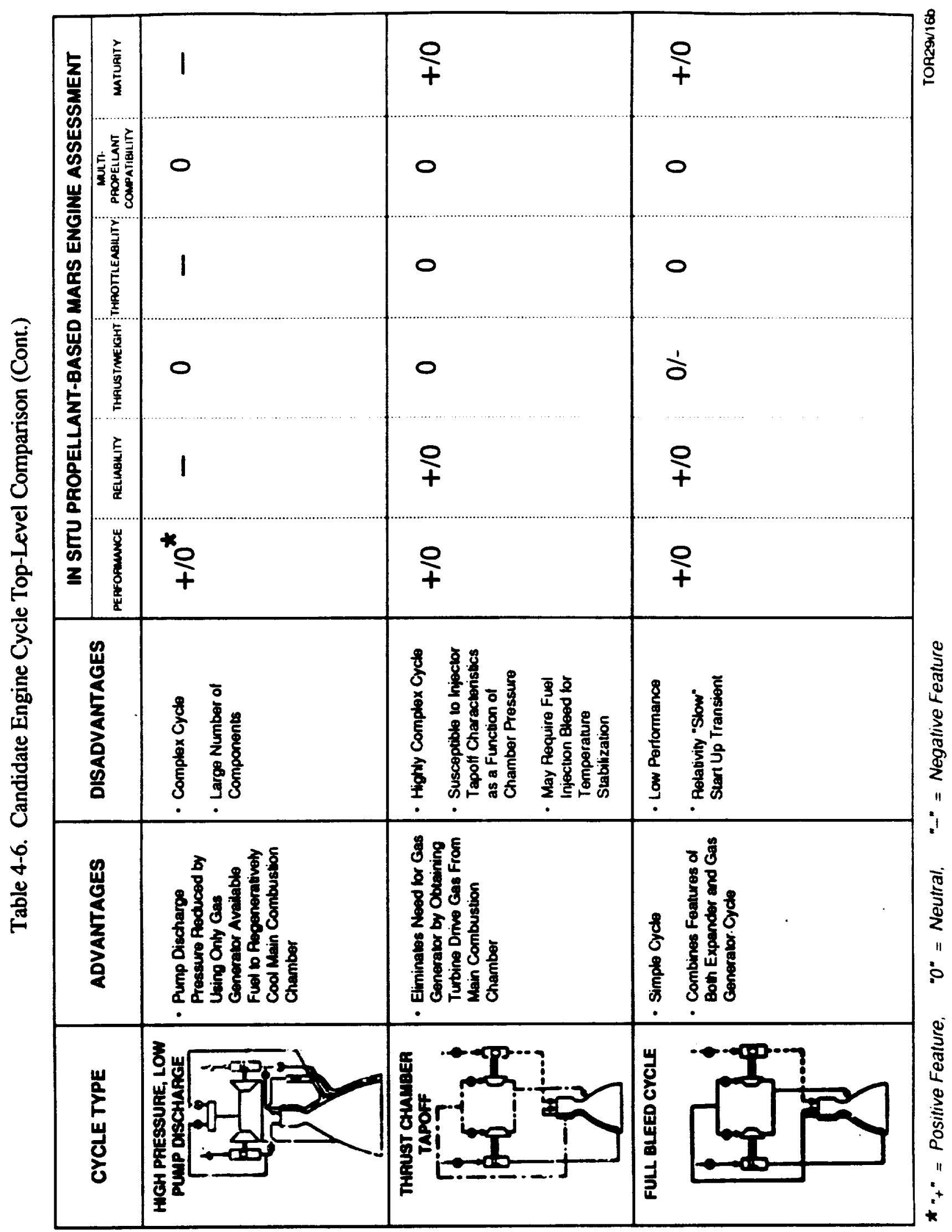


Based on this assessment, expander and gas generator engine cycles were selected for further study. The cycles demonstrate many key engine features, shown in Table 4-7, that are typical of Mars in situ propellant-based engine design options. By examining both engine cycles one bounds, from a technical perspective, the range of available options. The expander cycle, which is high performance, complex, and exhibits low thrust-to-weight, represents one class of engine system designs, while the gas generator cycle, which is simpler, with moderate performance and high thrust-to-weight characteristics, represents an engine class substantially different than the expander cycle. Both engine cycles have been demonstrated in operational systems and have been shown to be highly reliable.

Table 4-7. Engine Cycles Which Demonstrate Many Key Engine Features of Interest

- Expander
- High Performance
- Low Thrust/Weight Ratio
- Coupled Design/Operation
- Gas Generator
- Moderate Performance
- High Thrus/Weight Ratio
- Decoupled Design/Operation
- Both
- Highly Reliable
- Demonstrated Maturity

Another key result of the assessment was that for all the engine systems to be investigated, all of them are to be cooled with LOX through all modes of their operation. This engine system design feature was selected because: 1) oxygen is a common lunar/Mars in situ propellant resource, and 2) it eliminated multipropellant cooling design issues that were discussed in more detail in Secrion 3.0.

The generic tripropellant engine system cycles selected for detailed study are displayed in Figure 4-2. For these LOX-cooled systems, note that a common multipropellant-compatible fuel tank, LOX tank and feed system, autonomous pressurization system, injector, thrust chamber, and nozzle are used in all operating modes. Each fuel has its own independent feed system, as previously mentioned. 


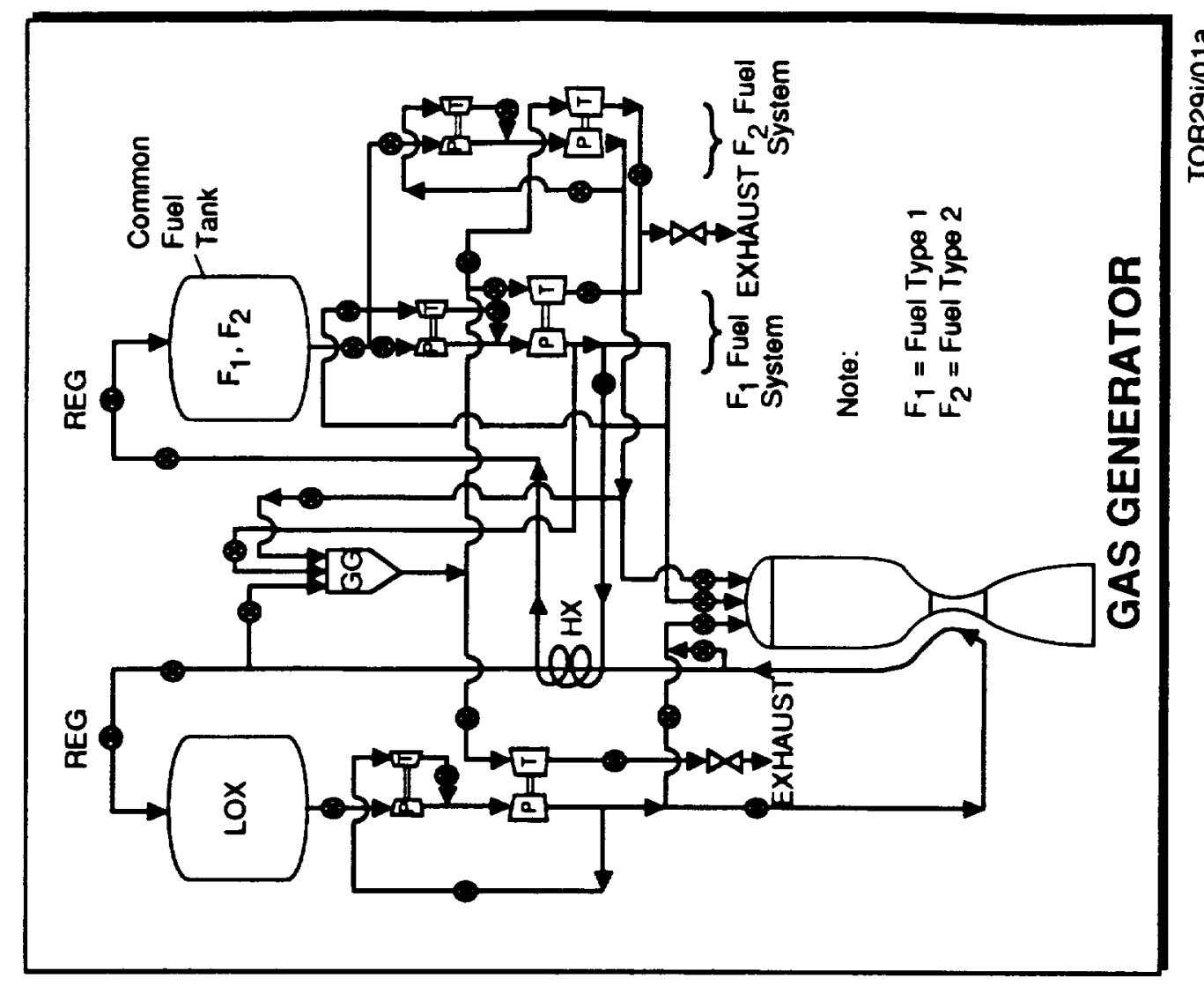

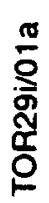

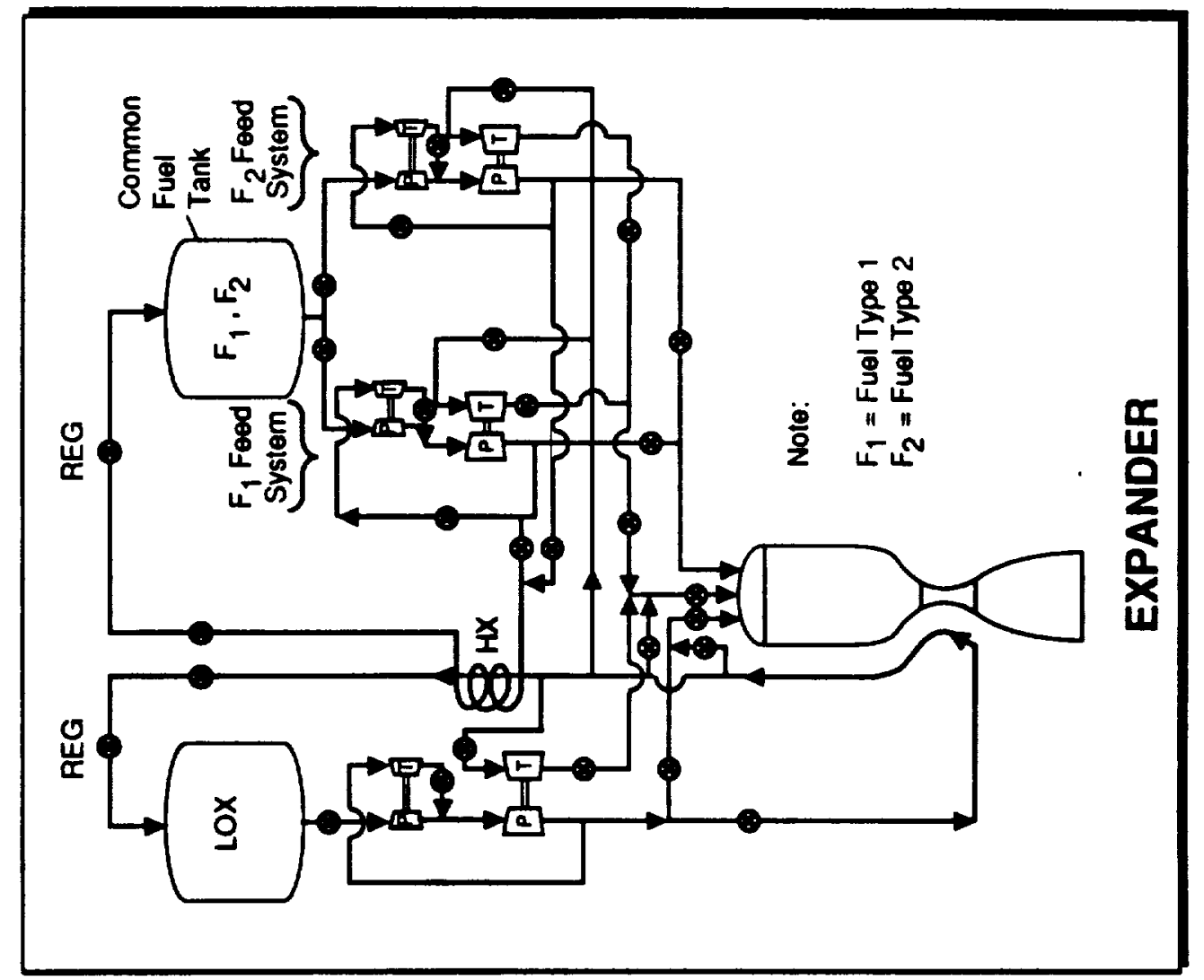




\subsection{Engine System Assessment}

Based on initial engine system requirement/concept definition results discussed in Section 4.1, many candidate baseline propulsion system configurations were defined and analyzed in detail with SAIC's version of the ELES analysis code. Numerous engine system design sensitivity trades were conducted on the candidate baseline engine concepts. From these results, baseline tripropellant MTV and bipropellant engine system designs were identified and characterized. These engine system designs were then used to update overall mission performance, and to identify critical technology and design issues that are discussed in Sections 5.0 and 6.0, respectively. The following sections discuss the analysis approach, assumptions, and results associated with the assessment of the engine system designs.

\subsubsection{Assessment Approach and Assumptions}

Numerous baseline engine systems were defined and characterized. Three tripropellant engine systems for MTV applications and many bipropellant engine system versions of these engines for LEV and MEV applications were assessed. Expander and gas generator engine versions of each engine option were evaluated. Table 4-8 summarizes these baseline engine system options. This translates into a family of engines for each engine concept, as is shown in Figure 4-3.

Table 4-8. Baseline Engine Systems Defined

- Three (3) Engine Concepts (Propellant Combinations):

- MTV Engine Options:

.. LOX $/ \mathrm{H}_{2} / \mathrm{CO}-175,000 \mathrm{lbf}$ Thrust

.- LOX/ $/ \mathrm{H}_{2} / \mathrm{CH}_{4}-250,000 \mathrm{lbf}$ Thrust

.. LOX/CH $4 / \mathrm{CO}-175,000 \mathrm{lbf}$ Thrust

- LEV and MEV Engine Options:

-. LOX/H

-. LOX/CO Many Engine Versions as a Function of Engine Concept

.. LOX $\left./ \mathrm{CH}_{4}\right\}$

- Expander and Gas Generator Engine Cycle Versions Were Evaluated for Each Engine Option Listed Above

As previously mentioned, SAIC's version of the ELES analysis code was used to characterize the baseline engine systems. ELES, see Ref. 4-1 and 4-2, is an industrial standard analysis code that designs and determines operational parameters and performance of liquid propulsion systems. It employs empirical and mechanistic design approaches to predict overall 
propulsion system and subsystem dimensions, weights, operating characteristics, and performance. It has the capability to model a wide range of engine cycles, cooling options, engine and tankage configurations, system component parameters, and construction materials. Additionally, it has the capability to perform vehicle stage and tank system designs. ELES has been verified extensively against real operational propulsion systems, see Ref. 4-3.

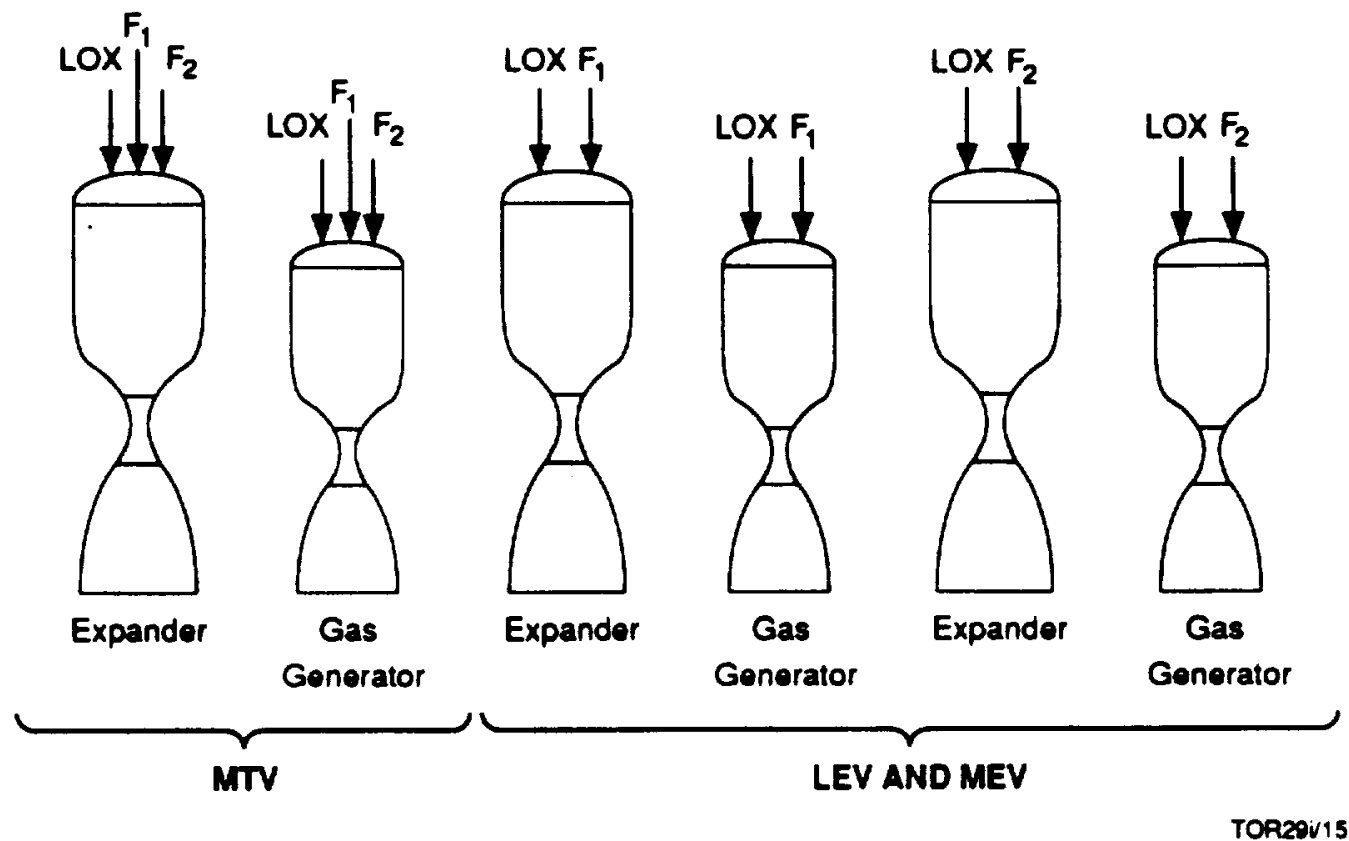

Figure 4-3. Definition of an Engine Family for Each Engine Concept

To perform the engine system analysis, a $\mathrm{CO}$ propellant properties library and an offdesign engine operation analysis capability were incorporated in ELES. The off-design analysis capability is an essential requirement to characterize the tripropellant engine options. This is because once an engine system hardware design is established for one operational mode using one bipropellant combination, it then must be characterized for a different operational mode that uses, possibly, a different bipropellant combination. Appendix B summarizes the modifications that were performed to ELES to provide the off-design analysis capability.

In performing the many engine design sensitivity trade studies, numerous parameters were investigated. Major parameters examined are listed in Table 4-9. Key screening criteria used in evaluating the trade study results are given in Table 4-10. All screening criteria were considered and sound engineering practice was applied in assessing the results. Specific impulse, engine system weight, size and operating conditions, and their comparison to state-of-the-art (SOA) technology limits were primary evaluation considerations; the impact of an engine design parameter 
on in situ architecture infrastructure requirements was given secondary importance. Engine parameter ranges and design features that produce engine systems which exhibit one or more of the following engine system traits: 1) high specific impulse, 2) low engine system weight, 3) small size, 4) do not stress the design technology, and 5) reduce in situ infrastructure requirements are features that would be considered for inclusion in a baseline engine system design.

Table 4-9. Major Engine System Design Parameters Examined

- Chamber Pressure
- Mixture Ratio
- Regen Chamber Bypass
- Turbine Bypass
- Area Ratio
- \% Nozzle Length
- Chamber Length
- Injector Type
- Injector Density

Table 4-10. Key Screening Criteria Used

- Specific Impulse

- Engine System Weight

- Size

- Operating Conditions All Within State-of-the-Art Limits

- Effect on In Situ Architecture Infrastructure Requirements

Other design assessments and comparisons were also conducted in this study effort. These included: evaluating, translating nozzle design packaging and its associated weight and performance impact for expander engines, turbine material effects on expander engine cycle operation, and the feasibility of using a common duel fuel turbopump feed system in the baseline tripropellant engine designs.

All the engine system designs considered in this analysis incorporated SOA materials and rocket propulsion system design practices, where appropriate. Table 4-11 summarizes these technology level considerations. Additionally, weight savings and possible gain in performance associated with the use of SOA robust engineering design analysis tools were incorporated in the analysis, and where possible the legacy of a given design assumption is shown. 
Table 4-11. Engine System Design Technology Level Considerations

- Use SOA Material Technology Where Appropriate

- Nozzle and Its Extension

- Turbopump Turbine

- Electronics

- Thrust Mount

- Incorporate SOA Rocket Design Practices

- Efficien//Stable Injectors/Injection

- High Chamber Pressure

- High Chamber Temperature

- High Heat Flux Nozzle

- High Turbopump Turbine Inlet Temperatures and Speeds

- High Pump Discharge Pressure

- Fast Response, Integrated Controls Available

The baseline engine designs feature a three-section thrust/chamber design shown in Figure 4-4. It uses a Rao nozzle contour ( $90 \%$ length) that incorporates a slotted, cooper regenerative LOX-cooled thrust chamber nozzle section to a downstream area ratio (E) of 6:1, an inconed LOX cooled tube construction segment from $E$ of $6: 1$ to an $E$ of 25:1 where a radiation cooled carboncarbon extension is attached. The extension extends to an $E$ of $400: 1$ or as specified. Some large low pressure expander engine designs incorporate a nozzle extension that translates. Chamber length in the study is defined from the injector to the nozzle throat.

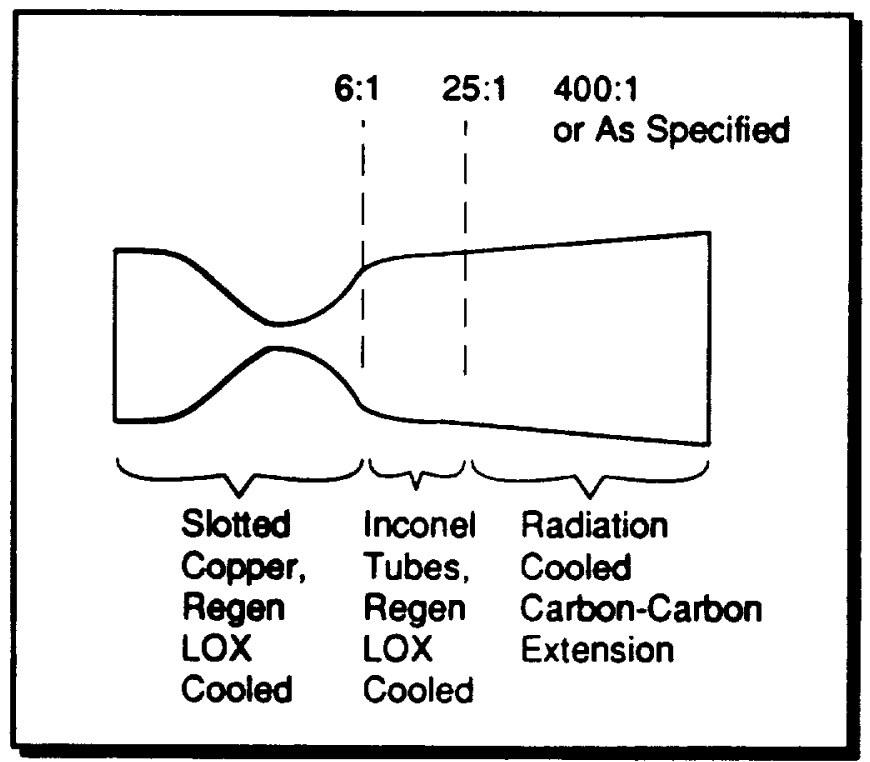

TOR29h/22

Figure 4-4. Baseline Thrust Chamber Nozzle Design Features Assumed 
Other design analysis factors and assumptions are presented in Table 4-12. The LOX/CO and $\mathrm{LOX} / \mathrm{CH}_{4}$ thrust chamber wall temperature limits are based on SOA materials compatibility data discussed in Section 3.0. The $\mathrm{LOX} / \mathrm{H}_{2}$ wall temperature limits are based on SSME experience. The turbopump limits have been well demonstrated by the SSME and the OTV, the technology demonstration engine. Minimum nozzle thickness is determined by quality control uncertainty associated with the manufacturing of a large high area ratio composite nozzle. Another key design analysis assumption is that associated with the impact of engine system weight as a function of engine throttling requirements. The ELES default weight multiplying correlation was assumed, which is shown in Figure 4-5. This correlation is based on past Lunar Excursion Module propulsion system design studies, see Ref. 4-1. Table 4-13 shows the safety factors assumed in the analysis. These safety factors are similar to those used in the SSME design. Thus, reusable, long life design margin is considered inherent in the design analysis.

Table 4-12. Other Key Design Analysis Factors/Assumptions

- Thrust Chamber Wall Temperature Limits

- $\mathrm{LOX} / \mathrm{CO}=700^{\circ} \mathrm{K}$

- $\mathrm{LOX} / \mathrm{CH}_{4}=778^{\circ} \mathrm{K}$

- $\mathrm{LOX} / \mathrm{H}_{2}=778^{\circ} \mathrm{K}$

- Turbopump Limits

- Turbine Inlet Temperature $\leq 950^{\circ} \mathrm{K}$

- Speed $\leq 60,000$ RPM

- Outlet Pressures $\leq 7,000$ psia

- Minimum High Area Ratio Nozzle Extension

Exit Thickness $=2.5 \mathrm{~mm}(0.1 \mathrm{in}$.)

- Lightweight Carbon-Carbon Nozzle Translation Mechanism Assumed

- Baseline Tank Used for Engine System Analysis

- 68,050 kg Total Propellant

- Run Time Range: 220-400 Seconds

- Diameter: $457 \mathrm{~cm}$

- Length Range: $560-685 \mathrm{~cm}$ 


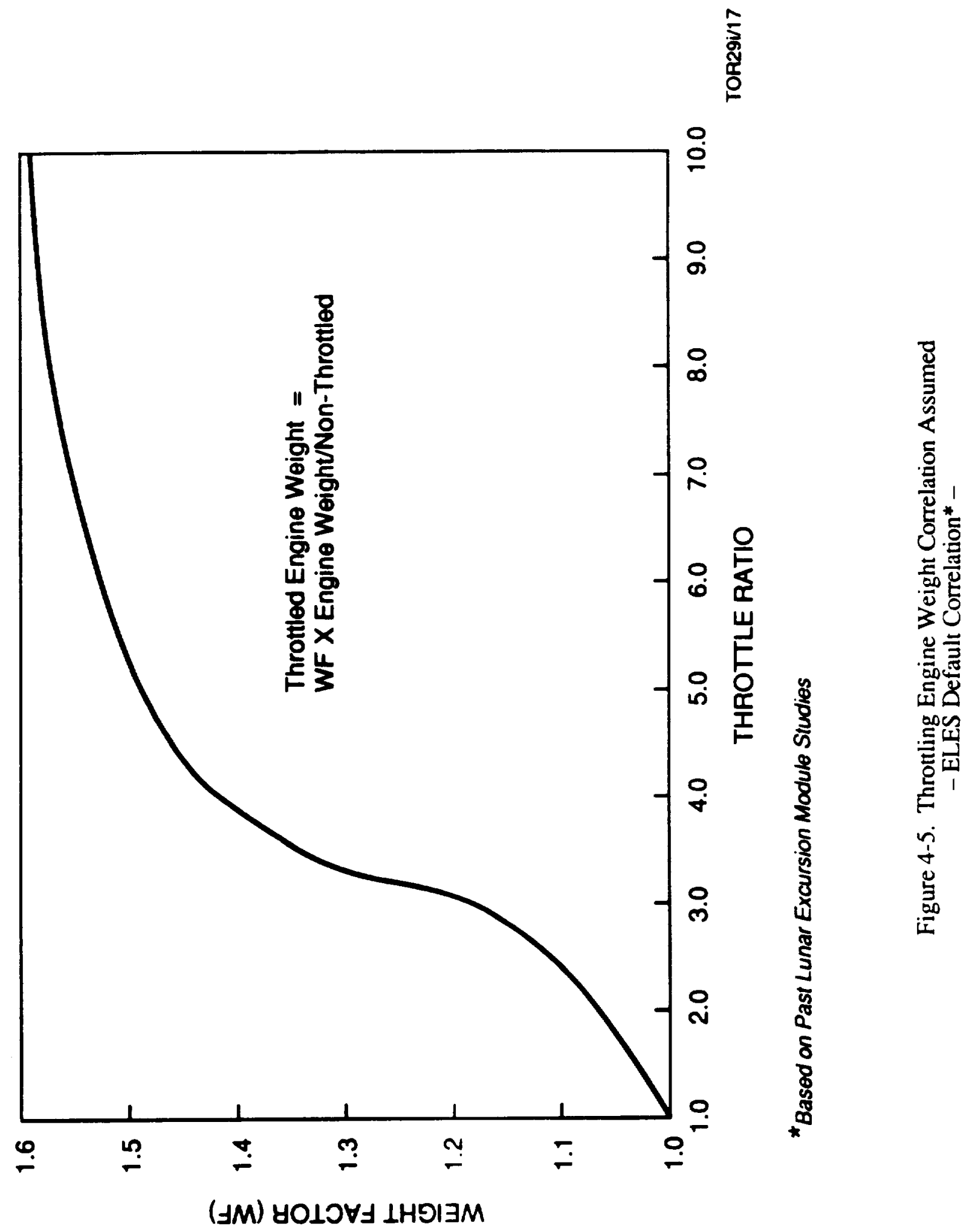


Table 4-13. Safety Factors Assumed

- All Components, Except Lines:

- 1.1 of Yield

- 1.4 of Ultimate

- Lines - 2.0 Ultimate

Major engine component materials and design approaches employed in all the engine designs evaluated are summarized in Table 4-14. All materials and design approaches considered have a strong operational and/or development base legacy. Likewise, the materials selected for each design should be compatible with the propellants and combustion products, as well as the operating conditions to which they are exposed.

Table 4-14. Major Engine Component Materials and Design Approaches Assumed

\begin{tabular}{|c|c|c|c|}
\hline Component(s) & Meterial & Deslgn Approach & Comment(s) \\
\hline Injector & Inconel & $\begin{array}{l}\text { - High Density, Co-Axial } \\
\text { Design }\end{array}$ & $\begin{array}{l}\text { - Used on SSME } \\
\text { - Extensive R\&D Base }\end{array}$ \\
\hline $\begin{array}{l}\text { Thrust Chamber and } \\
\text { Upstream Nozzle } \\
-\quad \varepsilon \text { altachment }=6: 1\end{array}$ & Copper Alloy & $\begin{array}{l}\text { - High Heat Flux Thin } \\
\text { Slotted Wall Construction } \\
\text { - LOX Cooled }\end{array}$ & $\begin{array}{l}\text { - Used on SSME } \\
\text { - Extensive R\&D Base }\end{array}$ \\
\hline $\begin{array}{l}\text { Nozzle } \\
-\quad \text { Eldownstream }=6: 1 \text { to } \\
\text { Eldownstream }=25: 1\end{array}$ & Inconel & $\begin{array}{l}\text { - Tube Constructed } \\
\text { - LOX Cooled }\end{array}$ & $\begin{array}{l}\text { Used on SSME and } \\
\text { Many Other Engines }\end{array}$ \\
\hline $\begin{array}{l}\text { Nozzle Extension } \\
- \text { Eldownstream }=25: 1 \text { to } \\
\text { Eldownstream }=400: 1 \\
\text { or as specified }\end{array}$ & $\begin{array}{l}\text { High Temperature Carbon-Carbon } \\
\text { With Oxidation Resistant Coating } \\
\text { - Renium or Nirobium } \\
\text { Coating Candidates } \\
\text { - Translating Nozzle } \\
\text { Design, if Specified }\end{array}$ & $\begin{array}{l}\text { - Radiation and/or } \\
\text { Film Cooled }\end{array}$ & $\begin{array}{l}\text { - Based on Solid } \\
\text { Propulsion, NASP, } \\
\text { and R\&D Technology } \\
\text { B ases }\end{array}$ \\
\hline $\begin{array}{l}\text { Main Fuel and Oxidizer } \\
\text { Valves }\end{array}$ & Inconel & - & $\begin{array}{l}\text { - Material Used } \\
\text { in SSME }\end{array}$ \\
\hline $\begin{array}{l}\text { Low Pressure Fuel and } \\
\text { Oxidizer Turbopumps }\end{array}$ & Inconel & - Bootstrap Boost Pump & $\begin{array}{l}- \text { Material Used } \\
\text { in SSME }\end{array}$ \\
\hline $\begin{array}{l}\text { High Pressure Fuel and } \\
\text { Oxidizer Turbopumps } \\
\text { - Pumps } \\
\text { - Turbine } \\
\text { - Housing }\end{array}$ & $\begin{array}{l}\text { - Inconel } \\
\text { - Monel Alloy (500) } \\
\text { - Inconel }\end{array}$ & $\begin{array}{l}\text { - Direct Drive Turbopumps } \\
\text { - Axial Turbine } \\
\text { - Centrifugal Pump }\end{array}$ & $\begin{array}{l}\text { - Used in SSME } \\
\text { - R\&D Base and OTV } \\
\text { Technology Dev. } \\
\text { - Used in SSME }\end{array}$ \\
\hline Gas Generator & Inconel & $\begin{array}{l}\text { - Uses Multi-Propellants } \\
\text { - Low Pressure } \\
\text { - Low Mixture Ratio }\end{array}$ & - Used in SSME \\
\hline $\begin{array}{l}\text { Propellant Lines/ } \\
\text { Valves/Supports }\end{array}$ & Inconel & $\rightarrow$ & - Used in SSME \\
\hline
\end{tabular}


The overall engine system trade space evaluation process is displayed in Figure 4-6. In defining a tripropellant engine system, an optimum or near-optimum design would be established first for one bipropellant combination. Then, the other bipropellant combination is analyzed through the fixed engine design to determine its performance and operational characteristics. The expander cycle engine designs were established first; these were followed by the gas generator cycle engine designs. During the analysis, as optimal design parameter(s) or feature(s) were identified for a given propellant combination and design type, they were then baselined for similar engine design concepts.
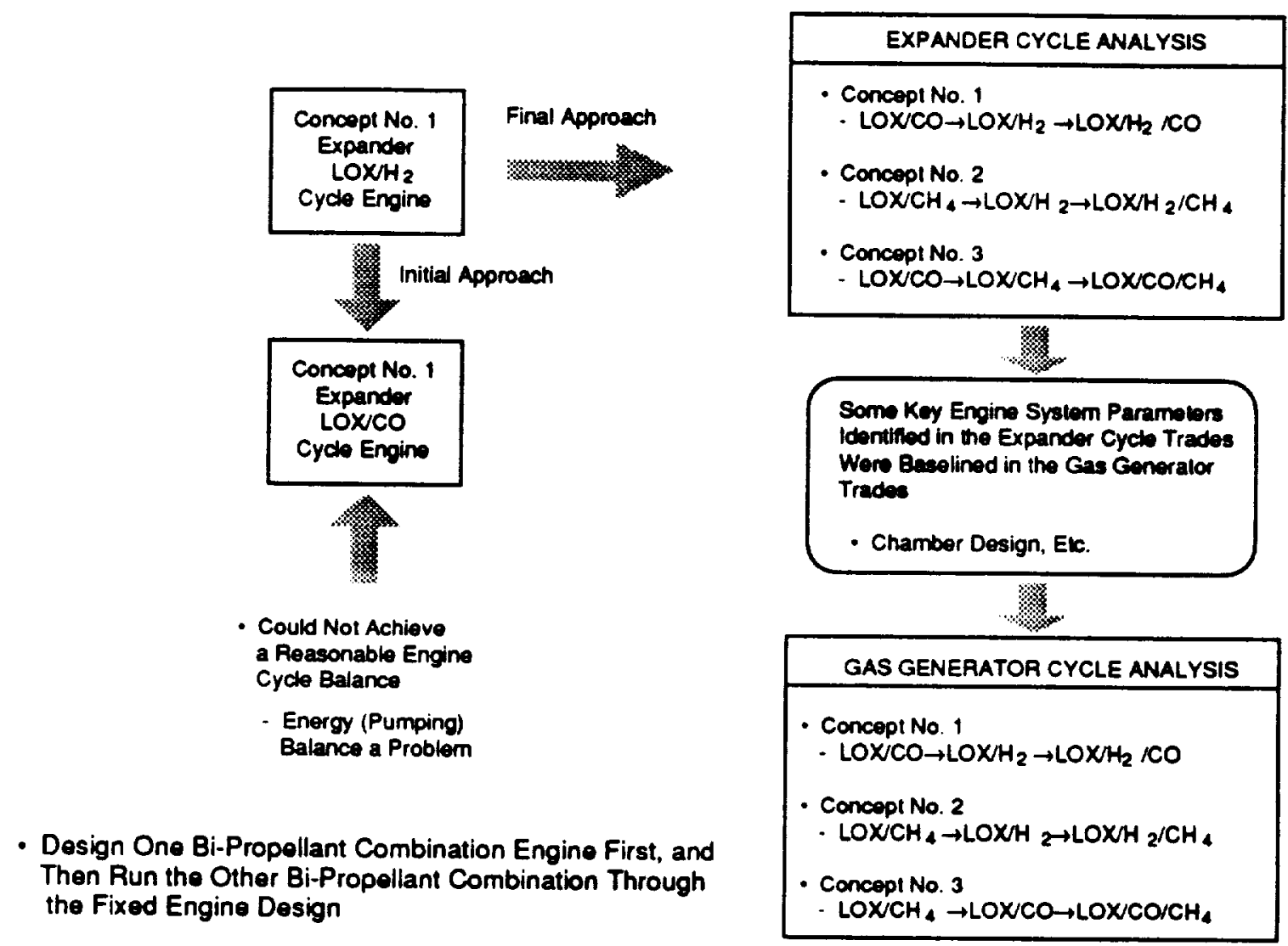

TOA29h21

Figure 4-6. Overall Engine System Trade Space Evaluation Process

At the beginning of the analysis it was felt that chamber heat loading and propellant pumping would be the key cycle balance driving factors. As shown in Figure 4-6, the Concept No. 1 expander cycle $\mathrm{LOX} / \mathrm{H}_{2}$ engine design was defined initially. This initial starting attempt addressed heat load issues associated with expander cycle $\mathrm{LOX} / \mathrm{H}_{2}$ engine designs. It was then found for Engine Concept No. 1 that the LOX/CO operation mode could not achieve a reasonable engine cycle balance. It was then determined that propellant pumping requirements drove the 
operation of such engines. Hence, the higher pumping requirement engine operation mode was designed first. It was also found during the engine system evaluation process that the pumping requirements are much more coupled for the expander cycle engines than for the gas generator cycle engines.

\subsubsection{Design Sensitivity Trades}

Engine system trades were conducted in accordance with the overall process summarized in Figure 4-6 and the assumptions previously discussed. From these sensitivity trades, optimal or near-optimal design features and operating characteristics for each engine design concept were identified. Based on these results, baseline engine systems were established for each of the three concept categories, which are presented in Section 4.2.3. Detailed engine system sensitivity trade results for each engine system concept are depicted graphically in Appendix C.

In the process of identifying optimal engine system design features, performance, weight, size and operational technology limitations were considered equally. Sound fundamental engineering judgment was also incorporated in the evaluation process.

The initial sensitivity trades were performed on representative Engine Concept No. 1, an expander cycle engine system that operated in a $\mathrm{LOX} / \mathrm{H}_{2}$ propellant combination mode. Key observations and results from this effort were: 1) that a nozzle area ratio greater than 200:1 would be required to achieve the desired performance to support its intended mission, 2) that the use of turbine and chamber regenerative cooling bypass had little effect on engine system performance and weight, and 3) that for the tripropellant in situ engine designs of interest, the heat loading associated with an engine operating in the $\mathrm{LOX} / \mathrm{H}_{2}$ mode at low chamber pressure, $\mathrm{Pc}<3000$ psia, should not be an issue. From these observations it was directed for the reminder of the trade study that: 1) a nozzle area ratio of $400: 1$ be baselined, 2) further turbine and regenerative bypass trade be omitted, and 3) the tripropellant engines initially be defined by the operating mode that drives pumping requirements (LOX/CO or $\mathrm{LOX} / \mathrm{CH}_{4}$ operating modes), as previously discussed.

After this initial trade assessment effort, detailed trades were then conducted for the candidate expander and gas generator engine concepts, respectively. Appendix $\mathrm{C}$ summarizes the results of these key trades. Key engine system design parameters and features identified from these trades are shown in Tables 4-15 and 4-16 for the expander and gas generator engine designs, respectively. 
Table 4-15. In Situ Propellant Expander Cycle Engines

- Key Engine Design Parameters and Features, Baselined -

\begin{tabular}{|l|c|c|}
\hline \multicolumn{1}{|c|}{ Parameter/Feature } & LOX/CO & LOX/CH \\
\hline Chamber Pressure (psia) & 550 & 700 \\
Mixture Ratio & 0.55 & 3.60 \\
Injector Density (Elements/in²) & 10 & 10 \\
Injector Type (Co-Axial) & 3.0 & 3.0 \\
Turbine Bypass (\%) & 0.0 & 0.0 \\
Chamber Regen Bypass (\%) & 0.0 & 0.0 \\
Chamber Length (cm) & 91.4 & 66.0 \\
Area Ratio(s) & $400: 1 / 165: 1$ & $400: 1 / 140: 1$ \\
Percent Nozzle (\%) & 90.0 & 90.0 \\
\hline
\end{tabular}

Table 4-16. In Situ Propellant Gas Generator Cycle Engines

- Key Engine Design Parameters and Features, Baselined -

\begin{tabular}{|l|c|c|}
\hline \multicolumn{1}{|c|}{ Parameter/Feature } & LOX/CO & LOX/CH4 \\
\hline Chamber Pressure (psia) & 2,000 & 2,000 \\
Mixture Ratio & 0.55 & 4.0 \\
Chamber Length (cm) & 91.4 & 66.0 \\
Gas Generator Mixture Ratio & 0.05 & 0.4 \\
Area Ratio(s) & $400: 1$ & $400: 1$ \\
\hline
\end{tabular}

Both the $\mathrm{LOX} / \mathrm{CO}$ and $\mathrm{LOX} / \mathrm{CH}_{4}$ expander engine designs operate at low chamber pressures, $<700 \mathrm{psia}$, and at mixture ratios that produced near-optimum performance. Both engines incorporate well-proven moderate element density, co-axial injector designs. No turbine or chamber regenerative bypass are included in the designs. The chamber length of the LOX/CO engine $(91.4 \mathrm{~cm})$ is approximately $30 \%$ longer than that associate with the $\mathrm{LOX} / \mathrm{CH}_{4}$ engine, 66.0 $\mathrm{cm}$. Engine system performance, length, weight, and thrust chamber regen cooling pressure drop were considered in the selection of the chamber length of each engine. The baseline nozzle on both engines systems uses 90 percent length Rao contour nozzles which were found to be a good compromise in terms of packaging, weight, and performance. 
Due to the low operating pressures associated the expander cycle class of engines, they were found to be somewhat heavy in terms of weight and extremely large. Because of their size, each baseline engine system had two baseline versions - one which incorporated a nozzle area ratio of 400:1 and another which had a nozzle exit diameter limited to $457-\mathrm{cm}$ diameter. The $457-\mathrm{cm}$ diameter is based on the maximum usable diameter of the Space Shuttle's payload bay. As shown in Table 4-15, baseline systems which considered this packaging constraint, translated into nozzle area ratio of either 165:1 or 140:1 for the expander engine systems.

The gas generator cycle engine systems incorporated many of the same features as those associated with the expander engine systems. These operate at substantially higher chamber pressure, $\mathrm{Pc}=2000 \mathrm{psia}$, than that characteristic of the expander cycle engines. These higher chamber pressure engines are more compact and do not require truncated or translating nozzle designs. The selection of the gas generator mixture ratio was based on the compromise between overall engine system performance, weight, and turbine inlet temperature.

\subsubsection{Baseline Engine Systems}

Based on the engine sensitivity trade assessment, just discussed, baseline expander and gas generator engine system designs were established. The baseline expander and gas generator cycle engine designs are summarized in Tables 4-17 and 4-18, respectively. Key overall engine system parameters and features are given by each engine operating mode. As previously noted, each baseline expander cycle engine system comes in two design versions: one for a nozzle area ratio of 400:1 and the other with a specified area ratio, which was previously discussed. The 400:1 nozzle expander cycle engine system design version assumes that a lightweight translating nozzle is used. Note that engine system design Versions $C$ and $D$, which are bipropellant design derivations of the tripropellant engines that support LEV and/or MEV applications, include only the hardware required to support bipropellant operation. Thus, only one fuel feed system is included in its weight budget compared to two fuel feed systems for the tripropellant engine designs. Likewise, for the lighter LEV and MEV engine system design the support hardware is resized.

Detailed descriptions and data associated with the baseline engine designs are given in Appendix D. Features and descriptions for all of the baseline expander and gas generator engine system designs at full rated power and at throttled (off-design) conditions are presented in Appendix D. Typically, engine operating conditions, chamber/coolant, and chamber/injector design compatibility characteristics are given. 


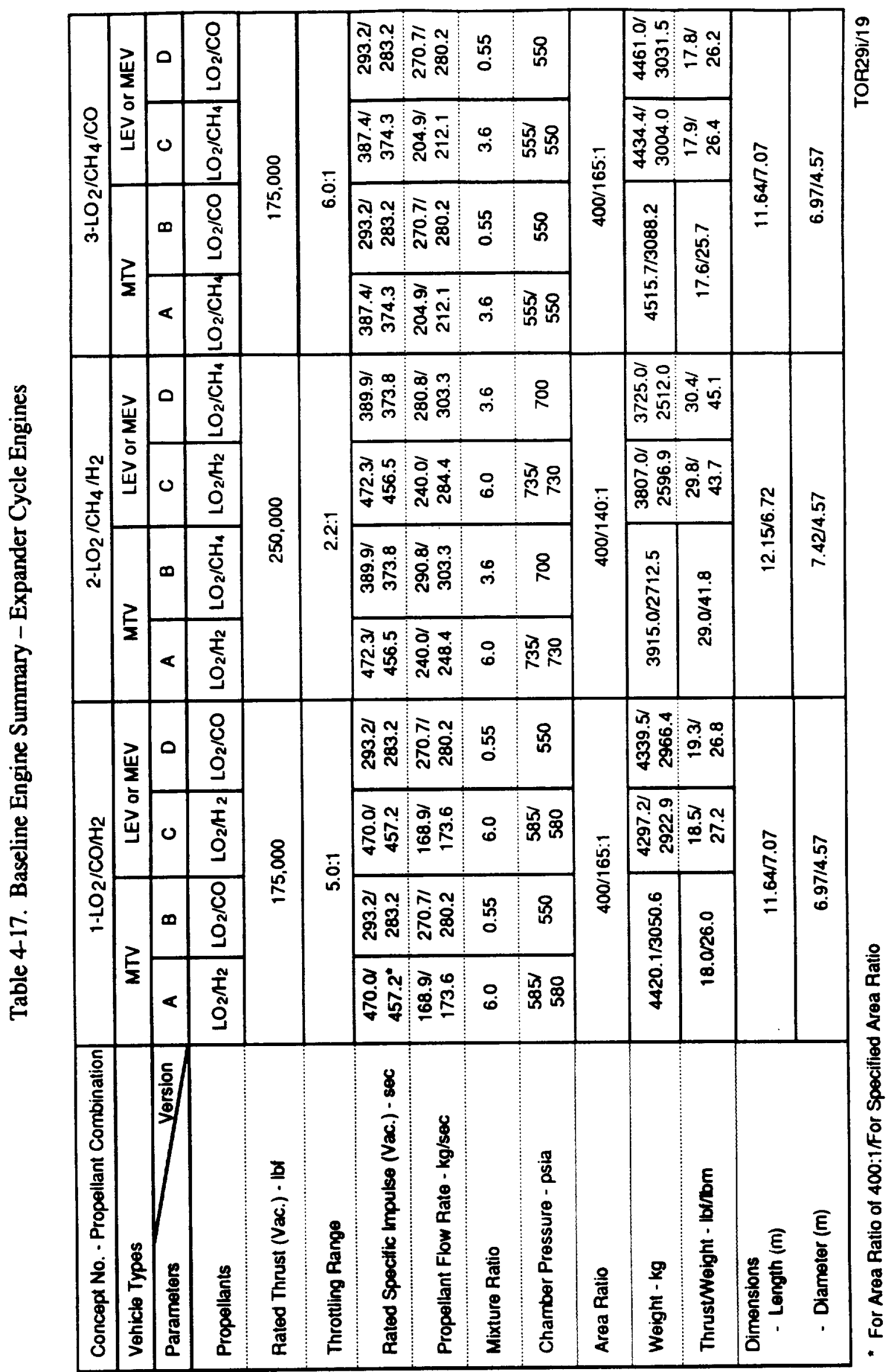




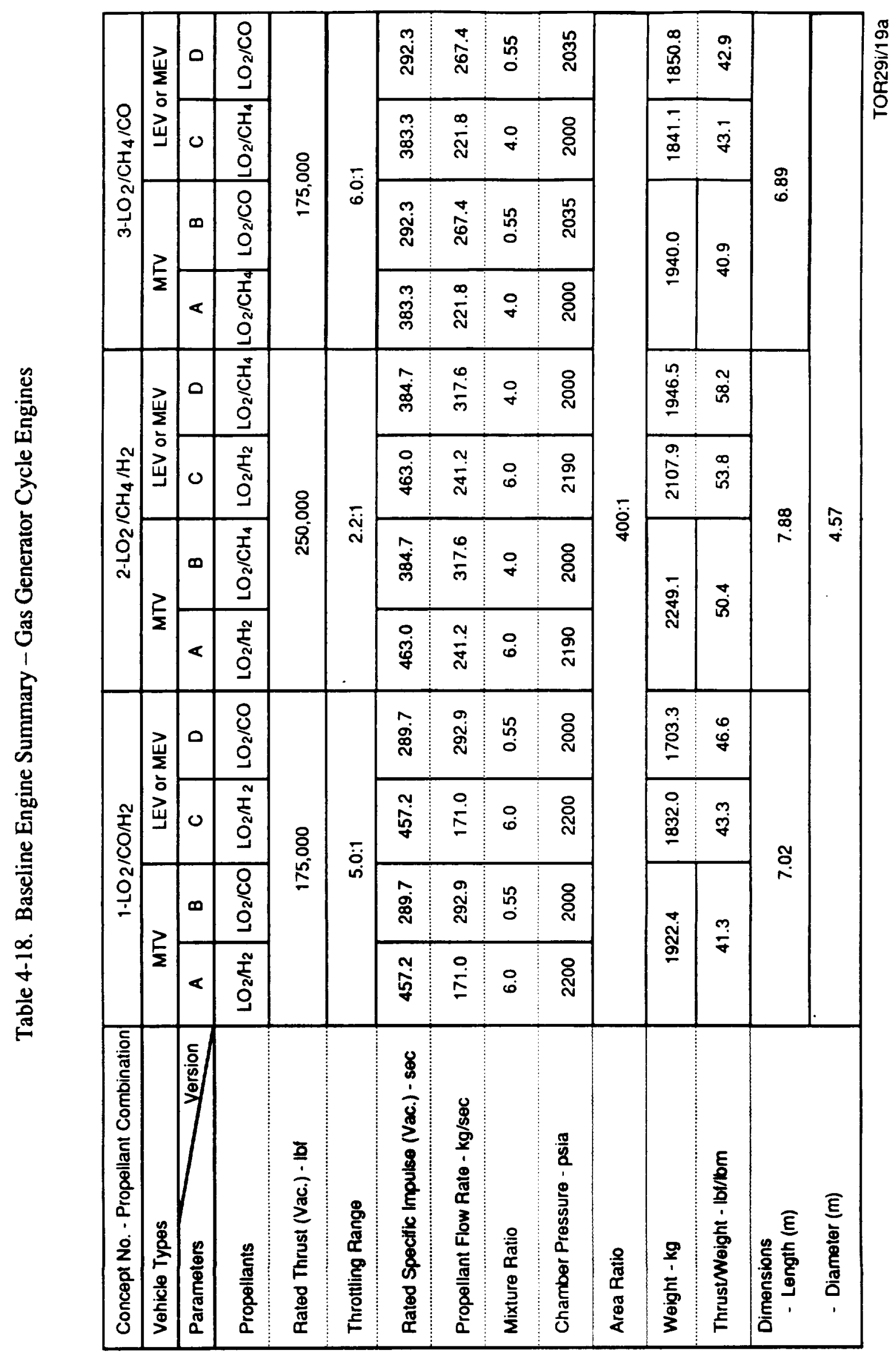


Baseline engine system thrust-to-weight is compared to other operational, development, conceptual engine designs in Figure 4-7. These engine systems exhibit a substantially lower thrust-to-weight ratio when compared to other engines in their thrust class. Most of these other engine are expendable designs with little or no throttling capability and some operate at higher chamber pressures than those associated with baseline engine designs, and are optimized for ETO operation which may imply low nozzle area ratio designs. The differences in these design features give some insight into their thrust-to-weight disparity. The thrust-to-weight ratio of the baseline engine system is in the same range or a little higher than those associated with lower thrust OTV engine systems. Though somewhat lower in thrust, the OTV engine systems have many similarities with the baseline engine system designs. These similarities include that many of these engines are throttleable and that they are optimized for performance, which implies large-area-ratio nozzle designs. The baseline tripropellant engine designs exhibit lower thrust-to-weight than Aerojet designs because they operate at substantially higher thrust levels and chamber pressures. Likewise, the baseline tripropellant engine designs have low thrust-to-weight because they include the weight of two independent feed systems. The baseline gas generator cycle engine system designs also have a substantially greater thrust-to-weight ratio than those characteristic of the baseline expander cycle engine systems, as shown in Figure 4-7.

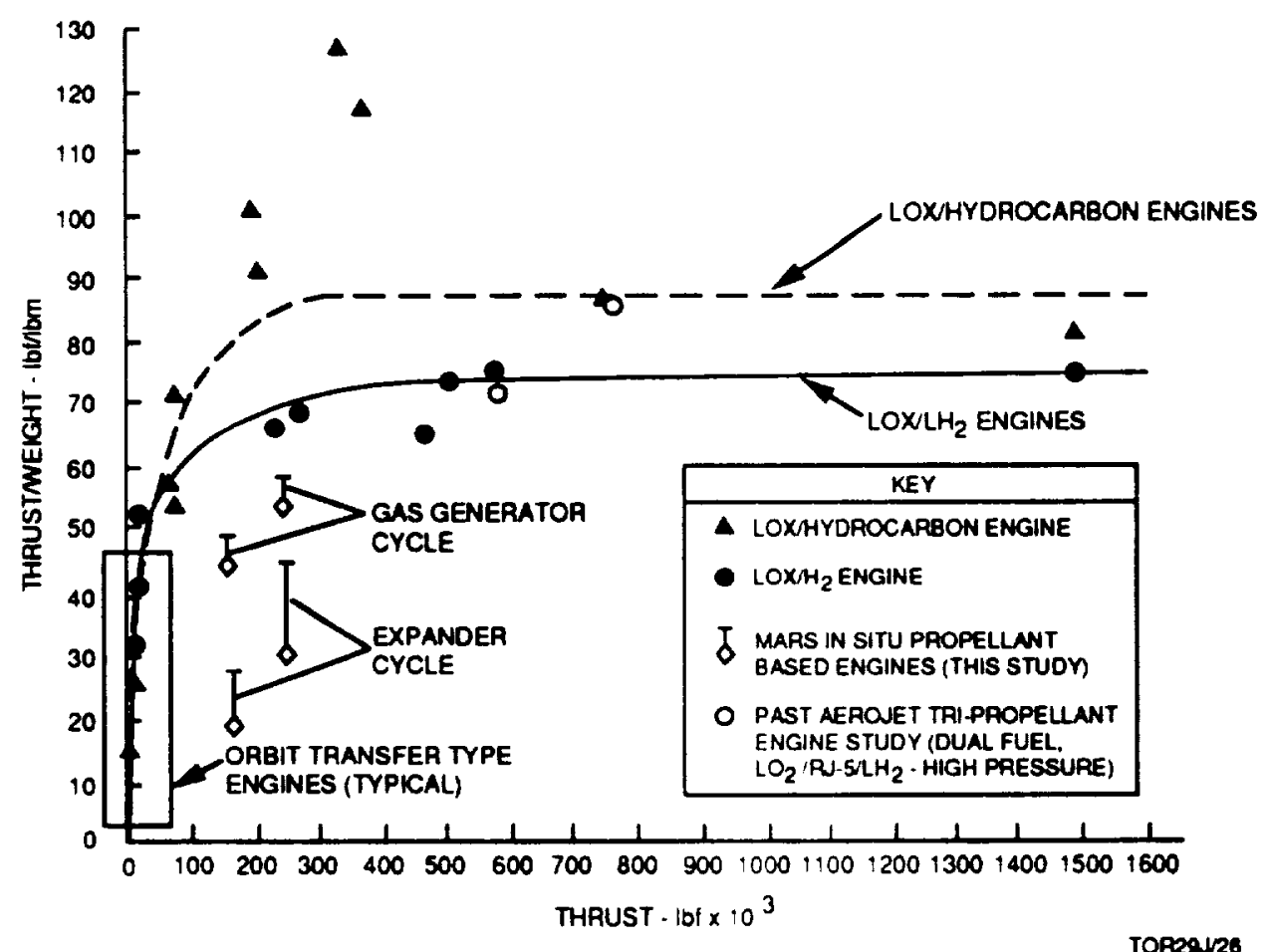

Figure 4-7. Engine Thrust-to-Weight as a Function of Thrust - Comparison - 


\subsubsection{Other Engine Design Comparisons}

Top-level engineering assessment studies were also performed that addressed some of the key design issues that were identified during the definition and evaluation effort associated with the baseline engine designs. These studies addressed: 1) the use of translating nozzles in terms of packaging and weight for expander cycle engines, 2) the influence of turbopump turbine blade strength on the maximum chamber pressure for expander cycle engines, and 3) the feasibility/ compatibility of multifuel-compatible feed systems for the tripropellant engine systems considered. The following discusses these studies in more detail.

\subsubsection{Translating Nozzle Assessment}

A translating design nozzle concept was studied for the baseline tripropellant expander cycle engine systems to determine its impact on packing and weight. Due to large size of the low chamber pressure expander cycle engines, see Section 4.2.3, packaging the engine into a launch vehicle could be difficult. The nozzle incorporates a lightweight, screw rod translating design which moves its carbon-carbon high area ratio extension into position, where it locks in place. Three screw rods are placed 120 degrees apart about the periphery of the engine. It is made of a lightweight carbon, composite structure. Before the nozzle extension is deployed, it is stowed around the outer portion of the engine.

The results of this assessment are shown in Table 4-19. For each tripropellant engine design, the packaging length is reduced substantially (approximately 29\%). The overall engine system weight is increased substantially by incorporating a translating nozzle for each baseline engine design considered. The weight is increased by approximately $45 \%$ for the baseline $\mathrm{LOX} / \mathrm{CO} / \mathrm{H}_{2}$ and $\mathrm{LOX} / \mathrm{CO} / \mathrm{CH}_{4}$ engine systems while the weight is increased by $76 \%$ for the LOX/CH $/ \mathrm{CH}_{2}$ baseline engine system design. As was previously mentioned, it is felt that the packaging is a major issue with the expander cycle baseline engines and a translating nozzle was incorporated in their design.

\subsubsection{Turbine Blade Strength Assessment}

It was observed during engine system sensitivity trades evaluation effort that the selection of the turbopumps turbine blade strength had a major influence on the maximum chamber pressure achievable for the expander cycle engines. These engines designs assumed warm $\mathrm{O}_{2}$ driven turbopumps to feed the propellants through the engine. Because these engine designs use warm 
$\mathrm{O}_{2}$ to drive their turbopumps, turbine material options are limited because of chemical compatibility considerations. MONEL 500 was selected as the turbine material for all the engine systems considered in this study because it is compatible with warm $\mathrm{O}_{2}$ and has adequate yield stress $(>80,000 \mathrm{psi})$ at the operating conditions of interest.

Table 4-19. Translating Nozzle Effects in Terms of Packaging and Weight

- Expander Cycle Engines -

\begin{tabular}{|c|c|c|c|c|c|}
\hline $\begin{array}{c}\text { Engine } \\
\text { Concept } \\
\text { Number }\end{array}$ & Propellants & $\begin{array}{c}\text { Stowed } \\
\text { Length AR } \\
\mathbf{4 0 0 : 1 \quad ( m )}\end{array}$ & $\begin{array}{c}\text { Total } \\
\text { Deployed } \\
\text { Length (m) }\end{array}$ & $\begin{array}{c}\text { Engine Weight } \\
\text { w/o Translating } \\
\text { Nozzle (kg) }\end{array}$ & $\begin{array}{c}\text { Engine Weight } \\
\text { w/Translating } \\
\text { Nozzle (kg) }\end{array}$ \\
\hline 1 & LOX/CO/H $/ \mathrm{H}_{2}$ & 8.27 & 11.64 & 2963.2 & 4420.1 \\
2 & $\mathrm{LOX} / \mathrm{CH}_{4} / \mathrm{H}_{2}$ & 8.81 & 12.15 & 2227.7 & 3915.0 \\
3 & $\mathrm{LOX} / \mathrm{CO} / \mathrm{CH}_{4}$ & 8.27 & 11.64 & 3058.1 & 4515.0 \\
\hline
\end{tabular}

This assessment was performed to give some insight into the inherent design margin associated with the selection of MONEL 500 as the turbine blade material. A LOX/CH $\mathrm{CH}_{4}$, expander cycle engine design was used in this evaluation that operated at a mixture ratio of 3.6, a thrust level of $250,000 \mathrm{lbf}$, and incorporates a nozzle area ratio of $400: 1$. The minimum turbine blade yield stress was varied and the maximum operating chamber pressure was identified. These results are shown in Table 4-20. It is concluded from these results that turbine blade materials with only a minimum yield stress of 40,000 psi can adequately support operation of the baseline engine systems of interest. Hence, the selection of MONEL 500 as the turbine material has a substantial design margin for its intended application in the low chamber pressure baseline engine systems.

Table 4-20. Turbine Blade Strength Influence on Chamber Pressure

\begin{tabular}{|c|c|}
\hline $\begin{array}{c}\text { Maximum Chamber } \\
\text { Pressure (psia) }\end{array}$ & $\begin{array}{c}\text { Minimum Turbine } \\
\text { Yield Stress (psi) }\end{array}$ \\
\hline 400 & 30000 \\
700 & 40000 \\
\hline
\end{tabular}

* Ultimate Stress $=1.20 \times$ Yield Stress in Analysis

\subsubsection{Common Fuel Turbopump Assessment}

This assessment addressed the feasibility of using one single common fuel turbopump (feed system) for the baseline tripropellant engine systems that incorporate two independent fuel 
systems. If found feasible, such a design approach has the potential to reduce tripropellant engine system weight and increase its simplicity which translates into higher reliability. All baseline engine systems were evaluated in this assessment. It was found that using a baseline engine $\mathrm{CH}_{4}$ or $\mathrm{CO}$ turbopump for pumping $\mathrm{H}_{2}$ was not possible. This result is not surprising due to the large density difference between the fuels. For the baseline $\mathrm{LOX} / \mathrm{CH}_{4} / \mathrm{CO}$ gas generator cycle engine, it was found that a single turbopump design could adequately pump both $\mathrm{CH}_{4}$ and $\mathrm{CO}$. Table 4-21 shows the design and operational characteristics for such an engine over a large thrust level range. All the other baseline engine system designs that incorporated a common fuel turbopump design were found not to be feasible.

\subsection{Propellant Tank Design Assessment}

Top-level engineering design assessment of candidate propellant tankage for Mars in situbased propulsion/vehicle system was performed to investigate key design issues and to identify promising design options. This assessment was based on the results of the initial mission requirements discussed in Section 2.0 and used the baseline engine system designs presented in Section 4.2.3. Tankage systems for MTV applications were examined because they showed the potential for a substantial weight savings due to using common propellant tanks through all or some phases of their mission flight profile.

The preliminary design analysis of candidate tank design options was performed using SAIC's ELES program, see Refs. 4-1 through 4-3, and the PSDOC (Protection Structures Design Optimization Code) model, see Ref. 4-4, which defined meteoroid protection system requirements. Trade studies were conducted that addressed: 1) in situ multipropellant tank commonality/ compatibility issues such as sizing, materials compatibility and pressurization, 2) boiloff and 3) meteoroid protection system requirements and design. Results from these trades were compared to comparable SOA LOX/H $\mathrm{H}_{2}$ tank systems. The design assumptions, considerations, and key results associated with this assessment are presented in the following sections.

\subsubsection{Design Requirements/Considerations}

In addition to tank size, which is a strong function of $\Delta \mathrm{V}$ for a given mission segment, other tankage system requirements must be characterized to accurately design a propellant tank system. These other key requirements are the propellant exposure (storage) time in space, the thermal environment, the space debris environment/protection requirements, acceleration loading, and geometric envelope constraints, which are usually dictated by the ETO launch system. 


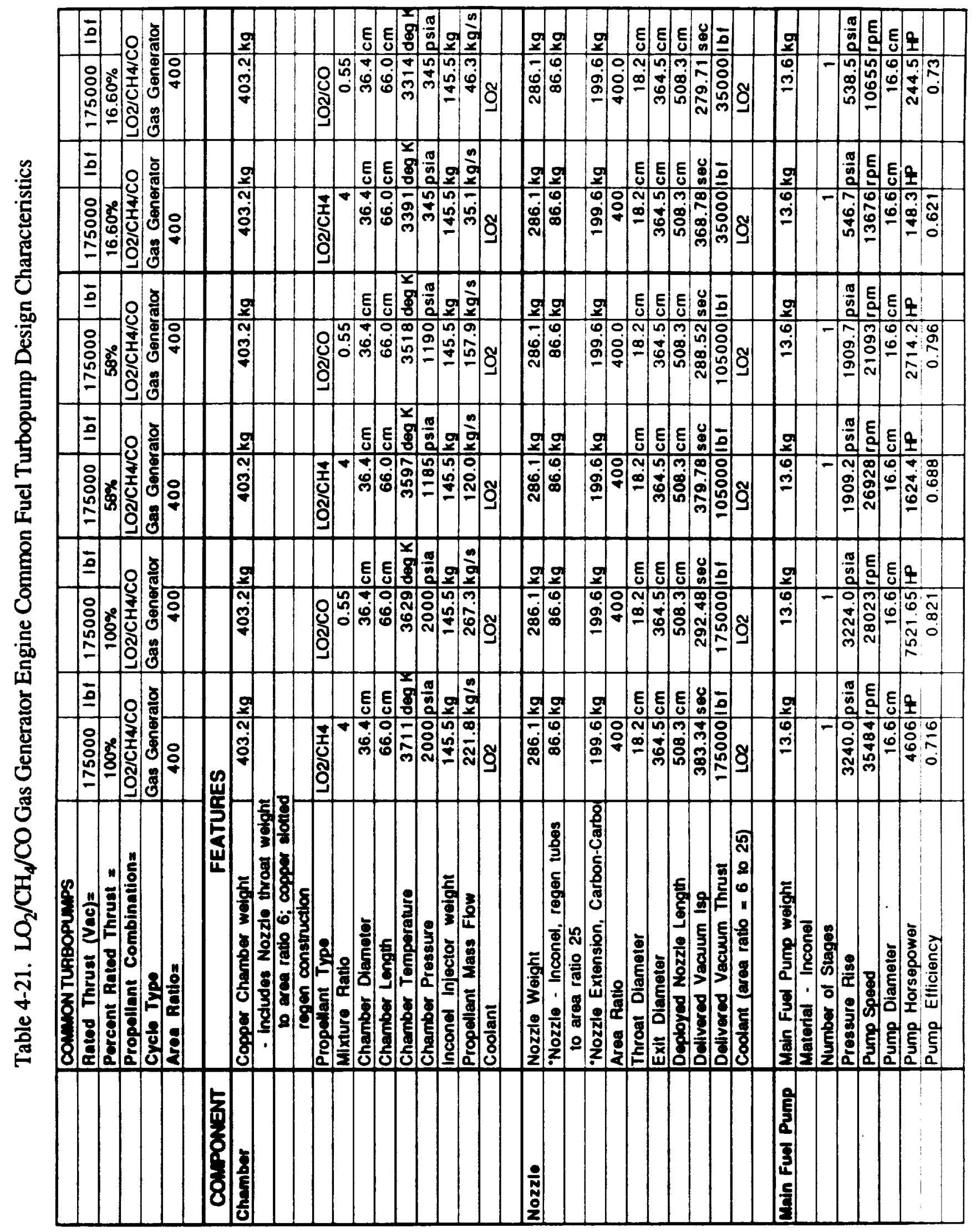




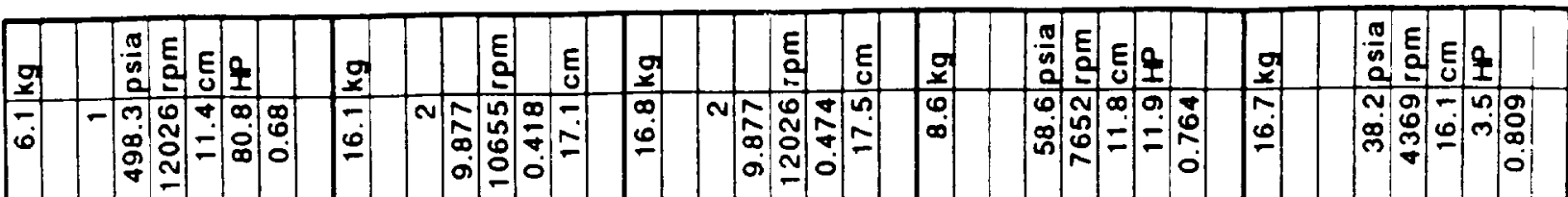

芦

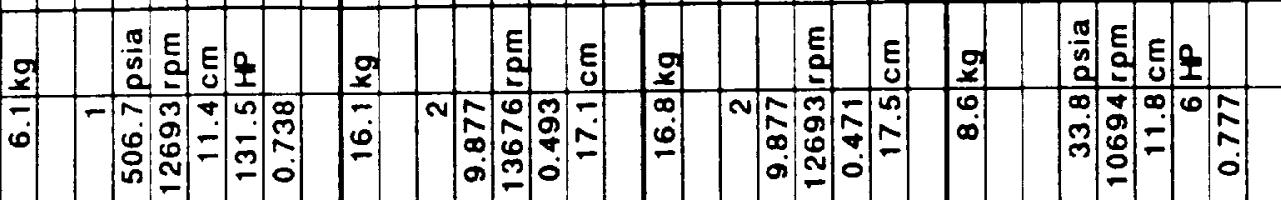

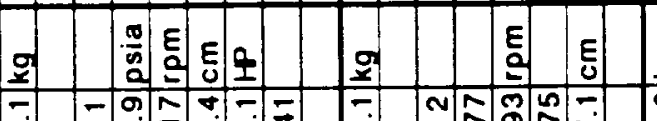

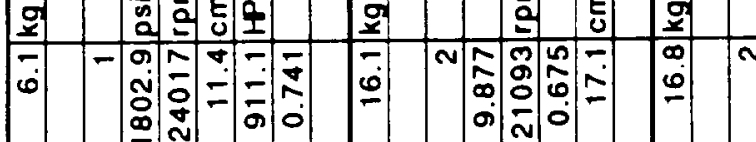

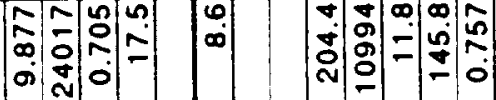

임 - \pm 00

열

. $90-0$

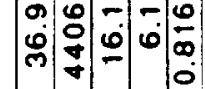

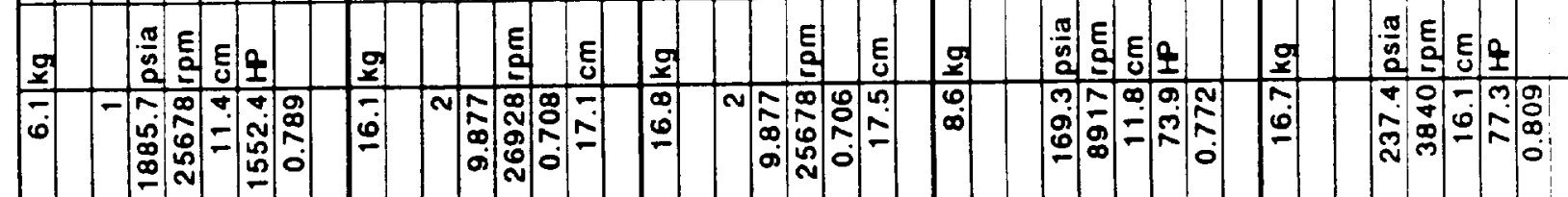

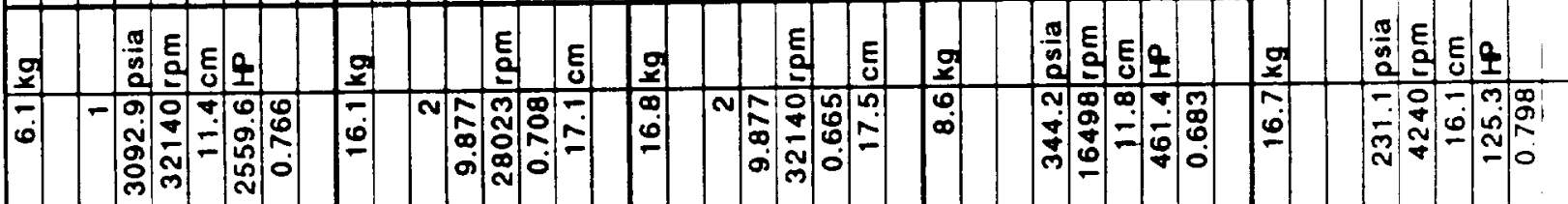

:

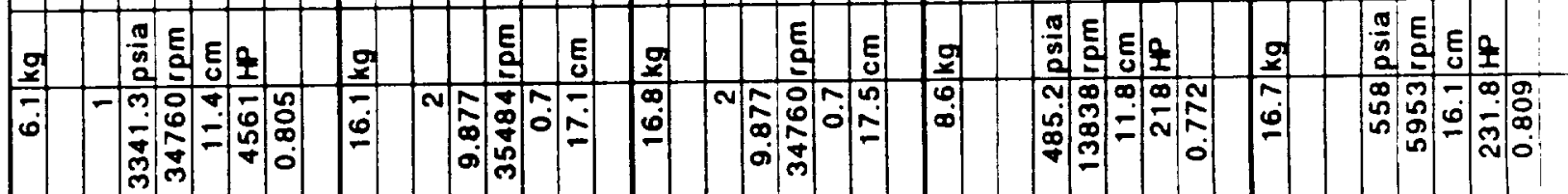

8

$\stackrel{8}{0}$

:

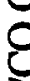

$\mathcal{8}$ 역

茫

S

$\dot{y}$

总

흘

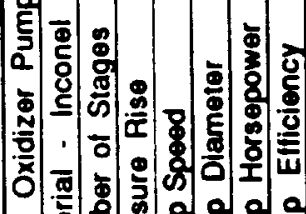

흥

등 $\sqrt{3}$ 등

흥 $\quad$ 혛

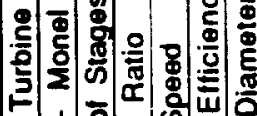

을 क

氕:

5)

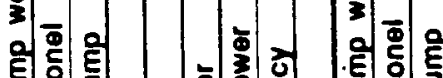

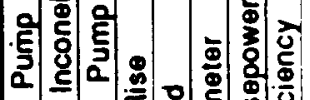

事

ه 즌 글 동
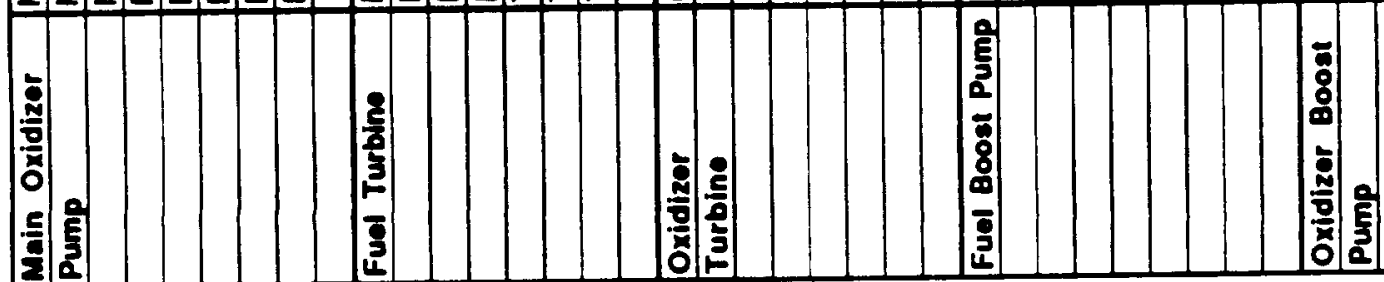


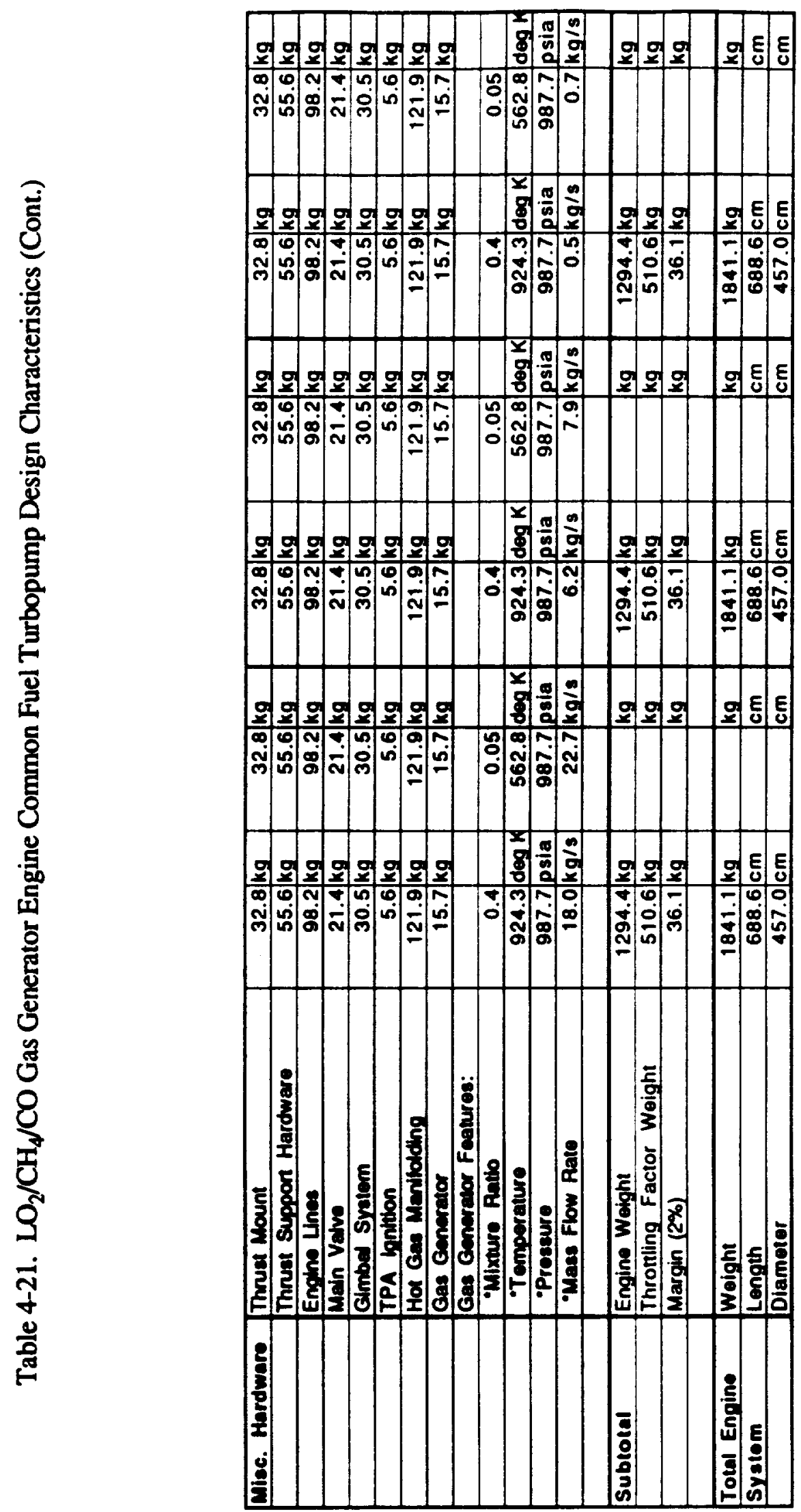


Typically, the propellant exposure time and thermal environment (distance from the sun) greatly influence the boiloff characteristics/requirements of propellant tankage system. For this study, a typical 435-day Mars mission was used in the assessment which is shown in Figure 4-8. Due to the nature of this mission the propellant tankage system must be able to survive a dynamic space debris environment. Key tankage space debris conditions/design considerations by mission segment are summarized in Table 4-22. General tankage systems features and requirements were identified and are shown in Table 4-23.

Table 4-22. Key Space Debris Tank Design Considerations by Mission Segment

\begin{tabular}{|l|l|}
\hline \multicolumn{1}{|c|}{ Mission Segment } & \multicolumn{1}{c|}{ Conditions/Design Considerations } \\
\hline LEO & $\begin{array}{l}\text { Earth-Orbital Space Debris, Cometary Meteoroids, Earth Shielding, } \\
\text { Gravitational Defocusing, Altitude, Inclination, Configuration }\end{array}$ \\
\hline Transit & $\begin{array}{l}\text { Asteroidal and Cometary Meteoroids, Trajectory and Schedule, } \\
\text { Configuration }\end{array}$ \\
\hline Mars Orbit & $\begin{array}{l}\text { Asteroidal and Cometary Meteoroids, Mars/Phobos/Deimos } \\
\text { Shielding, Gravitational Defocussing, Altitude, Configuration }\end{array}$ \\
\hline $\begin{array}{l}\text { Martian Surface Excursion } \\
\text { Supply/Surface Vehicles }\end{array}$ & $\begin{array}{l}\text { Asteroidal and Cometary Meteoroids, Surviving Particle Mass to } \\
\text { Surface, Primary Impacts on Surface, Secondary Ejecta, } \\
\text { Configuration }\end{array}$ \\
\hline
\end{tabular}

To support the Mars transportation systems considered in this study, an ETO launch system based on a growth version of the Advanced Launch System, discussed in Ref. 1-1, was assumed. Figure 4-9 shows this ETO launch system with its key payload performance and geometric features listed.

Additionally, an assessment of tank system sizing was performed by scenario type and mission segment to identify common propellant tank volumes. This was based on the initial mission requirements, see Section 2.0, as previously discussed. Table 4-24 shows the tank system sizing assessment results. Based on these results, the other design considerations and issues, and the overall assessment goal to examine candidate tank designs that best display design differences and issues, propellant tank designs for the following mission scenarios were evaluated. They are: 1) Scenario No. 2 - Lunar LOX, Mars LOX/CO, and 2) Scenario No. 4 - Lunar LOX $/ \mathrm{CH}_{4}$, Mars LOX/CO. In addition to these, tank system designs associated with the all Earth LOX/ $\mathrm{H}_{2}$ based system (Scenario No. 1) were also evaluated so that the in situ propellant-based tank designs could be compared. 

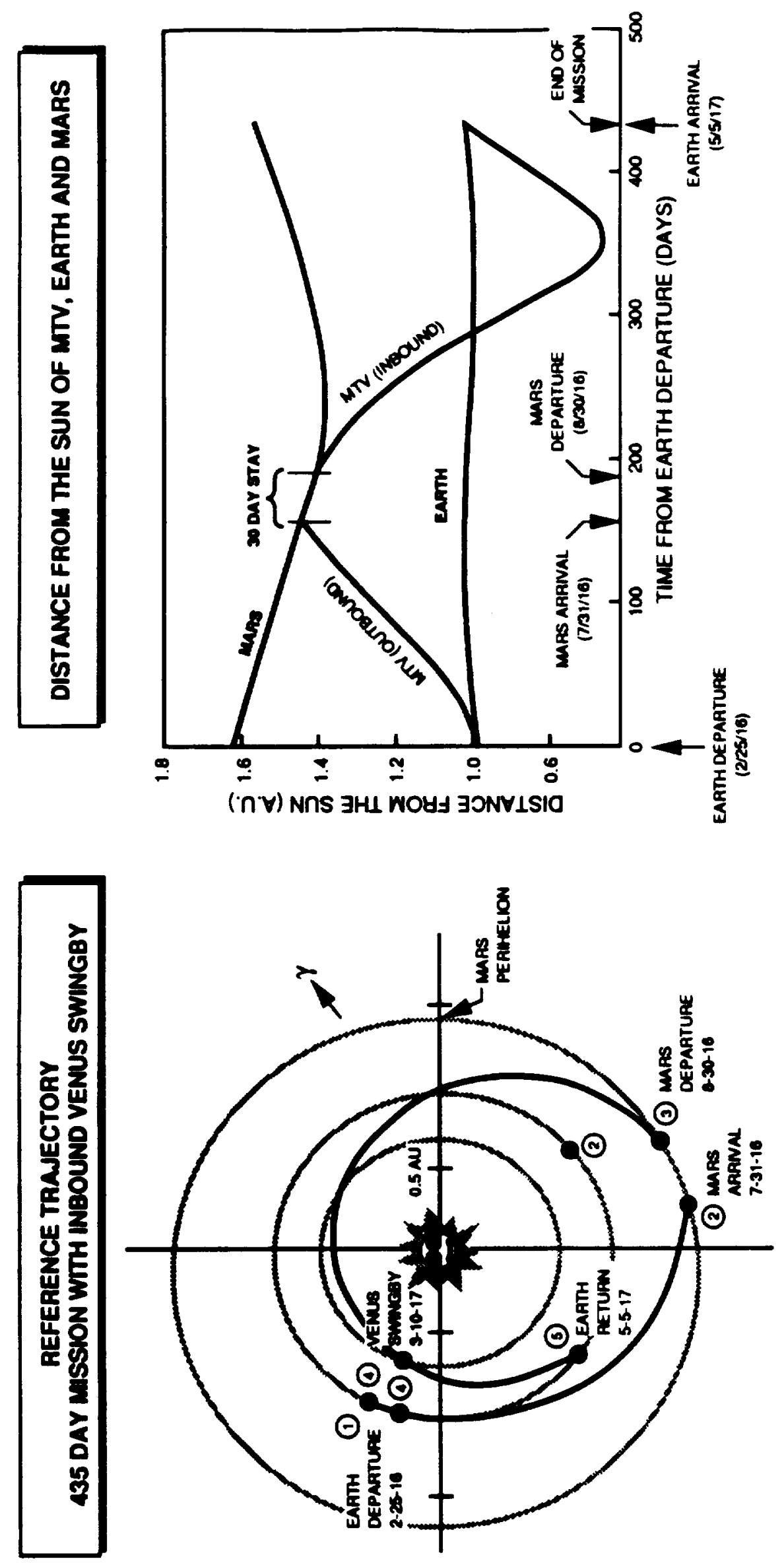

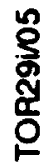




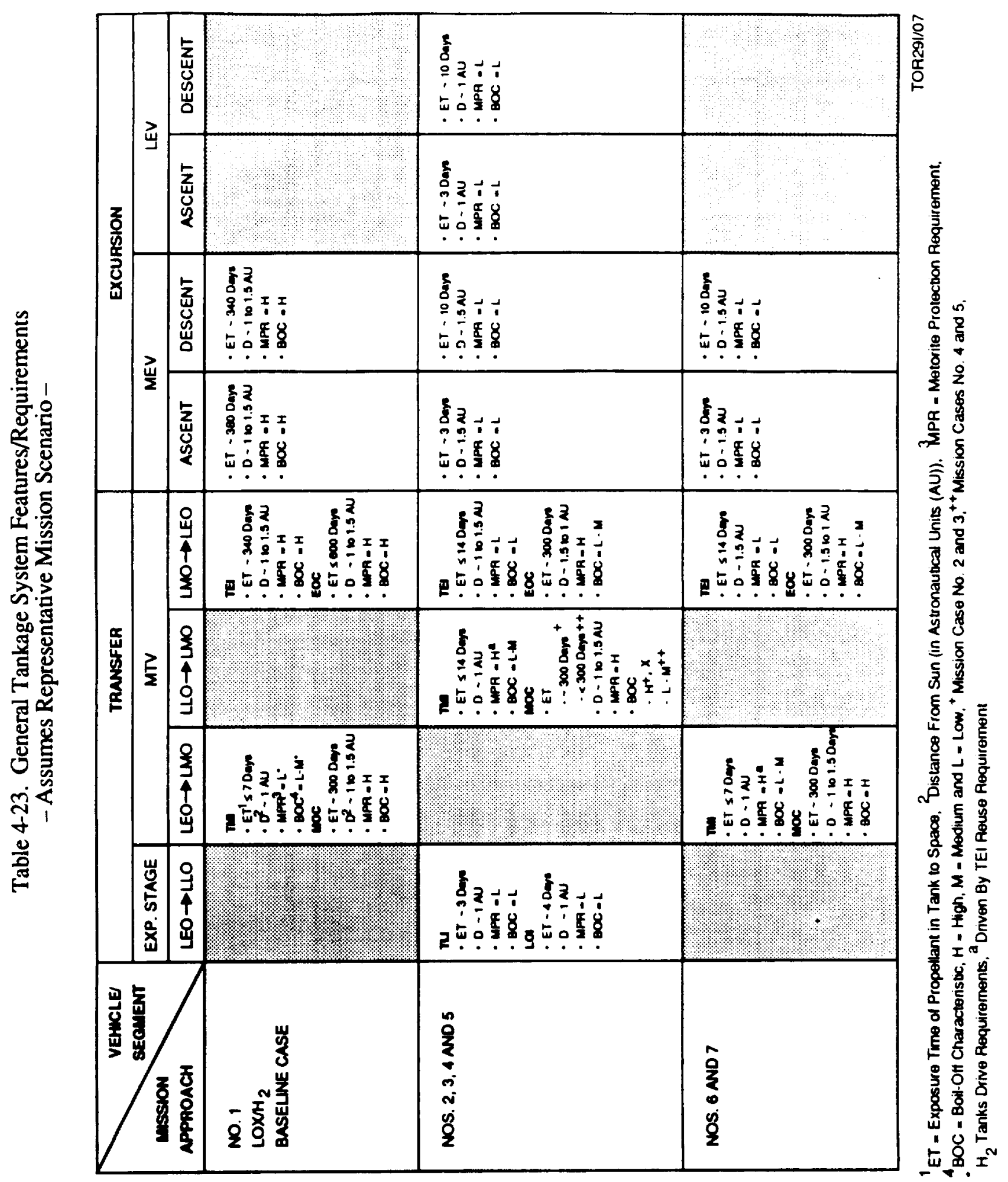




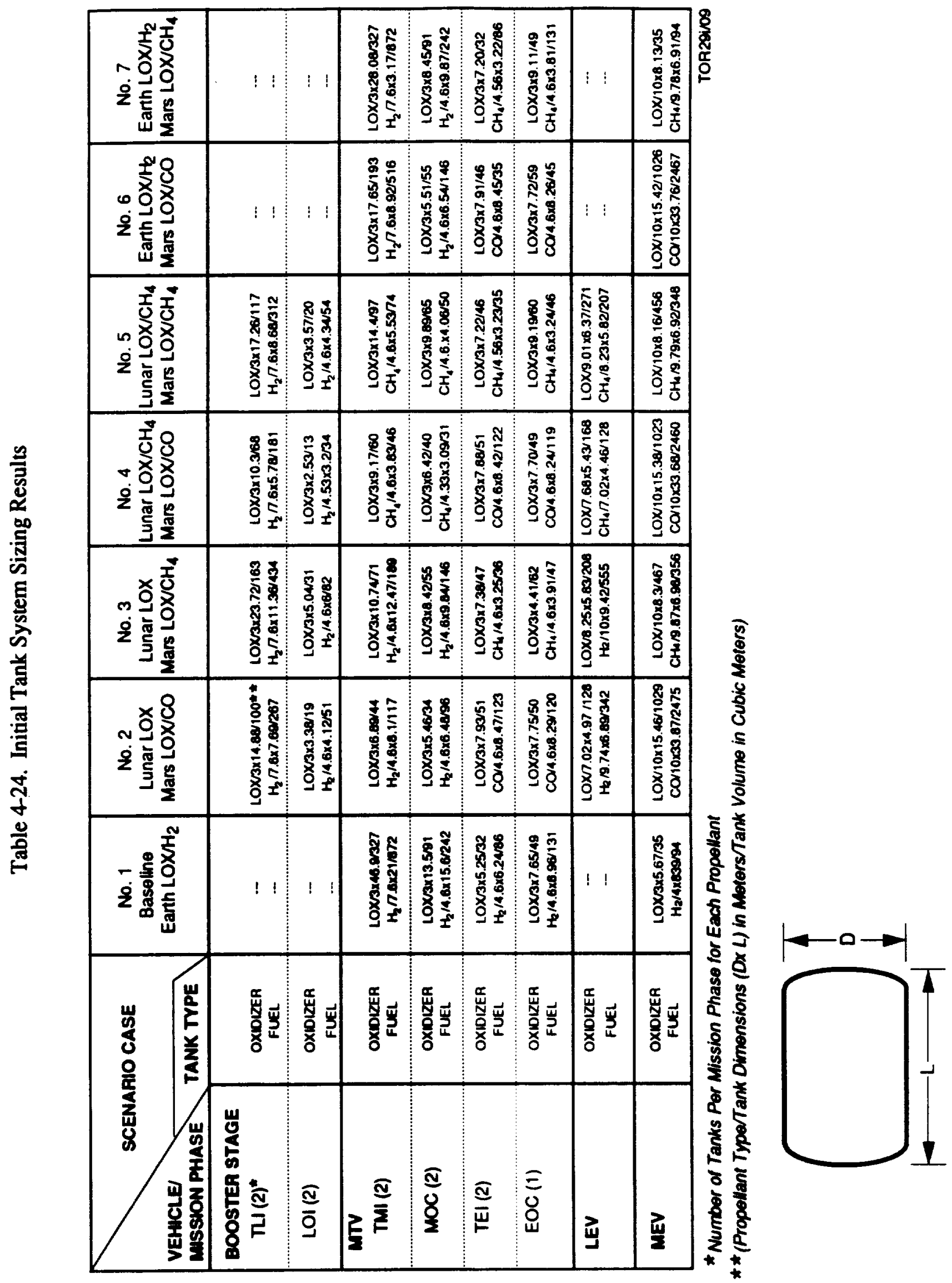




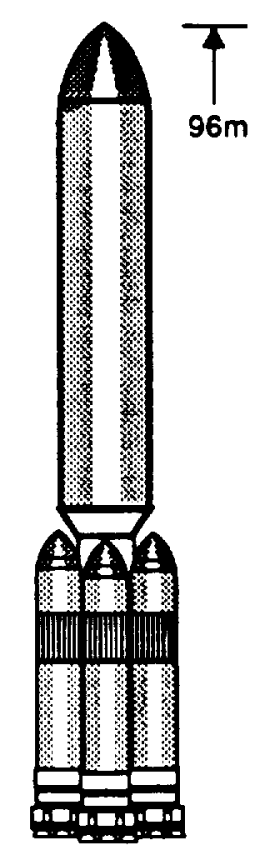

- 140 t to Space Station Freedom

- $12.5 \mathrm{~m} \mathrm{D} \times 30 \mathrm{~m} \mathrm{~L}$

Payload Envelope

TOR29J/31

Figure 4-9. Growth Version of the Advanced Launch System

Scenario No. 2 was selected because it addressed the influence of employing the in situ propellant $\mathrm{CO}$ on the tank design compared to a conventional Earth $\mathrm{H}_{2}$ tank design. The potential of ISPP, reduced boiloff, and cryogenic $\left(\mathrm{LH}_{2}\right)$ /storable $(\mathrm{CO})$ propellant compatibility on MTV tank design were key reasons to examine this mission scenario. Scenario No. 4 demonstrates a tankage system that uses only in situ propellants.

For these scenarios, MTV vehicle tankage systems were selected for the design assessment because it was felt that such systems had the highest potential to reduce weight over other mission segment vehicles (LTVs and MTVs) by employing common propellant tanks. MTV vehicle tankage configuration strategies considered in the assessment were: 1) individual bum tanks, 2) common propellant tanks, 3) mission segmented common tanks, and 4) common/mission segmented propellant tanks. These configuration strategies are summarized in Table 4-25.

Other tank system design approaches considered in the assessment were: identify tank system design which made the maximum use of LOX tankage throughout the mission; modular tank sizing; and performing a complete change out of tanks at the Moon and/or Mars. For the latter 


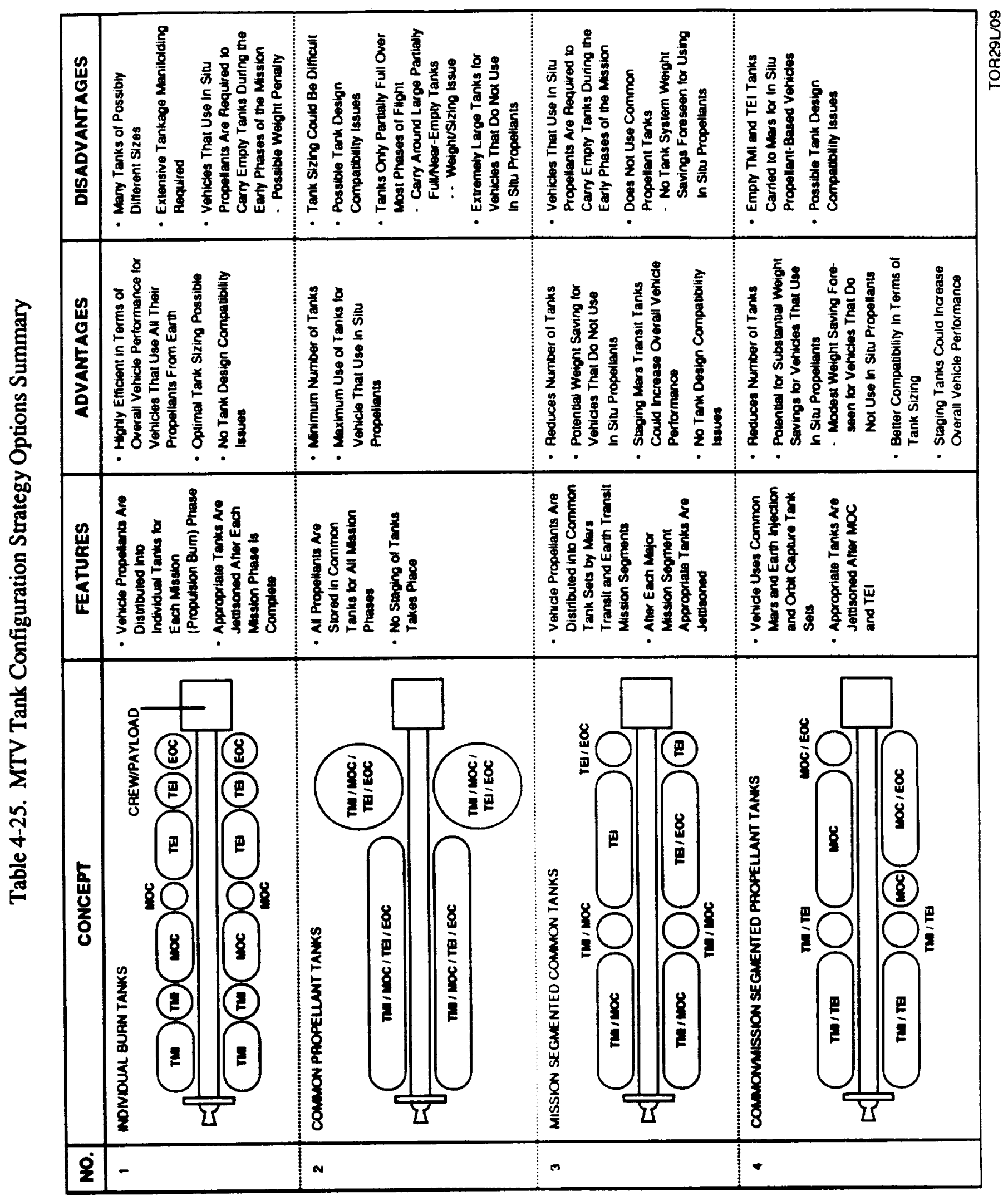


approach tank production from in situ materials would be extremely attractive because tanks associated with MTV return propellant would not have to be reused or carried from Earth. This approach would have a major impact on in situ material production infrastructure requirements. A major tradeoff assessment would be required to quantify the impact of these requirements as compared to the life cycle saving possible for the MTV transportation system.

Inflatable propellant tanks, shown in Figure 4-10, may also be another attractive option to store in situ propellants. Weight savings may be possible with such a tankage concept because of its reduced susceptibility to meteoroid penetrations while in its stored, folded position during a portion of the flight. There are many technology issues associated with such a concept. An example of such an issue is the chemical compatibility of a highly flexible material with the propellants at the operating conditions of interest.

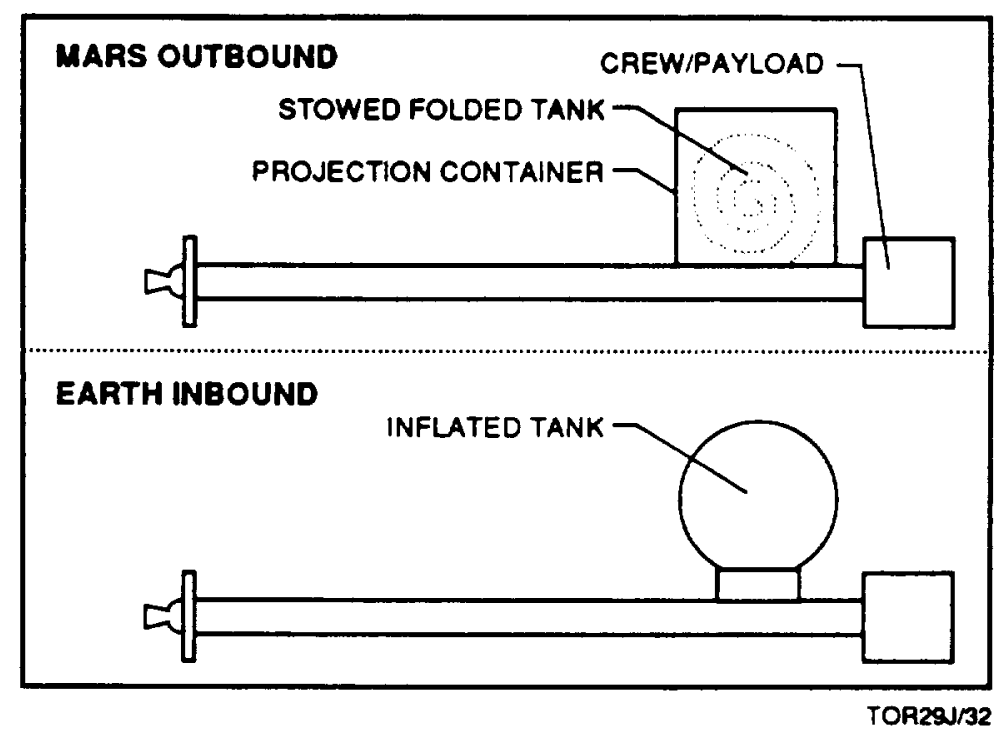

Figure 4-10. Inflatable Tanks May Be Attractive to Store In Situ Propellants

\subsubsection{Analysis Approach and Results}

Tank design analysis was performed using the ELES design program, as previously discussed. The ELES program characterized the tank design in terms of its boiloff characteristics, but meteoroid shield protection system design analysis could not be performed. The tank meteoroid shield design evaluation was performed using SAIC's PSDOC which was recently developed for NASA MSFC, see Ref. 4-4. 
The PSDOC model incorporates probabilistic space environment debris characteristics that includes deterministic hypersonic impact predictor models. It models many of the key meteoroid protection factors that drive the design of a protection system. These factors include: the space debris environment; spacecraft operational period; spacecraft exposure area and orientation; and mission altitude and inclination. In this evaluation a $7.8 \mathrm{~g} / \mathrm{cm}^{3}$ average debris mass was assumed, which is typical of a meteoroid with high iron content. This is the typical asteroid/meteoroid debris environment associated with the transit to and from Mars and its surface. A bumper shield meteoroid protection system was assumed in the evaluation. Figure 4-11 shows this concept and the basic tank geometry modeled. Candidate meteoroid impact shielding materials were also identified and assessed. This assessment is summarized in Table 4-26. Aluminum alloys were baselined in the evaluation because of their well defined properties. Though some of the other material options showed potential to produce a weight savings, more impact and space environment compatibility characterization testing is required for these candidates.
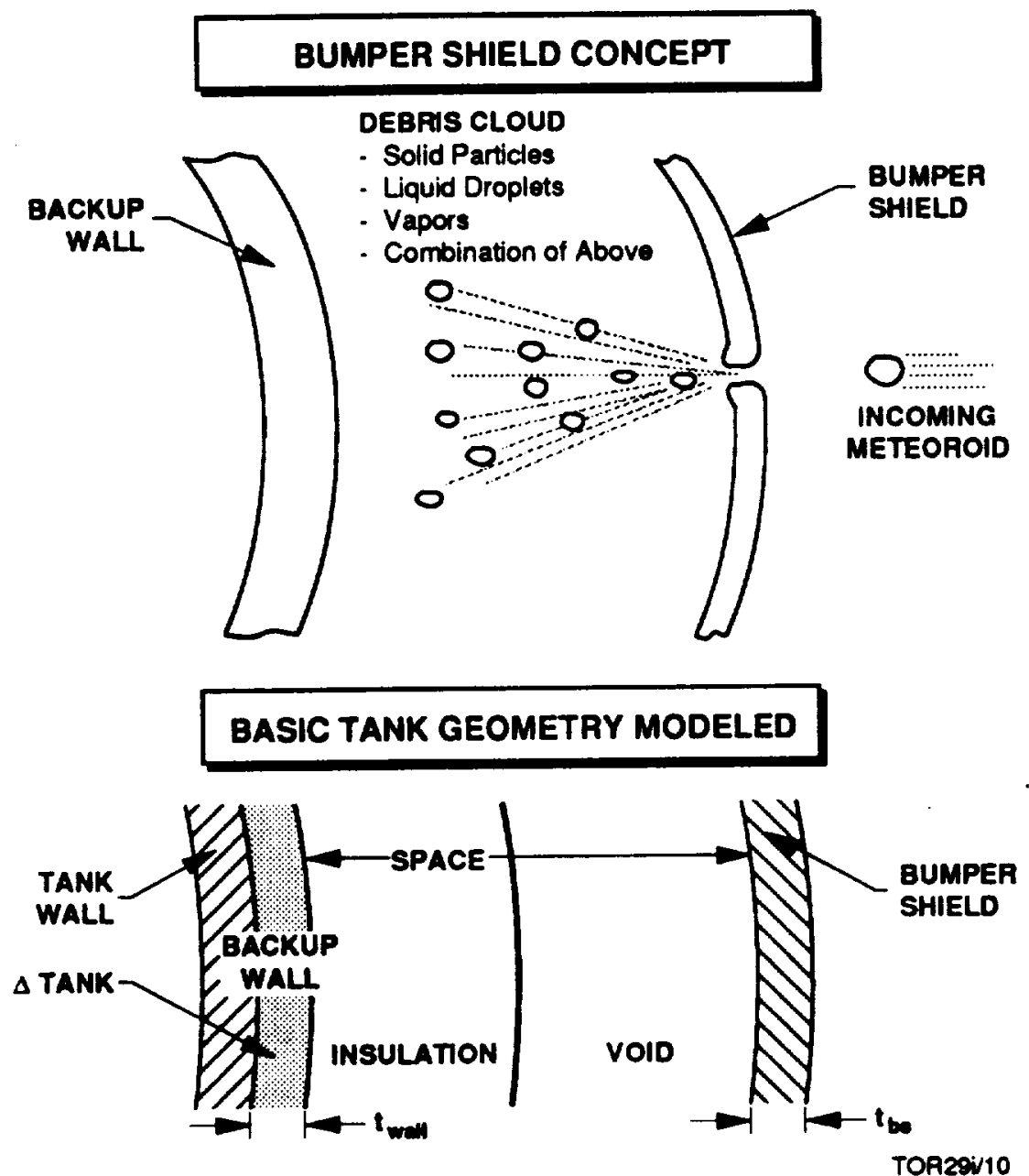

Figure 4-11. The Tank Meteoroid Shield Penetration Concept Evaluated 
Table 4-26. Impact Shielding Materials/Options Considerations

\begin{tabular}{|c|c|c|}
\hline MATERIAL & PROS & CONS \\
\hline $\begin{array}{l}\text { Aluminum Alloys } \\
\text { (e.g. 6061-T6, 2219-T87) }\end{array}$ & $\begin{array}{l}\text { Well-Known, Well-Tested, Good } \\
\text { All-Around Properties }\end{array}$ & $\begin{array}{l}\text { Wide Variance in Impact Resistance } \\
\text { Among Alloys, May Nol Be Optimal }\end{array}$ \\
\hline Titanium Alloys & $\begin{array}{l}\text { Well-Known, Good Properties, Some } \\
\text { Alloys Appear Superior to Best } \\
\text { Aluminum Alloys }\end{array}$ & $\begin{array}{l}\text { Not as Well-Tested for Impacts. } \\
\text { Potentially Wide Variances }\end{array}$ \\
\hline $\begin{array}{l}\text { Metal Matrix Composites } \\
\text { (e.g. Graphite Aluminum) }\end{array}$ & $\begin{array}{l}\text { Greater Flexibility for Tailoring. } \\
\text { Potentially Weight Efficient }\end{array}$ & $\begin{array}{l}\text { Not Well-Studied for Impacts. } \\
\text { Potential Problems for Other Space } \\
\text { Environments }\end{array}$ \\
\hline Graphite Epoxies & $\begin{array}{l}\text { Greater Flexibility for Tailoring, } \\
\text { Potentially Weight Efficient }\end{array}$ & $\begin{array}{l}\text { Not Very Well-Studied. Potential } \\
\text { Problems for Other Environments, } \\
\text { Particularly for Epoxy Materials }\end{array}$ \\
\hline Ceramic Composites & $\begin{array}{l}\text { Well-Tested for DoD Applications, } \\
\text { Good Impact Resistance }\end{array}$ & Potential Weight Problems \\
\hline
\end{tabular}

${ }^{\star}$ Selected for Initial Functional Screening Analysis

The evaluation parametrically characterized the baseline meteoroid shield design concept in terms of: 1) mission duration, 2) tank size (surface area) and 3) probability of no penetration $\left(P_{R F}\right)$. The results of this evaluation are shown in Figures 4-12 and 4-13. As shown in Figure 4-12, the $P_{R F}$ for deep space missions will likely be greater than 0.980 because inspection, maintenance, and repairs will be unlikely for such missions. For the results displayed in Figure 4-13 $\mathrm{P}_{\mathrm{RF}}=0.990$ was assumed. The meteoroid protection system weights for the tank designs were extrapolated from these results.

The overall analysis approach used to assess common tank designs is presented in Figure 4-14. The general tank design features assessed in the analysis are summarized in Table 4-27. The tank designs examined in this assessment are displayed in Table 4-28. By evaluating these tank designs for a given mission scenario and mission segment, a large number of tank design comparisons can be made. These tank design comparisons are presented in Table 4-29. A large number of sizing compatibility and technology options are addressed in this evaluation trade space. 


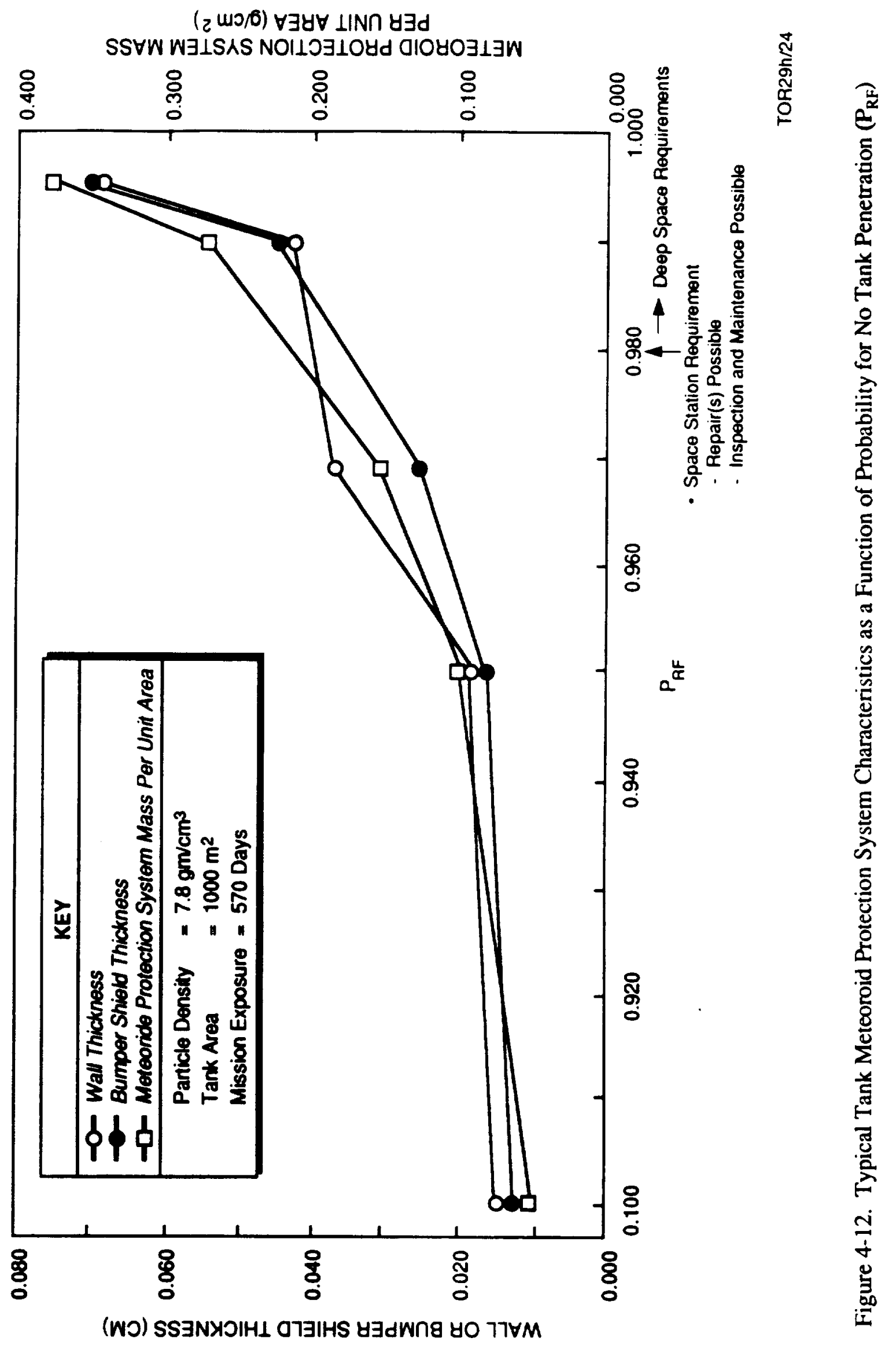




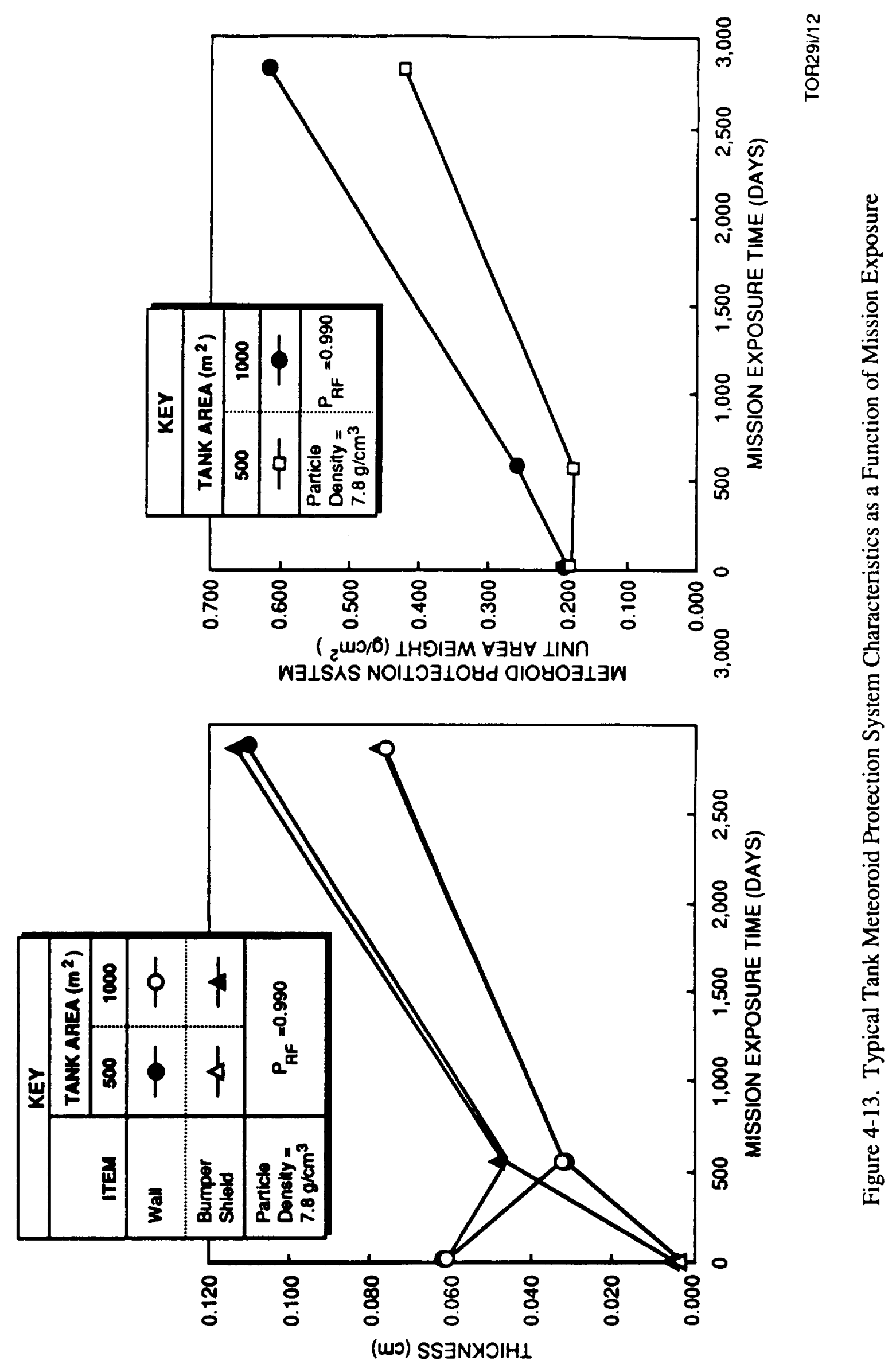




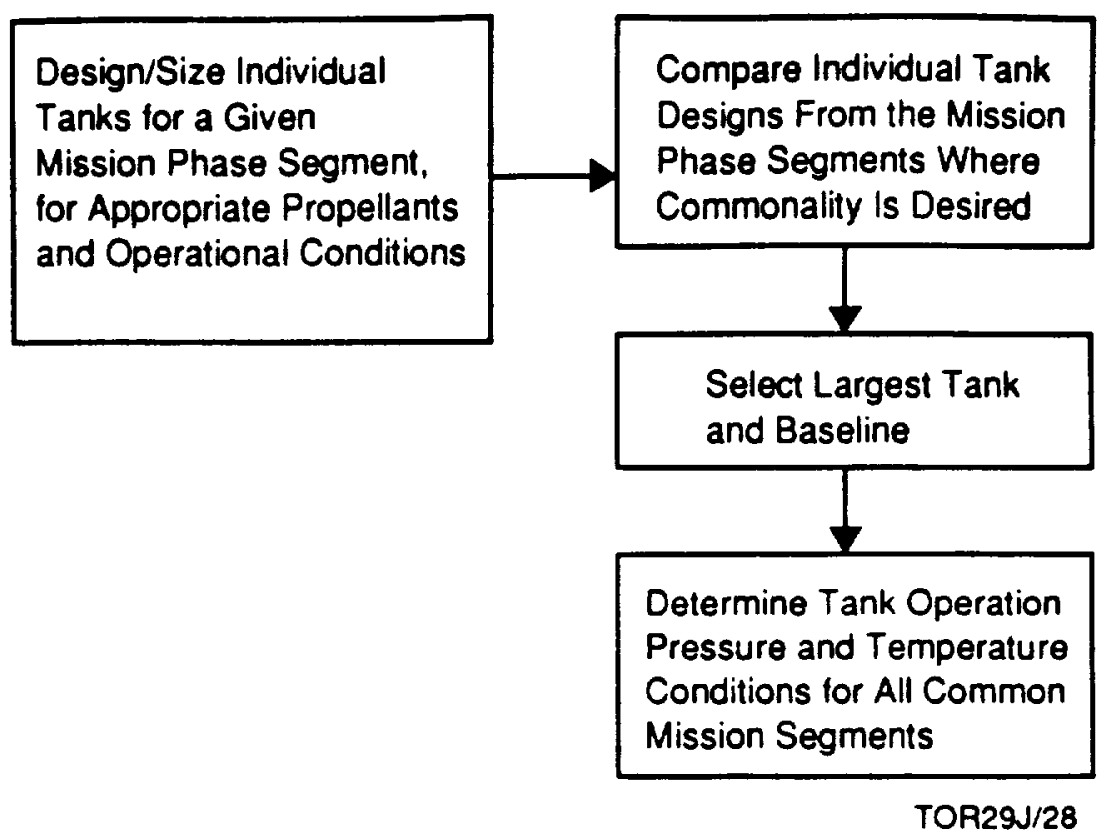

Figure 4-14. Common Tank Sizing Analysis Approach

Table 4-27. General Tank Design Features Assumed

- Suspended Nonloading Tankage Design with External Lines

- Separated Dome Tanks (where applicable)

- Spherical Tanks Except Where Tank Diameter Would Be Greater Than 11.8 meters (Compatible with Launch Vehicle Payload Envelope Constraints). Otherwise, Cylindrical Tanks with Elliptic Tank Domes Assumed

- $2 \%$ ullage

- Surface Tension Propellant Acquisition Devices

- Tank Materials

- Weldalite*

- Al 2219-T87

- Insulation

- SUPERFLOC*

- Conventional MLI

- Meteoroid Shield Material

- Al 2219-T87 (Conventional Aluminum Alloy)

- Autonomous Pressurization

- Helium Startup Pressure System (2 tanks per stage)

- Average Propellant/Space Exposure Time Used

- Average Distance and Worst-Case Radiation Exposure Assumed

- Trademark 
Table 4-28. Tank Design Systems Evaluated by Mission Segment

\begin{tabular}{|c|c|c|c|c|}
\hline \multirow[b]{2}{*}{ Scenario No./Vehicle/Tank Configuration } & \multicolumn{4}{|c|}{ MISSION SEGMENT } \\
\hline & TMI & MOC & TEI & EOC \\
\hline $\begin{array}{l}\text { 1. Baseline Earh LOX/H } \\
\text { - Individual Bum Tanks }\end{array}$ & -* & - & - & \\
\hline $\begin{array}{l}\text { 2. Lunar LOX, Mars LOX/CO } \\
\text { - Individual Burn Tanks }\end{array}$ & - & & - & \\
\hline - Common/Mission Segmented Propellant Tanks & $\bullet$ & & - & \\
\hline $\begin{array}{l}\text { 4. Lunar LOX/CH } 4 \text {, Mars LOX/CO } \\
\text { - Individual Burn Tanks }\end{array}$ & - & - & - & \\
\hline - Common/Mission Segmented Propellant Tanks & - & - & - & \\
\hline
\end{tabular}

- Complete Tank Set (Fuel and Oxidizer)

Table 4-29. Tank Design Comparison Rationale

\begin{tabular}{|c|c|c|}
\hline $\begin{array}{l}\text { Comparison } \\
\text { Case No. }\end{array}$ & Tank System Elements & Rationale/Insight \\
\hline 1 & $(1 / \mathrm{TMI})^{*},(1 / \mathrm{MOC}),(1 / \mathrm{TEI})$ & $\begin{array}{l}\text { - Establishes baseline } \mathrm{LOX} / \mathrm{H}_{2} \text { cryogenic tank } \\
\text { system design }\end{array}$ \\
\hline 2 & $1 /(\mathrm{TMI})$ vs. $(2 / \mathrm{TMI})$ vs. $(4 / \mathrm{TMI})$ & $\begin{array}{l}\text { - Evaluates the impact of in situ propellant tank } \\
\text { designs vs. cryogenic propellant tank designs for } \\
\text { TMI } \\
\text { - A direct comparison of the lunar } \mathrm{LOX} / \mathrm{H}_{2} \text { vs. } \\
\text { lunar } \mathrm{LOX} / \mathrm{CH}_{4} \text { for } \mathrm{TMI}\end{array}$ \\
\hline 3 & $\begin{array}{l}(1 / T M I)+(1 / \text { TEI }) v s \\
(2 / T M I)+(2 / T E I)\end{array}$ & $\begin{array}{l}\text { - Compares a tank design for TMI and TEI for } \\
\text { Scenario } 2 \text { against the conventional LOX/H } \\
\text { baseline system }\end{array}$ \\
\hline 4 & $\begin{array}{l}(1 / \mathrm{TMI})+(1 / \mathrm{TEI}) \text { vs. } \\
(4 / \mathrm{TMI})+(4 / \mathrm{TEI})\end{array}$ & $\begin{array}{l}\text { - Compares a tank design for TMI and TEI for } \\
\text { Scenario } 4 \text { against the conventional LOX/H } \\
\text { baseline }\end{array}$ \\
\hline$\overline{5}$ & $\begin{array}{l}\text { (2/TMI) + (2/TEI) vs. } \\
(4 / \mathrm{TMI}+(4 / \mathrm{TEI}) \\
\end{array}$ & $\begin{array}{l}\text { - Comparison of tank designs between Scenarios } \\
2 \text { and } 4\end{array}$ \\
\hline 6 & $(1 / \mathrm{MOC})$ vs. (4/MOC) & 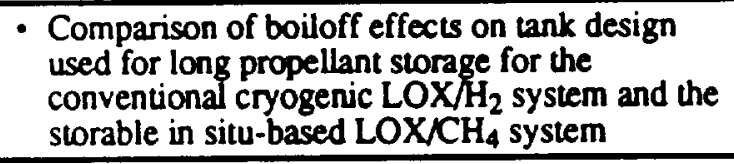 \\
\hline 7 & (1/TEI) vs. (2/TEI) & $\begin{array}{l}\text { - Comparison of tank designs for long-term } \\
\text { exposure to space for the conventional LOX/H } \\
\text { system and the in sitw-based LOX/CO system }\end{array}$ \\
\hline 8 & $\begin{array}{l}(1 / \mathrm{TMI})+(1 / \mathrm{MOC})+(1 / \mathrm{TEI}) \text { vs. } \\
(4 / \mathrm{TMI})+(4 / \mathrm{MOC})+(4 / \mathrm{TEI})\end{array}$ & $\begin{array}{l}\text { - Comparison of tank designs for an all cryogenic } \\
\text { LOX/H } / \mathrm{H}_{2} \text { system versus an all in situ propellant- } \\
\text { based } \mathrm{LOX}_{\mathrm{COH}} \text { and LOX/CO system }\end{array}$ \\
\hline 9 & $(1 / \mathrm{MOC})$ and $(4 / \mathrm{MOC})$ & $\begin{array}{l}\text { - Tank insulation type varied, effect of boiloff } \\
\text { compared }\end{array}$ \\
\hline 10 & (1/TMI) and (4/TEI) & - Tank material varied, system weight compared \\
\hline 11 & $(4 / \mathrm{TMI})$ & - Tank pressure varied, system weight compared \\
\hline
\end{tabular}

* (Scenario No.Mission Segment) 
Detailed results for the tank designs analyzed, see Table 4-28, are given in Appendix F. Tables 4-30, 4-31 and 4-32 summarize the tank design comparison results. Detailed mass tank design weight comparisons results are shown in Table 4-30. Substantial reductions in the dry weight of the tank systems which employ $\mathrm{LOX} / \mathrm{CO}$ and $\mathrm{LOX} / \mathrm{CH}_{4}$ can be realized when compared to systems that use Earth-based LOX/H2 $\mathrm{H}_{2}$. Use of SUPERFLOC insulation and Weldalite tank materials reduces tank system weight substantially when compared to conventional tank materials and insulations. Tank pressure over the range investigated had little effect on overall tank system mass.

Total tankage system mass fractions are summarized in Table 4-31 for the tank designs evaluated. Tankage systems which store $\mathrm{LOX} / \mathrm{H}_{2}$ have total tankage system mass fractions greater than 0.020 . Those tank systems which hold the in situ-based propellant combinations of LOX/CO and $\mathrm{LOX} / \mathrm{CH}_{4}$ exhibit mass fractions in the range of 0.011 to 0.016 . The high mass fractions associated with the $\mathrm{LOX} / \mathrm{H}_{2}$ tank design are attributed to the large size from increased boiloff and the low density associated with $\mathrm{H}_{2}$. These mass fraction shown in Table 4-31 are considered highly representative of such systems and should be considered for incorporation in future toplevel mission and vehicle design studies.

Table 4-32 presents the estimated dry tankage system weight savings by employing common propellant tanks for the MTV for each mission scenario considered. Employing a common tank MTV can reduce tank system weight by approximately $40 \%$ compared to using individual tanks for the in situ-based scenario. Developing tank technologies to support such common tank designs would have a high payoff. 
Table 4-30. Tank Design Comparison Results Summary

\begin{tabular}{|c|c|c|}
\hline $\begin{array}{c}\text { Comparison } \\
\text { Case No. }\end{array}$ & Mass Comparisons (lbm) & Comment(s) \\
\hline 1 & $\begin{array}{l}\text { - } 1 / \text { TMI* } \\
\text { - Propellant Carried }=1,099,183 \\
\text { - Oxidizer Tank }=4,603.9 \\
\text { - Fuel Tank }=16,643.8 \\
\text { - Other }=5,186.3 \\
\text { - Total (wet) }=1,125,608 \\
\text { - } 1 / \text { MOC } \\
\text { - Propellant Carried }=605,699 \\
\text { - Oxidizer Tank }=2,862.6 \\
\text { - Fuel Tank }=6,716.3 \\
\text { - Other }=2,869.5 \\
\text { - Total (wet) }=618,147.4 \\
\text { - } \text { TEI } \\
\text { - Propellant Carried }=202,832 \\
\text { - Oxidizer Tank }=1,386.6 \\
\text { - Fuel Tank }=3,378.8 \\
\text { - Other }=1,147.4 \\
\text { - Total (wet) }=208,739.8 \\
\end{array}$ & - \\
\hline 2 & $\begin{array}{l}\text { - 1/TMI } \\
\text { - Same as Comparison Case No. } 1 \\
\text { - 2/TMI } \\
\text { - Propellant Carried }=273,022 \\
\text { - Oxidizer Tank }=1,698.0 \\
\text { - Fuel Tank }=3,998.1 \\
\text { - Other }=1,393.3 \\
\text { - Total (wet) }=280,111.4 \\
\text { - 4/TMI } \\
\text { - Propellant Carried }=384,128 \\
\text { - Oxidizer Tank }=1,991.8 \\
\text { - Fuel Tank }=1,896.8 \\
\text { - Other }=1,680.9 \\
\text { - Total (wet) }=389,697.5\end{array}$ & $\begin{array}{l}\text { - Substantial reduction in tankage system weight } \\
\text { is possible using in situ-based propellants for } \\
\text { the TMI mission segment } \\
\text { - Scenario No. } 1 \text { vs. Scenario No. } 2 \\
\text { - Oxidizer tank }=63.1 \% \text { reduction } \\
\text { - Fuel tank }=76.0 \% \text { reduction } \\
\text { - Total dry weight }=73.2 \% \text { reduction } \\
\text { - Scenario No. } 1 \text { vs. Scenario No. } 4 \\
- \text { Oxidizer tank }=56.7 \% \text { reduction } \\
\text { - Fuel tank }=88.6 \% \text { reduction } \\
\text { - Total dry weight }=78.9 \% \text { reduction } \\
\text { - Scenario No. } 4 \text { TMI tankage system dry weight } \\
\text { is } 21.4 \% \text { lighter than that associated with } \\
\text { Scenario No. } 2 \\
\text { - Major differences in total wet weight for all } 3 \\
\text { scenarios } \\
\text { - Influenced by mission approach, propellant } \\
\text { density, and engine specific impulse effects }\end{array}$ \\
\hline 3 & $\begin{array}{l}\text { - 1/TMI } \\
\text { - Same as Comparison Case No. } 1 \\
\text { - 1/TEI } \\
\text { - Same as Comparison Case No. } 1 \\
\text { - 2/TMI } \\
\text { - Same as Comparison Case No. } 2 \\
\text { - 2/TEI } \\
\text { - Propellant Carried }=325,607 \\
\text { - Oxidizer Tank }=1,053.9 \\
\text { - Fuel Tank }=2,148.5 \\
\text { - Other }=1,570.6 \\
\text { - Total (wet) }=330,380\end{array}$ & $\begin{array}{l}\text { - Using the tank design approach for Scenario } \\
\text { No. } 2 \text { for the MTV transit flight phases reduces } \\
\text { cotal tankage system dry weight } 63.3 \% \\
\text { - Not influenced by boiloff }\end{array}$ \\
\hline
\end{tabular}

* Tankage Concept No. (see Table 4-25)/Mission Segment 
Table 4-30. Tank Design Comparison Results Summary (Cont.)

\begin{tabular}{|c|c|c|}
\hline $\begin{array}{c}\text { Comparison } \\
\text { Case No. }\end{array}$ & Mass Comparisons (lbm) & Comment(s) \\
\hline 4 & $\begin{array}{l}\text { 1/TMI } \\
\text { - Same as Comparison Case No. } 1 \\
\text { - 1/TEI } \\
\text { - Same as Comparison Case No. } 1 \\
\text { - 4/TMI } \\
\text { - Same as Comparison Case No. } 2 \\
\text { - 4/TEI } \\
\text { - Propellant Carried }=731,017 \\
\text { - Oxidizer Tank }=1,789.0 \\
\text { - Fuel Tank }=3,251.4 \\
\text { - Other }=3,258.1 \\
\text { - Total (wet) }=739,315.5\end{array}$ & $\begin{array}{l}\text { - Using the tank design approach for Scenario } \\
\text { No. } 4 \text { for the MTV transit flight phases reduces } \\
\text { total tankage system dry weight } 63.3 \% \\
\text { - Not influenced by boiloff }\end{array}$ \\
\hline 5 & $\begin{array}{l}\text { - 2/TMI } \\
\text { - Same as Comparison Case No. } 2 \\
\text { - 2/TEI } \\
\text { - Same as Comparison Case No. } 3 \\
\text { - 4/TMI } \\
\text { - Same as Comparison Case No. } 2 \\
\text { - 4/TEI } \\
\text { - Same as Comparison Case No. } 4\end{array}$ & $\begin{array}{l}\text { - Total dry tankage system weight for Scenario } 2 \\
\text { is only reduced } 14.2 \% \text { when compared to } \\
\text { Scenario } 4\end{array}$ \\
\hline 6 & $\begin{array}{l}\text { - 1/MOC } \\
\text { - Same as Comparison Case No. } 1 \\
\text { 4/MOC } \\
\text { - Propellant Carried }=261,979 \\
\text { - Oxidizer Tank }=1,546.0 \\
\text { - Fuel Tank }=1,477.6 \\
\text { - Other }=1,229.9 \\
\text { - Total (wet) }=266,232.5\end{array}$ & $\begin{array}{l}\text { - Scenario } 4 \mathrm{MOC} \text { dry tankage system weight is } \\
65.8 \% \text { less than that associated with the } \\
\text { comparable baseline } \mathrm{LOX} / \mathrm{H}_{2} \text { tankage system } \\
\text { - Boiloff, engine performance and propellant } \\
\text { density influence this result }\end{array}$ \\
\hline 7 & $\begin{array}{l}\text { - 1/TEI } \\
\text { - Same as Comparison Case No. } 1 \\
\text { - 2/TEI } \\
\text { - Same as Comparison Case No. } 3\end{array}$ & $\begin{array}{l}\text { - Using LOX/CO for TEI reduces the dry tankage } \\
\text { system approximately } 19.2 \% \text { compared to the } \\
\text { LOX/H } / \mathrm{H}_{2} \text { scenario baseline }\end{array}$ \\
\hline 8 & $\begin{array}{l}\text { - 1/TMI } \\
\text { - Same as Comparison Case No. } 1 \\
\text { - I/MOC } \\
\text { - Same as Comparison Case No. } 1 \\
\text { - 1/TEI } \\
\text { - Same as Comparison Case No. } 1 \\
\text { - 4/TMI } \\
\text { - Same as Comparison Case No. } 2 \\
\text { - 4/MOC } \\
\text { - Same as Comparison Case No. } 6 \\
\text { - 4/TEI } \\
\text { - Same as Comparison Case No. } 4\end{array}$ & $\begin{array}{l}\text { MTV dry tankage system weight can be reduced } \\
\text { by } 59.5 \% \text { by using all in situ propellant } \\
\text { scenarios (Scenario No. 4) compared to an all } \\
\text { Earth LOX/H } / \mathrm{H}_{2} \text { system }\end{array}$ \\
\hline
\end{tabular}


Table 4-30. Tank Design Comparison Results Summary (Cont.)

\begin{tabular}{|c|c|c|}
\hline $\begin{array}{c}\text { Comparison } \\
\text { Case No. }\end{array}$ & Mass Comparisons (Ibm) & Comment(s) \\
\hline 9 & $\begin{array}{l}\text { - 1/MOC } \\
\text { - Same as Comparison Case No. } 1 \\
\text { - 1/MOC } \\
\text { - Propellant Carried }=611,696 \\
\text { - Oxidizer Tank }=3,151.8 \\
\text { - Fuel Tank }=7,626.8 \\
\text { - Total (wet) }=625,342.3 \\
\text { - 4/MOC (Baseline) } \\
\text { - Same as Comparison Case No. } 6 \\
\text { - 4/MOC } \\
\text { - Propellant Carried }=263,764 \\
\text { - Oxidizer Tank }=1,694.5 \\
\text { - Fuel Tank }=1,623.6 \\
\text { - Other }=1,227.9 \\
\text { - Total (wet) }=268,310 \\
\end{array}$ & $\begin{array}{l}\text { - Use of conventional MLI for the MOC baseline } \\
\text { LOX/ } \mathrm{H}_{2} \text { tankage system increases its total dry } \\
\text { weight by } 56.7 \% \text { compared to a system which } \\
\text { uses SUPERFLOC } \\
\text { - Using MLI or SUPERFLOC has litule effect on } \\
\text { the Scenario } 4 \text { MOC tankage system. Only a } \\
6.4 \% \text { increase in weight is predicted by using } \\
\text { SUPERFLOC }\end{array}$ \\
\hline 10 & $\begin{array}{l}\text { - 1/TMI (Baseline) } \\
\text { - Same as Comparison Case No. } 1 \\
\text { - 1/TMI } \\
\text { - Propellant Carried }=1,099,189 \\
\text { - Oxidizer Tank }=6,582.2 \\
\text { - Fuel Tank }=24,558.8 \\
\text { - Other }=5,209.7 \\
\text { - Total (wet) }=1,135,539.7 \\
\text { - 4/TEI (Baseline) } \\
\text { - Same as Comparison Case No. } 4 \\
\text { - 4/TEI } \\
\text { - Propellant Carried }=731,012 \\
\text { - Oxidizer Tank }=1,832.2 \\
\text { - Fuel Tank }=3,890.2 \\
\text { - Other }=3,257.7 \\
\text { - Total (wet) }=739,992.1 \\
\end{array}$ & $\begin{array}{l}\text { - Employing Al } 2219-\mathrm{T} 87 \text { tank materials } \\
\text { increases the Scenario } 1 \mathrm{TMI} \text { dry tankage weight } \\
\text { by } 27.3 \% \\
\text { - Employing Al } 2219-\mathrm{T} 87 \text { tank materials } \\
\text { increases the Scenario } 4 \mathrm{TMI} \text { dry tankage weight } \\
\text { by only } 7.6 \%\end{array}$ \\
\hline 11 & $\begin{array}{l}\text { - 4/TMI (Baseline) } \\
\text { - Same as Comparison Case No. } 2 \\
\text { - 4/TMI } \\
\text { - Propellant Carried }=368,289 \\
\text { - Oxidizer Tank }=1,992.1 \\
\text { - Fuel Tank }=1,904.3 \\
\text { - Other }=1,753.3 \\
\text { - Total (wet) }=391,938.7 \\
\text { - 4/TMI } \\
\text { - Propellant Carried }=388,476 \\
\text { - Oxidizer Tank }=1,995.2 \\
\text { - Fuel Tank }=1,918.0 \\
\text { - Other }=1,754.4 \\
\text { - Total (wet) }=394,143.6\end{array}$ & $\begin{array}{l}\text { - Pressure ranges examined } \\
\text { - Oxidizer tank: } 22.8 \text { to } 62.8 \text { psia } \\
\text { - Fuel tank: } 35.0 \text { to } 52.5 \text { psia } \\
\text { - Increasing tank pressure had liule effect on } \\
\text { tankage system dry weight }(<1.7 \%)\end{array}$ \\
\hline
\end{tabular}


Table 4-31. Summary of Total Tankage System Mass Fractions

\begin{tabular}{|c|c|c|}
\hline $\begin{array}{c}\text { Scenario } \\
\text { No. }\end{array}$ & $\begin{array}{c}\text { Mission } \\
\text { Segment }\end{array}$ & $\begin{array}{c}\text { Total Tankage System } \\
\text { Mass Fraction* }\end{array}$ \\
\hline \multirow{3}{*}{1} & TMI & 0.024 \\
\cline { 2 - 3 } & MOC & 0.020 \\
\cline { 2 - 3 } & TEI & 0.028 \\
\hline 2 & TMI & 0.025 \\
\cline { 2 - 3 } & TEI & 0.014 \\
\hline \multirow{3}{*}{4} & TMI & 0.014 \\
\cline { 2 - 3 } & MOC & 0.016 \\
\cline { 2 - 3 } & TEI & 0.011 \\
\hline
\end{tabular}

* Baseline design assumptions assumed; individual burn tank design approach used.

Table 4-32. Summary of Potential Tankage System Weight Savings by Employing Common Propellant Tanks for MTV Earth-Mars-Earth Mission Segments

\begin{tabular}{|c|c|c|c|}
\hline $\begin{array}{c}\text { Scenario } \\
\text { No. }\end{array}$ & $\begin{array}{c}\text { Tank } \\
\text { Type }\end{array}$ & $\begin{array}{c}\text { Mission Segment } \\
\text { Which Drives Tank } \\
\text { Commonality }\end{array}$ & $\begin{array}{c}\text { Estimate of Dry } \\
\text { Tankage System } \\
\text { Weight Savings (\%) }\end{array}$ \\
\hline \multirow{2}{*}{1} & Oxidizer & TMI & 18.3 \\
\cline { 2 - 3 } & Fuel & TMI & \multirow{2}{*}{40.2} \\
\hline \multirow{2}{*}{2} & Oxidizer & TMI & \\
\cline { 2 - 4 } & Fuel & TMI & \multirow{2}{*}{42.0} \\
\hline \multirow{2}{*}{4} & Oxidizer & TMI & \\
\cline { 2 - 4 } & Fuel & TEl & \\
\hline
\end{tabular}




\subsection{MISSION PERFORMANCE AND COMPARISON}

Mission performance was reassessed using the baseline multipropellant engine designs described in Section 4.2.3. Details of the approach and assumptions used in this updated analysis, except as noted, are the same as those used in the initial mission analysis effort described in Section 2.0. This section compares candidate mission scenarios and engine cycles, and describes the results of trade studies defining sensitivity of mission performance to engine design parameters such as mass, Isp, and nozzle area ratio. Also discussed is an assessment of alternative propellant tank reuse/staging strategies. A summary of all scenarios described in this section is shown in Table 5-1. All figures in this section refer to the scenario designations from this table. Scenario 5, which was included in the initial mission assessment effort (see Section 2.0) for comparison to the other candidate scenarios, was excluded from these final performance assessments because it does not require a multipropellant engine.

For these final performance calculations, more refined tank sizing assumptions were also employed. In the initial calculations, mass was simply computed as a percentage of the propellant inside the tank. For the final calculations, a specific $\mathrm{Al} / \mathrm{Li}$ alloy is assumed for the tank wall material. On top of this alloy, a layer of foam is sprayed, and MLI insulation, a vaporcooled shield, and a micrometeoroid shield are added (see Table 5-2). For tanks containing the TMI propellant, only $5 \mathrm{~cm}$ of MLI is assumed, since these tanks have a much shorter space storage time than the other tanks.

For each scenario, vehicle and plant mass were calculated for expander and gas generator engines of 400:1 area ratio for all vehicles (booster stage, MTV, LEV, and MEV). A 165:1 expander engine was also assessed for Scenario 6, along with trades investigating the effect of higher or lower engine mass and higher or lower Isp for a 400:1 area ratio engine. Additionally for Scenario 7, trades were performed for alternatives in which tanks and/or engines would be reused within the same mission or from one mission to the next.

The final mission performance tables in Appendix E provide the propellant requirements for each mission burn, showing the mass of the vehicle immediately prior to each burn, $\Delta \mathrm{V}$ requirements, engine masses, Isp's, thrust levels, and engine thrust/burn times. 
Table 5-1. Mission Performance Assessment Scenarios

\begin{tabular}{|c|c|c|c|c|c|}
\hline Scenario & $\begin{array}{l}\text { Outbound } \\
\text { Propellant }\end{array}$ & $\begin{array}{c}\text { Return } \\
\text { Propellant }\end{array}$ & $\begin{array}{c}\text { Engine Thrust } \\
\text { (klb) }\end{array}$ & $\begin{array}{l}\text { Engine } \\
\text { Cycle }\end{array}$ & Options \\
\hline $\mathbf{1 A}$ & Earth $\mathrm{LOX} / \mathrm{H}_{2}$ & Earth $\mathrm{LOX} / \mathrm{H}_{2}$ & 250 & Expander & $400: 1$ area ratio \\
\hline 1B & Earth $\mathrm{LOX} / \mathrm{H}_{2}$ & Earth $\mathrm{LOX} / \mathrm{H}_{2}$ & 250 & GG & $400: 1$ area ratio \\
\hline $2 \mathrm{~A}$ & Lunar LOX/ Earth $\mathrm{H}_{2}$ & Mars LOX/CO & 175 & Expander & $400: 1$ area ratio \\
\hline 2B & Lunar LOX/ Earth $\mathrm{H}_{2}$ & Mars LOX/CO & 175 & GG & $400: 1$ area ratio \\
\hline 3A & Lunar LOX/ Earth $\mathrm{H}_{2}$ & Mars LOX/CH & 250 & Expander & $400: 1$ area ratio \\
\hline 3B & Lunar LOX/ Earth $\mathrm{H}_{2}$ & Mars LOX/CH & 250 & GG & $400: 1$ area ratio \\
\hline $4 \mathrm{~A}$ & Lunar $\mathrm{LOX} / \mathrm{CH}_{4}$ & Mars LOX/CO & 175 & Expander & $400: 1$ area ratio \\
\hline 4B & Lunar $\mathrm{LOX} / \mathrm{CH}_{4}$ & Mars LOX/CO & 175 & GG & $400: 1$ area ratio \\
\hline $6 A$ & Earth $\mathrm{LOX} / \mathrm{H}_{2}$ & Mars LOX/CO & 175 & Expander & $400: 1$ area ratio \\
\hline 6B & Earth $\mathrm{LOX} / \mathrm{H}_{2}$ & Mars LOX/CO & 175 & Expander & $165: 1$ area ratio \\
\hline 6C & Earth $\mathrm{LOX} / \mathrm{H}_{2}$ & Mars LOX/CO & 175 & GG & $400: 1$ area ratio \\
\hline 6D & Earth $\mathrm{LOX} / \mathrm{H}_{2}$ & Mars LOX/CO & 175 & Expander & $\begin{array}{l}400: 1 \text { area ratio } \\
+10 \% \text { eng. mass }\end{array}$ \\
\hline $6 E$ & Earth $\mathrm{LOX} / \mathrm{H}_{2}$ & Mars LOX/CO & 175 & Expander & $\begin{array}{l}400: 1 \text { area ratio } \\
-10 \% \text { eng. mass }\end{array}$ \\
\hline $6 F$ & Earth $\mathrm{LOX} / \mathrm{H}_{2}$ & Mars LOX/CO & 175 & Expander & $\begin{array}{c}400: 1 \text { area ratio } \\
+10 \% \text { Isp }\end{array}$ \\
\hline $6 \mathrm{G}$ & Earth $\mathrm{LOX} / \mathrm{H}_{2}$ & Mars LOX/CO & 175 & Expander & $\begin{array}{c}400: 1 \text { area ratio } \\
-10 \% \text { Isp }\end{array}$ \\
\hline $7 \mathrm{~A}$ & Earth $\mathrm{LOX} / \mathrm{H}_{2}$ & Mars LOX/CH 4 & 250 & Expander & $400: 1$ area ratio \\
\hline 7B & Earth $\mathrm{LOX} / \mathrm{H}_{2}$ & Mars LOX/CH & 250 & Expander & $\begin{array}{c}400: 1 \text { area ratio } \\
\text { MTV MOC tanks reused } \\
\text { for TEI+EOC }\end{array}$ \\
\hline $7 \mathrm{C}$ & Earth $\mathrm{LOX} / \mathrm{H}_{2}$ & Mars $\mathrm{LOX} / \mathrm{CH}_{4}$ & 250 & Expander & $\begin{array}{c}\text { 400:1 area ratio } \\
\text { No tank/engine staging } \\
\end{array}$ \\
\hline 7D & Earth $\mathrm{LOX} / \mathrm{H}_{2}$ & Mars LOX/CH & 250 & GG & $400: 1$ area ratio \\
\hline $7 E$ & Earth $\mathrm{LOX} / \mathrm{H}_{2}$ & Mars LOX/CH & 250 & Expander & $\begin{array}{l}400: 1 \text { area ratio } \\
2 \text { MOC tank sets: } \\
1 \text { MOC set reused for } \\
\text { TEI and then staged; } \\
1 \text { MOC set sized for } \\
\text { EOC propellant } \\
\text { (reused for EOC) }\end{array}$ \\
\hline
\end{tabular}


Table 5-2. Propellant Tank Mass Allocations

\begin{tabular}{|l|c|c|}
\hline Layer & $\begin{array}{c}\text { Thickness } \\
(\mathrm{cm})\end{array}$ & $\begin{array}{c}\text { Areal Density } \\
\left(\mathbf{k g} / \mathrm{m}^{2}\right)\end{array}$ \\
\hline Tank Wall & 0.4 & 10.95 \\
Foam & 1.27 & 0.55 \\
SUPERFLOC MLI & $5(60$ layers $)$ & 1.115 \\
Vapor-Cooled Shield & - & 1.27 \\
SUPERFLOC MLI & 5 & 1.115 \\
Micrometeoroid Shield & 0.05 & 2.80 \\
\hline \multicolumn{2}{|c|}{ Total Areal Density $\left(\mathrm{kg} / \mathrm{m}^{2}\right)=17.8$} \\
\hline
\end{tabular}

\subsection{Expander vs. Gas Generator Cycle Engine Assessment}

Figure 5-1 shows a comparison of lunar and Mars propellant plant mass for each scenario for vehicles using both expander and gas generator cycle engines that use a 400:1 nozzle area ratio. These plant masses are representative of the front-end investment required to support a given scenario. The plant masses required for scenarios employing expander-type engines are consistently higher than those that employ gas generator cycle engines. Although the expander cycle engines have slightly higher Isp's than the gas generator engines, the performance advantage of the higher Isp expander engine is overshadowed by its significantly higher engine mass, and, therefore, requires more propellant and a larger ISPP plant. The greatest plant mass difference occurs for the Mars LOX/CO propellant plant of Scenario 4, where the plant required for the gas generator engine scenarios is $16.4 \%$ lighter than that for expander engine scenarios. The smallest plant mass difference occurs for the lunar propellant plant of Scenario 3, where the plant required for gas generator engines is $1.7 \%$ lighter than that required for expander engines.

The Mars LOX/CO plant mass used in Scenarios 2, 4, and 6 is substantially greater than any of the other plant masses, as depicted in Figure 5-1. This is due mainly to the refrigeration requirement to separate $\mathrm{CO}$ from a $\mathrm{CO}-\mathrm{CO}_{2}$ gas mixture obtained during processing of the Mars atmosphere. Alternative technologies for this separation are currently under investigation by several researchers and may enable production of Mars LOX/CO with much smaller ISPP plant sizes. 


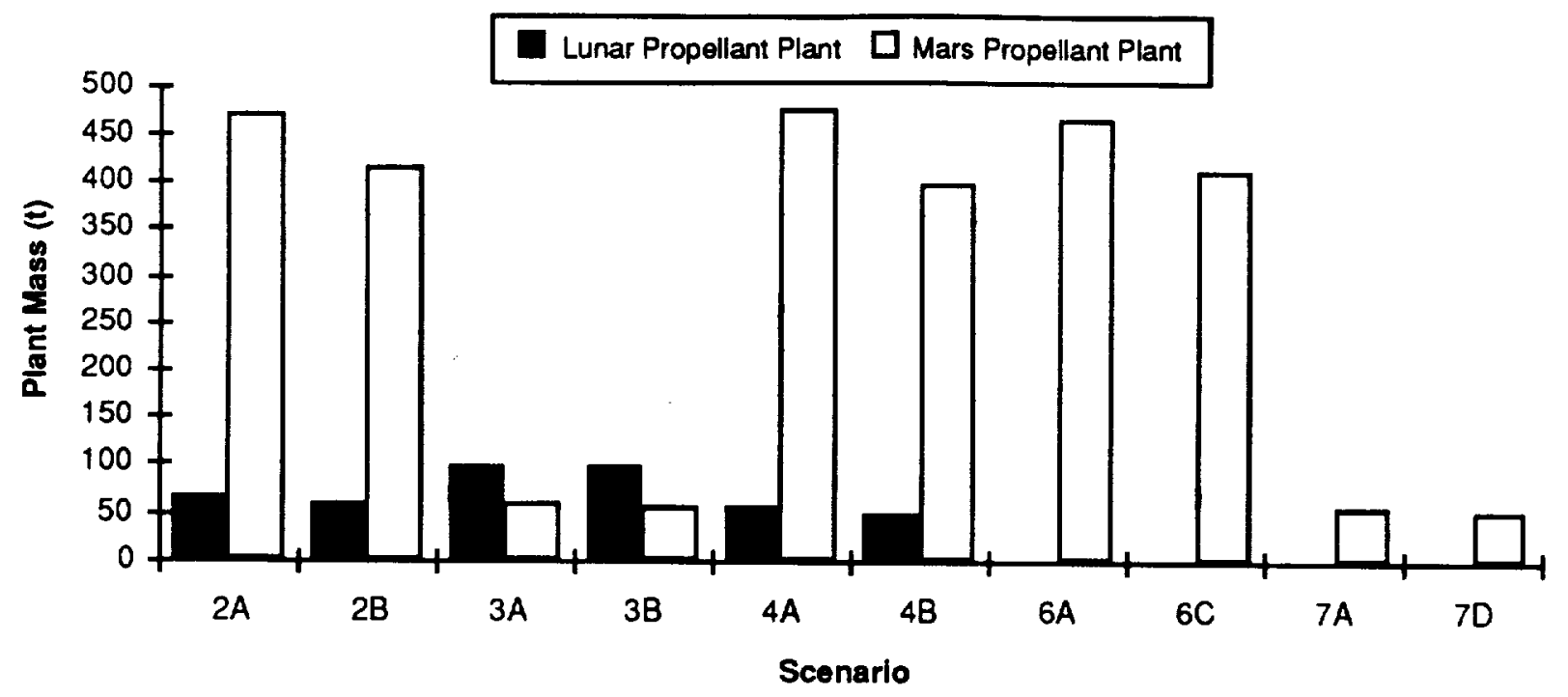

Figure 5-1. ISPP Plant Mass Comparison: Expander vs. Gas Generator Cycle Engine Assessment

Figure 5-2 shows MEV dry mass for each scenario for both expander and gas generator engines. The vehicles using the expander engines are consistently heavier than those using the gas generator engines, since the gas generator engines are anywhere from $43 \%$ to $61 \%$ lighter than the expander engines (see Tables 4-15 and 4-16). The MEV mass in scenarios where Mars LOX/CO is used is markedly higher than that in scenarios using Mars $\mathrm{LOX} / \mathrm{CH}_{4}$. This difference is because LOX/CO propellant has an Isp of about 290 seconds, compared to $\mathrm{LOX} / \mathrm{CH}_{4}$ which has an Isp of about 390 seconds. Therefore, much more LOX/CO propellant is needed to perform the mission than $\mathrm{LOX} / \mathrm{CH}_{4}$ propellant.

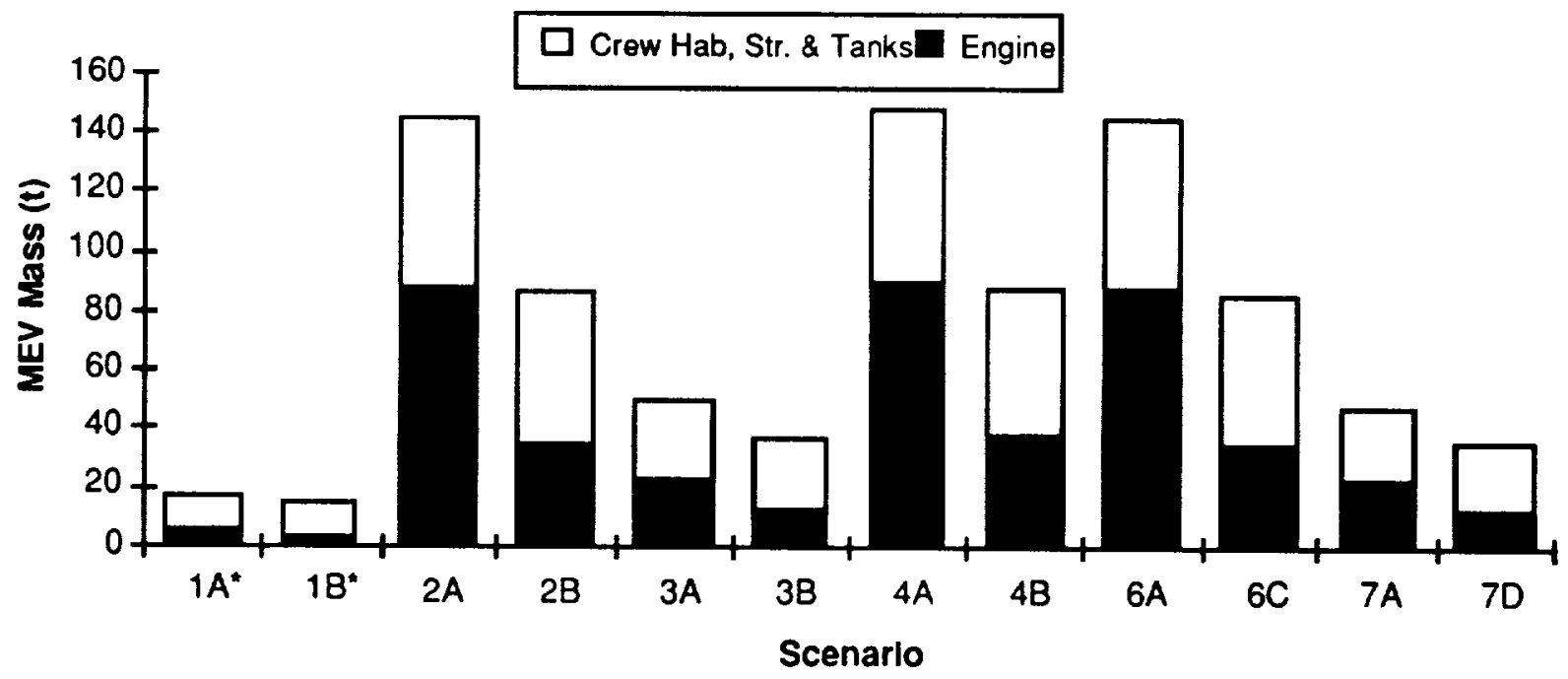

* These masses are for a single MEV, while all the other scenarios (bars) refer to the combined masses of 2 MEVs.

Figure 5-2. MEV Mass Comparison: Expander vs. Gas Generator Cycle Engine Assessment 
LEV dry mass is shown in Figure 5-3 for the in situ scenarios in which lunar propellant is used. Similar to the MEV case, the LEVs using expander cycle engines are heavier than those using gas generator engines. The LEVs in Scenarios 2 and 3 use lunar-produced LOX in combination with Earth-produced $\mathrm{H}_{2}$. The vehicles carry lunar-produced LOX up to LLO and transfer it into the MTV tanks. The MTV makes the trip from LLO to LMO using this lunar LOX along with Earth $\mathrm{H}_{2}$. In these two scenarios, the LEV not only transports oxygen plant resupply materials down to the lunar surface, but it also has to carry down the Earth-produced $\mathrm{H}_{2}$ it needs to perform the next surface-to-LLO-to-surface mission. This $\mathrm{H}_{2}$ is brought out to the Moon on the expendable booster and is transferred to the LEV in orbit.

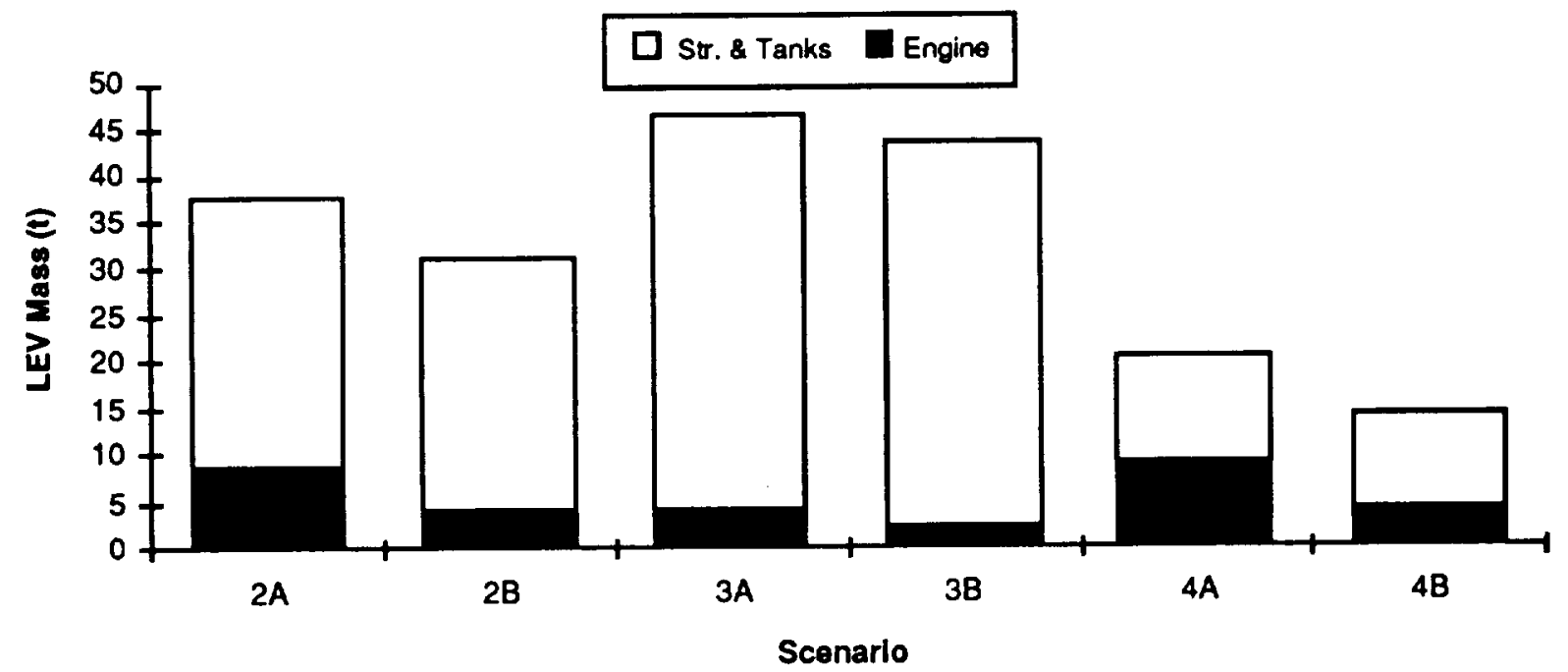

Figure 5-3. LEV Mass Comparison: Expander vs. Gas Generator Cycle Engine Assessment

In Scenario 4, the LEV uses lunar-produced $\mathrm{LOX} / \mathrm{CH}_{4}$ for propellant. Here, all of the propellant used by the LEV is lunar-produced $\mathrm{LOX} / \mathrm{CH}_{4}$. The dry mass is lower here than in the cases using lunar LOX/Earth $\mathrm{H}_{2}$, since it does not have to carry Earth-produced propellant back down to the surface.

Figure 5-4 shows a comparison of MTV dry mass for all the scenarios for expander vs. gas generator engines. As expected, the vehicles with expander engines have higher mass than those with gas generator engines. The shaded portion of each bar is the MTV engine mass. Again, the heavier expander engines' performance is slightly improved (higher Isp) over the gas generator engines, but results in a higher vehicle weight. The white portion of each bar represents the combined mass of a $30 \mathrm{t}$ crew habitat module, core EOI propellant tanks, and structure. The masses shown here do not include the mass of the crew and consumables (totaling approximately $7 \mathrm{t}$ ). 


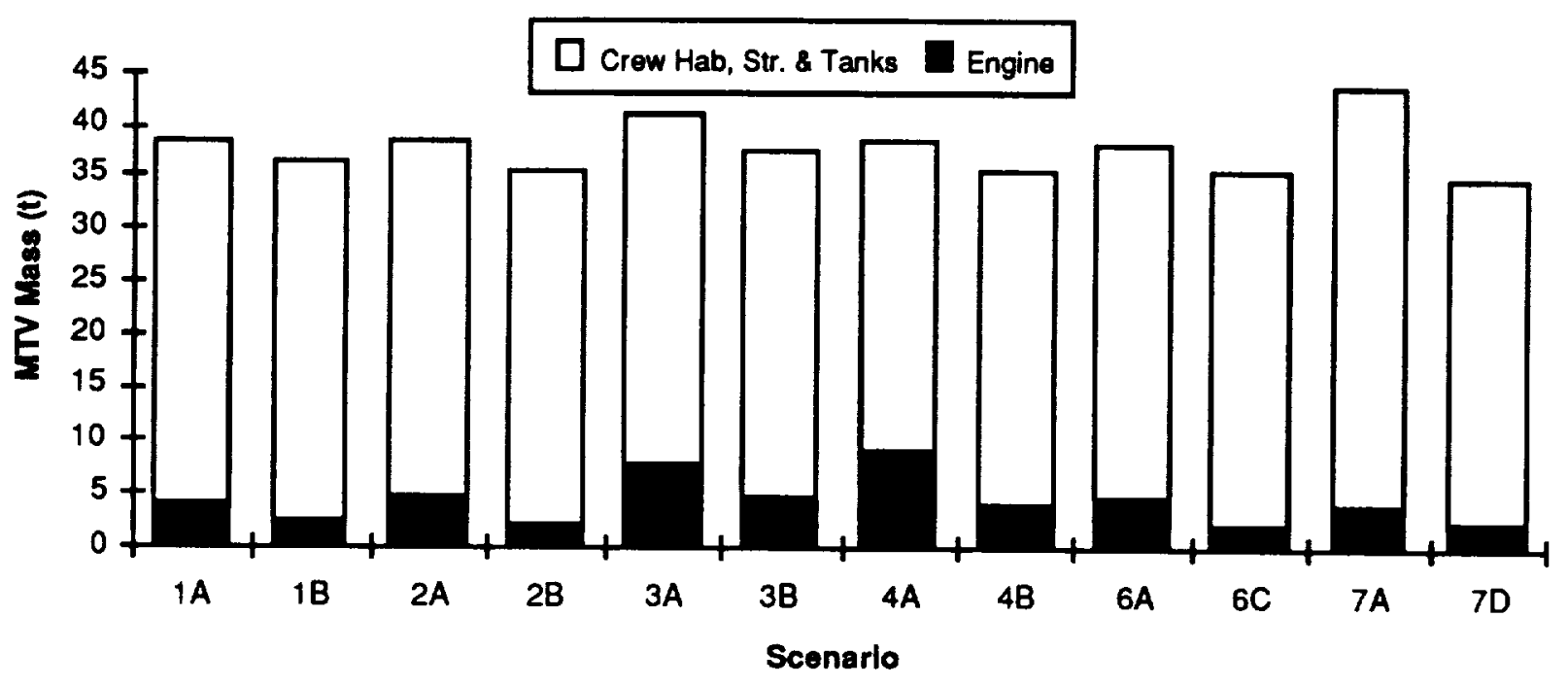

Figure 5-4. MTV Mass Comparison: Expander vs. Gas Generator Cycle Engine Assessment

Steady-state Earth Launch Mass (ELM) per mission is displayed in Figure 5-5 for each scenario for both expander and gas generator engine types. The legend at the top of this figure shows the elements that comprise the steady-state ELM and include (from top of each bar down): 1) the $25 \mathrm{t}$ Mars mission payload; 2) the 4 crew members and their consumables; 3) the MEV aeroshell used for decelerating the MEV during descent to the Mars surface; 4) the engines that are staged during the mission; 5) the staged propellant tanks; 6) propellant supplied from Earth; 7) refurbishment and consumable resupply for the Mars ISPP plant; and 8) refurbishment and consumable resupply for the lunar ISPP plant used only in Scenarios 2, 3, and 4.

The significance of Figure 5-5 is that it shows the launch mass savings achievable per mission over the long term by employing in situ propellant production at the Moon and/or Mars. Scenarios using expander cycle engines (1A, 2A, 3A, 4A, 6A, 7A) depict the potential ELM savings as great as $81 \%$ (Scenario $4 \mathrm{~A}$ ) over the baseline chemical propulsion scenario (1A), which uses no in situ propellant. The major mass savings is in reduction of the amount of Earthsourced propellant required to perform the mission. In Scenarios 2 and 3, Earth-supplied LOX $/ \mathrm{H}_{2}$ is needed by the expendable booster to transport the MTV from LEO to LLO, and Earth-supplied $\mathrm{H}_{2}$ is needed to fuel the LEV and the MTV for the LLO to LMO leg of the trip. In Scenario 4, Earth-supplied LOX/H $/ \mathrm{H}_{2}$ is needed only by the booster to carry the MTV from LEO to LLO, while in Scenarios 6 and 7, Earth-supplied LOX/H $/ \mathrm{H}_{2}$ is used for the LEO to LMO leg of the MTV trip. The scenario using the least Earth-supplied propellant is Scenario 4. 


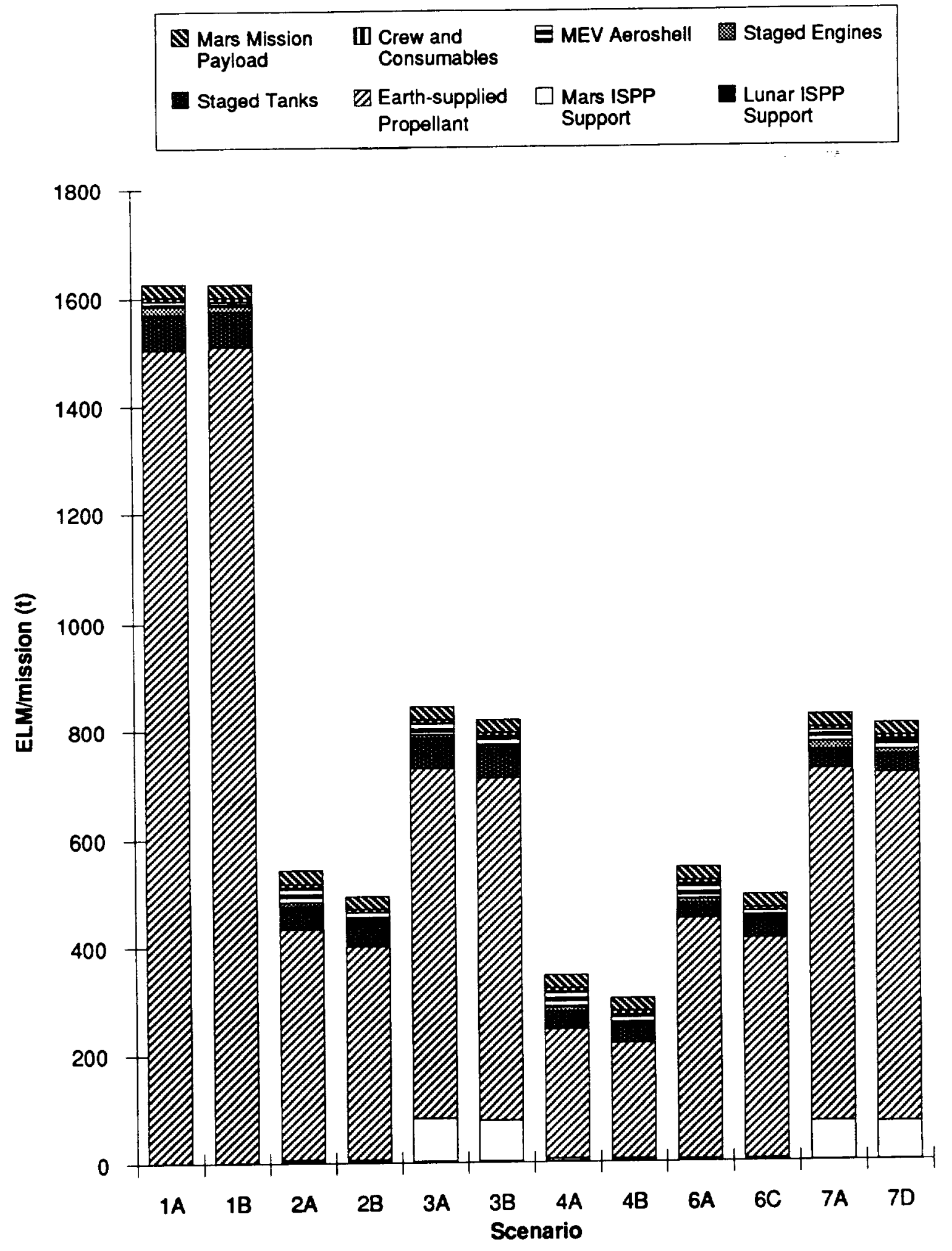

Figure 5-5. Steady-State Earth Launch Mass per Mission Comparison: Expander vs. Gas Generator Cycle Engine Assessment 
An interesting observation is that even though the Mars plant mass is substantially higher in Scenarios 2, 4, and 6 than it is in Scenarios 3 and 7, the ELM is lower because no reagent resupply is needed by the Mars LOX/CO plant, see Figure 5-2. For the $\mathrm{LOX} / \mathrm{CH}_{4}$ plant, however, over $70 \mathrm{t}$ of Earth-produced $\mathrm{H}_{2}$ is needed for reagent resupply. This necessity increases ELM substantially.

Note that Figure 5-5 shows ELM per mission in the steady-state operation, after the plants have been constructed at the Moon and/or Mars. Figure 5-5 does not show the ELM required for the first few missions that emplace the infrastructure elements. The infrastructure elements are: 1) the fully operational lunar and Mars ISPP plants; 2) the surface excursion vehicles (LEVs and MEVs) needed to transport propellant from the plants up to the MTV and to bring crew, mission payload, and plant resupply down to the surface; and 3) the MTV. The masses represented by each bar are the masses of elements that are resupplied for each mission. These elements are shown in the legend at the top of Figure 5-5.

\subsection{Engine Design and Tank Reuse Trades}

To better understand the sensitivity of the mission performance assessment to engine design parameters, several trades were performed for Scenarios 6 and 7. In Scenario 6, these trades included investigations of mission performance using different engine mass and Isp values, and using an engine with a lower nozzle area ratio. Additionally, in Scenario 7, three propellant tank reuse strategies were assessed to identify potential savings by using a tank for more than one burn. All other scenarios staged tanks after being emptied and carried empty tanks for fuel obtained from the Moon or Mars.

Results for the engine design and tank reuse trades are characterized by three key elements. The first is the mass of the ISPP plant required on the Mars surface to enable the production levels needed for the return trip to Earth. This comparison is shown in Figure 5-6. The second element is the mass of the transfer and excursion vehicles used and is representative of the requirements for vehicle replacement missions. These results are shown in Figure 5-7. The third element is the ELM requirements for steady-state operation. These requirements are shown in Figure 5-8 and can be compared to the case using all Earth propellants, which requires 1,627 t delivered to Earth orbit for support of a single mission. A discussion of these results follows. 


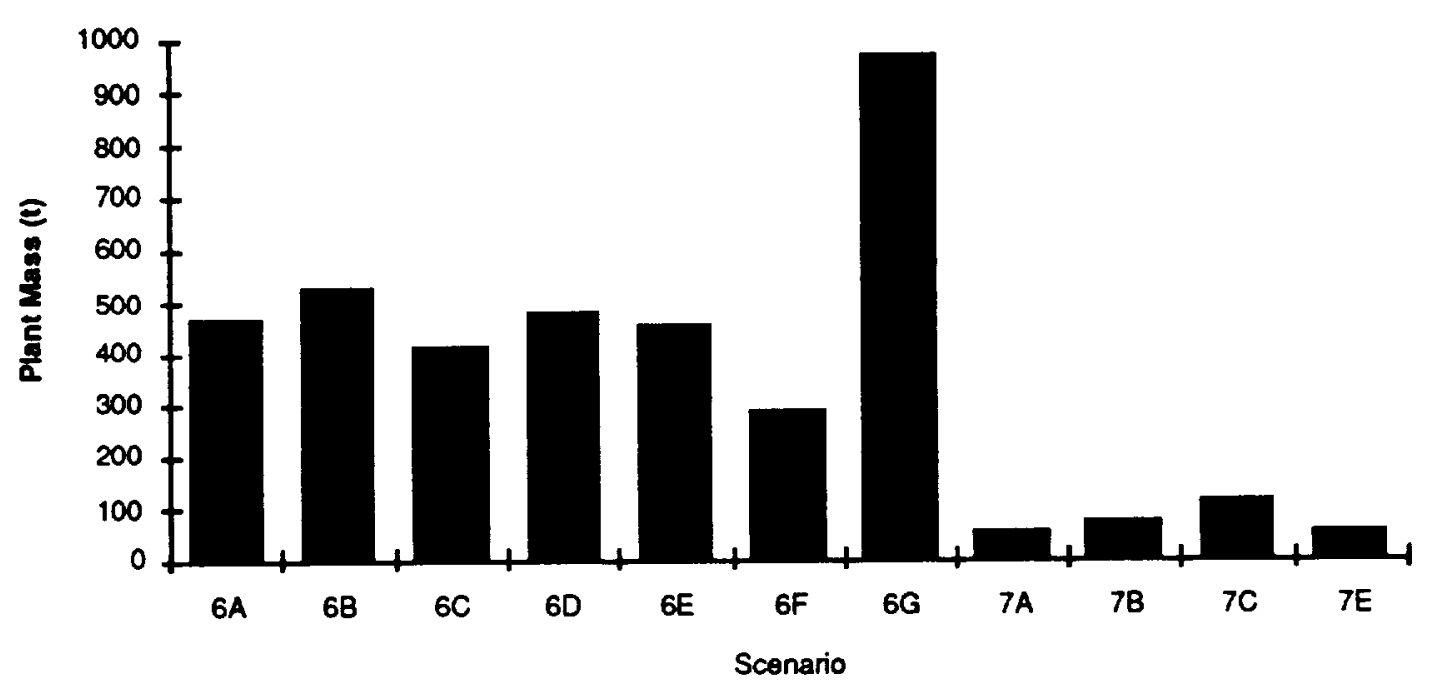

Figure 5-6. Mars Plant Mass Comparison: Engine Design and Tank Reuse Trades
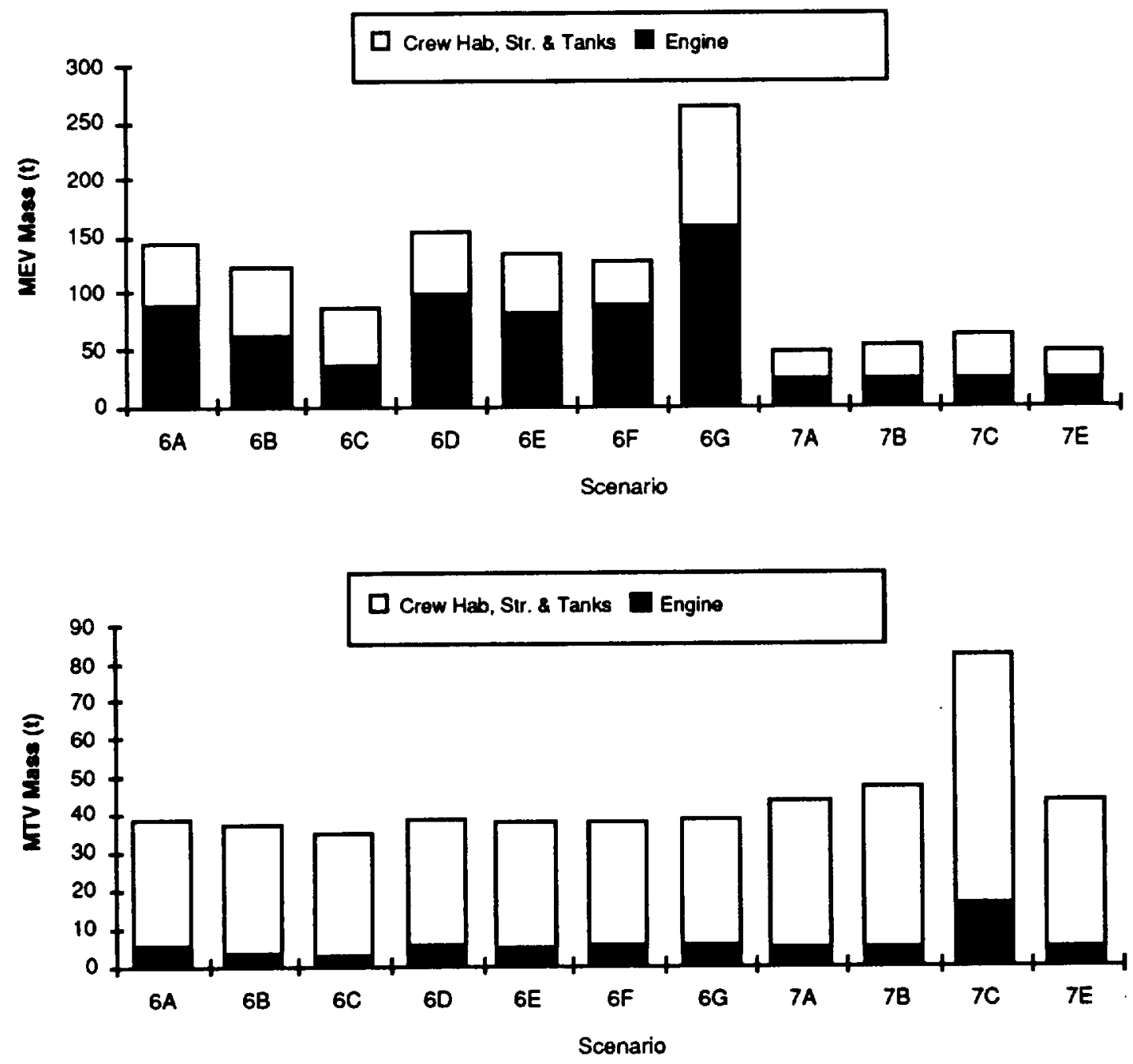

Figure 5-7. MEV and MTV Mass Comparison: Engine Design and Tank Reuse Trades 


\subsubsection{Engine Mass}

Engine mass sensitivity analyses were performed for the case that departs Earth orbit with Earth $\mathrm{LOX} / \mathrm{H}_{2}$ for the outbound trip and refuels with LOX/CO produced at Mars for the return trip (Scenario 6). The engine design used is the $\mathrm{LOX} / \mathrm{CO} / \mathrm{H}_{2}$ expander cycle engine with a 400:1 area ratio. The results are shown in Figures 5-6 through 5-8 and refer to Scenarios $6 \mathrm{D}$ and $6 \mathrm{E}$. Scenario $6 \mathrm{~A}$ uses the engine design obtained from the engine system assessment portion of this study described in Section 4.2.3. Scenario $6 \mathrm{D}$ adds $10 \%$ to the engine mass from $6 \mathrm{~A}$. Scenario $6 \mathrm{E}$ uses an engine with $10 \%$ less mass than in $6 \mathrm{~A}$. Comparing the results of Scenarios $6 \mathrm{D}$ and $6 \mathrm{E}$ to $6 \mathrm{~A}$ shows low sensitivity of mission performance results to a $\pm 10 \%$ change in engine mass. The impacts of this change in engine mass on the masses of the Mars ISPP plant, MEV, MTV, and steady-state Earth launch requirements to support one mission are shown in Figure 5-9. Although the change in steady-state Earth launch mass requirements is not more than $\pm 3 \%$ with a $\pm 10 \%$ change in engine mass, the reduction of ELM with a $-10 \%$ change in engine mass is twice the increase of ELM with a $+10 \%$ change in engine mass. This suggests that further reductions in engine mass, without a loss of performance, may yield even greater savings in ELM requirements.

\subsubsection{Engine Performance}

Engine performance sensitivity analyses were performed for the same case and with the same engine design as described above. These results are shown in Figures 5-6 through 5-8 and refer to Scenarios $6 \mathrm{~F}$ and $6 \mathrm{G}$. Scenario $6 \mathrm{~F}$ adds $10 \%$ to the Isp used for $6 \mathrm{~A}$ and Scenario $6 \mathrm{G}$ reduces the Isp from $6 \mathrm{~A}$ by $10 \%$. These results are summarized in Figure 5-10. The sensitivity of mission performance to engine Isp appears significantly higher than the sensitivity to engine mass. Because engine Isp directly affects propellant requirements, which in turn affect the Mars ISPP plant mass and support requirements, which affect the size of the payload transported to Mars, mission performance is strongly impacted. The steady-state Earth launch mass penalty for a $-10 \%$ change in Isp is over $60 \%$, although a $+10 \%$ change saves only about $20 \%$. This sensitivity may not be as great working with a different engine design with a higher Isp (LOX/CO Isp for the return trip is only $293 \mathrm{sec}$ ). These results suggest that if engine Isp can be increased with only a small increase in engine mass, additional Earth launch mass savings may be attainable. 


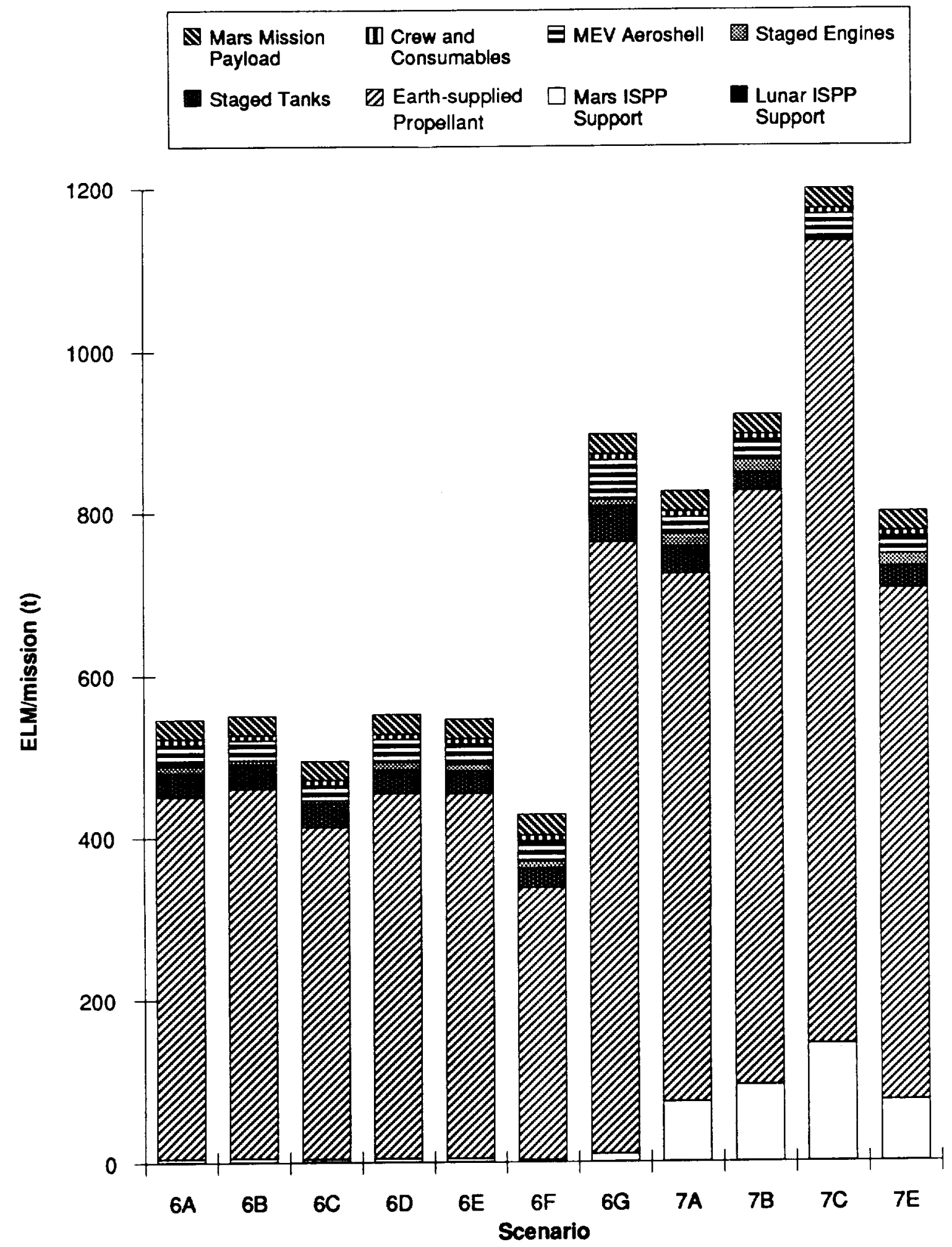

Figure 5-8. Steady-State Earth Launch Mass per Mission Comparison: Engine Design and Tank Reuse Trades 


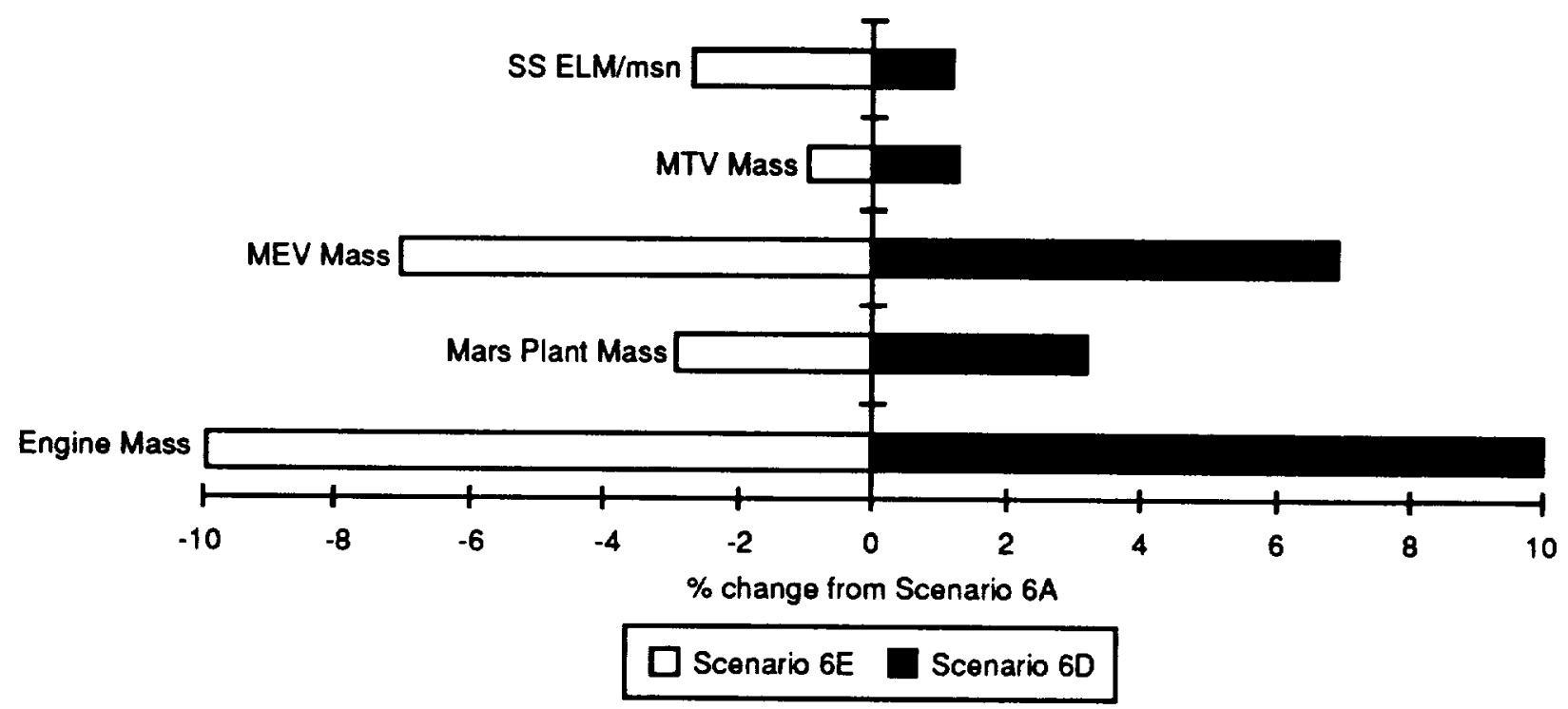

Figure 5-9. Results of Engine Mass Trade Study

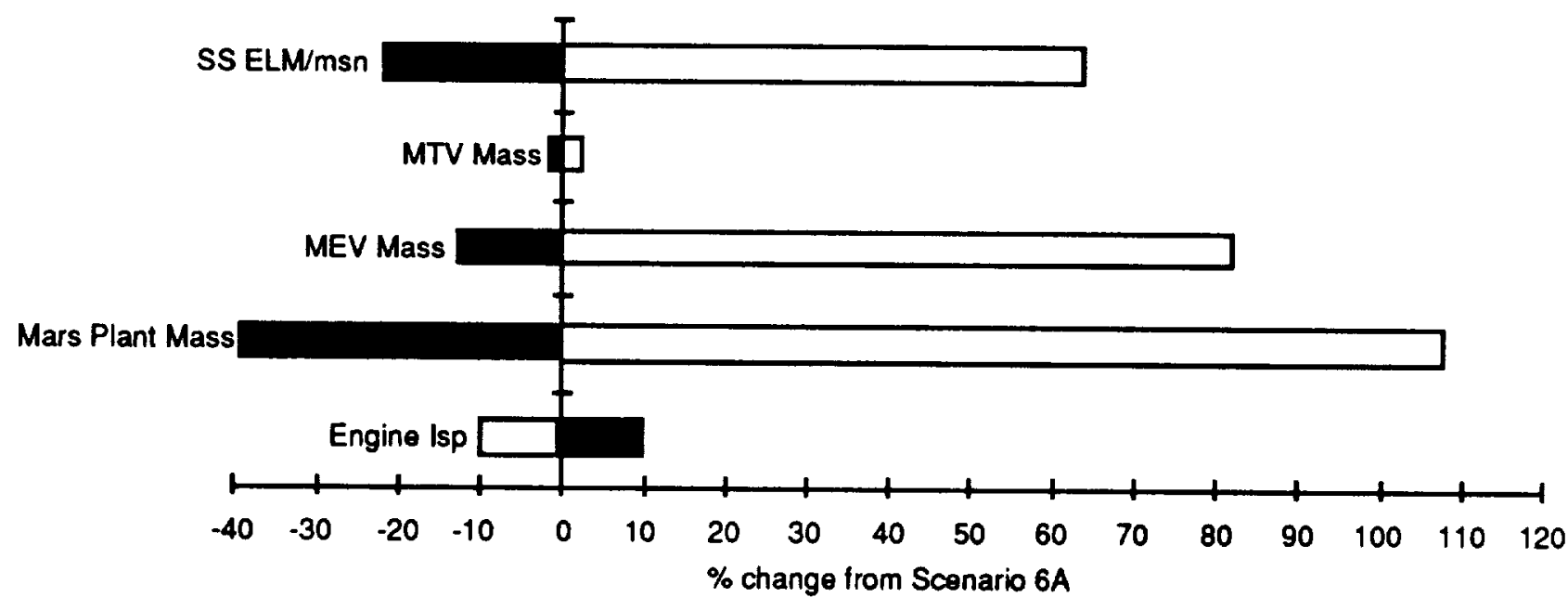

\section{Scenario 6G Scenario 6F}

Figure 5-10. Results of Engine Isp Trade Study

\subsubsection{Nozzle Area Ratio}

The effect of using an engine with an nozzle area ratio of $165: 1$, versus $400: 1$, for the same scenario and engine concept as in the engine mass sensitivity analyses was investigated and is shown as Scenario 6B in Figures 5-6 through 5-8. The effect of reducing the area ratio resulted in about a $30 \%$ decrease in engine mass with only about a $3 \%$ decrease in engine Isp. 
Impacts on the Mars ISPP plant mass, MEV, MTV, and steady-state Earth launch mass are shown in Figure 5-11. The result of the lower engine mass and Isp is less than a $1 \%$ increase in steady-state ELM required. The masses of the transfer and excursion vehicles will reduce requirements for vehicle replacement missions, but the higher mass of the Mars ISPP plant will drive up the front-end costs of emplacing the needed ISPP plant and push back the time to the ELM break-even point. One advantage of using the lower area ratio engine that is not shown in the mission performance analysis is that this engine should be easier to package in the cargo bay of an Earth-launched vehicle.

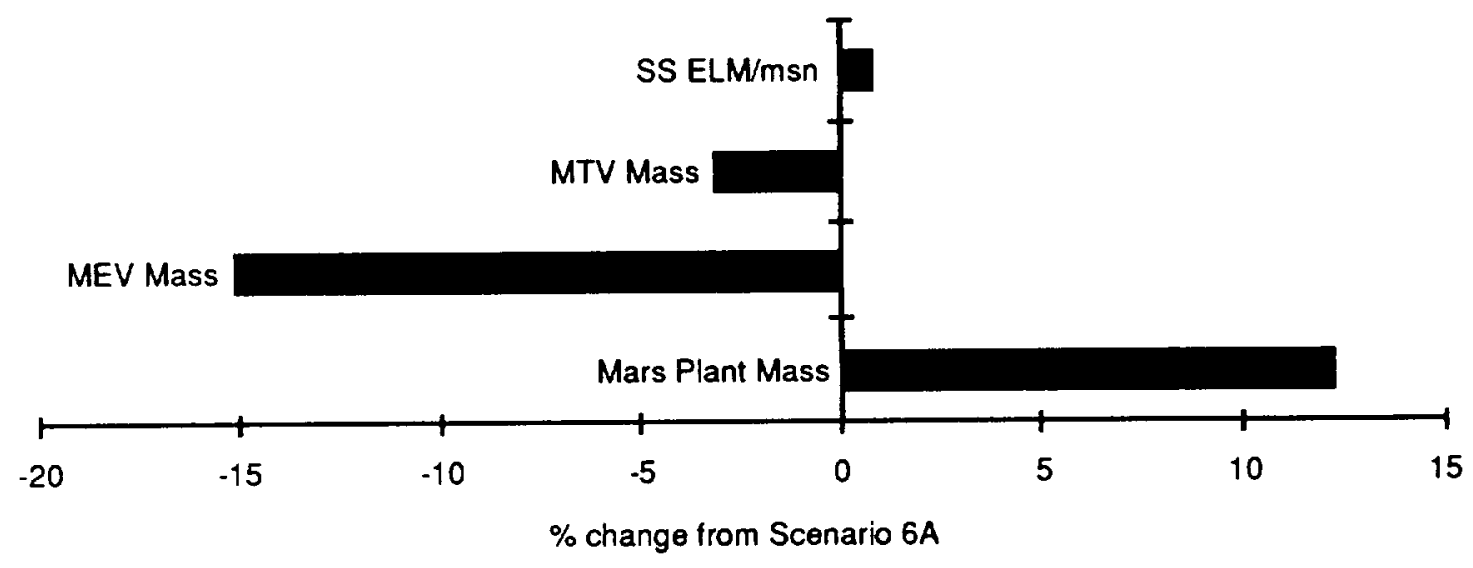

Figure 5-11. Results of Engine Nozzle Area Ratio Trade Study

\subsubsection{Tank Reuse Strategies}

For Scenario 7, several tank reuse strategies were investigated to identify effects on mission performance. Baseline mission performance does not reuse tanks, except for the core MTV tanks holding EOI propellant, and carries empty tankage to fill at Mars for the return trip. The MTV basically consists of a core with tanks, engine(s), and crew habitat module and several sets of stageable tanks which jettison after TMI, MOC, and TEI burns. In Scenario 7, the MTV uses Earth $\mathrm{LOX} / \mathrm{H}_{2}$ for the outbound trip and returns with Mars $\mathrm{LOX} / \mathrm{CH}_{4}$. The engine concept used is the expander cycle LOX/ $/ \mathrm{CH}_{4} / \mathrm{H}_{2}$ engine with a 400:1 area ratio. This case was chosen because tank volumes needed for the outbound trip with $\mathrm{LOX} / \mathrm{H}_{2}$ were anticipated to be close to the volumes needed for the return trip with $\mathrm{LOX} / \mathrm{CH}_{4}$.

The strategies investigated are shown schematically in Figure 5-12 and are depicted in Figures 5-6 through 5-8 as Scenarios 7B, 7C, and 7E. In Scenario 7B, TMI tanks are staged after TMI and the tanks used for MOI are sized to hold the propellant for the return trip and are carried with the MTV back to LEO. In Scenario 7C, no tanks are staged. These strategies were selected to reduce the steady-state ELM by minimizing the mass of replacement propellant tanks needed 
for a mission. The approach used for Scenario $7 \mathrm{E}$ attempts to minimize the mass of empty tankage carried through Earth departure and Earth return $\Delta V$ s. In this scenario, the TMI tanks are staged after TMI and the MOI tanks are separated into two sets. One MOI tank set is sized for EOI so that no empty tankage would be carried through this $\Delta \mathrm{V}$. The other MOI tank set is sized to hold the remainder of the MOI propellant, which occupies a volume slightly greater than the TEI propellant requires. This second MOI tank set is staged after TEI, leaving a full tank set holding the EOI propellant that is reused for the next mission. A summary of the tank reuse/staging strategy analyses is shown in Figure 5-13. All alternative staging strategy scenarios required an increase in Mars ISPP requirements because empty tankage is carried on the return trip in each of these scenarios. However, the increase is relatively minimal for Scenario $7 \mathrm{E}$, where the strategy focused on minimizing the acceleration of empty tankage. Of these scenarios, only 7E achieved a lower steady-state ELM than the baseline scenario, 7A, although this savings is small (approximately $3 \%$ ).
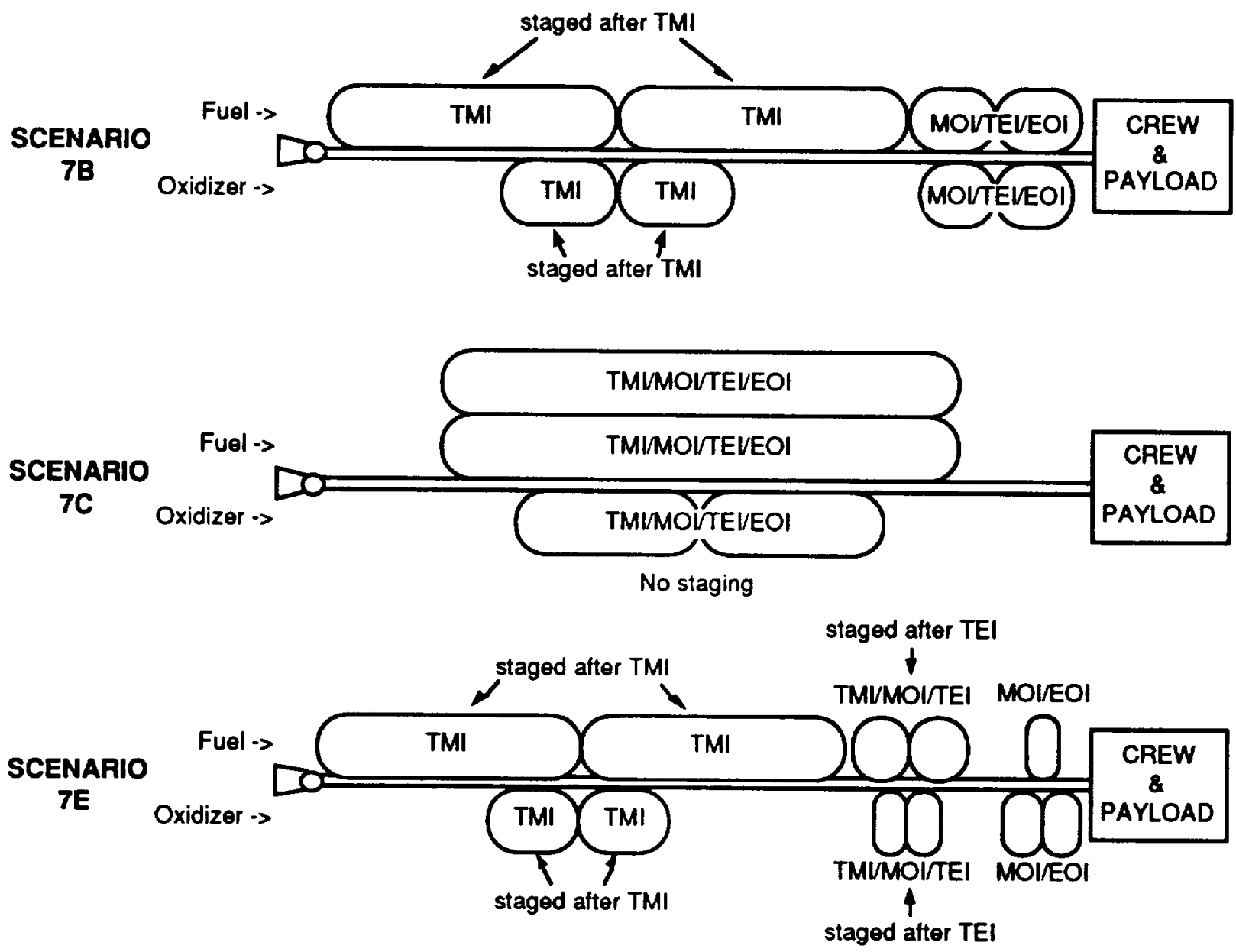

Figure 5-12. Alternative Tank Reuse/Staging Strategies 


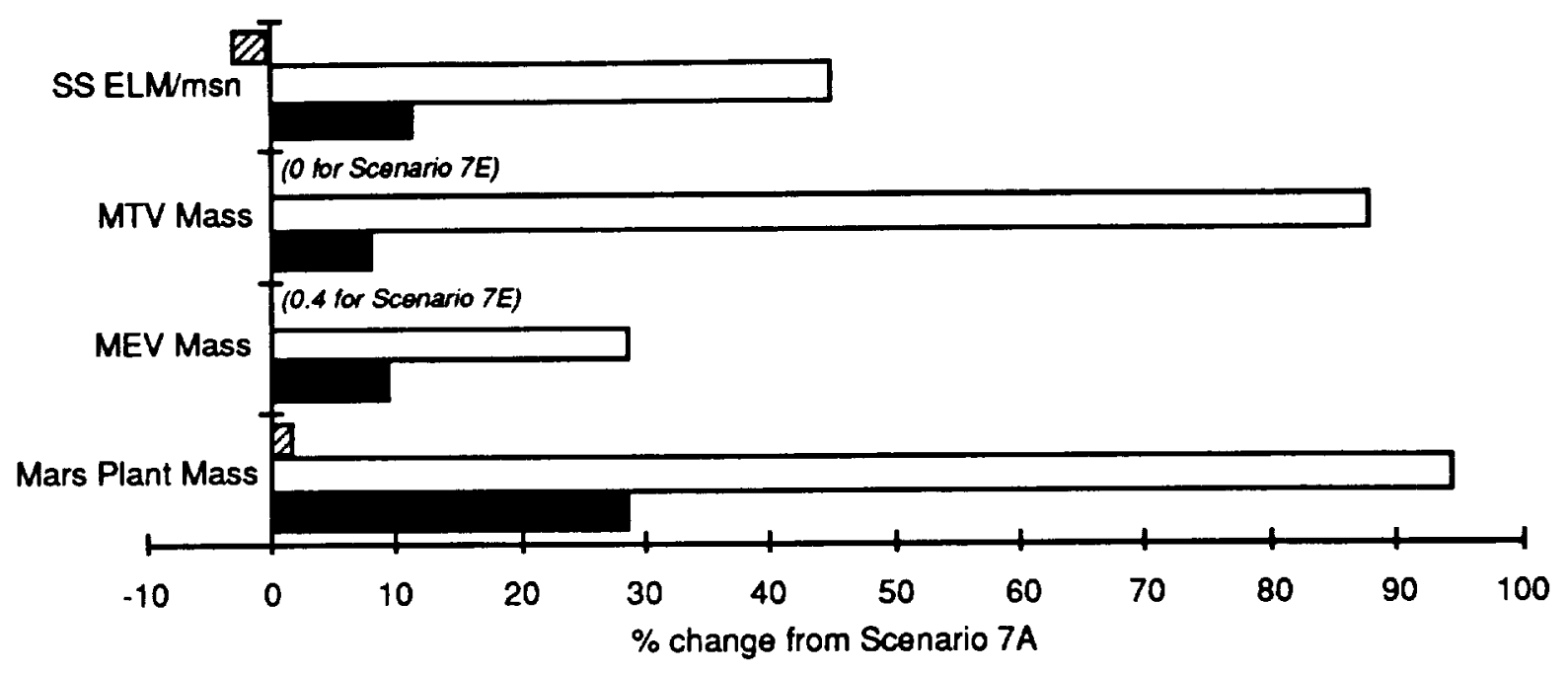

Scenario 7B $\square$ Scenario 7C $\square$ Scenario 7E

Figure 5-13. Results of Tank Reuse/Staging Strategy Analyses

\subsection{Mission Performance Conclusions and Recommendations}

From the final mission performance predictions, summarized in Table 5-3, steady-state ELM is reduced substantially if in situ lunar and Mars propellants are used to fuel the MTV and MEV. Plant masses, propellant masses, vehicle masses, and ELM are all lower in scenarios that utilize gas generator cycle engines rather than expander cycle engines, due to the substantially lower mass of the gas generator engines. For the LOX/CO/H $/ \mathrm{H}_{2}$ expander engine, going from a 400:1 nozzle area ratio to a 165:1 ratio does not significantly affect steady-state ELM. The mission performance assessments for Scenario 6 indicate that a 10\% change in engine Isp has a greater performance impact than does a $10 \%$ change in engine mass. Propellant tank reuse can reduce ELM if the tanks are sized such that acceleration of empty tank volume is minimized as much as possible. However, completely reusing all propellant tanks for the entire mission (i.e., no tank staging), can significantly increase ELM. In terms of reducing steady state ELM, the most favorable scenario is Scenario 4, which utilizes lunar $\mathrm{LOX} / \mathrm{CH}_{4}$ and Mars LOX/CO. For all the scenarios, Earth-supplied propellant comprises a majority of ELM requirements.

It is recommended for further study that a comprehensive year-by-year performance assessment be performed that includes propellant plant set-up missions and vehicle change-out missions to characterize multimission performance. While propellant plant masses and vehicle masses were calculated, the requirements for emplacing these elements were not evaluated. This 


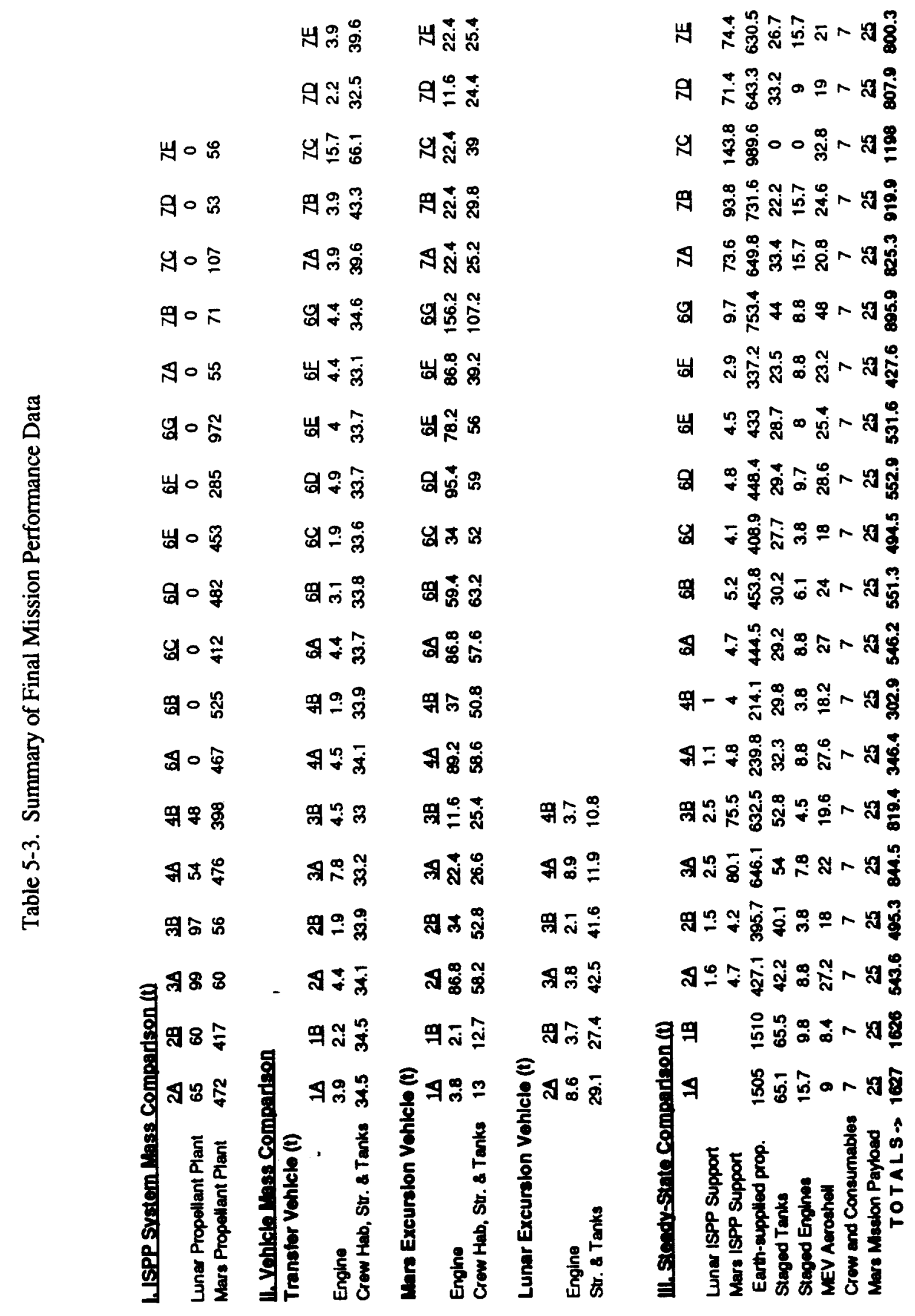


is a key consideration in evaluating in situ propellant use because, although the ISPP steady-state mission ELM may be considerably reduced over the non-ISPP case, the set-up and vehicle replacement requirements may be substantial and will affect the number of missions to ELM payback and savings over the course of multiple missions.

Other sensitivity analyses may improve insight into understanding the impacts on mission performance of ISPP requirements, vehicle design, and mission design. Trades can be run to investigate the effect of lower lunar and Mars ISPP plant masses on required ELM. Also, possible engine improvements that may increase Isp without significantly increasing engine mass should be investigated. Tank sizing and staging strategies should also be more closely examined, including the possibility of using common-sized tanks for all the vehicles. Also, the use of aerocapture at Mars and Earth should be considered. Other possibilities for improved performance would be to base the MTV in LLO, so that is does not have to be boosted out of LEO for each mission, or to transport lunar propellant to LEO, so that the MTV would not have to go to the Moon at all. Most importantly, enhancement of our understanding of the ISPP requirements, through laboratory studies on Earth and technology investigations on the lunar and/or Mars surface, is necessary to more accurately define mission performance improvements. 



\subsection{TECHNOLOGY MATURATION PLAN}

A technology maturation plan has been established that addresses the development and demonstration of critical technologies and systems required to support a decision at the turn-of-thecentury (year 2000+) to develop an operational Mars in situ propellant-based propulsion system. The technology research and development plan, as well as the technology assessment and major assumptions that support it, are discussed in the remainder of this section.

It was assumed that development of a Mars in situ propellant-based propulsion system would draw upon ongoing cryogenic space propulsion system technologies, see Ref. 6-1 and 6-2, and on technologies that address unique technology and design issues of such systems. This development consideration is displayed in Figure 6-1. The technology plan established in this study addresses only the technology and design developments required that are unique to Mars in situ propellant-based propulsion system. Many of the technologies and design issues for deep space cryogenic engines are also similar to those associated with engine systems of interest to this study. An example of this is the generic engine system characteristics associated with space-based engine systems, shown in Table 6-1, which are applicable to both cryogenic and Mars in situ propellant-based engine systems.

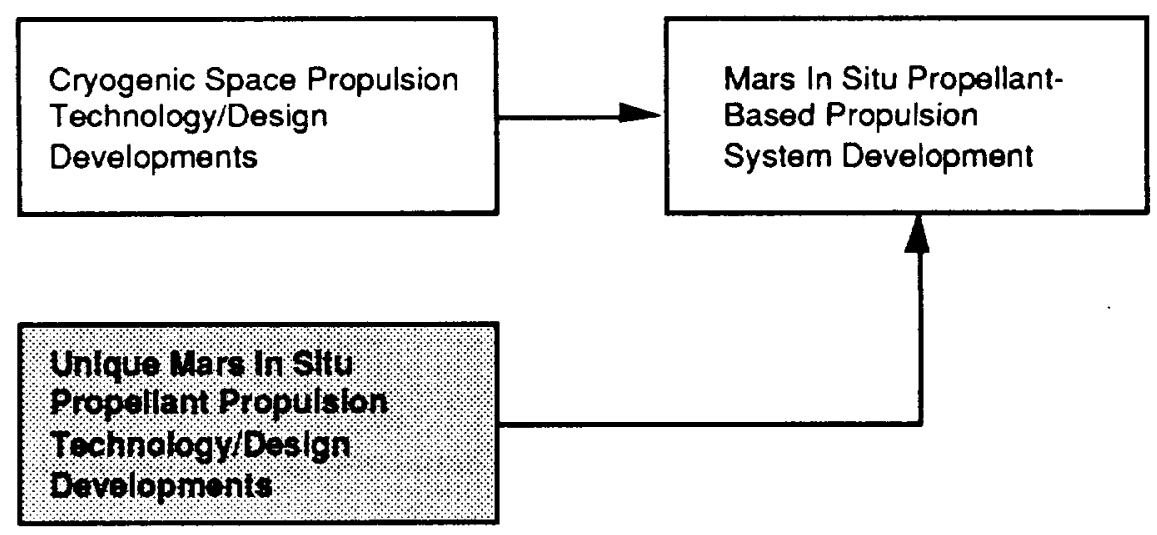

Figure 6-1. Development of a Mars In Situ Propellant-Based Propulsion System 
Table 6-1. Engine System Characteristics to Meet Space Basing Requirements

- Automated Pre-Mission Checkout

- Real-Time Safety Monitoring

- Incipient Failure Mode Detection

- Post-Firing Trend Monitoring

- Long Duration Space Exposure

- Minimum Maintenance

- Engine Servicing in Space

- Replaceable Modular Systems/Robotic Engine Changeout

- Minimize Fluid Requirements

A technology readiness assessment was conducted in four fundamental engineering areas associated with development of Mars in șitu propellant-based engine systems. The areas assessed involved: 1) materials compatibility, 2) cooling, 3) ignition/combustion and 4) pumping. The assessment was based on results associated with the technology review and engine system design analysis discussed in Sections 2.0 and 4.0, respectively, and by applying the NASA technology readiness level definition given in Table 6-2. Results of this assessment are presented in Table 6-3. For engine systems that use more conventional bipropellants such as $\mathrm{LOX} / \mathrm{H}_{2}$ and $\mathrm{LOX} / \mathrm{CH}_{4}$ technology readiness is very high. This is based on the extensive research and development experience associated with $\mathrm{LOX} / \mathrm{H}_{2}$ and $\mathrm{LOX} / \mathrm{CH}_{4}$ launch and upper stage/space engines over the past 30 years, as well as operational experience with $\mathrm{LOX} / \mathrm{H}_{2}$ engines systems. Bipropellant LOX/CO and tripropellant engine systems lack a strong experience base and are rated low (1 to 3 ) in terms of technology readiness in all of the key engineering areas.

Based on the propulsion system assessment reported in Section 4.0, an evaluation was performed by each major propulsion system, subsystem, or component to identify the technology improvements that may be required. These improvements were then rated in terms of their confidence to achieve the required goal. The results of this evaluation are presented in Table 6-4. The relative confidence rating is based on the probable difficulties to achieve the goal.

From the previous two assessments, just mentioned, key research and development issues were then identified and categorized. Table 6-5 summarizes these issues. These key issues are unique to Mars tripropellant propulsion systems. The issues are categorized as either being enabling or enhancing. An enabling issue is one that must be addressed and successfully demonstrated by one or more solutions to ensure the feasibility of a Mars in situ propellant-based 


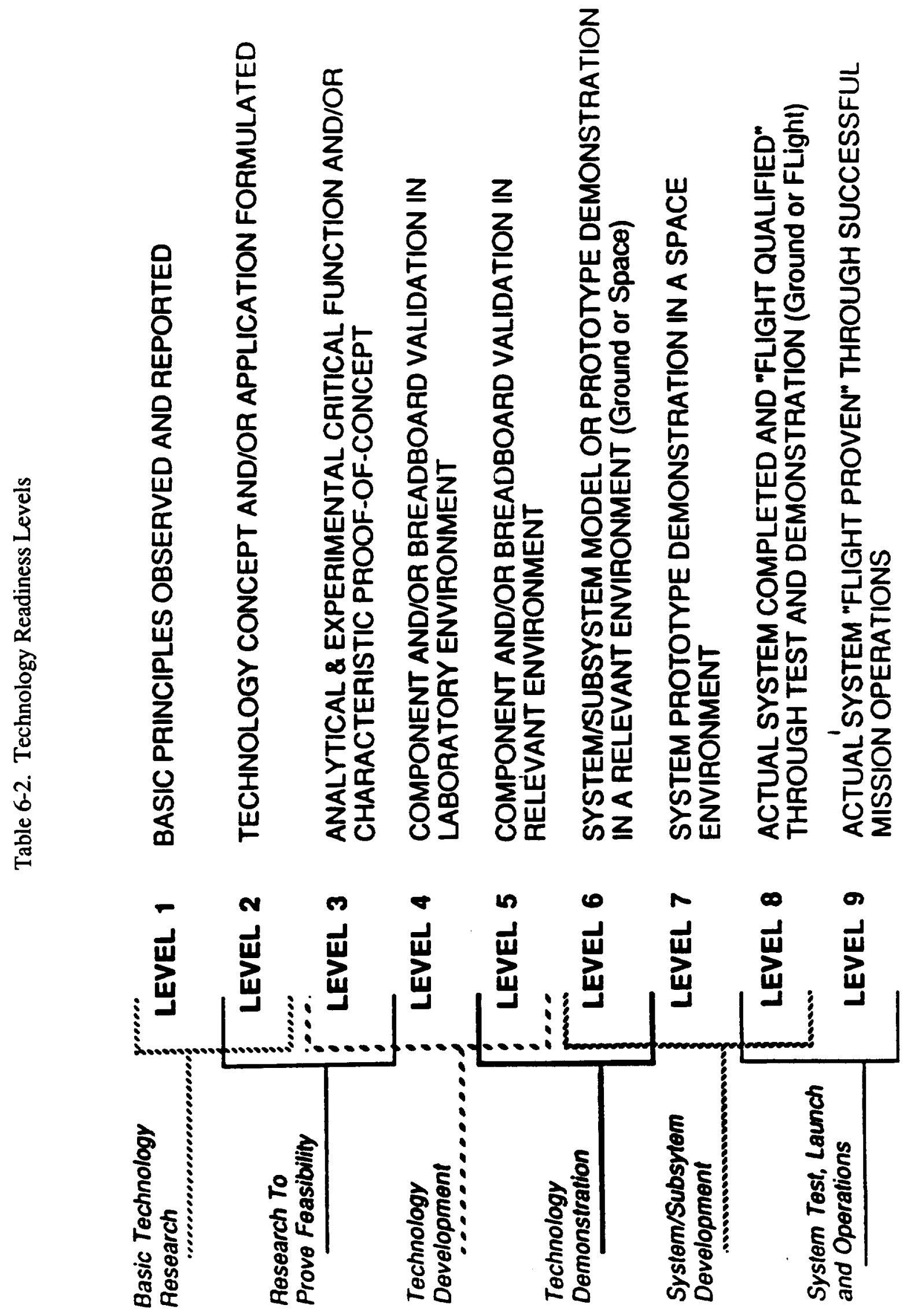


Table 6-3. Technology Readiness of Fundamental Research Issues Associated With In Situ Mars Propellant-Based Engines

\begin{tabular}{|c|c|c|c|c|}
\hline \multirow{2}{*}{$\begin{array}{c}\text { Propellant } \\
\text { Combinations }\end{array}$} & $\begin{array}{c}\text { Materials } \\
\text { Compatibility }\end{array}$ & Cooling & $\begin{array}{c}\text { Ignition/ } \\
\text { Combustion }\end{array}$ & Pumping \\
\cline { 2 - 5 } $\begin{array}{c}\text { Bipropellants } \\
\text { LOX/H }\end{array}$ & 9 & 9 & 9 & 9 \\
\hline LOX/CO & $1-2$ & $1-2$ & $1-2$ & $1-2$ \\
\hline LOX/CH4 & $5-6$ & $5-6$ & $5-6$ & $5-6$ \\
\hline $\begin{array}{c}\text { Tripropellants } \\
\text { LOX } / \mathrm{H}_{2} / \mathrm{CO}\end{array}$ & 1 & 1 & 1 & 1 \\
\hline LOX $/ \mathrm{H}_{2} / \mathrm{CH}_{4}$ & 3 & 3 & 3 & 2 \\
\hline LOX $/ \mathrm{CO} / \mathrm{CH}_{4}$ & 1 & 2 & 1 & 1 \\
\hline
\end{tabular}

Table 6-4. Propulsion System Subsystem/Component Evaluation

\begin{tabular}{|c|c|c|}
\hline $\begin{array}{l}\text { Subsystem or } \\
\text { Component }\end{array}$ & Options & $\begin{array}{l}\text { Relative Confidence } \\
\text { to Achieve } \\
\text { Improvements(s) }\end{array}$ \\
\hline Propellant Tankage & $\begin{array}{l}\text { - Lightweight structure, and meteoroid shell, high } \\
\text { performance insulation } \\
\text { - Common fuel tankage } \\
\text { - Common propellant tankage } \\
\text { - Fuel and oxidizer } \\
\text { - Lightweight, inflatable propellant tankage } \\
\text { - Integrated, high performance tank/refrigeration }\end{array}$ & $\begin{array}{l}\text { High } \\
\text { Medium } \\
\text { Low } \\
\text { Low } \\
\text { Low }\end{array}$ \\
\hline Feed System & $\begin{array}{l}\text { - Lightweight, reliable, highly throttleable } \\
\text { turbopumps } \\
\text { - Common fuel turbopumps } \\
\text { - Common turbopumps } \\
\text { - Fuel and oxidizer } \\
\text { - Lightweight, common propellant lines, valving } \\
\text { - Compatible composite structures/materials } \\
\text { - Turbine drive systems using multiple fuel-rich, } \\
\text { high-temperature gases } \\
\text { - Stoichiometric gas generator } \\
\text { - High temperature turbine materials for oxygen- } \\
\text { rich drive gases }\end{array}$ & $\begin{array}{l}\text { Medium } \\
\text { Medium } \\
\text { Low } \\
\text { High } \\
\text { Low } \\
\text { High } \\
\text { Medium }\end{array}$ \\
\hline Injector & $\begin{array}{l}\text { - Common, high performance multiple propellant } \\
\text { injector design } \\
\text { - At design and throttled conditions }\end{array}$ & Low \\
\hline
\end{tabular}

* Low = Difficult; Medium = Moderate Difficulty; High = Low Difficulty 
Table 6-4. Propulsion System Subsystem/Component Evaluation (Cont.)

\begin{tabular}{|l|l|c|}
\hline \multicolumn{1}{|c|}{$\begin{array}{c}\text { Subsystem or } \\
\text { Compon ent }\end{array}$} & \multicolumn{1}{c|}{ Options } & $\begin{array}{c}\text { Relative Confidence } \\
\text { to Achieve } \\
\text { Improvements(s)* }\end{array}$ \\
\hline Thrust Chamber & $\begin{array}{l}\text { - High performance, oxygen cooled thrust } \\
\text { chamber } \\
\text { - High performance and high chamber pressure } \\
\text { cooled thrust chamber } \\
\text { - Common multiple fuel cooled thrust chamber } \\
\text { - Common fuel or oxygen cooled thrust chamber }\end{array}$ & $\begin{array}{c}\text { Medium } \\
\text { Low }\end{array}$ \\
\hline Nozzle & $\begin{array}{l}\text { - Lightweight nozzle extension } \\
\text { - Lightweight translate nozzle extension }\end{array}$ & $\begin{array}{c}\text { Low } \\
\text { Medigh }\end{array}$ \\
\hline Control System & $\begin{array}{l}\text { - Lightweight, radiation environment compatible } \\
\text { - Highly robust, adaptive control system to } \\
\text { support multimode engine operation with } \\
\text { various propellant combinations } \\
\text { - Sensors compatible with more than one } \\
\text { propellant }\end{array}$ & $\begin{array}{c}\text { High } \\
\text { High }\end{array}$ \\
\hline Mounts and Support & $\begin{array}{l}\text { - Lightweight thrust mounts and supports } \\
\text { - Highly integrated feed system/thrust mount } \\
\text { support system design }\end{array}$ & Medium \\
\hline
\end{tabular}

* Low = Difficult; Medium = Moderate Difficulty; High = Low Difficulty

Table 6-5. Key Research and Development Issues

\begin{tabular}{|c|c|c|}
\hline Issues & $\begin{array}{l}\text { Rationale/ } \\
\text { Comments }\end{array}$ & $\begin{array}{l}\text { Type (Enabling } \\
\text { or Enhancing) }\end{array}$ \\
\hline $\begin{array}{l}\text { - Materials } \\
\text { - Compatibility } \\
-\mathrm{CO} \\
\text { - LOX } \\
\\
\text { - Common Multipropellants } \\
-\mathrm{CO} / \mathrm{H}_{2} \\
-\mathrm{H} / \mathrm{CH}_{4} \\
-\mathrm{CO} / \mathrm{CH}_{4}\end{array}$ & $\left.\begin{array}{l}\text { Little data available on } C O \text { at high temperature and } \\
\text { pressure conditions } \\
\text { Additional research required to identify materials that } \\
\text { are compatible with LOX at temperature higher than } \\
\text { present day options } \\
\text { - Turbine materials } \\
\text { - Thrust chamber materials } \\
\text { Litule or no data available } \\
\text { - Tank materials which support } \\
\text { common tank designs } \\
\text { - Common pumping/ } \\
\text { cooling engine systems }\end{array}\right\}$ Reduced Weight & $\begin{array}{l}\text { Enabling* } \\
\text { Enhancing }\end{array}$ \\
\hline
\end{tabular}

* Impacts Mission Scenarios 2, 4, and 6 Only. 
Table 6-5. Key Research and Development Issues (Cont.)

\begin{tabular}{|c|c|c|}
\hline Issues & $\begin{array}{l}\text { Rationale/ } \\
\text { Comments }\end{array}$ & $\begin{array}{l}\text { Type (Enabling } \\
\text { or Enhancing) }\end{array}$ \\
\hline $\begin{array}{l}\text { - Cooling } \\
\text { - } \mathrm{CO}\end{array}$ & $\begin{array}{l}\text { Little fundamental data available on CO cooling at } \\
\text { high heat flux and pressure conditions }\end{array}$ & Enabling* \\
\hline $\begin{array}{l}\text { - Ignition/Combustion } \\
\text { - LOX/CO }\end{array}$ & $\begin{array}{l}\text { Little fundamental data available on the ignition } \\
\text { and combustion of LOX/CO at the conditions of } \\
\text { interest }\end{array}$ & Enabling* \\
\hline $\begin{array}{l}\text { - Pumping } \\
\text { - } \mathrm{CO}\end{array}$ & $\begin{array}{l}\text { Little fundamental data available on pumping of } \\
\mathrm{CO} \text { at the conditions of interest }\end{array}$ & Enabling* \\
\hline $\begin{array}{l}\text { - Common Multipropellant } \\
\text { Injector Design }\end{array}$ & $\begin{array}{l}\text { Little design data available associated with main } \\
\text { injector and gas generator (preburner) designs that } \\
\text { can operate with more than one propellant } \\
\text { combination of interest over a wide operating } \\
\text { range (required for throttling) }\end{array}$ & Enabling \\
\hline $\begin{array}{l}\text { - Common Multipropellant Feed } \\
\text { System/Turbopump Design }\end{array}$ & $\begin{array}{l}\text { Design database lacking to support design of a } \\
\text { common pump-fed (including turbopump) feed } \\
\text { system that can efficiently pump more than one } \\
\text { fuel of interest over a wide operating range }\end{array}$ & Enhancing \\
\hline $\begin{array}{l}\text { - Common Thrust Chamber } \\
\text { Design }\end{array}$ & $\begin{array}{l}\text { Design database lacking to support design of a } \\
\text { common thrust chamber that is cooled by more } \\
\text { than one propellant over the operating range of } \\
\text { interest }\end{array}$ & Enabling \\
\hline $\begin{array}{l}\text { - Ignition/Gas Generator Design } \\
\text { - LOX/CO }\end{array}$ & $\begin{array}{l}\text { Little data available associated with design and } \\
\text { operation of a LOX/CO gas generator at low } \\
\text { temperature and pressure operating conditions }\end{array}$ & Enhancing* \\
\hline $\begin{array}{l}\text { - Common Control/Health } \\
\text { Monitoring System }\end{array}$ & $\begin{array}{l}\text { Little experience available associated with the } \\
\text { design and operation of control/health monitoring } \\
\text { system for an engine system that uses different } \\
\text { propellant conditions during various operating } \\
\text { modes }\end{array}$ & Enabling \\
\hline $\begin{array}{l}\text { - Common Propellant Tank } \\
\text { Design and Supporting } \\
\text { Operations }\end{array}$ & $\begin{array}{l}\text { Little experience/design database available on the } \\
\text { design and operations (such as refilling in space) of } \\
\text { tanks that can store more than one propellant of } \\
\text { interest }\end{array}$ & Enhancing \\
\hline $\begin{array}{l}\text { - Lightweight, Compact High Area } \\
\text { Ratio Nozzle Design }\end{array}$ & $\begin{array}{l}\text { Low chamber pressure in situ Mars propellant- } \\
\text { based engines may require high weight translating } \\
\text { high area ratio nozzle or an alternative design due } \\
\text { to packaging constraints }\end{array}$ & Enhancing* \\
\hline
\end{tabular}

* Impacts Mission Scenarios 2, 4, and 6 Only. 
propulsion system. If an engineering solution cannot be found for a given issue, development of the propulsion system will not be possible. An enhancing issue addresses area(s) of possible improvements, over the state-of-the-art engineering solution, that can produce a high payoff typically in areas of performance, mass savings, and/or mission flexibility, for example. Some of the issues identified in Table 6-5 are associated with propulsion systems that employ only $\mathrm{CO}$ as a fuel. Many of the issues address common multipropellant combustion hardware component design that is critical for the proposed MTV propulsion systems.

It should be noted that there are many research and development issues which are characterized as enabling in Table 6-5. This should not be interpreted that high-risk technology breakthroughs are required in these areas to develop a Mars tripropellant propulsion system. Presently, many of these issues lack an adequate technology base. These issues can be successfully addressed by implementing focused technology development programs in these areas.

A technology development plan was then defined that addresses the key technology/design issues given in Table 6-5 as well as demonstrates the feasibility of the Mars tripropellant engine system concept employing extensive common engine system hardware. Tables 6-6 and 6-7 list the major planning assumptions and key areas to be addressed, respectively, which are associated with the technology development plan. As previously mentioned, the technology development plan draws on ongoing space propulsion technology developments and only addresses technology and design issues associated with Mars tripropellant propulsion systems.

Table 6-6. Major Assumptions in Defining Technology Development Plan

- Development decision associated with Mars in situ propellant propulsion systems will be made at the turn of the century (year 2000)

- Technology available from other propulsion areas (such as advanced $\mathrm{LOX} / \mathrm{H}_{2}$ space engines) will be available to support development of Mars in situ propellant-based propulsion systems

- Existing United States and possibly world propulsion system development testing facilities will be available to support development of Mars in situ propellant-based propulsion system

- No new major testing facilities required, only modification/ upgrading of current facilities will be required 
Table 6-7. Key Areas to Be Addressed by the Technology Development Plan

- Establish fundamental database associated with candidate propellant and material options

- Investigate feasibility of common propulsion system hardware design approach

- Demonstrate overall in situ Mars propellant engine system feasibility

- Assess the impact of engine system technology capabilities on overall mission architecture and vehicle design

The technology development plan is comprised of four major phases. They are: 1) fundamental research, 2) exploratory development, 3) breadboard engine system demonstration, and 4) system engineering studies. Table 6-8 summarizes these major phases. The first three phases focus on propulsion system technology/design issues, while the other provides the overall systems engineering/integration development function. In this development phase emerging mission, vehicle and engine system designs are identified and assessed as new technology data becomes available from the other technology plan development phases. Figure 6-2 shows the overall technology development plan process, which would last for 7 years from go-ahead. If the initial program go-ahead were approved for Government Fiscal Year 1993, a flight system development decision at Fiscal Year 2000 could be supported by the proposed technology development plan program. For each technology plan development phase, programs addressing key technology/design issues were defined. Table 6-9 summarizes these programs. Detailed descriptions of each technology development plan program element are given in Appendix G. Figure 6-3 provides an overall technology development plan schedule and the estimated required funding by program element and fiscal year to accomplish it.

The overall funding required for the 7-year maturation plan is approximately $\$ 104$ million. The initial program funding requirements for the first 2 years is a little over $\$ 3$ million per year which focuses on the fundamental research aspects of development. At the conclusion of this development phase if major fundamental research issues are still outstanding, the Mars common tripropellant propulsion system approach should be completely be reassessed. If after this development phase, results look encouraging, an exploratory development and a breadboard engine system demonstration would then be initiated, as shown in Figure 6-3. Yearly funding requirements would then increase (ramp up) accordingly to a maximum of $\$ 26.5$ million in the fifth year of the technology maturation plan. At the conclusion of this program, necessary data should be available to establish the feasibility of Mars in situ propellant-based propulsion systems and provide the insight to make a knowledgeable decision to develop an operational flight system. 
It is estimated that 5 to 7 years would be required to develop and certify a flight engine system if the development decision is approved. Based on the technology plan just discussed, the earliest initial operational capability of such an engine system would be in FY2005.

Table 6-8. Summary of Goal(s) and Activities by Development Phase

\begin{tabular}{|c|c|c|}
\hline $\begin{array}{l}\text { Development } \\
\text { Phase }\end{array}$ & Goal(s) & Activities \\
\hline $\begin{array}{l}\text { Fundamental } \\
\text { Research }\end{array}$ & $\begin{array}{l}\text { Establish fundamental material, thermal- } \\
\text { hydraulic and combustion databases to } \\
\text { support definition and evaluation of } \\
\text { component, subsystem and propulsion } \\
\text { system concepts }\end{array}$ & $\begin{array}{l}\text { Fundamental experimental and theoretical } \\
\text { studies are performed in the areas of: } \\
\text { - Materials compatibility } \\
\text { - Cooling } \\
\text { - Combustion/ignition } \\
\text { - Pumping } \\
\text { - Other(s) }\end{array}$ \\
\hline $\begin{array}{l}\text { Exploratory } \\
\text { Development }\end{array}$ & $\begin{array}{l}\text { Demonstrate promising technologies and } \\
\text { designs (components and/or subsystems) } \\
\text { that can support development of high } \\
\text { performance, lightweight, reliable engine } \\
\text { system(s) that use Mars in situ } \\
\text { propellants }\end{array}$ & $\begin{array}{l}\text { Design manufacturing and component/ } \\
\text { subsystem testing: } \\
\text { - Injector(s) } \\
\text { - Turbopump(s) } \\
\text { - Thrust chamber(s) } \\
\text { - Ignition/gas generator design(s) } \\
\text { - Control/health monitoring system(s) } \\
\text { - Common tankage system(s) } \\
\text { - Translating high area ratio nozzle(s) }\end{array}$ \\
\hline $\begin{array}{l}\text { Breadboard } \\
\text { Engine System } \\
\text { Demonstration }\end{array}$ & $\begin{array}{l}\text { Demonstrate one or more complete } \\
\text { engine system concepts }\end{array}$ & $\begin{array}{l}\text { Design, manufacture and test one or more } \\
\text { promising engine system concepts that } \\
\text { use Mars in situ-based propellants; tests } \\
\text { will examine the following areas: } \\
\text { - Thrust range (throttling) } \\
\text { - Duty cycle compatibility } \\
\text { - Startup/shutdown/throttling } \\
\text { characteristics } \\
\text { - Performance } \\
\text { - Life } \\
\text { - Multipropellant compatibility }\end{array}$ \\
\hline $\begin{array}{l}\text { Systems } \\
\text { Engineering }\end{array}$ & $\begin{array}{l}\text { Provide propulsion system requirements } \\
\text { and guidance in identifying critical } \\
\text { technologies and design concepts, and } \\
\text { their impact on the overall mission and } \\
\text { vehicle design }\end{array}$ & $\begin{array}{l}\text { Mission and vehicle system design } \\
\text { studies as well as assessments of } \\
\text { emerging propulsion system concepts } \\
\text { and their supporting technologies }\end{array}$ \\
\hline
\end{tabular}




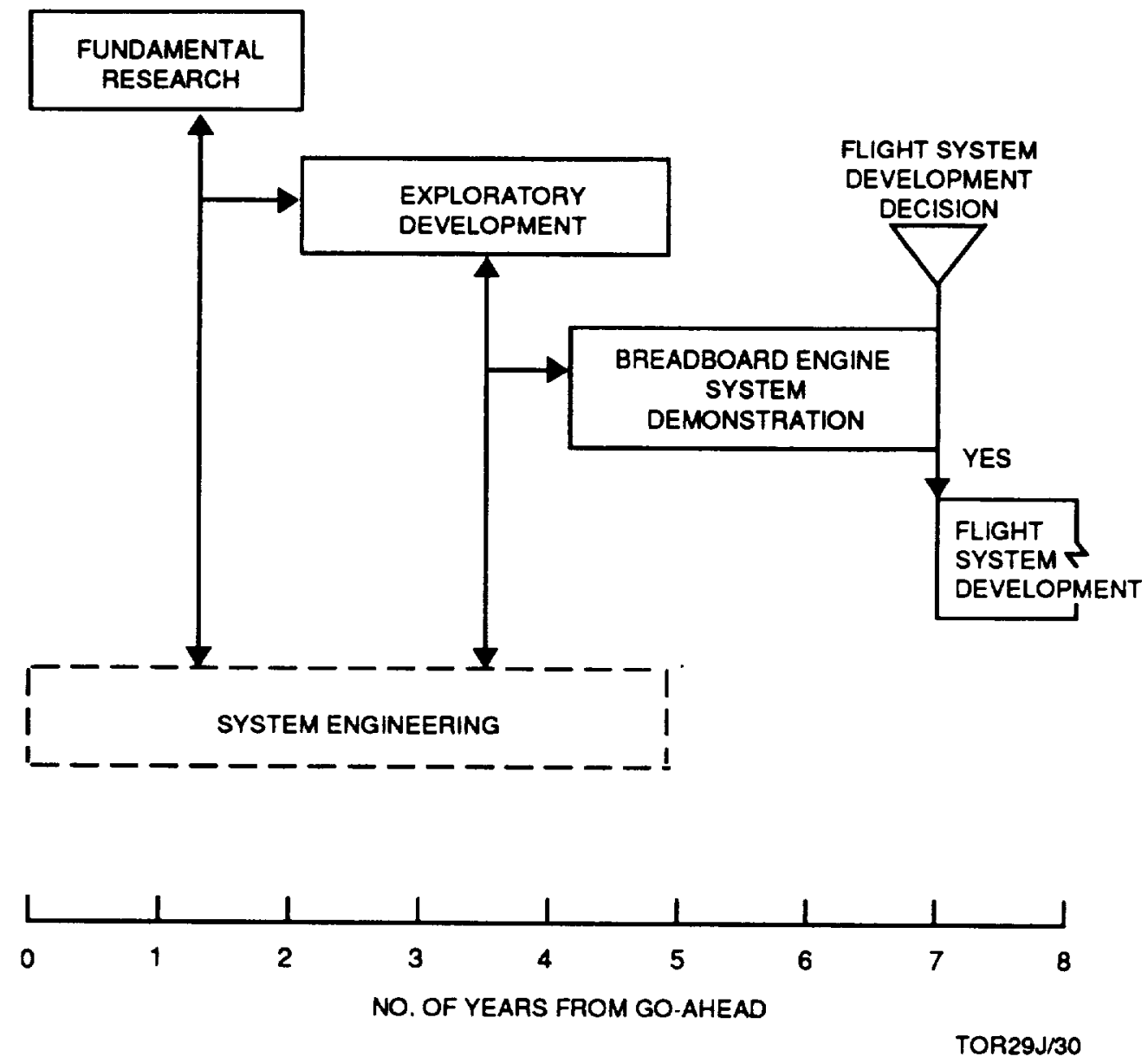

Figure 6-2. Overall Process to Support Development of an In Situ Mars Propellant-Based Propulsion System

Table 6-9. Summary of Technology Development Plan Program

\begin{tabular}{|c|l|c|l|}
\hline $\begin{array}{c}\text { Program } \\
\text { No. }\end{array}$ & \multicolumn{1}{|c|}{ Title } & $\begin{array}{c}\text { Development } \\
\text { Phase* }\end{array}$ & \multicolumn{1}{c|}{ Objective(s) } \\
\hline 1 & $\begin{array}{l}\text { Mars In Situ Propellant } \\
\text { Propulsion System } \\
\text { Materials Compatibility } \\
\text { Research }\end{array}$ & FR & $\begin{array}{l}\text { Identify propulsion system material candidates that } \\
\text { are compatible with potential Mars in situ propel- } \\
\text { lants and/or propellant combinations. Propellants } \\
\text { and/or propellant combinations for which material } \\
\text { compatibility should be investigated include: } \\
\text { CO/LOX, CO/H2, } \mathrm{H}_{2} / \mathrm{CH}_{4}, \mathrm{CO} / \mathrm{CH}_{4}\end{array}$ \\
\hline 2 & $\begin{array}{l}\text { Fundamental CO Cooling } \\
\text { Data Study }\end{array}$ & FR & $\begin{array}{l}\text { Establish a fundamental database associated with } \\
\text { CO cooling for conditions that are typical of thrust } \\
\text { chambers and turbopumps }\end{array}$ \\
\hline
\end{tabular}

* FR = Fundamental Research; ED = Exploratory Development; BED = Breadboard Engine Demonstration; $\mathrm{SE}=$ System Engineering 
Table 6-9. Summary of Technology Development Plan Program (Cont.)

\begin{tabular}{|c|c|c|c|}
\hline $\begin{array}{c}\text { Program } \\
\text { No. }\end{array}$ & Title & $\begin{array}{l}\text { Development } \\
\text { Phase* }\end{array}$ & Objective(s) \\
\hline 3 & $\begin{array}{l}\text { LOX/CO Ignition/ } \\
\text { Combustion Research }\end{array}$ & FR & $\begin{array}{l}\text { Establish a fundamental database associated with } \\
\text { LOX/CO injection and combustion for conditions } \\
\text { typical of an engine system }\end{array}$ \\
\hline 4 & $\begin{array}{l}\text { Fundamental CO Pumping } \\
\text { Database }\end{array}$ & FR & $\begin{array}{l}\text { Establish a CO pumping database for the range of } \\
\text { conditions typical of a LOX/CO engine }\end{array}$ \\
\hline 5 & $\begin{array}{l}\text { Common Multipropellant } \\
\text { Injector Design Feasibility } \\
\text { Study }\end{array}$ & $\mathrm{ED}$ & $\begin{array}{l}\text { Establish feasibility and identify promising } \\
\text { injector design(s) that can operate with more than } \\
\text { one Mars in situ-based propellant combination } \\
\text { over a wide operating range. Main injector and gas } \\
\text { generator designs are to be investigated }\end{array}$ \\
\hline 6 & $\begin{array}{l}\text { Common Multipropellant } \\
\text { Feed System/Turbopumps } \\
\text { Design Feasibility Study }\end{array}$ & $\mathrm{ED}$ & $\begin{array}{l}\text { Establish feasibility and identify promising feed } \\
\text { system/turbopump design(s) that can operate } \\
\text { efficiently with more than one Mars in situ-based } \\
\text { fuel over a wide operating range }\end{array}$ \\
\hline 7 & $\begin{array}{l}\text { Common Thrust Chamber } \\
\text { Design Feasibility Study }\end{array}$ & ED & $\begin{array}{l}\text { Establish feasibility and identify promising thrust } \\
\text { chamber design(s) that can operate with more than } \\
\text { one Mars in situ-based propellant over a wide } \\
\text { operating range }\end{array}$ \\
\hline 8 & $\begin{array}{l}\text { LOX/CO Gas Generator } \\
\text { Design Feasibility Study }\end{array}$ & ED & $\begin{array}{l}\text { Establish feasibility and identify LOX/CO gas } \\
\text { generator design(s) that can operate over a wide } \\
\text { range of operating conditions }\end{array}$ \\
\hline 9 & $\begin{array}{l}\text { Common Control/Health } \\
\text { Monitoring System Design } \\
\text { Feasibility Study }\end{array}$ & $\mathrm{ED}$ & $\begin{array}{l}\text { Establish feasibility and identify promising } \\
\text { common control/health monitoring system(s) that } \\
\text { can operate with numerous in situ Mars propellant } \\
\text { combinations for various engine system operating } \\
\text { modes }\end{array}$ \\
\hline 10 & $\begin{array}{l}\text { Common Propellant Tank } \\
\text { Design and Supporting } \\
\text { Operations Study }\end{array}$ & ED & $\begin{array}{l}\text { Establish feasibility and identify common } \\
\text { propellant tank design(s) and supporting operation } \\
\text { requirements and design approach(es), such as for } \\
\text { resupply. Identification of high payoff alternative } \\
\text { tank designs will also be considered }\end{array}$ \\
\hline 11 & $\begin{array}{l}\text { Lightweight, Compact High } \\
\text { Area Ratio Nozzle Design } \\
\text { Study }\end{array}$ & ED & $\begin{array}{l}\text { Identify lightweight, compact high area ratio } \\
\text { nozzle designs for Mars in situ tripropellant engine } \\
\text { systems employing LOX/CO as one of its two } \\
\text { propellant combinations }\end{array}$ \\
\hline 12 & $\begin{array}{l}\text { Mars Tripropellant Subscale } \\
\text { Engine System Demonstra- } \\
\text { tion Program }\end{array}$ & BED & $\begin{array}{l}\text { Successfully demonstrate and establish feasibility } \\
\text { of a subscale }(15,000-60,000 \mathrm{lbf} \text { thrust level }) \\
\text { candidate Mars in situ propellant-based } \\
\text { tripropellant engine system design concept }\end{array}$ \\
\hline 13 & $\begin{array}{l}\text { Preliminary Mars In Situ } \\
\text { Propellent Mission/Vehicle/ } \\
\text { Engine System Design } \\
\text { Studies }\end{array}$ & SE & $\begin{array}{l}\text { Assess the impact of engine technology data as it } \\
\text { becomes available, on evolving Mars in situ } \\
\text { propellant-based mission, vehicle and engine } \\
\text { system designs }\end{array}$ \\
\hline
\end{tabular}

* FR = Fundamental Research; ED = Exploratory Development; BED = Breadboard Engine Demonstration; $\mathrm{SE}=$ System Engineering 


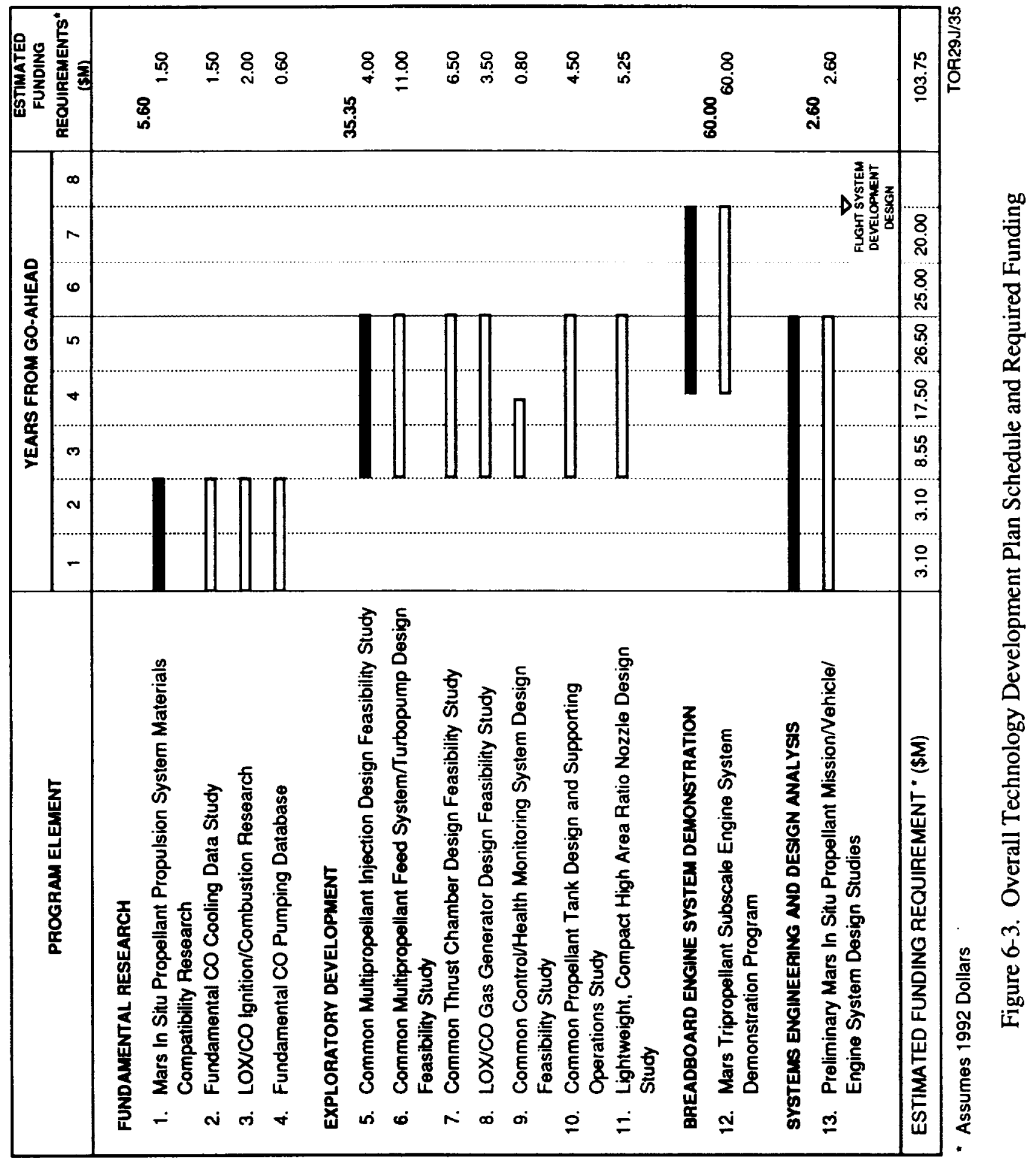




\subsection{CONCLUSIONS}

A top-level feasibility study was conducted that identified and characterized promising chemical propulsion system designs which use two or more of the following propellant combinations: $\mathrm{LOX} / \mathrm{H}_{2}, \mathrm{LOX} / \mathrm{CH}_{4}$ and $\mathrm{LOX} / \mathrm{CO}$. The engine systems examined emphasized the usage of common subsystem/component hardware where possible. In support of this study, numerous mission scenarios were characterized that used various combinations of Earth, lunar and Mars propellants to establish engine system requirements to assess the promising engine system design concept examined, and to determine overall exploration leverage of such systems compared to state-of-the-art cryogenic ( $\mathrm{LOX} / \mathrm{H}_{2}$ ) propulsion systems. Initially in the study, critical propulsion system technologies were assessed. Candidate expander and gas generator cycle $\mathrm{LOX} / \mathrm{H}_{2} / \mathrm{CO}, \mathrm{LOX} / \mathrm{H}_{2} / \mathrm{CH}_{4}$ and $\mathrm{LOX} / \mathrm{CO} / \mathrm{CH}_{4}$ engine system designs were parametrically evaluated. From this evaluation baseline, tripropellant MTV LOX cooled and bipropellant LEV and MEV engine systems were identified. Representative tankage designs for a MTV were also investigated. Re-evaluation of the missions using the baseline engine design showed that in general the slightly lower performance, smaller, lower weight gas generator cycle-based engines, required less overall mission Mars and ISPP infrastructure support compared to the larger, heavier, higher performing expander cycle engine systems.

Additionally, the study identified key technology and design issues that must be addressed to ensure the technical feasibility of such engine systems. A 7-year technology maturation plan was established that would address these issues in an efficient manner.

It is recommended in the near-term, that additional tripropellant engine system design studies be undertaken that consider propellants other than LOX as the engine system coolant. By assuming LOX as the coolant in engine systems examined in this study, chamber pressure was limited. Engines that employ the candidate fuel as their coolant may have the potential to operate at higher chamber pressures, hence possibly reducing the engine's size and weight substantially, for

a given thrust level. In parallel with this effort, it is recommended that a robust fundamental research program in the areas of materials compatibility, cooling, ignition/combustion and pumping be initiated as discussed in the technology maturation plan. This data is critical in the assessment of candidate tripropellant engine systems. Due to highly coupled interrelationship of the propulsion system, which uses in situ-derived lunar and/or Mars propellants, with the vehicle and ISPP infrastructure, additional mission/vehicle design studies are also recommended at this time. 



\subsection{REFERENCES}

1-1. "Report of the 90-Day Study on Human Exploration of the Moon and Mars," NASA Publications, November 1989.

1-2. "Report of the Synthesis Group on America's Space Exploration Initiative," U.S. Government Printing Office, May 1991.

1-3. Linne, D. L. and Meyer, M. L., "Technical Prospects for Utilizing Extraterrestrial Propellants for Space Exploration," IAA-91-669, presented at the 42nd Congress of the International Aeronautical Federation, Montreal, Canada, October 5-11, 1991.

1-4. Stancati, M. L., Jacobs, M. K., Cole, K. J., and Collins, J. T., "In Situ Propellant Production: Alternatives for Mars Exploration," NASA CR 187192; SAIC Report No. SAIC-91/1052, October 1991.

2-1. "Space Transfer Concepts and Analysis for Exploration Missions - Third Quarterly Review," Boeing Aerospace and Electronics Co., NASA Contract No. NAS8-37857, June 22, 1990.

3-1. Beichel, R. and O'Brien, C. J., "Dual-Fuel Engine for Single-Stage Shuttles," AIAA Paper No. 75-1249, presented at the AIAA/SAE 11th Propulsion Conference, Anaheim, California, September 29-October 1, 1975.

3-2. O'Brien, C. J., "Dual-Fuel, Dual-Throat Engine Preliminary Analysis," Aerojet Liquid Rocket Company, Report 32967F, Contract NAS-8-32967, August 1979.

3-3. O'Brien, "Dual-Nozzle Design Update," AIAA-82-1154, presented at the AIAA/SAE/ASME 18th Joint Propulsion Conference, Cleveland, OH, June 21-23, 1982.

3-4. Beichel, R., O'Brien, C. J. and Swiss, J. D., "Single-Stage-to-Orbit Advanced Propulsion," Aerojet Liquid Rocket Company, IR\&D Program 8776-06, Report No. 877606-F, November 1976.

3-5. Wheeler, D. B., "Tripropellant Engine Study," NASA-CR-150482, December 9, 1977.

3-6. LaBotz, R. J. and Ewen, R. L., "Thrust Chamber Technology for Advanced Earth-to-Orbit Rocket Engines," Aerojet Technology, Vol. 1, No. 1, 1983. 
3-7. Schoeman, L., "High-Pressure Propulsion - Advanced Concepts for Cooling," Acta Astronautica, Vol. 14, 1986.

3-8. Visek, W. A., "Future LOX/Hydrocarbon Booster Engines," SAE Paper No. 861813, presented at the Aerospace Technology Conference and Exposition, Long Beach, CA, October 13-16, 1986.

3-9. Worlund, A. L., Monk, J. C. and Bachtel, F. D., "NLS Propulsion Design Considerations," AIAA-92-1181, presented at the 1992 Aerospace Design Conference, Irvine, CA, February 3-6, 1992.

3-10. Cooper, L. A., "Propulsion Issues for Advanced Orbit Transfer Vehicles," NASA TM 83624, 1984.

3-11. Spencer, R. G., Rousar, D. C. and Price, H. G., "LOX-Cooled Thrust Chamber Technology Developments," Journal of Spacecraft, Vol. 17, No. 1, Jan-Feb 1980.

3-12. Dederra, H. and Kirner, E., "High Pressure Rocket Engine Liquid Oxygen Technology," IAF-76-174, presented at the 1976 International Astronautical Federation Conference, Anaheim, CA, October 10-16, 1976.

3-13. Roncace, E. A., "In Situ Propellant Rocket Engines for Mars Mission Ascent Vehicle," AIAA-91-2445, presented at the AIAA/SAE/ASME/ASEE 27th Joint Propulsion Conference, Sacramento, CA, June 24-27, 1991.

3-14. Armstrong, E. S., "Cooling of In Situ Propellant Rocket Engines for Mars Mission," NASA TM 103729, January 1991.

3-15. Linne, D. L., Roncace, R. and Groth, M. F., "Mars In Situ Propellants: Carbon Monoxide and Oxygen Ignition Experiments," AIAA-90-1894, presented at the AIAA/SAE/ASME/ASEE 26th Joint Propulsion Conference, Orlando, FL, July 16-18, 1990.

3-16. Morgan, D. and Beichel, R., "Stoichiometric Gas Generator - A Strategic Departure," AIAA-91-2584, presented at the AIAA/SAE/ASME/ASEE 27th Joint Propulsion Conference, Sacramento, CA, June 24-26, 1991. 
3-17. Buckmann, P. S., Shimp, M. R., Viteri, F. and Proctor, M., "Design and Test of an Oxygen Turbopump for a Dual Expander Cycle Rocket Engine," AIAA-89-2305, presented at the AIAA/ASME/SAE/ASEE 25th Joint Propulsion Conference, Monterey, CA, July 10-12, 1989.

3-18. Kurth, R., Private Communication, SAIC, June 1991.

3-19. Schoenman, L., "Selection of Burn -Resistant Materials for Oxygen-Driven Turbopumps," Journal of Propulsion and Power, Vol. 3, No. 1, Jan-Feb 1987.

3-20. Daniels, N. H. G., Syrell, B. C. and Jones, R. L., "Materials Requirements for Advanced Energy Systems - New Fuels, Volume 1, Interactions of Materials with New Fuels - Final Report," DARPA Contract No. DAHC15-73-C-0313, Stanford Research Institute, Menlo Park, CA, July 1974.

4-1. Taylor, C. E., "Expanded Liquid Engine Simulation Computer Program - Technical Information Manual," Aerojet Tech Systems Company, Report No. ELES-1984, August 1984.

4-2. Taylor, C. E., "Expanded Liquid Engine Simulation Computer Program - Programmer's Manual," Aerojet Tech Systems Company, Report No. ELES-1984, December 1984.

4-3. Taylor, C. E., "Expanded Liquid Engine Simulation Computer Program - Advanced User's Manual," Aerojet Tech Systems Company, Report No. ELES-1984, December 1984.

4-4. Mog, R. A. and Price, D. M., "Optimization Techniques Applied to Passive Measures for In-Orbit Spacecraft Survivability - Final Report," NASA Contract No. NAS8-37378, June 1991.

6-1. Zurawski, R. L., "Chemical Propulsion Technologies for Space Transfer Vehicles," presented at the AIAA/SAE/ASME/ASEE 26th Joint Propulsion Conference, Orlando, FL, July 16, 1990.

6-2. Stone, J. R., Shaw, L. M. and Aukerman, C. A., "Plans for the Development of Cryogenic Engines for Space Exploration," AIAA-91-3438, presented at the AIAA/NASA/OAI Conference on Advanced SEI Technologies, Cleveland, OH, September 4-6, 1991. 

APPENDIX A

INITIAL MISSION REQUIREMENTS DATA

A-1 



\section{APPENDIX A INITIAL MISSION REQUIREMENTS DATA}

This appendix contains summary data of the results from the initial mission performance analysis. Three outputs characterize each of the seven scenarios investigated:

1. Mission Description and Assumptions - describes the sequence of mission events, identifies required infrastructure elements and steady-state Earth launch requirements, and states major assumptions made.

2. Mass $\Delta V$, Specific Impulse (vacuum), Thrust, and Burn Time Summaries Arranged by Burn.

3. Engine Requirements Arranged by Vehicle.

These requirements provided a starting point for the engine system design effort and used rough engine performance and mass estimates. Section 2.0 summarized these efforts, and Section 5.0 contained the mission performance results using the specific propulsion system designs described in Section 4.0. 

SCENARIO 1

Baseline Scenario (No Lunar/Mars Propellant): Earth LOX/H $/ 2$ 



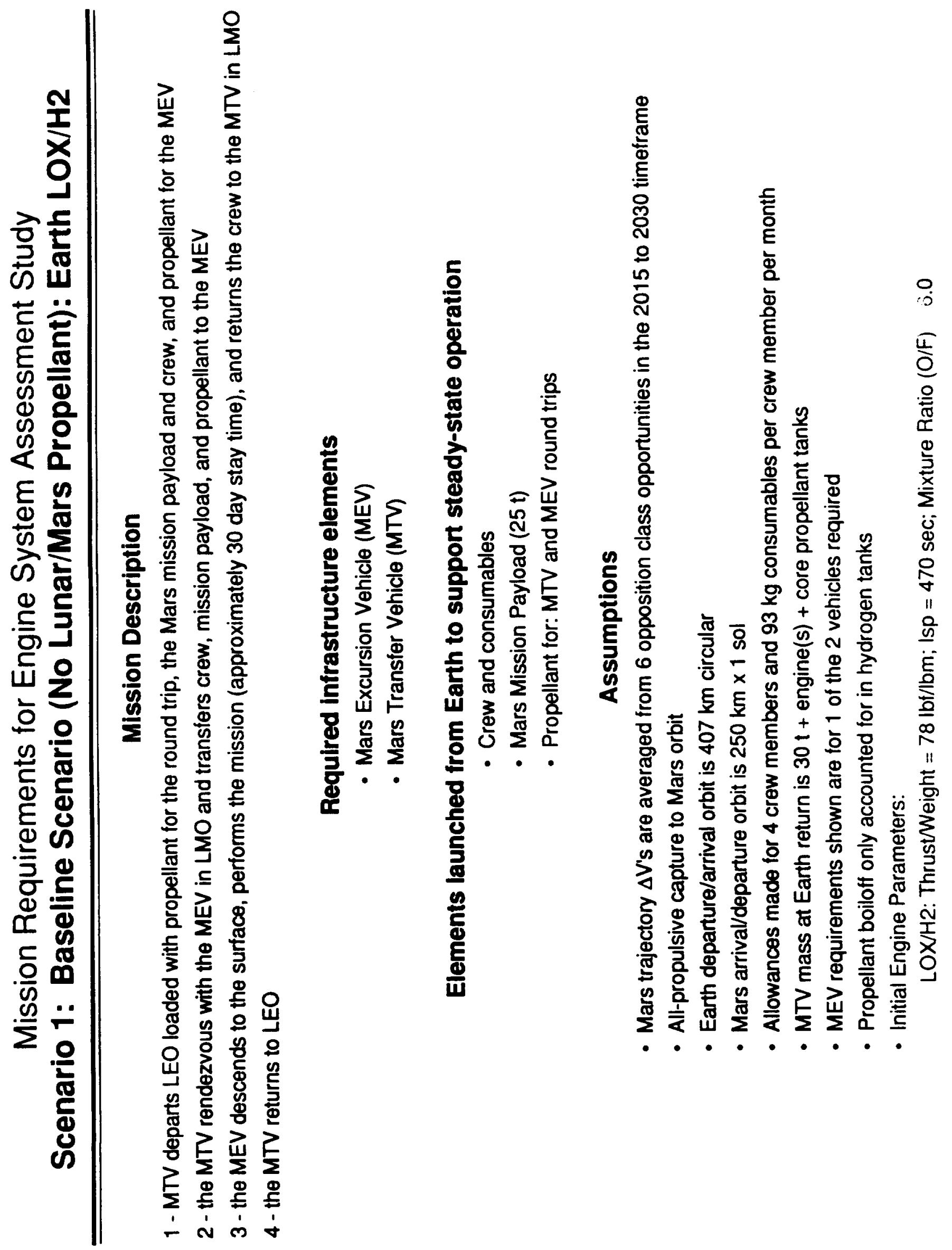





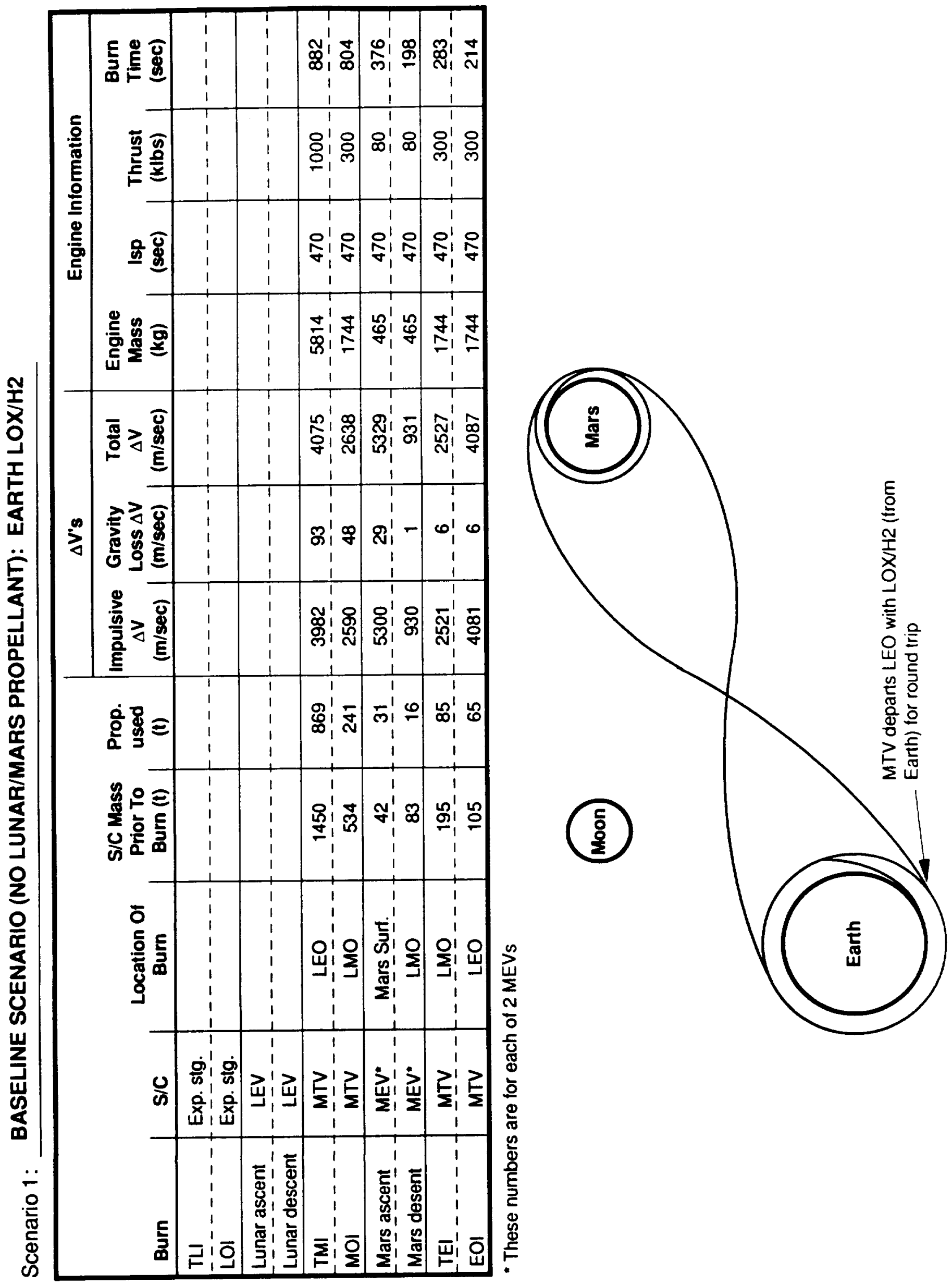





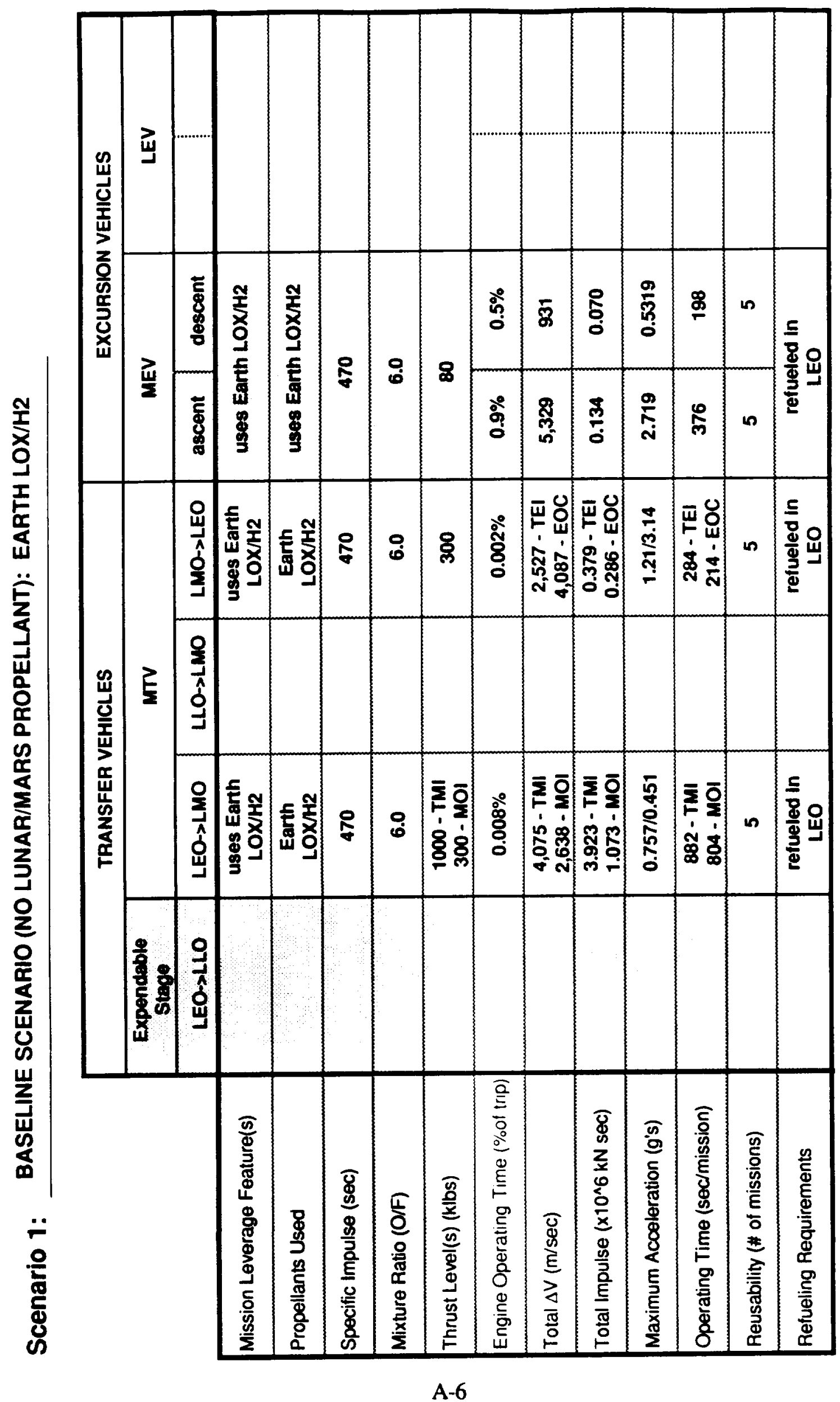



SCENARIO 2

Lunar LOX (Earth $\mathrm{H}_{2}$ ) for Outbound + Mars LOX/CO for Return 



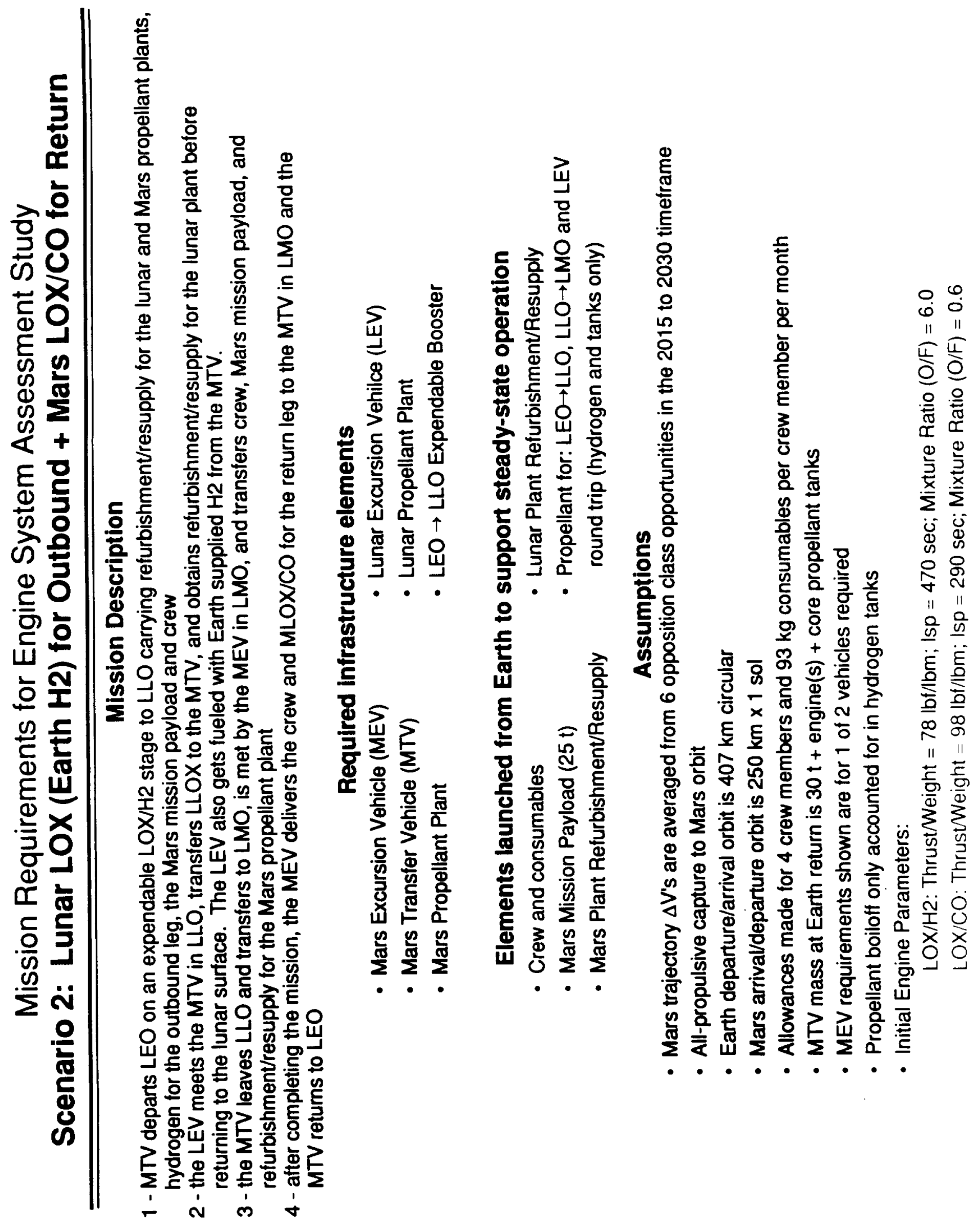





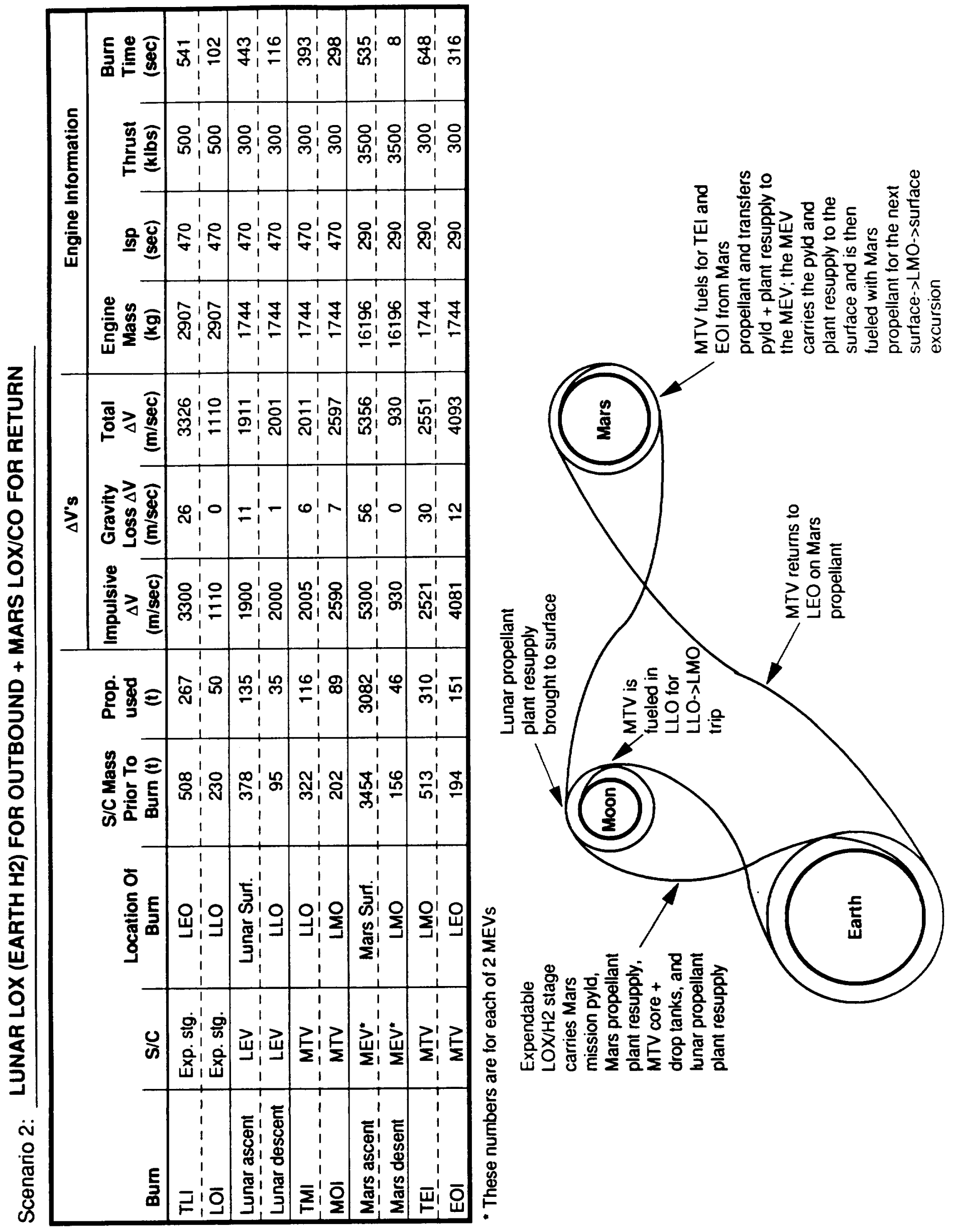





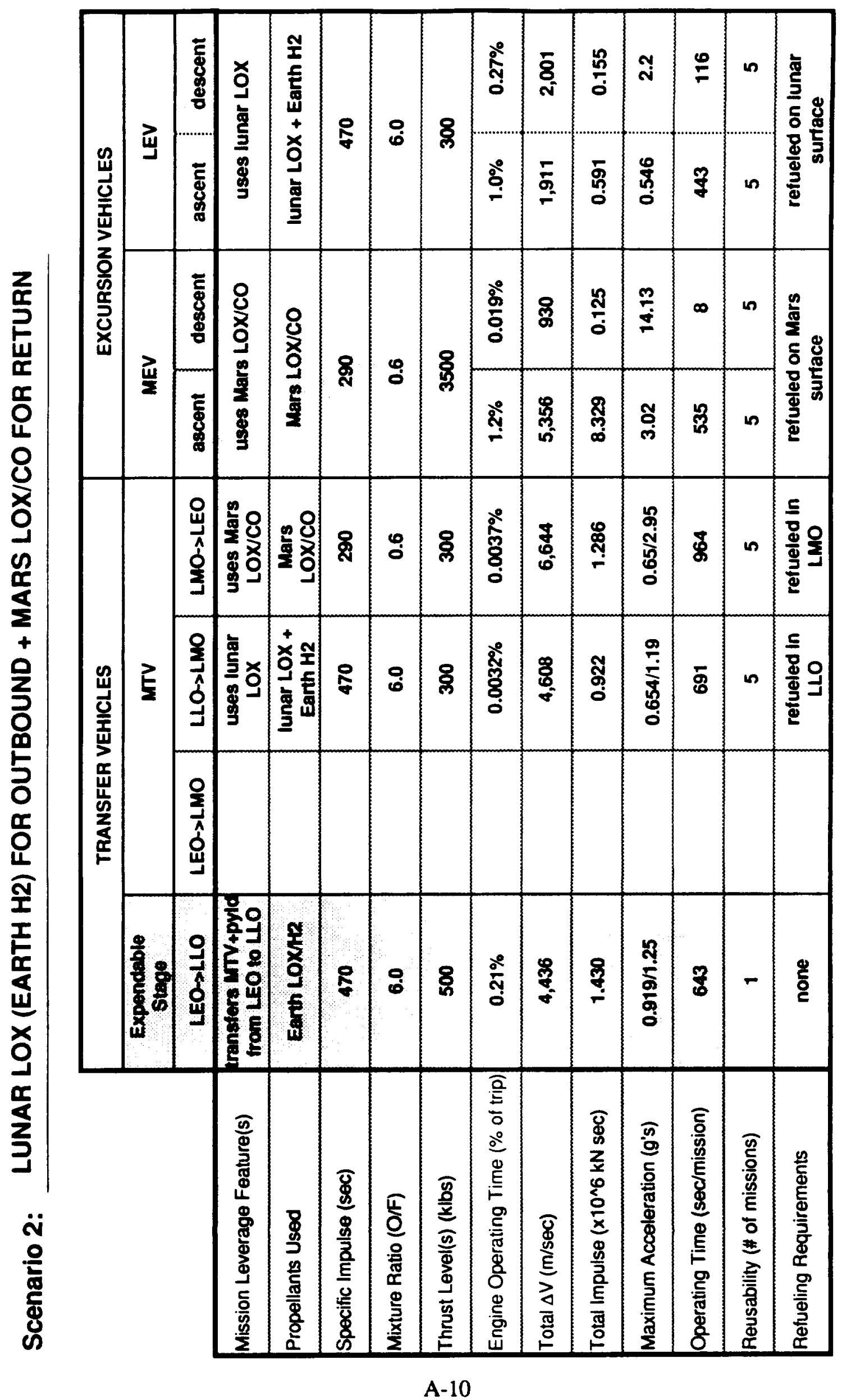



SCENARIO 3

Lunar LOX (Earth $\left.\mathrm{H}_{2}\right)$ for Outbound + Mars LOX/CH 4 for Return 



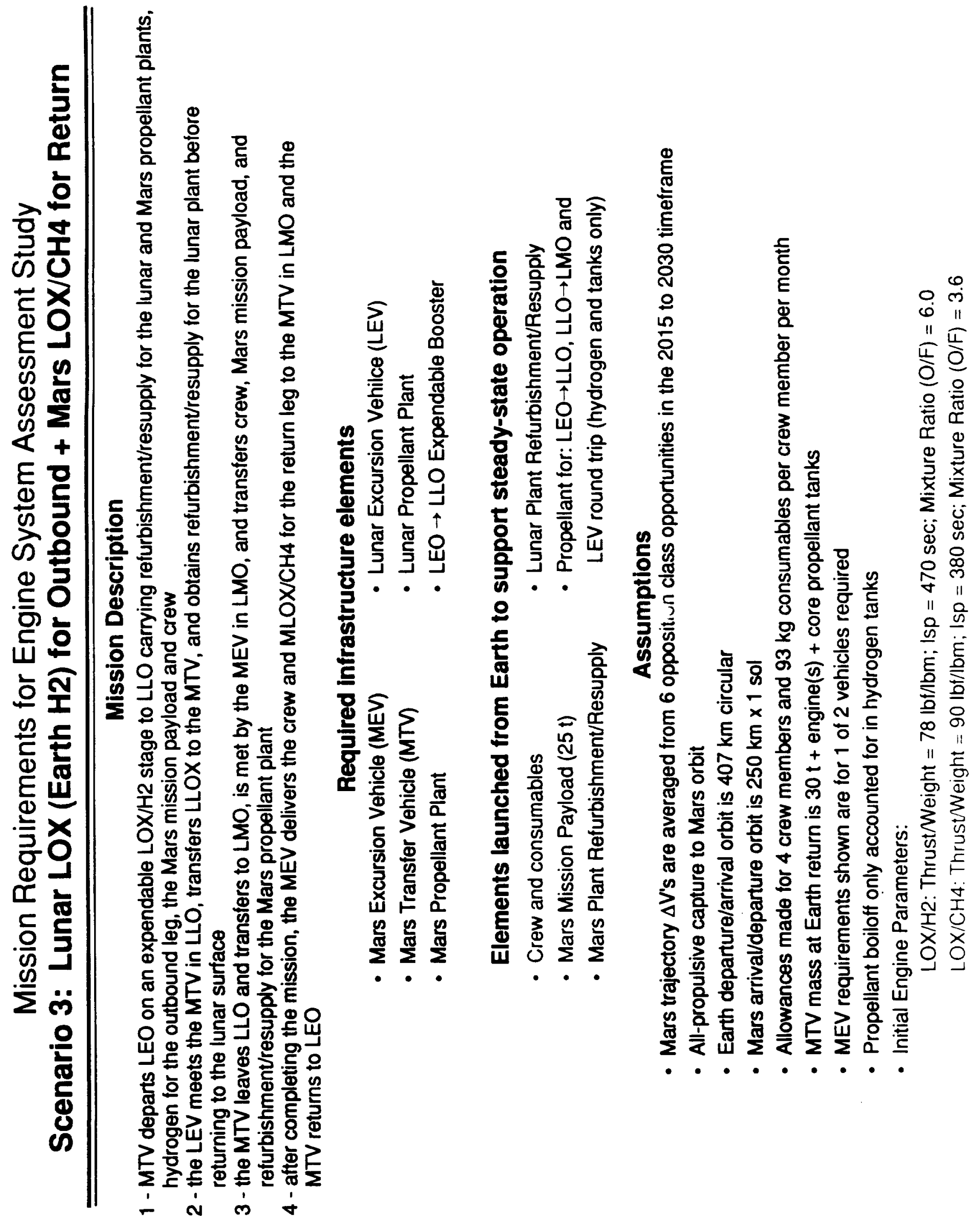





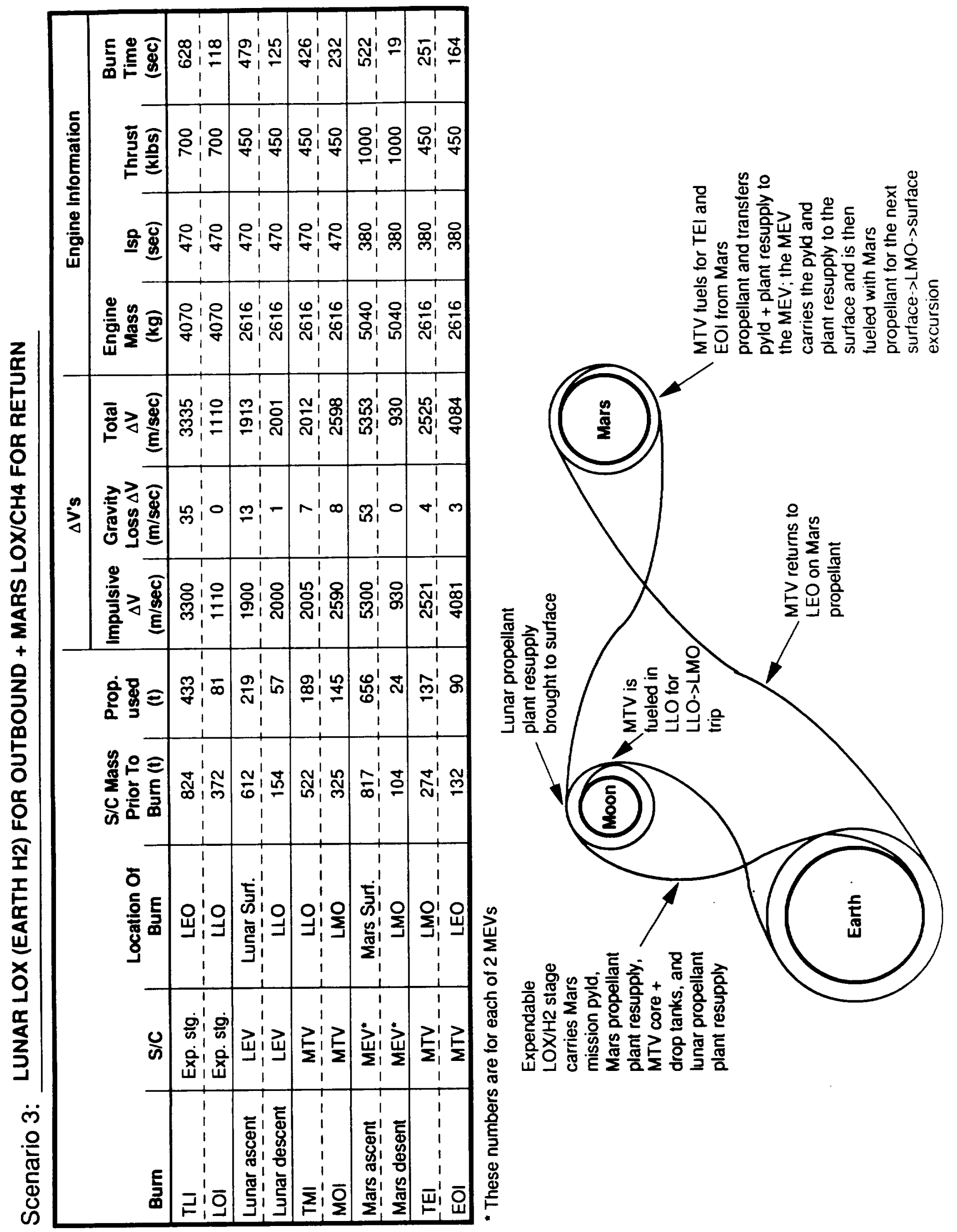





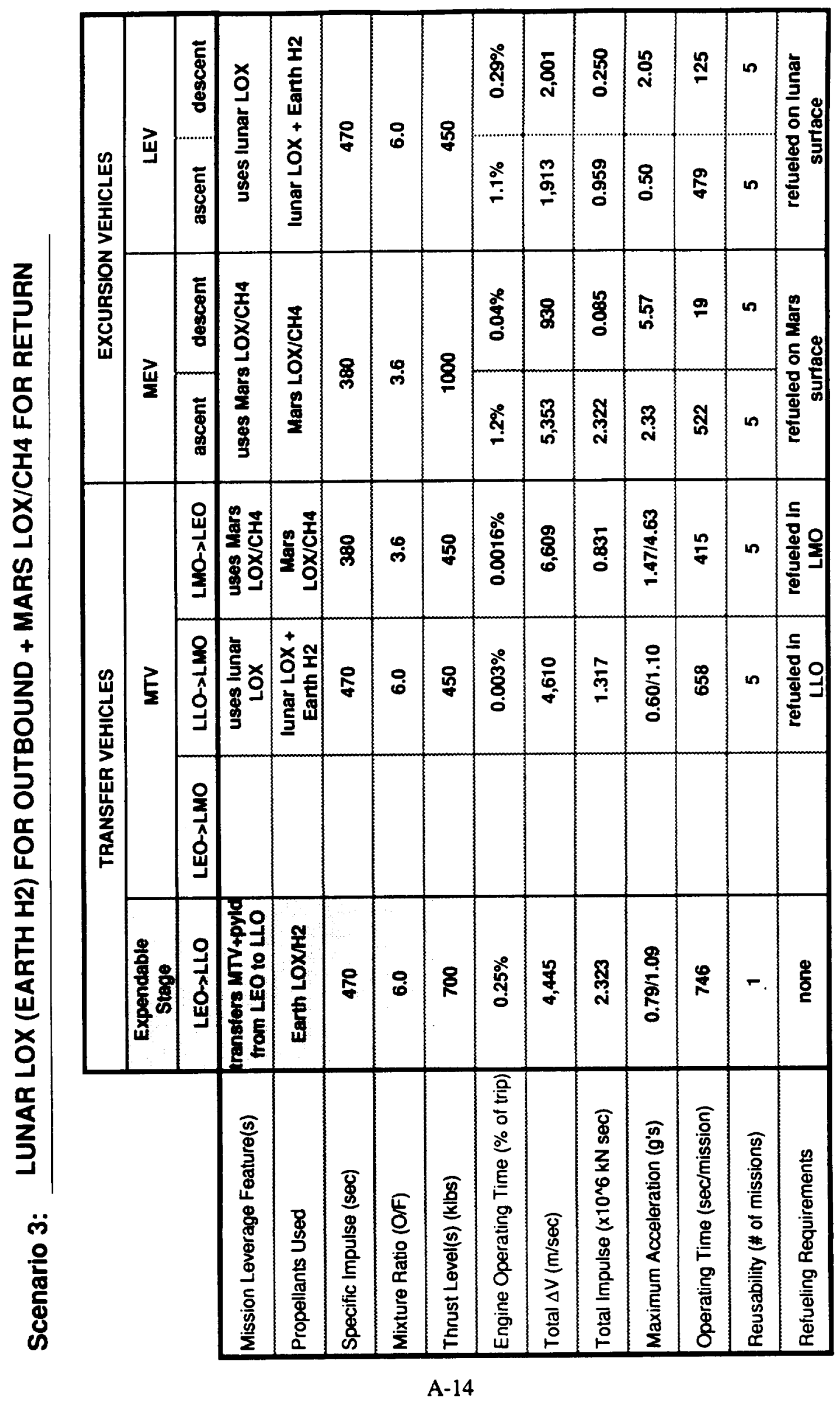



SCENARIO 4

Lunar LOX/CH 4 for Outbound + Mars LOX/CO for Return 



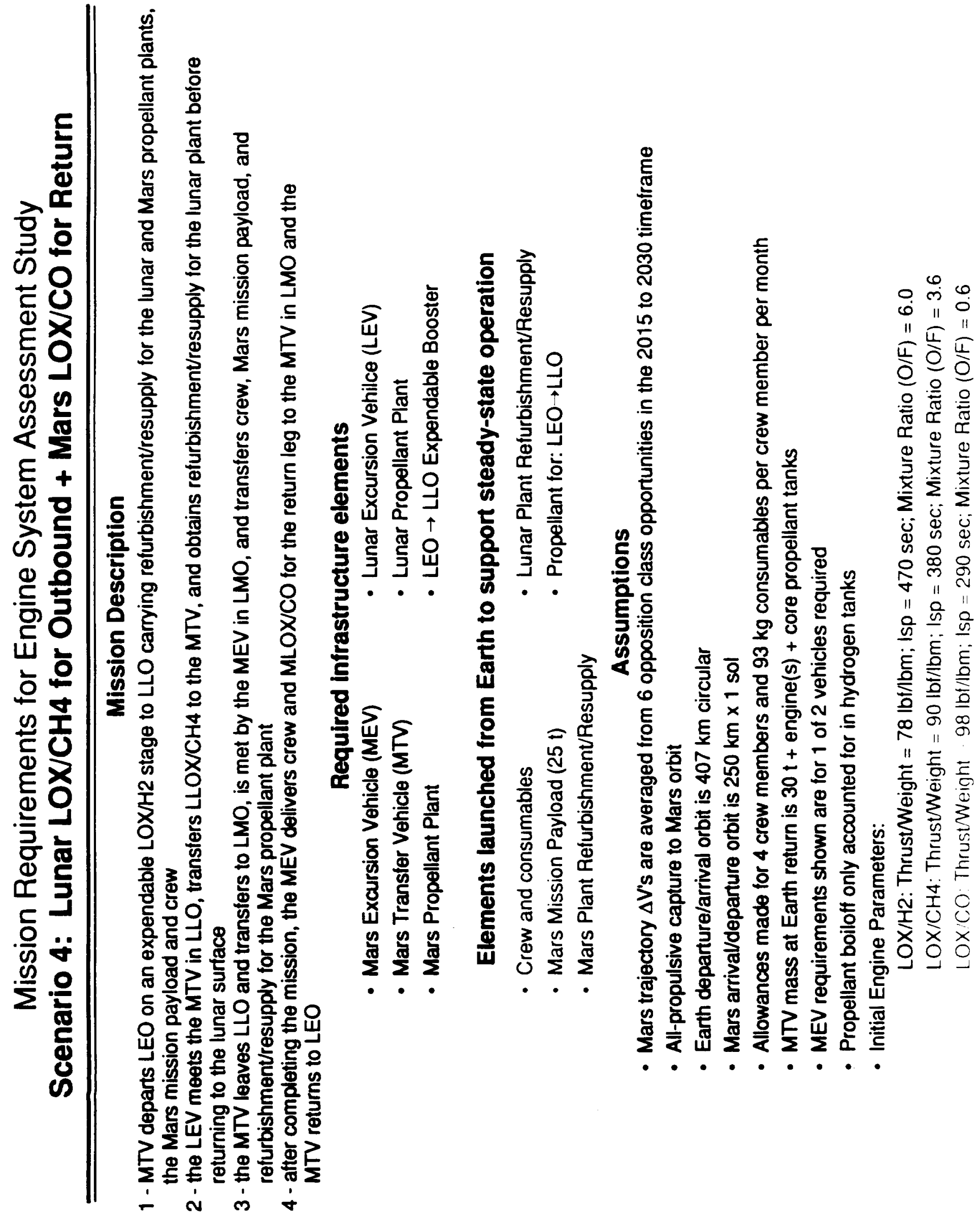





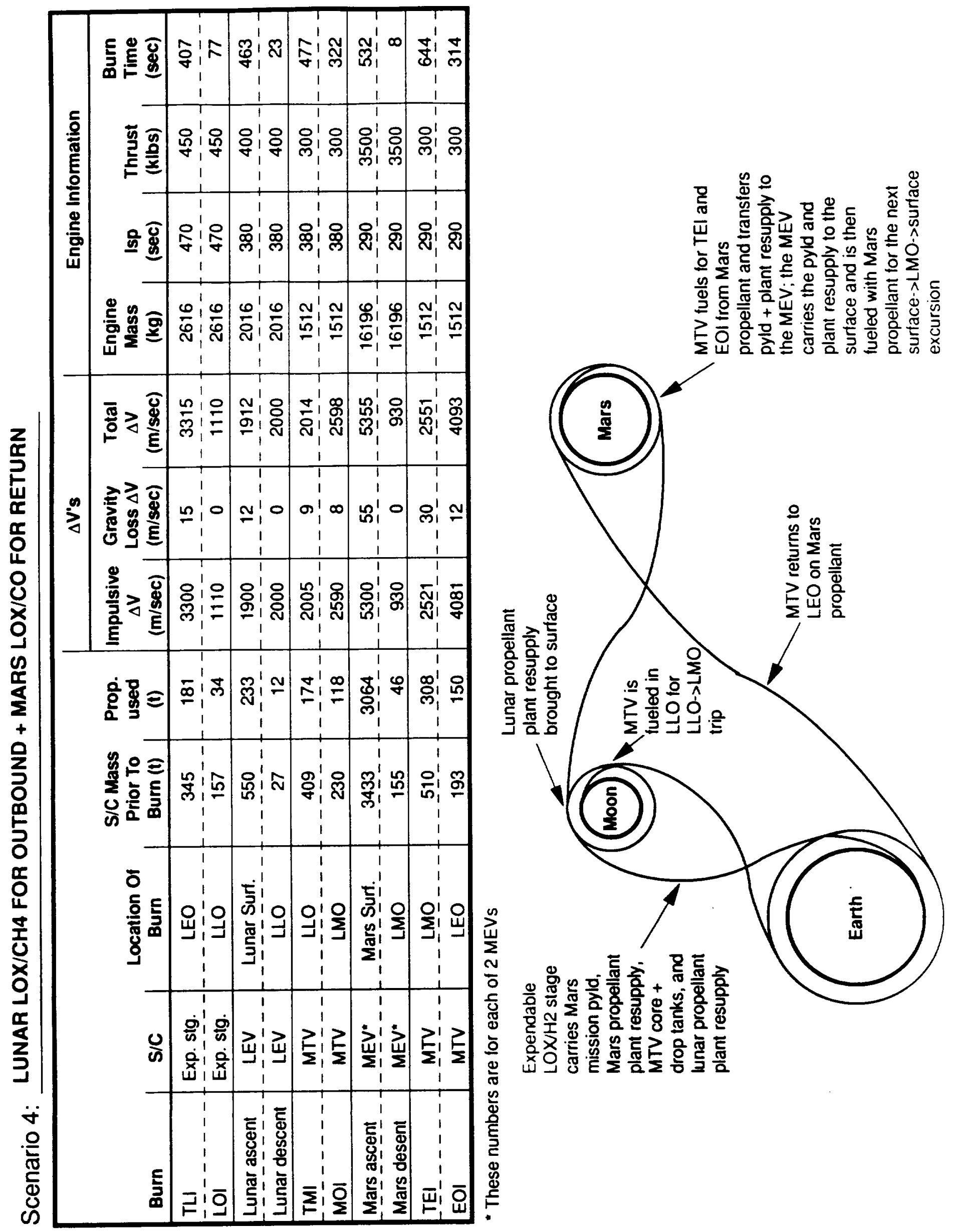





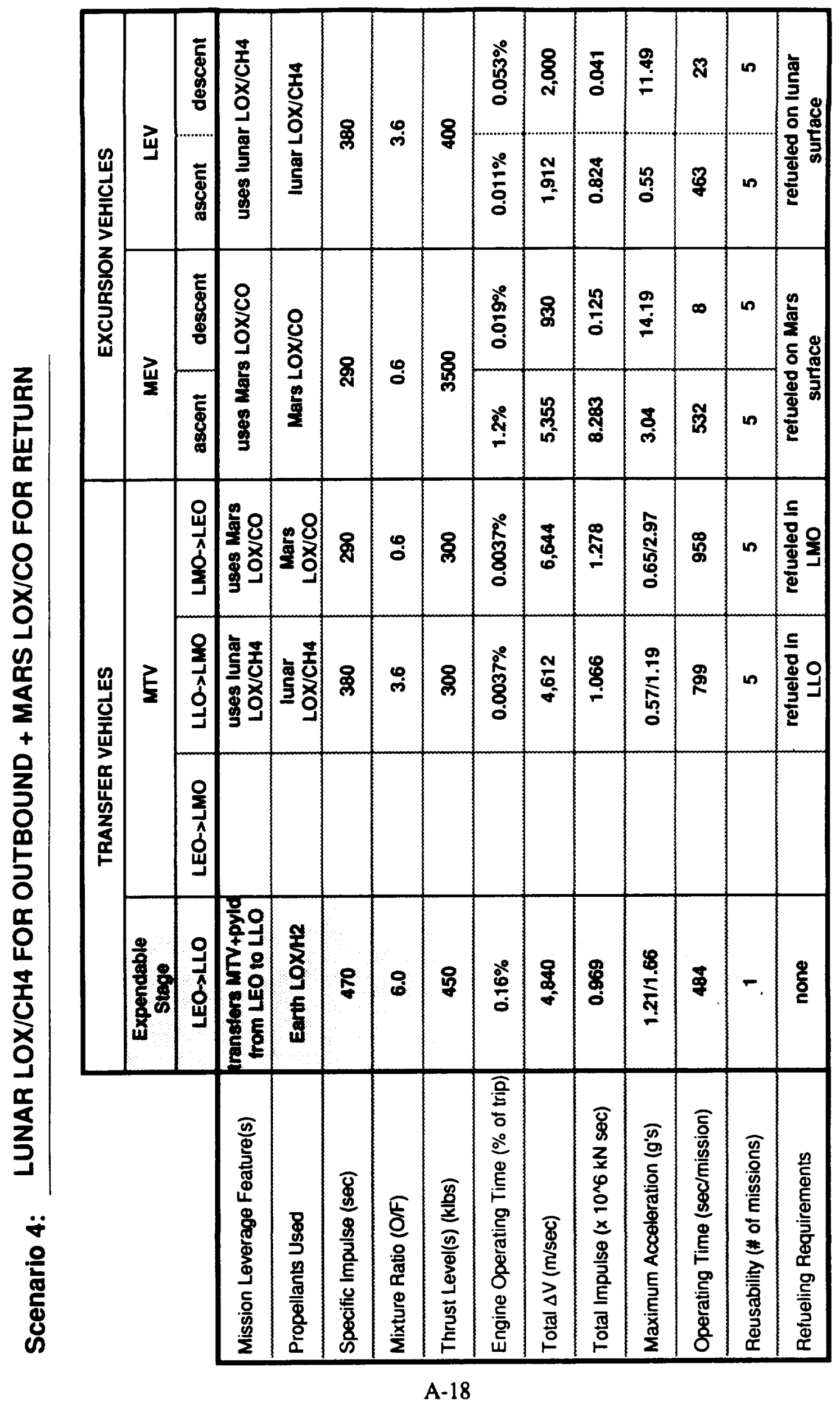





\section{SCENARIO 5}

\section{Lunar LOX/CH 4 for Outbound + Mars $\mathrm{LOX} / \mathrm{CH}_{4}$ for Return}





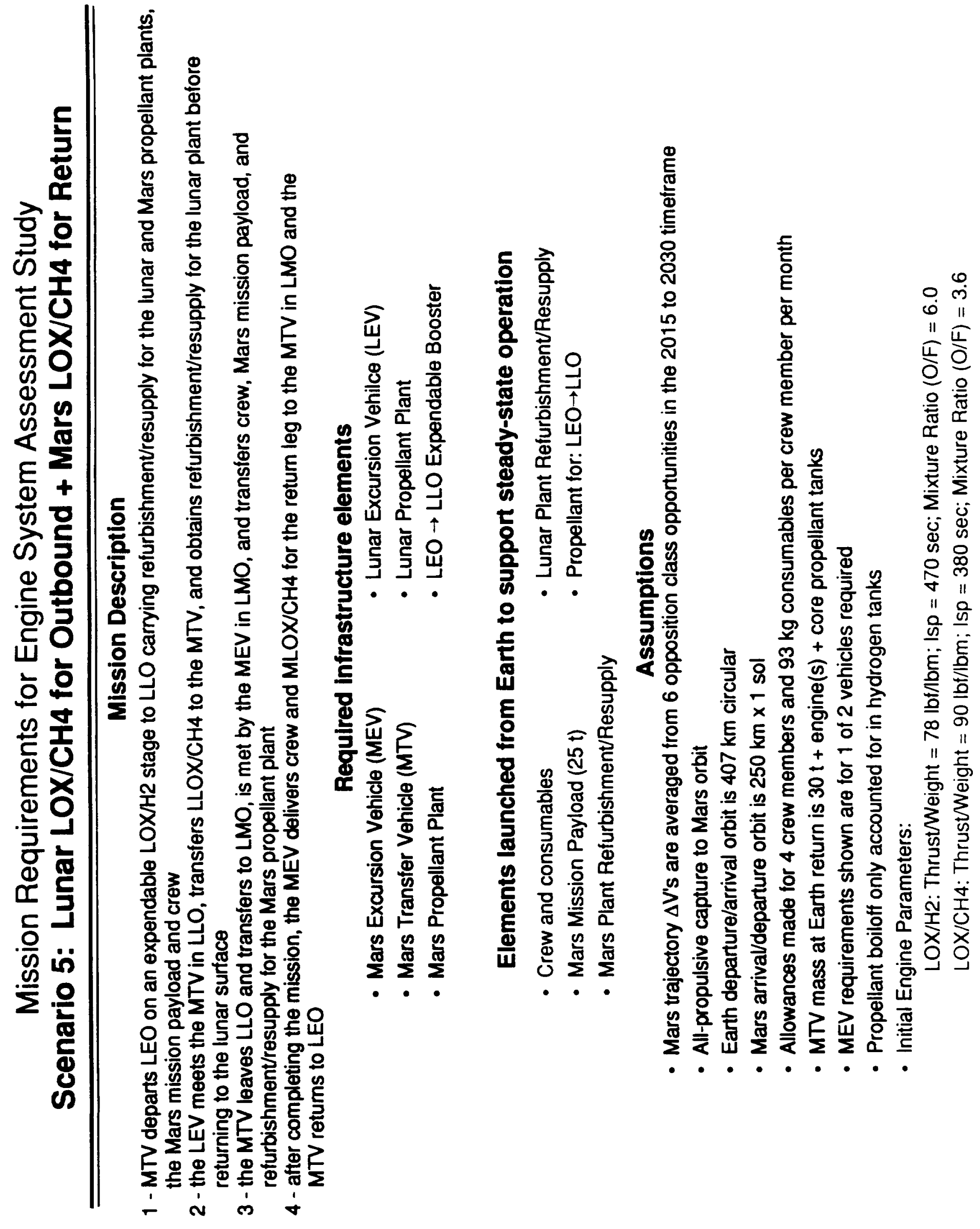





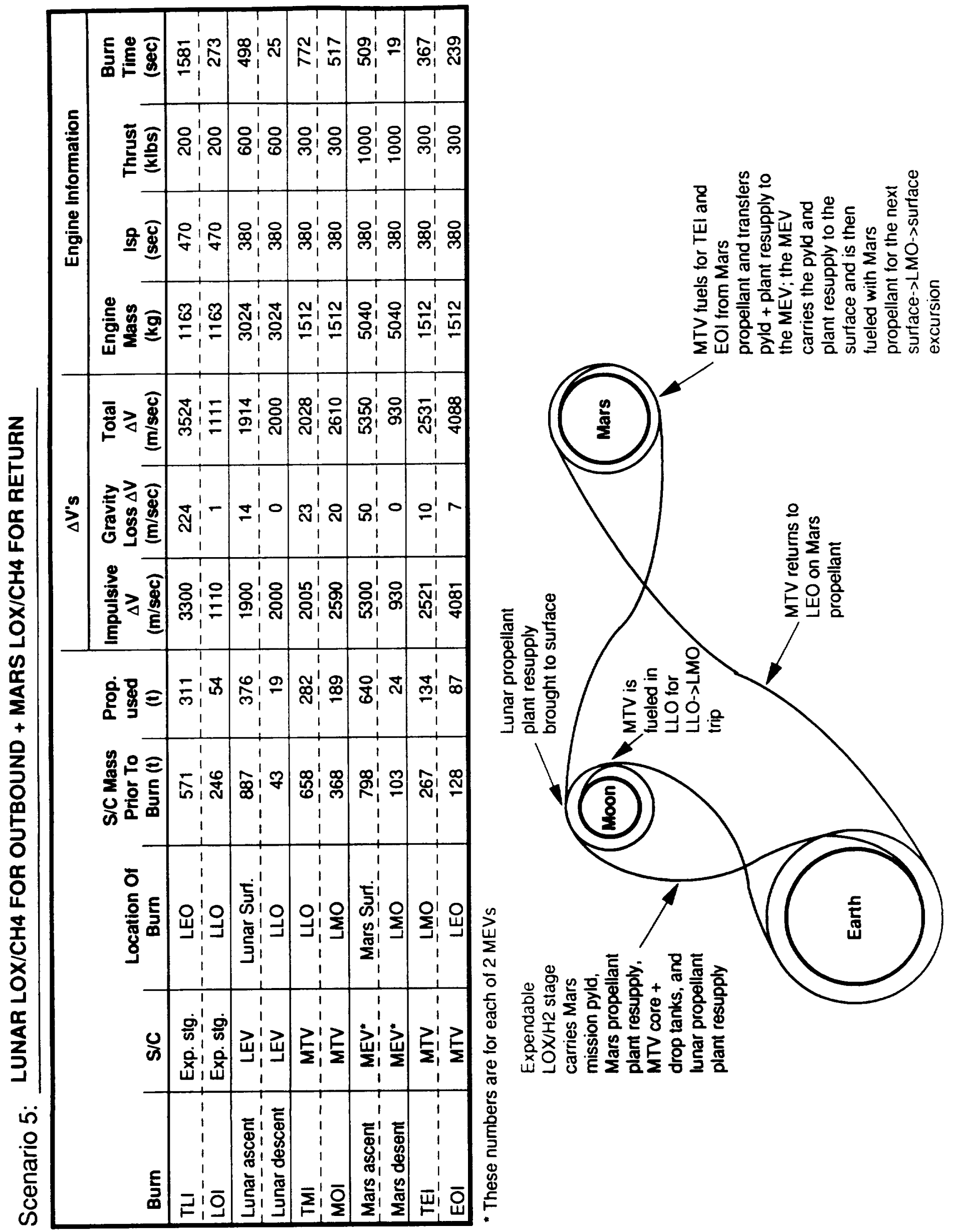





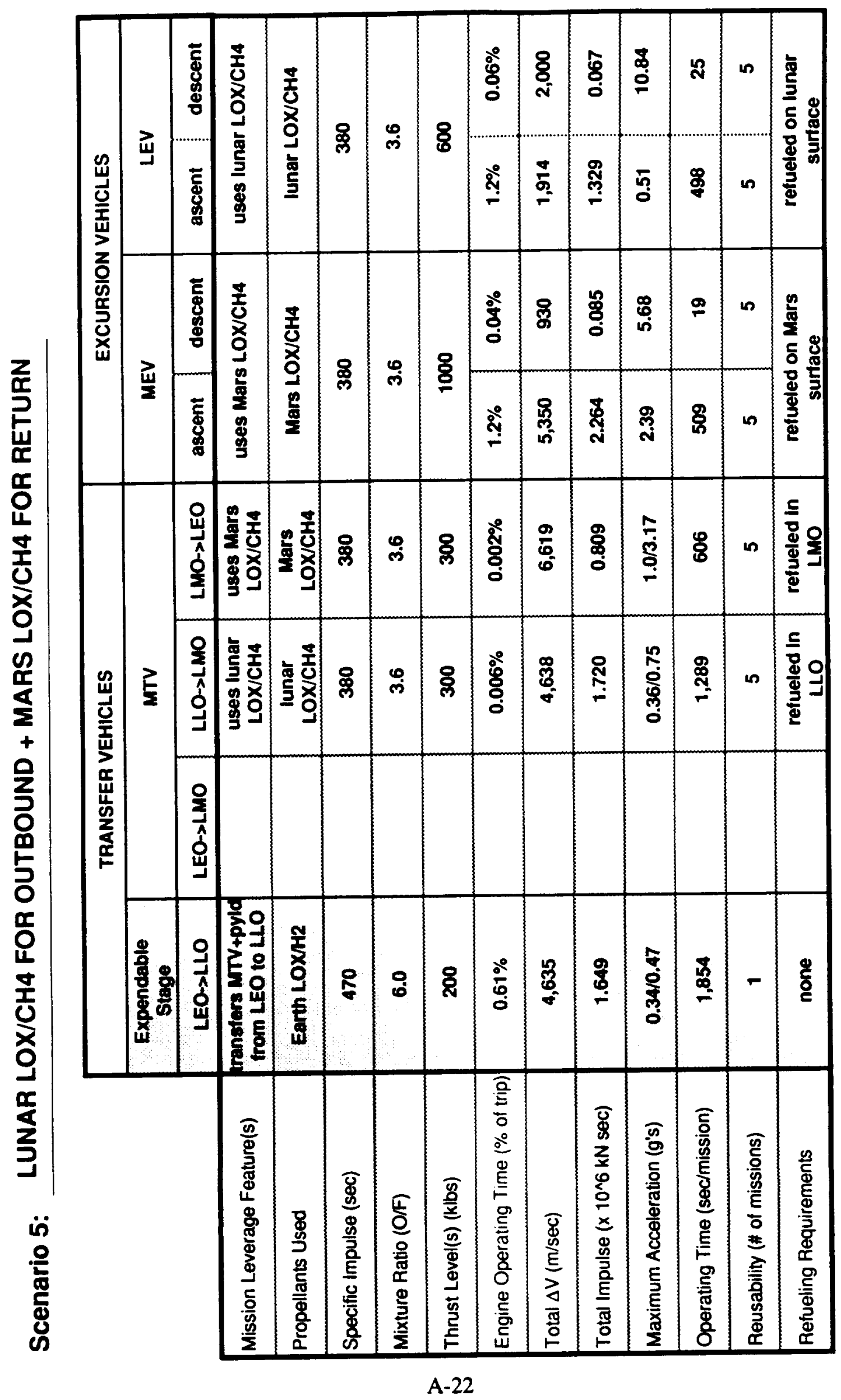





\section{SCENARIO 6}

\section{Earth LOX/H $/ \mathrm{H}_{2}$ for Outbound + Mars LOX/CO for Return}





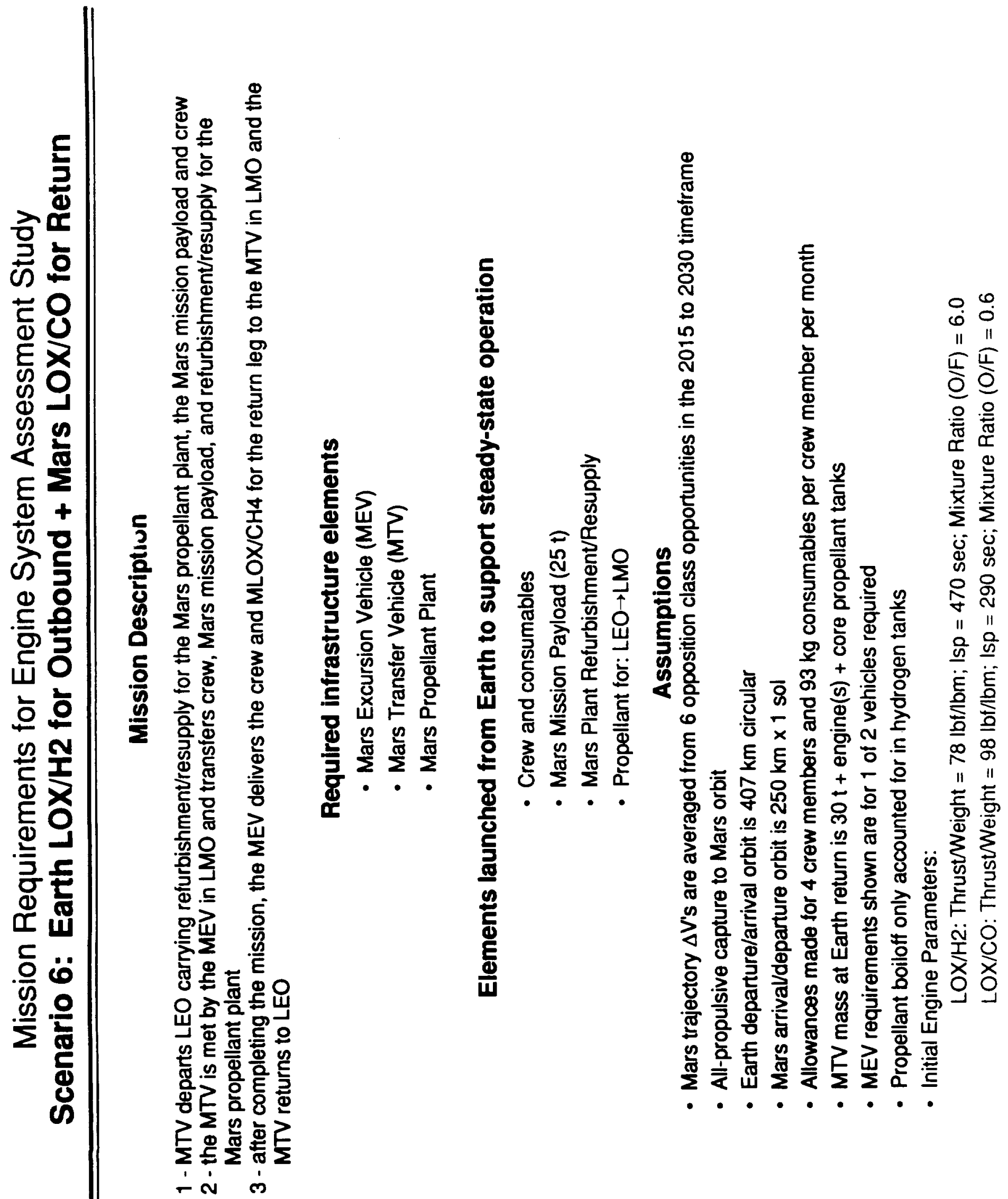





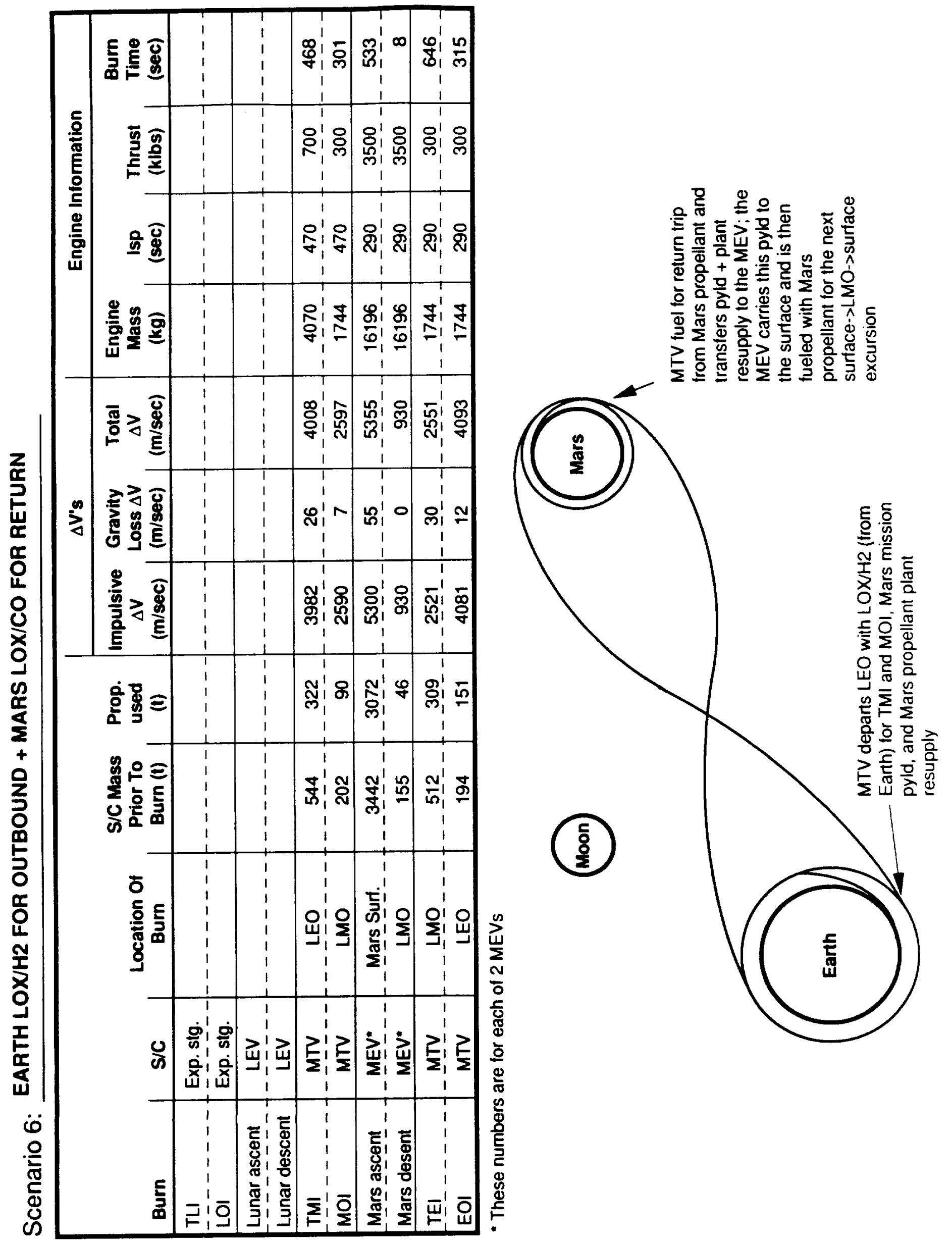





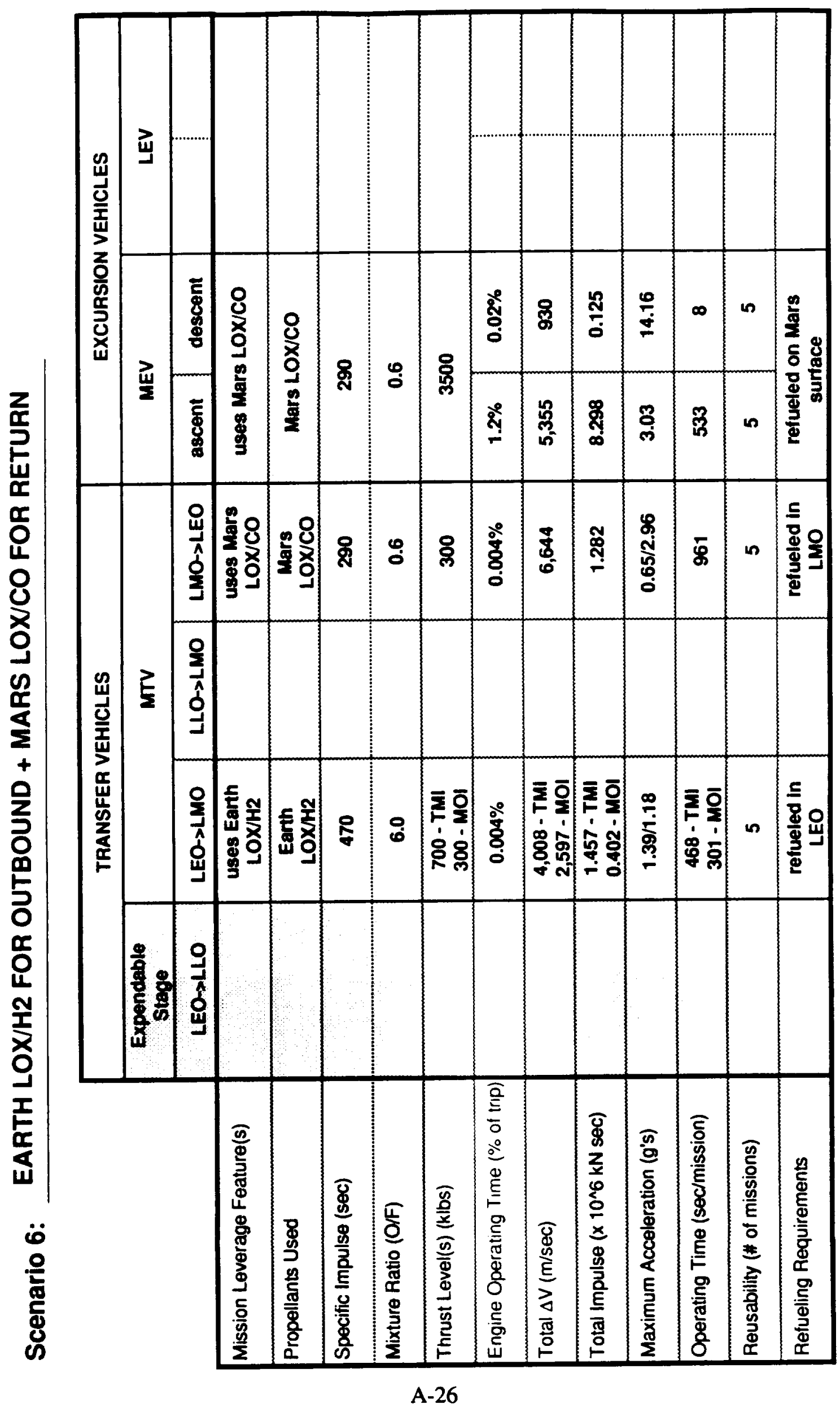





\section{SCENARIO 7}

\section{Earth LOX/H2 for Outbound + Mars $\mathrm{LOX} / \mathrm{CH}_{4}$ for Return}





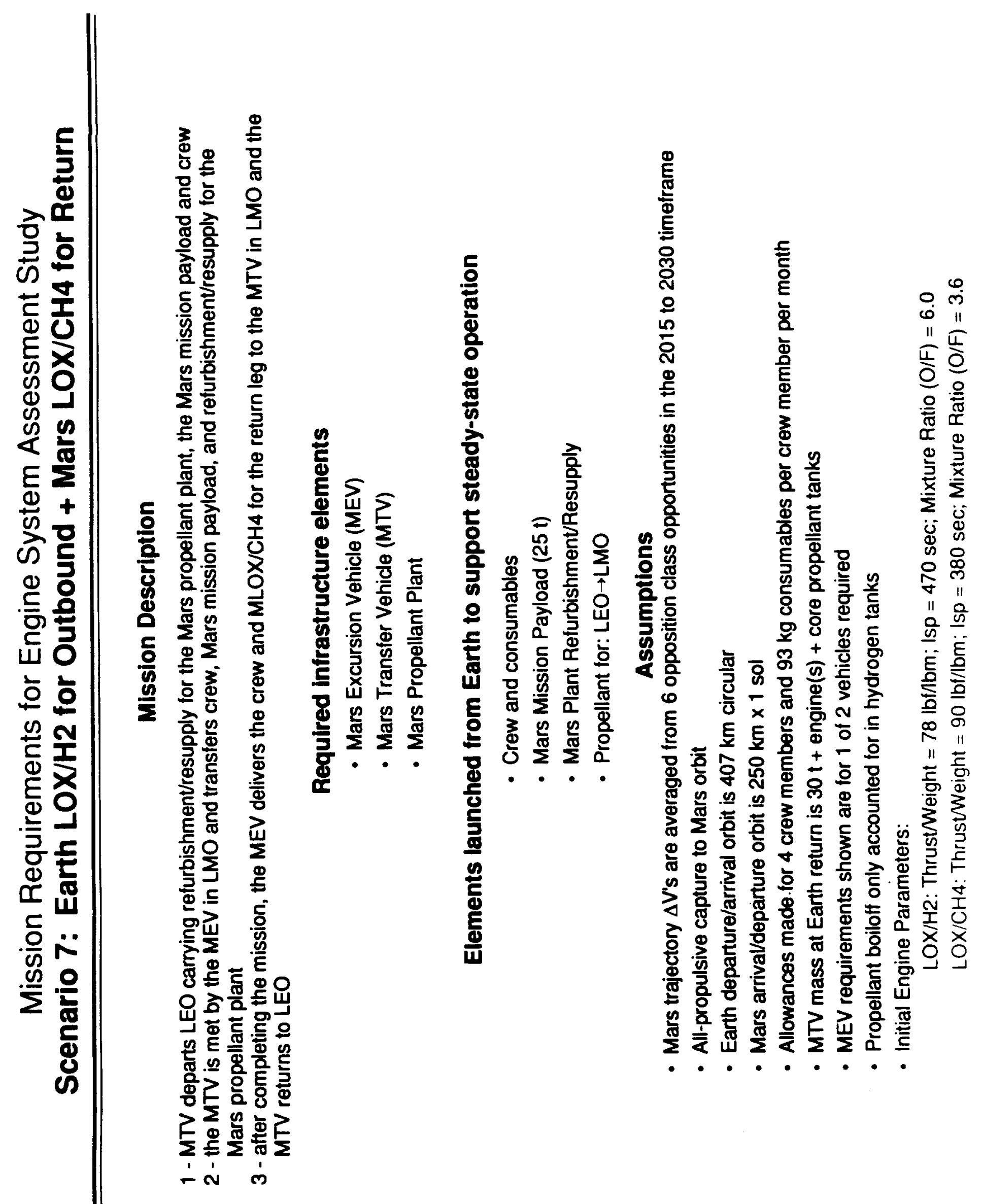





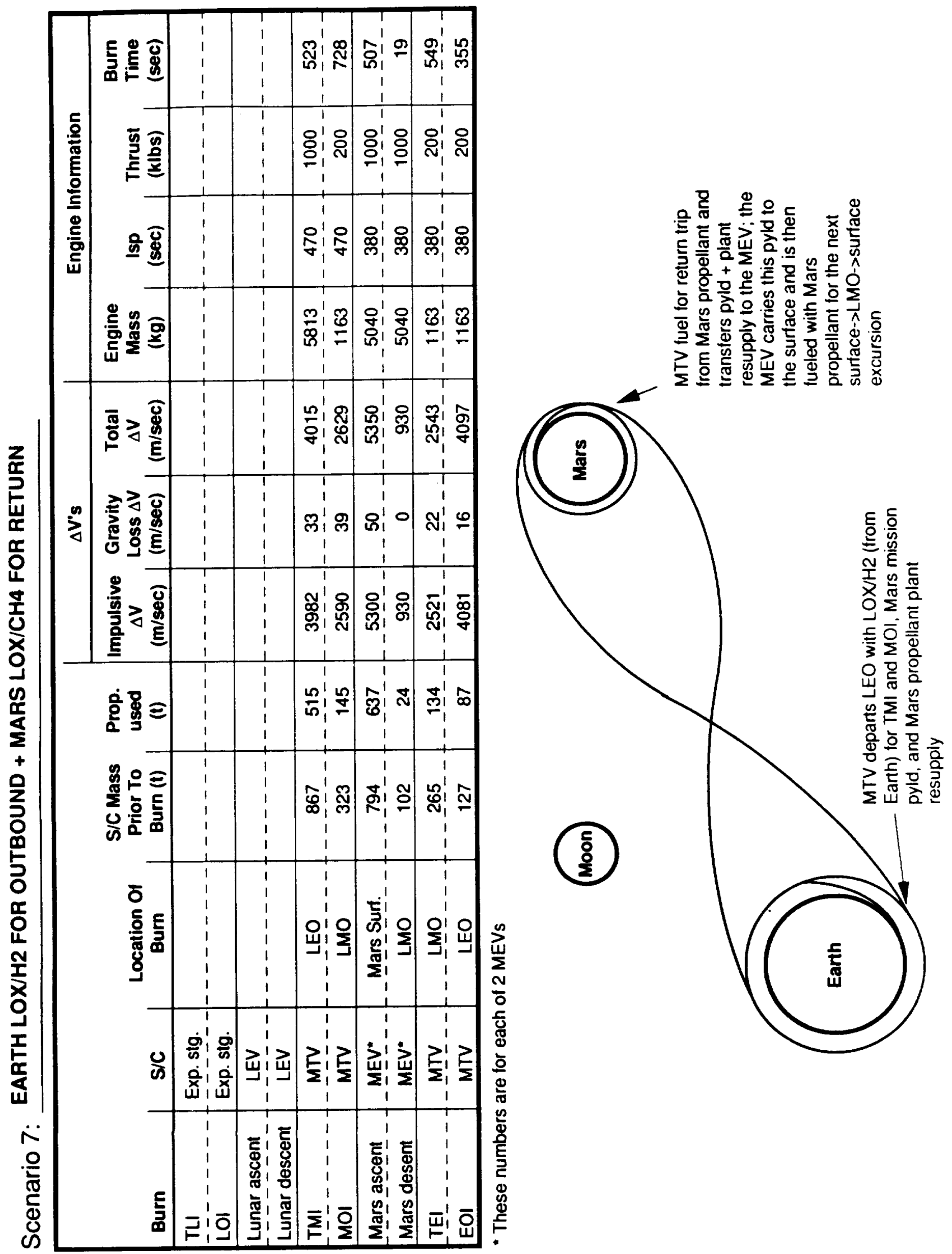





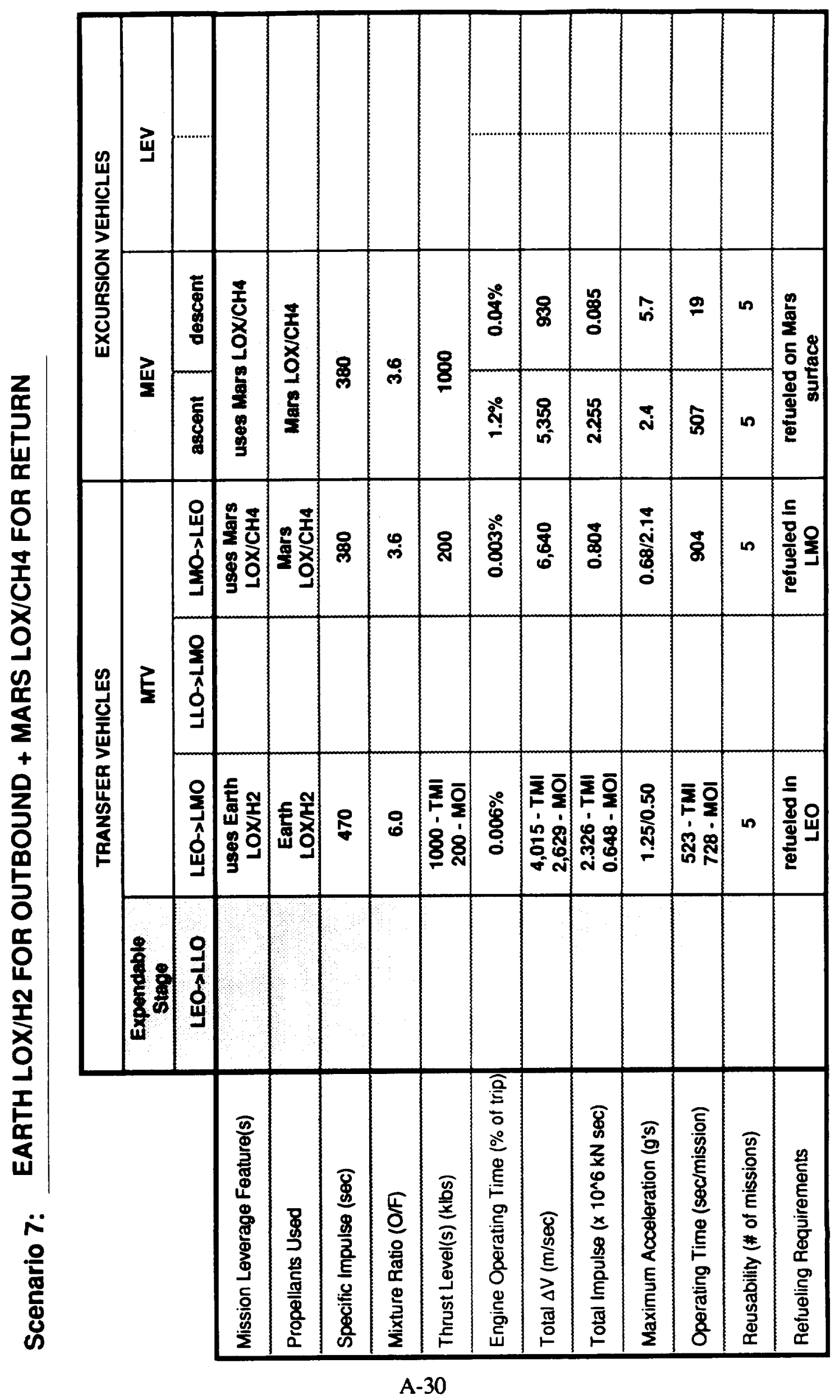





\section{APPENDIX B}

\section{OFF-DESIGN ELES ANALYSIS METHODOLOGY}

B-1 



\section{APPENDIX B \\ OFF-DESIGN ELES ANALYSIS METHODOLOGY}

The user-defined turbomachinery option of ELES allows evaluation of fuel and oxidizer pump and turbine performance at off-design operating characteristics and with a variety of propellants. The parameters input to define the TPA for off-design evaluation are detailed in the worksheets following, and include number of stages for all pumps and turbines, pump and turbine diameters, turbine annulus area, turbine admission fraction, and various gas generator parameters.

ELES calculates pump head rise and volumetric flowrate, and turbine horsepower, mass flowrate, and pressure ratio based on cycle balance requirements. Using these values, the pump $\mathrm{rpm}$ is calculated as a function of input pump diameter. To perform this calculation, a correlation had to be developed for pump head coefficient as a function of specific speed (standard cases interpolate this coefficient from a data table), and is of the form:

$$
\mathrm{HC}=\text { const } * \mathrm{SS}^{\mathrm{x}}
$$

where

$$
\begin{aligned}
& \mathrm{HC}=\text { head coefficient } \\
& \mathrm{SS}=\text { pump specific speed }
\end{aligned}
$$

For example, the main pump correlation is:

$$
\mathrm{HC}=3.7852 * \mathrm{SS}^{-0.28786}
$$

This correlation is different for main pumps and boost pumps. The specific speed is a function of pump rpm, head rise, and volumetric flowrate, as is shown below:

$$
\mathrm{SS}=\mathrm{RPM} * \mathrm{SQRT}(\text { volumetric flowrate }) /\left(\text { pump head rise } \mathrm{e}^{0.75}\right)
$$

The pump diameter is calculated as:

$$
\text { Dia }=\left(720 / \mathrm{pi}^{*} \mathrm{RPM}\right) * \mathrm{SQRT}(32.2 * \text { pump head rise/head coefficient })
$$



Substituting the head coefficient and specific speed equations into the equation for pump diameter and rearranging gives an equation for pump rpm's as a function of input pump diameter only. Once the rpm's are known, the specific speed, efficiency, and horsepower are easily found from the standard ELES equations.

The user-defined TPA version of ELES calculates the required turbine mass flowrate and horsepower and then evaluates the user input turbine to see how well it performs in meeting these requirements. The first step is to calculate the isentropic spouting velocity (Co) based on the number of turbine stages. Then, the ratio of turbine blade tangential velocity (U) to Co based on input turbine diameter $(\mathrm{U} / \mathrm{Co})$ is calculated and checked to determine whether this ratio is within the accepted range of 0.2-0.6. If U/Co is not within an acceptable range, a warning is printed. Next, the user-defined TPA version of ELES calculates the turbine inlet Mach number and checks whether it is below the accepted maximum value of 1.7. Finally, turbine specific speed, efficiency, and horsepower is calculated. The horsepower provided is then compared with the horsepower required and if not within $3 \%$, a new turbine pressure ratio is selected and the entire process is repeated.

When a gas generator cycle is being evaluated, the user can also input values for GG bleed efficiency, turbine/GG inlet temperature and pressure, Isp of GG bleed, and turbine and bleed nozzle flowrates. 



\section{APPENDIX C}

\section{ENGINE SYSTEM DESIGN SENSITIVITY TRADE RESULTS}

C-1 



\section{APPENDIX C ENGINE SYSTEM DESIGN SENSITIVITY TRADE RESULTS}

A detailed summary of engine system design sensitivity trade results are presented in this appendix. Numerous trades are presented for both expander and gas generator cycle engine systems using $\mathrm{LOX} / \mathrm{H}_{2}, \mathrm{LOX} / \mathrm{CO}$ and $\mathrm{LOX} / \mathrm{CH}_{4}$ propellant combinations. It is based on the assessment of this data presented herein that optimum or near-optimum engine system design operation conditions and features were identified. These are discussed in Section 4.2.2. 



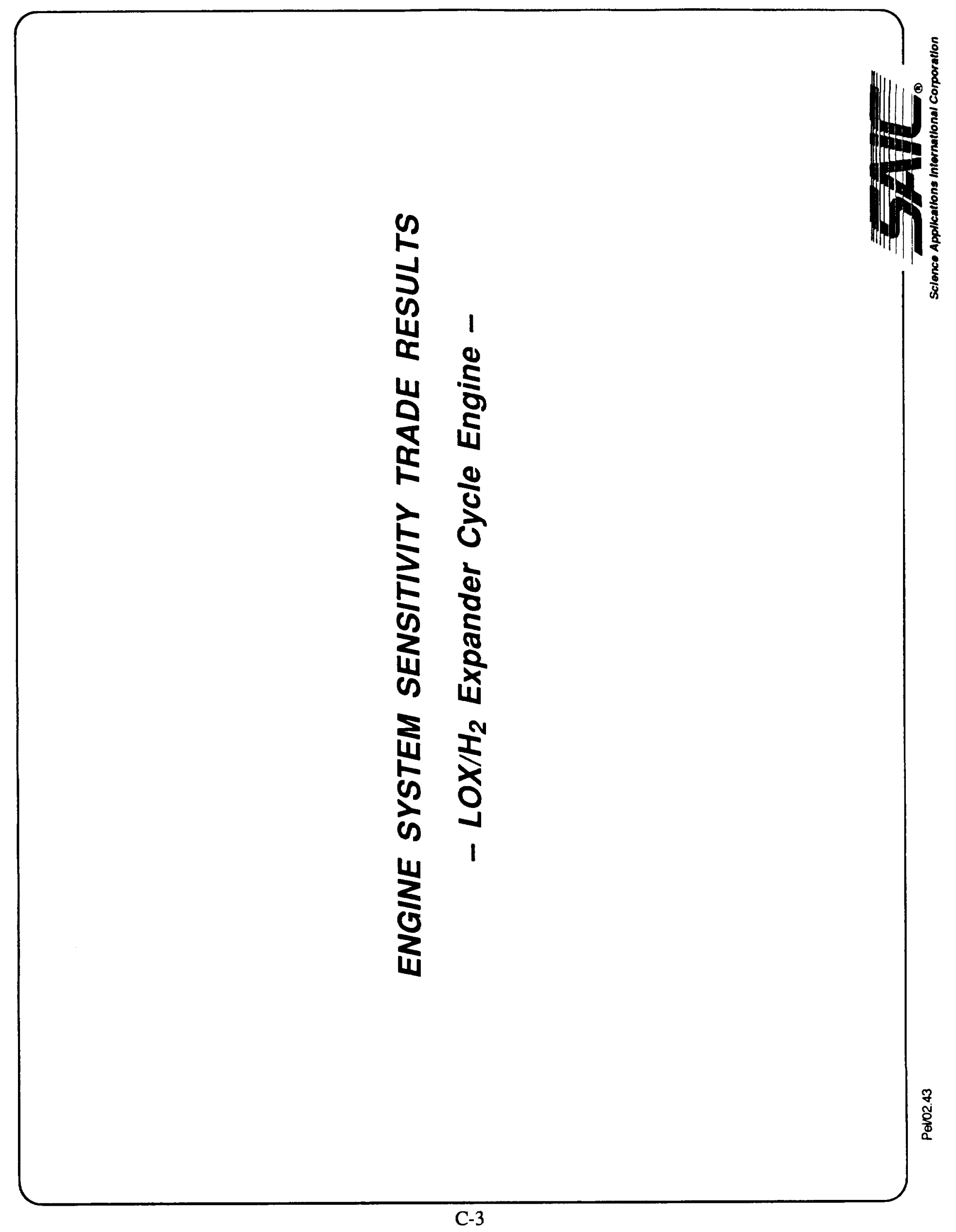





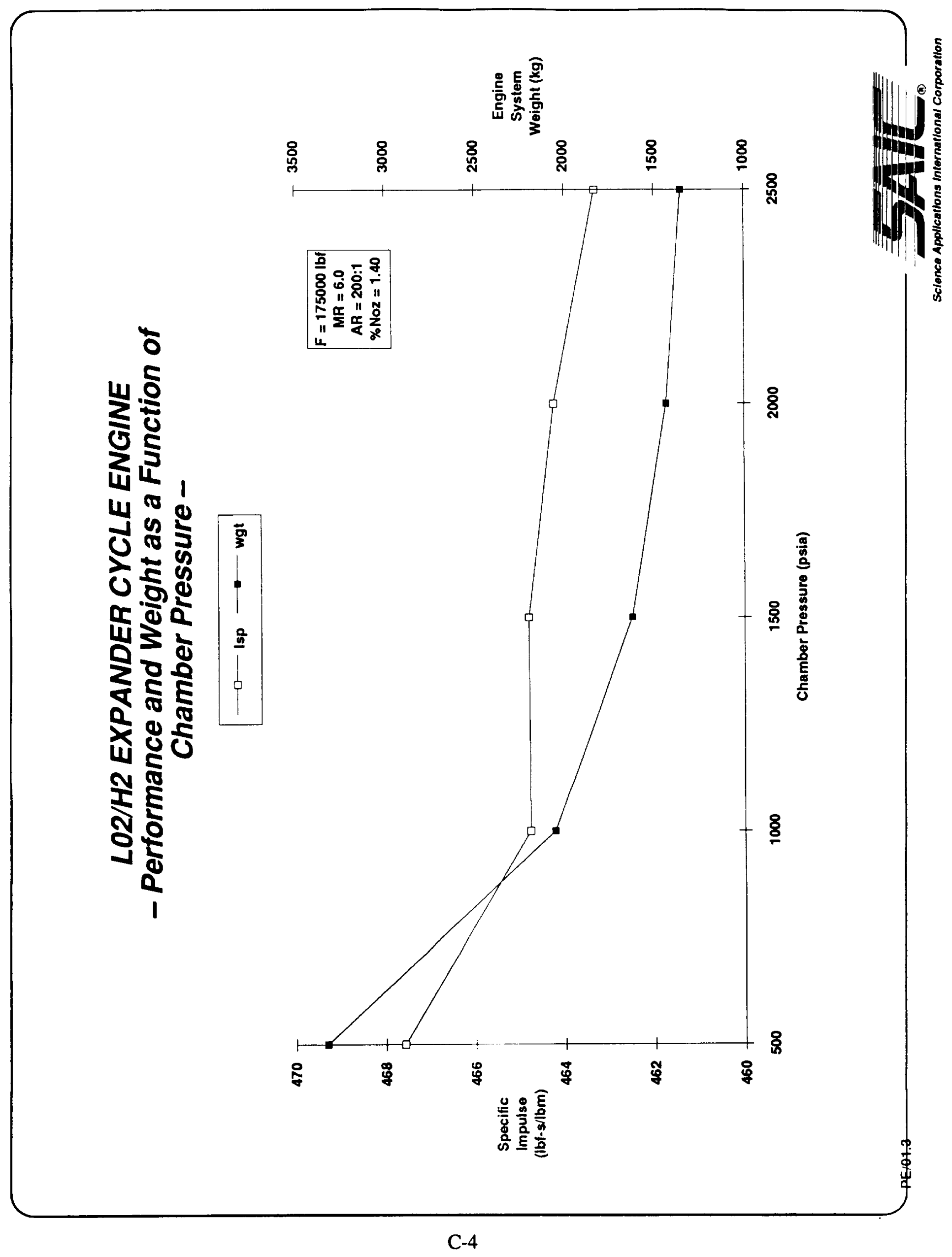





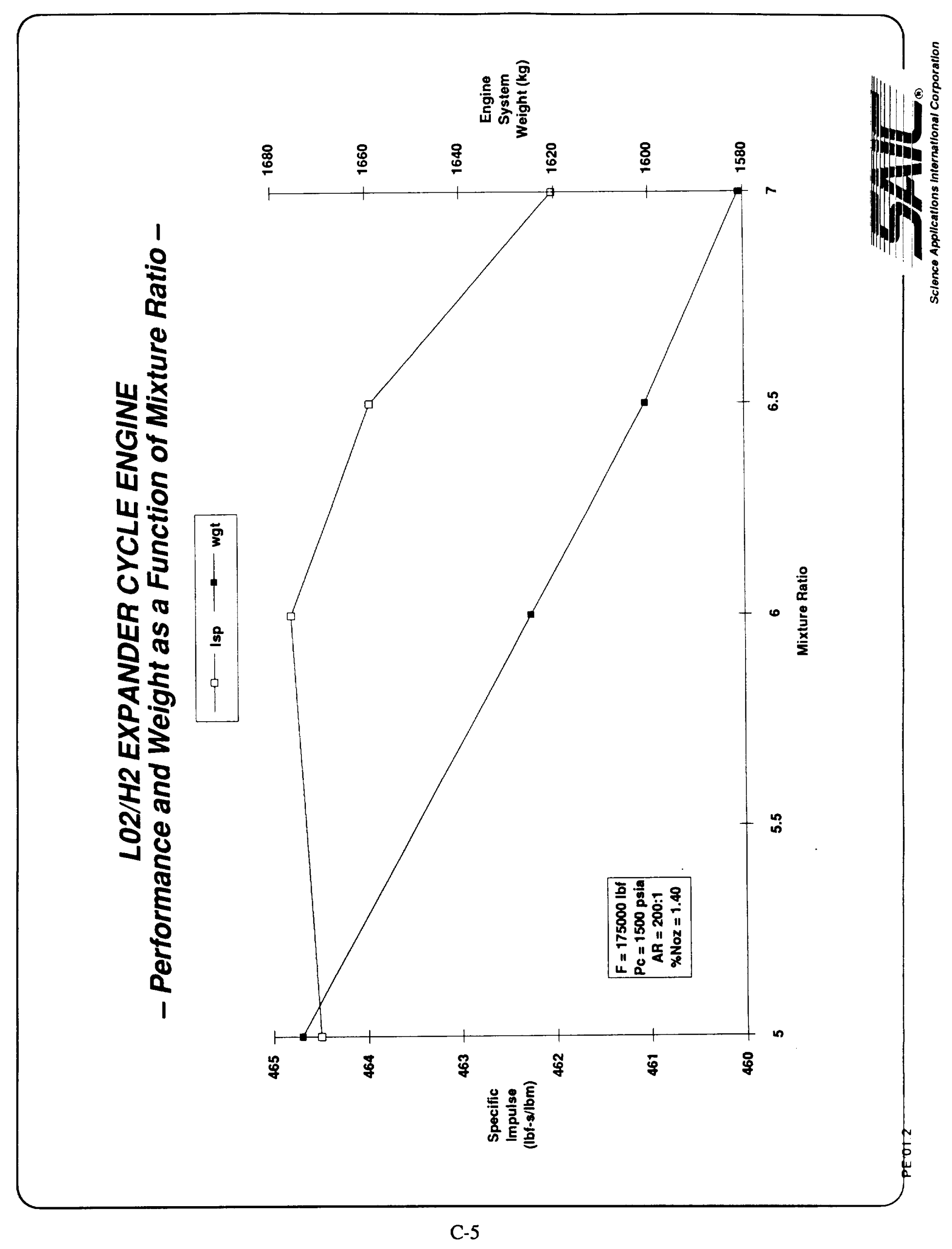





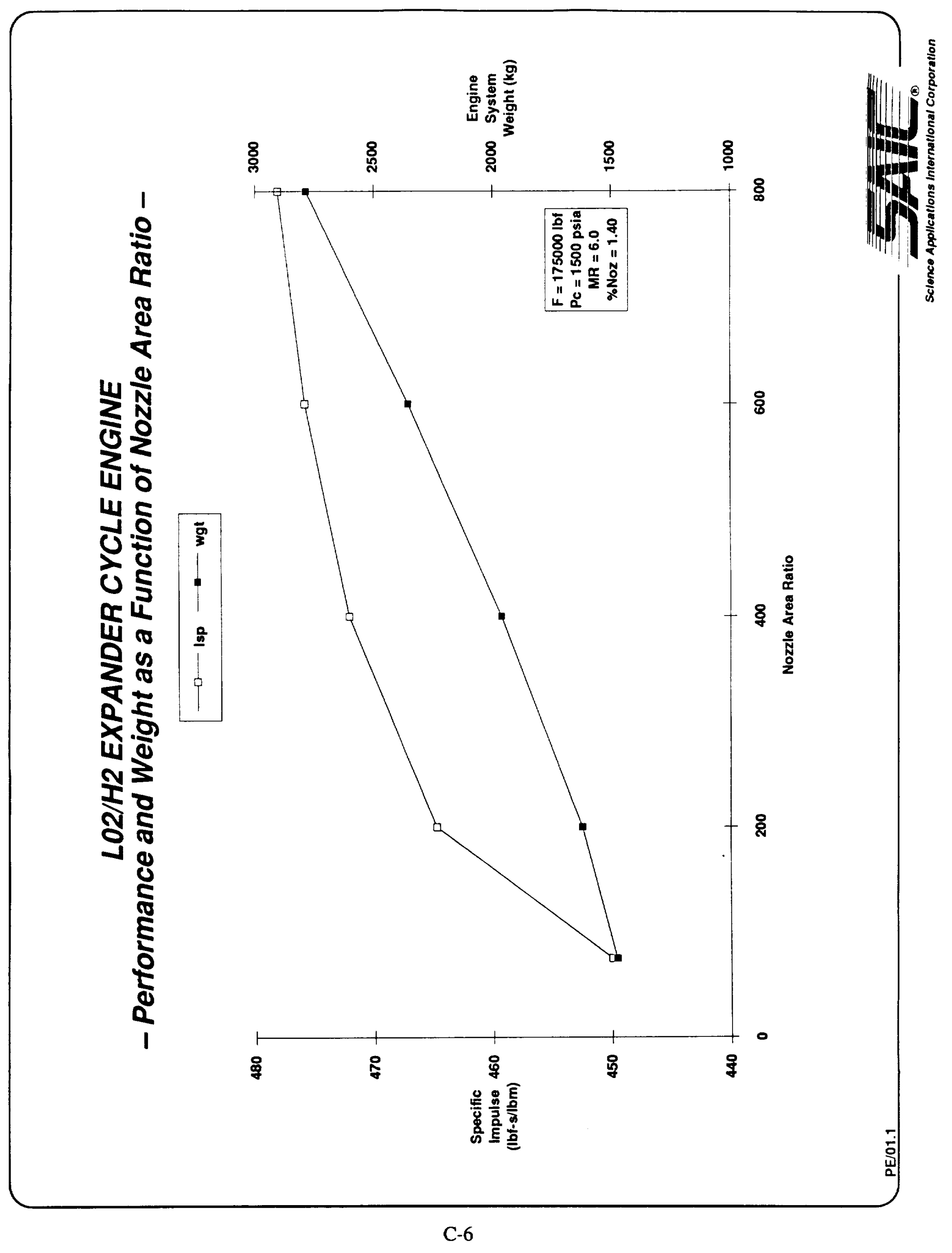





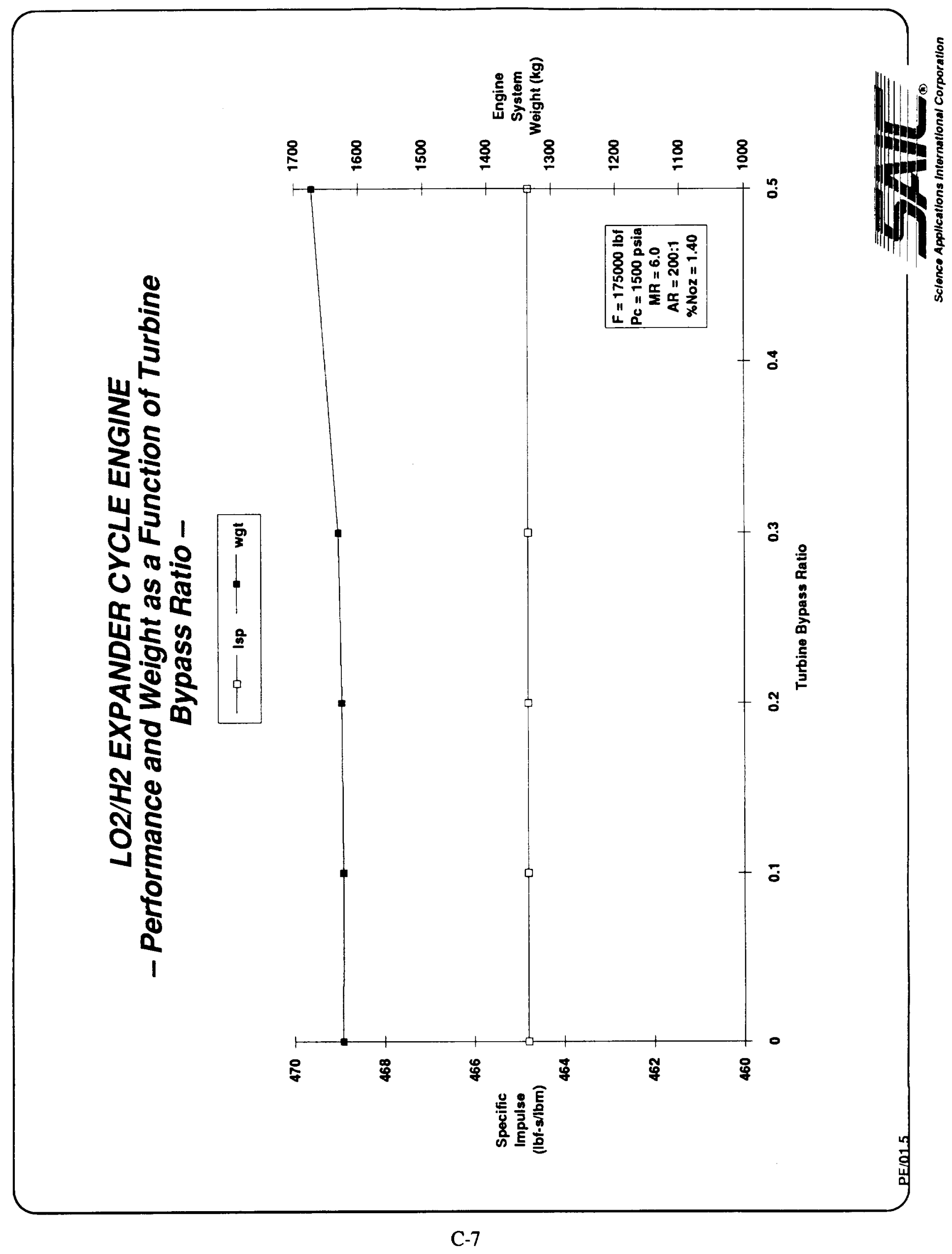





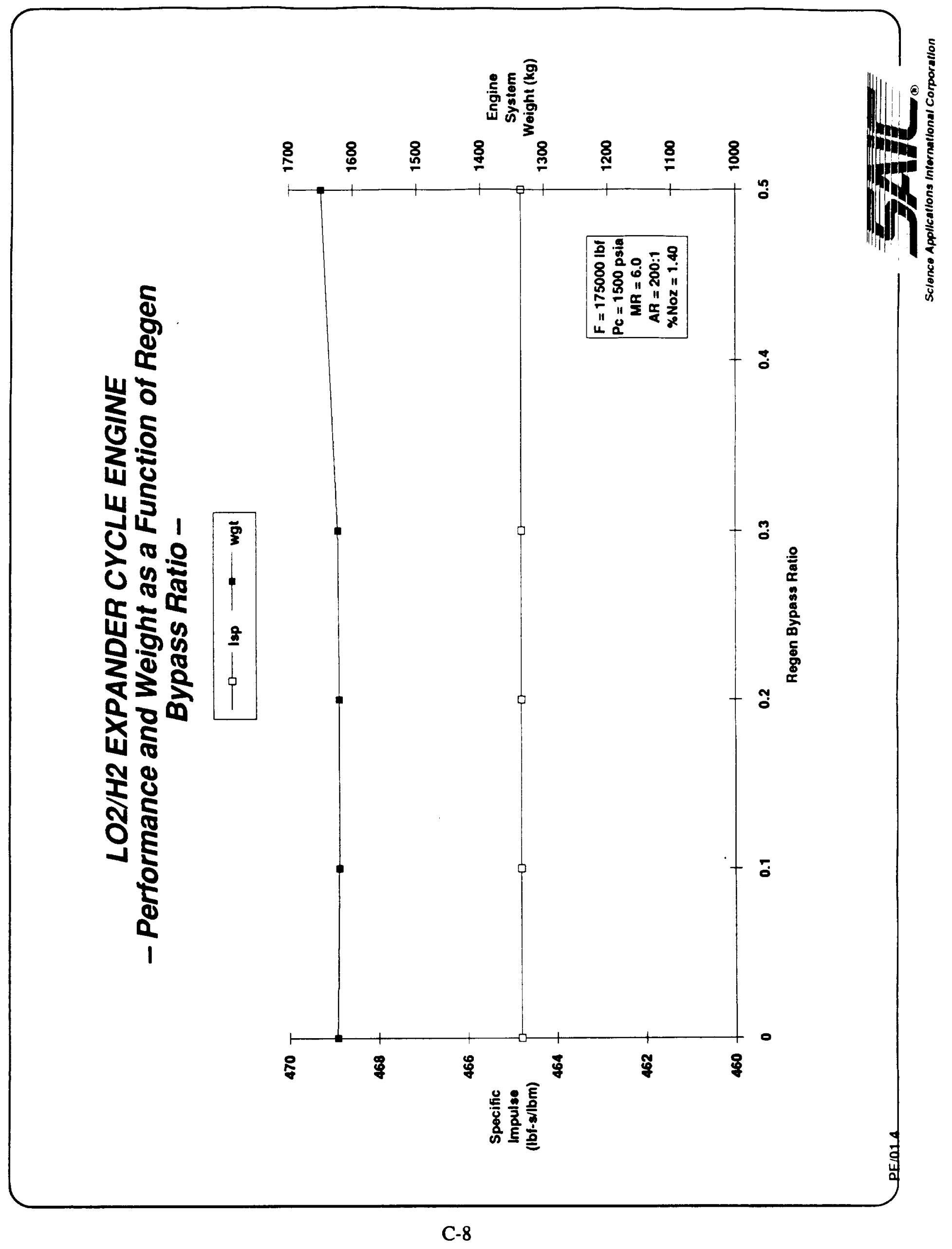




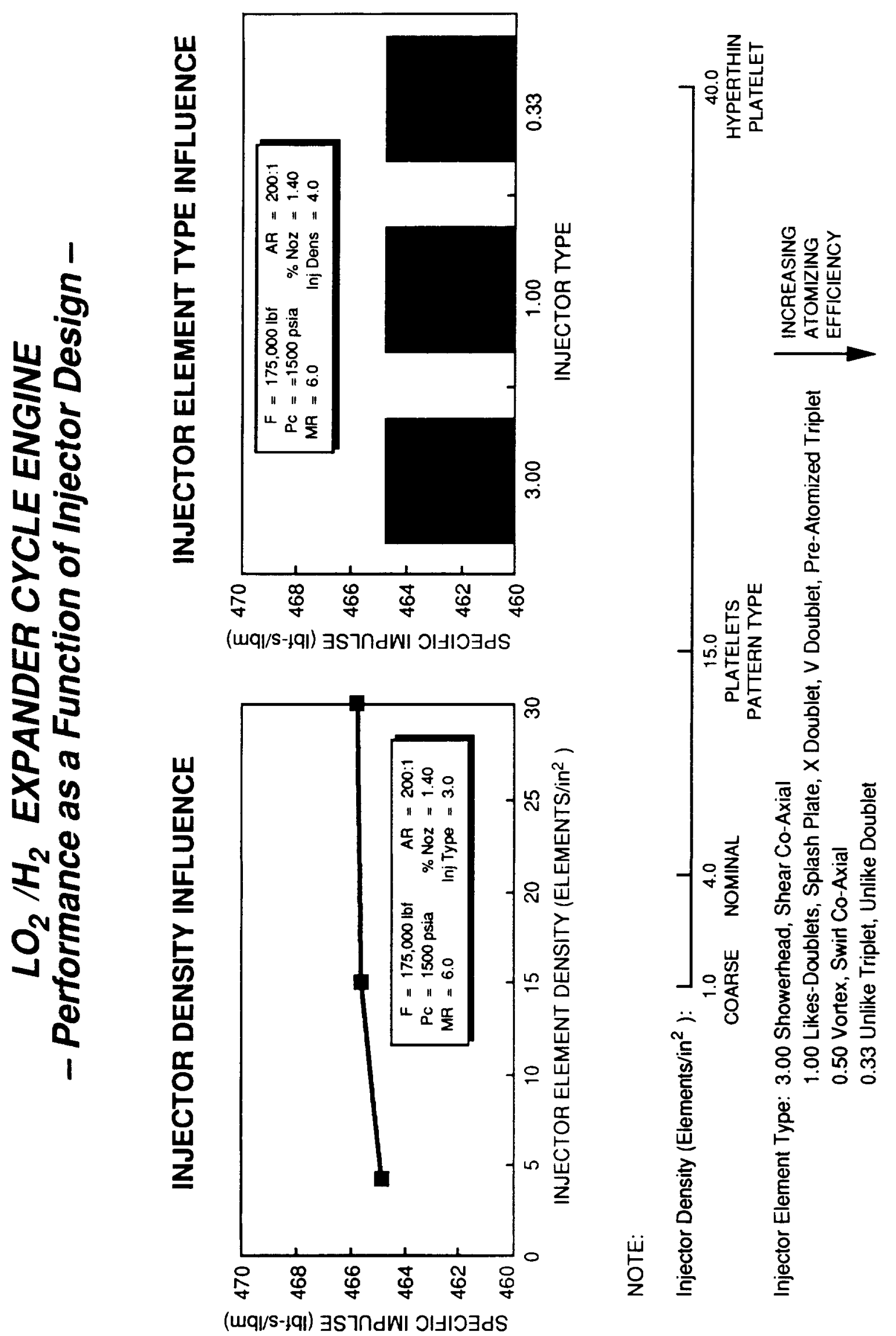



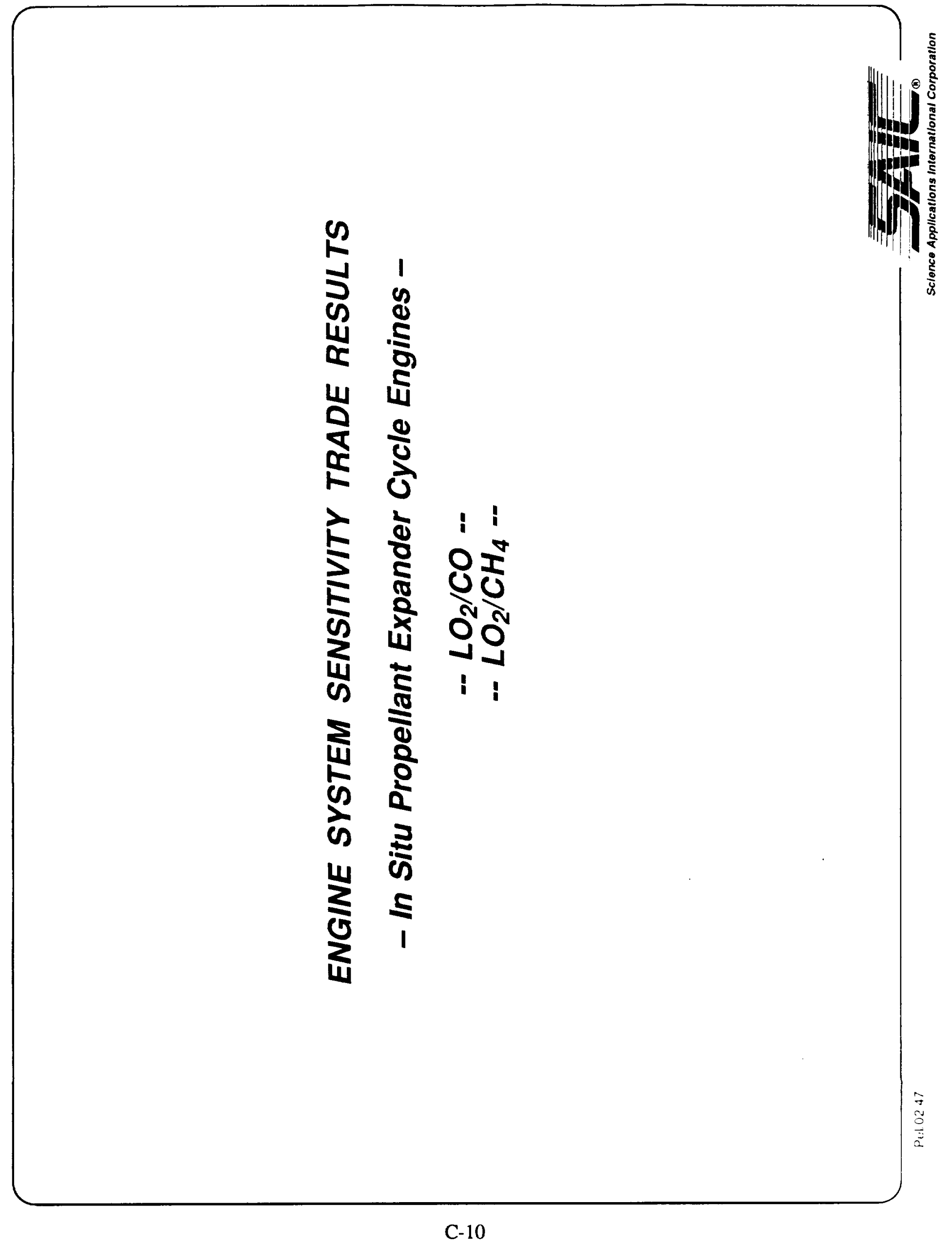





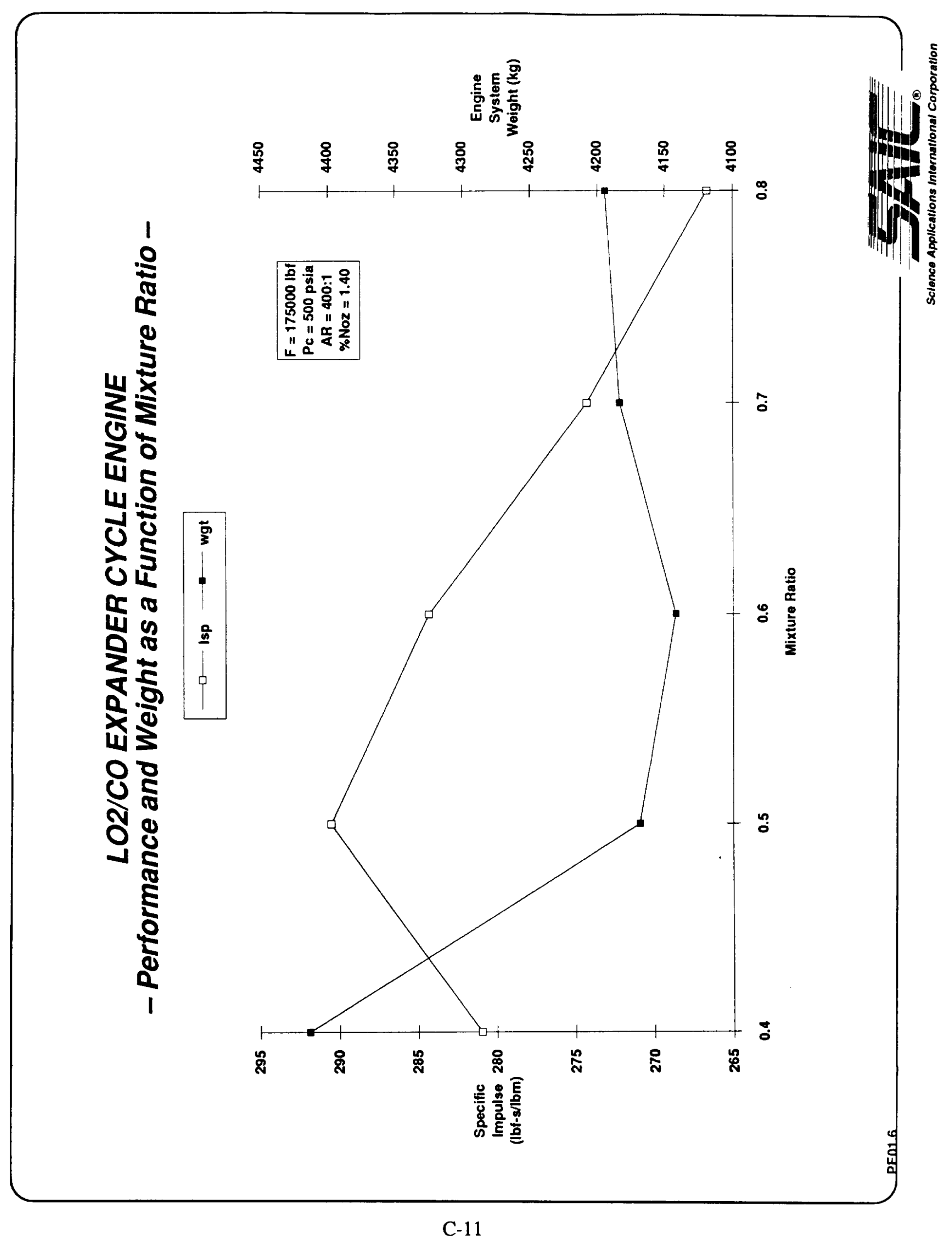





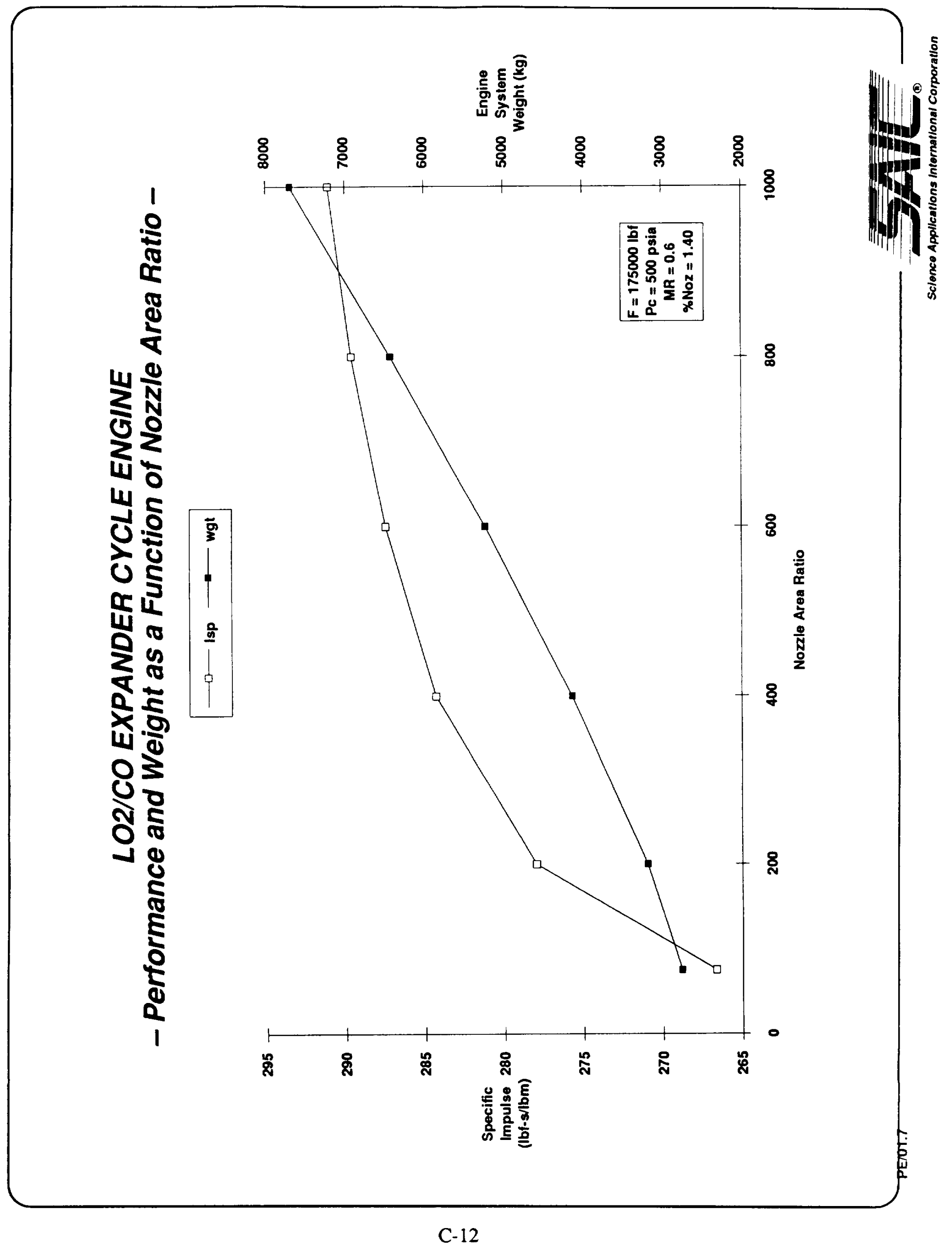




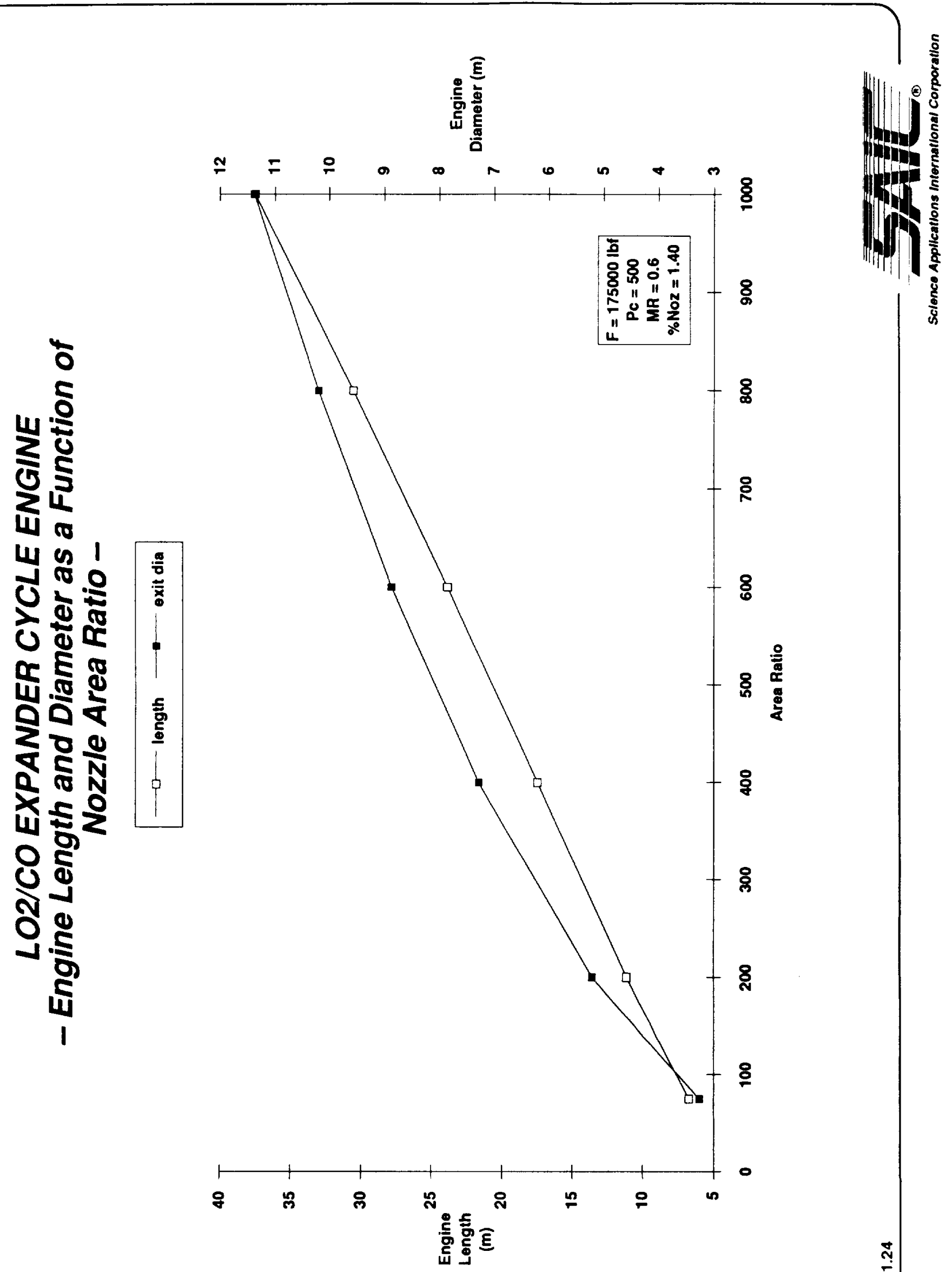


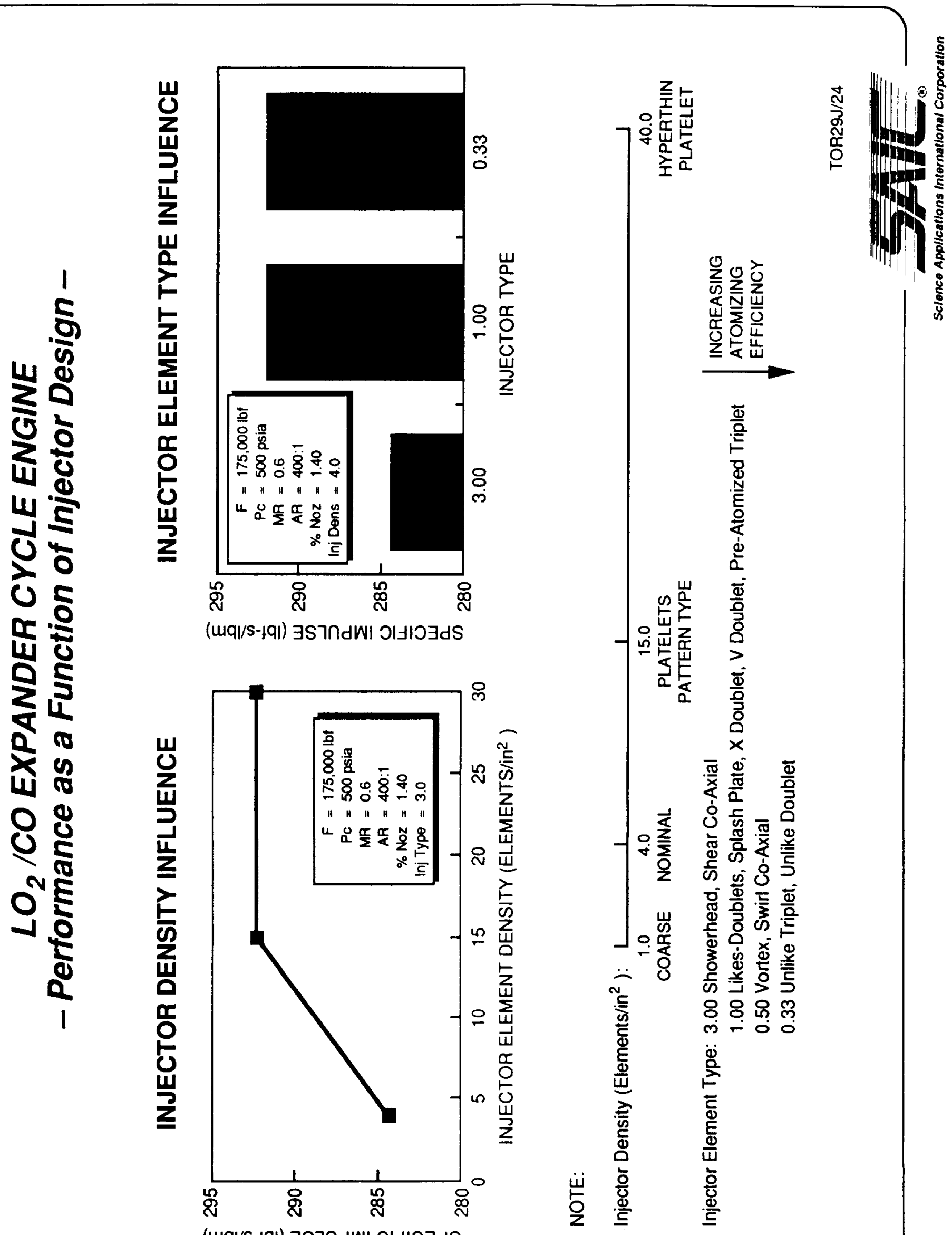

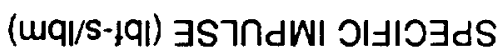





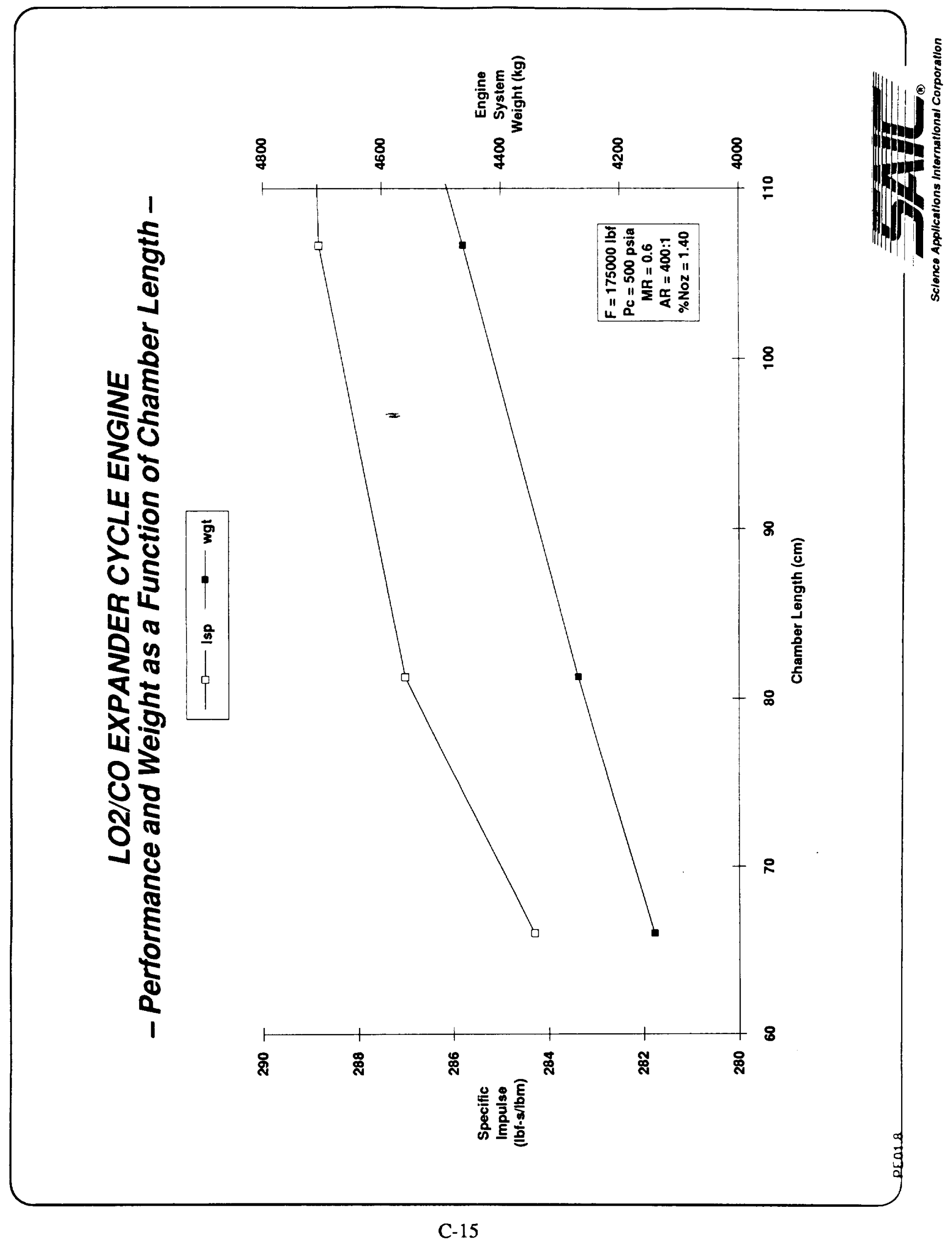





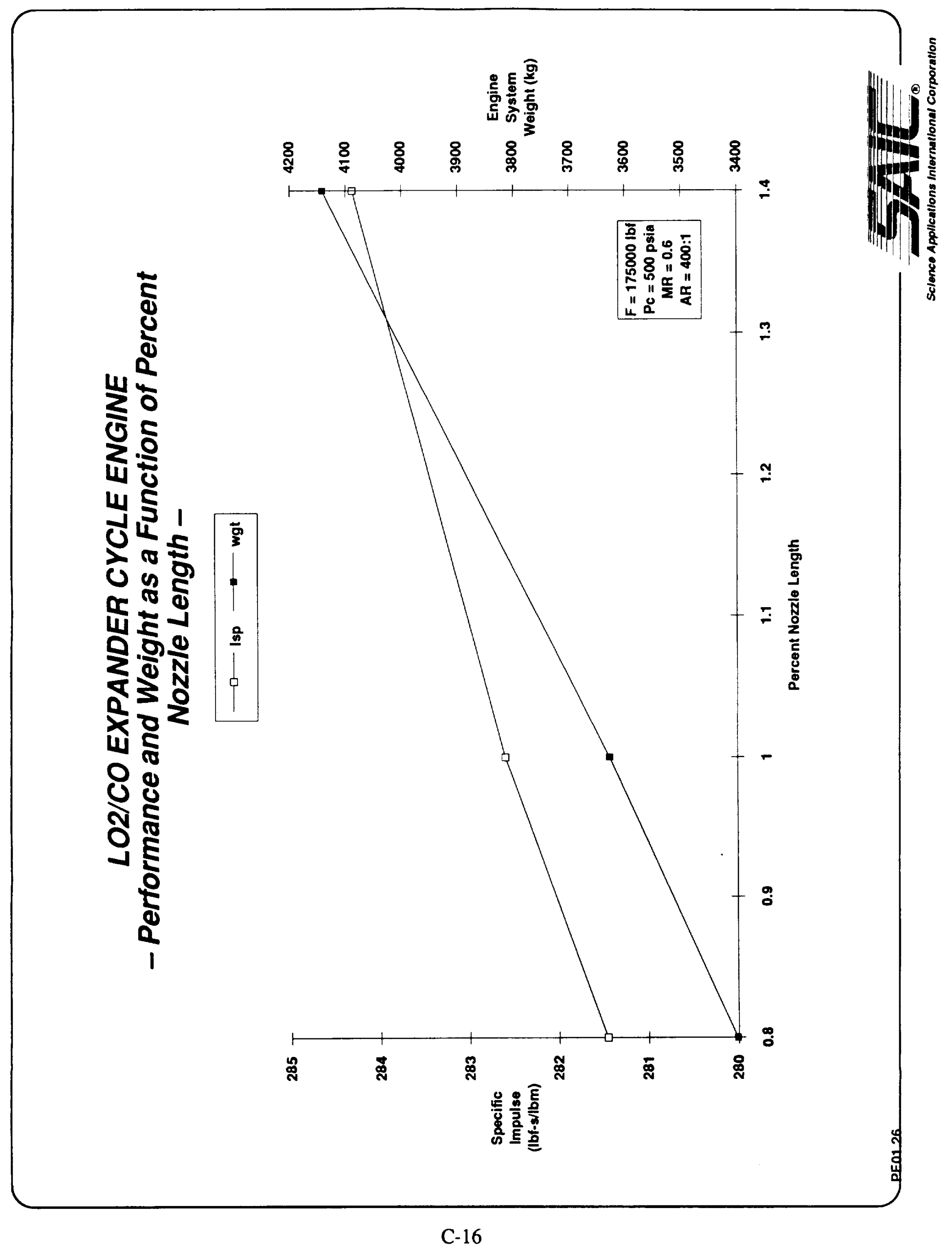





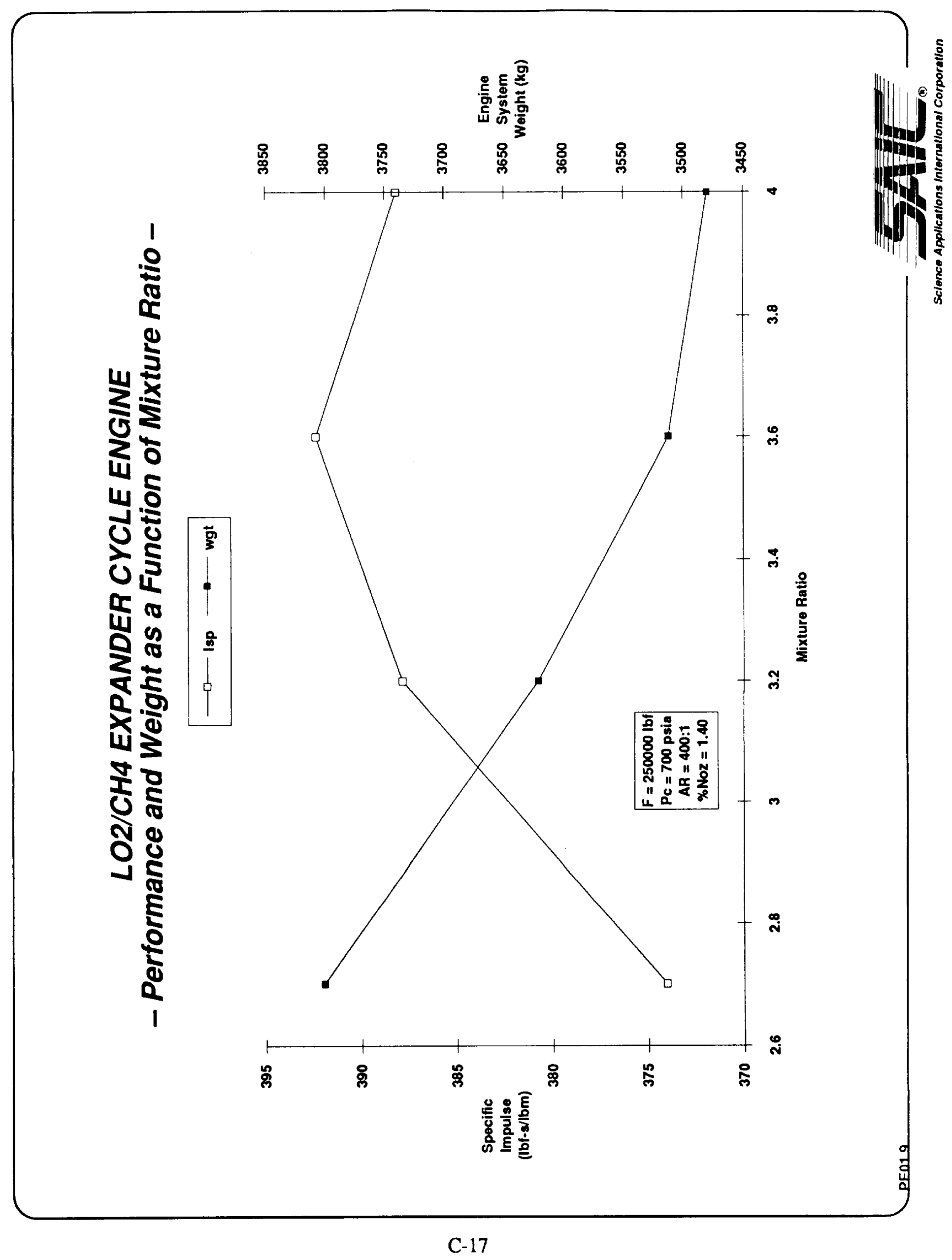





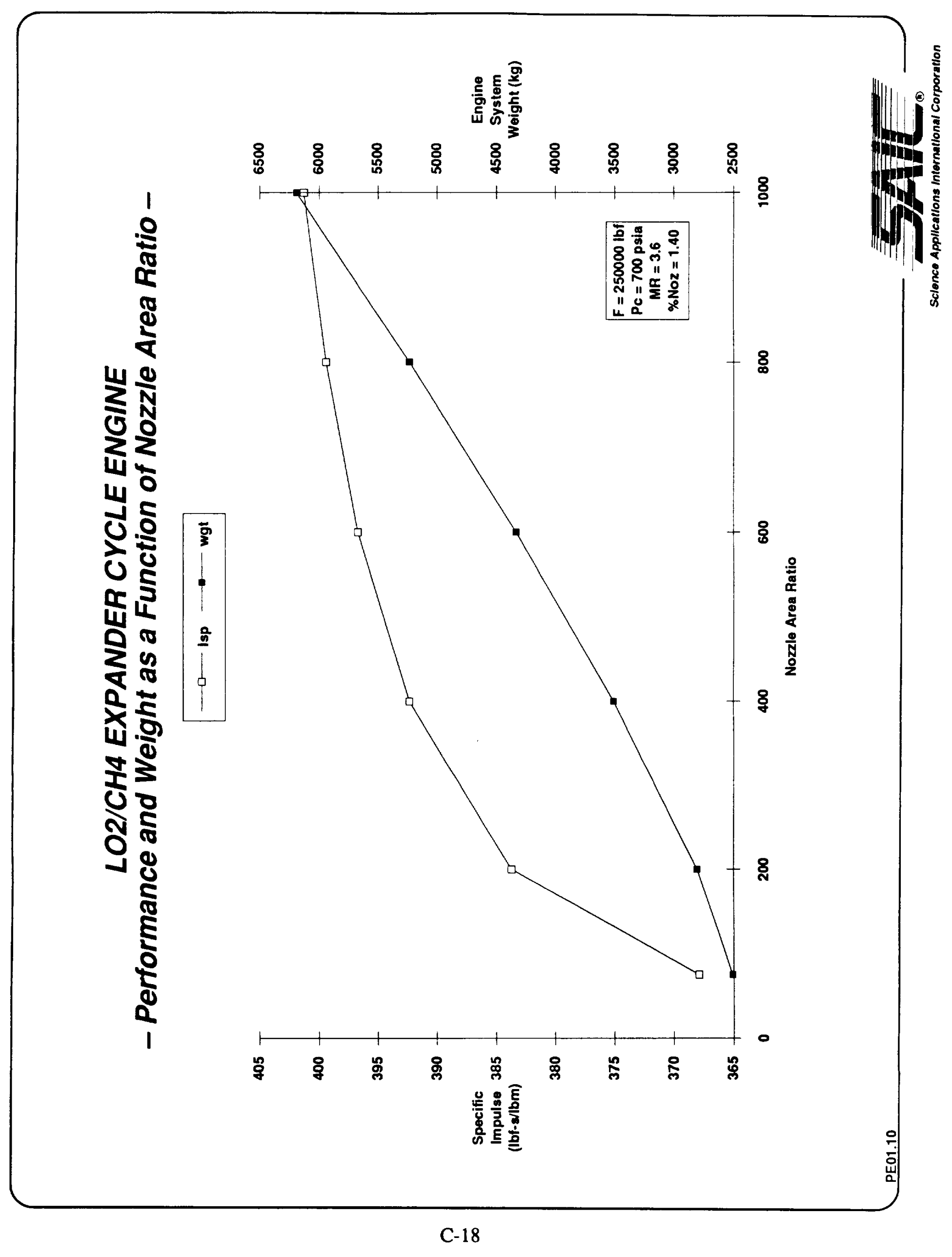





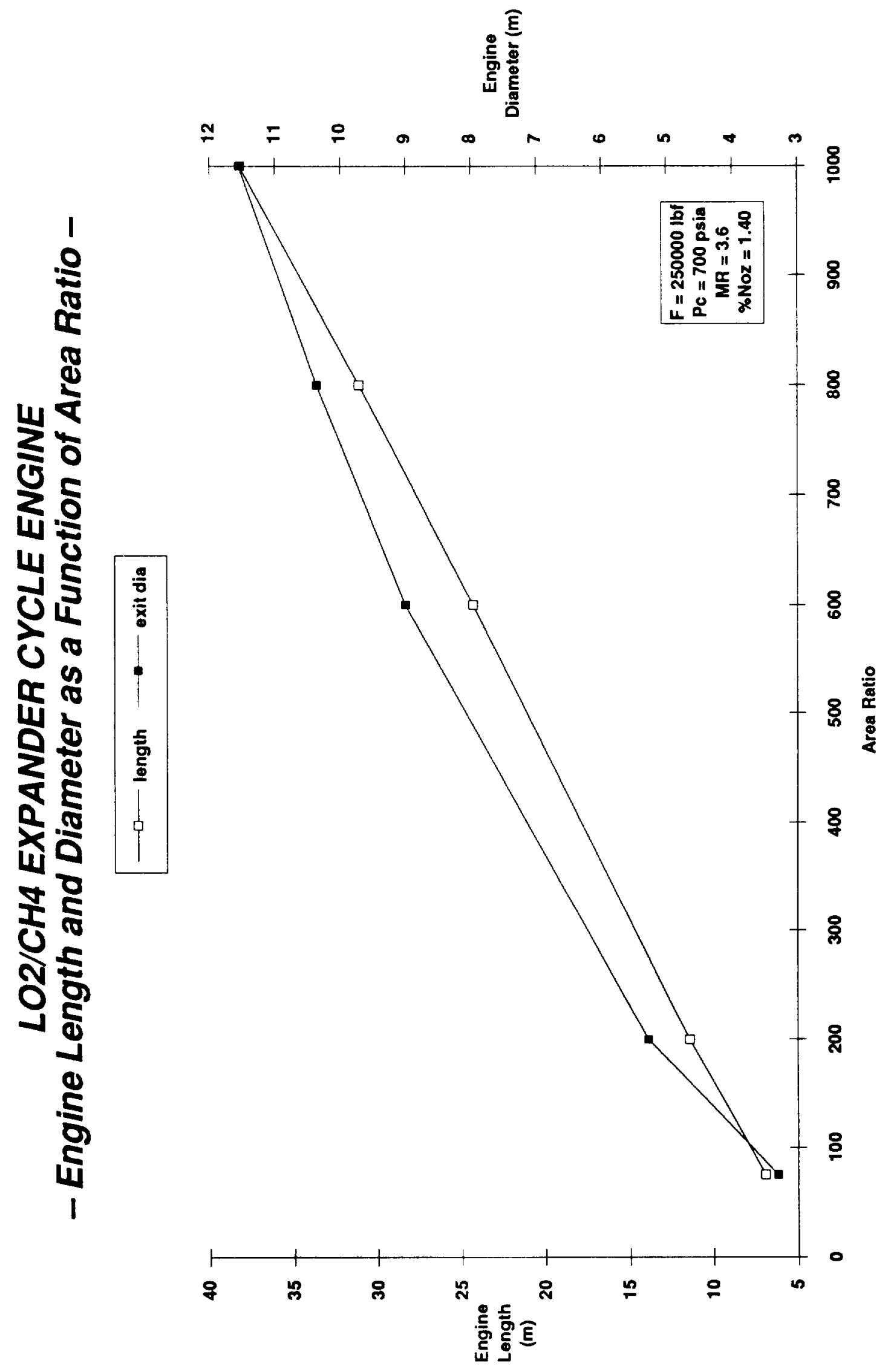

C-19 


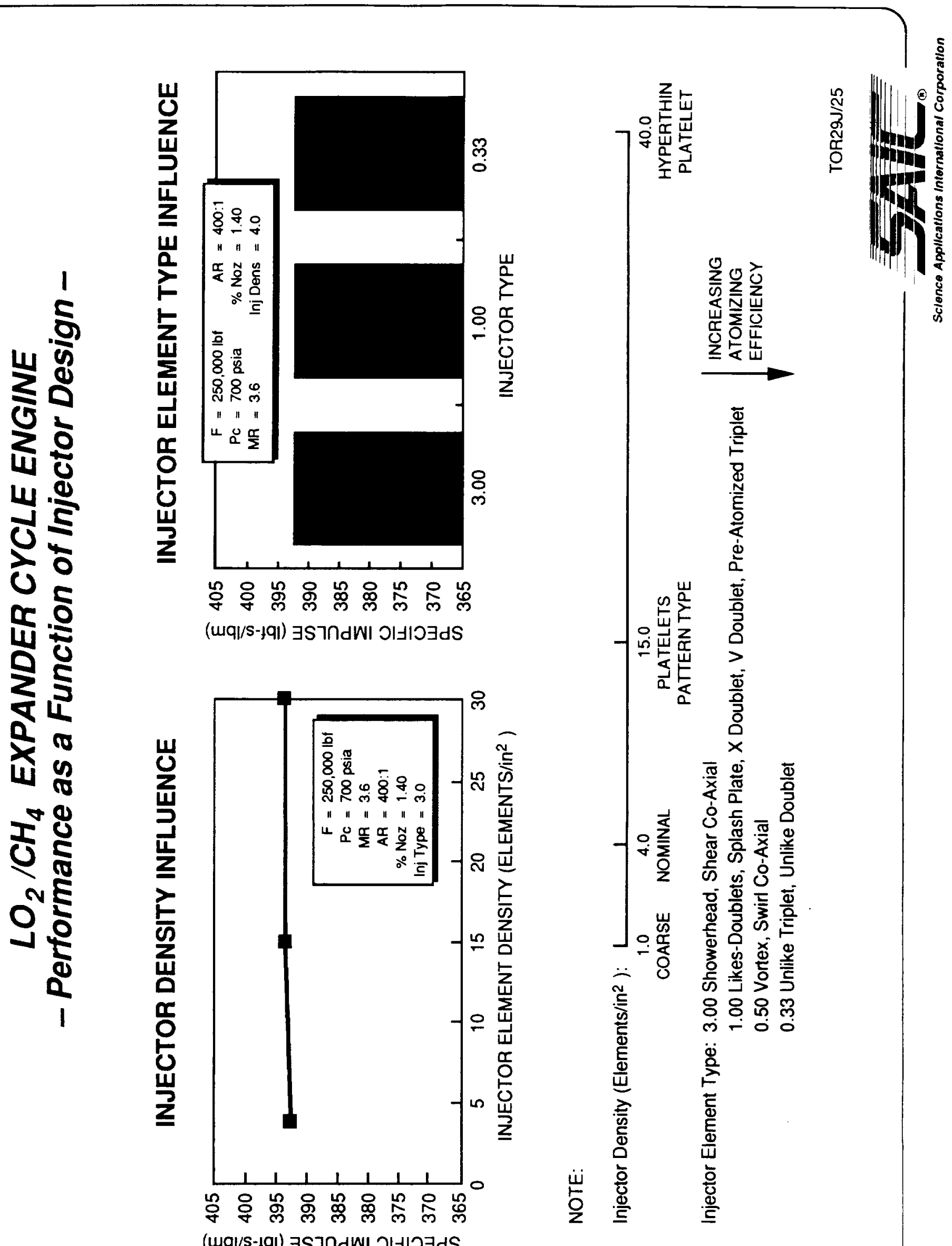

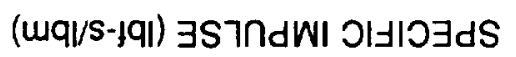





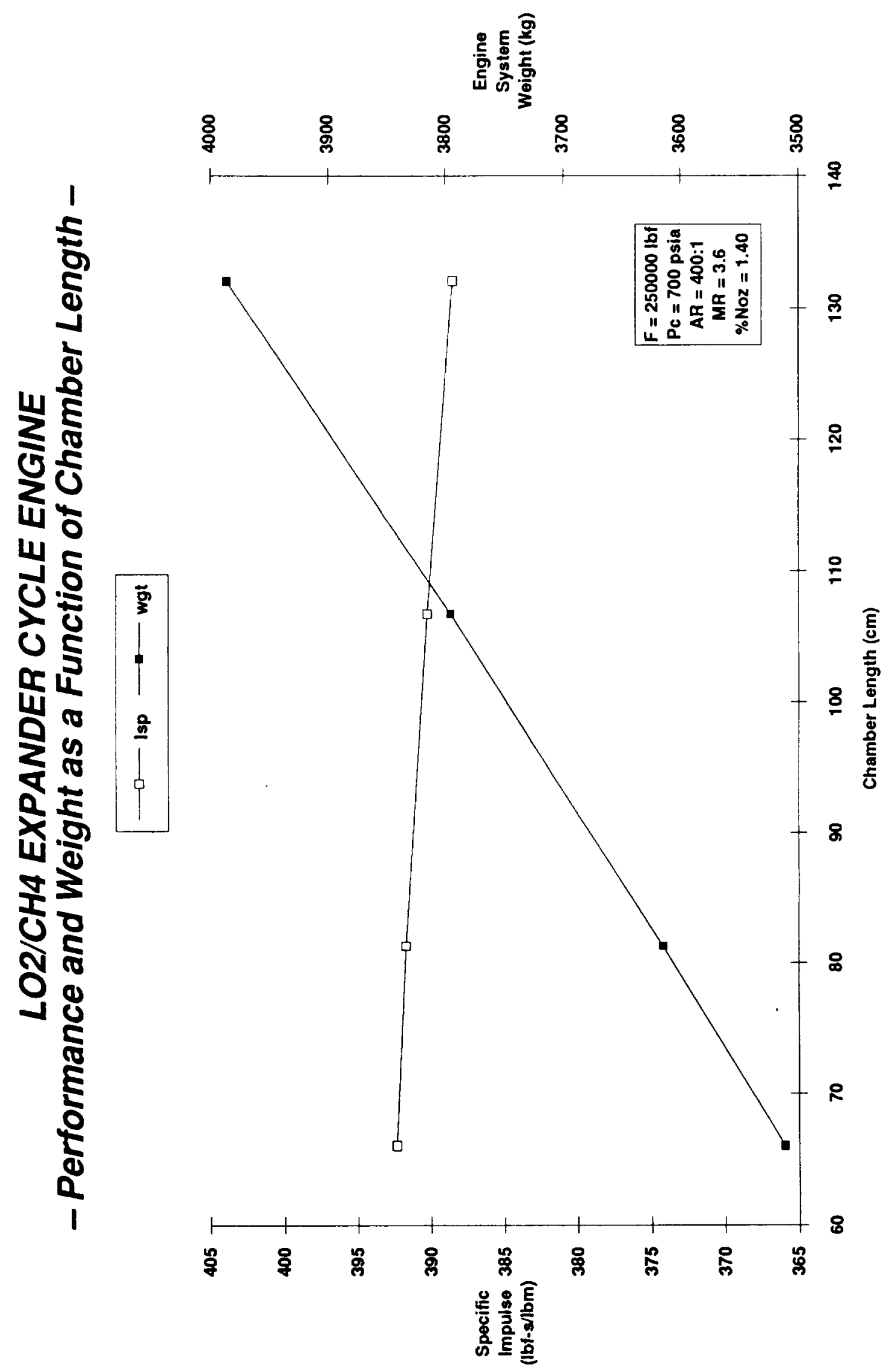





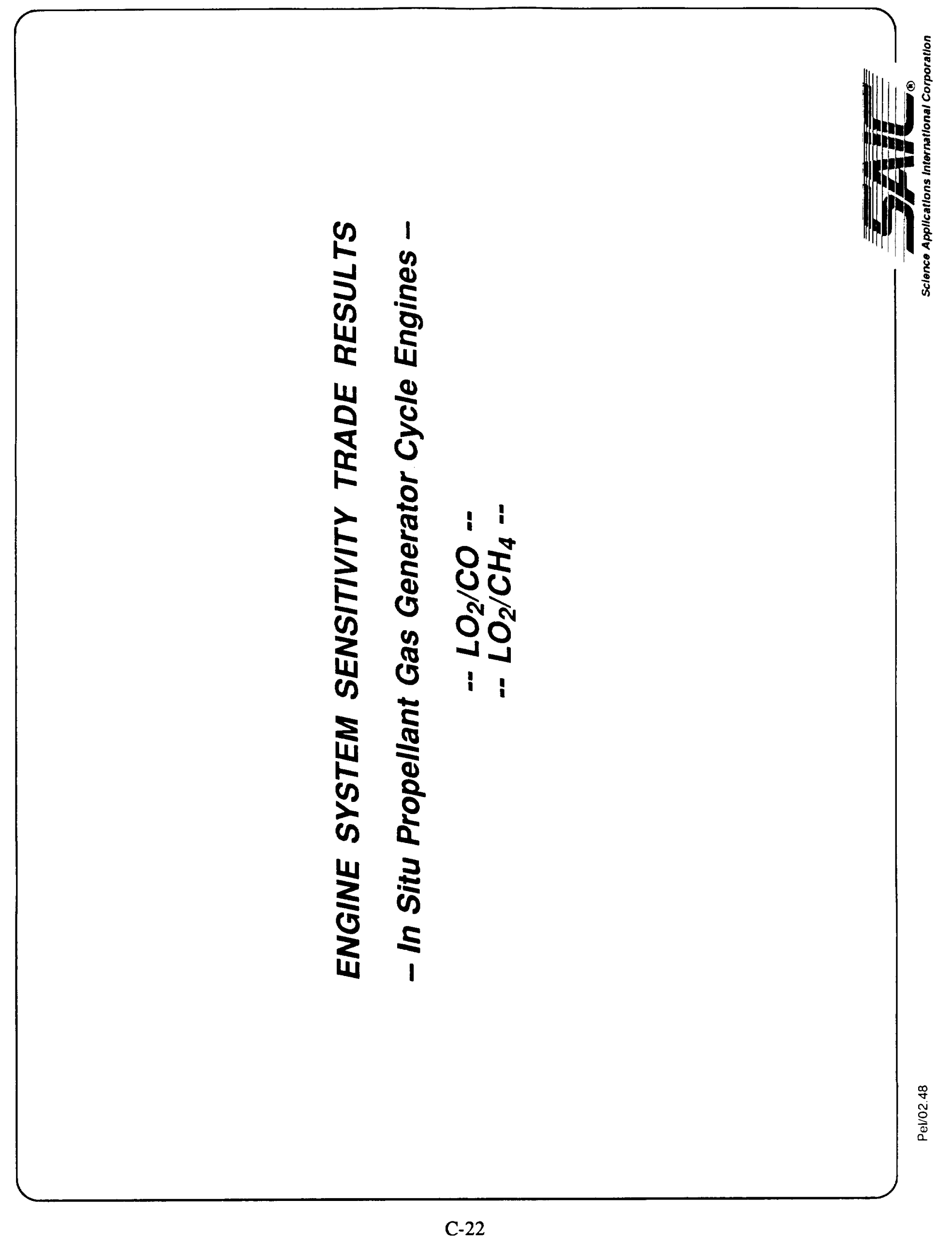





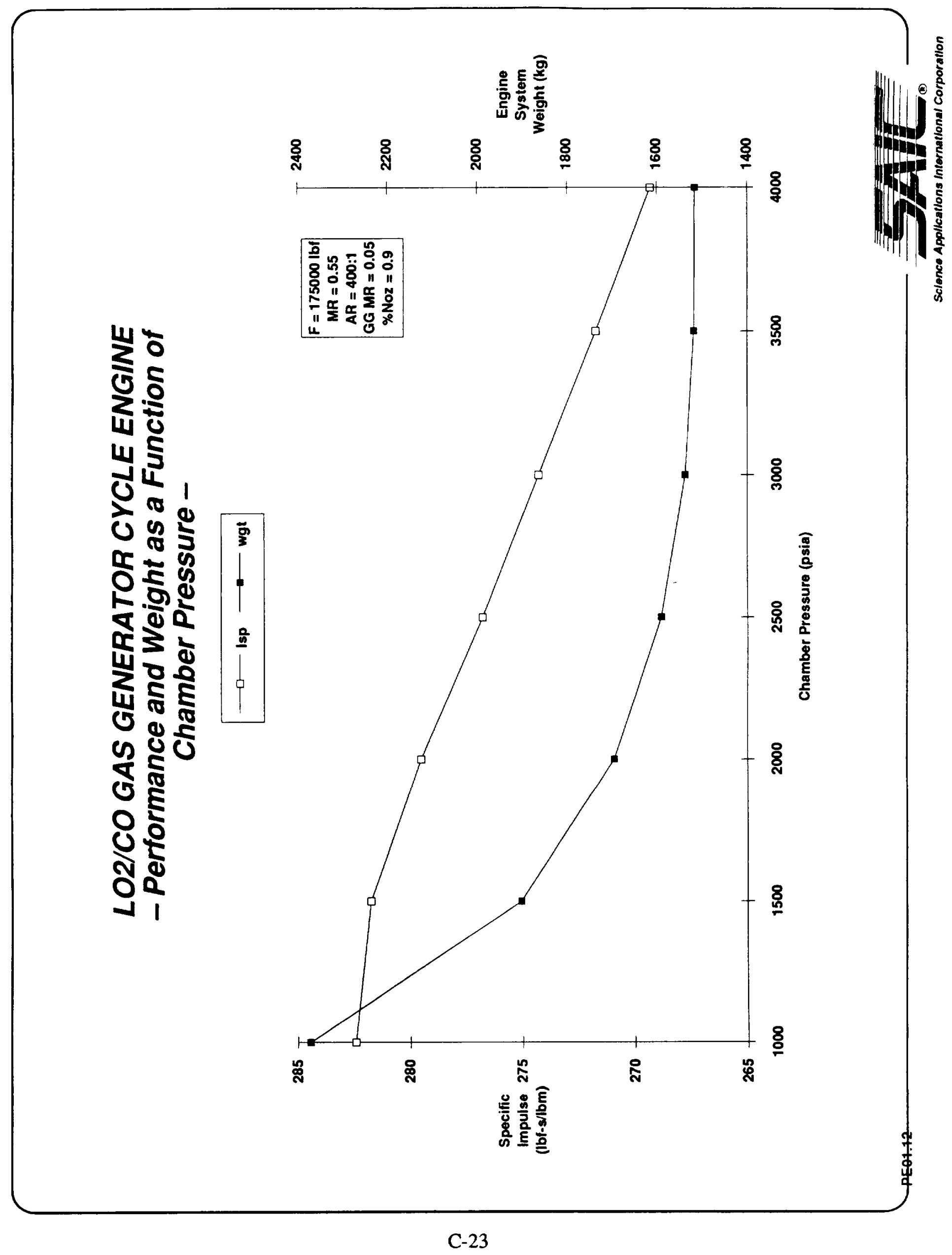





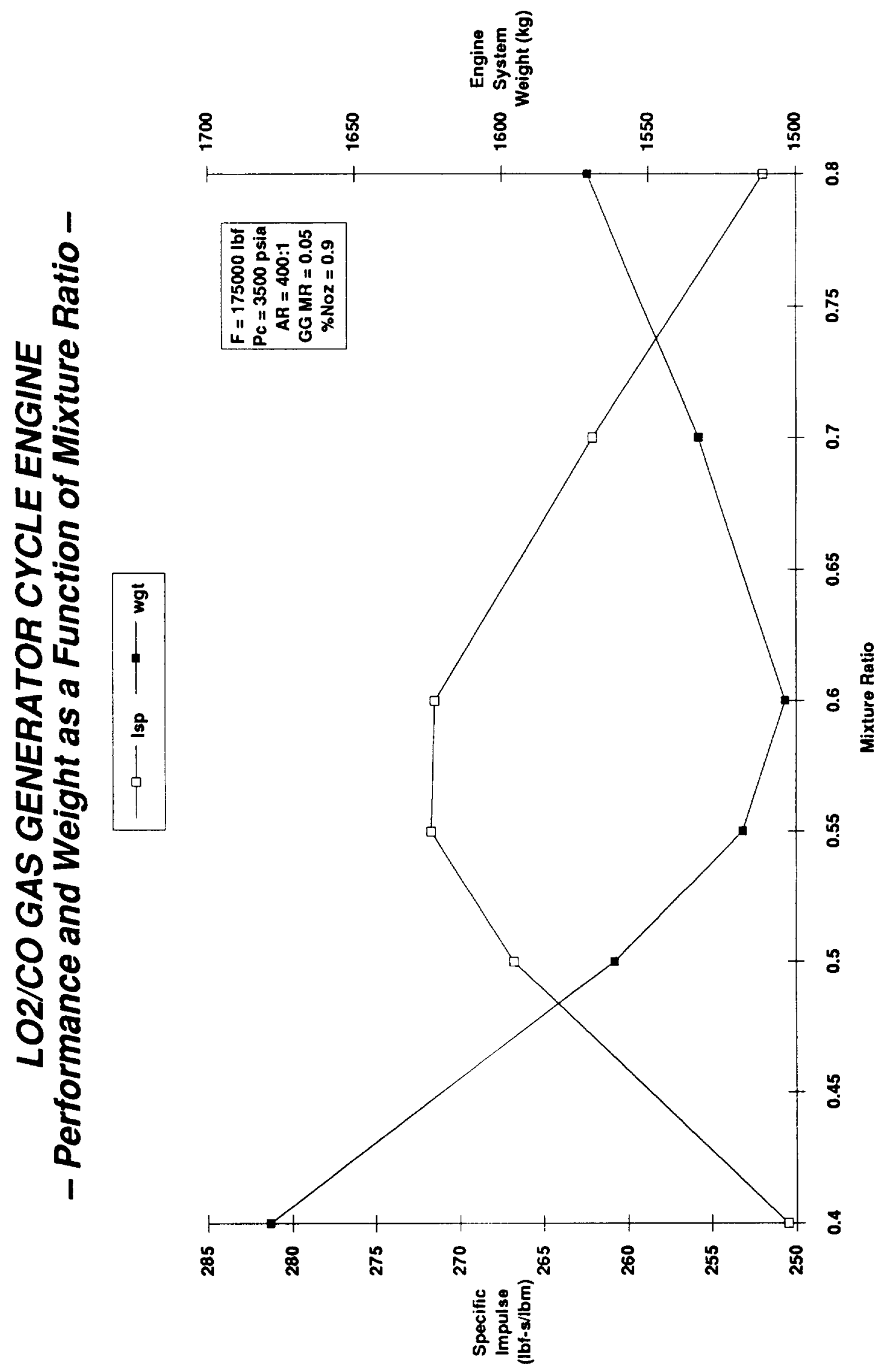

C-24 



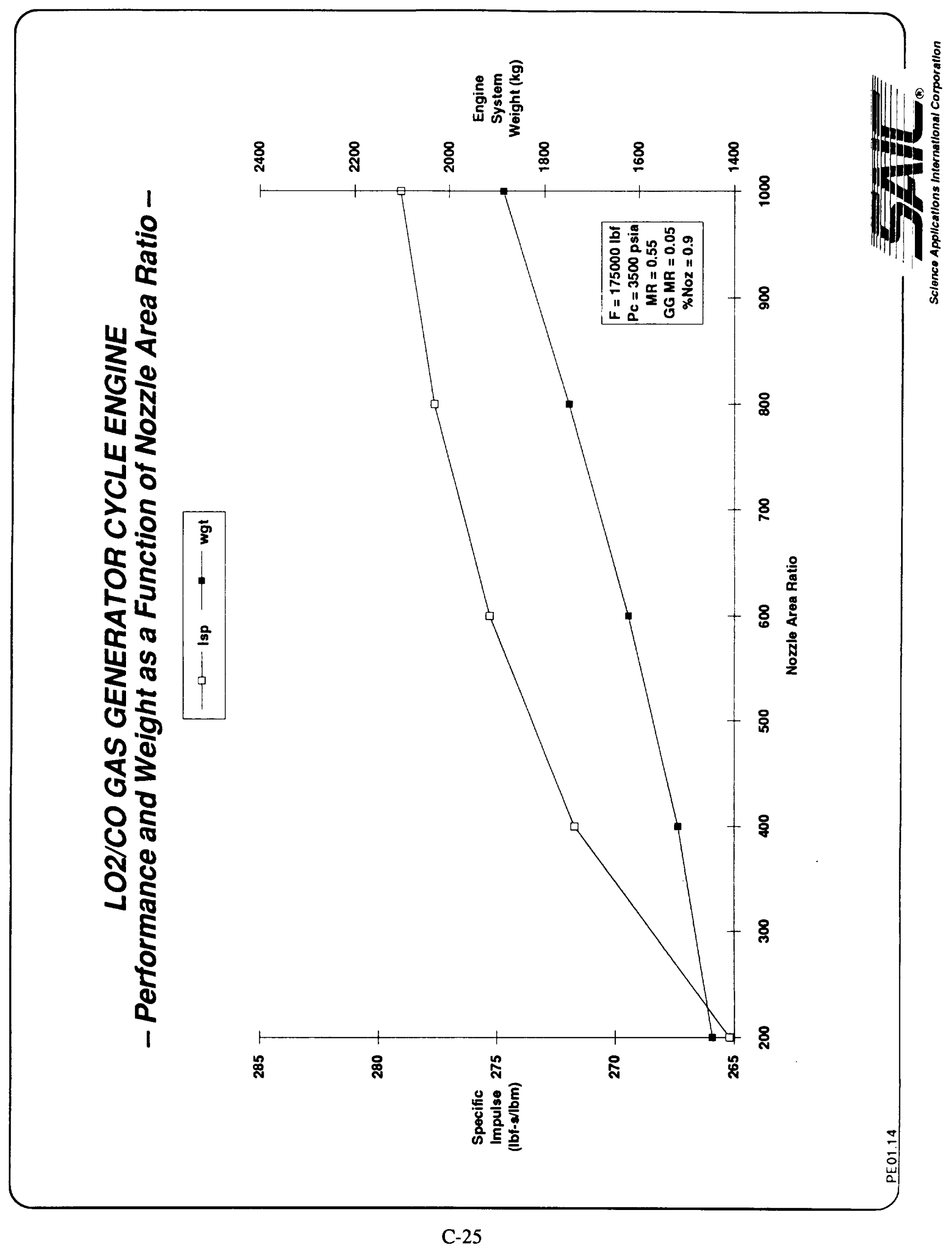





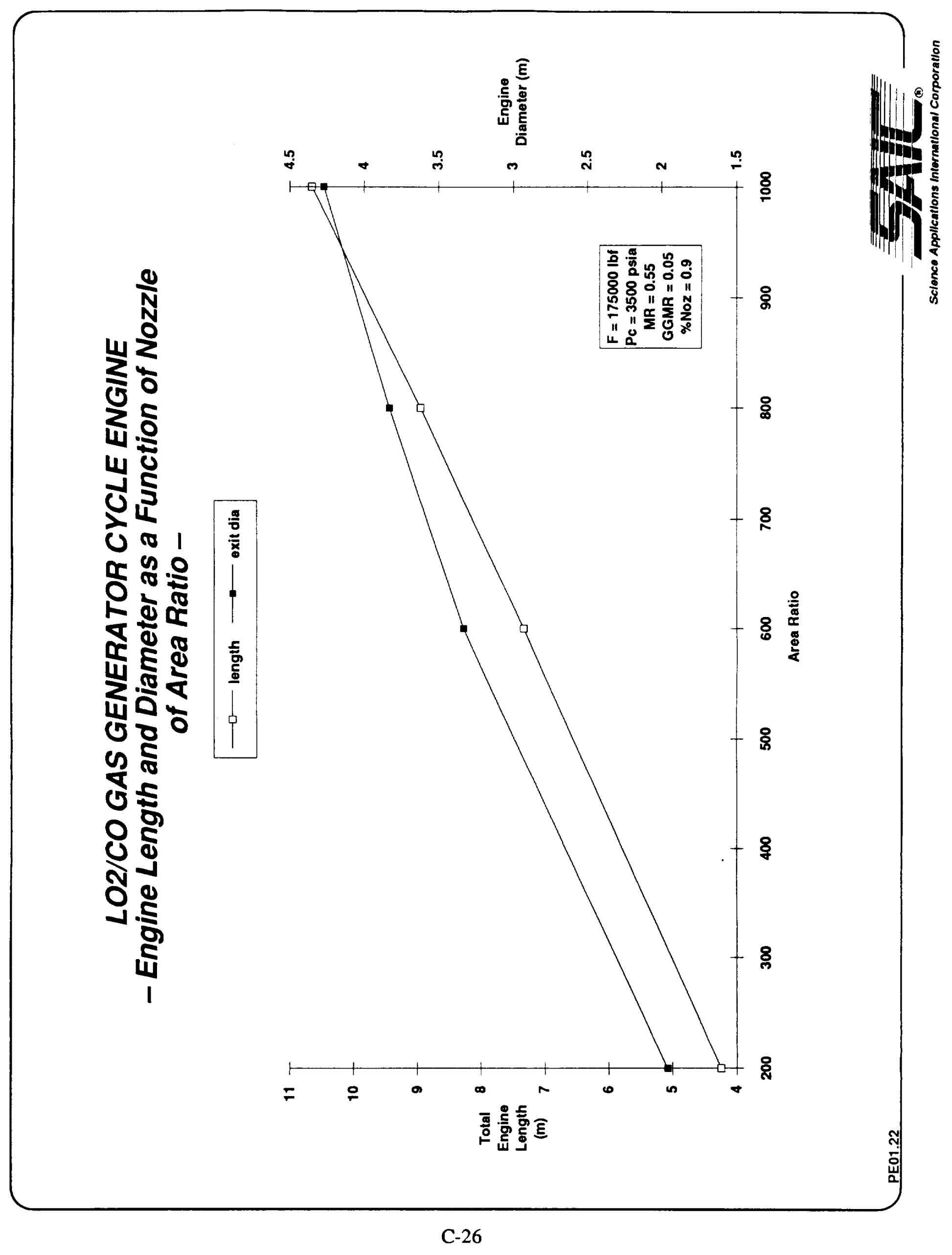





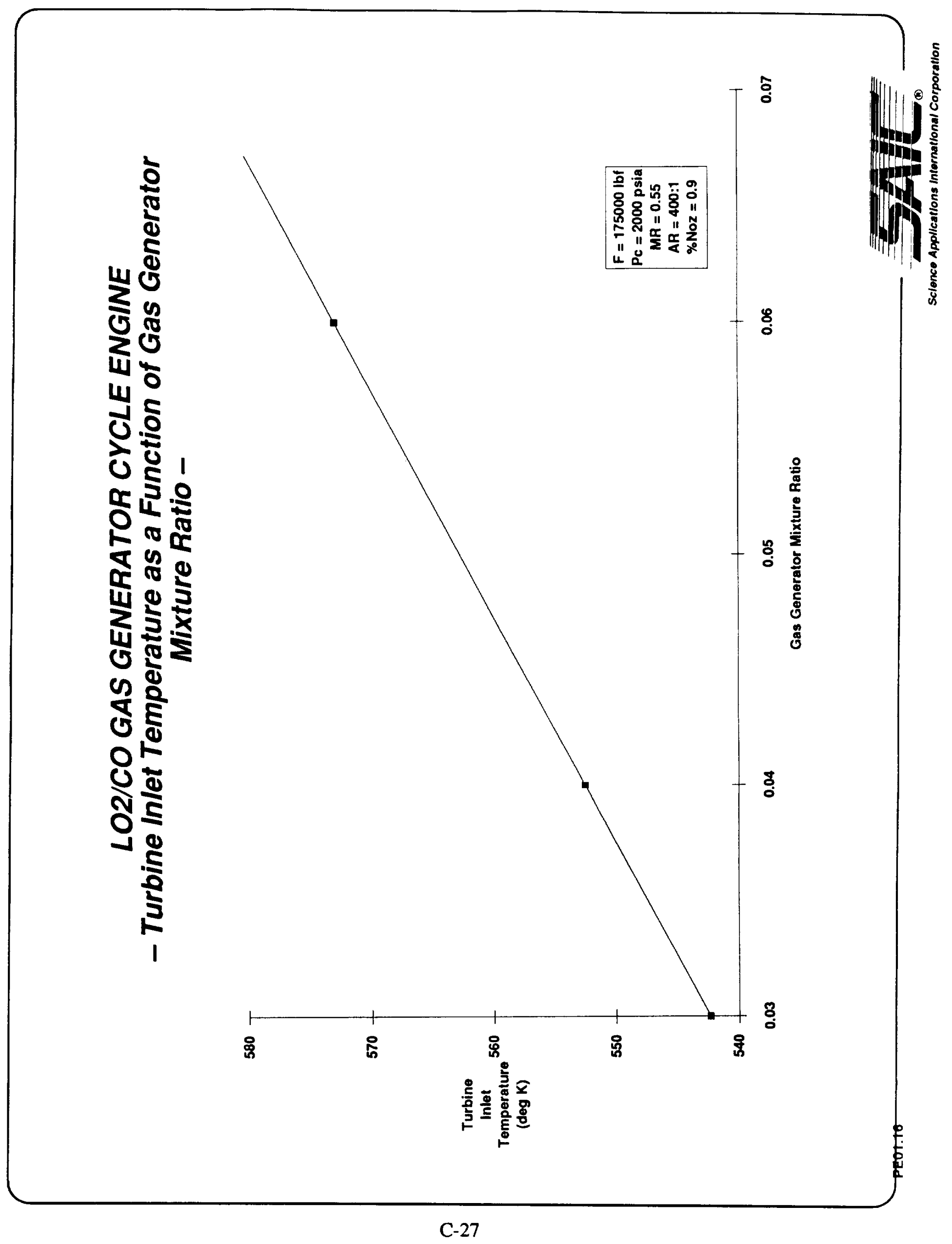





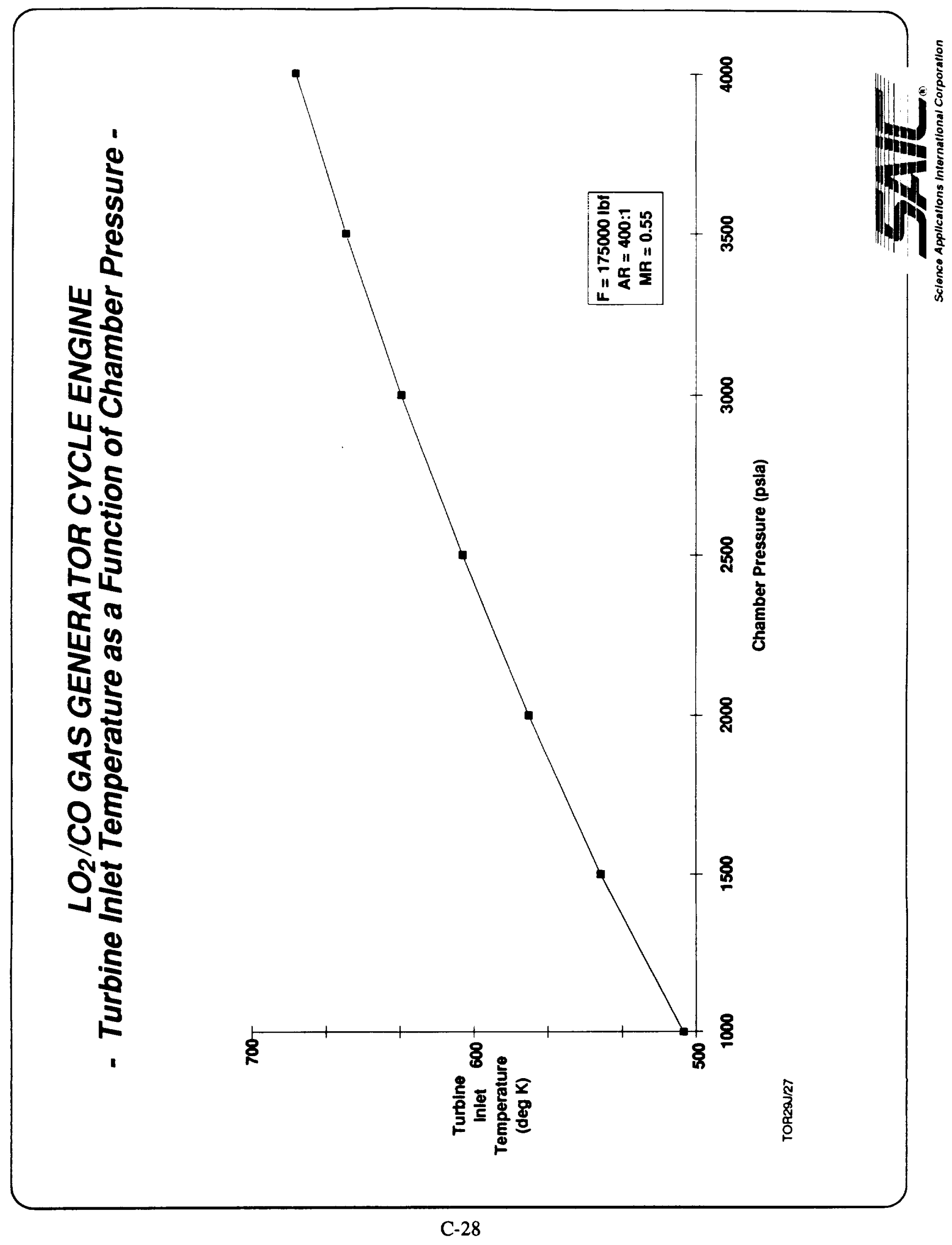





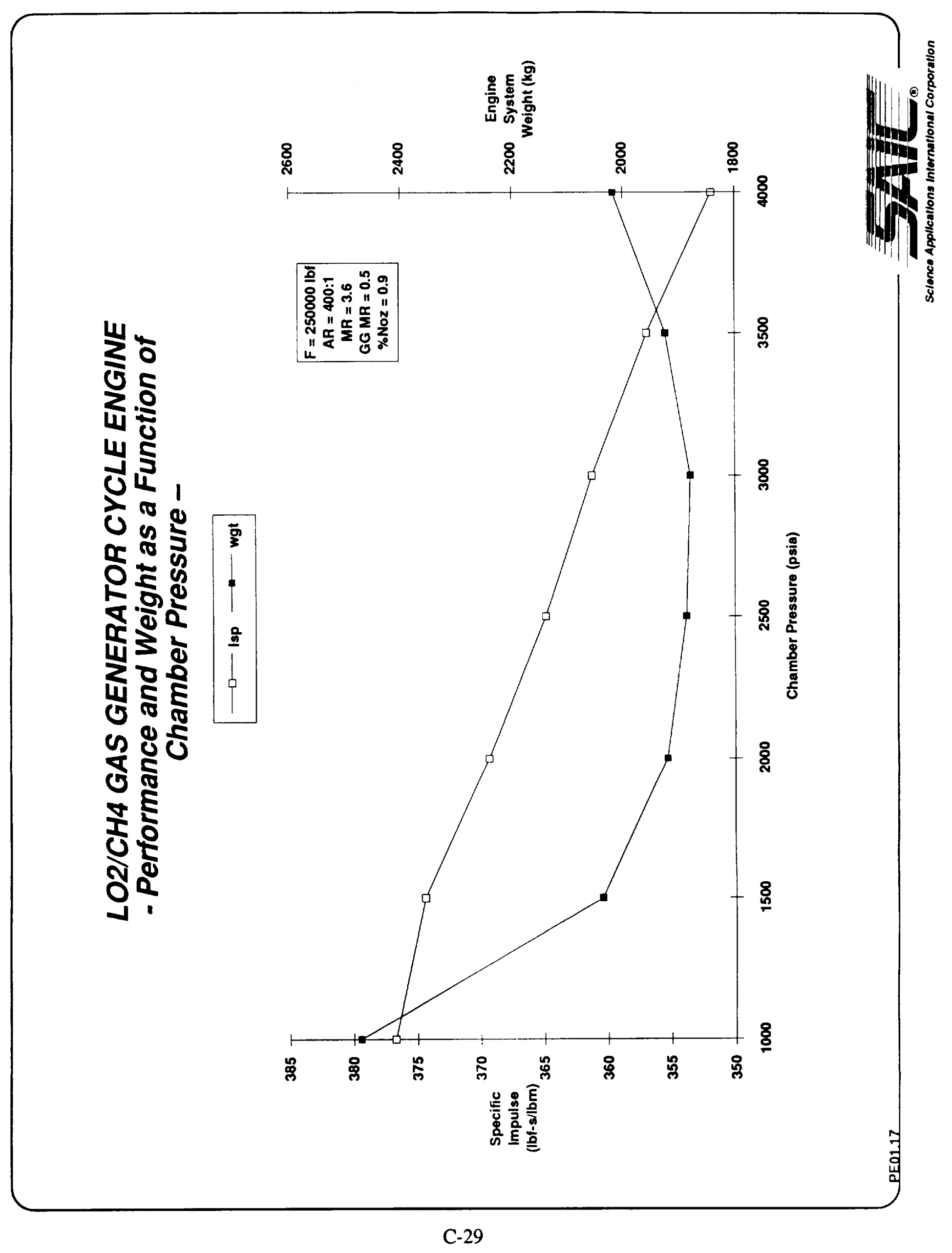





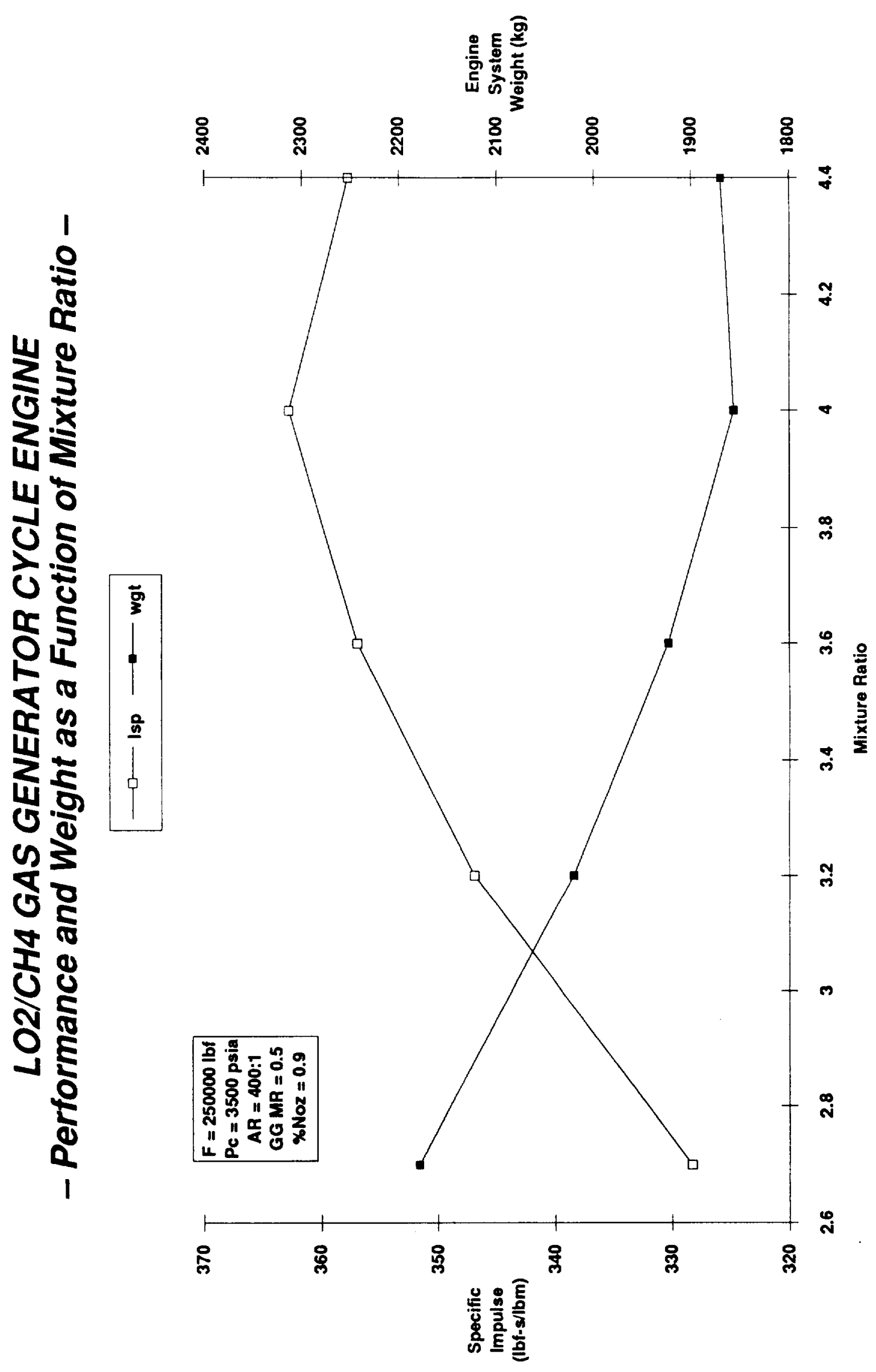

C-30 



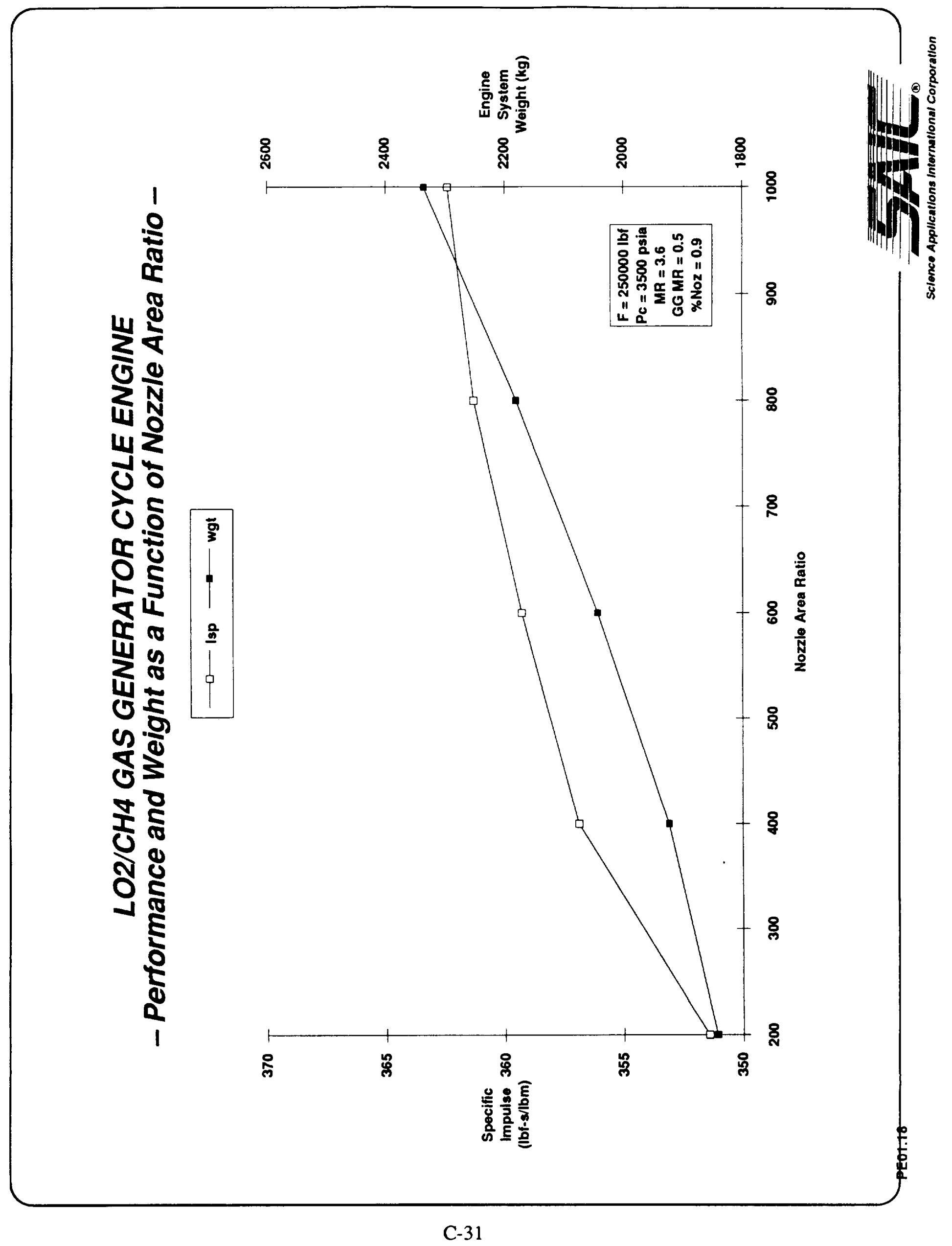





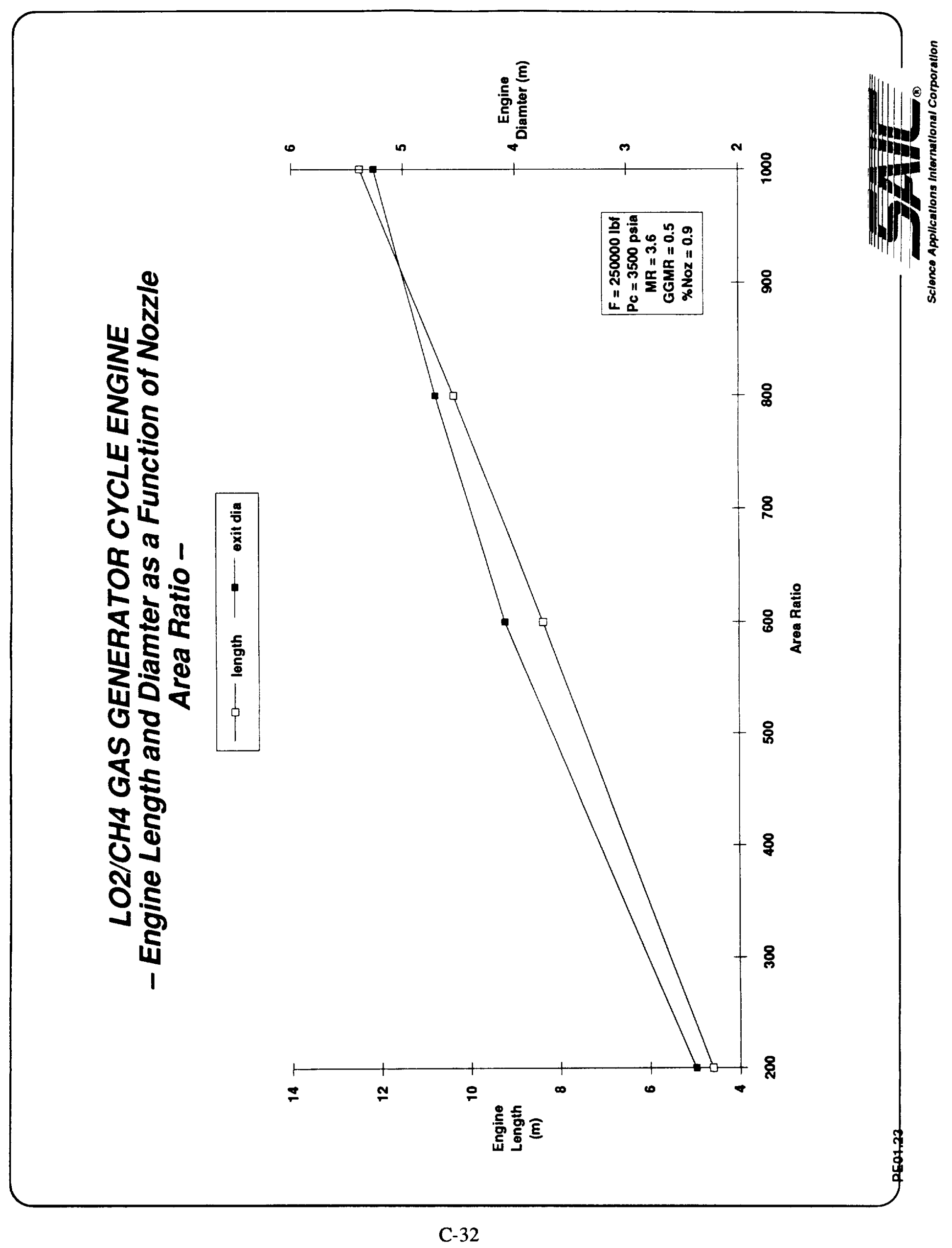





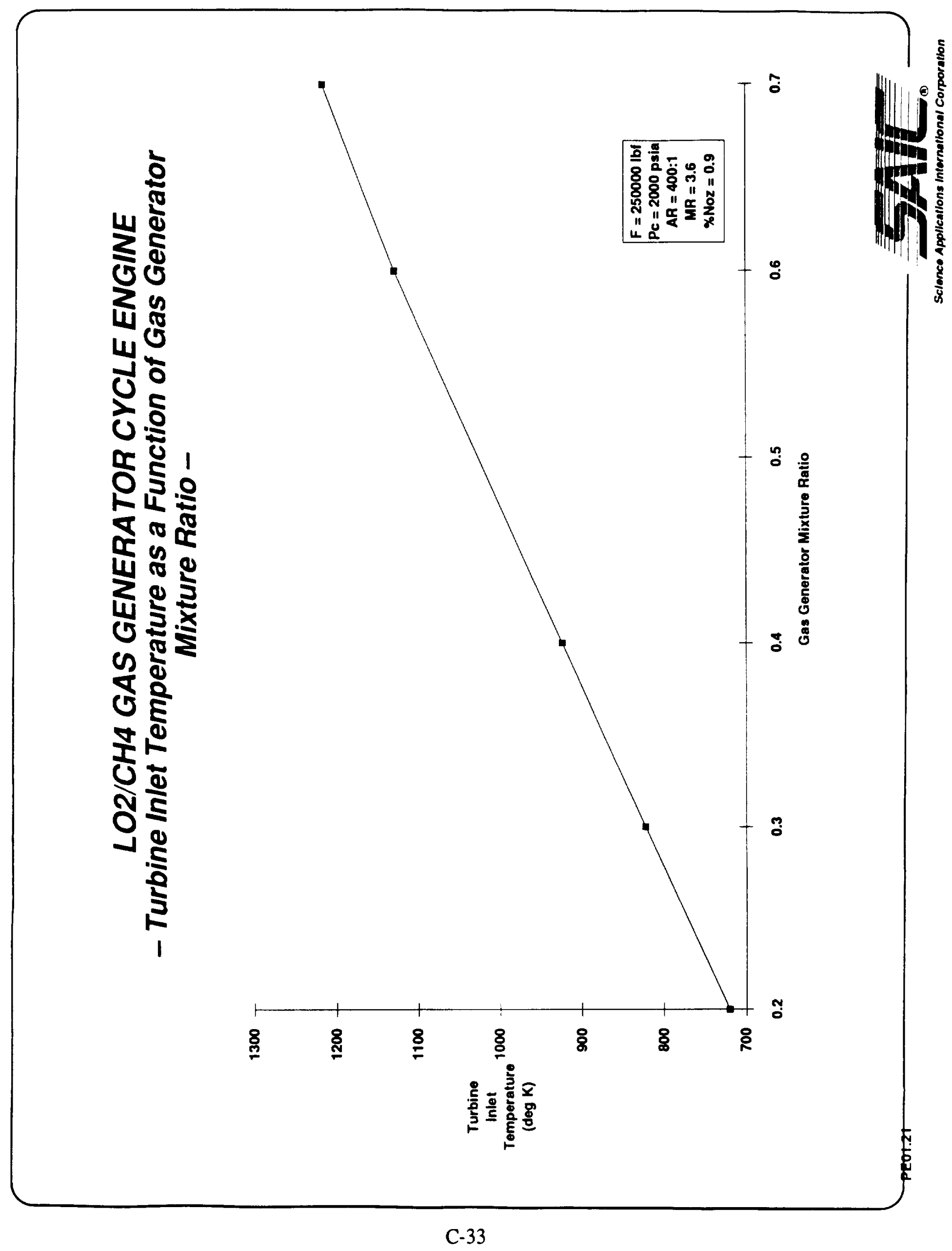





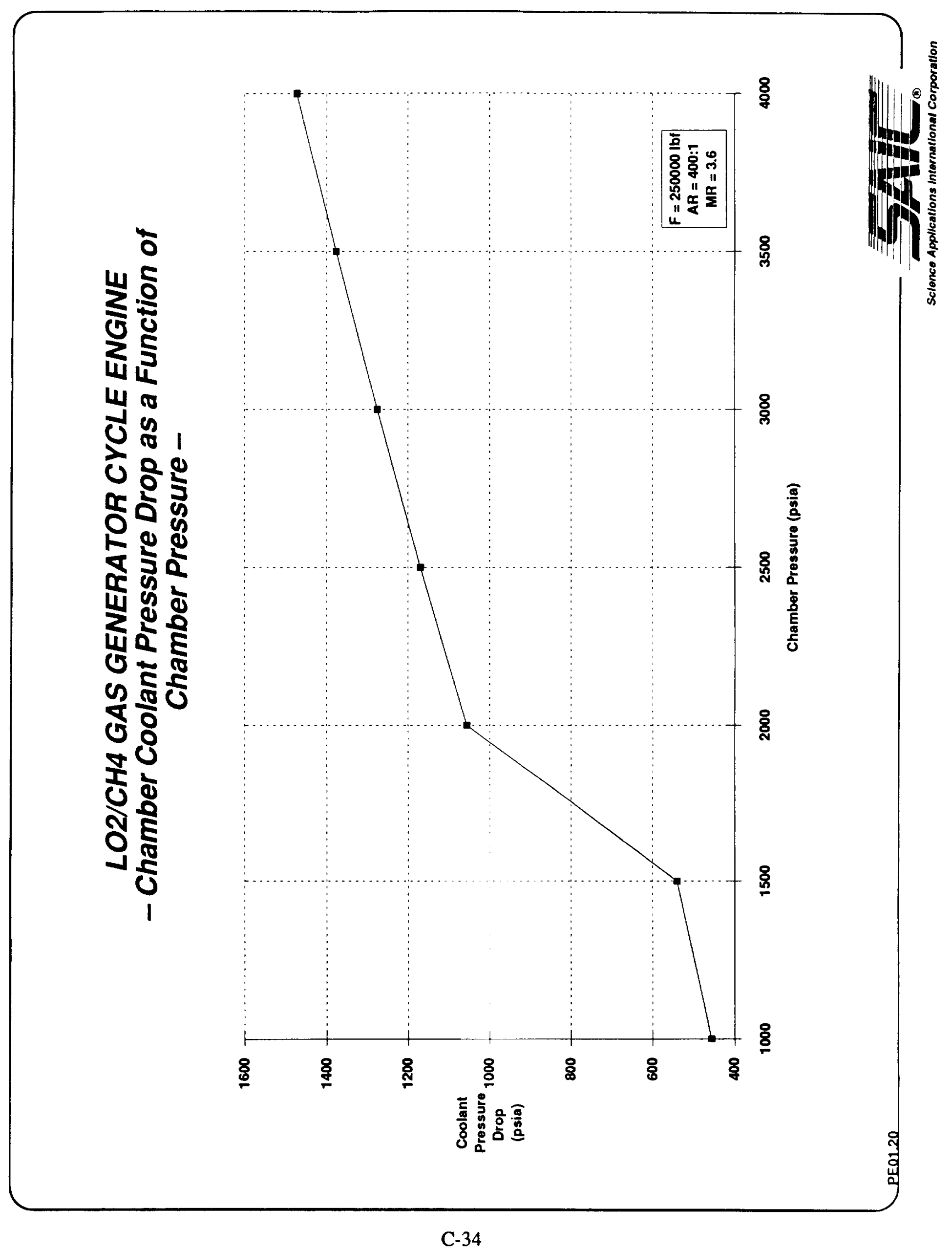





\section{APPENDIX D}

BASELINE ENGINE SYSTEM DESIGN DATA

D-1 



\section{APPENDIX D \\ BASELINE ENGINE SYSTEM DESIGN DATA}

This appendix contains detailed engineering description data of the baseline engine systems discussed in Section 4.2.3. This database includes data pertaining to all these tripropellant engine systems baselined in this study for MEV applications and their bipropellant-based derivative designs for LEV and MEV applications. These engine systems are characterized for full rated power (100\% thrust) and at reduced throttled (off-design) operating conditions. Typical engine system operational, thrust chamber/coolant, and chamber/injector design compatibility characteristics data are given in this appendix. 



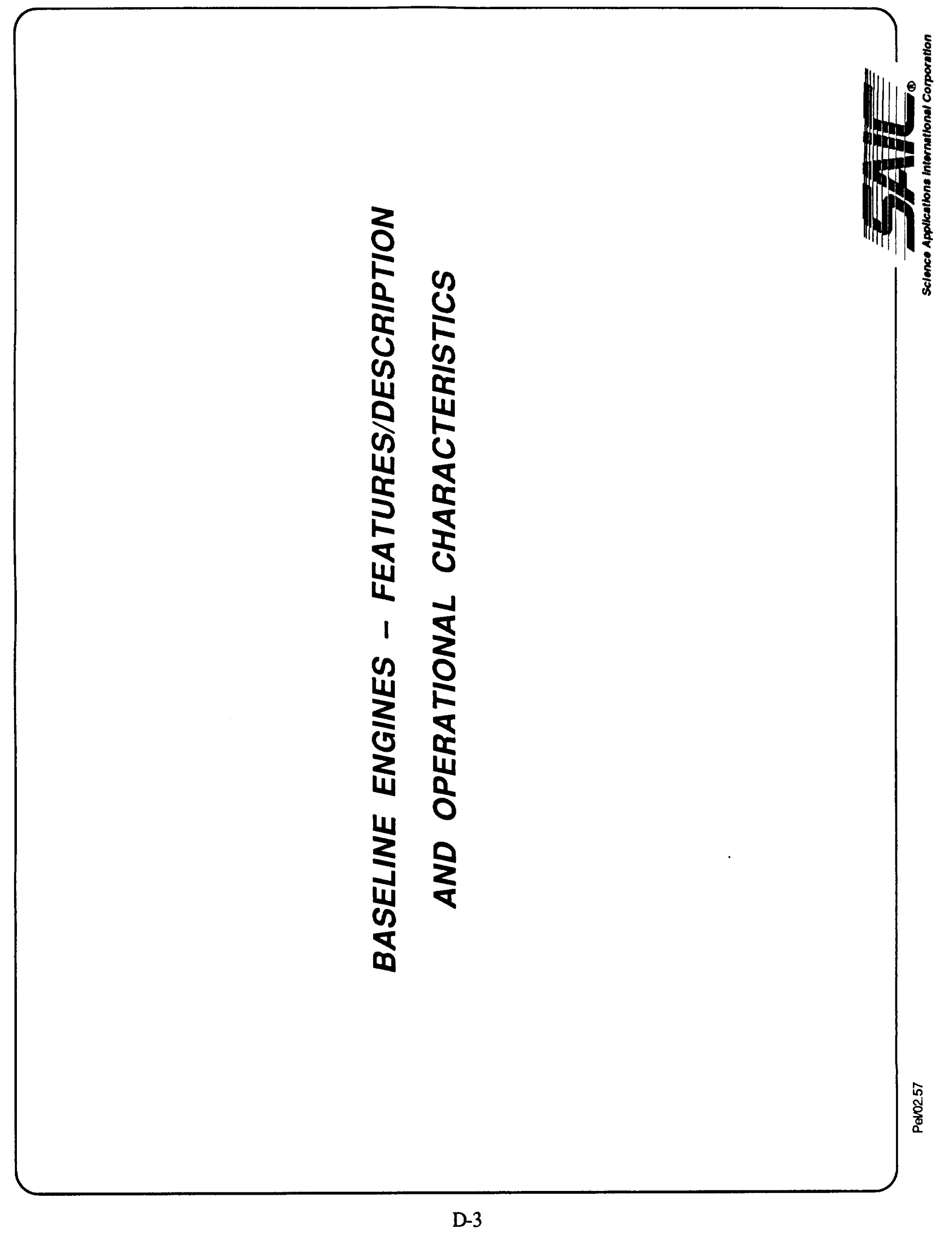





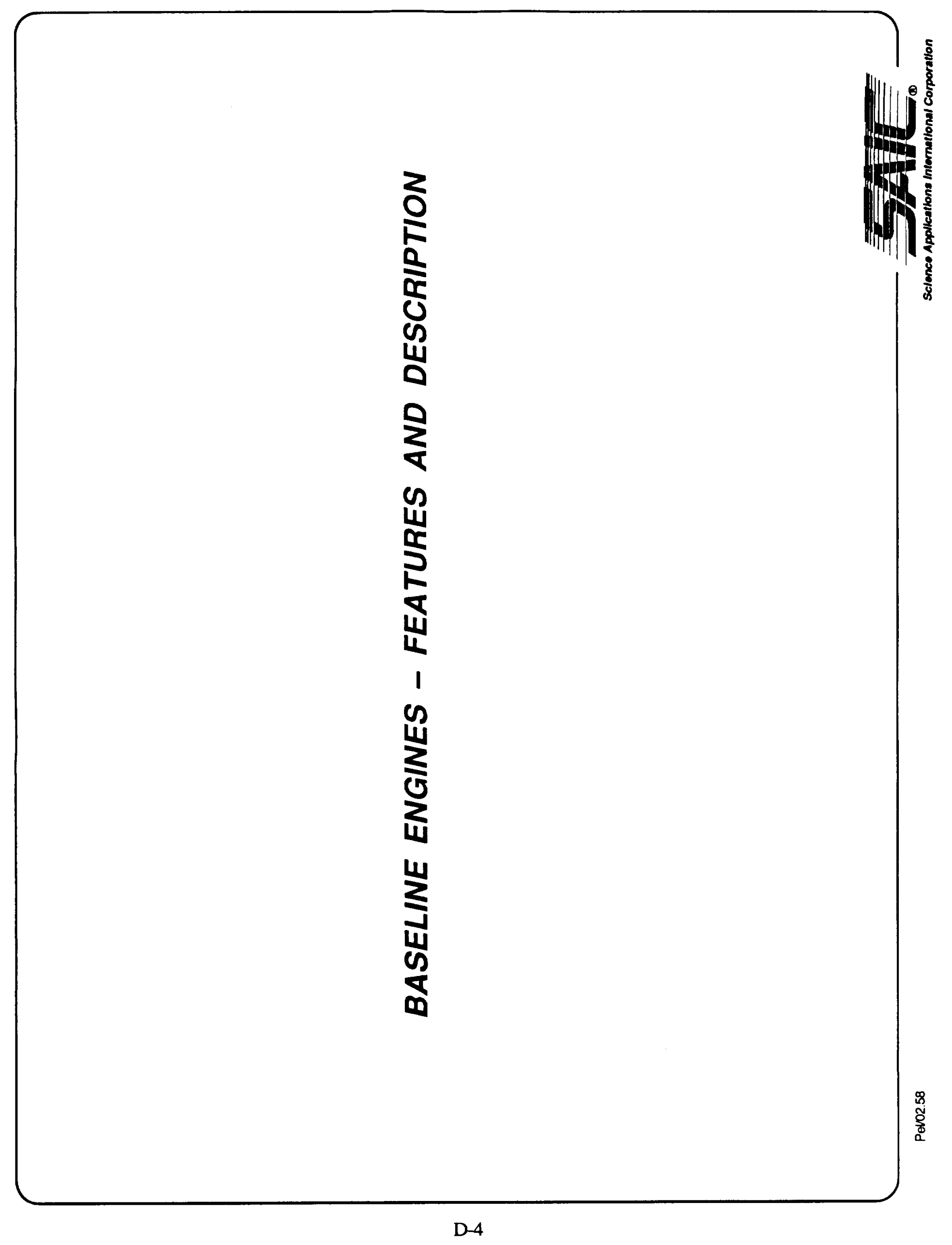





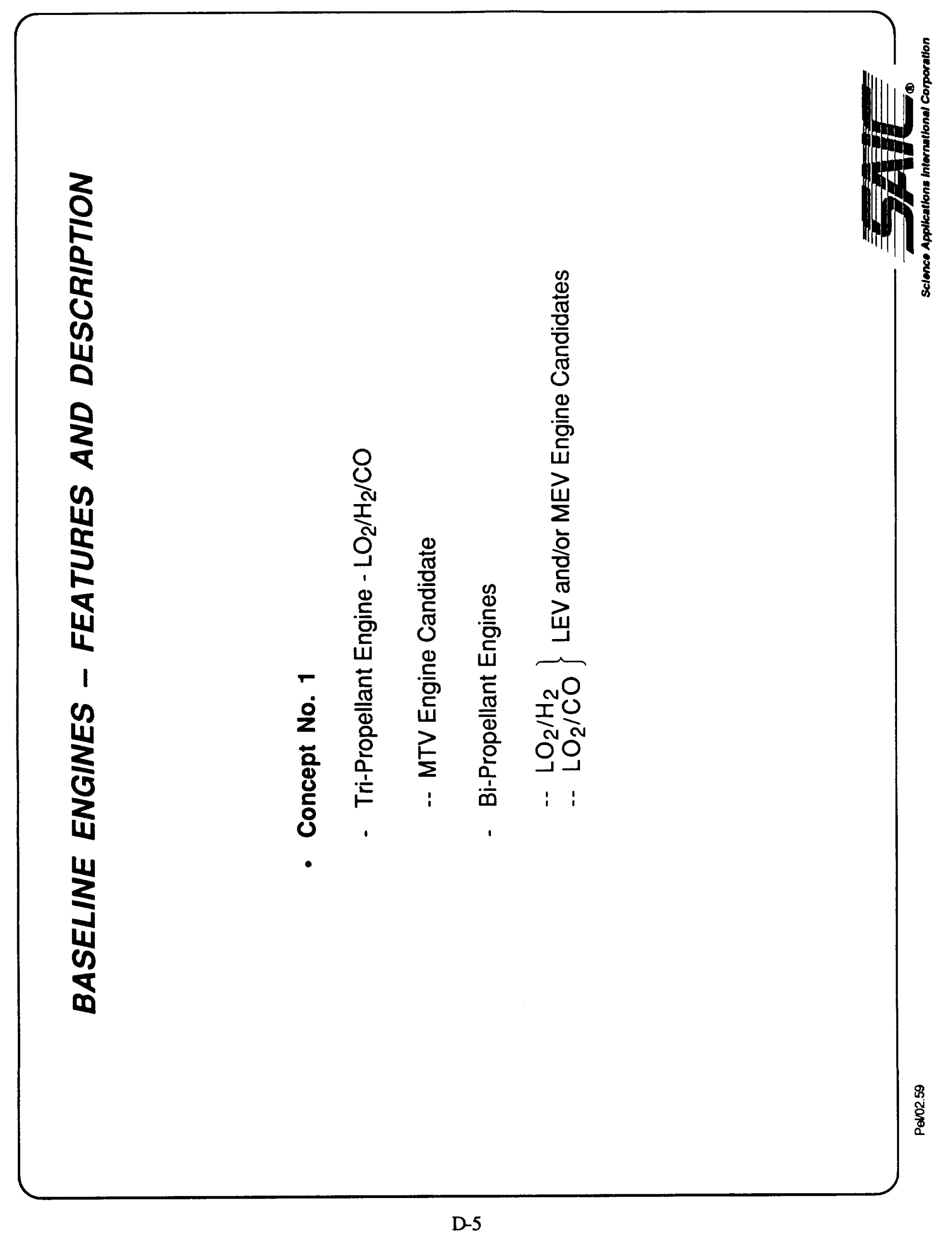





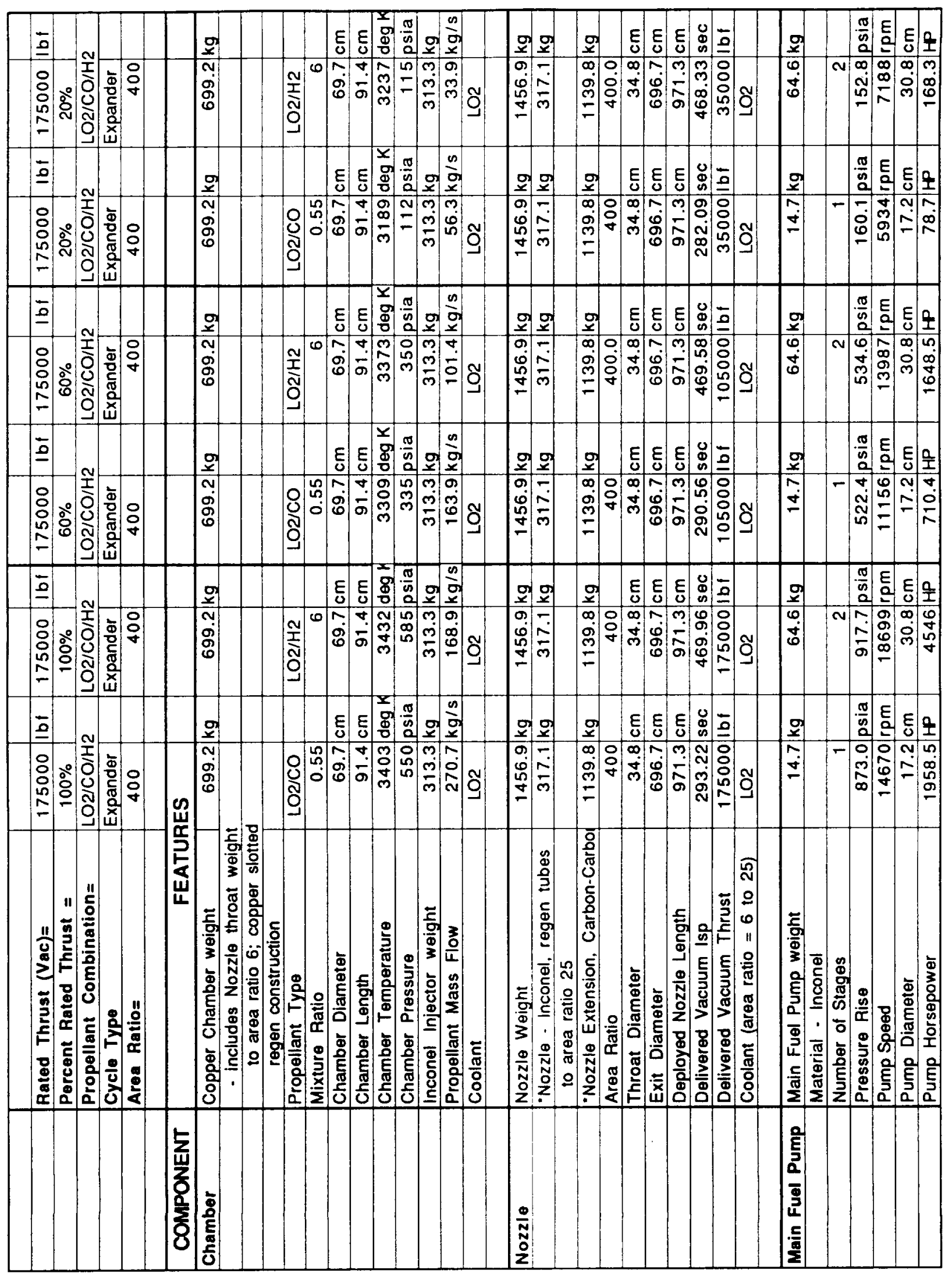





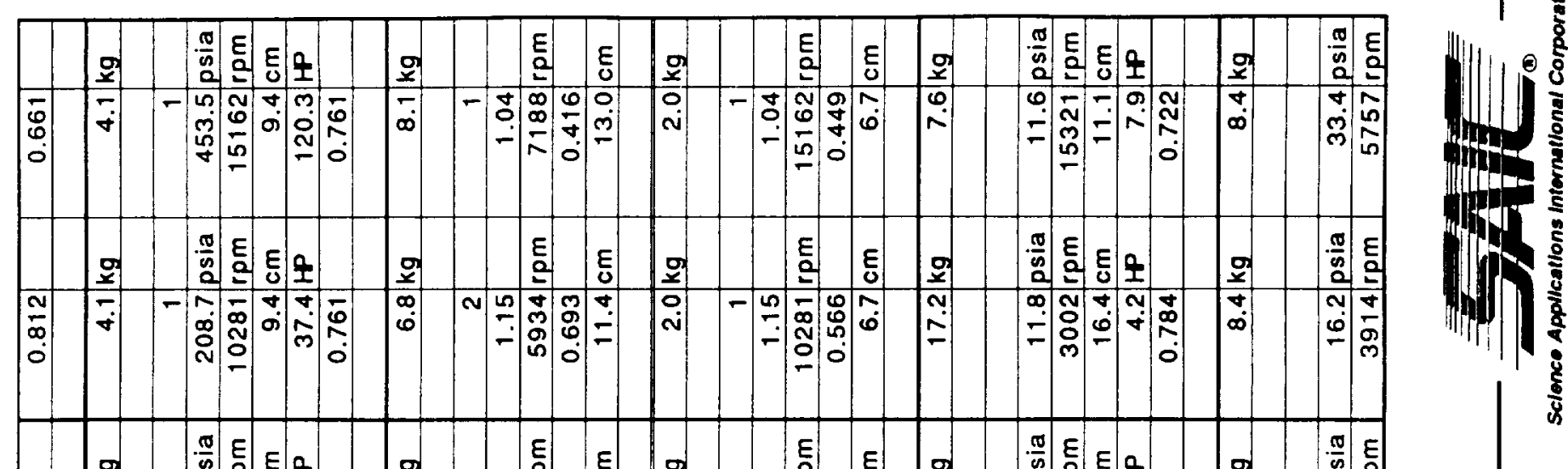

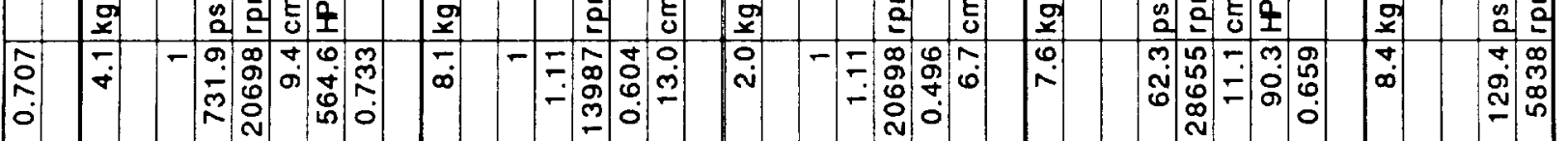

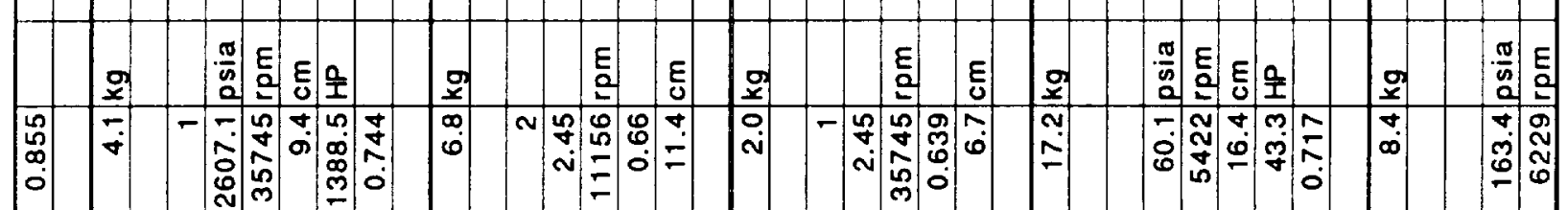

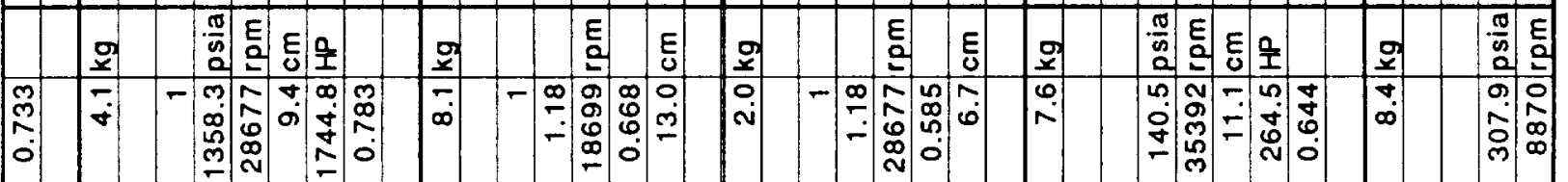

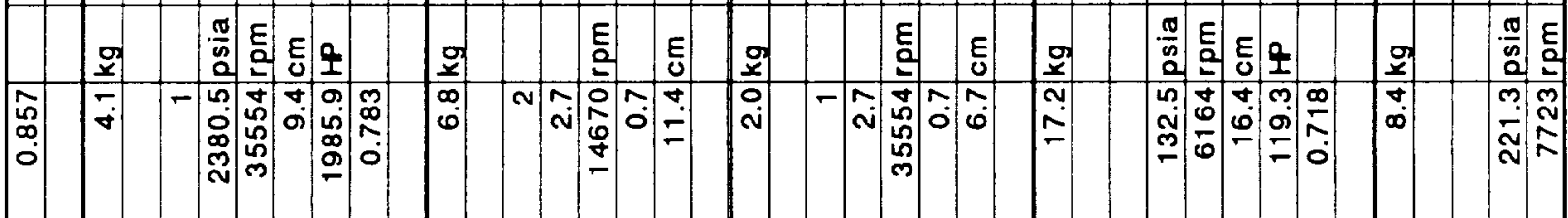

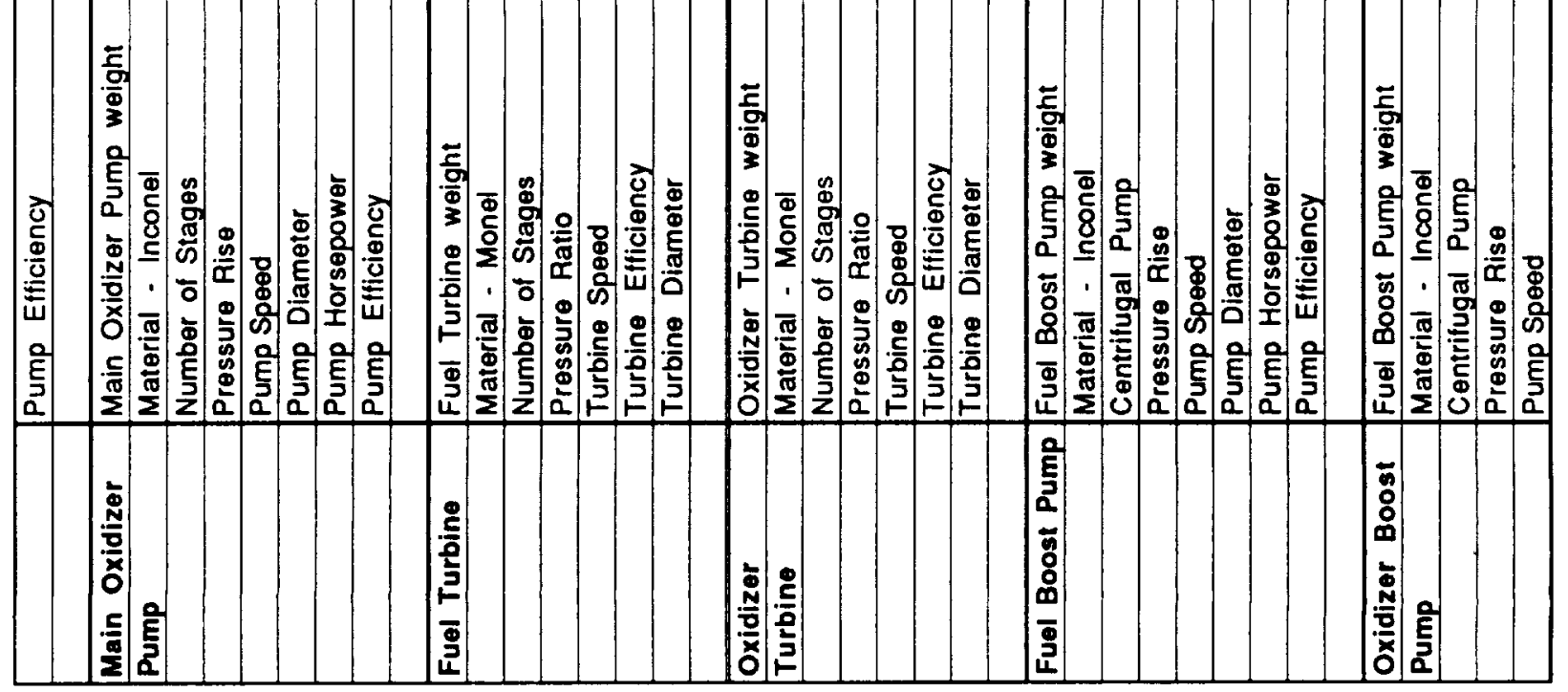





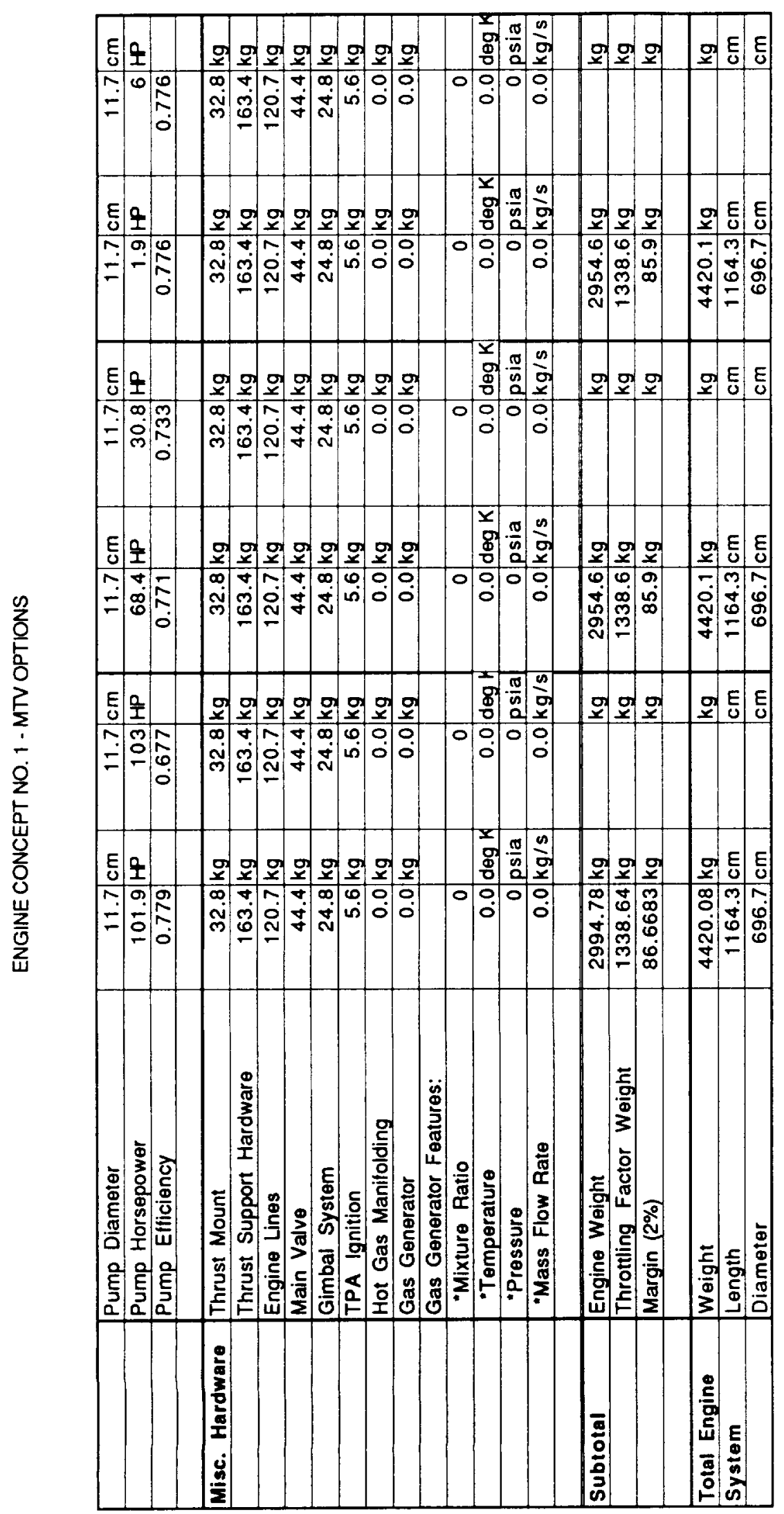





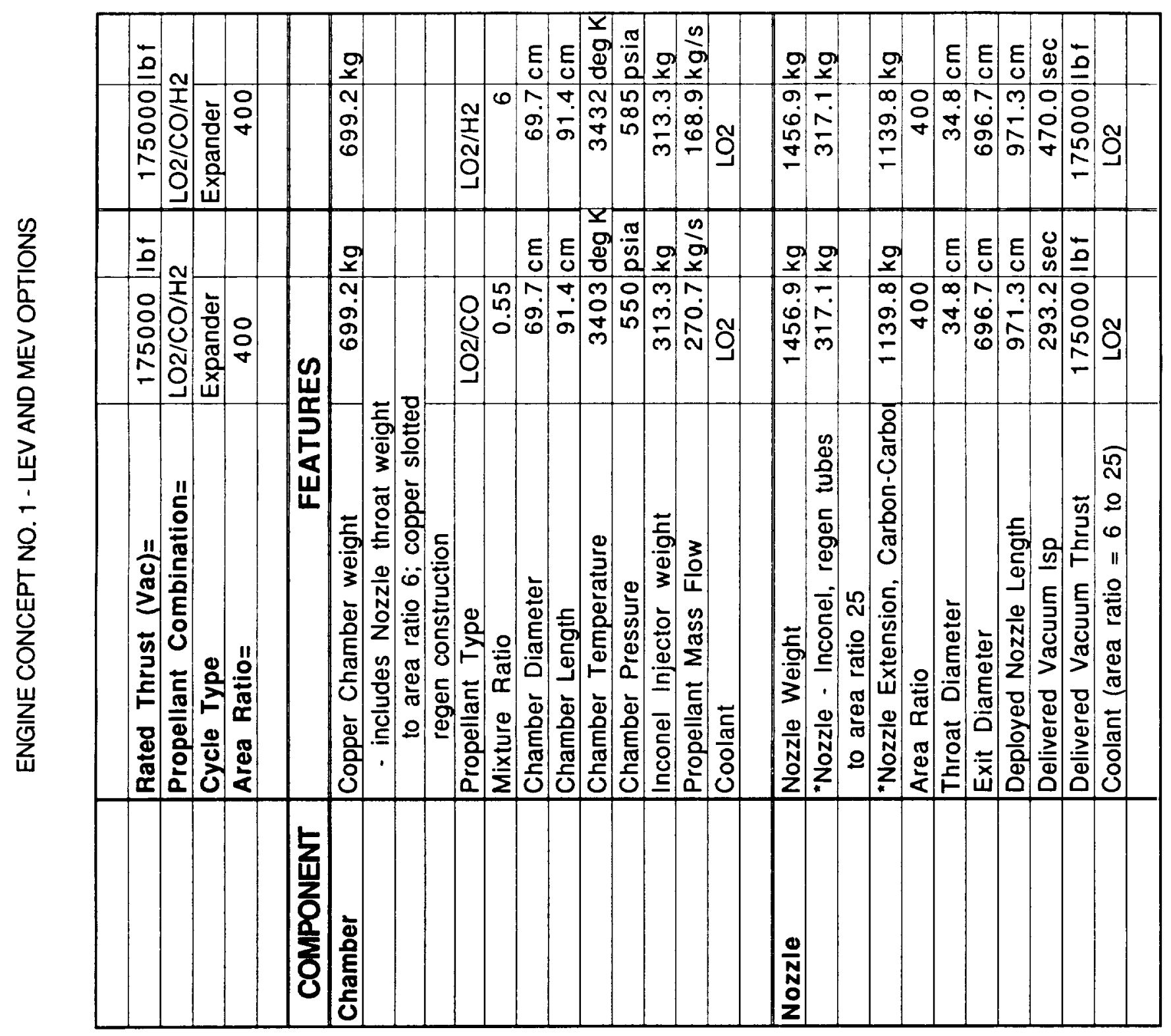




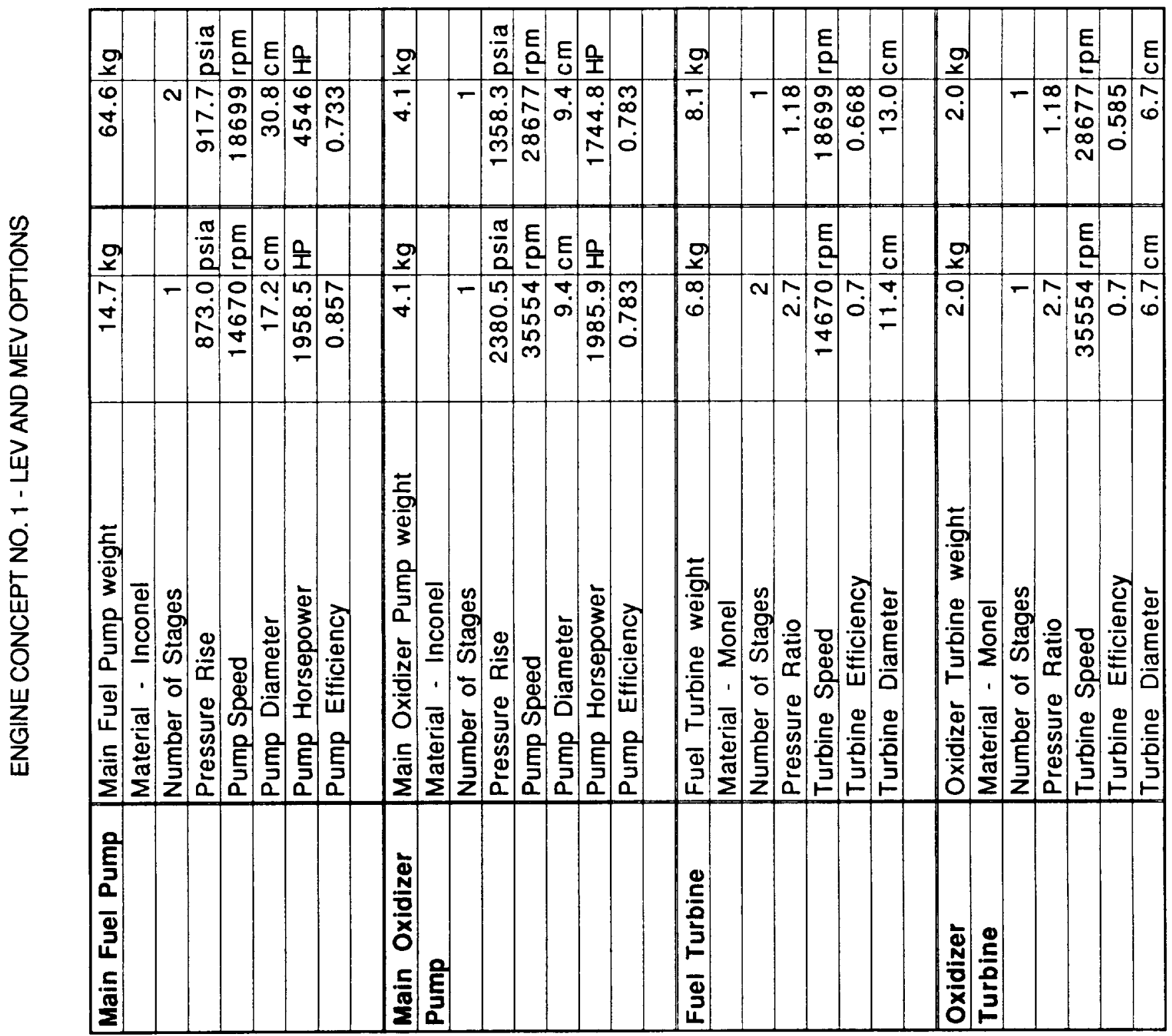



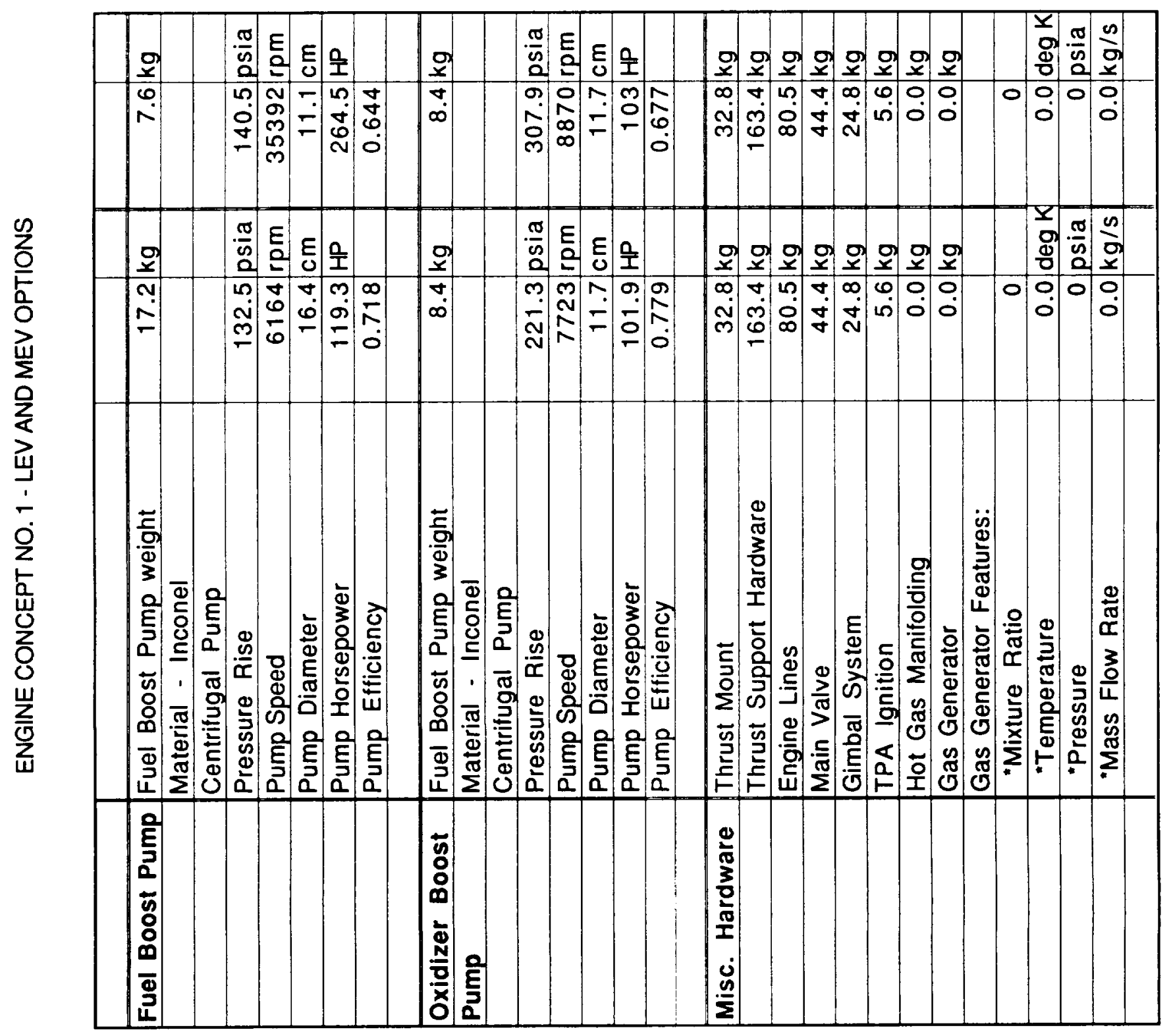





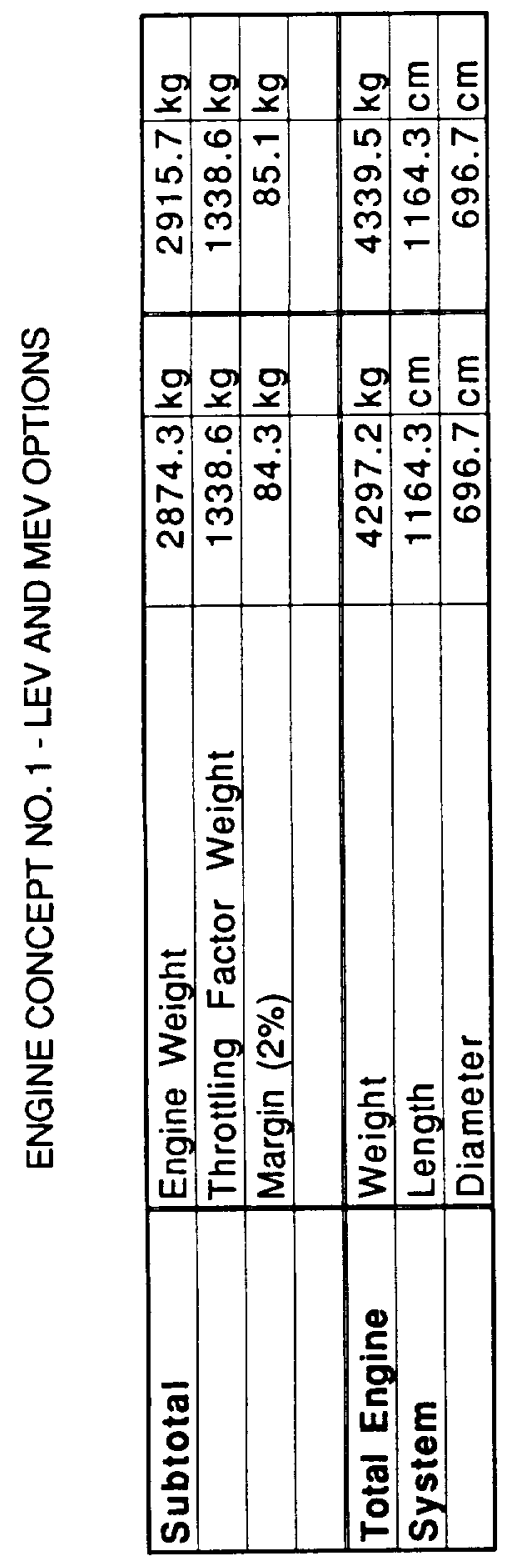

D-12 



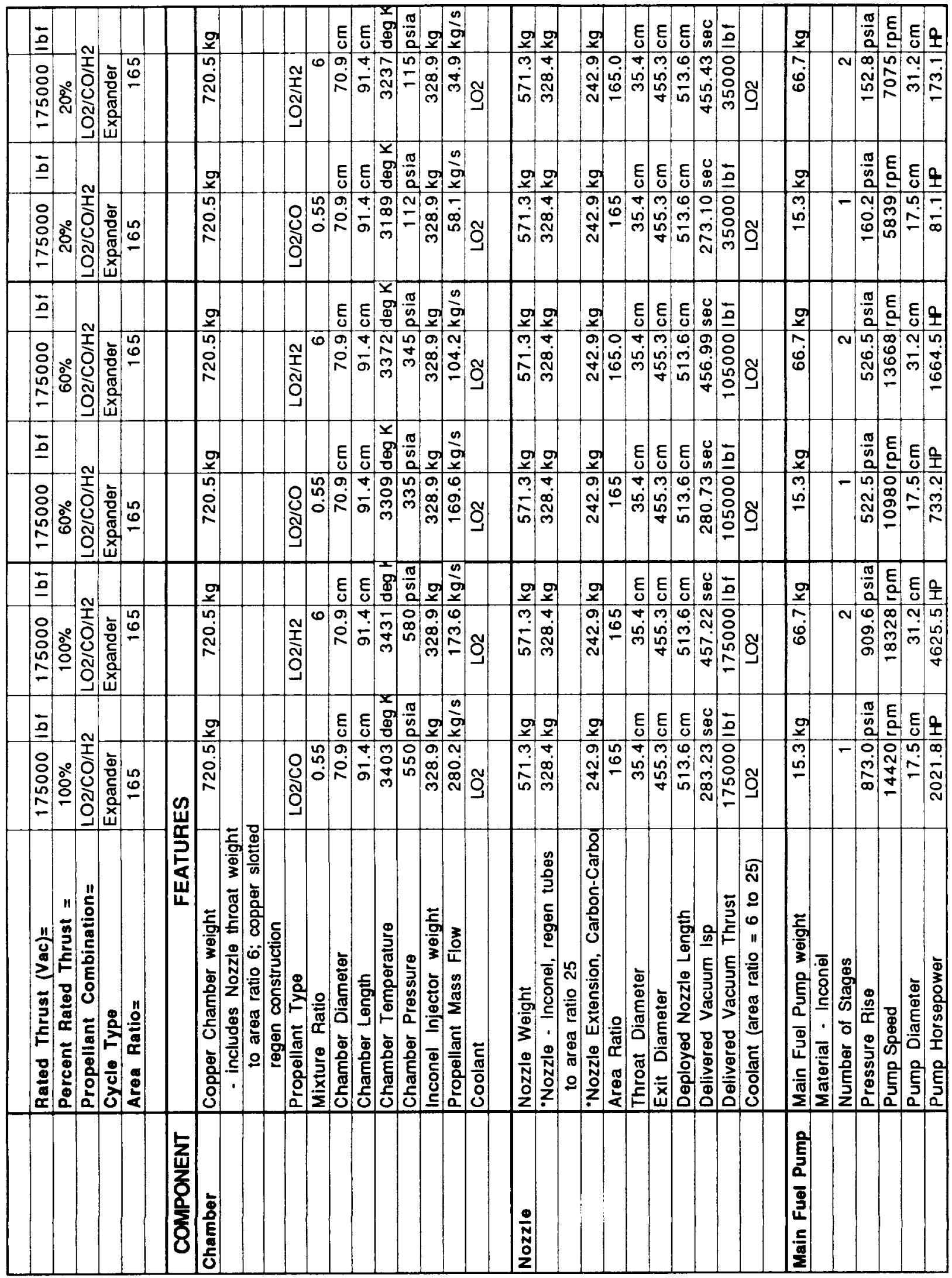





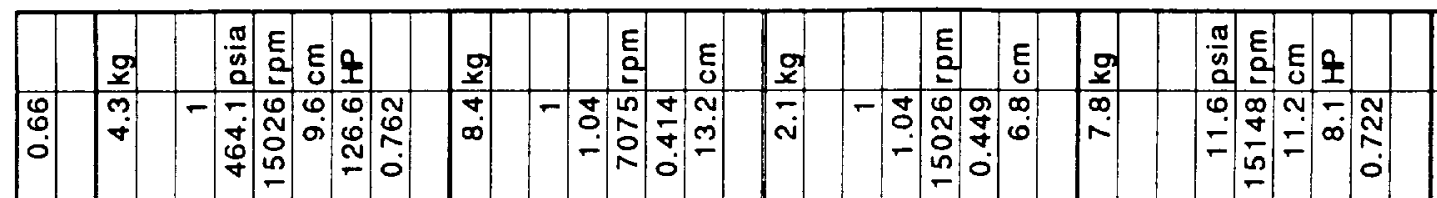

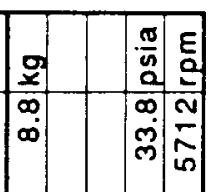

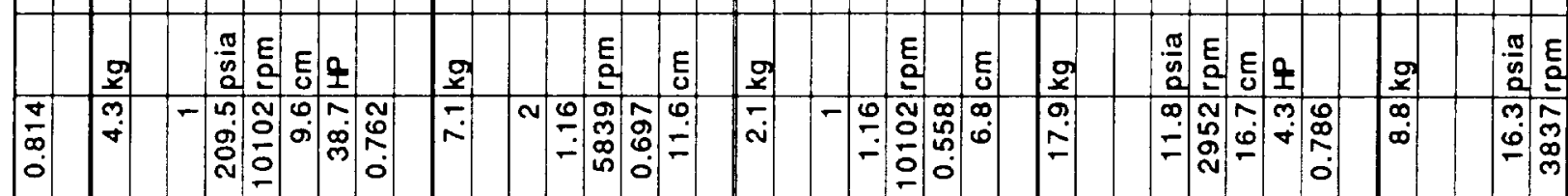

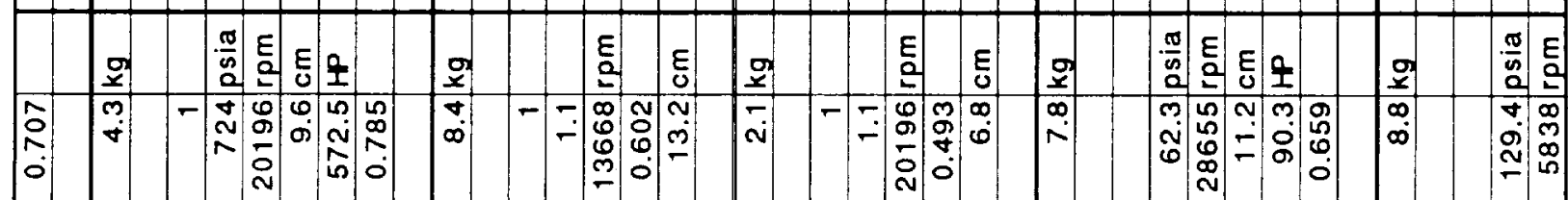

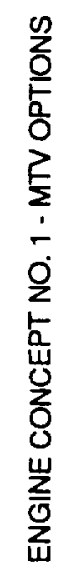

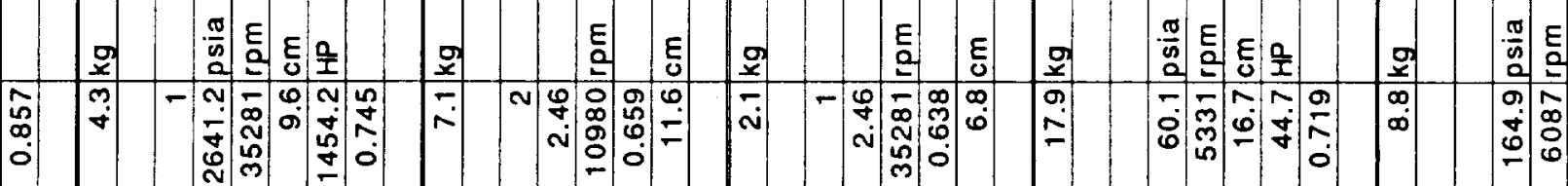

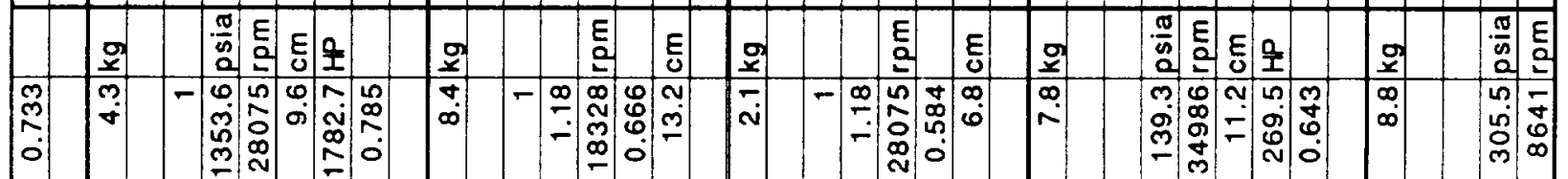

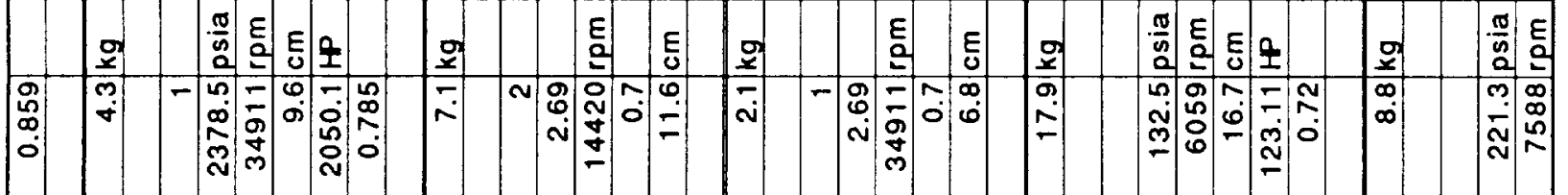

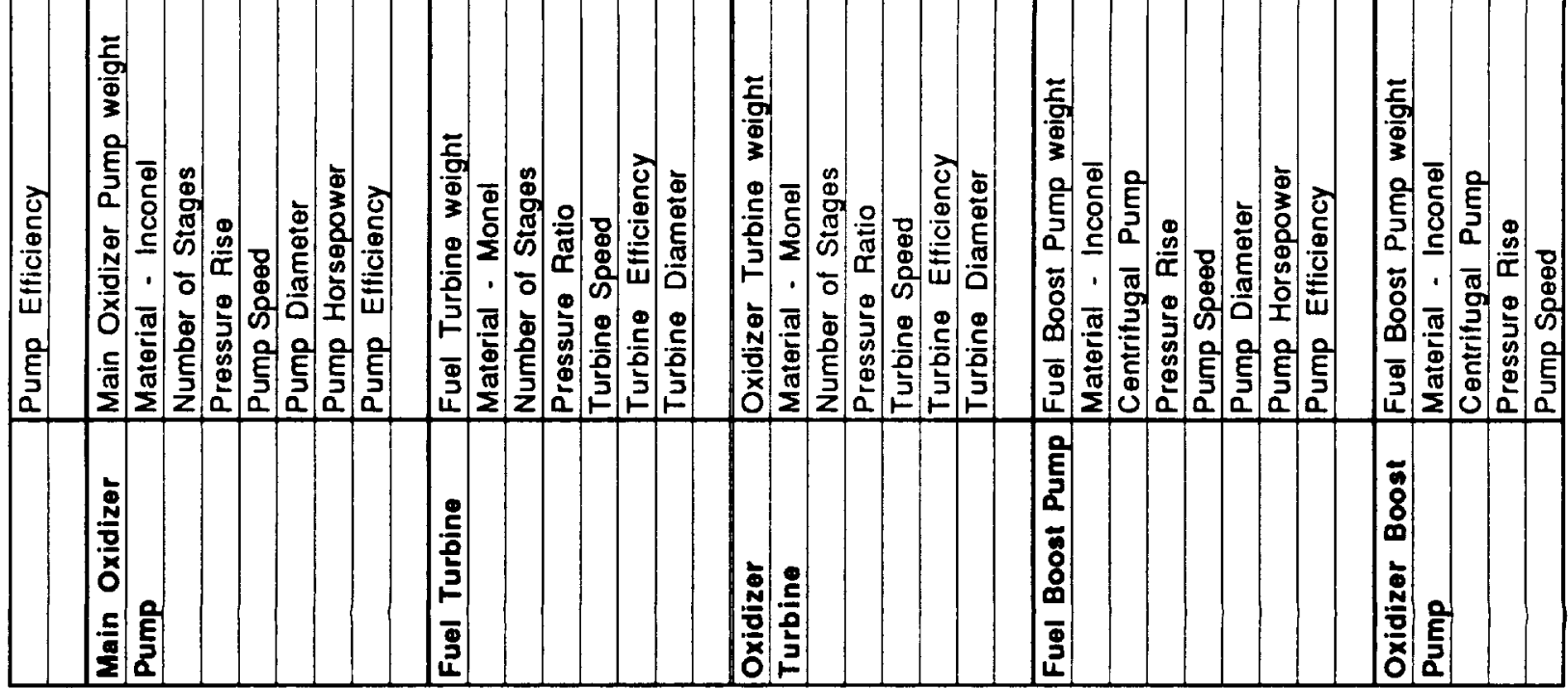





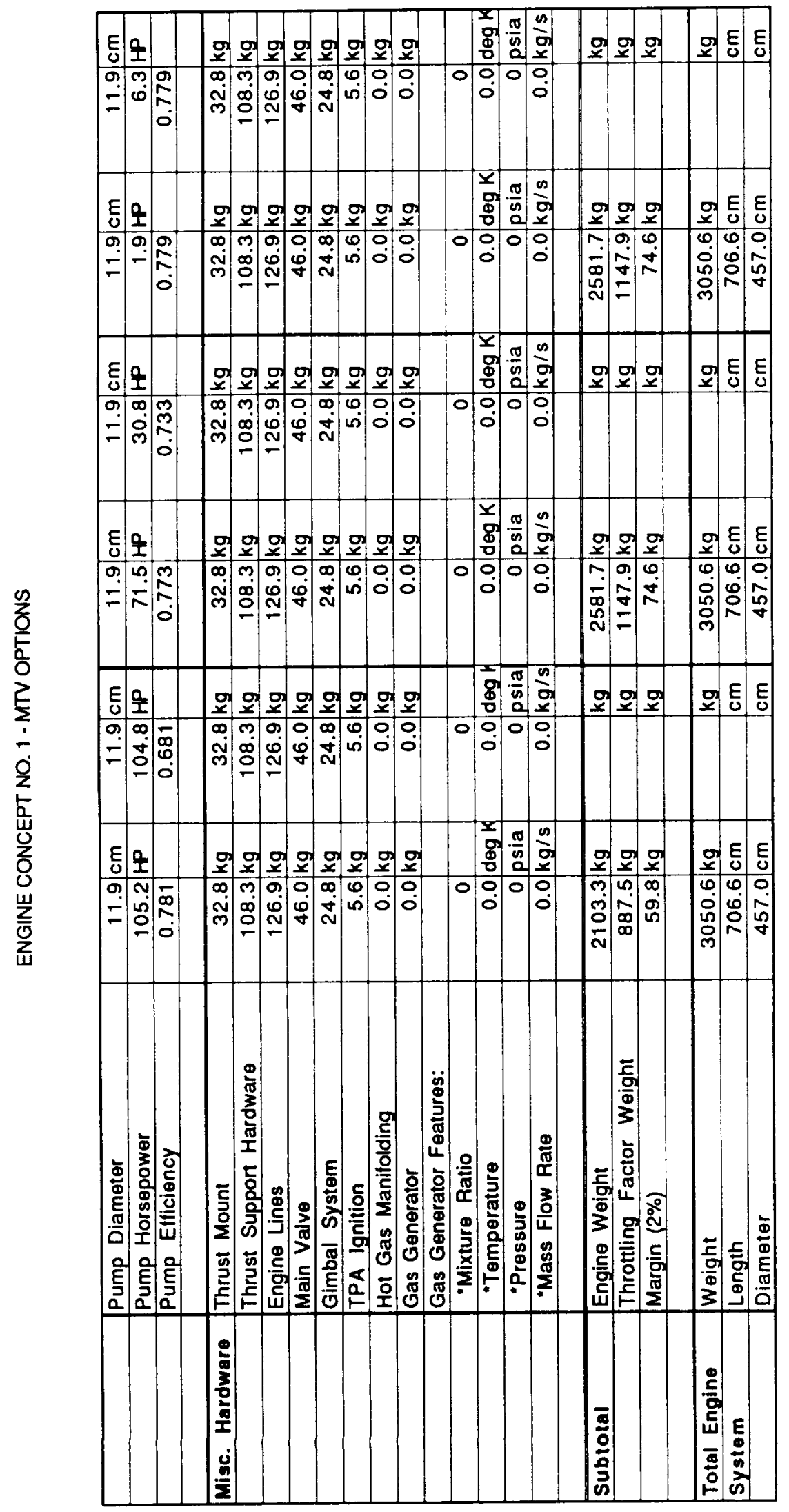





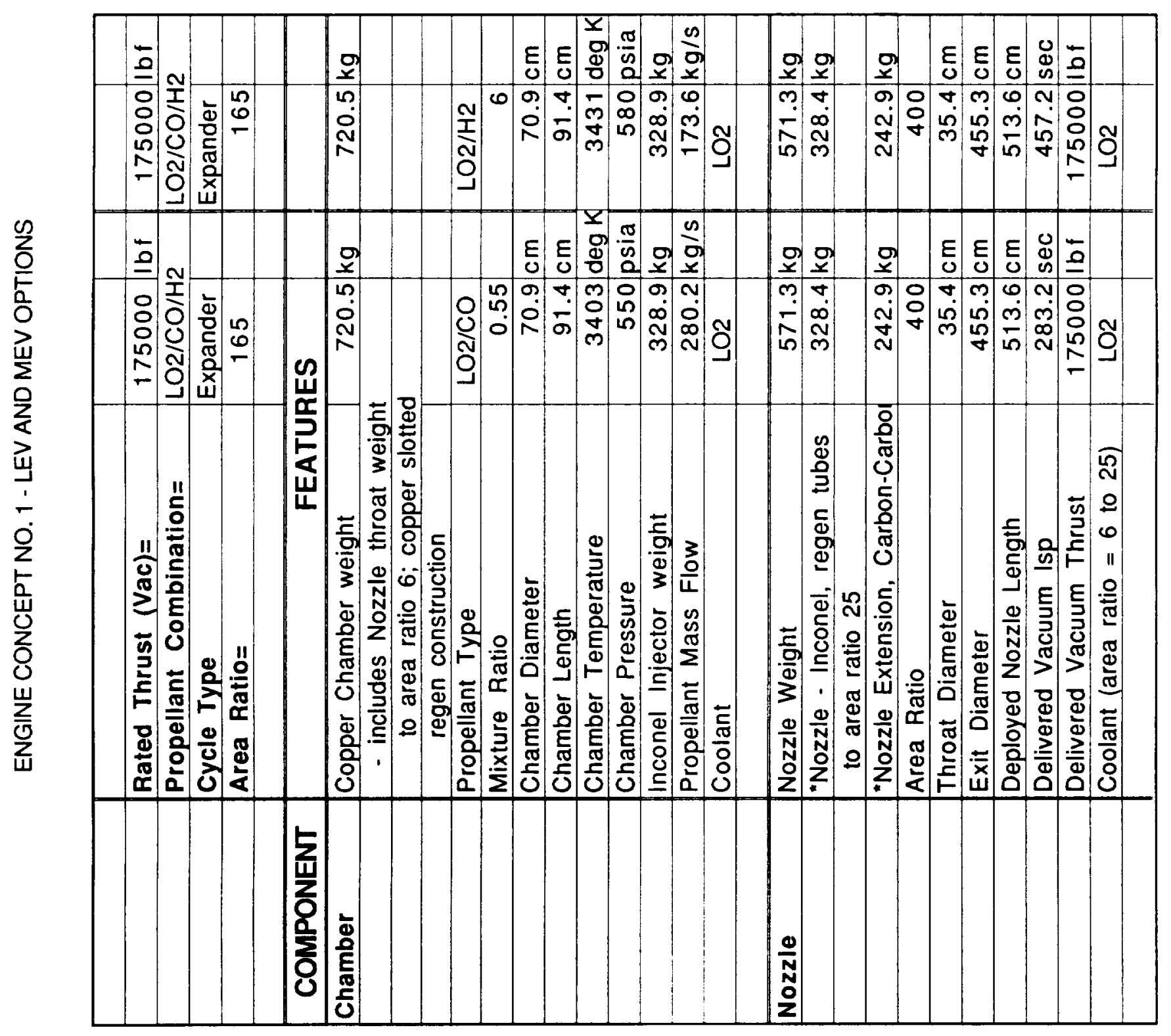





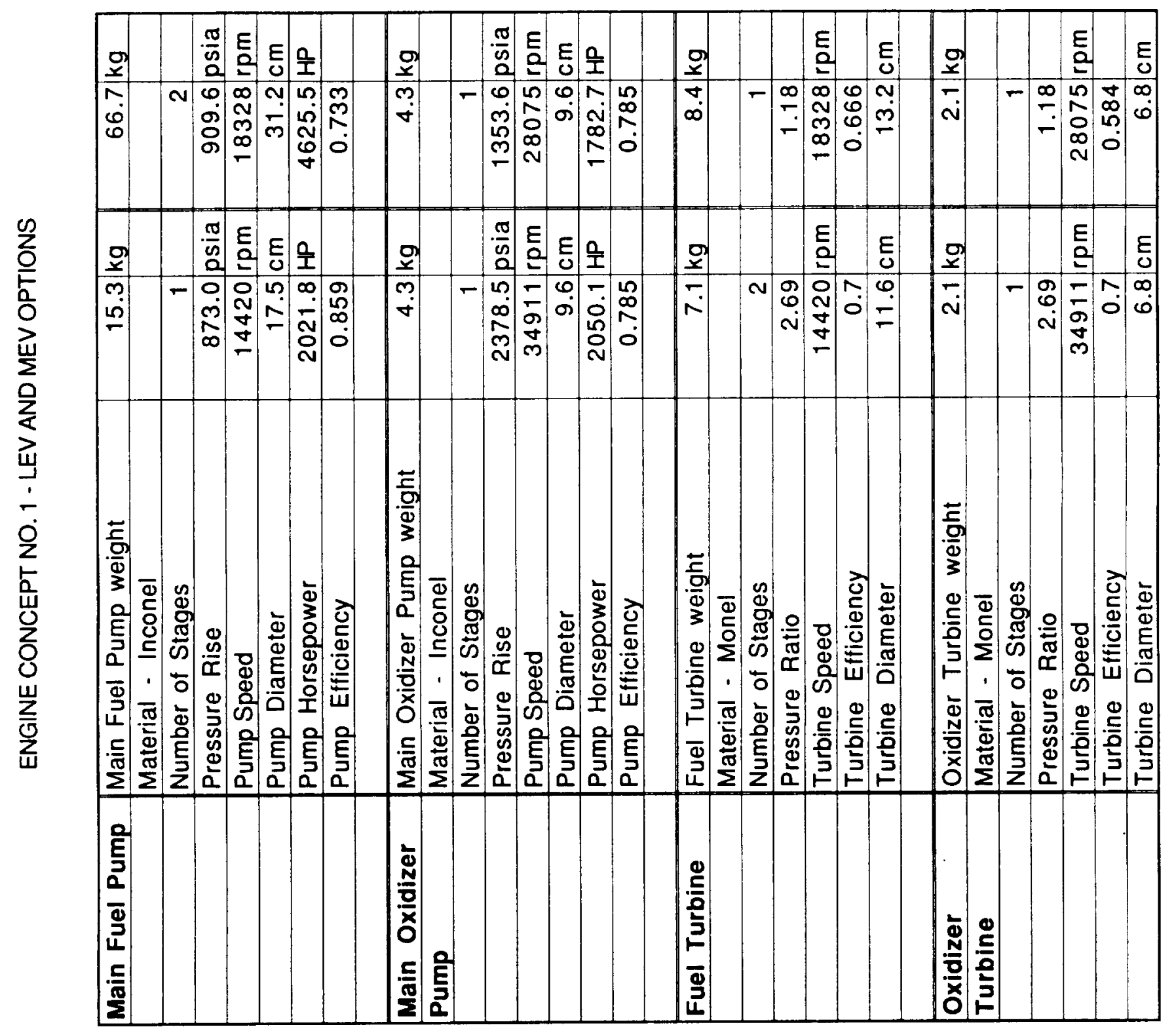





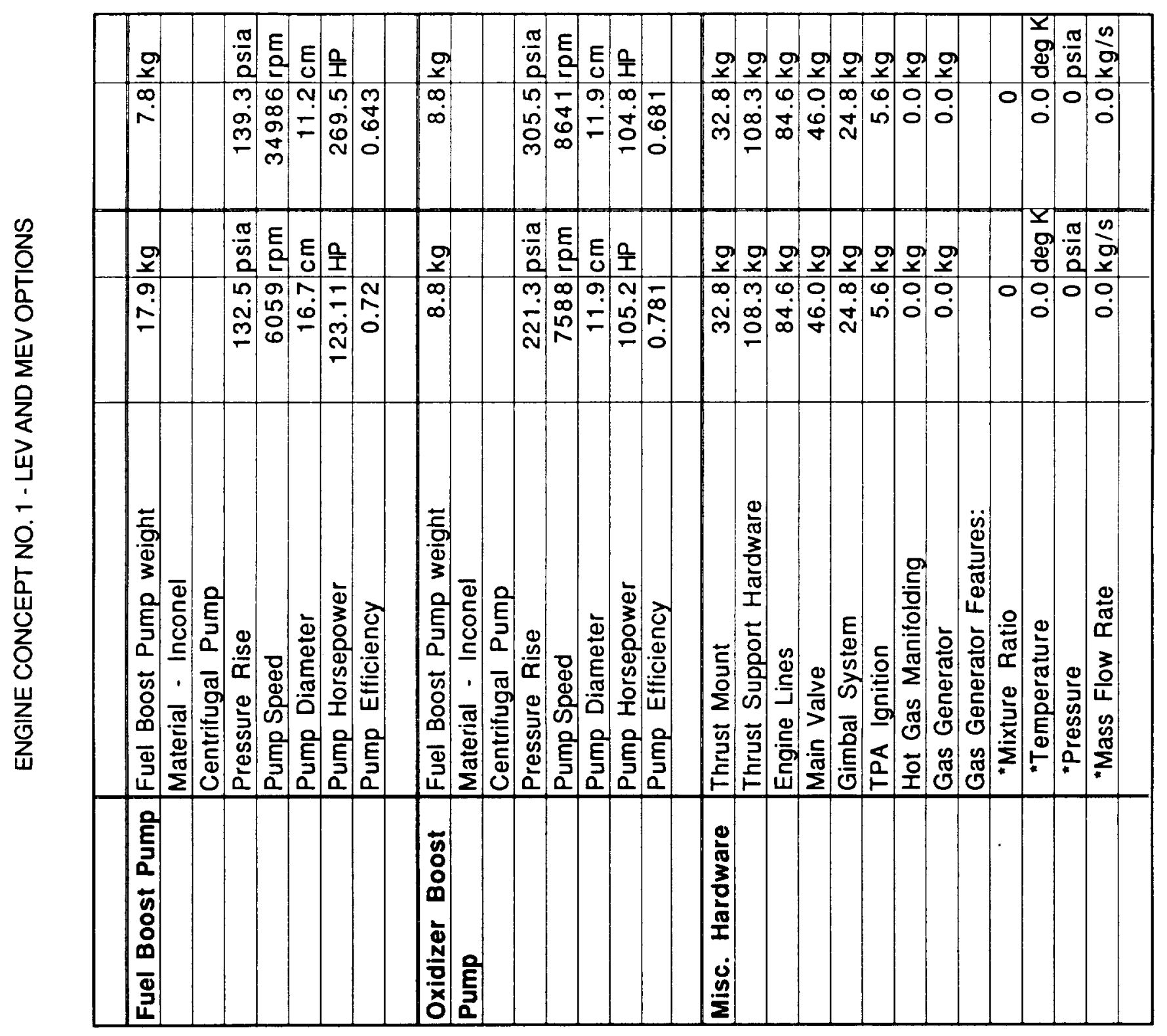





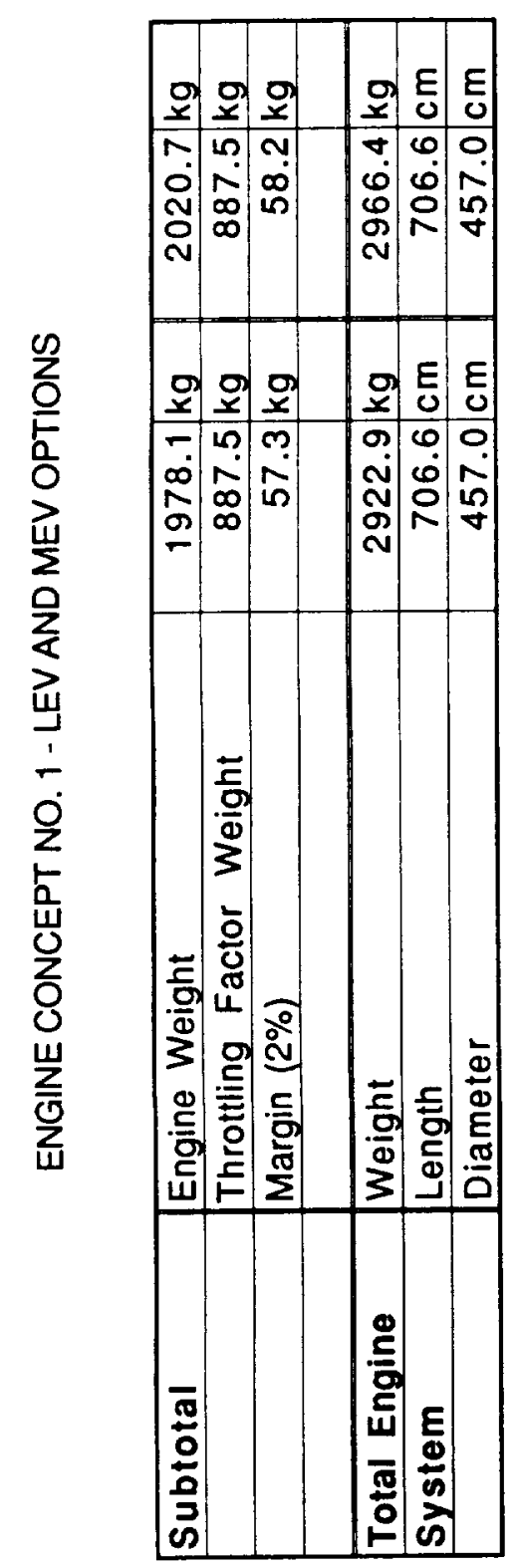

D-19 



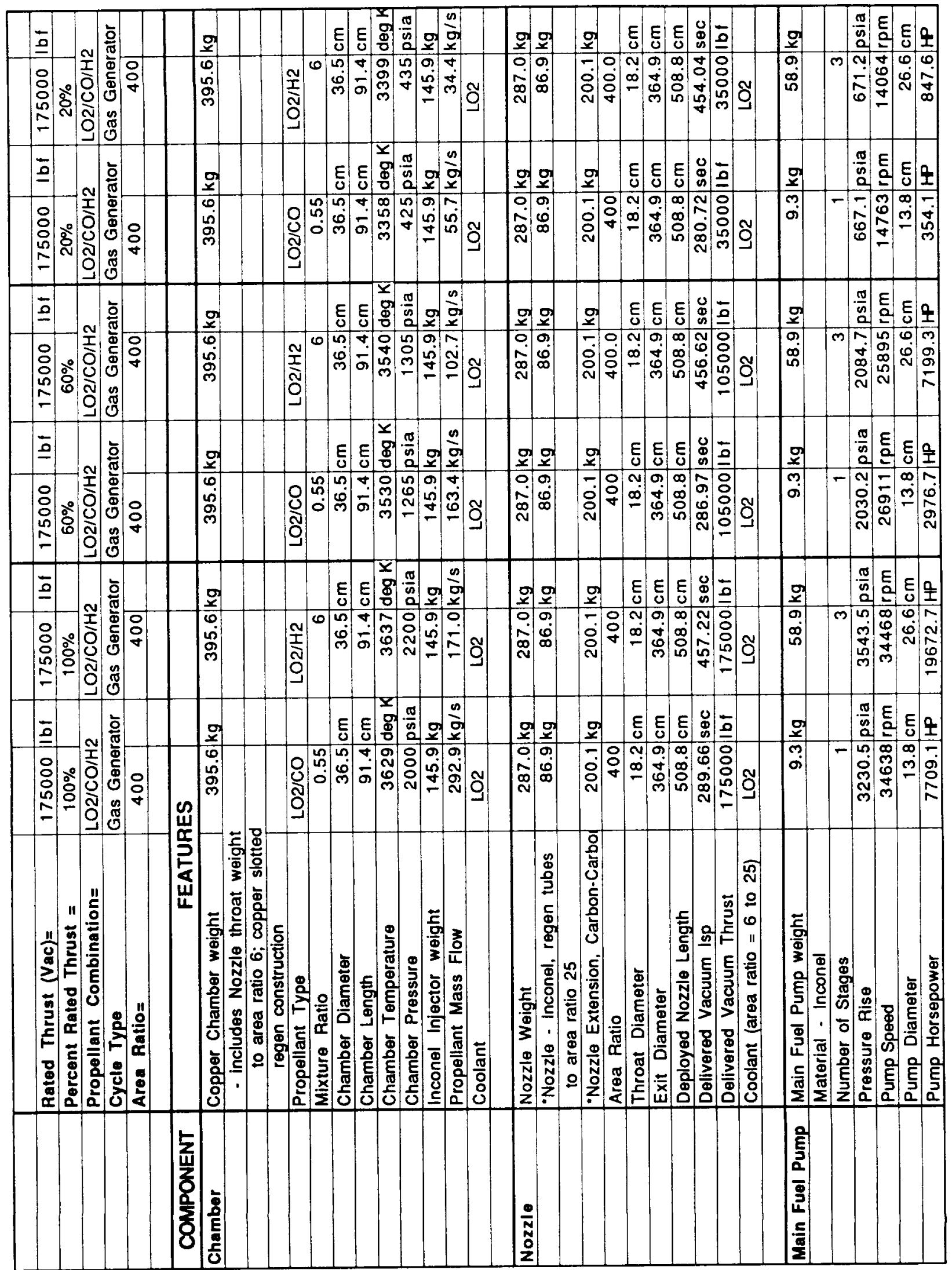





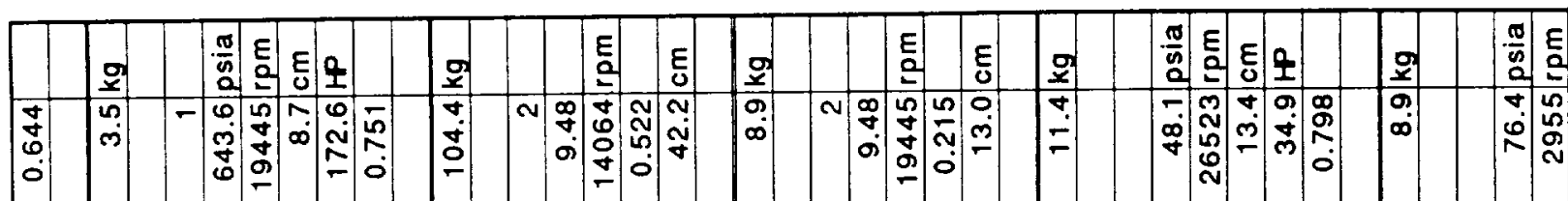

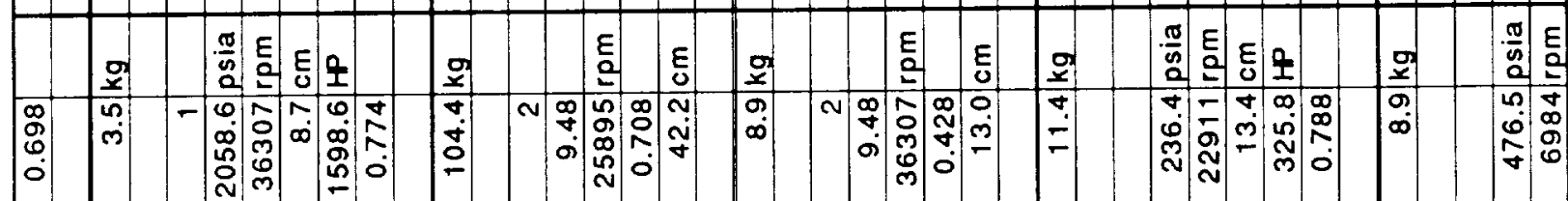

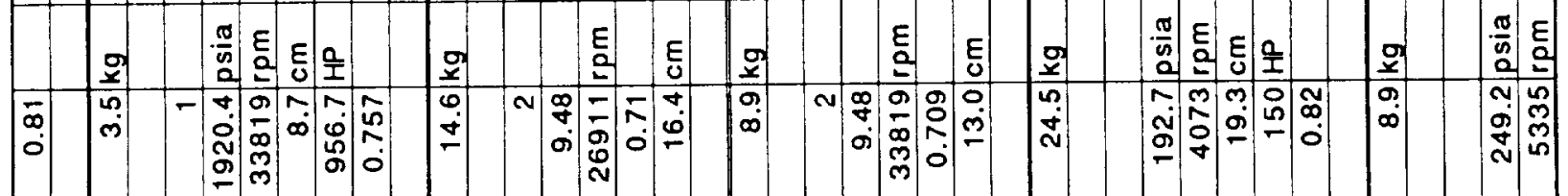

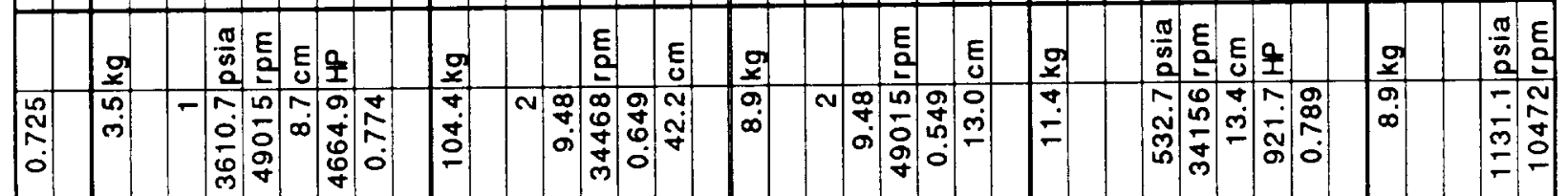

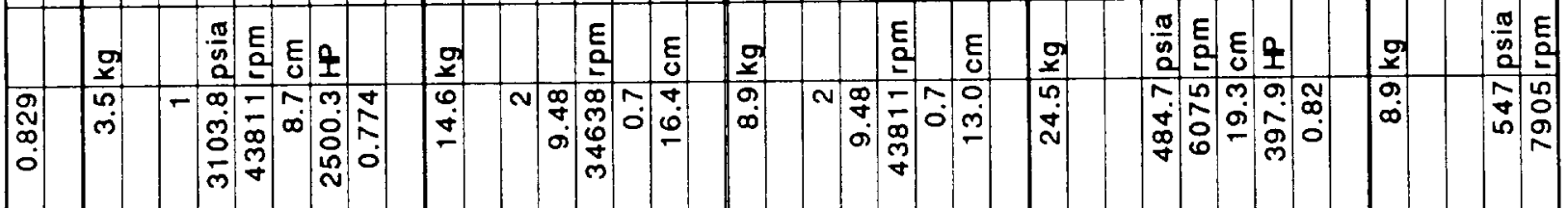

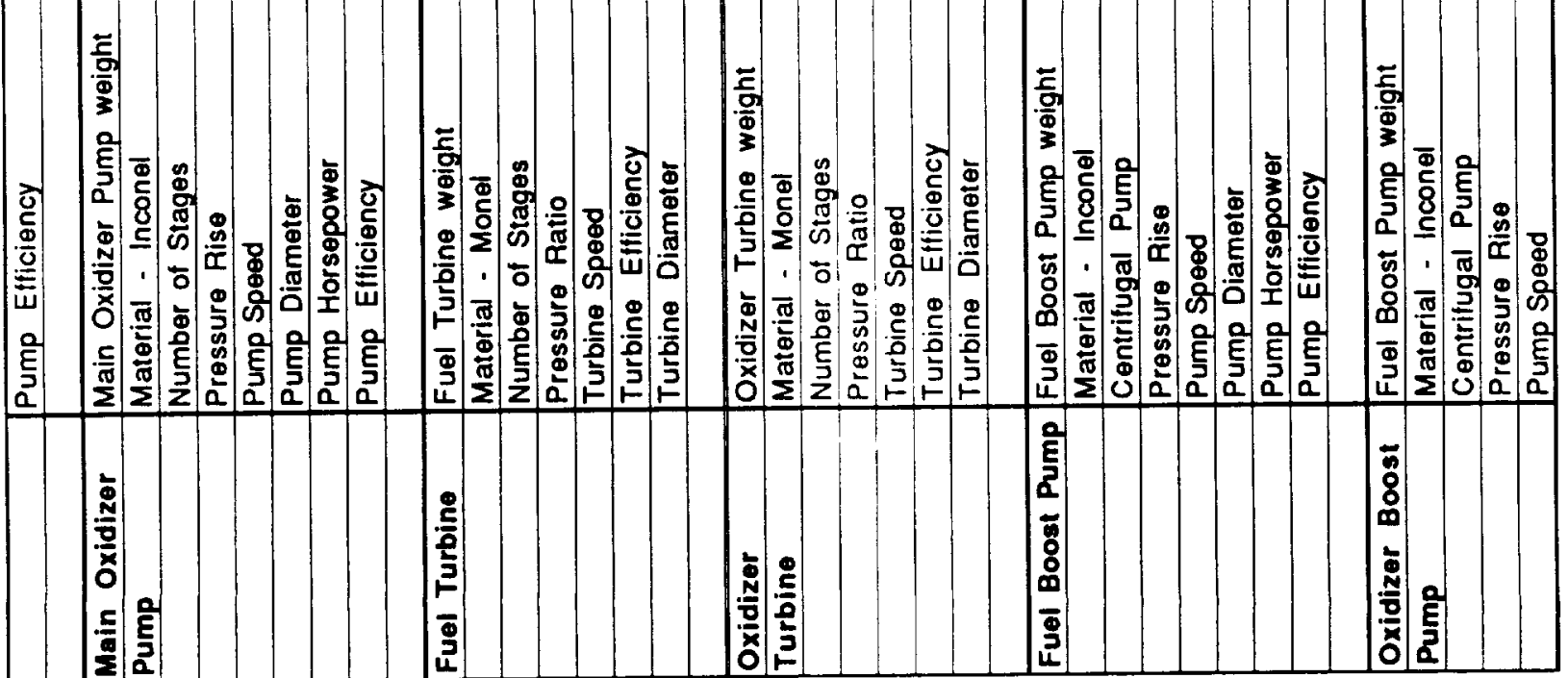





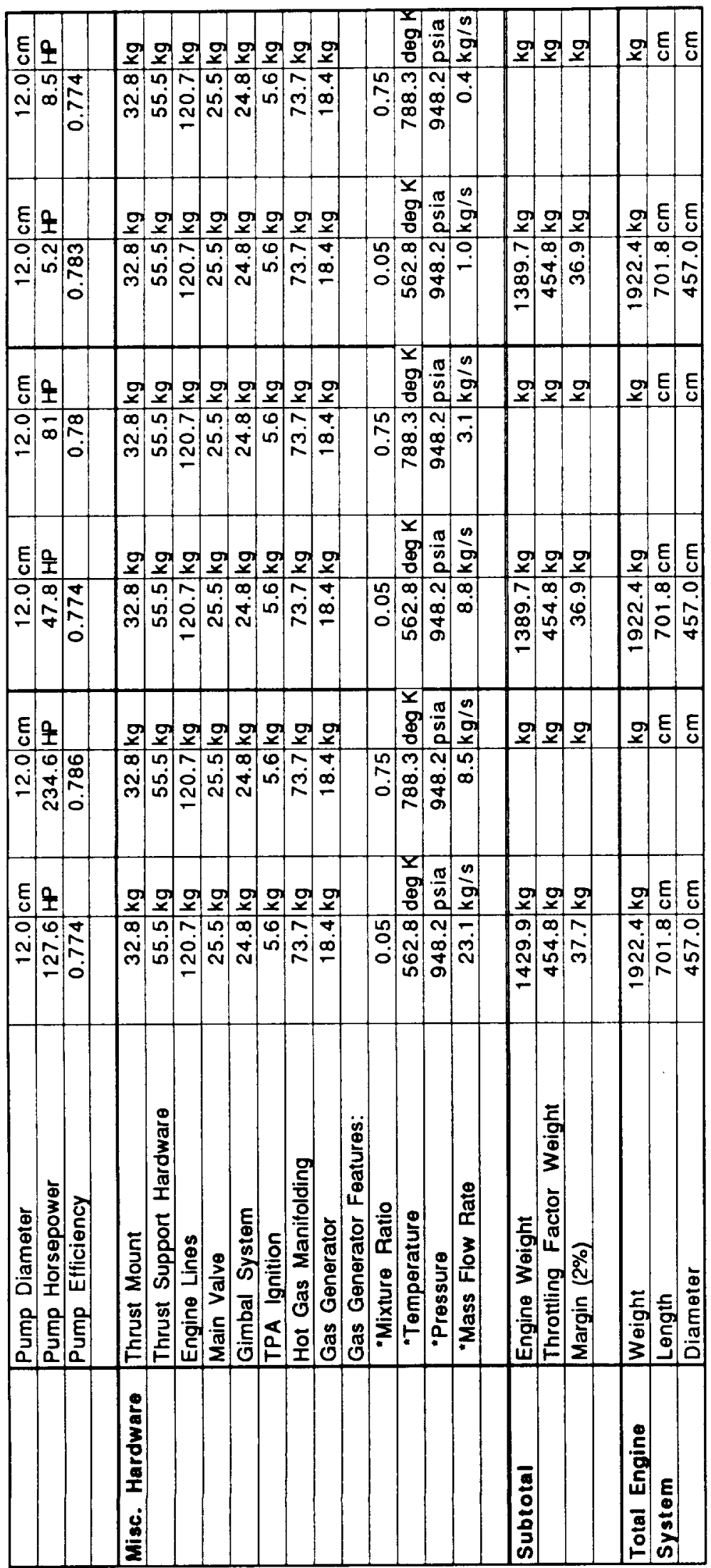





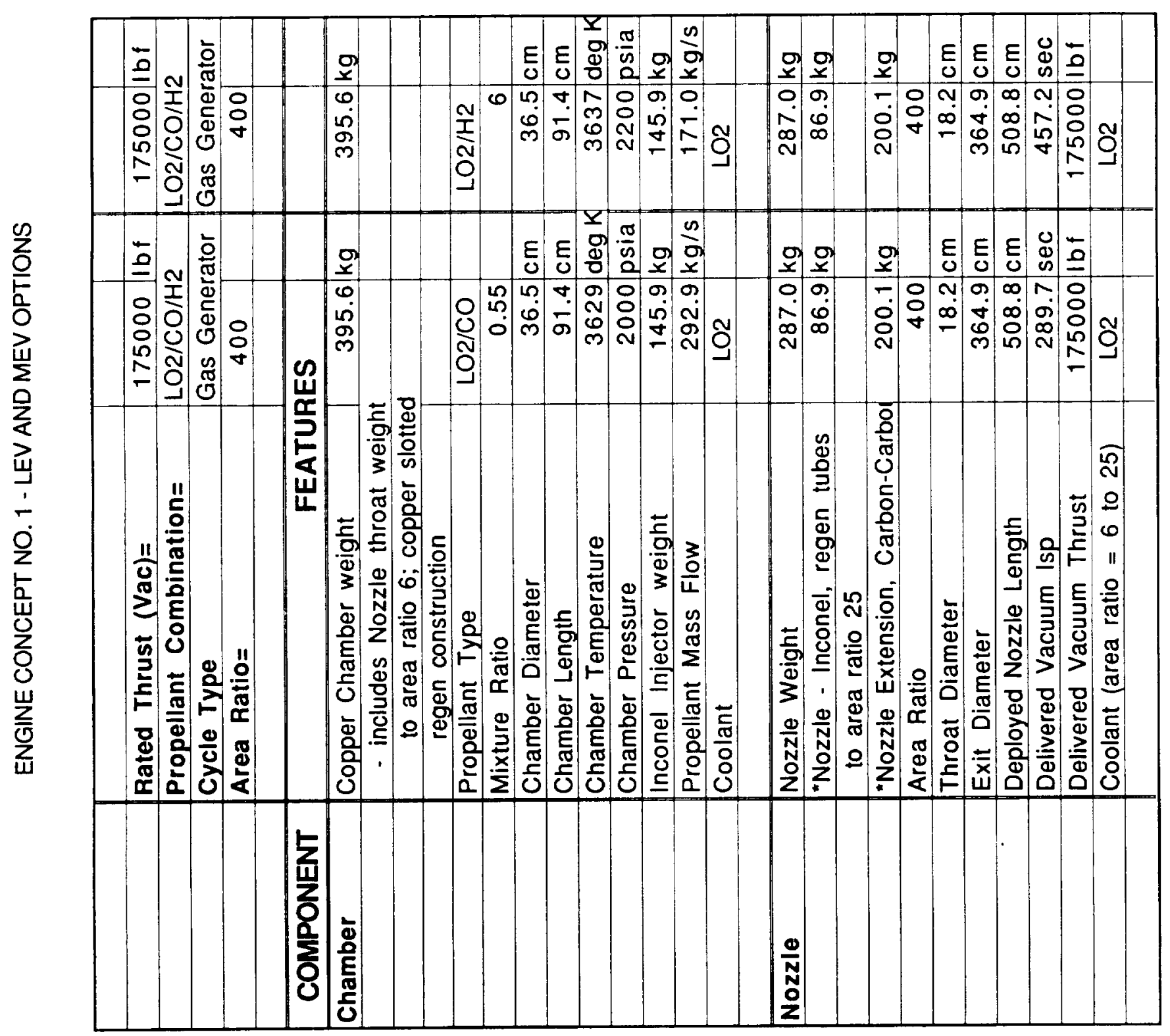





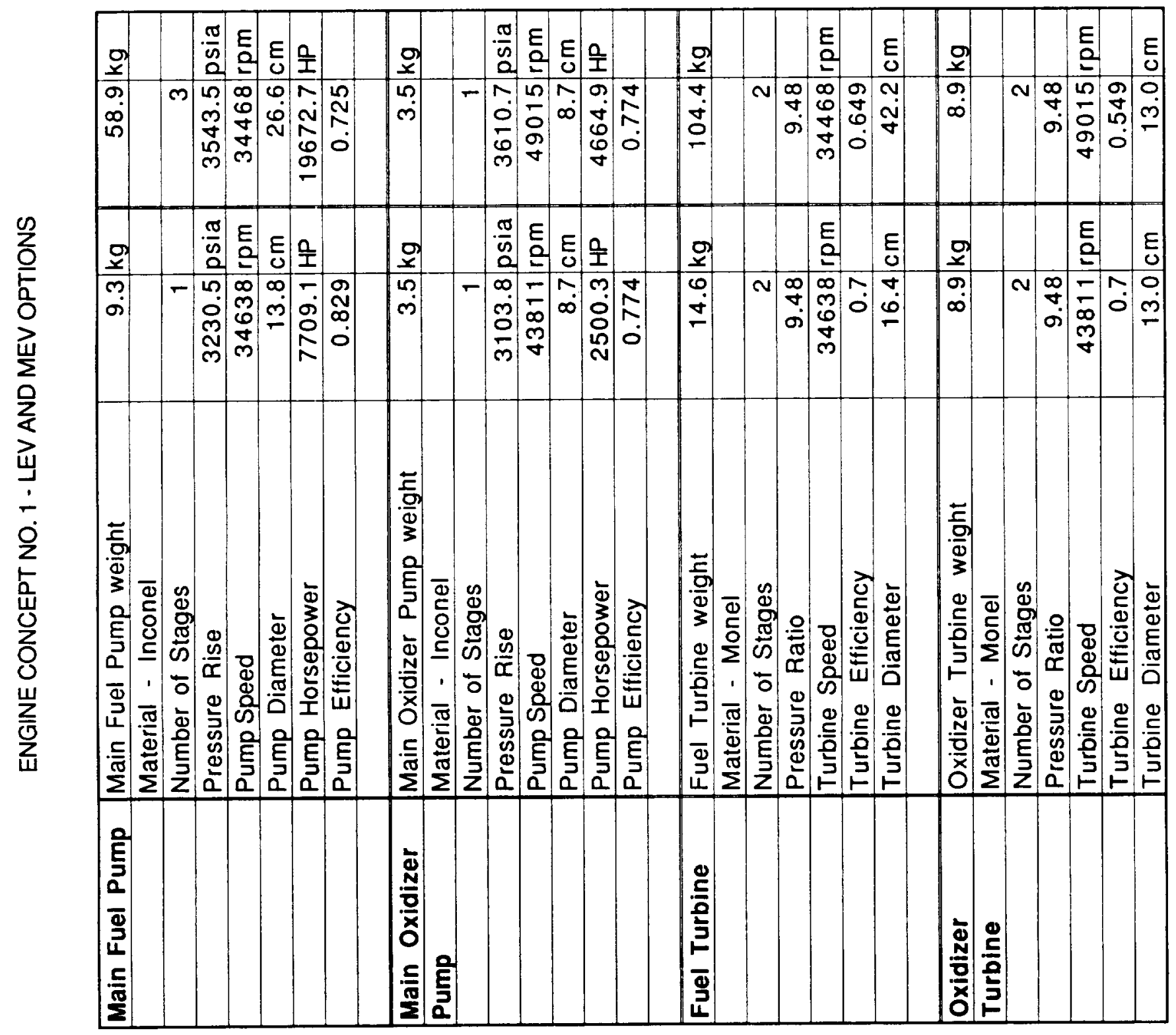





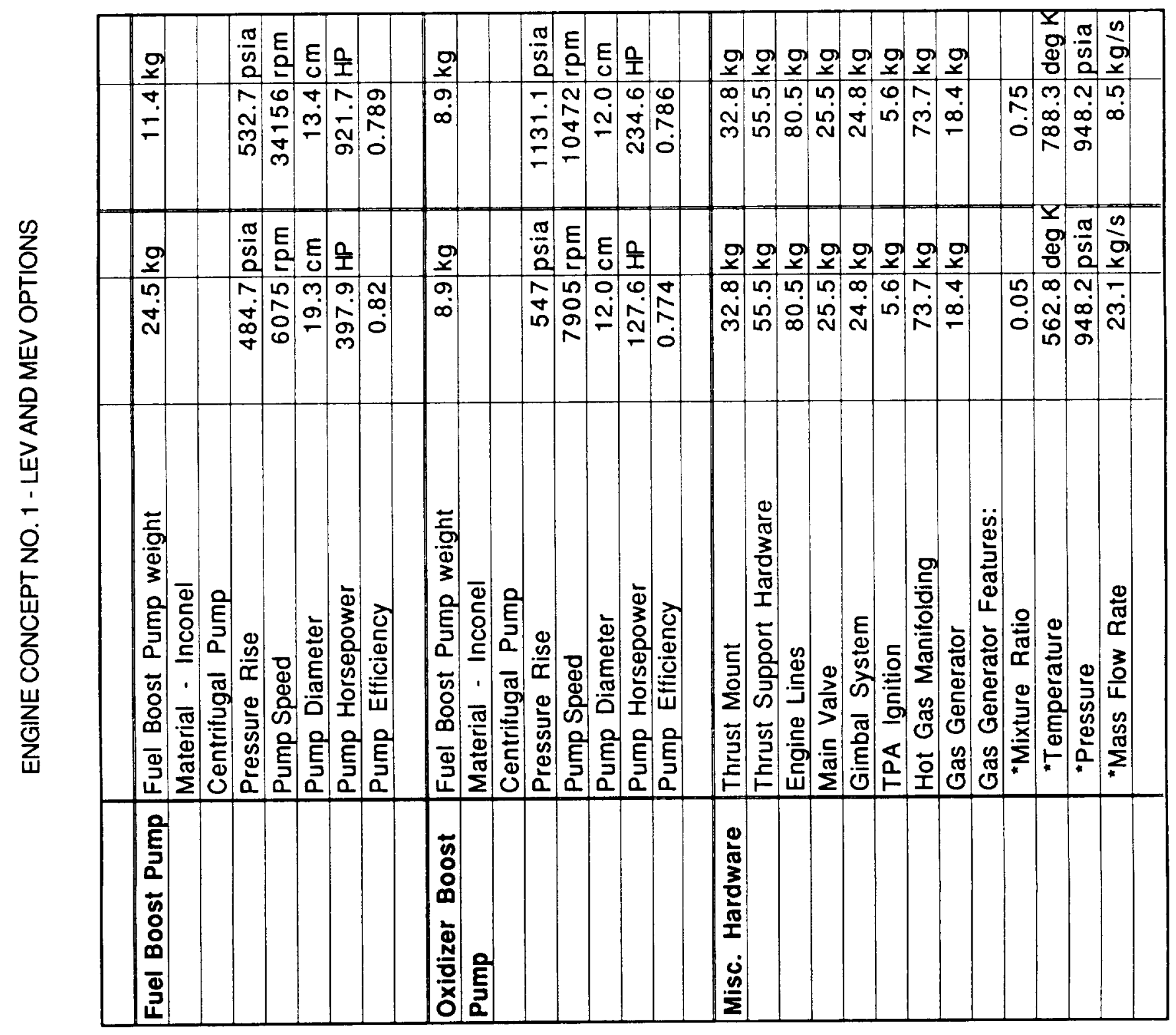





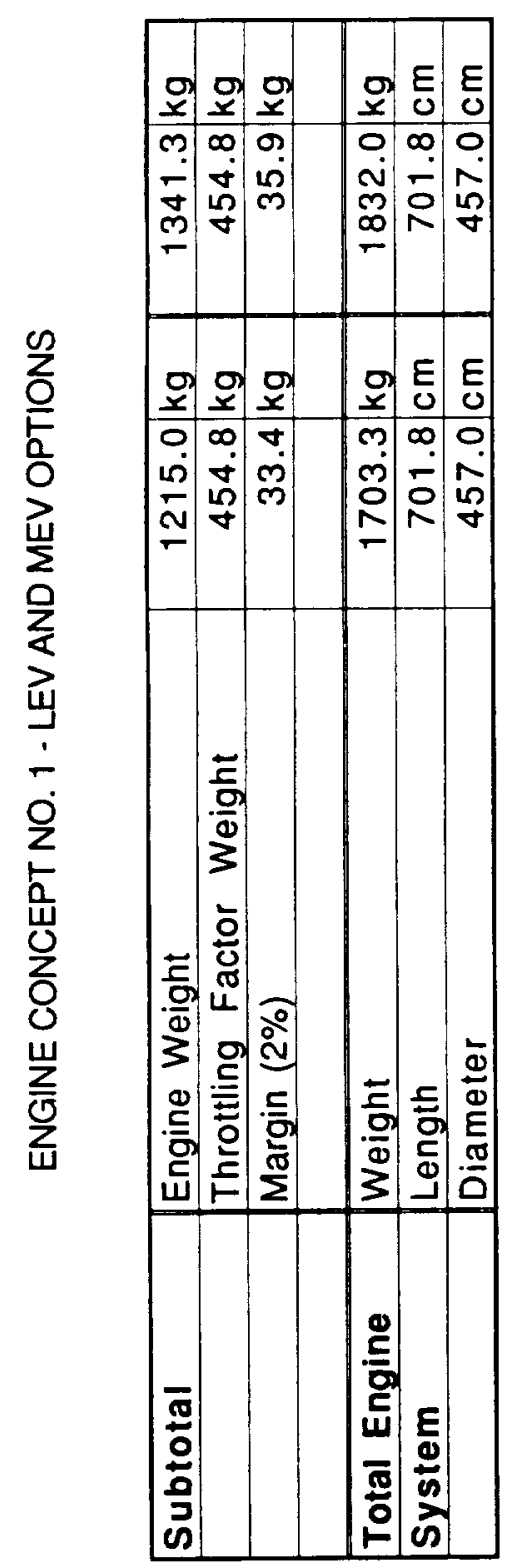





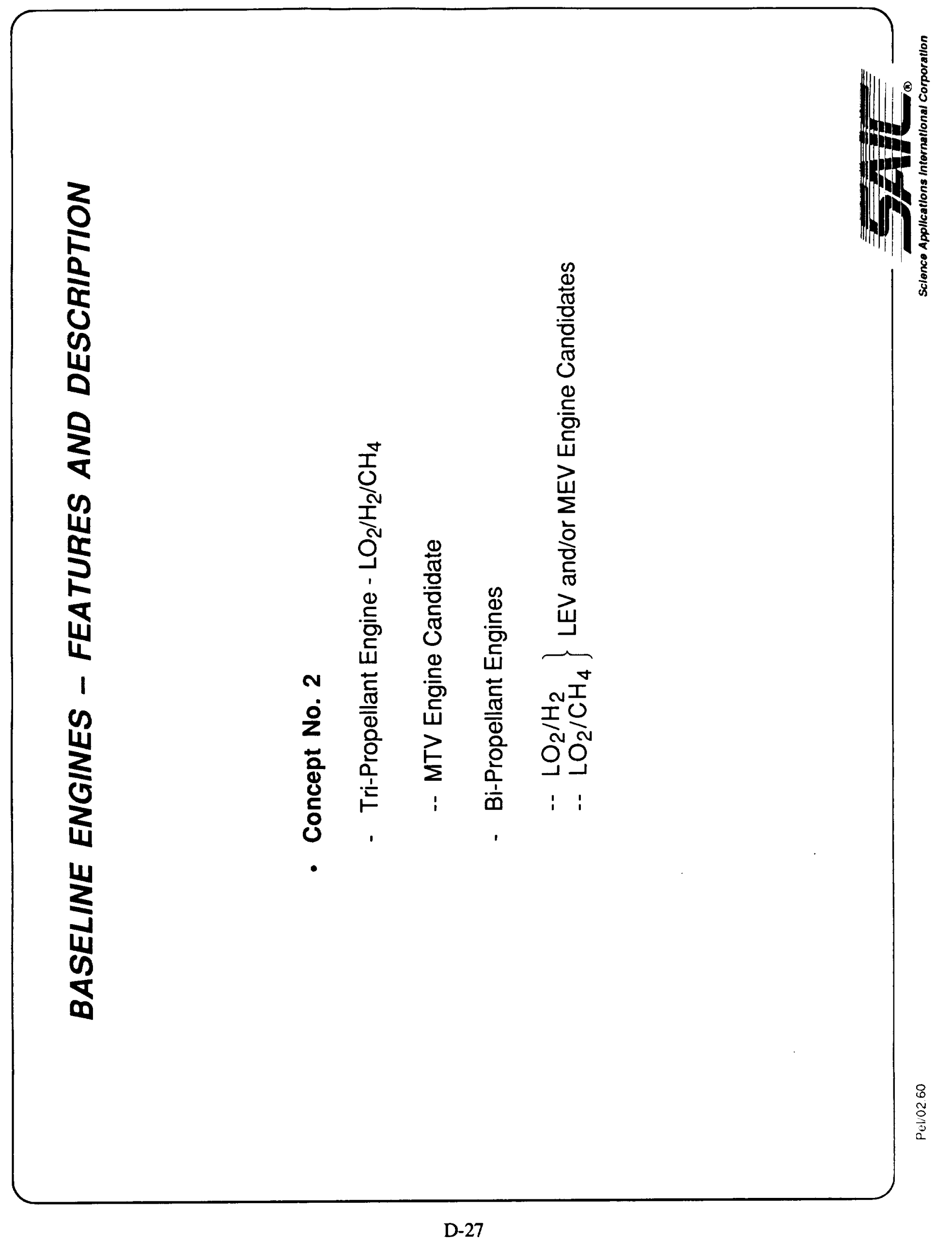





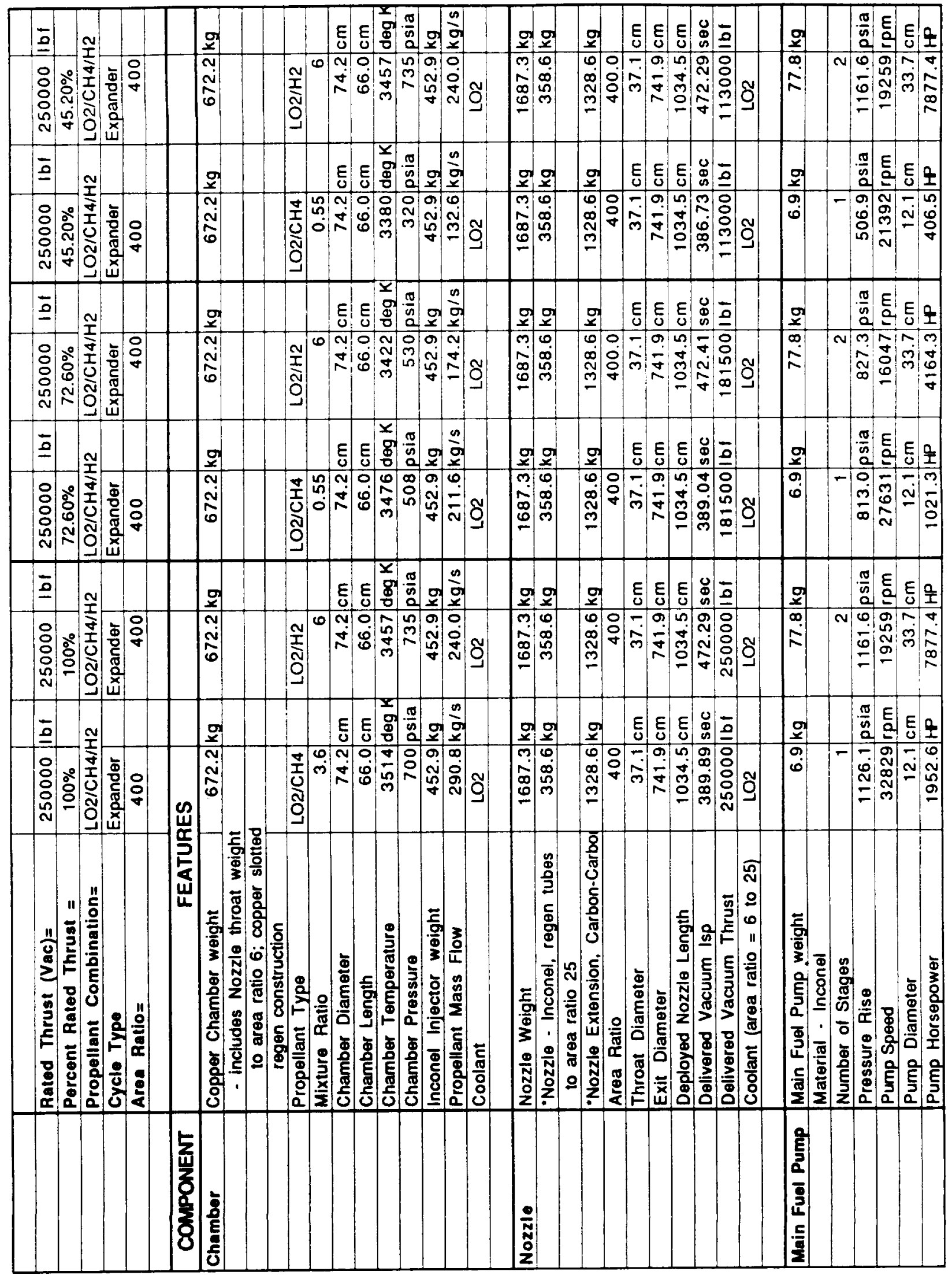





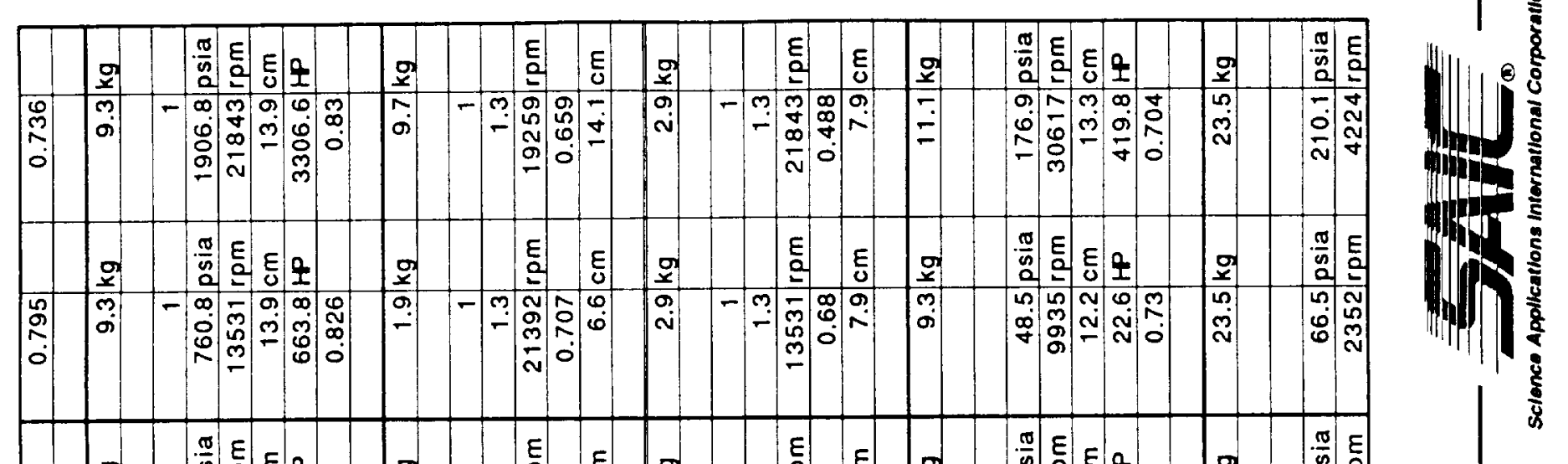

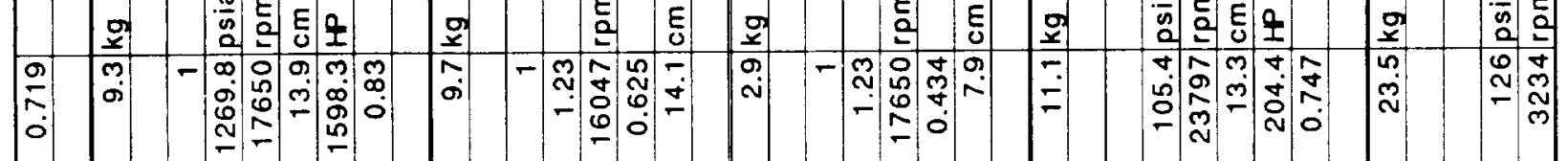

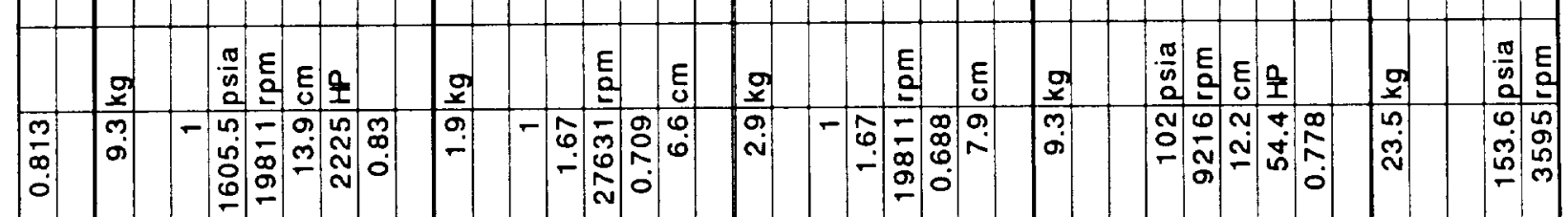

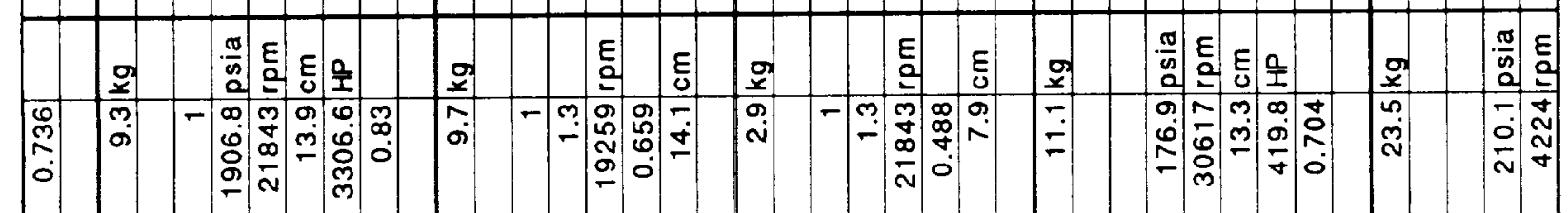

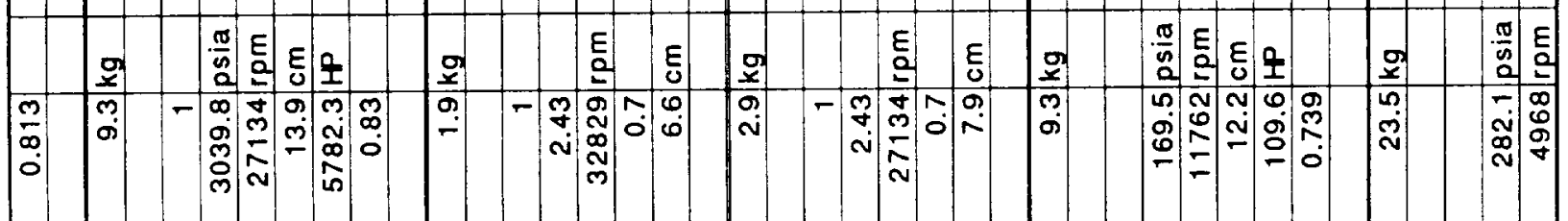

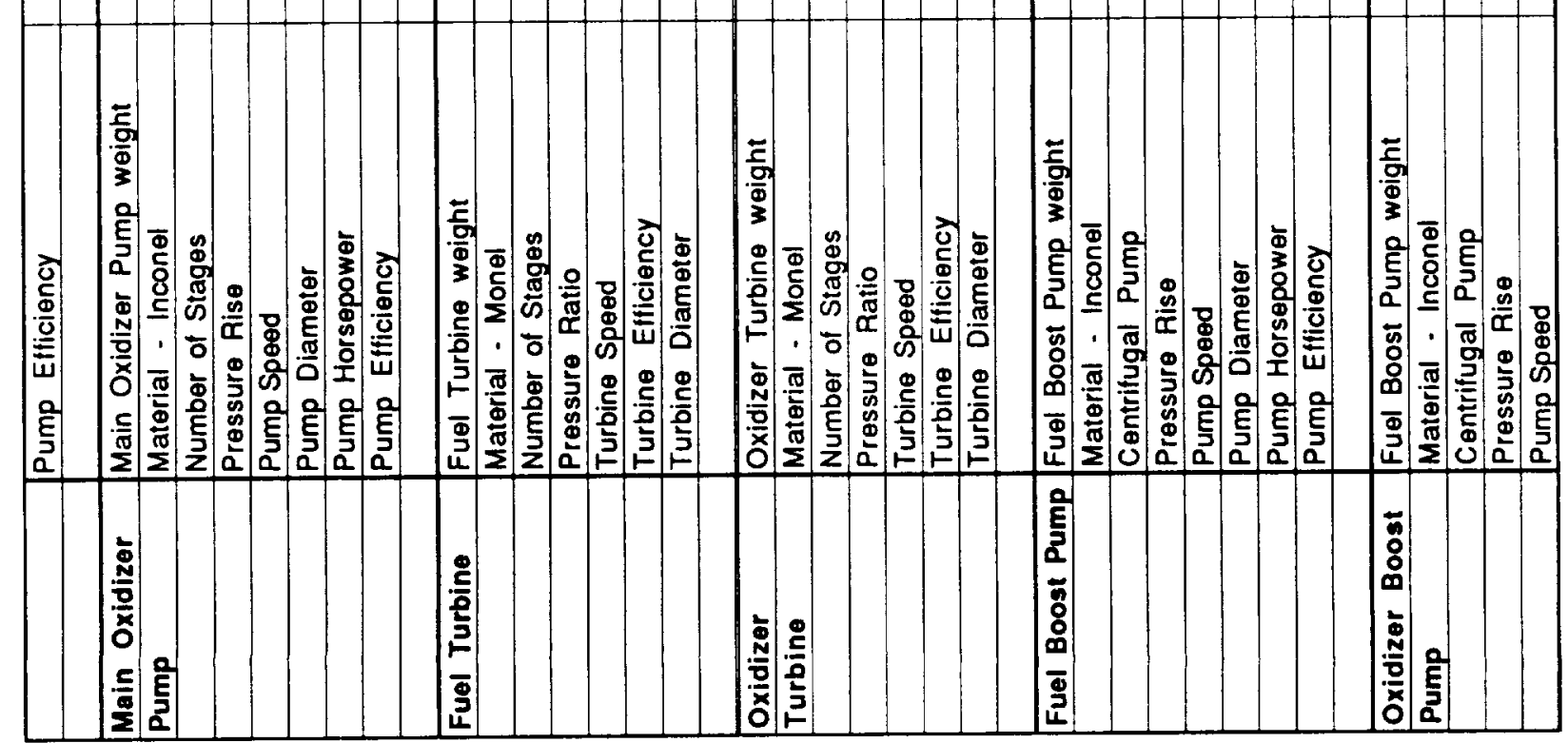





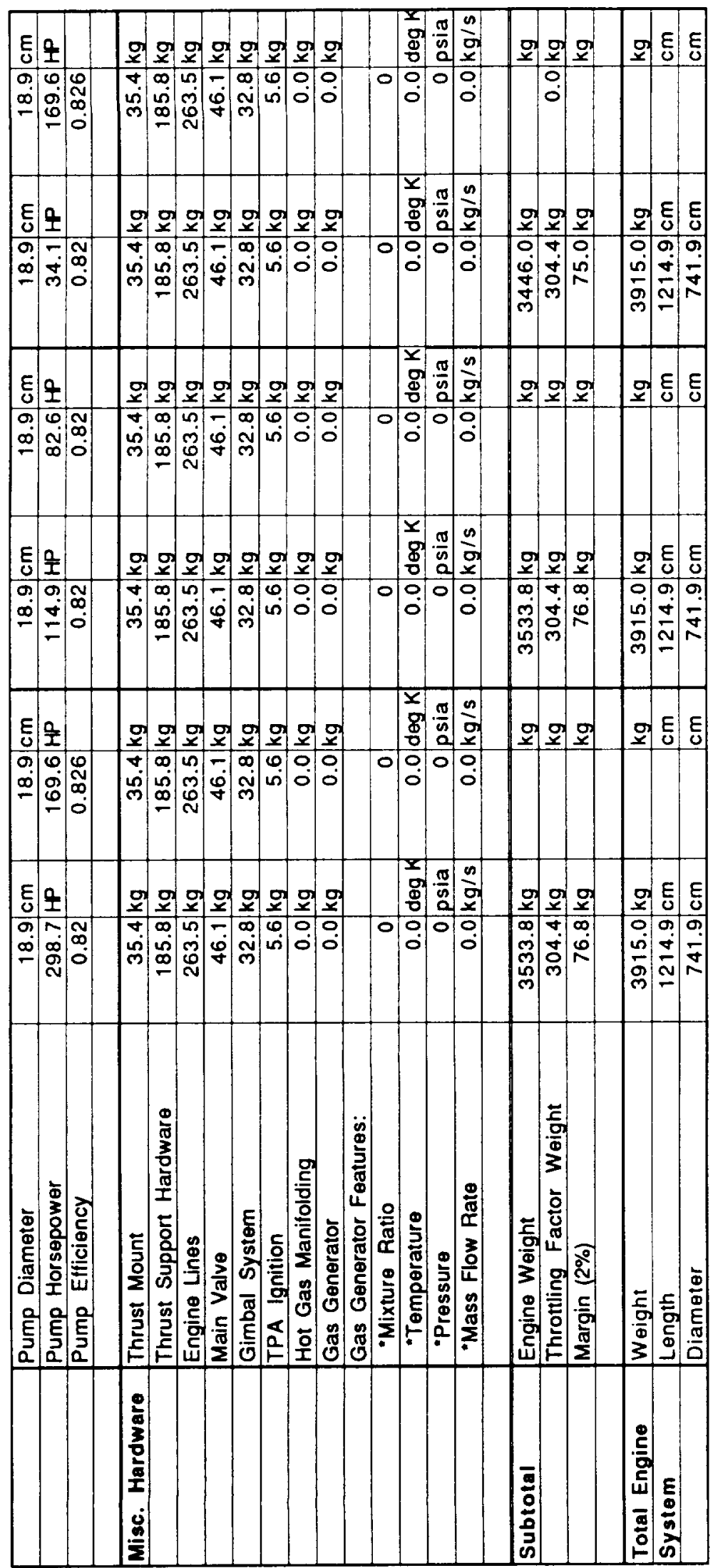





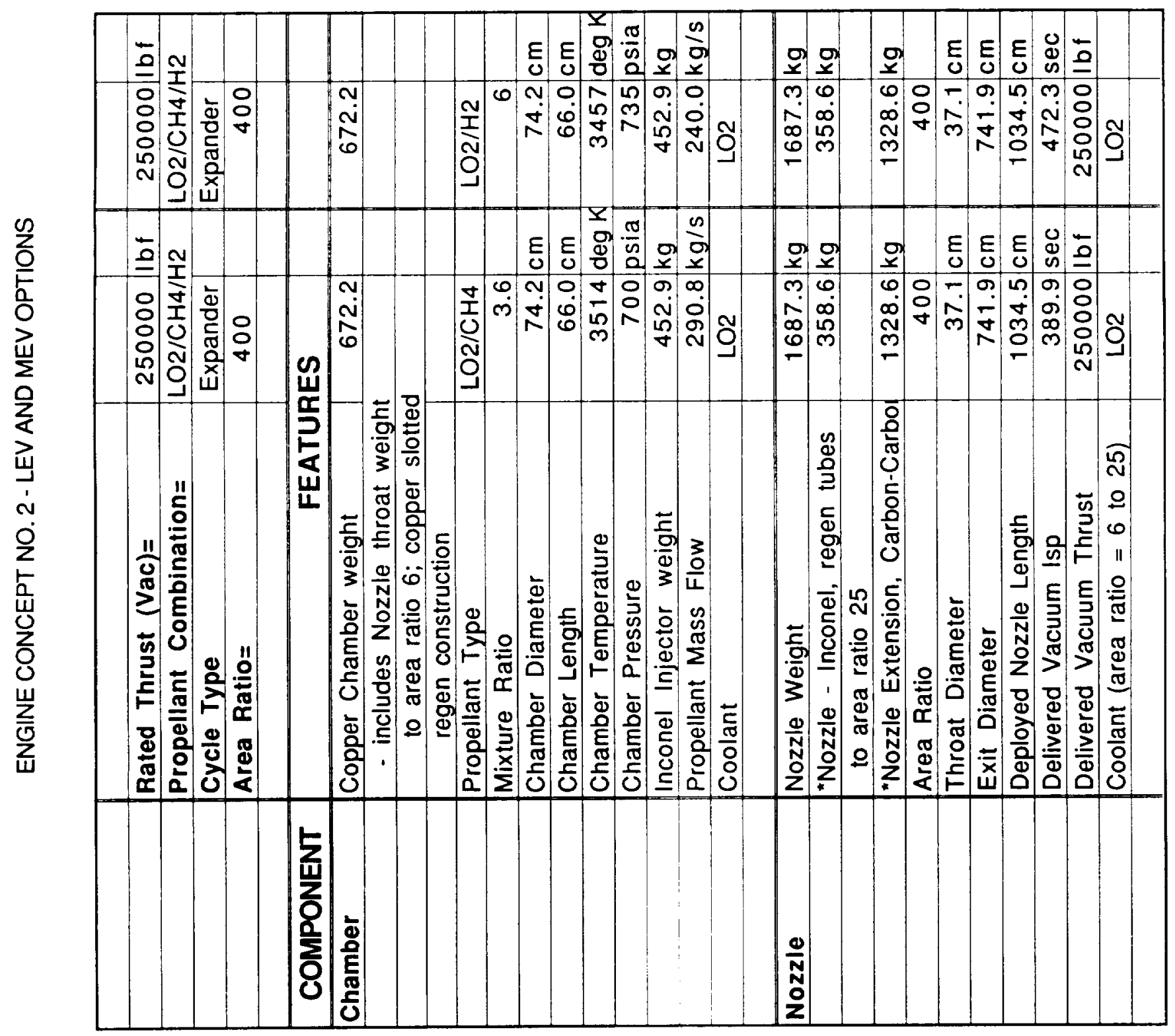





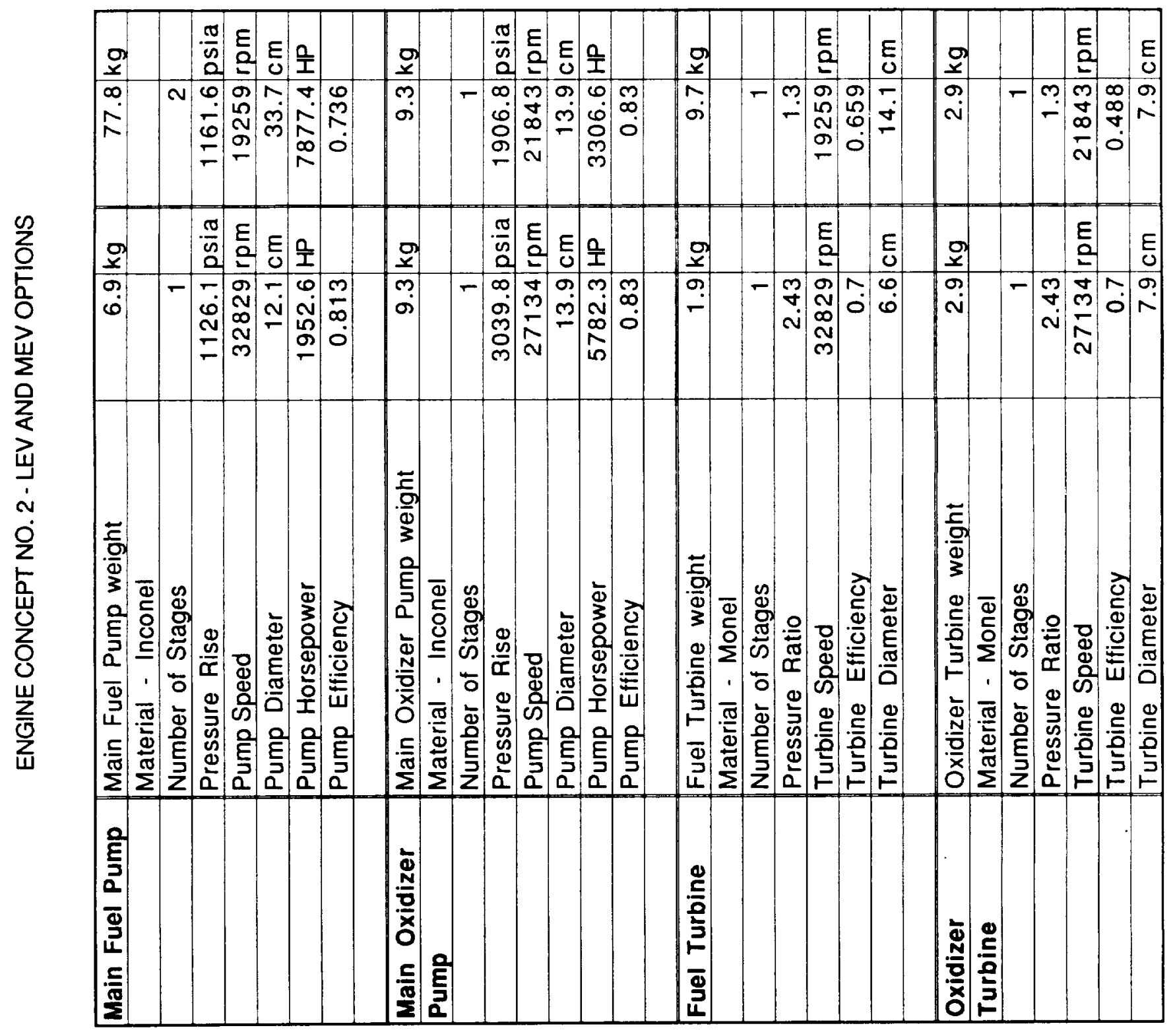





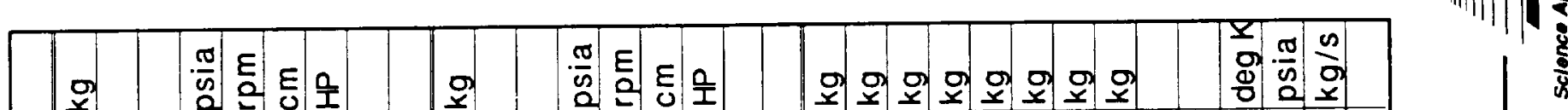

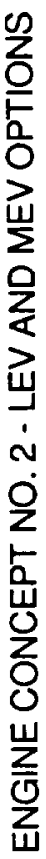

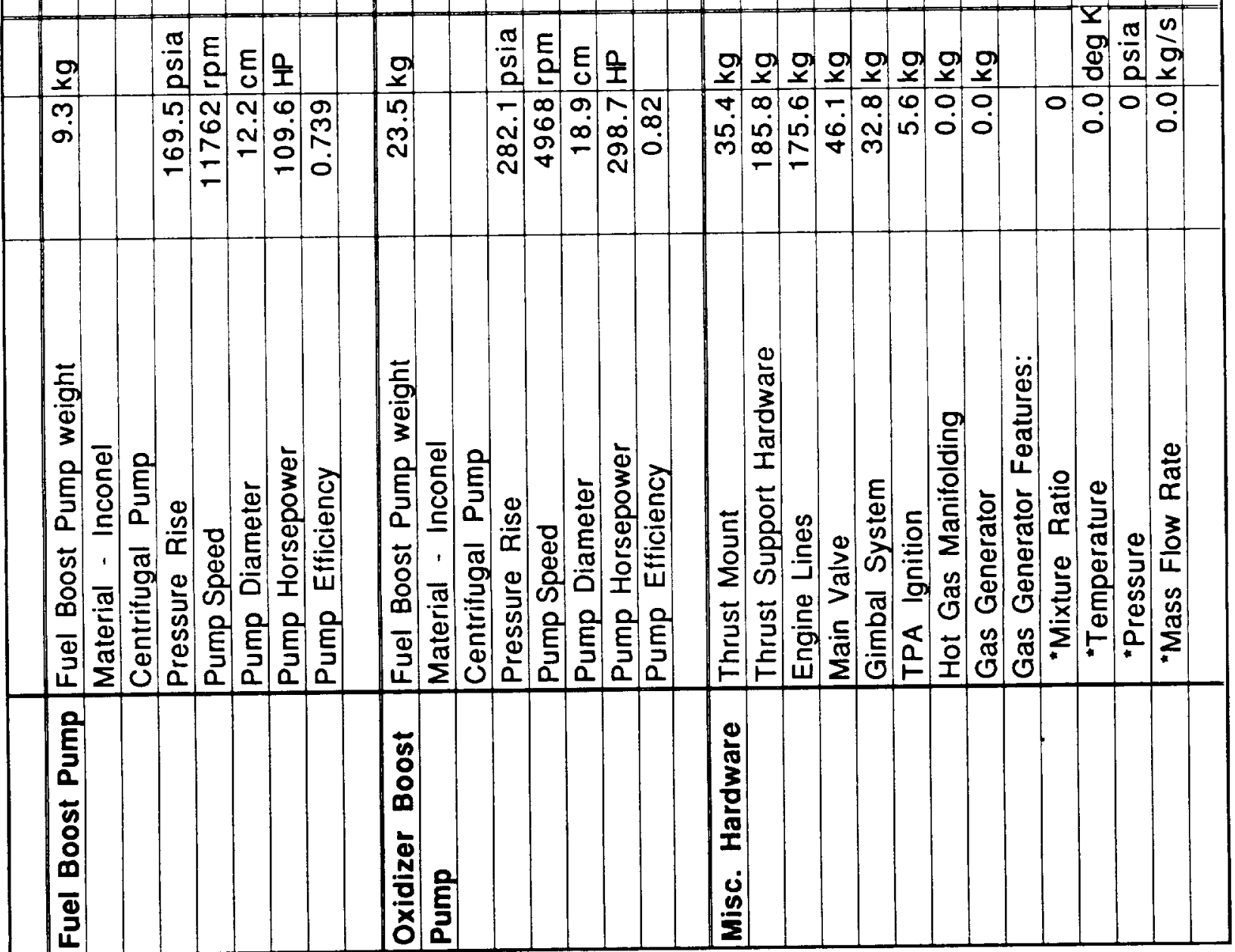





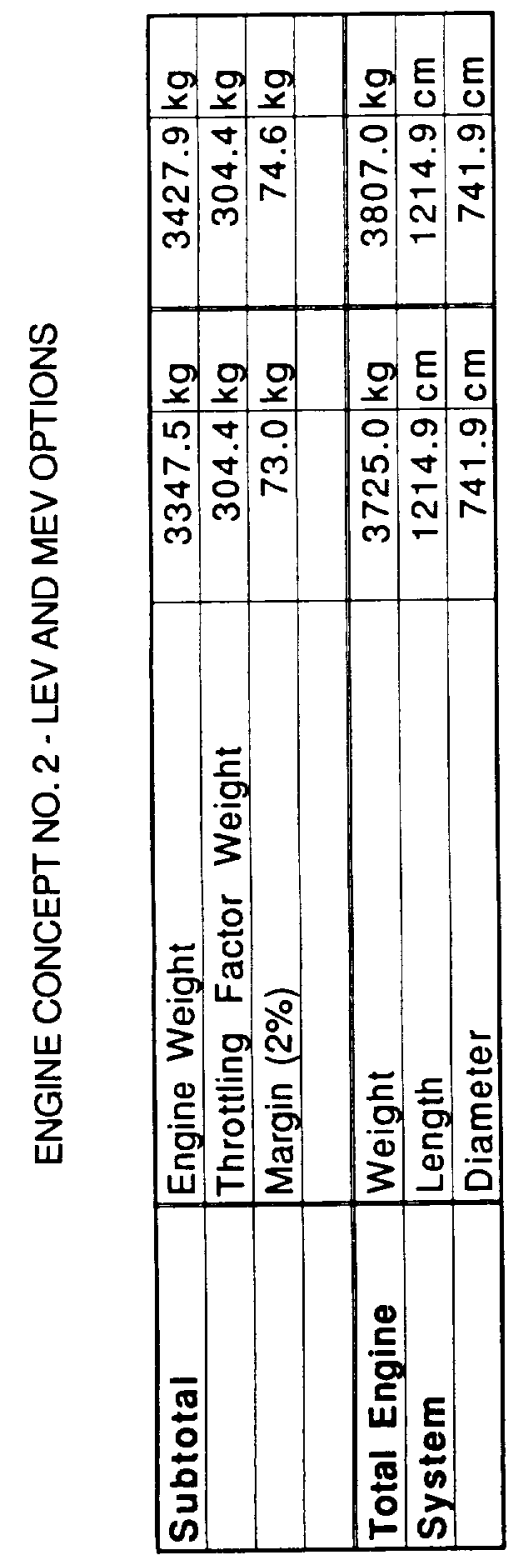





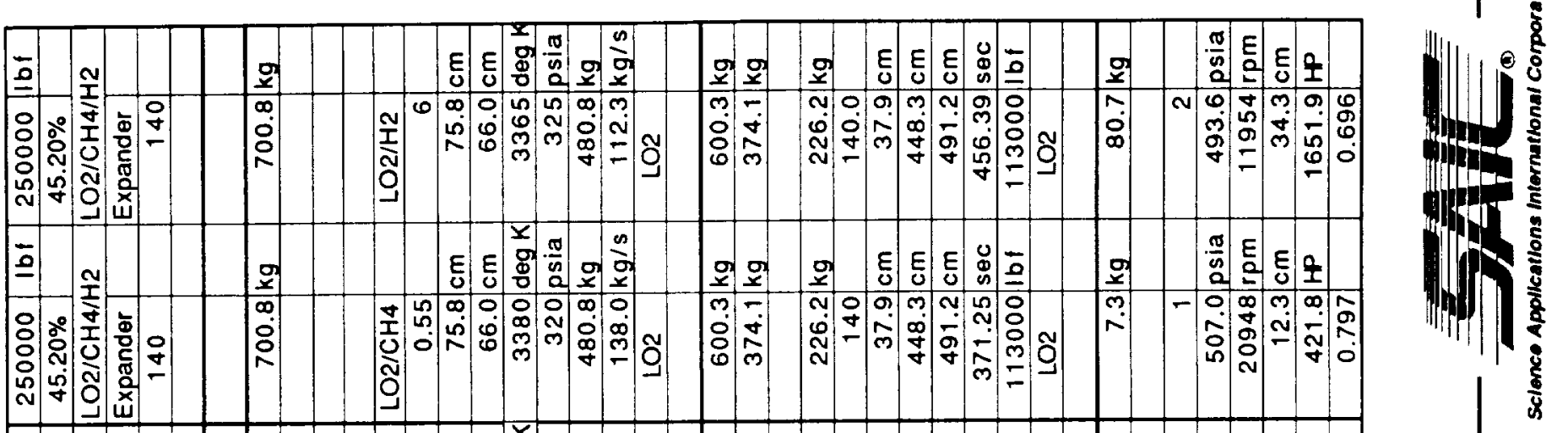

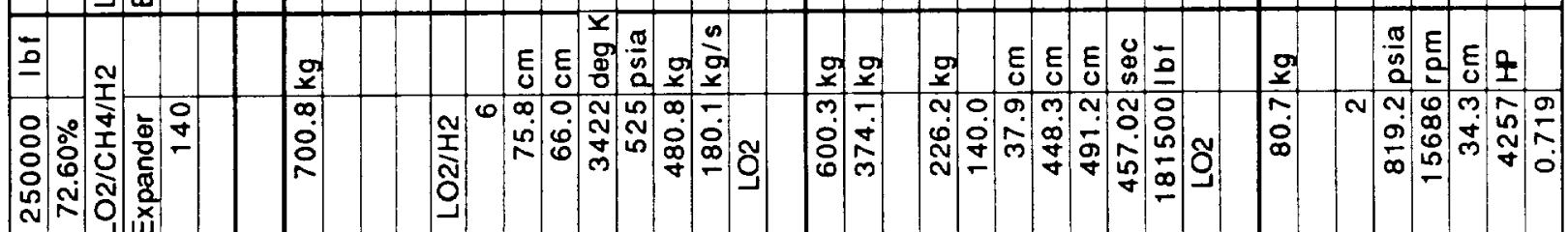

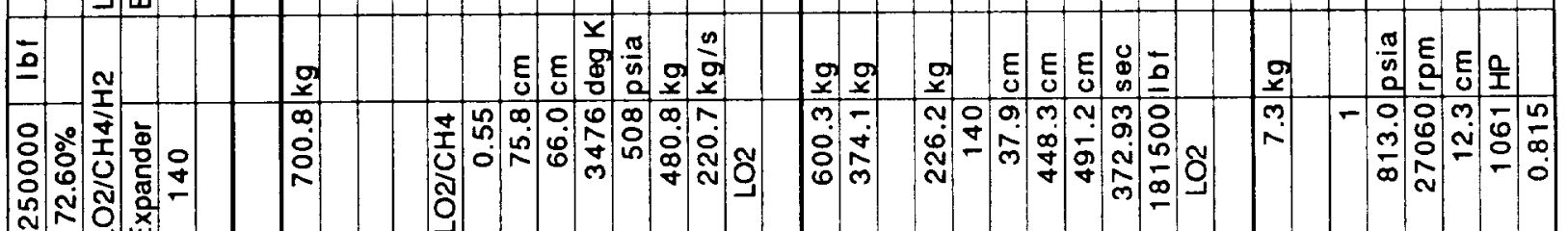
กิกู่

\begin{tabular}{|c|c|c|c|c|c|c|c|c|c|c|c|c|c|c|}
\hline & - & & & & -1 - & m & & & & & & & 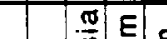 & \\
\hline & ㄴ. & ? & & & \begin{tabular}{l|l|l|l}
$E$ & $E$ & 0 & 0 \\
\end{tabular} & 2 우웡 & $9)^{0}$ & 9 & E & E & EE \begin{tabular}{|c|c}
0 \\
0
\end{tabular} & ? & 현ㅎํㄴ & E్ \\
\hline & 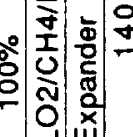 & $\mid$ & 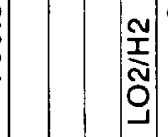 & & 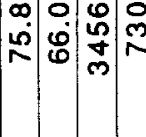 & 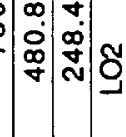 & $\left|\begin{array}{c|c}m & \bar{j} \\
0 & \dot{+} \\
0 & 0 \\
0\end{array}\right|$ & 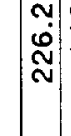 & 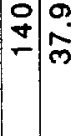 & 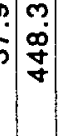 & 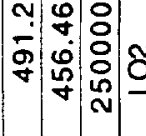 & $\mid \begin{array}{l}0 \\
\dot{\infty}\end{array}$ & 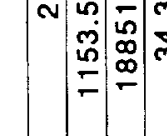 & 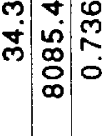 \\
\hline
\end{tabular}

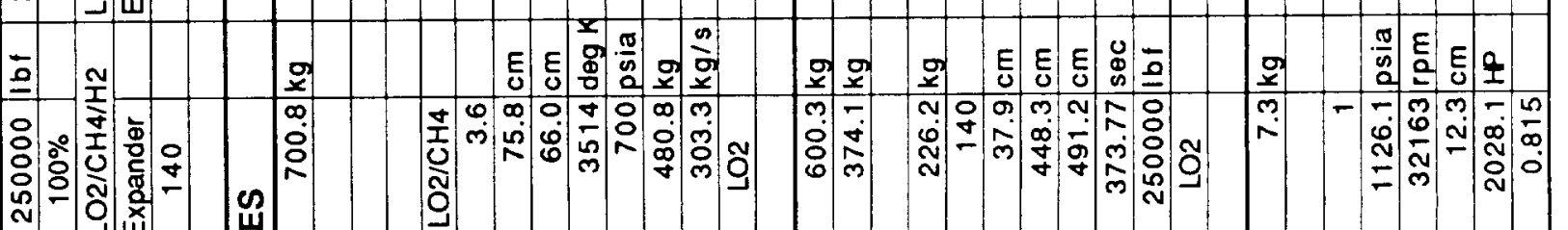

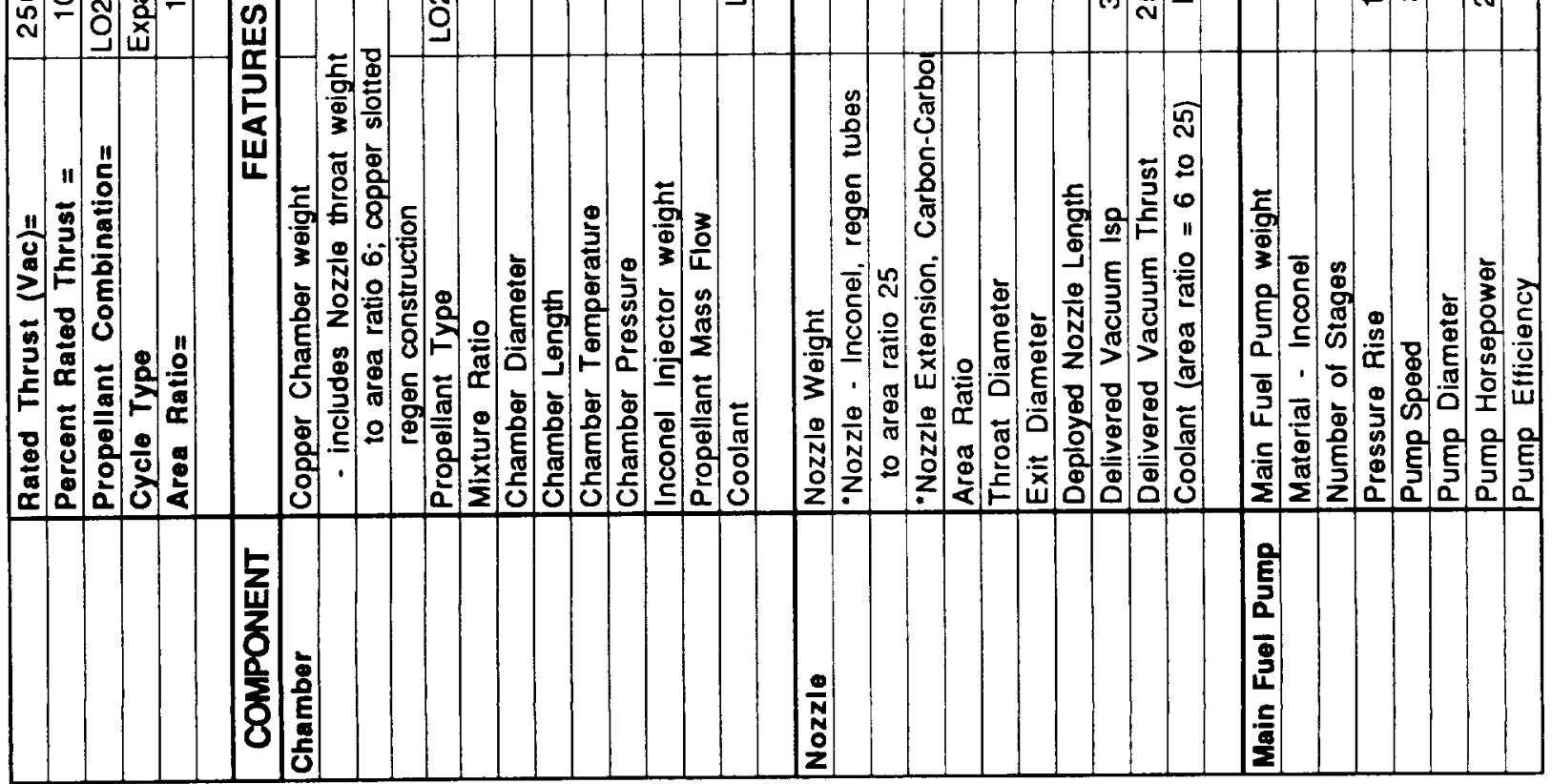





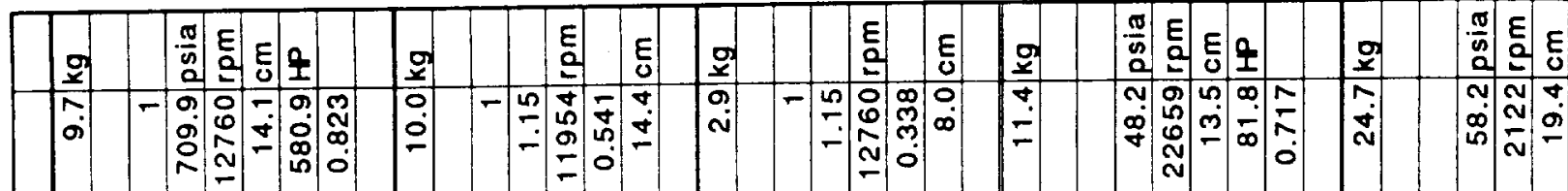

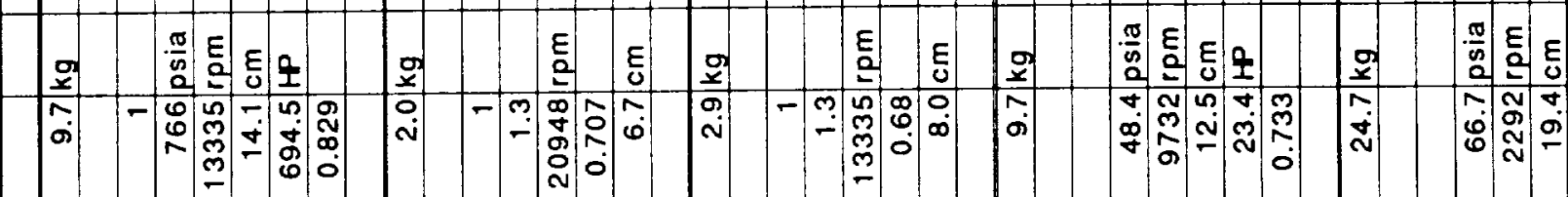

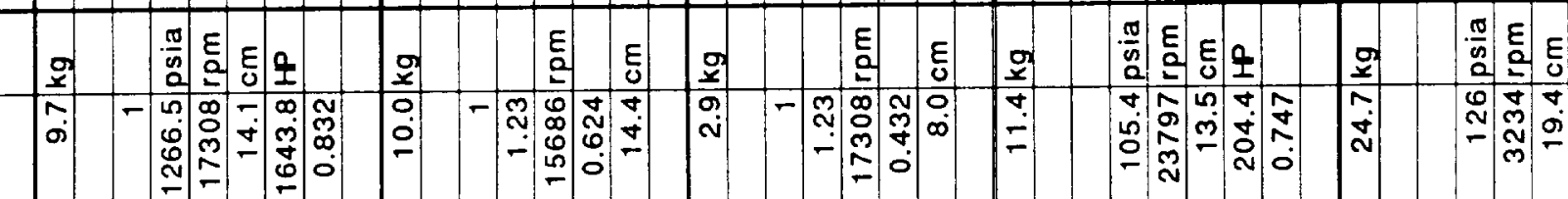

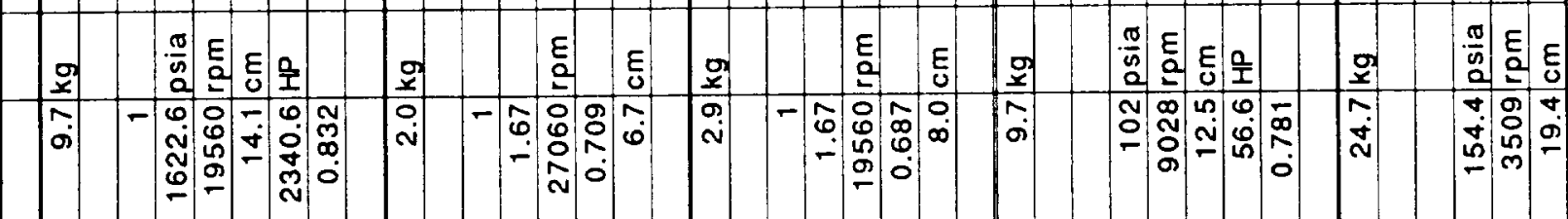

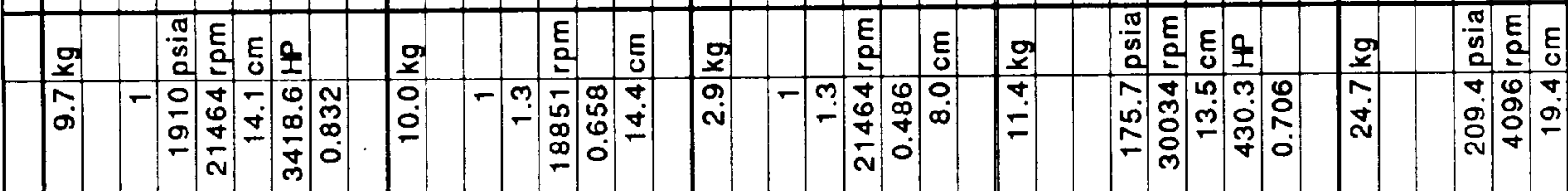

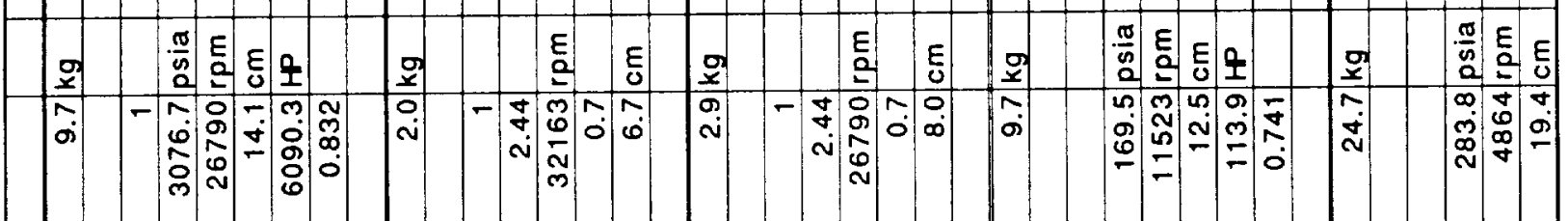

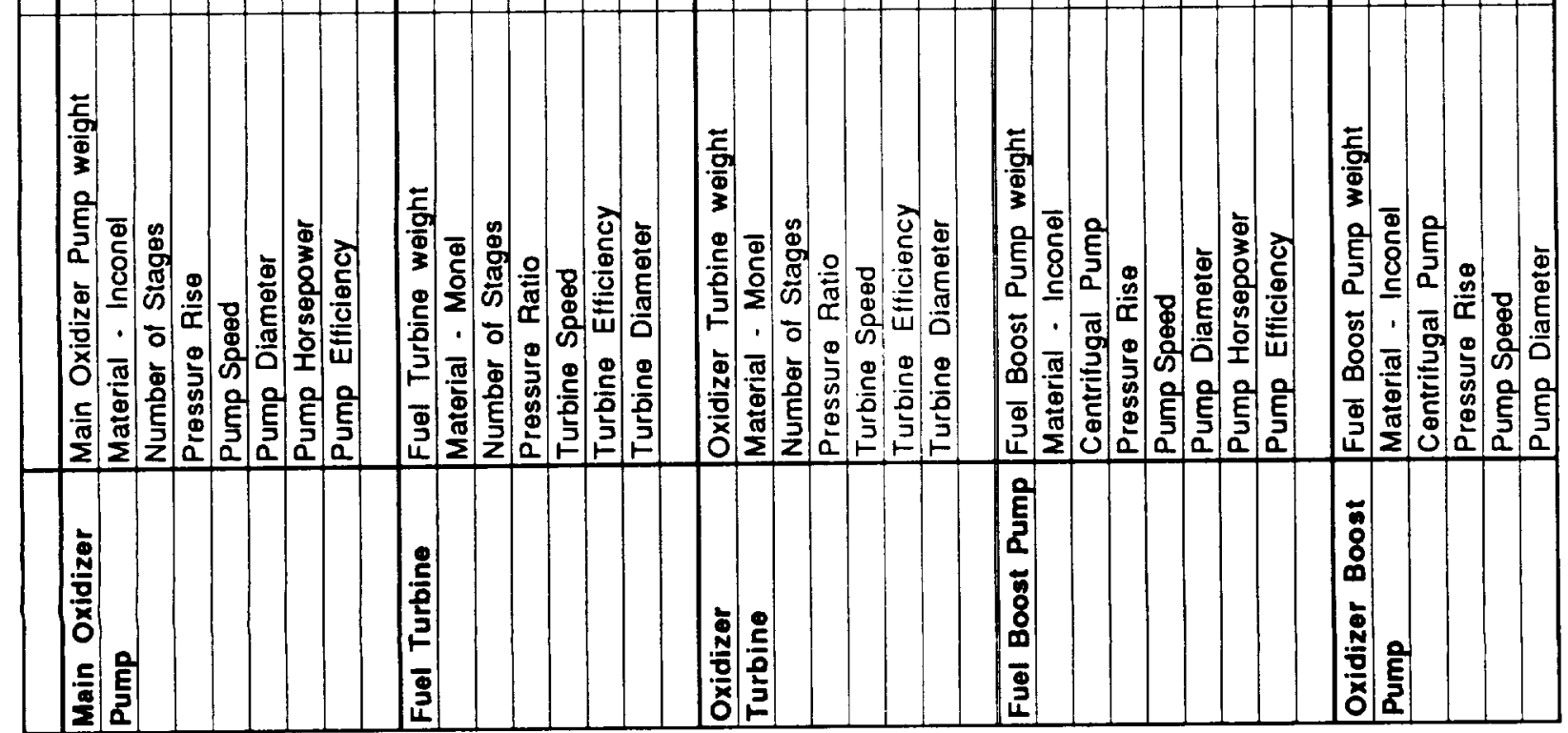





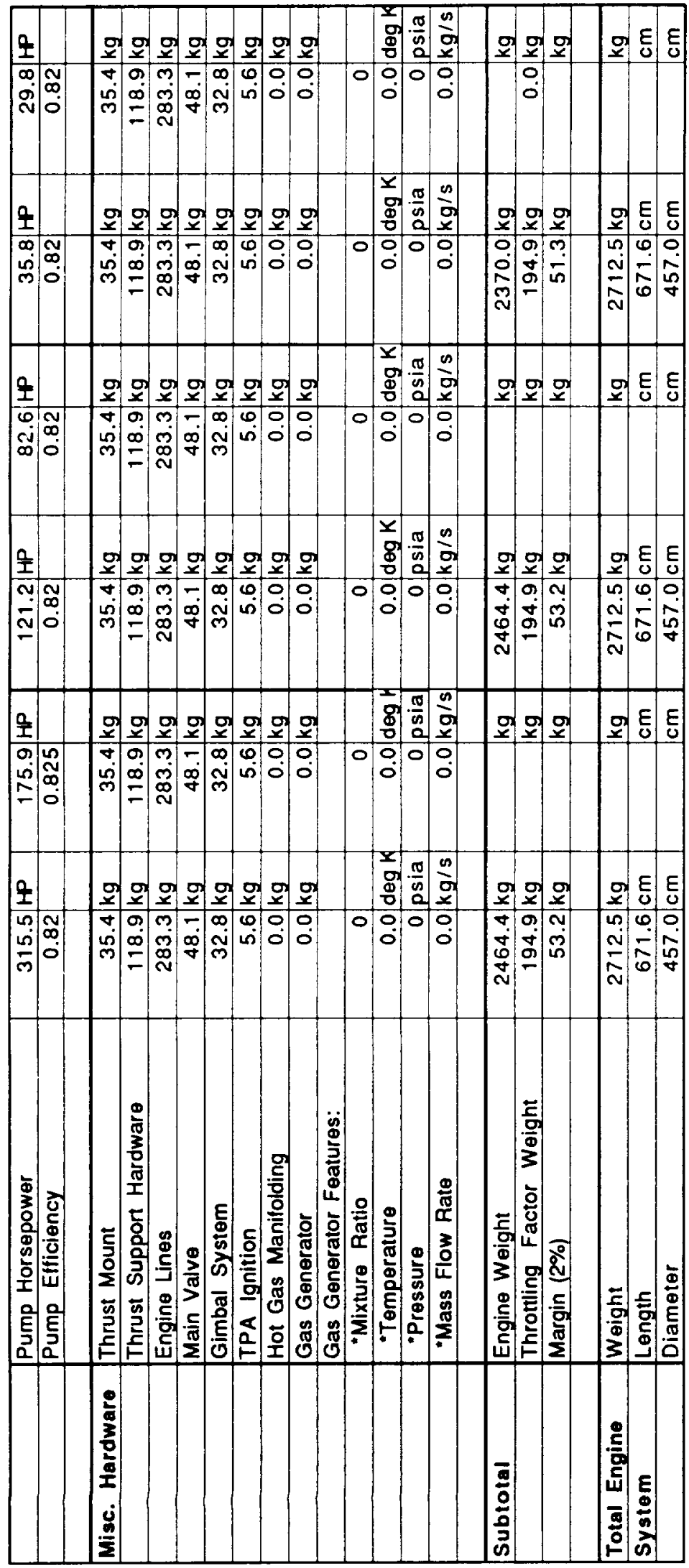





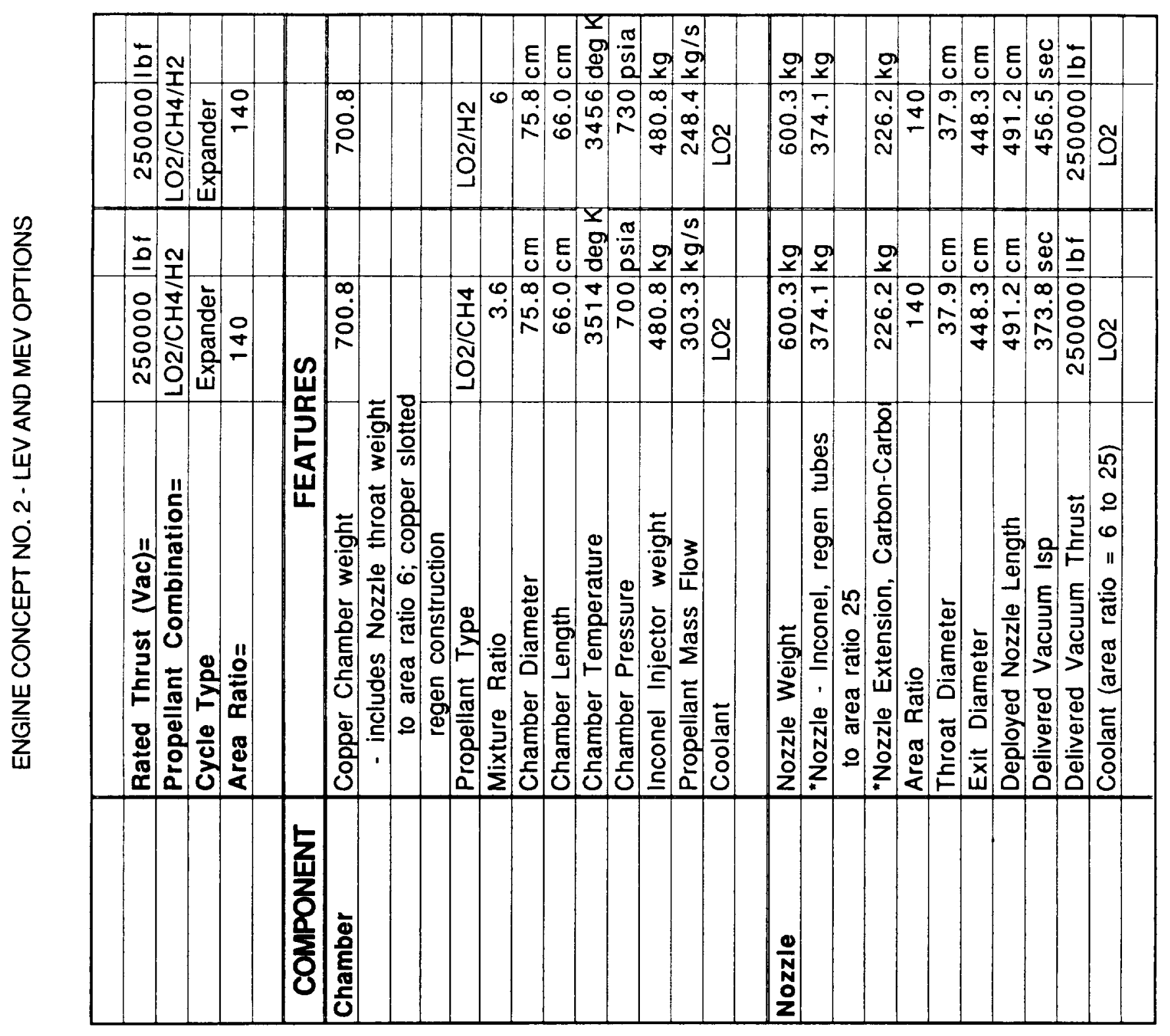





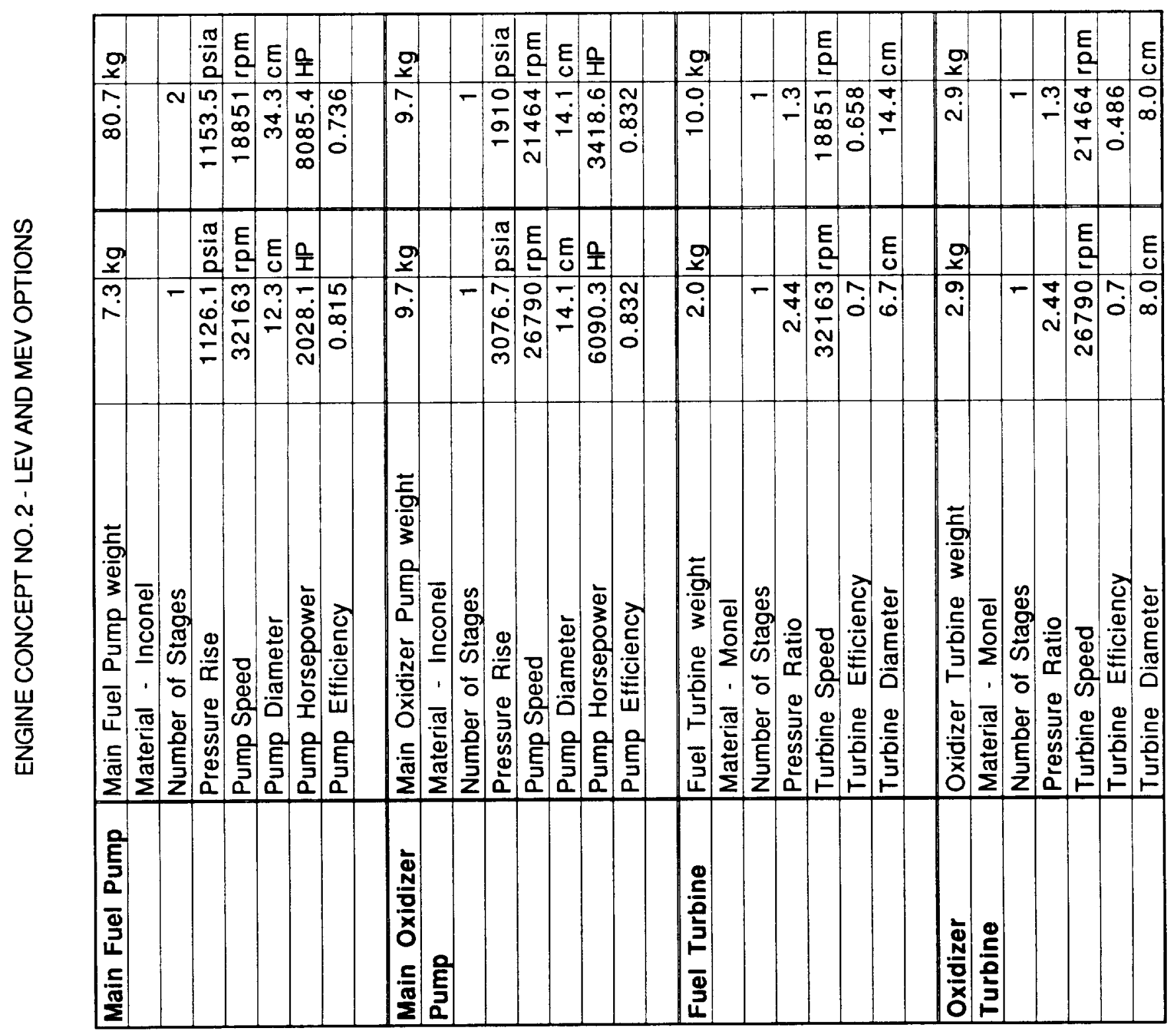





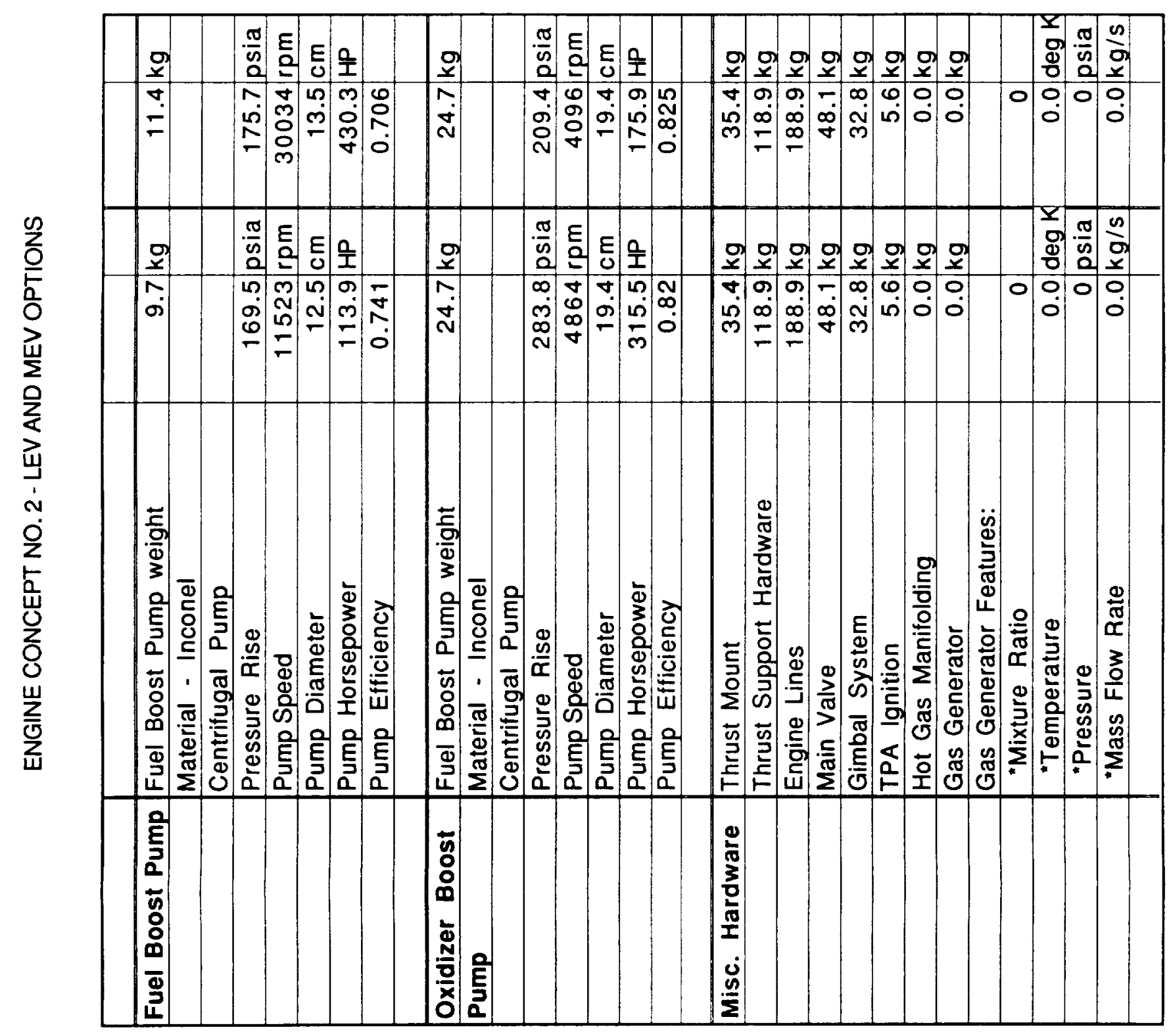





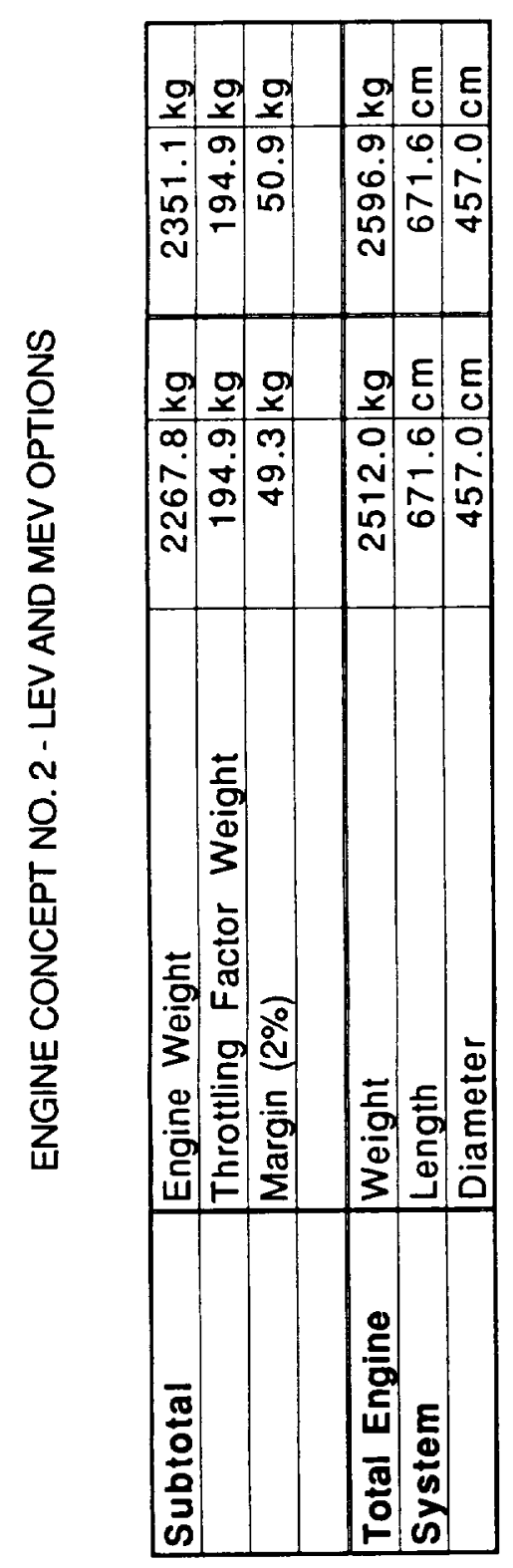





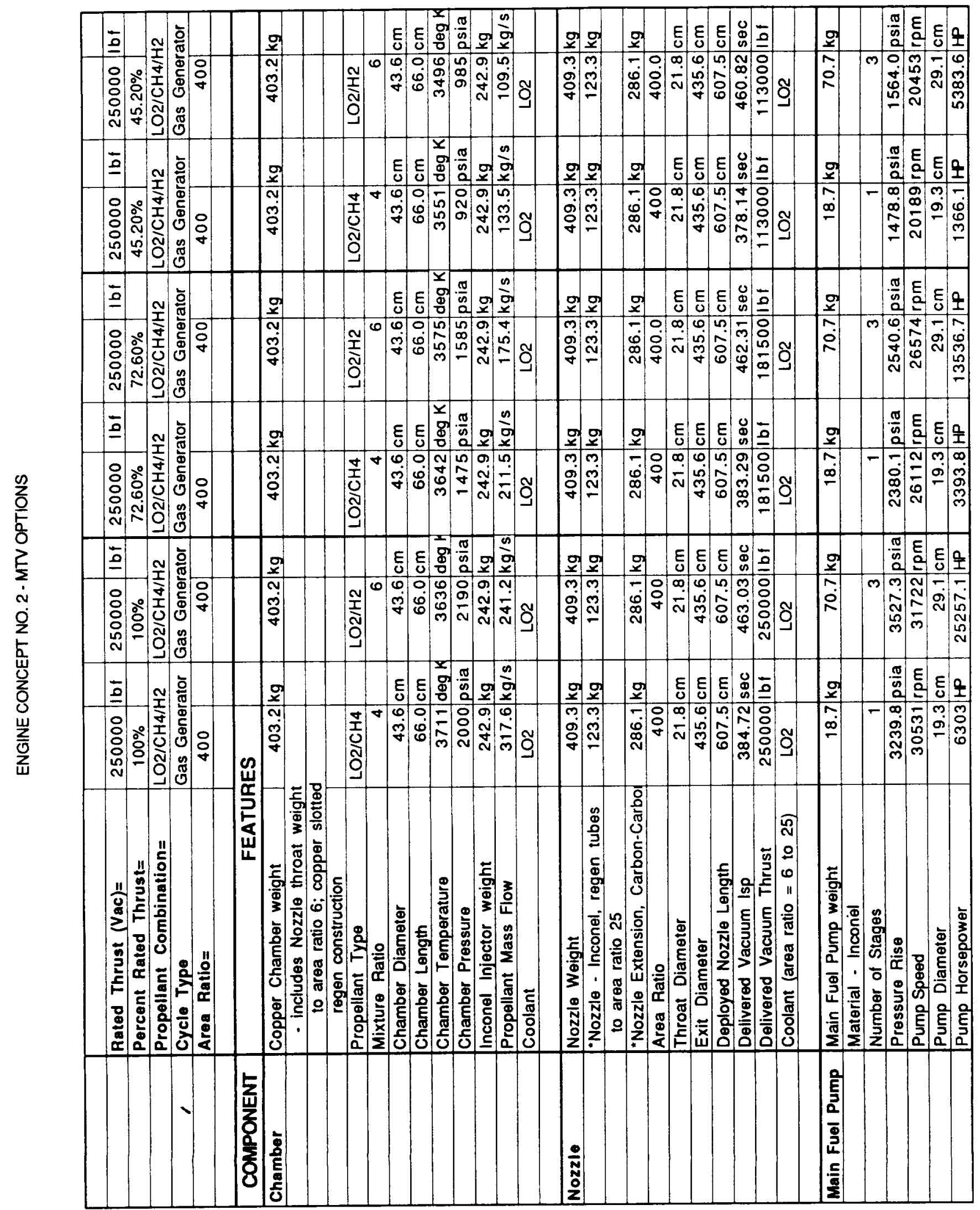





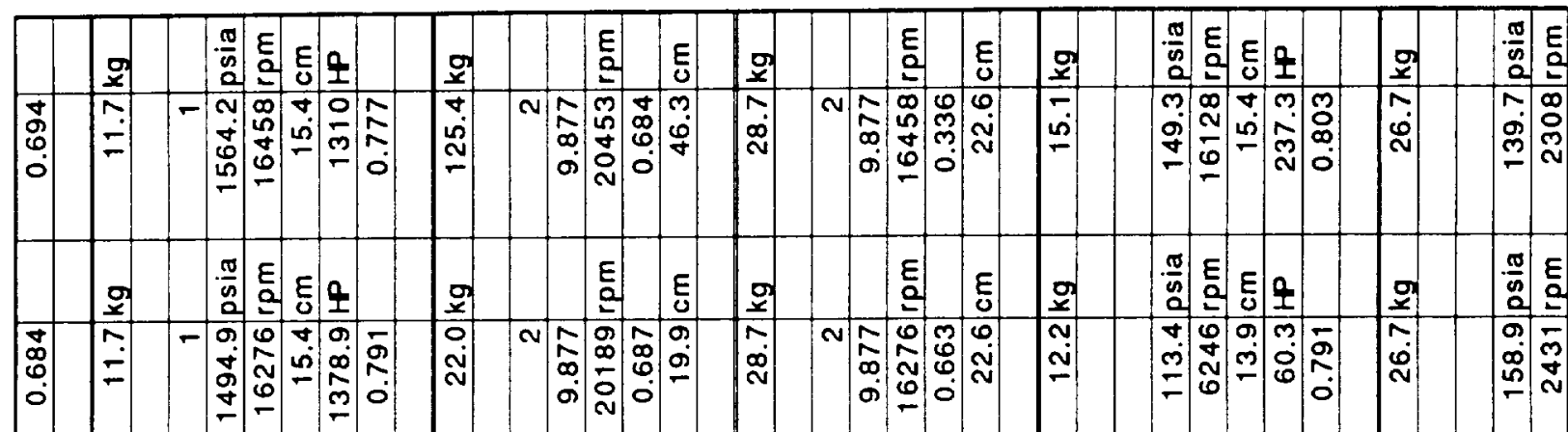

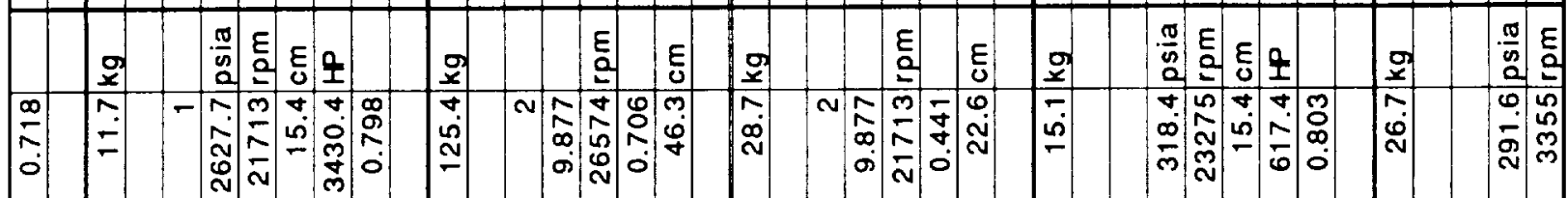

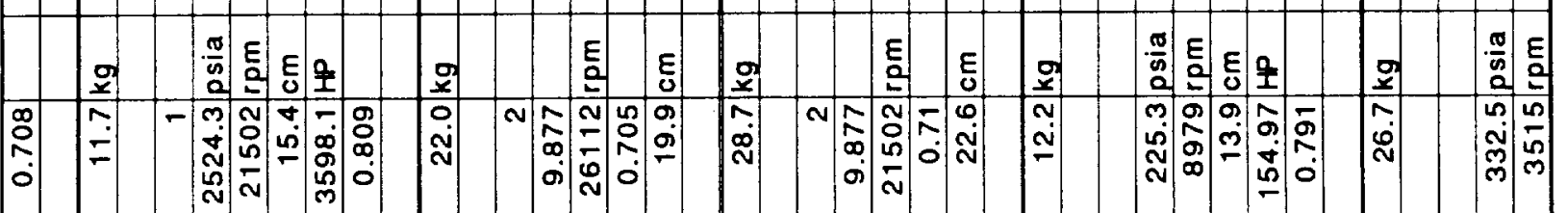

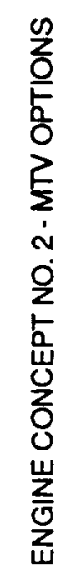

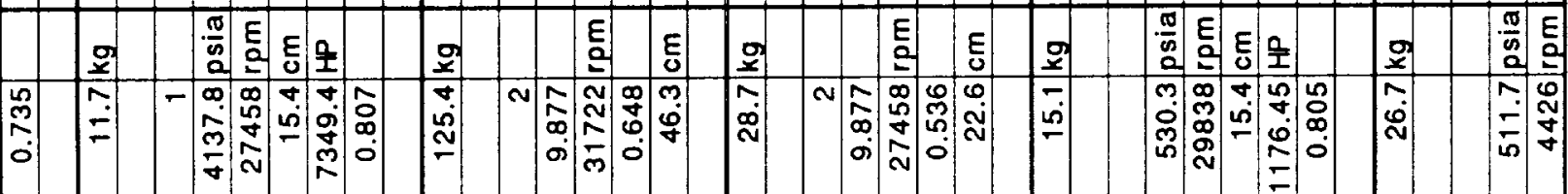

\begin{tabular}{|c|c|c|c|c|c|c|c|c|c|c|c|c|c|c|c|c|c|c|c|c|}
\hline & 9 & \begin{tabular}{|c|c|}
$\frac{a}{\omega}$ & $E$ \\
$a$ & $a$
\end{tabular} & El & & a & & & E & $\mid$\begin{tabular}{|c}
$E$ \\
$\mathbf{E}$
\end{tabular} & ? & & $\varepsilon$ & & E् & 足 & \begin{tabular}{|l|l|}
$\frac{\pi}{n}$ & $\varepsilon$ \\
2 & 0 \\
\end{tabular} & Eq & & a & $\begin{array}{cc}\frac{\pi}{\omega} & \varepsilon \\
\alpha & a\end{array}$ \\
\hline$\tilde{\tilde{T}}$ & $\underline{=}$ & $-\begin{array}{l}n \\
0 \\
0 \\
0 \\
0 \\
0\end{array}$ & \begin{tabular}{|c|c|}
0 \\
0 \\
0
\end{tabular} & 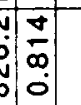 & $\mid \begin{array}{l}0 \\
\mathbf{N}\end{array}$ & & 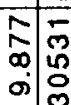 & $\hat{0}$ & 高 & \begin{tabular}{|c|} 
\\
$\infty$ \\
$\infty$ \\
$N$
\end{tabular} & & 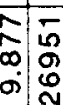 & & $\begin{array}{l}0 \\
\mathrm{~N} \\
\mathrm{~N}\end{array}$ & $\begin{array}{c}\mathbf{N} \\
\stackrel{\sim}{\sim}\end{array}$ & 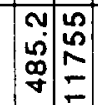 & & 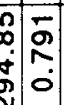 & $\left|\begin{array}{l}\hat{0} \\
\stackrel{N}{2}\end{array}\right|$ & 范 \\
\hline
\end{tabular}

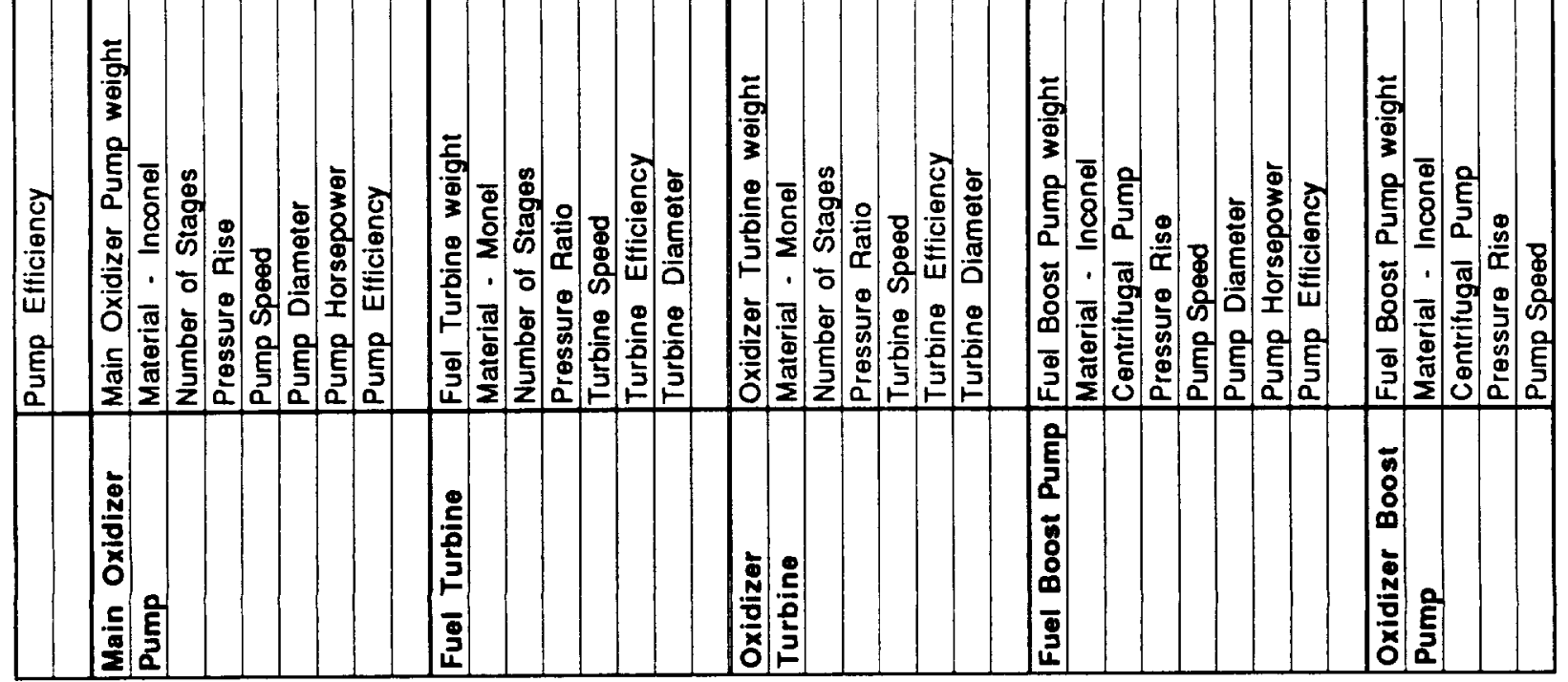





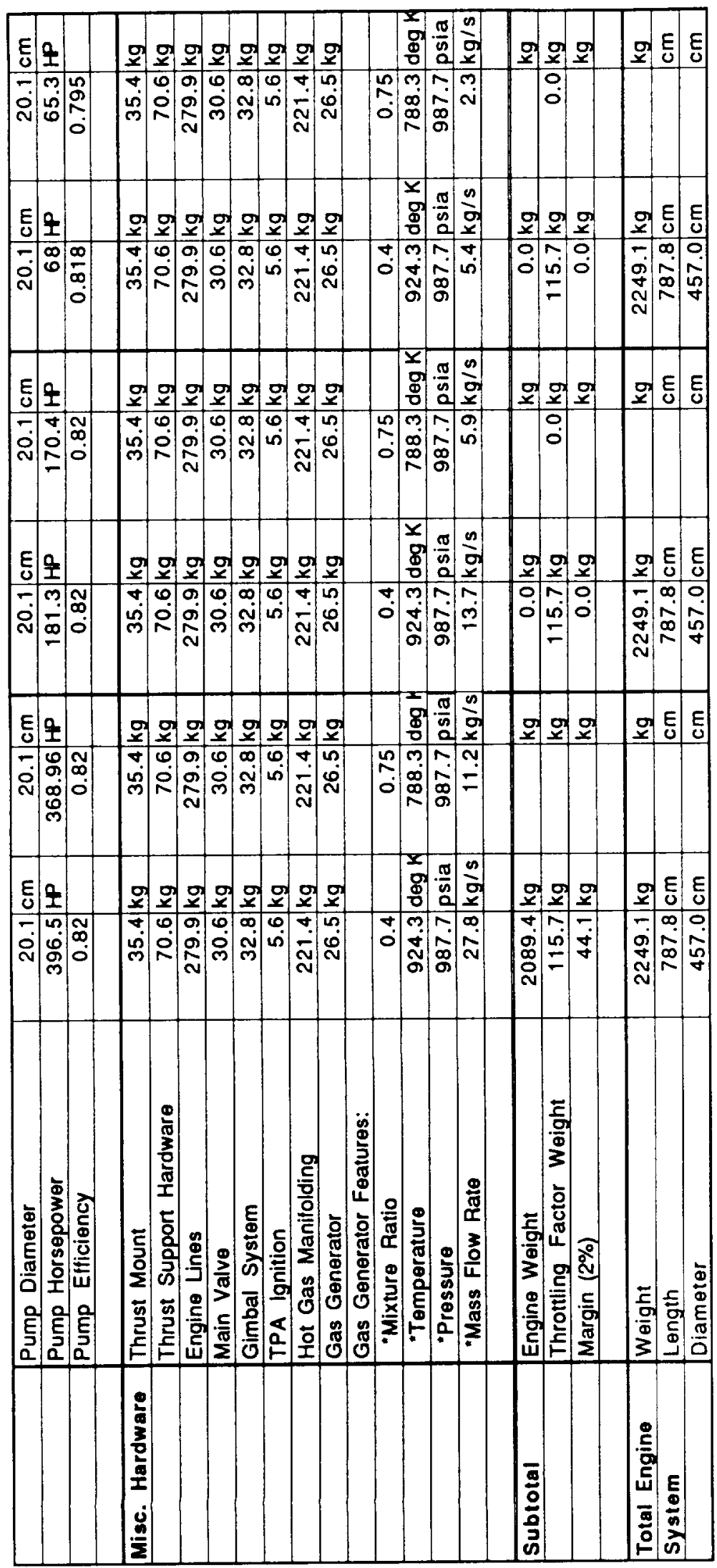





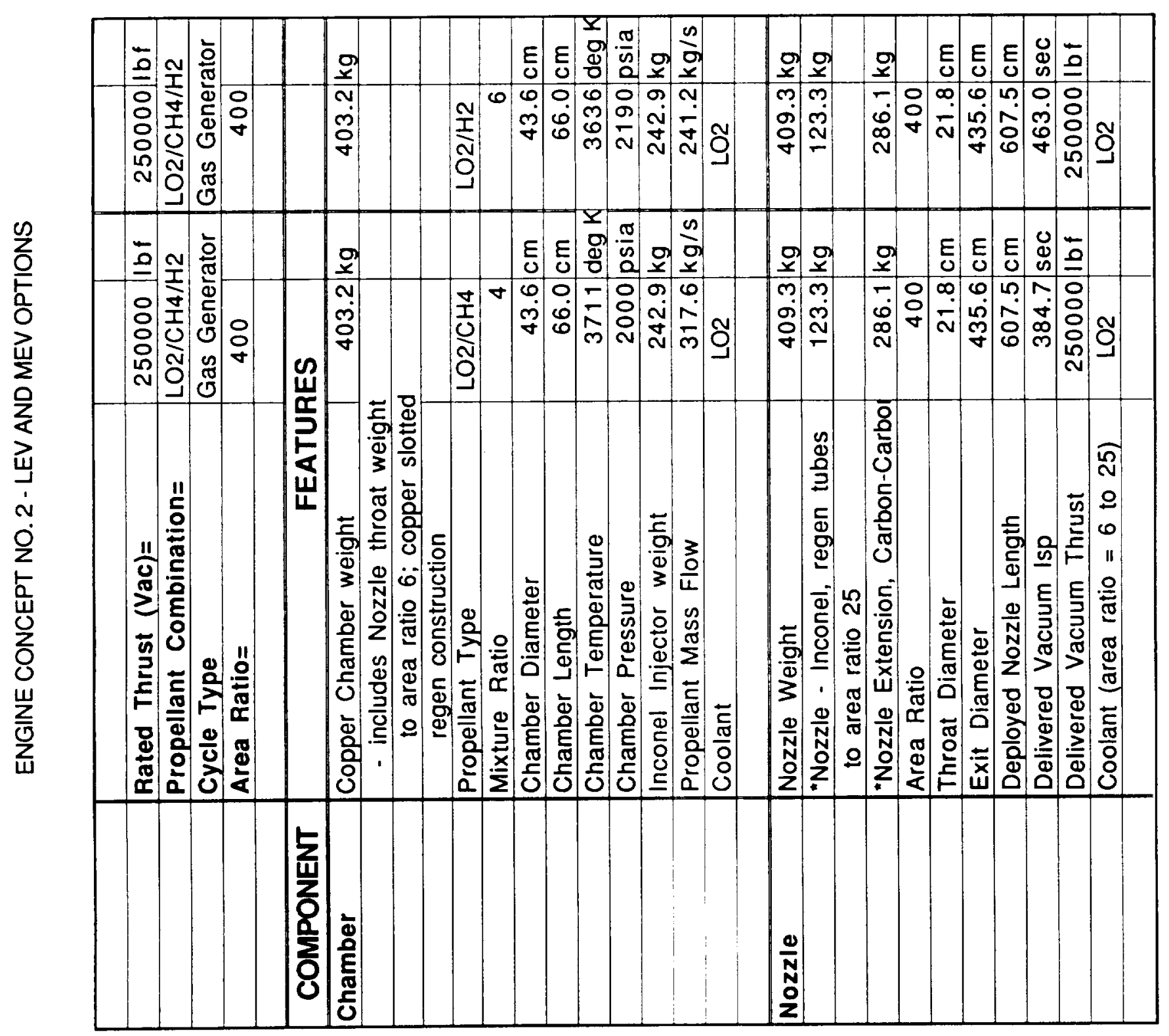





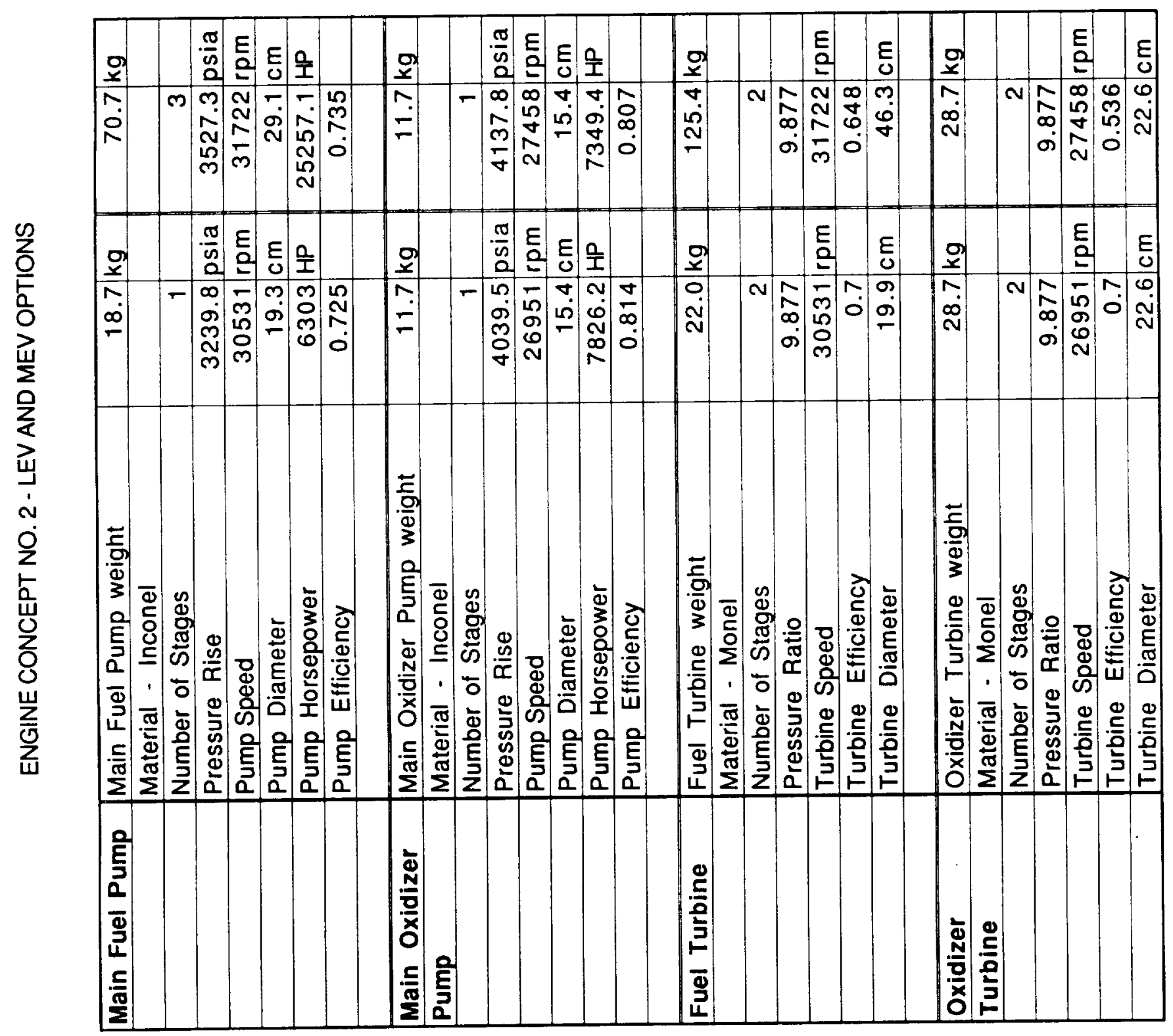





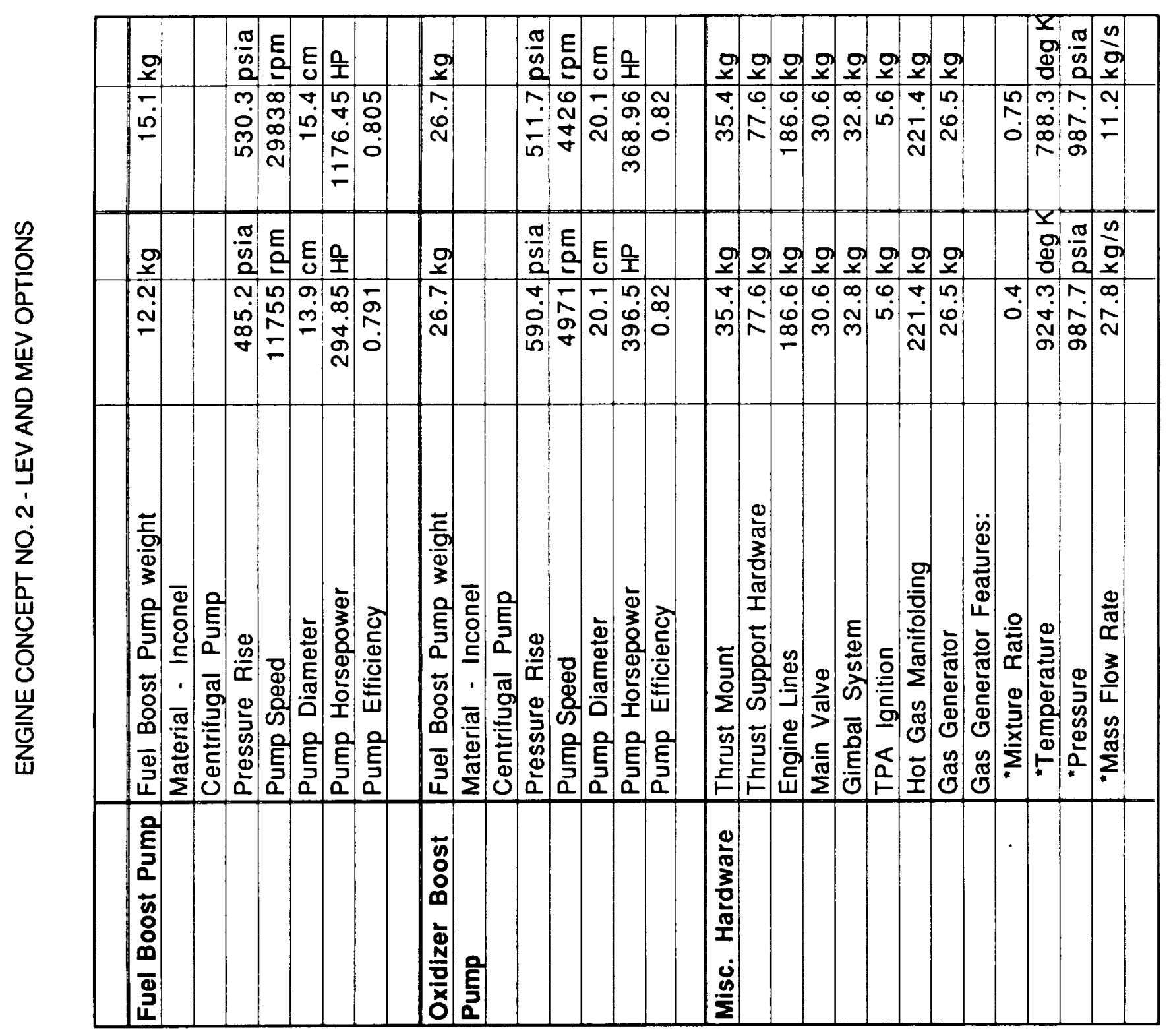





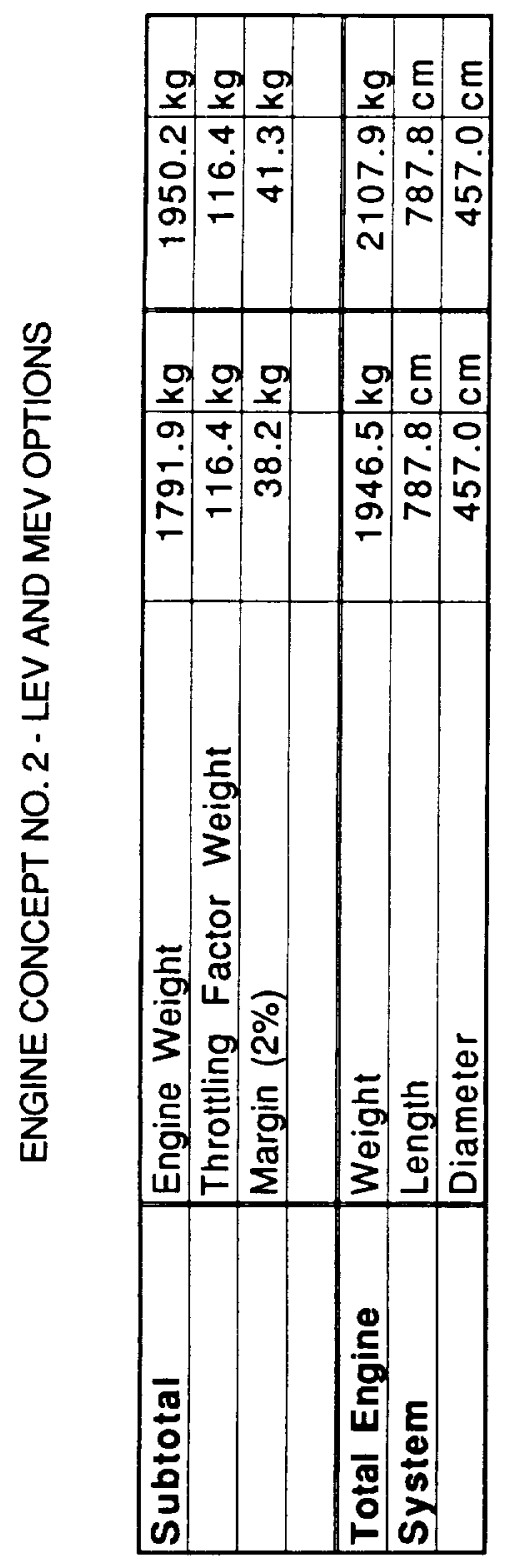





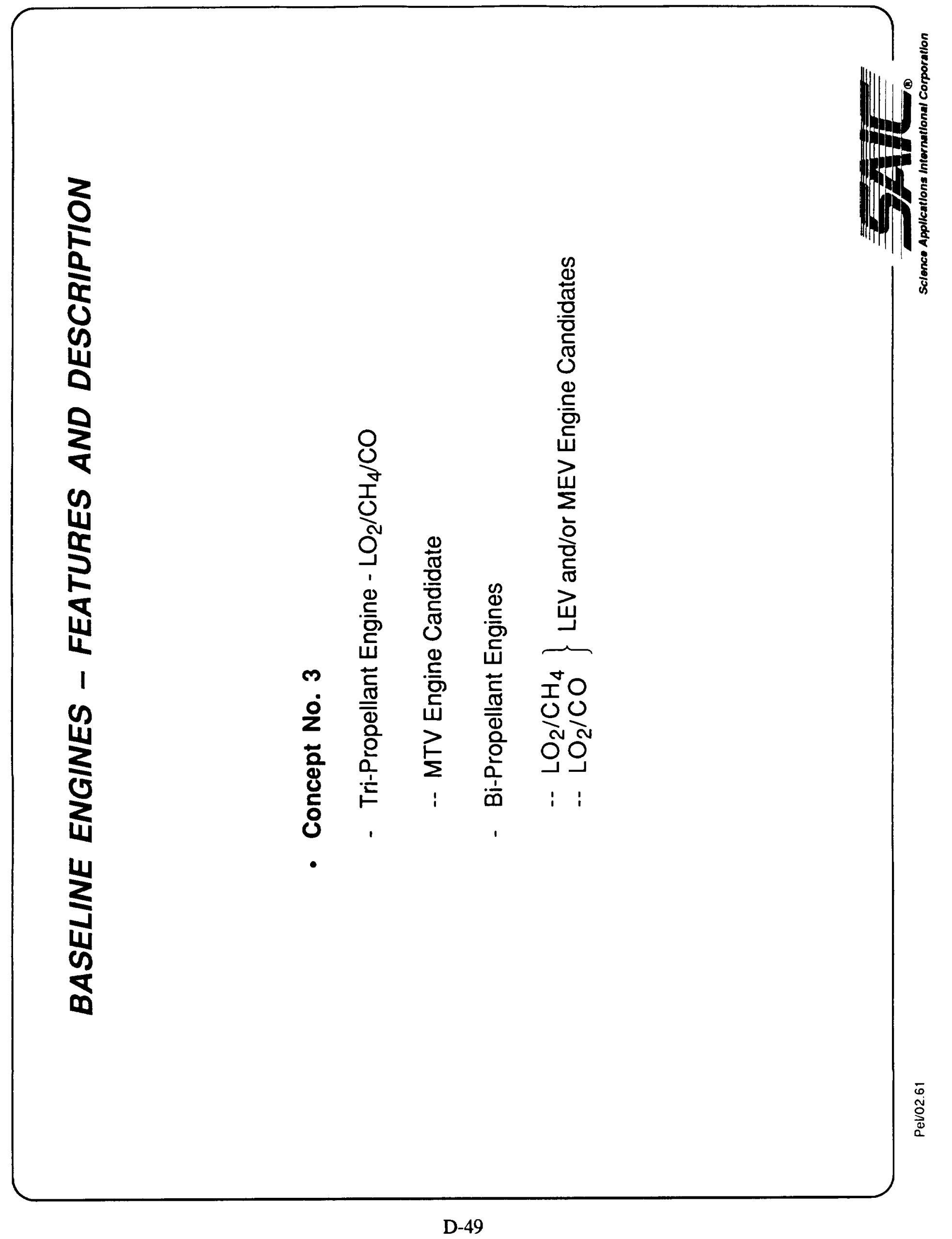





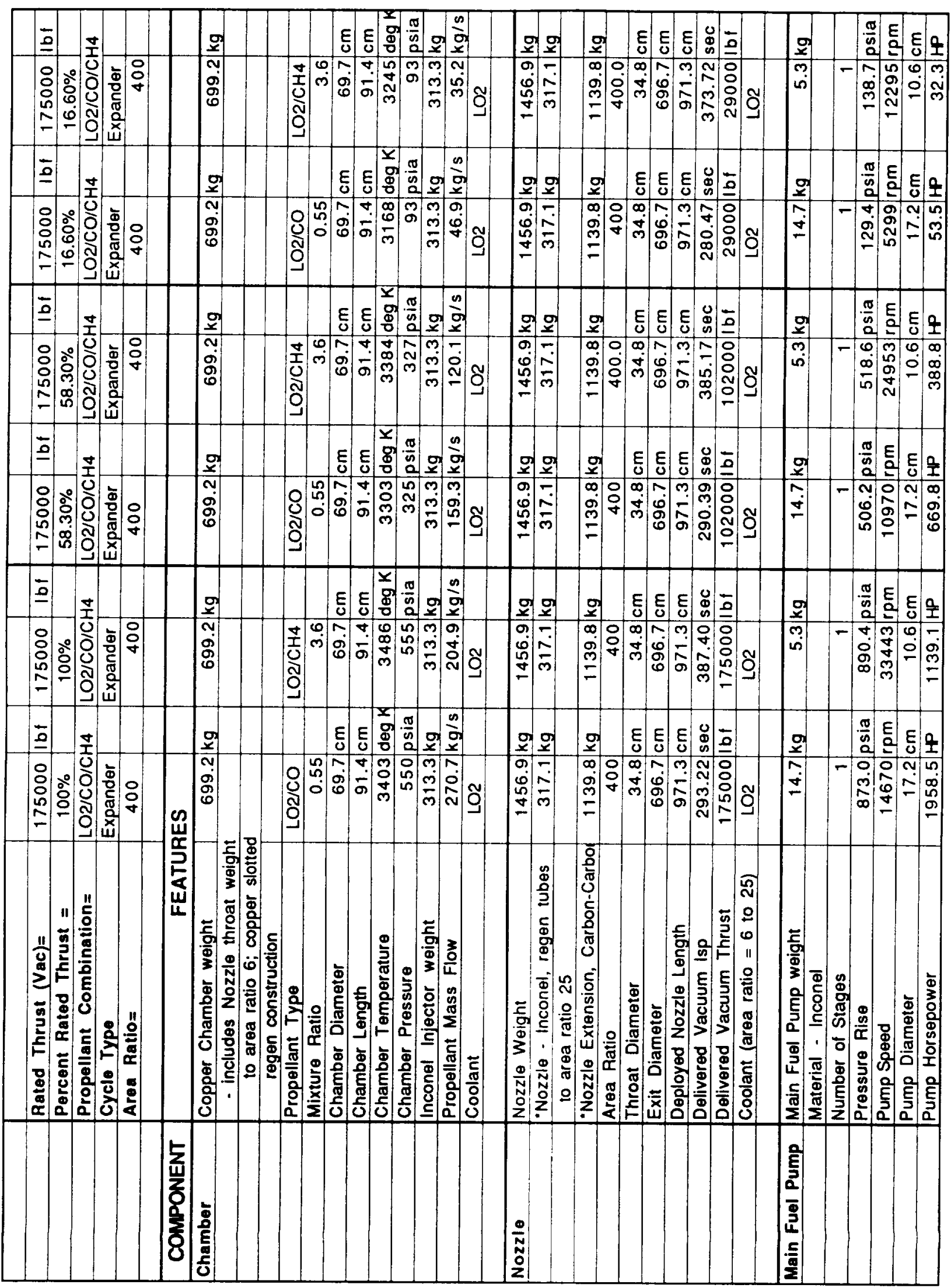





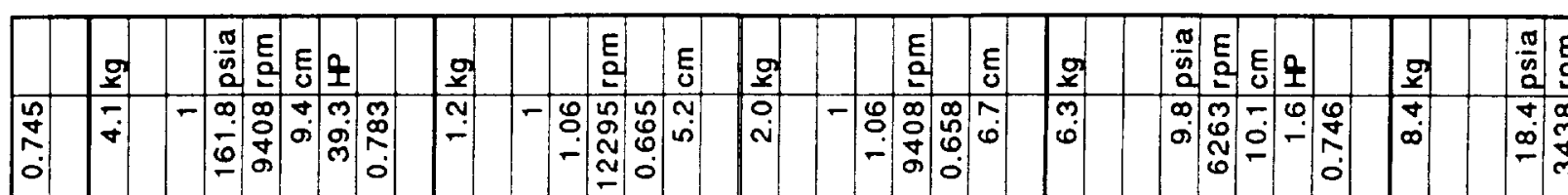

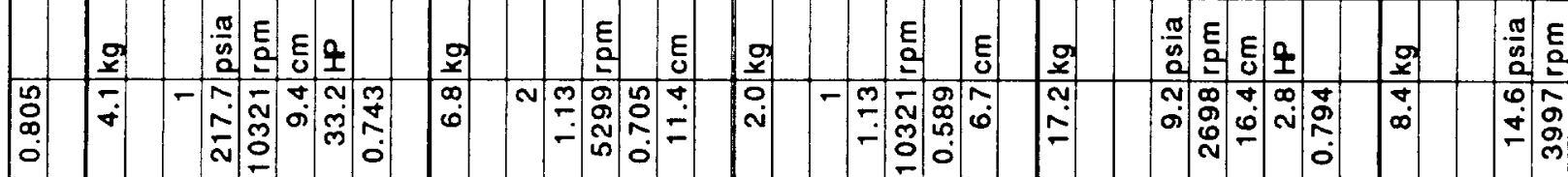

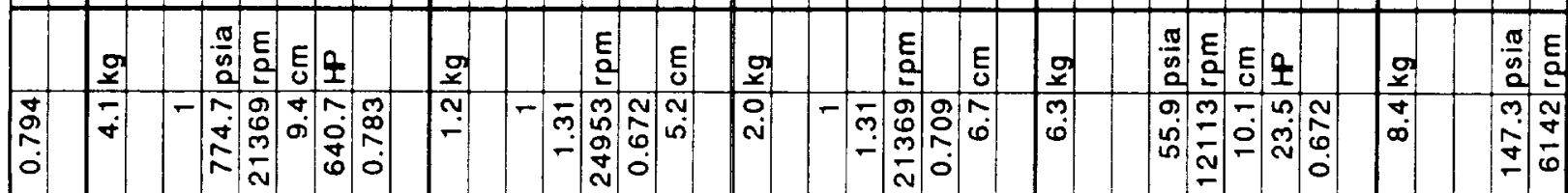

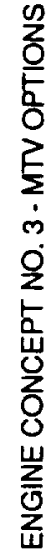

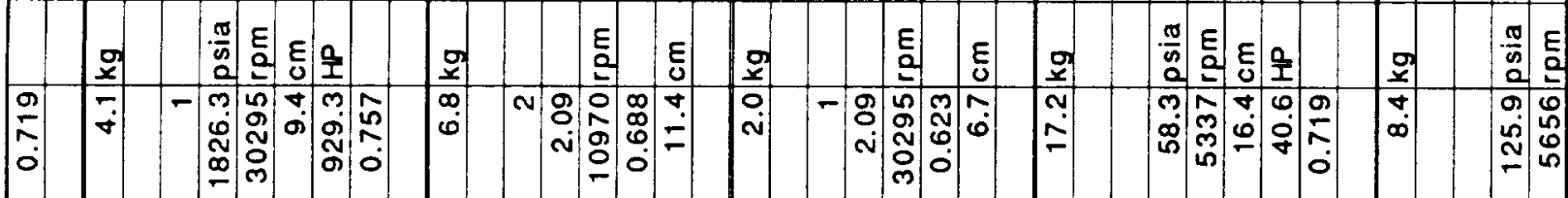

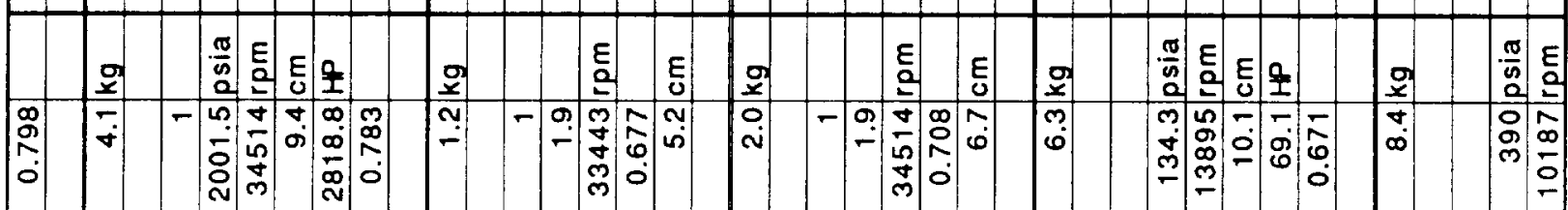

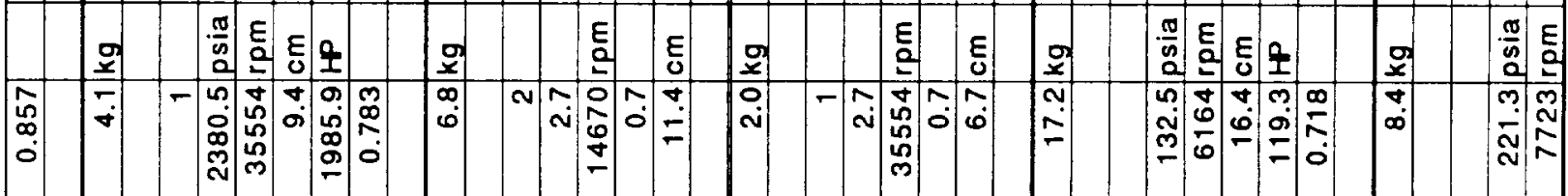

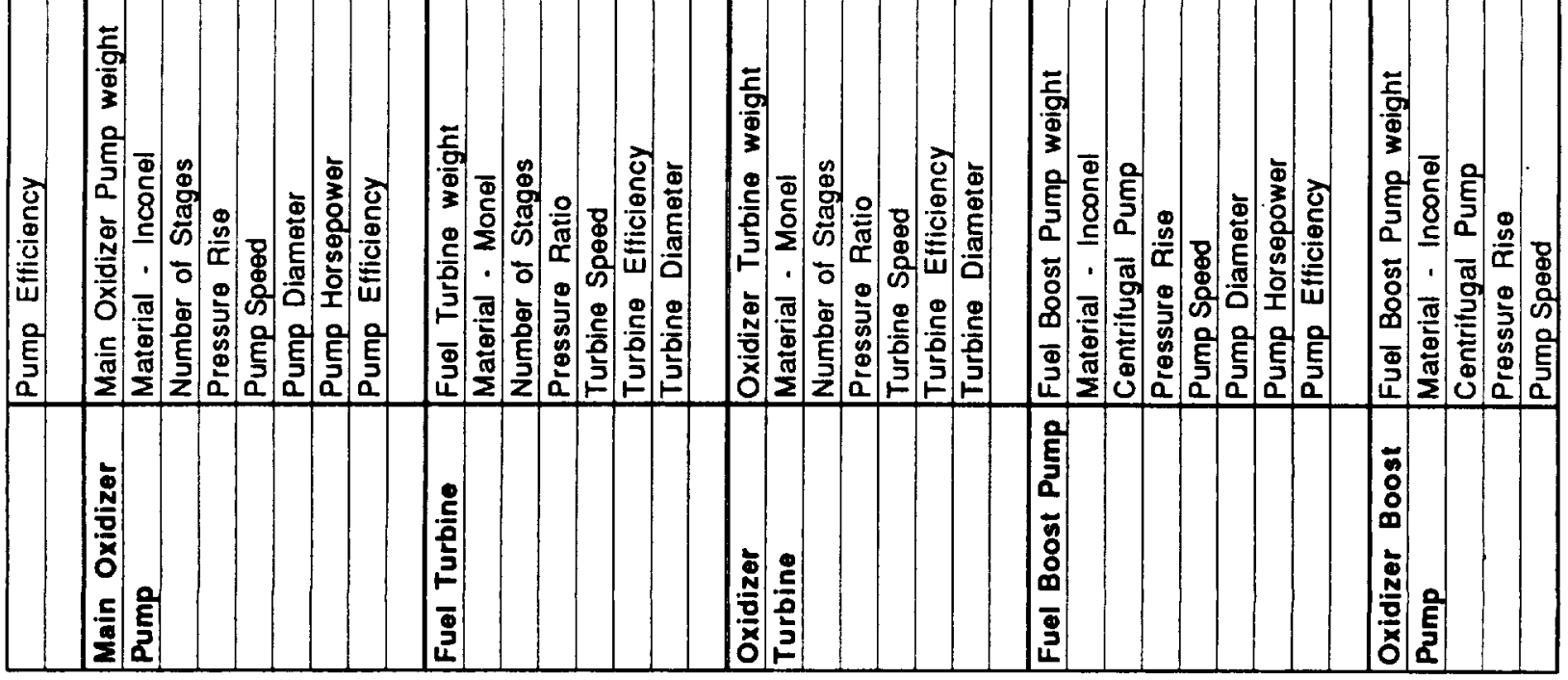





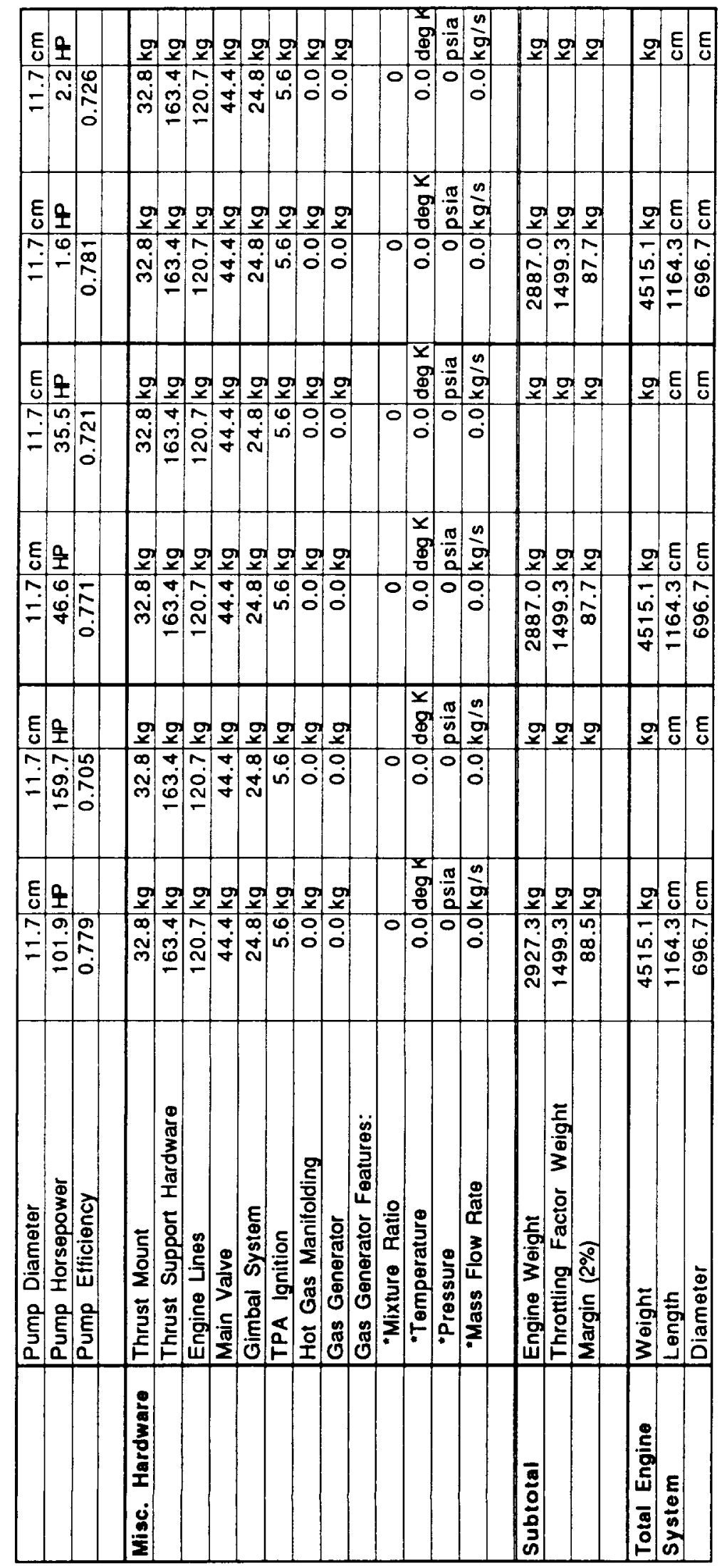





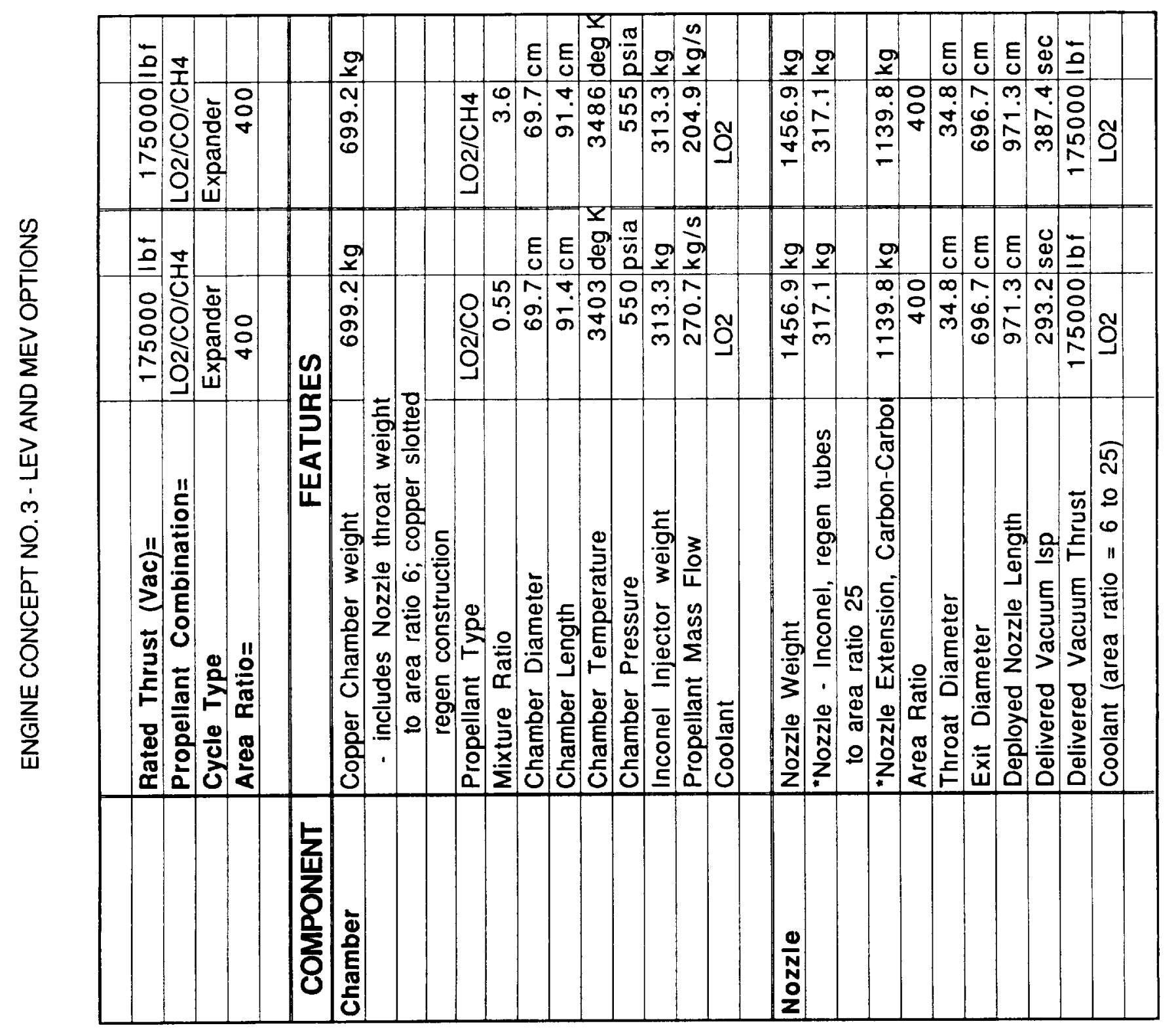





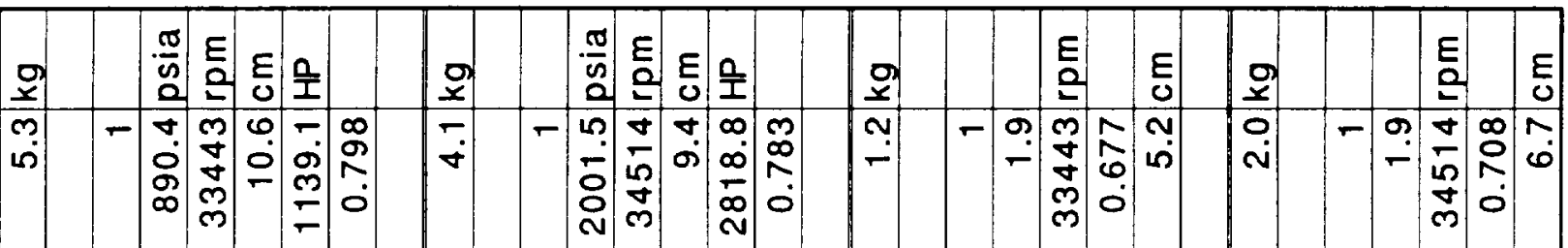

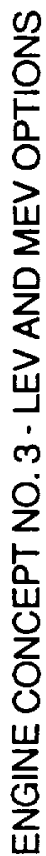

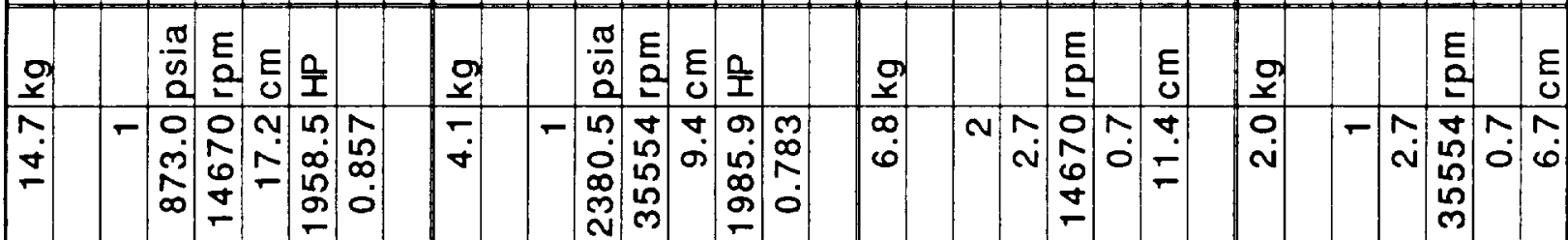

등

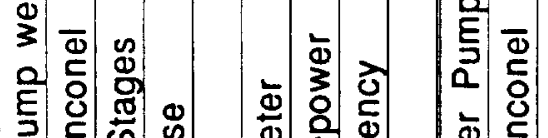

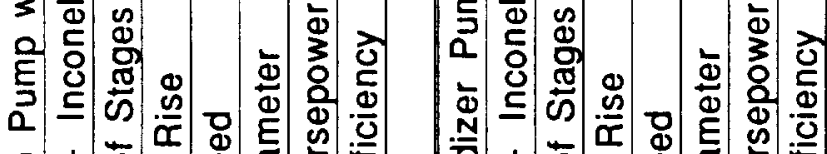

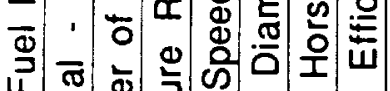

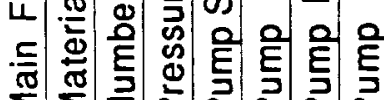

Nㅜㅁ

ठิ

등

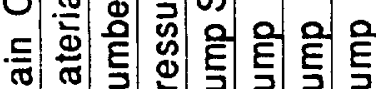

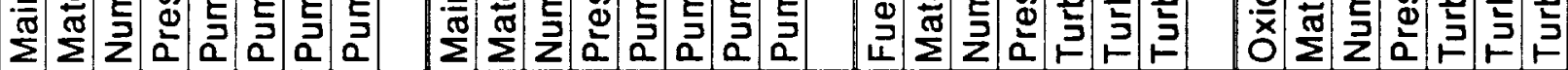

产

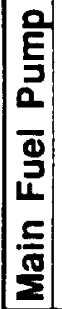

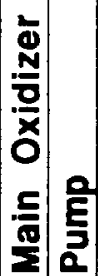

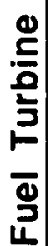

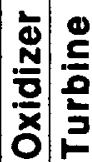





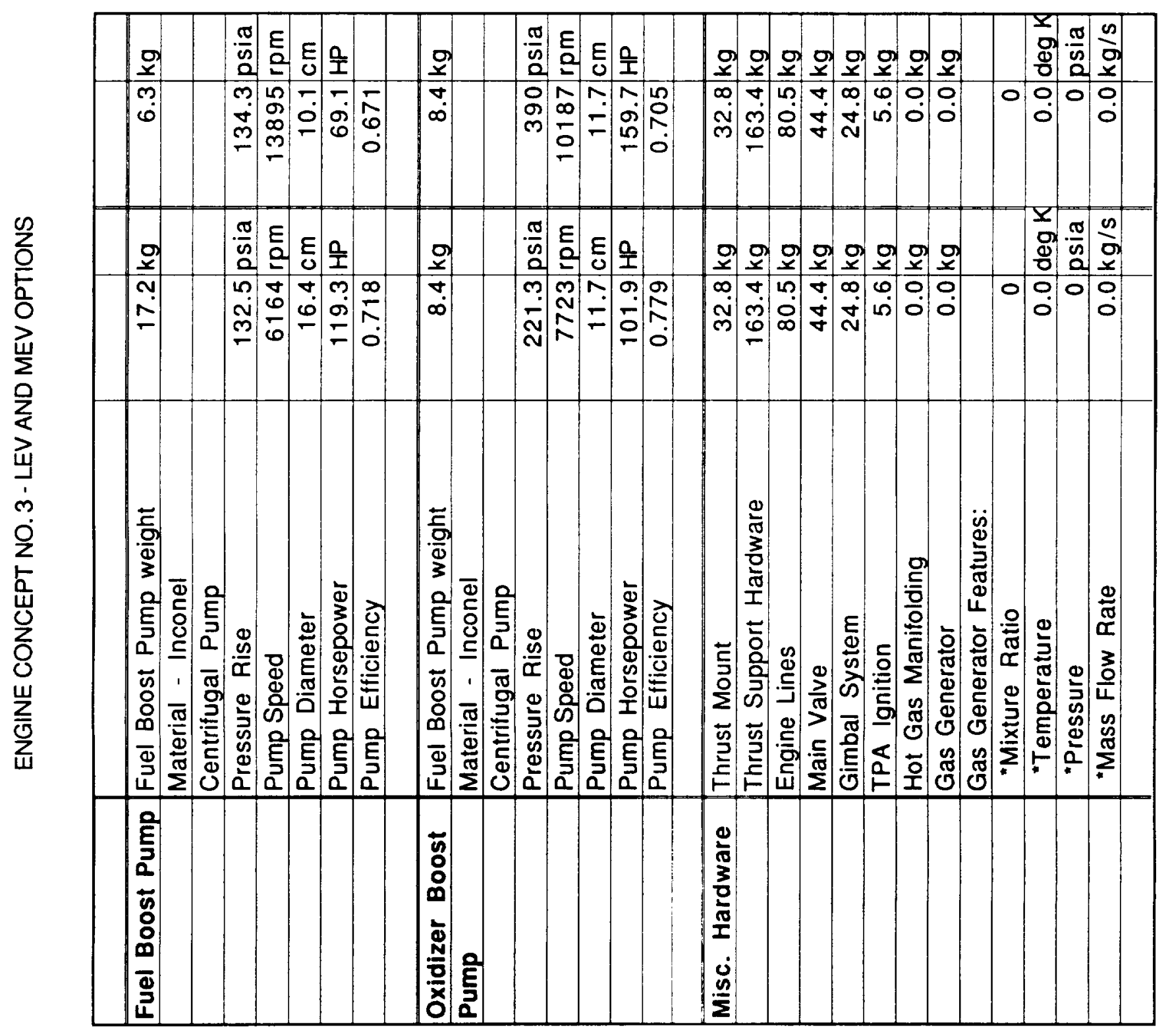





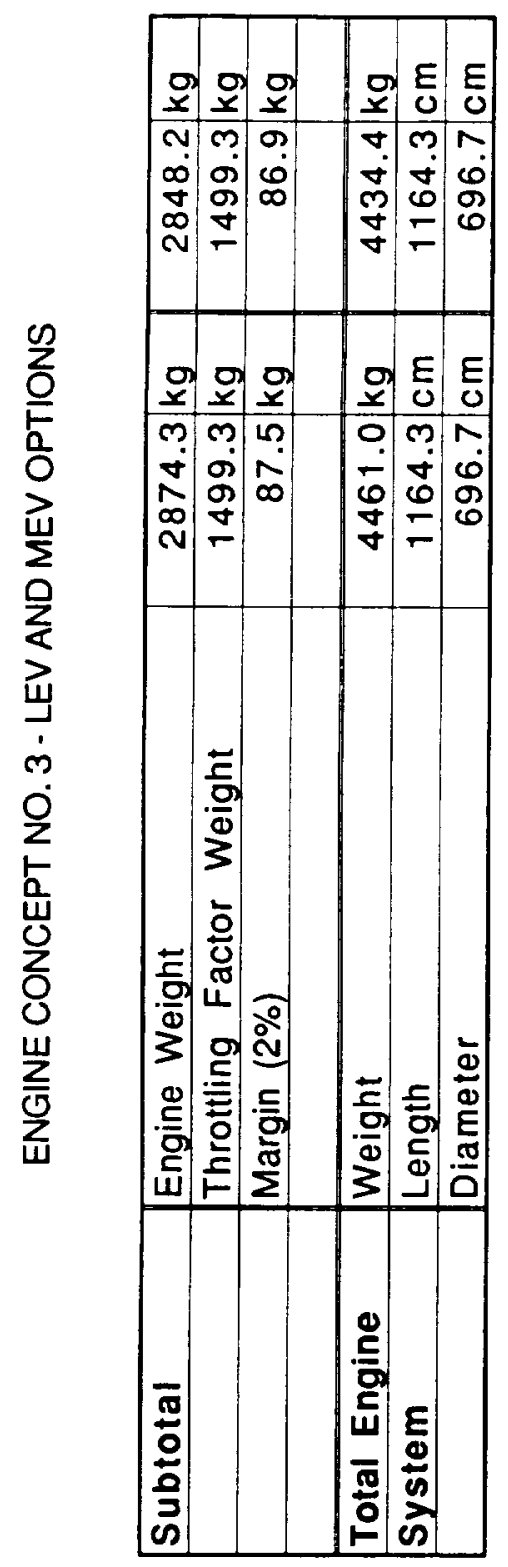





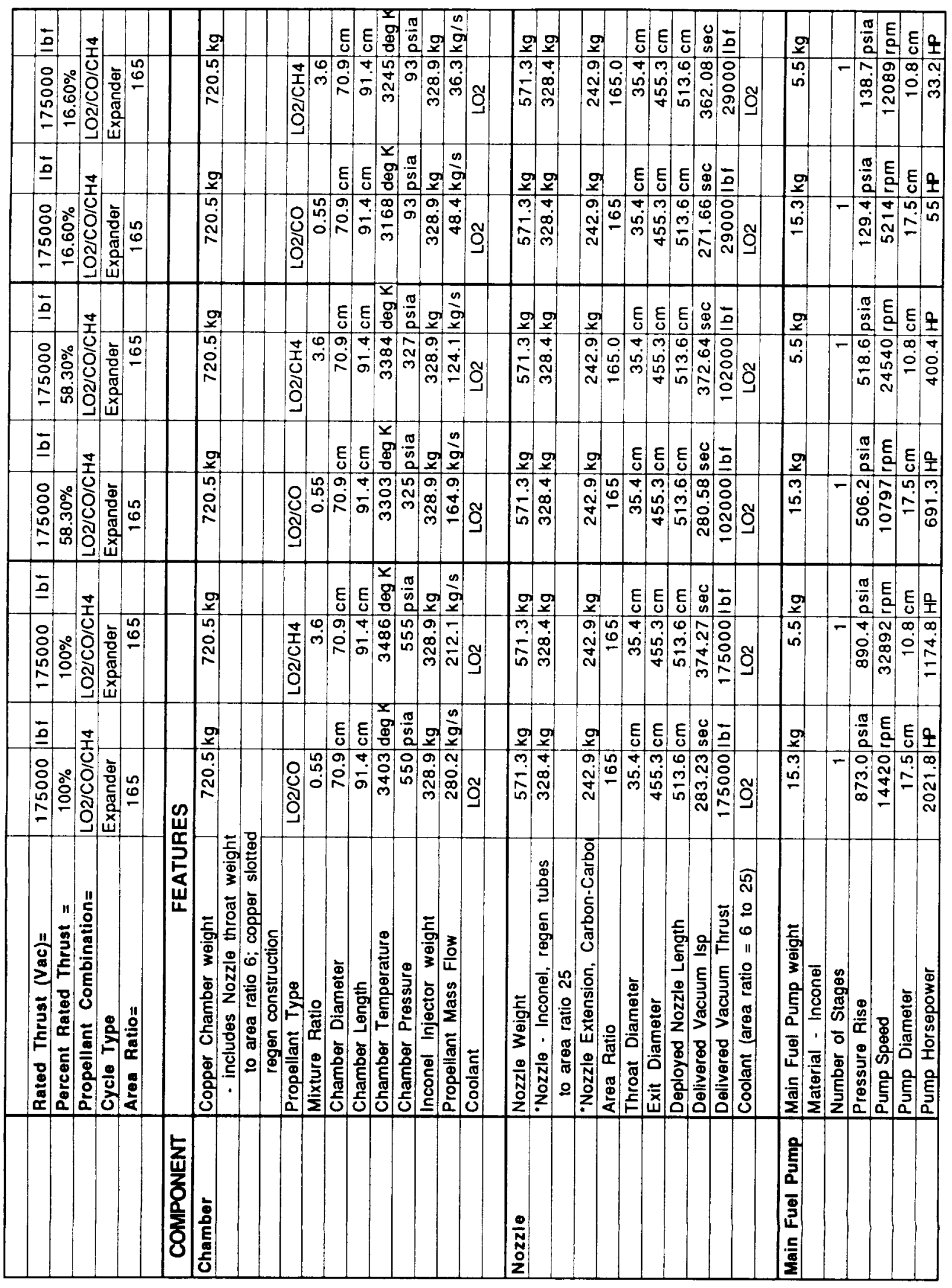





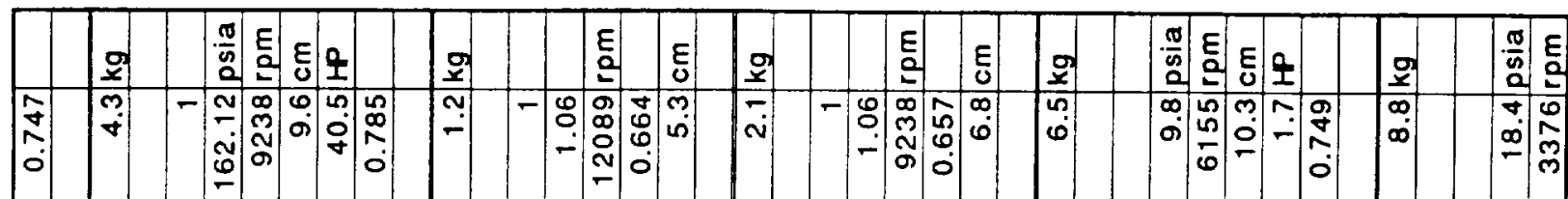

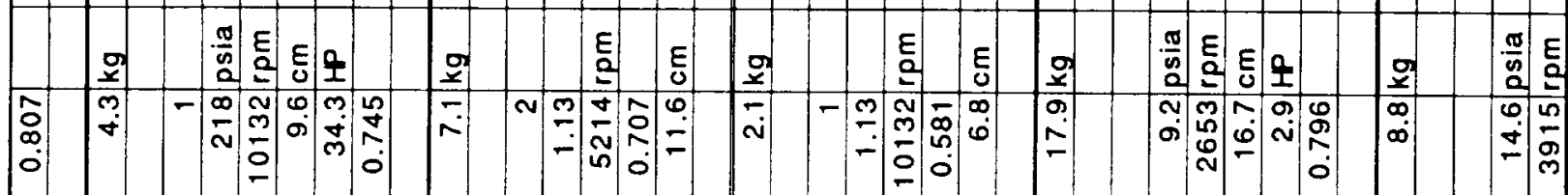

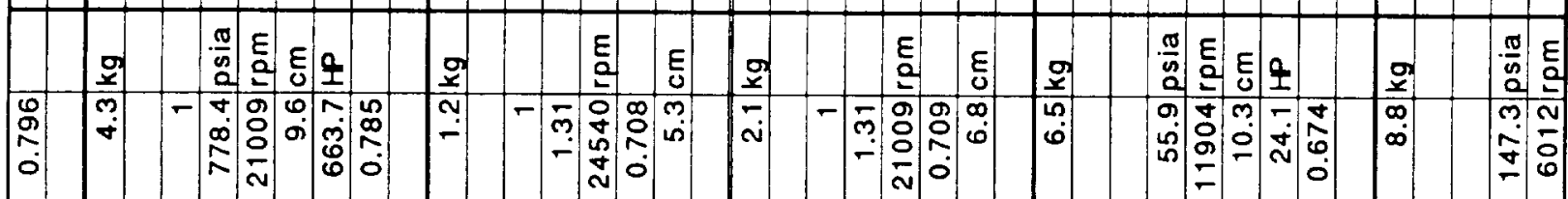

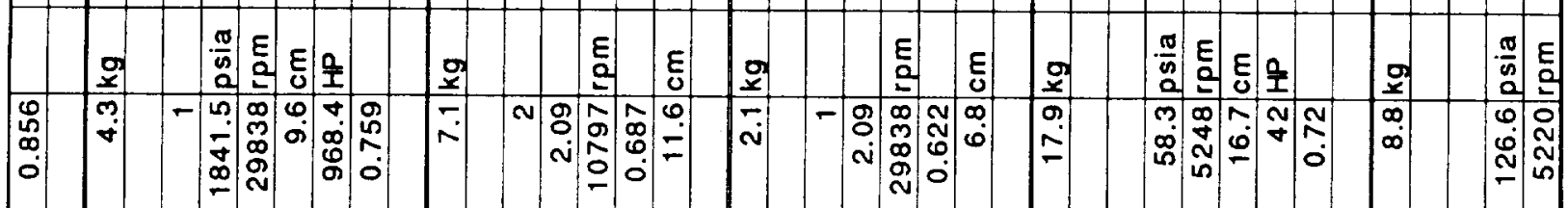

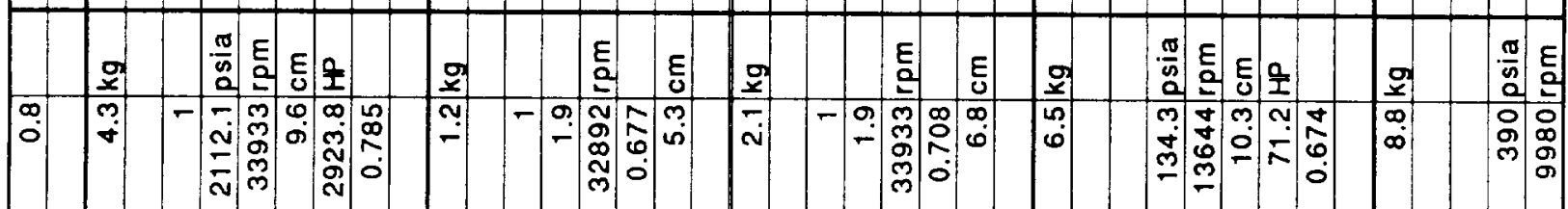

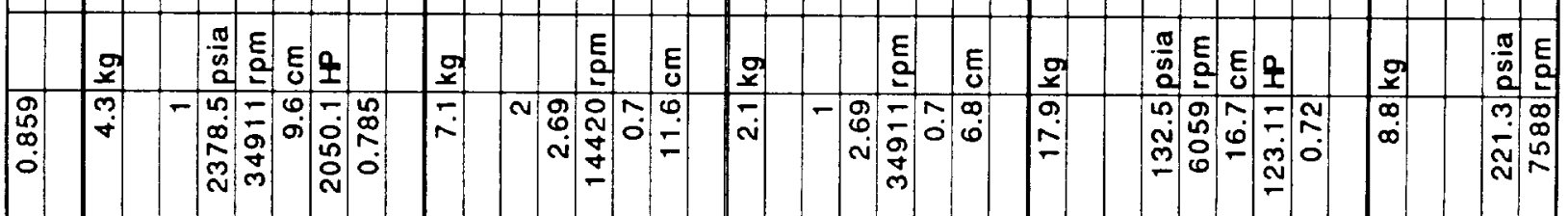

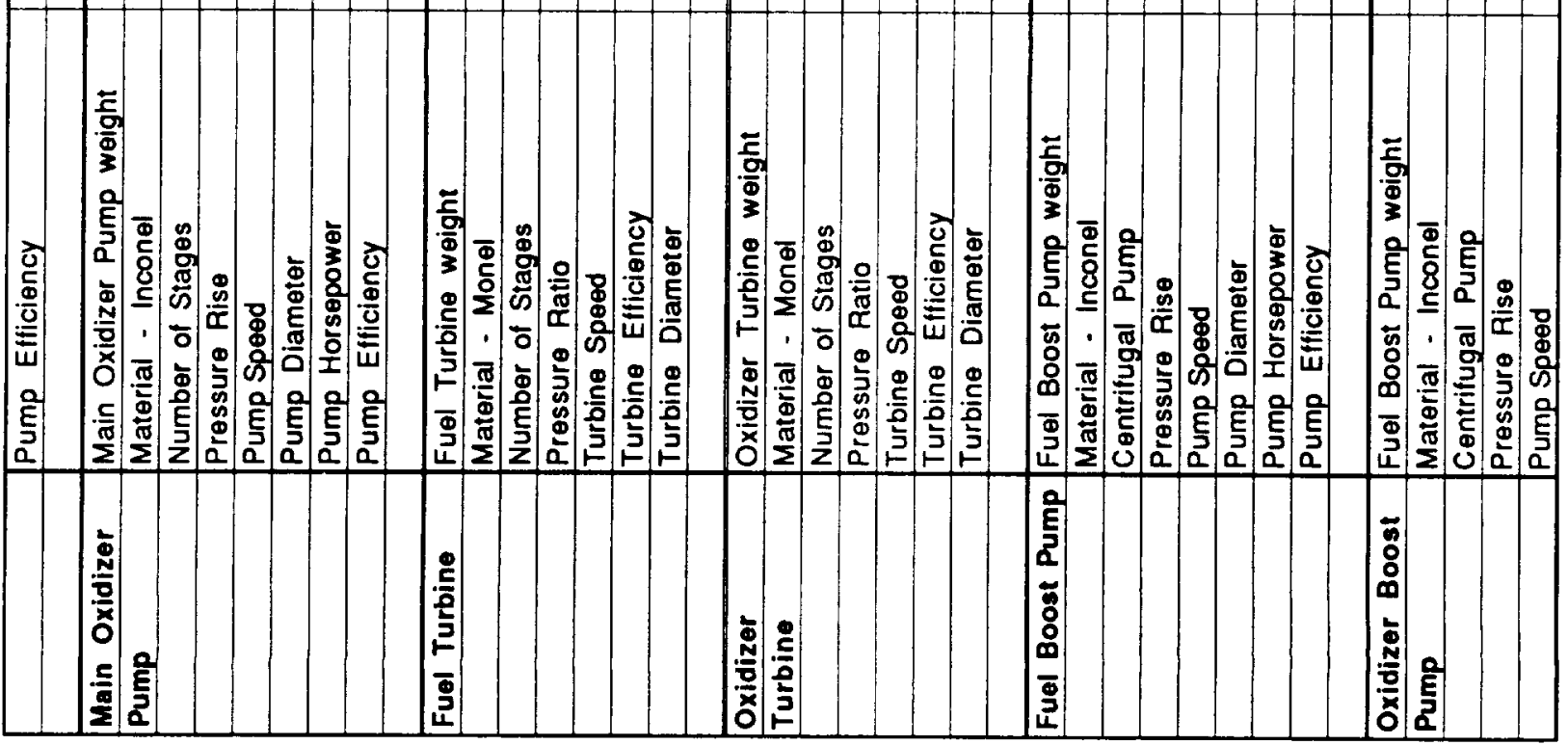





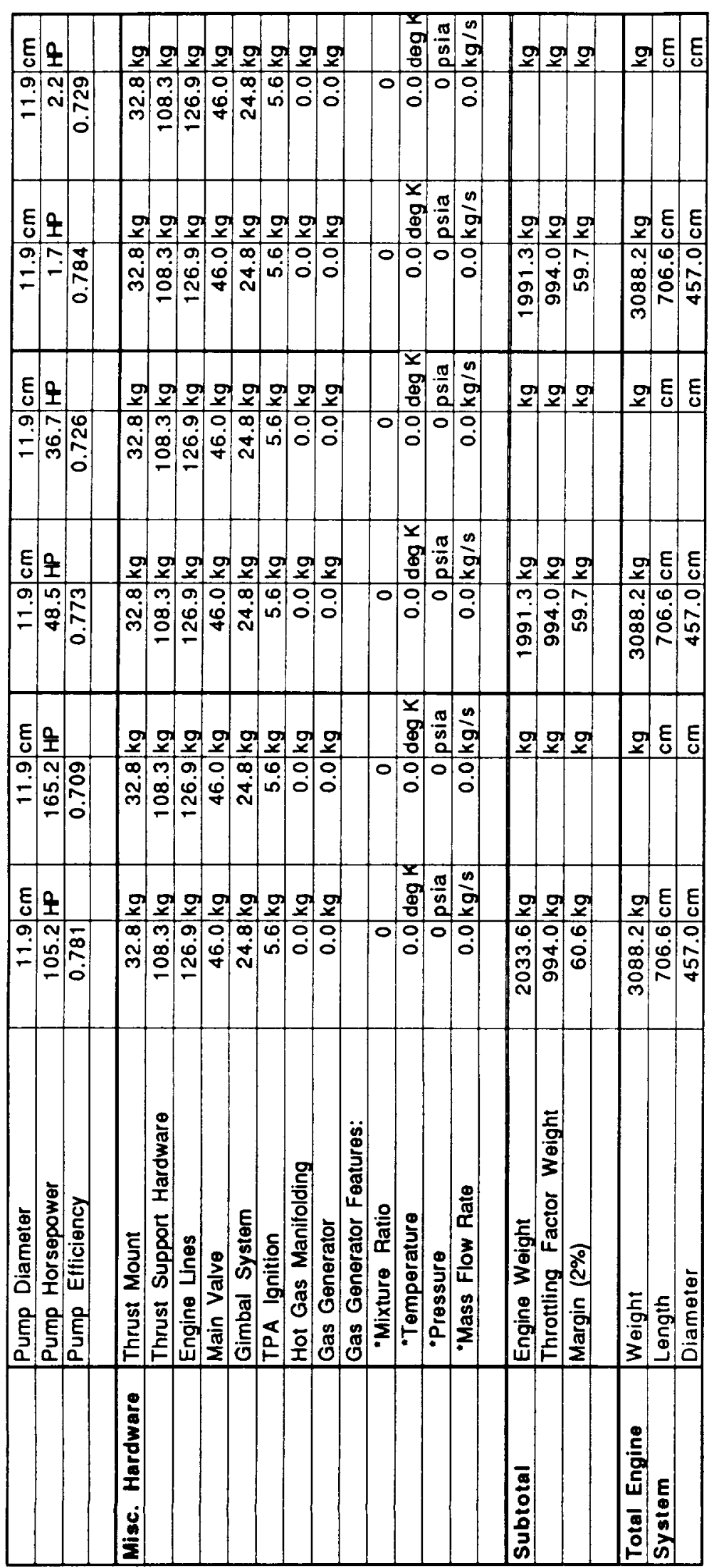





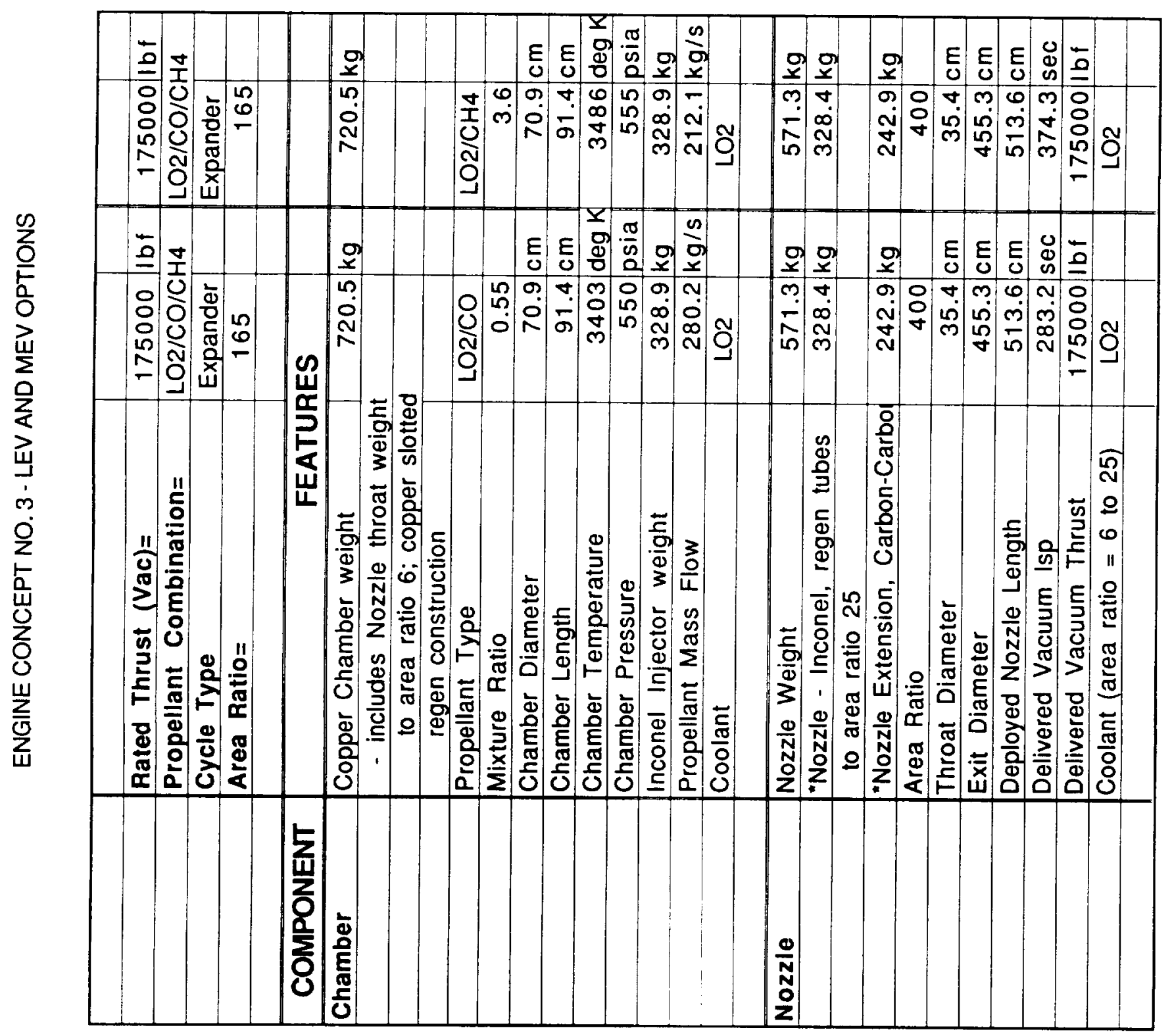





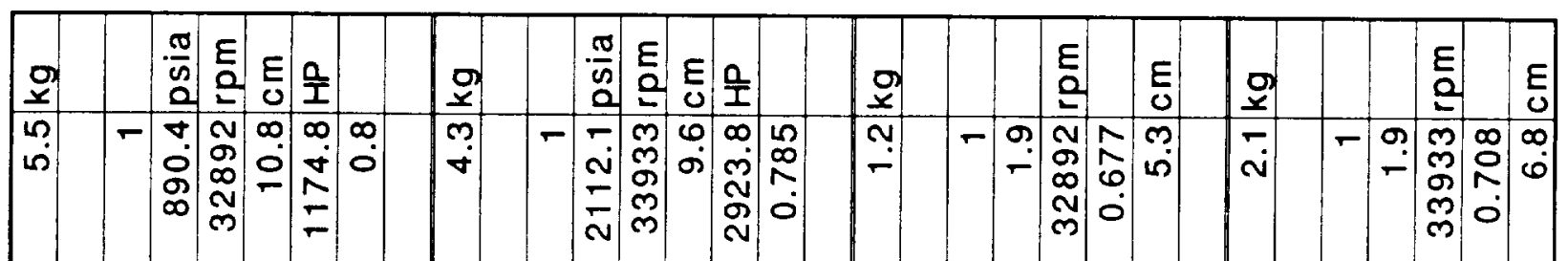

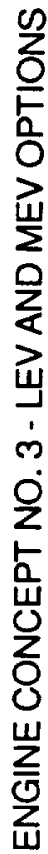

\begin{tabular}{|c|c|c|c|c|c|c|c|c|c|c|c|c|c|c|c|c|c|c|c|c|c|c|c|c|c|}
\hline 9 & & $\frac{\pi}{\infty}$ & 틍 & & 올 & & $\underline{x}$ & & $\frac{\pi}{n}$ & $\begin{array}{l}E \\
0 \\
\end{array}$ & $\begin{array}{l}E \\
0\end{array}$ & 오 & & 8 & & & 틍 & & $\begin{array}{l}\varepsilon \\
\text { U }\end{array}$ & $\begin{array}{l}9 \\
x \\
\end{array}$ & & & 튼 & & $\begin{array}{l}E \\
0 \\
\end{array}$ \\
\hline م. & - & $\begin{array}{c}0 \\
\dot{p} \\
\hat{\infty} \\
\infty\end{array}$ & 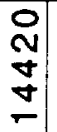 & $\stackrel{n}{n}$ & $\begin{array}{c}\infty \\
\vdots \\
\tilde{N} \\
0\end{array}$ & \begin{tabular}{|c|}
0 \\
1 \\
0 \\
0 \\
0
\end{tabular} & $\begin{array}{l}m \\
\dot{\sigma}\end{array}$ & - & 10 & $\begin{array}{l}\bar{z} \\
\sigma \\
\dot{m} \\
\end{array}$ & $\begin{array}{l}0 \\
0\end{array}$ & $\begin{array}{l}\bar{\sigma} \\
0 \\
0 \\
0\end{array}$ & \begin{tabular}{l|}
1 \\
$\infty$ \\
0 \\
0 \\
0
\end{tabular} & $\therefore$ & $\alpha$ & $\begin{array}{l}\sigma \\
0 \\
\sim\end{array}$ & 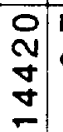 & $\hat{0}$ & $\begin{array}{l}\varphi \\
=\end{array}$ & $\bar{\sim}$ & - & $\begin{array}{ll} \\
0 \\
0 \\
0\end{array}$ & \begin{tabular}{|l|} 
\\
\\
\\
\\
\end{tabular} & $\tilde{0}$ & $\begin{array}{l}\infty \\
\dot{0}\end{array}$ \\
\hline
\end{tabular}

$$
\begin{array}{lllllllll}
\hline & & & & & & & & \\
\hline
\end{array}
$$

:

흔

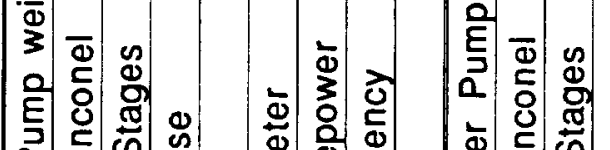

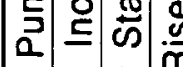

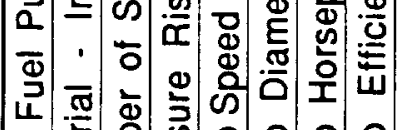

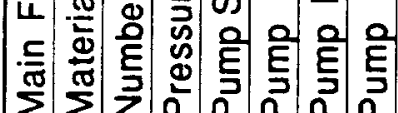

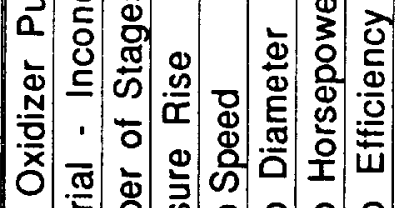

듷 $\frac{\Phi}{\Phi}$ है

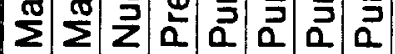

$5 \quad \sqrt{\frac{1}{9}}$

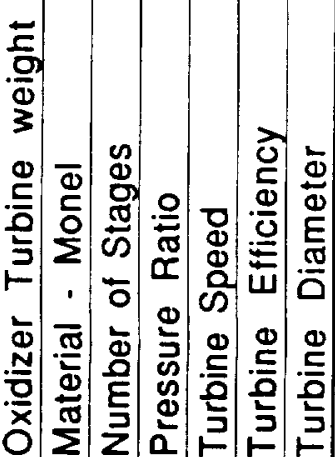

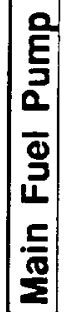

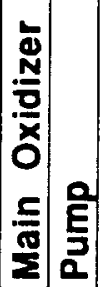

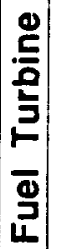





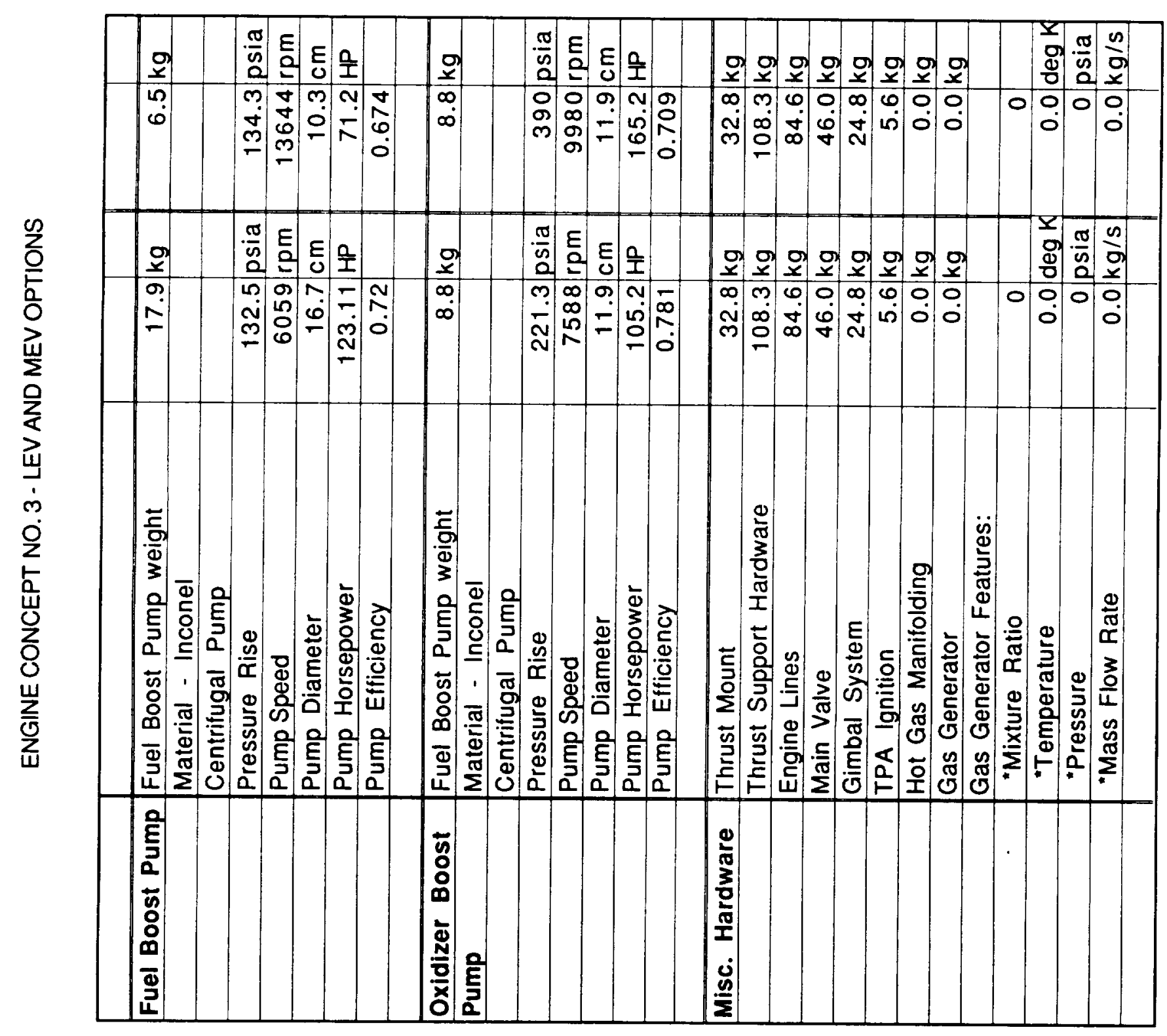




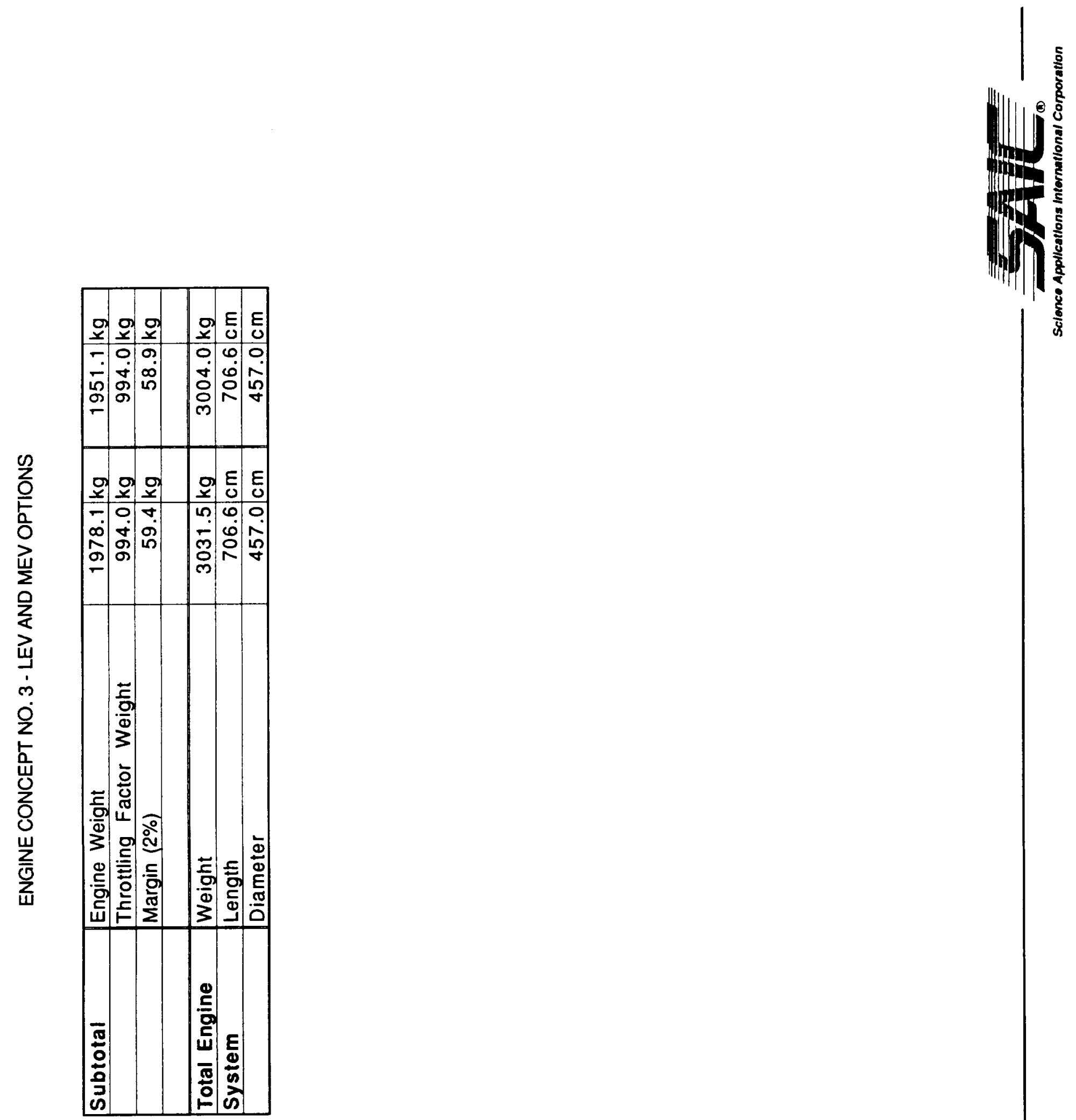



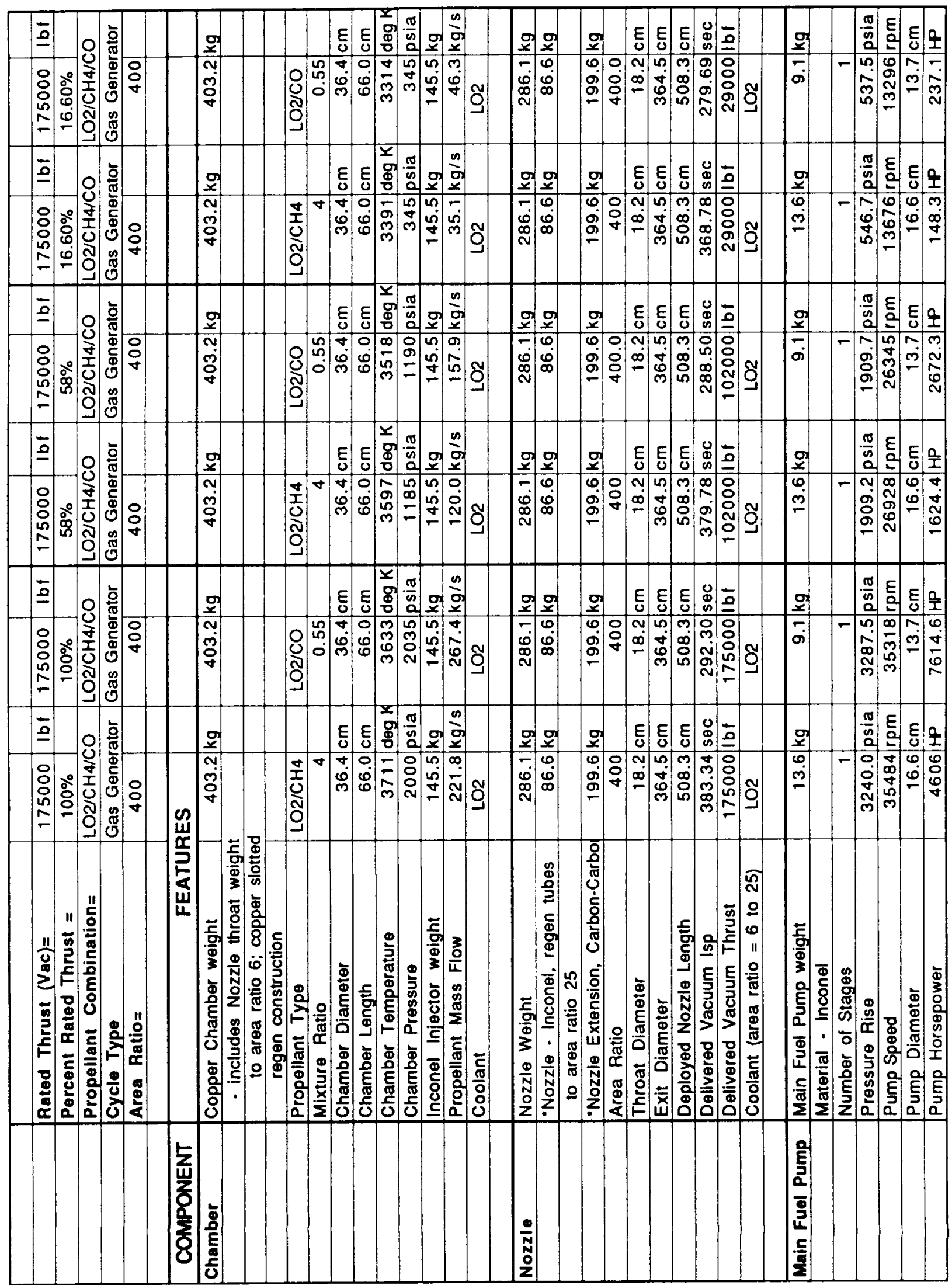





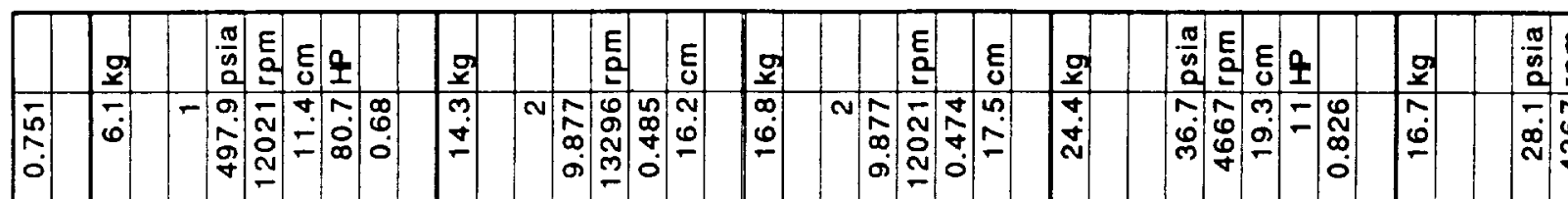

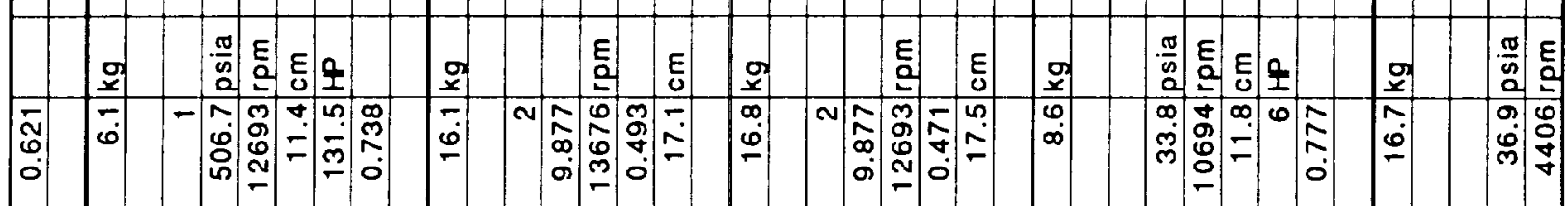

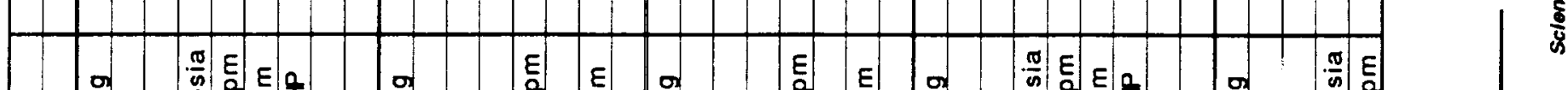

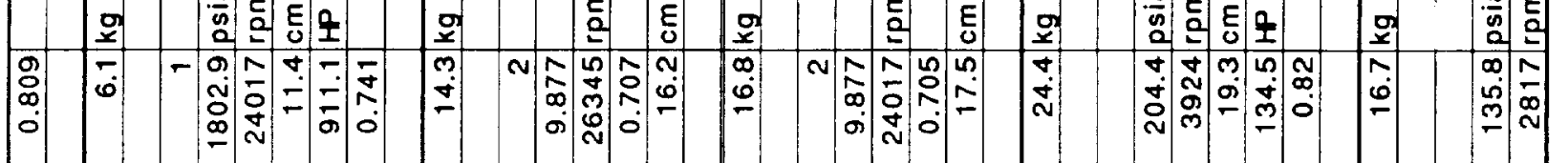

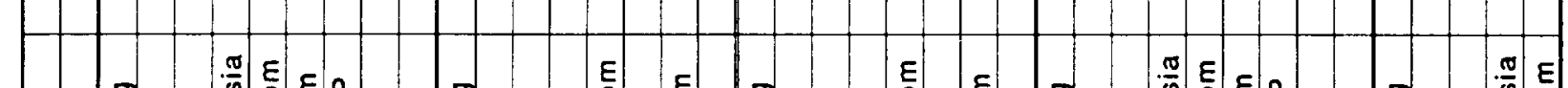

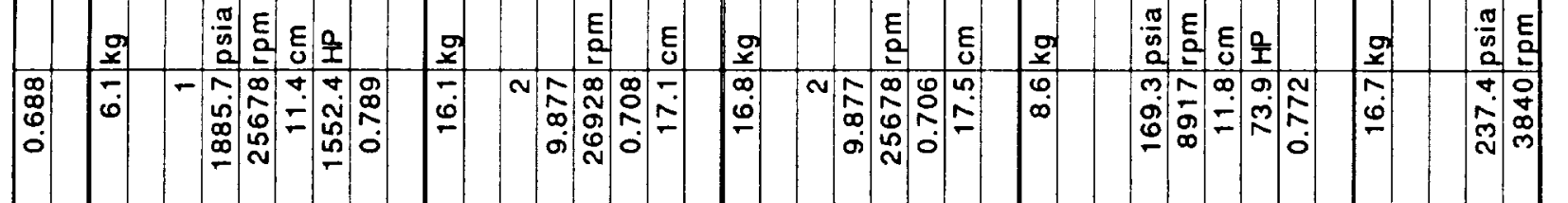

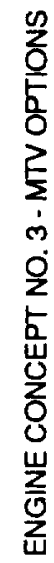

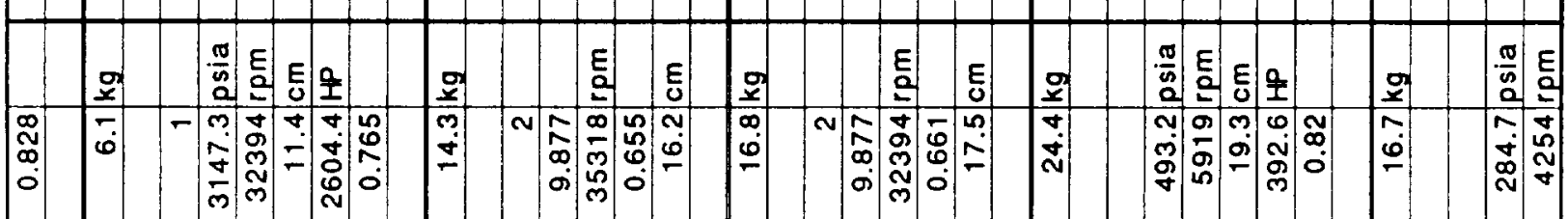

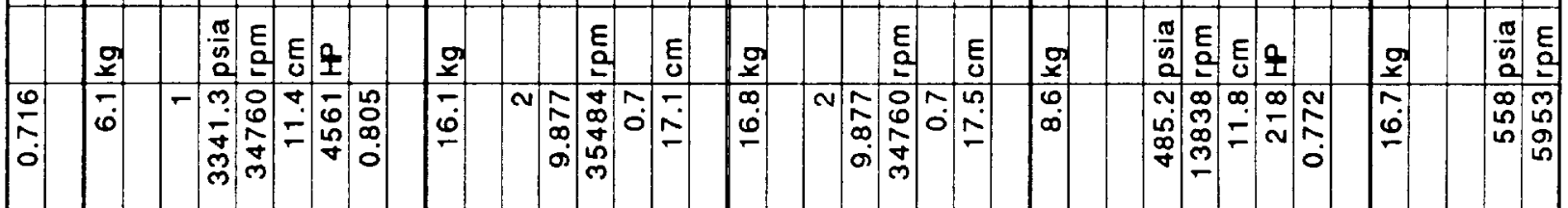

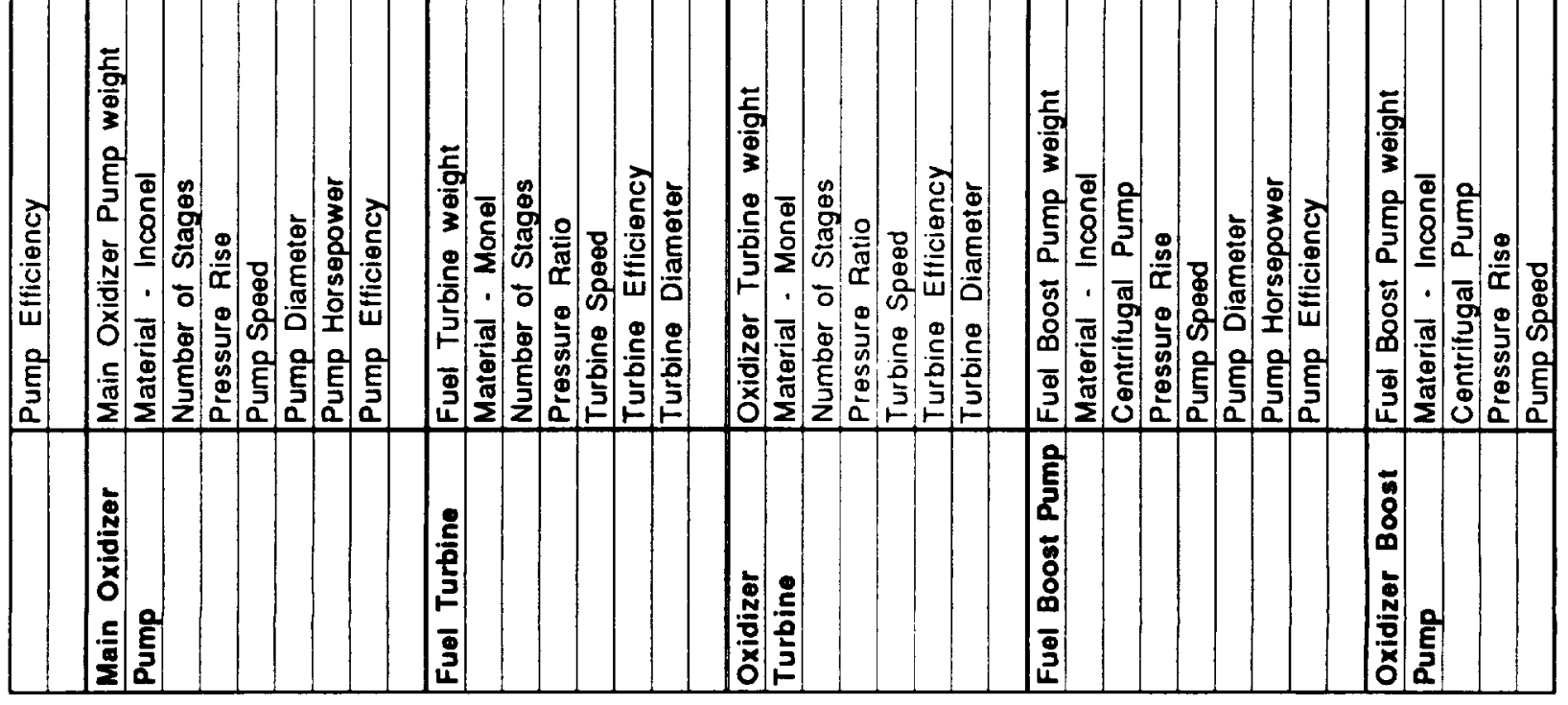





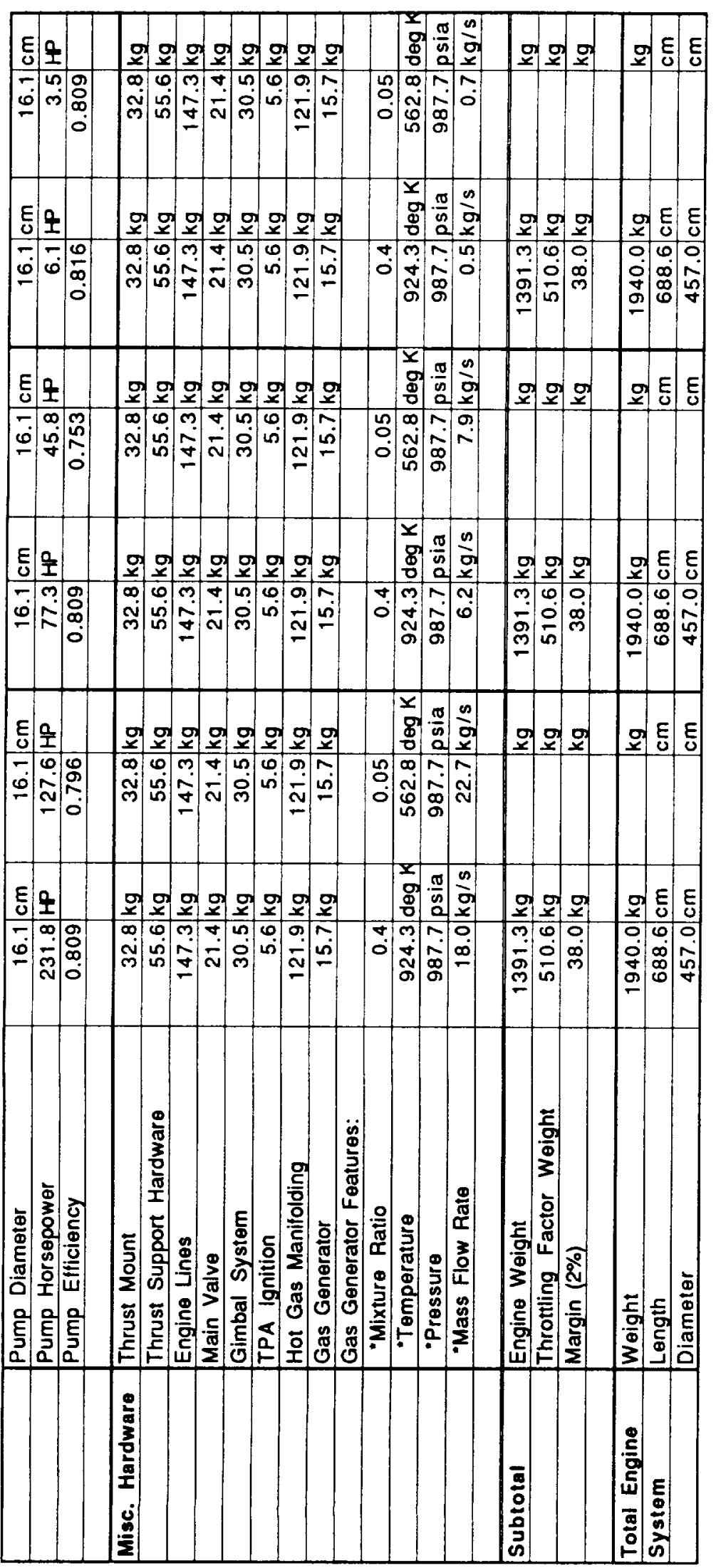





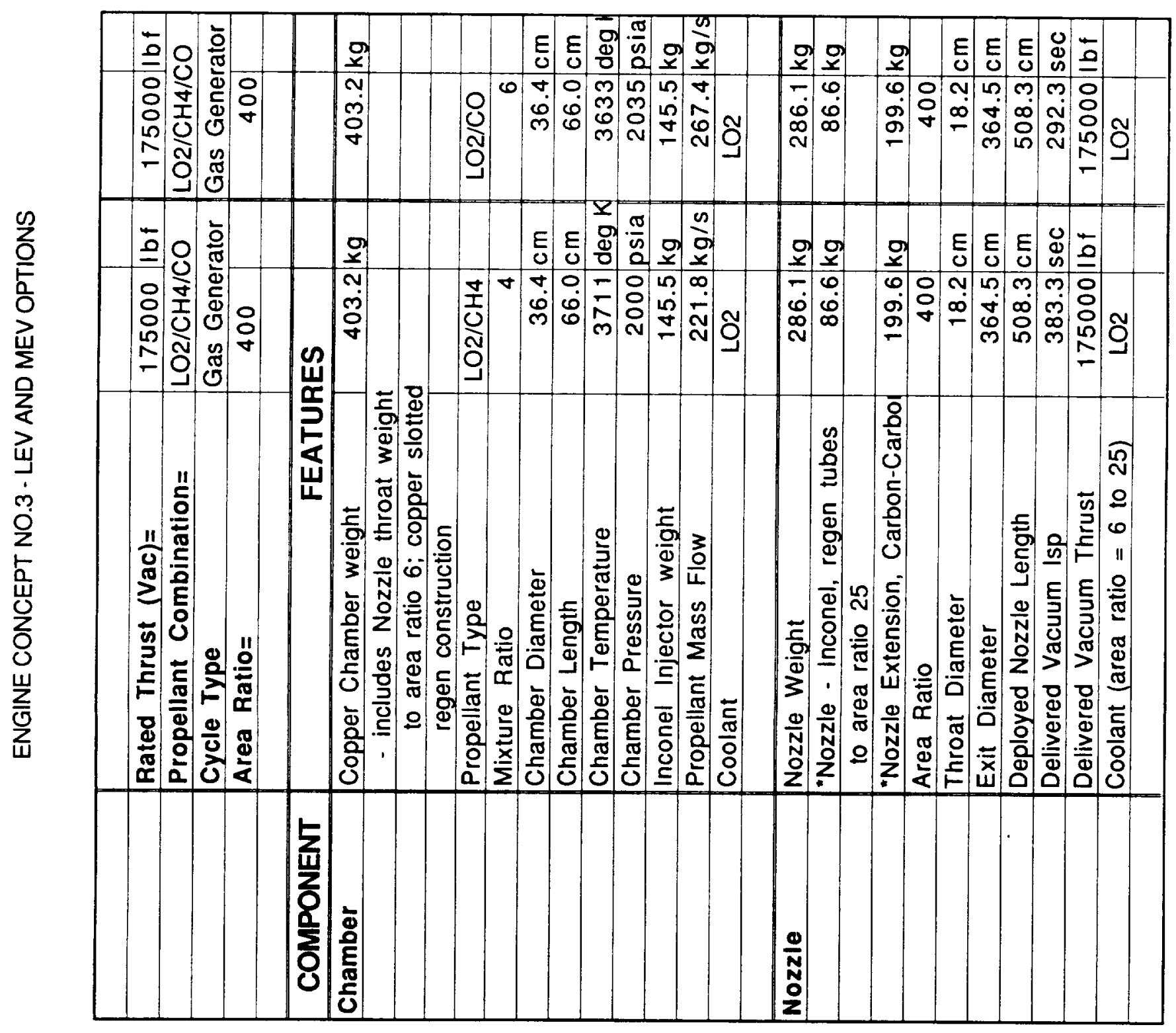





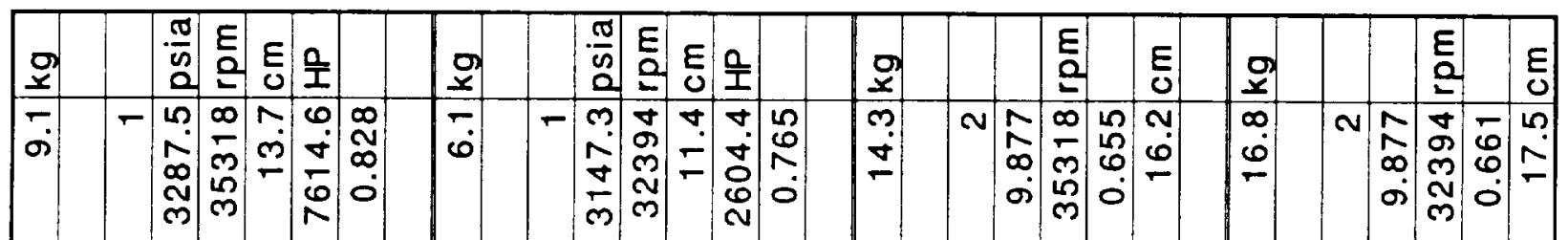

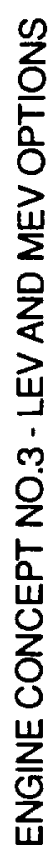

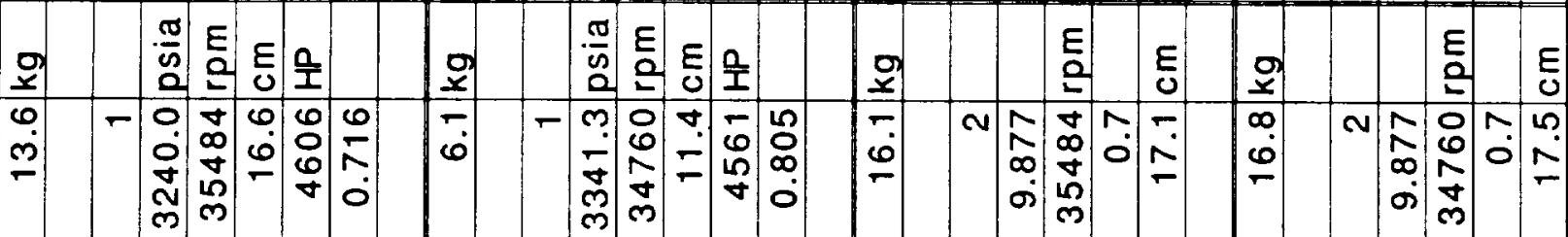

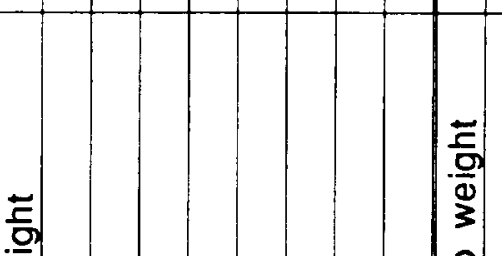

$\stackrel{9}{3}$

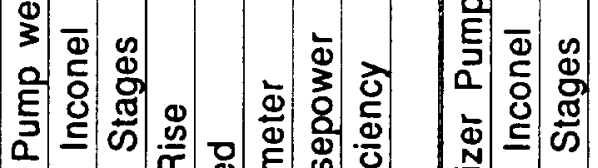

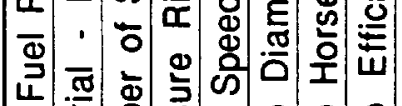

듬

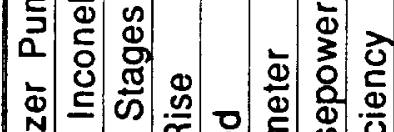

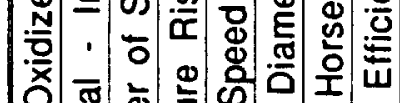

. 흫

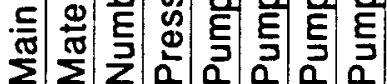

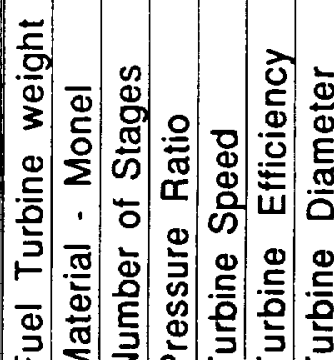

$\frac{\bar{F}}{\frac{1}{0}}$

$\sum \sum \sum$ a $a$

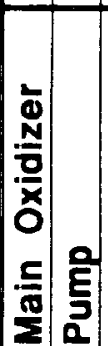

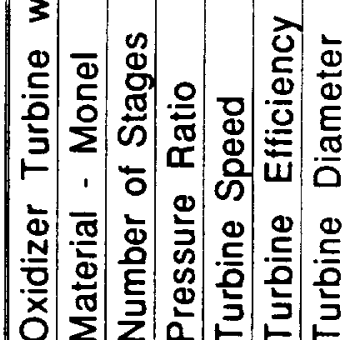

을

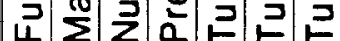

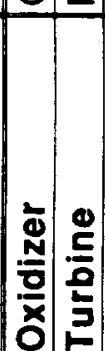





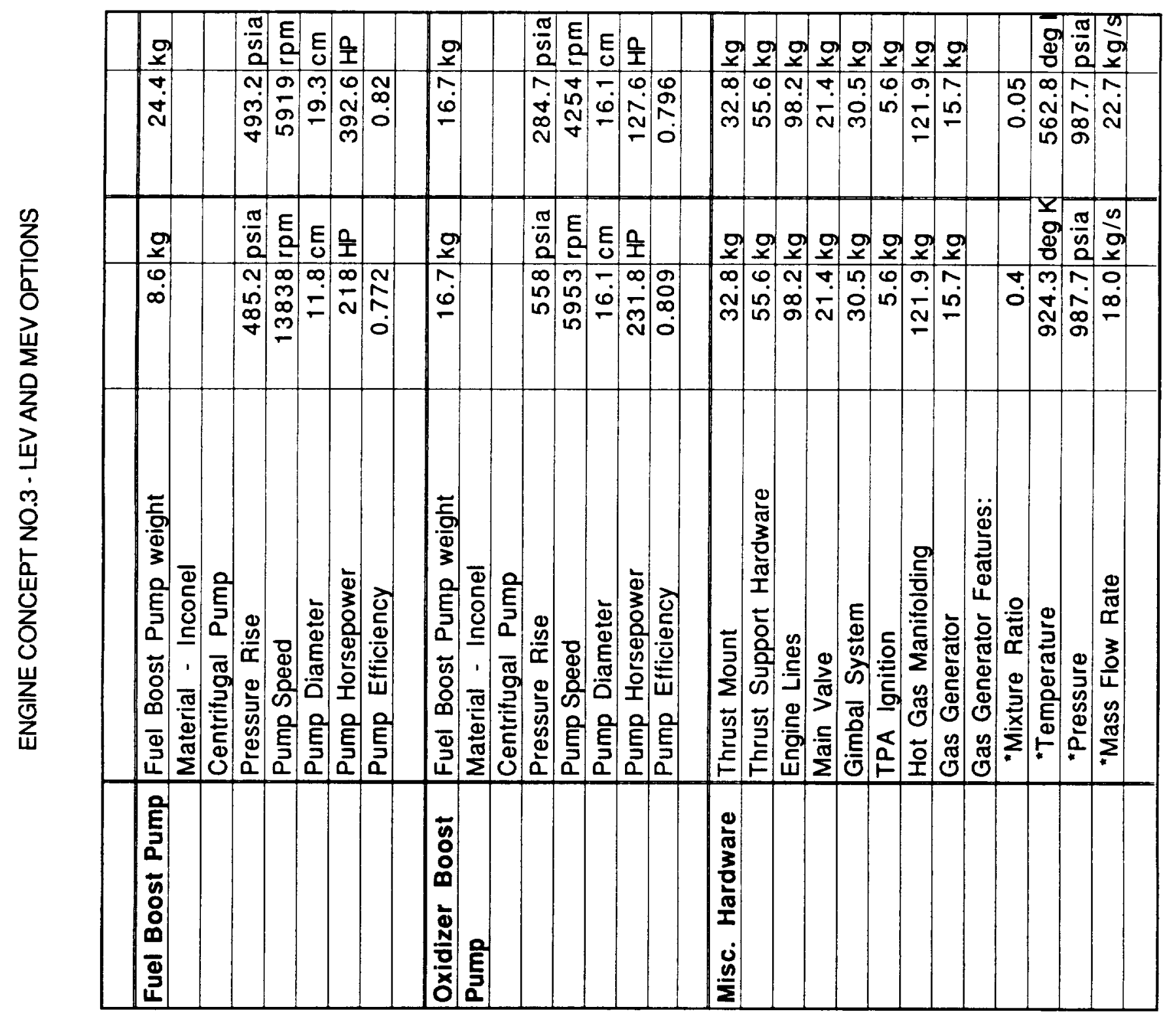





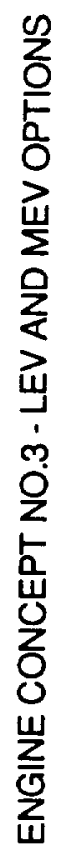

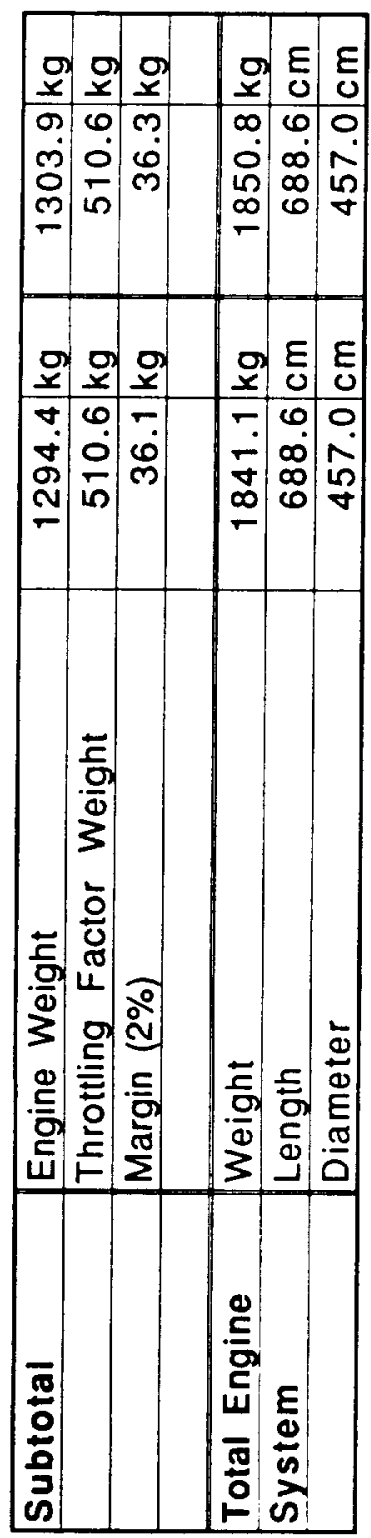

D-70 



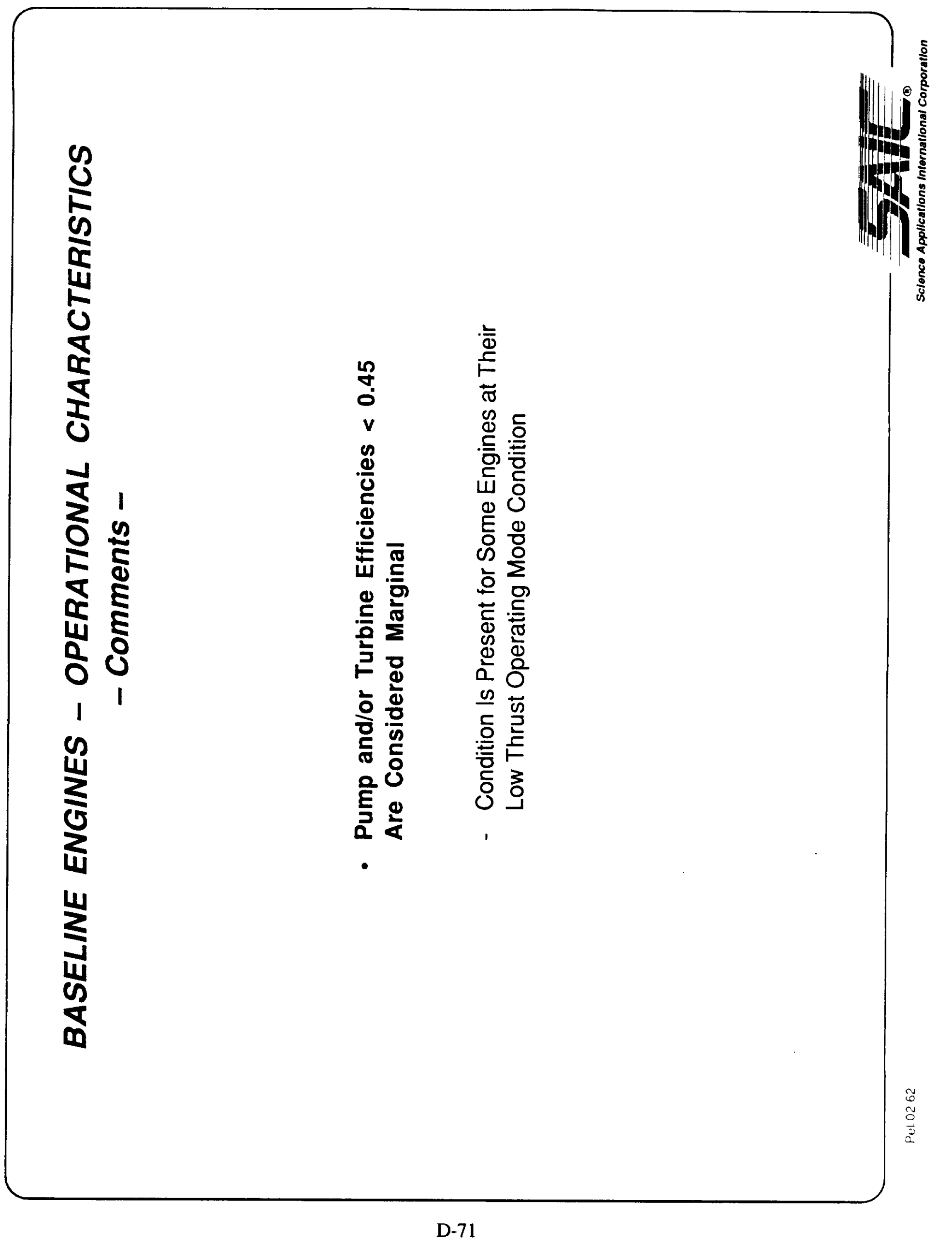





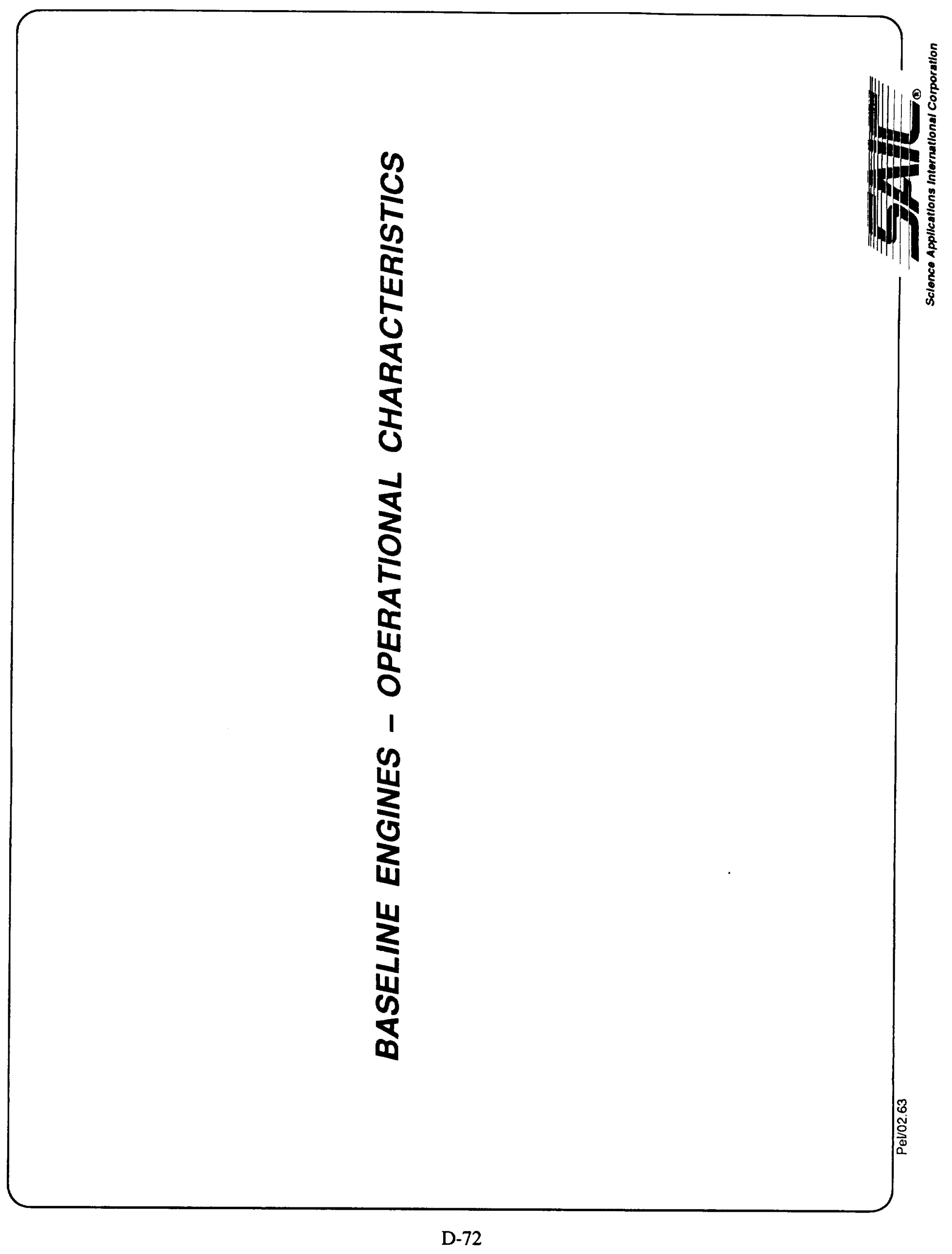





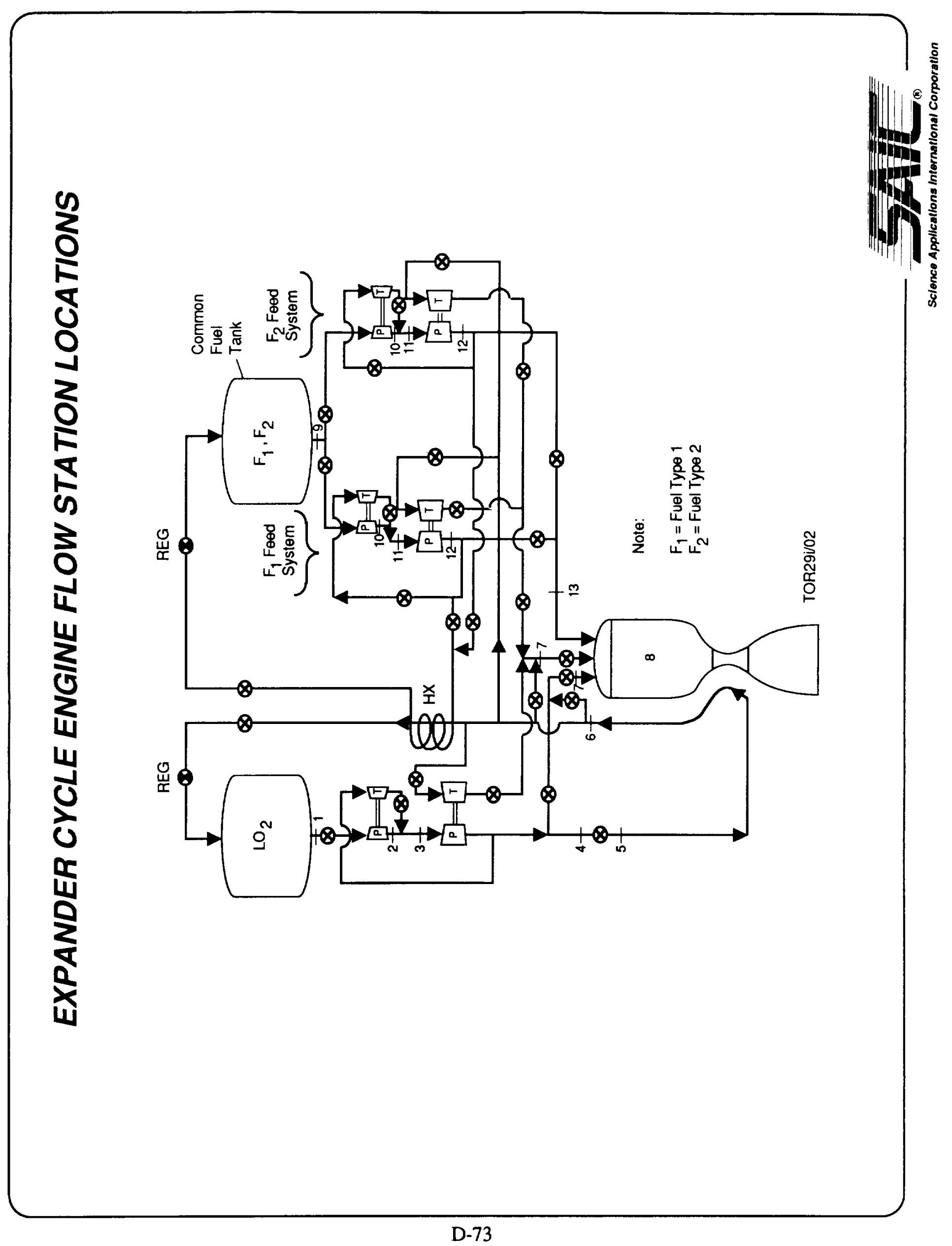





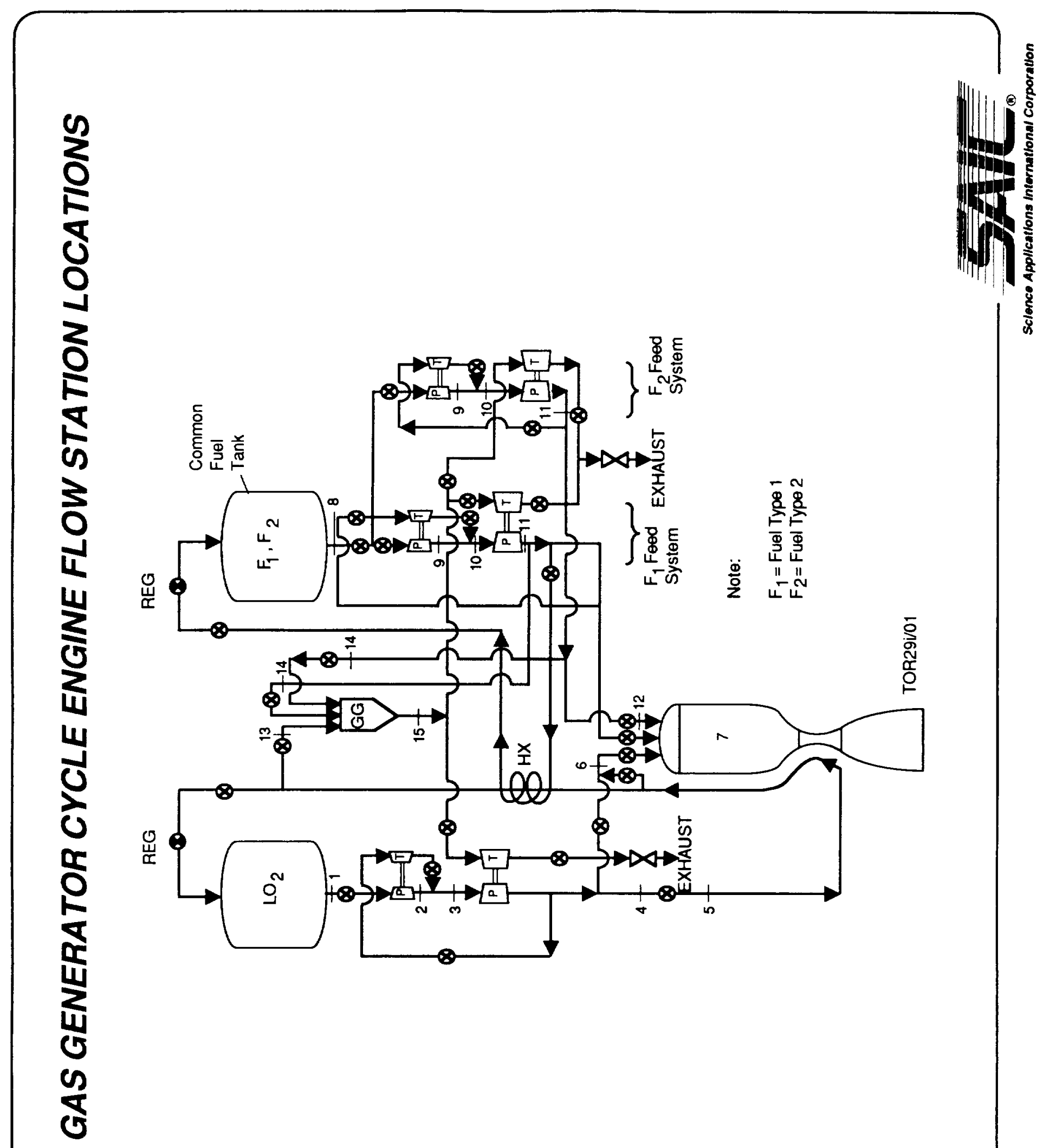




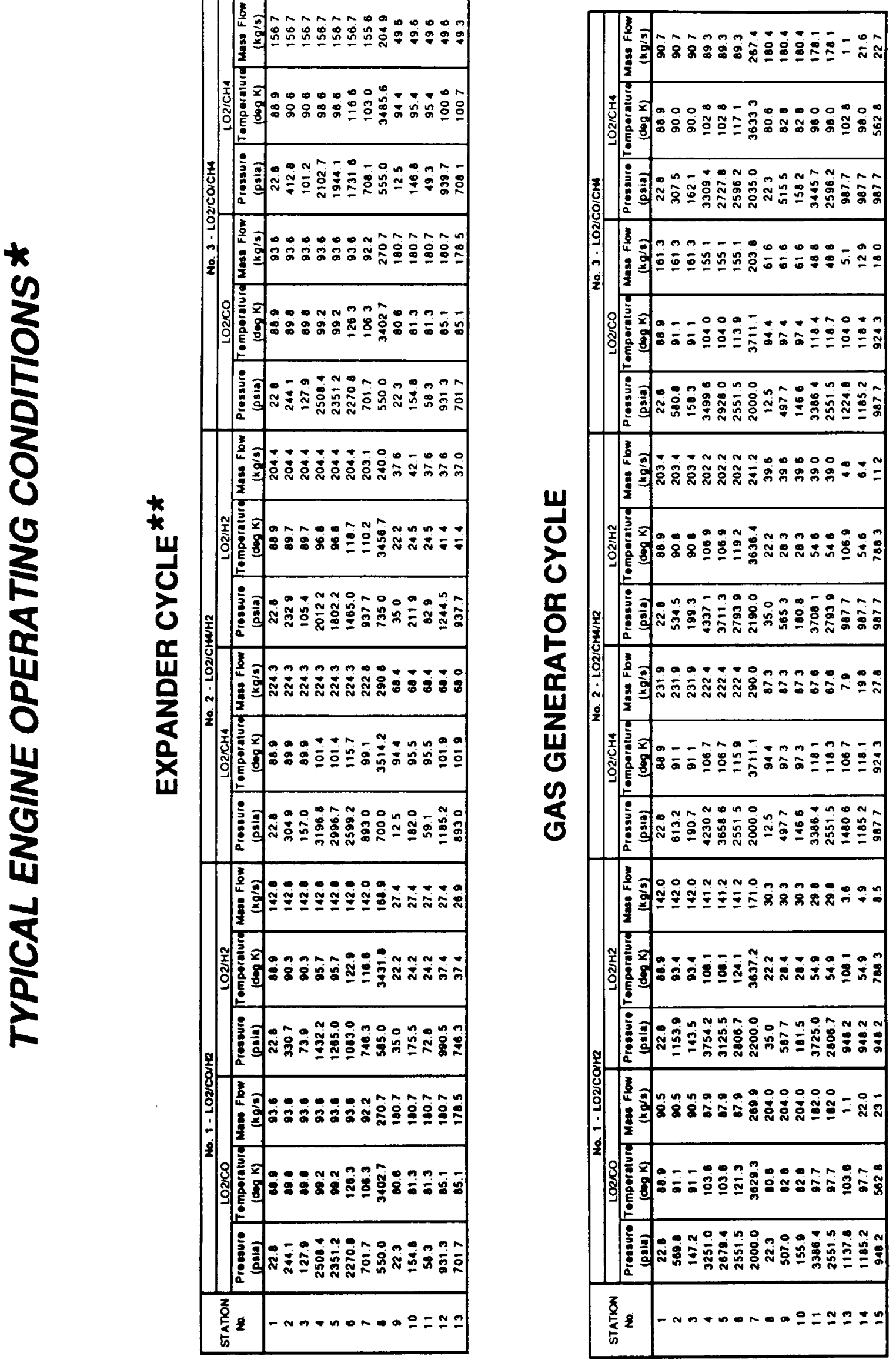

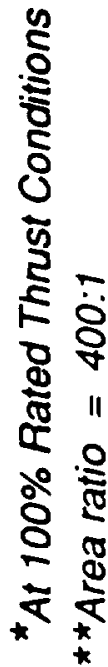





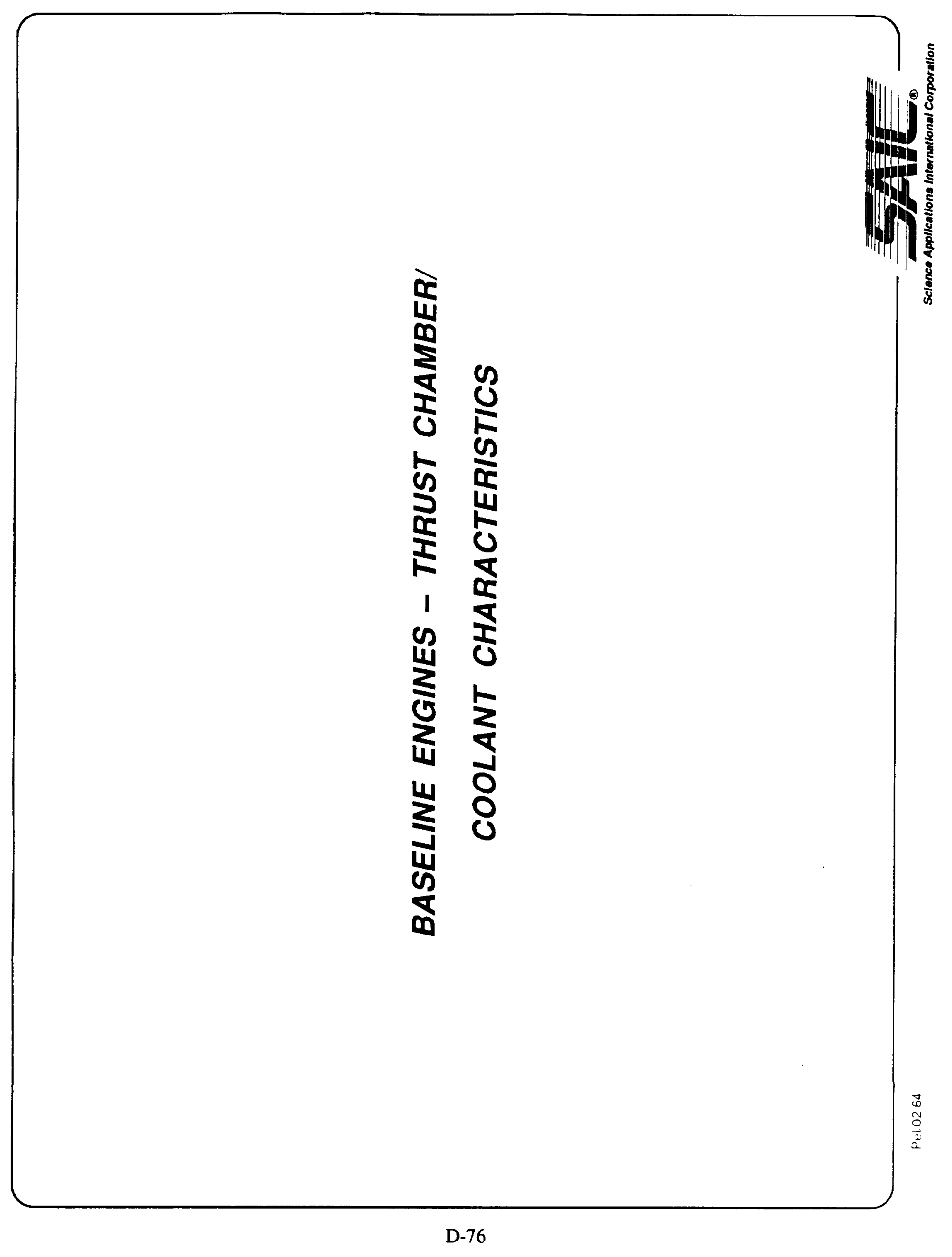




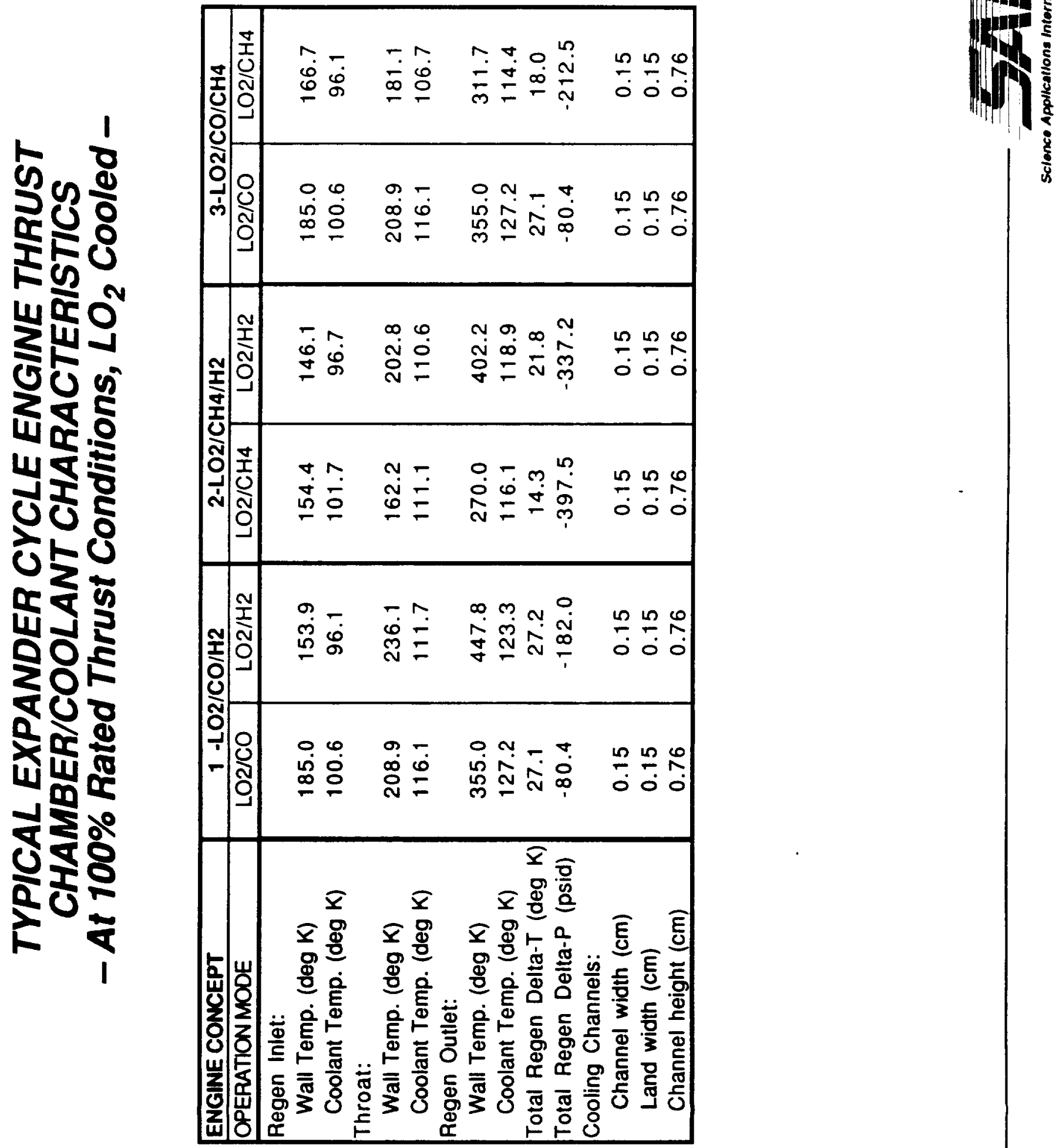


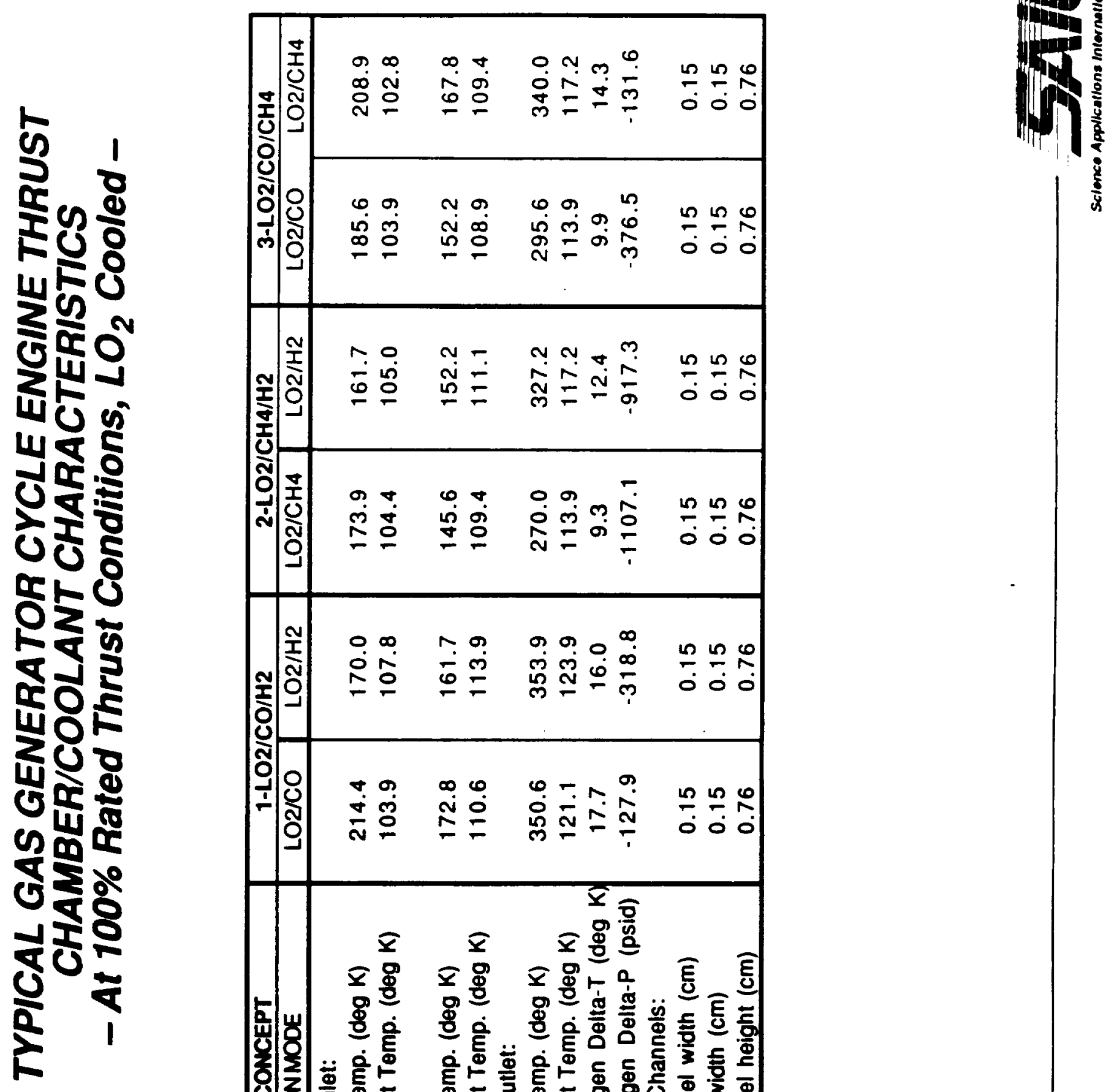

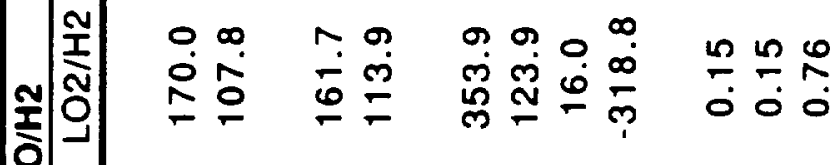

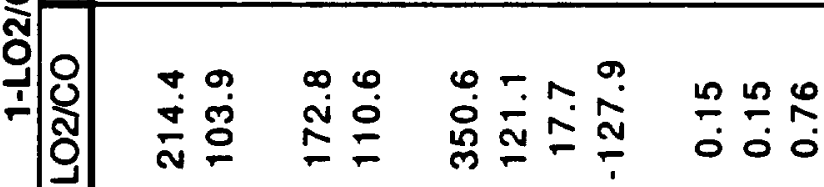

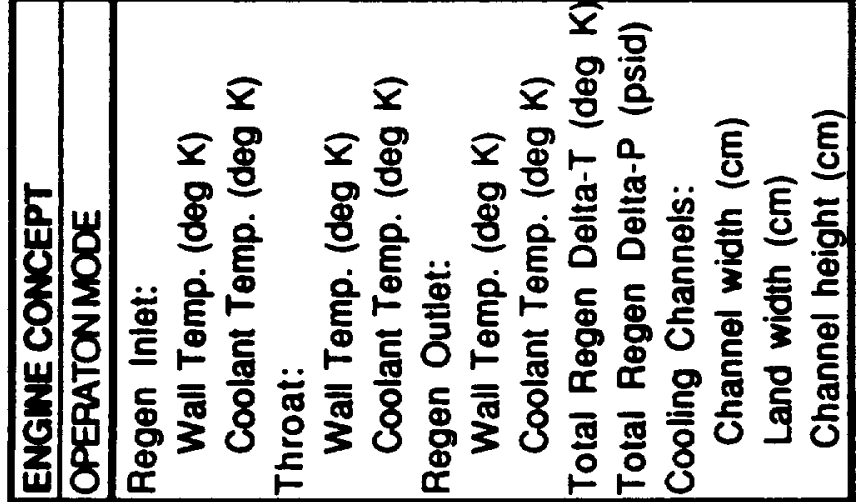




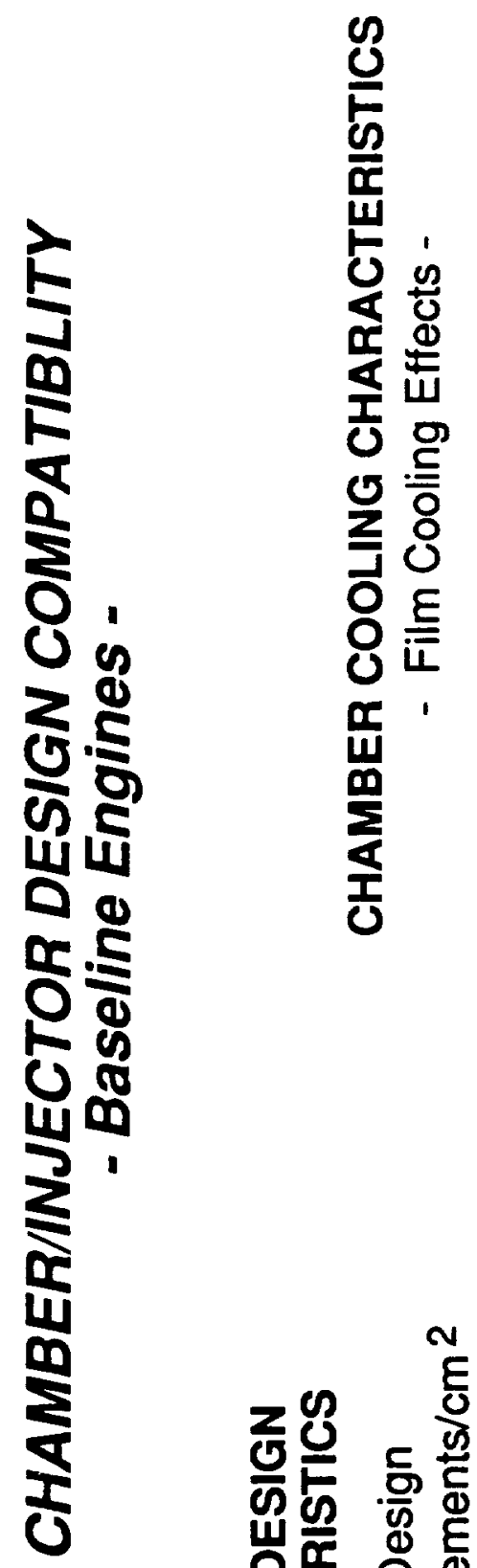

\begin{tabular}{|c|c|}
\hline 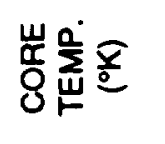 & | \\
\hline 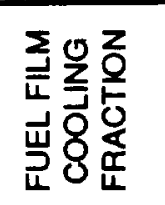 & 年 \\
\hline 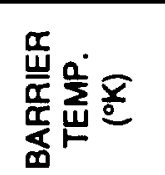 & 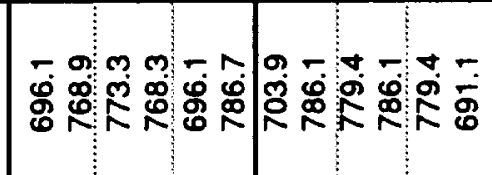 \\
\hline 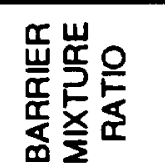 & 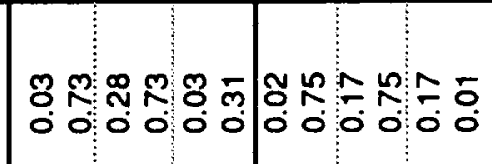 \\
\hline 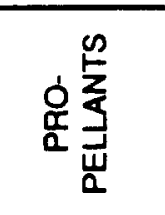 & 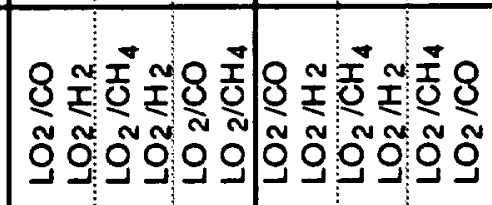 \\
\hline 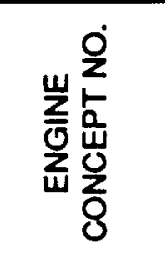 & 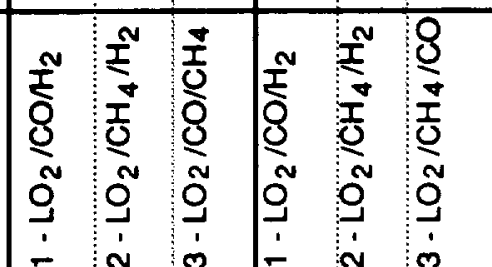 \\
\hline 芌 & 亮 \\
\hline
\end{tabular}

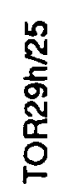

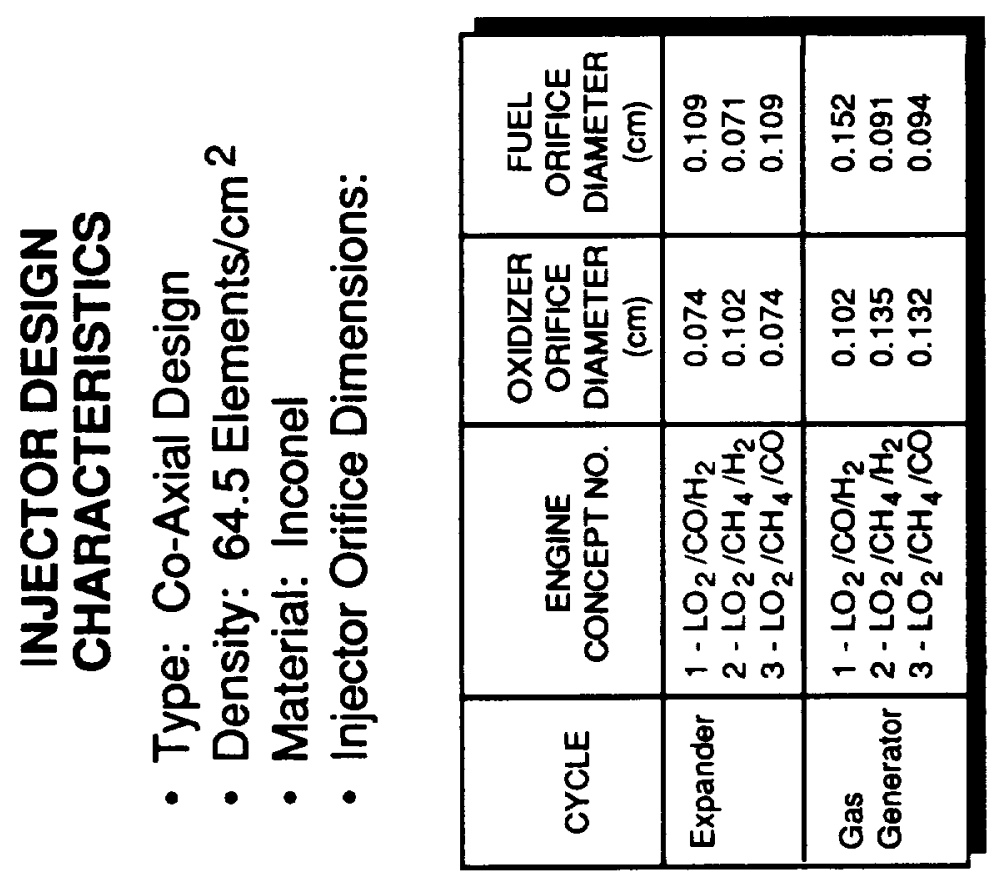





\section{APPENDIX E}

FINAL MISSION PROFILE/REQUIREMENTS DATA 



\section{APPENDIX E FINAL MISSION PROFILE/REQUIREMENTS DATA}

Detailed mission profile and requirements data is presented in this appendix for the mission scenarios examined in Section 5.0. This data is based on engine systems engineering data which is presented and discussed in Section 4.0. 


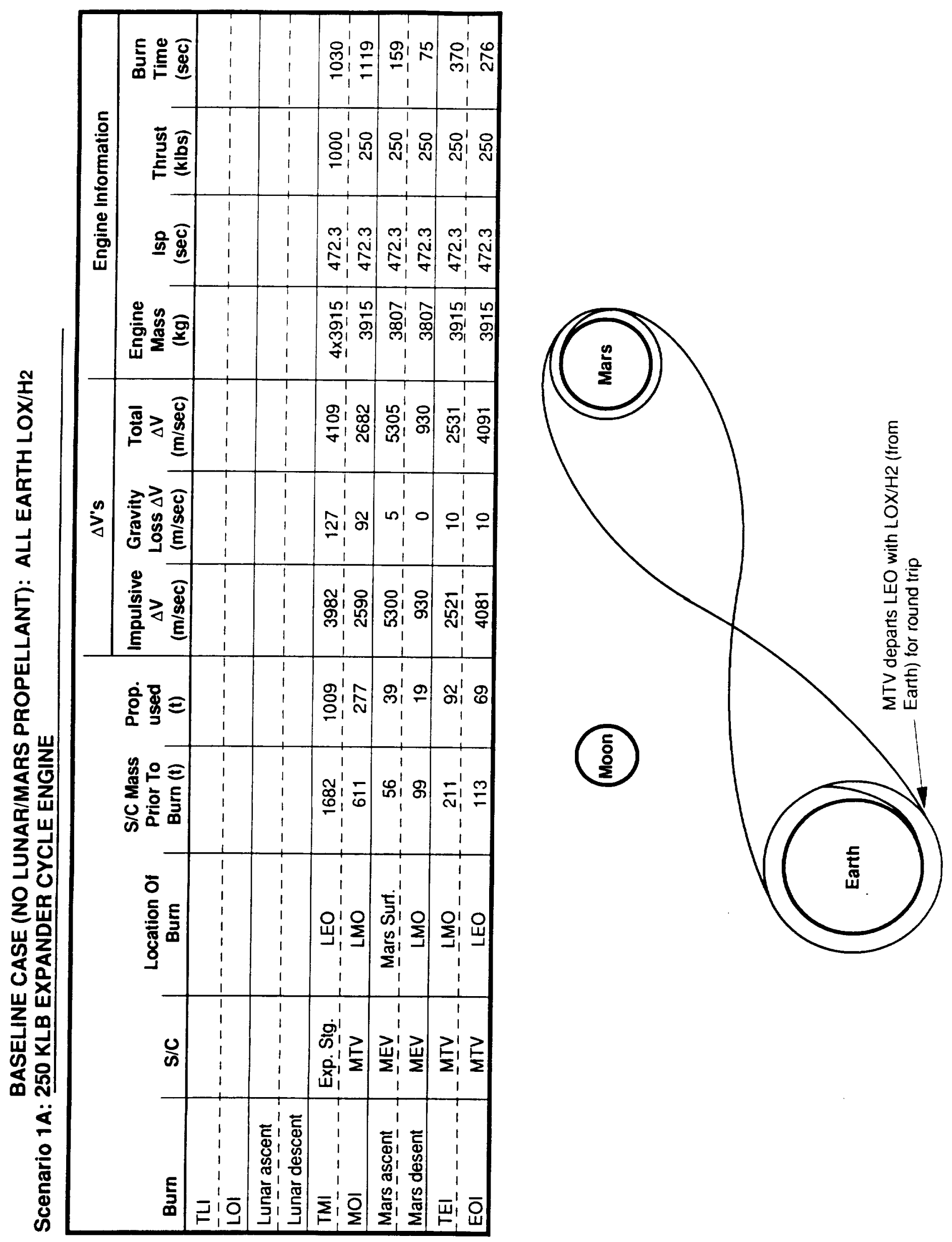



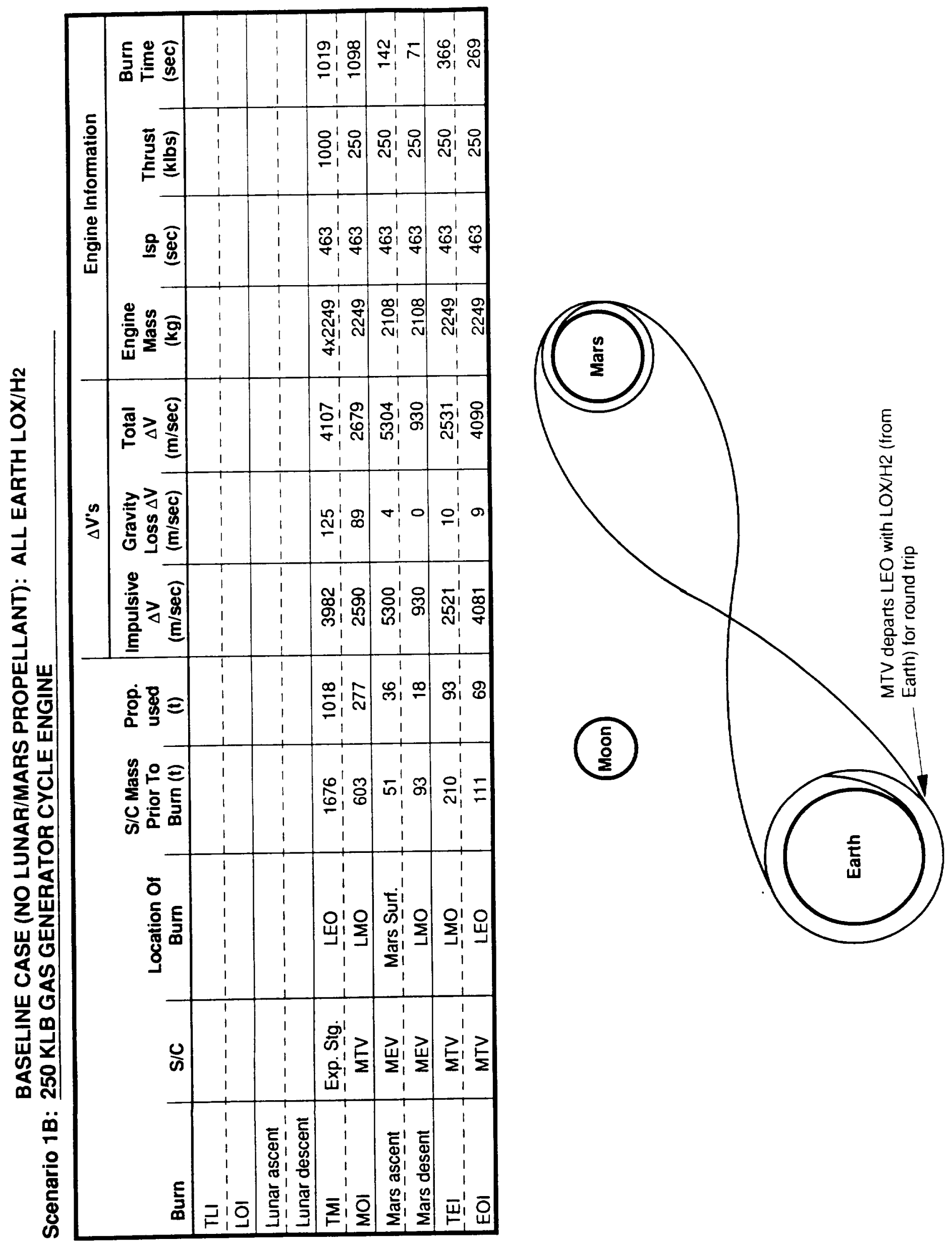





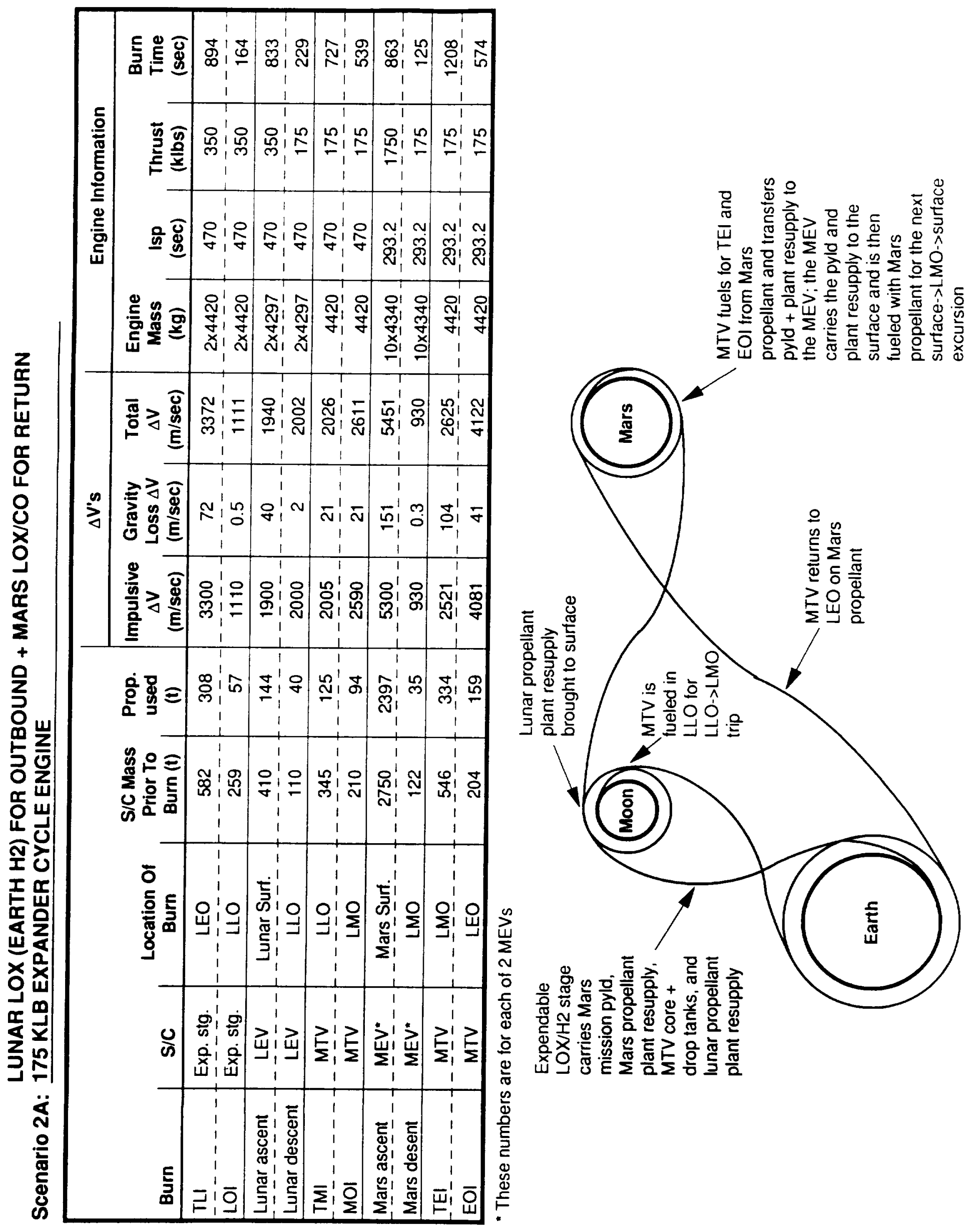





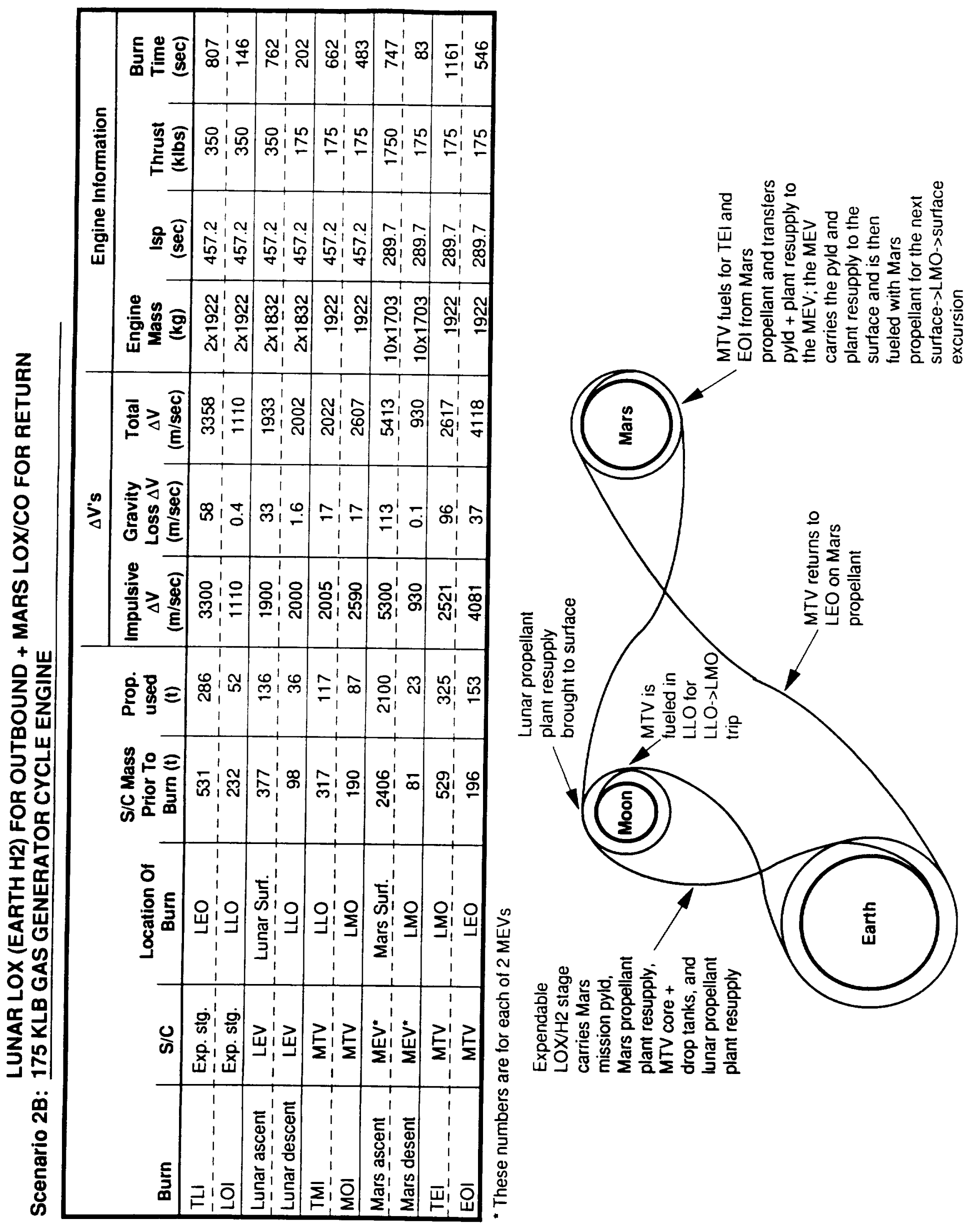





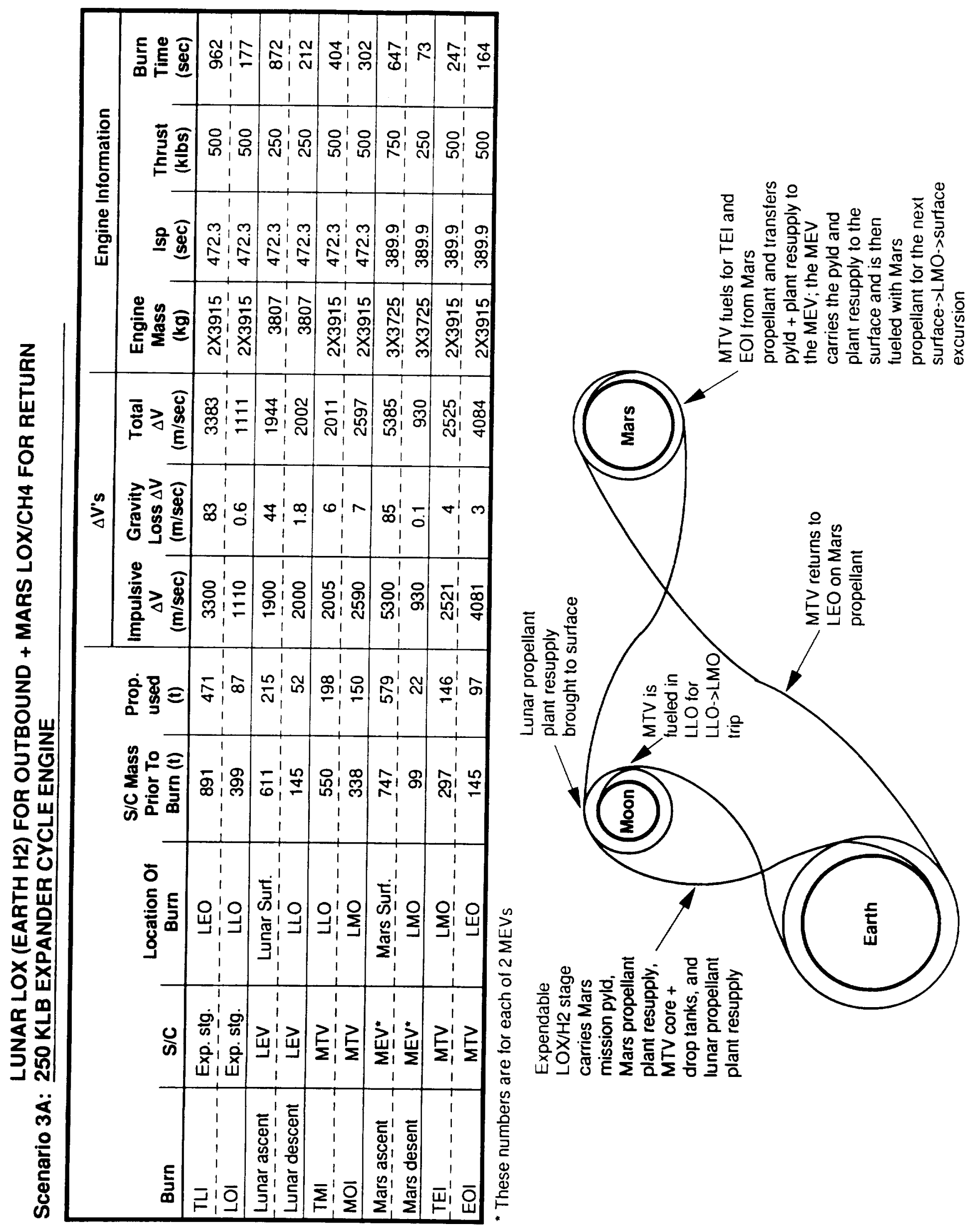





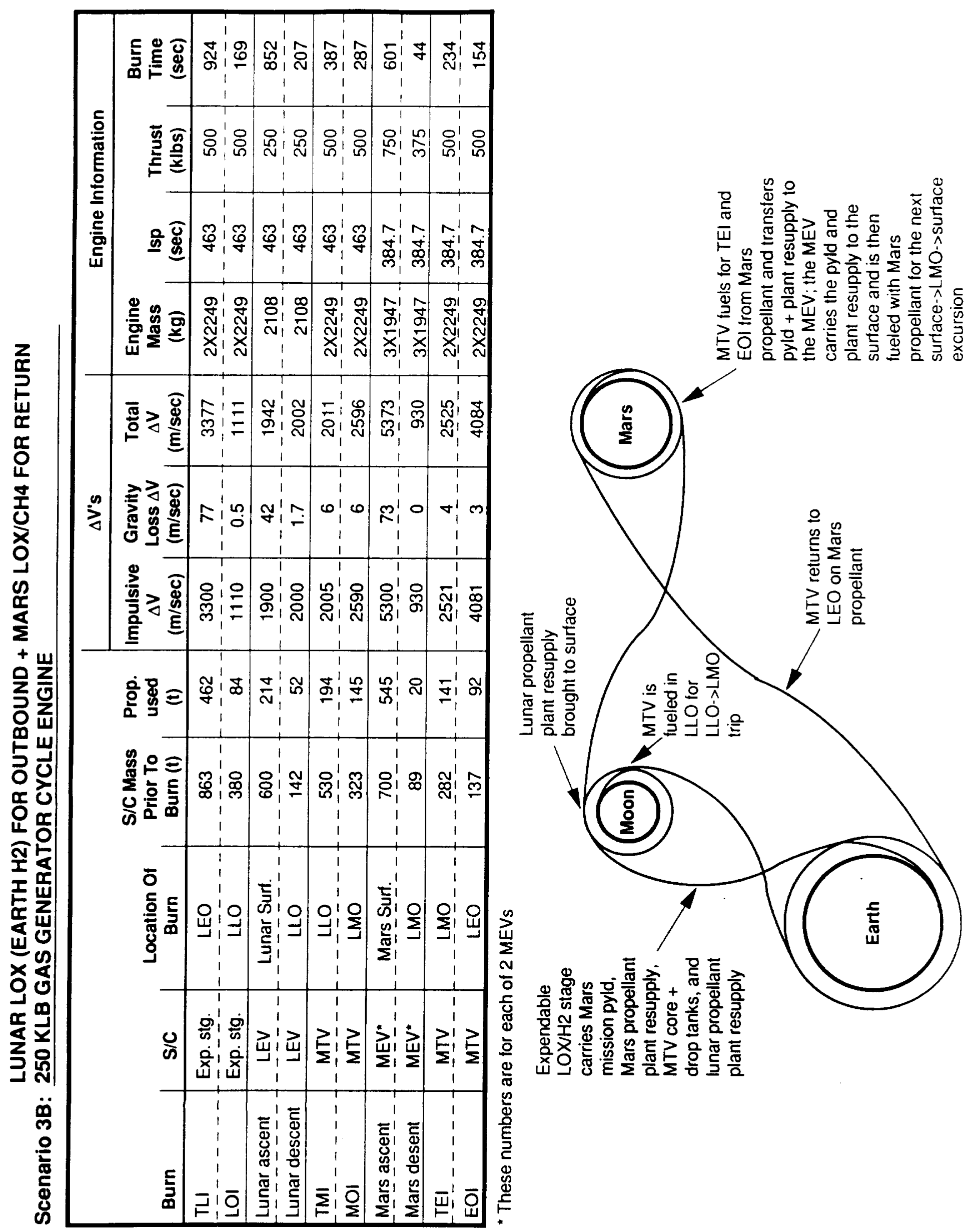





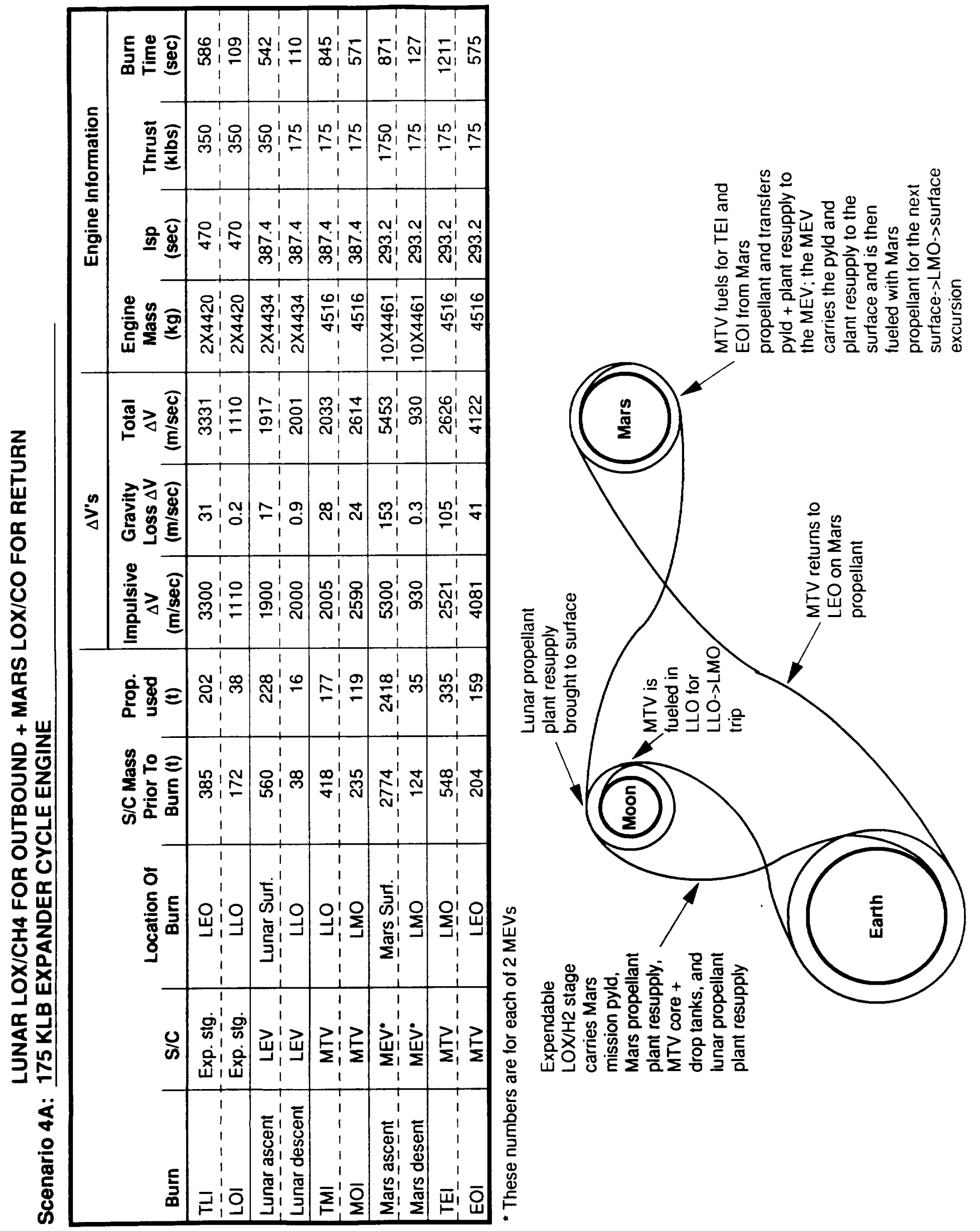





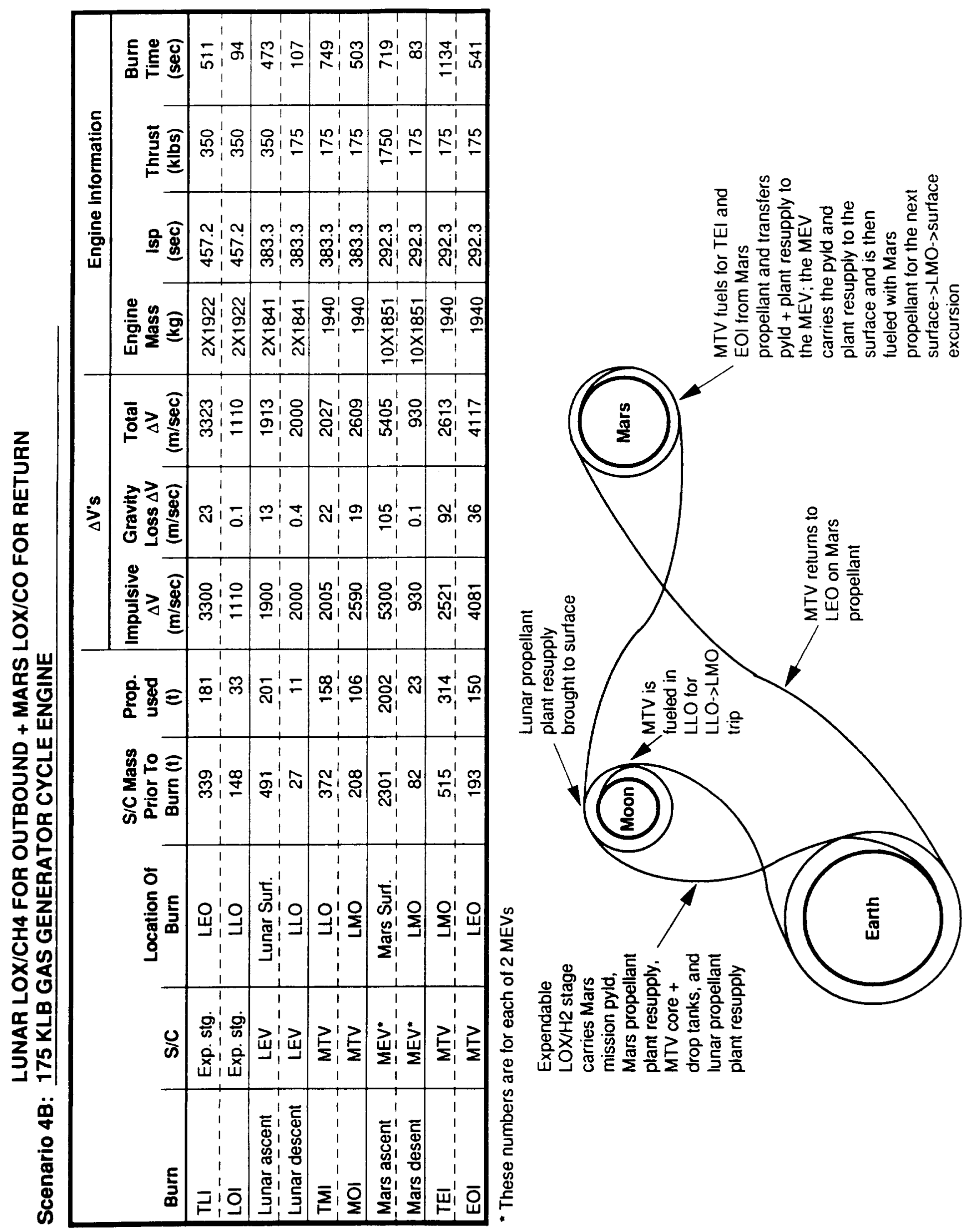





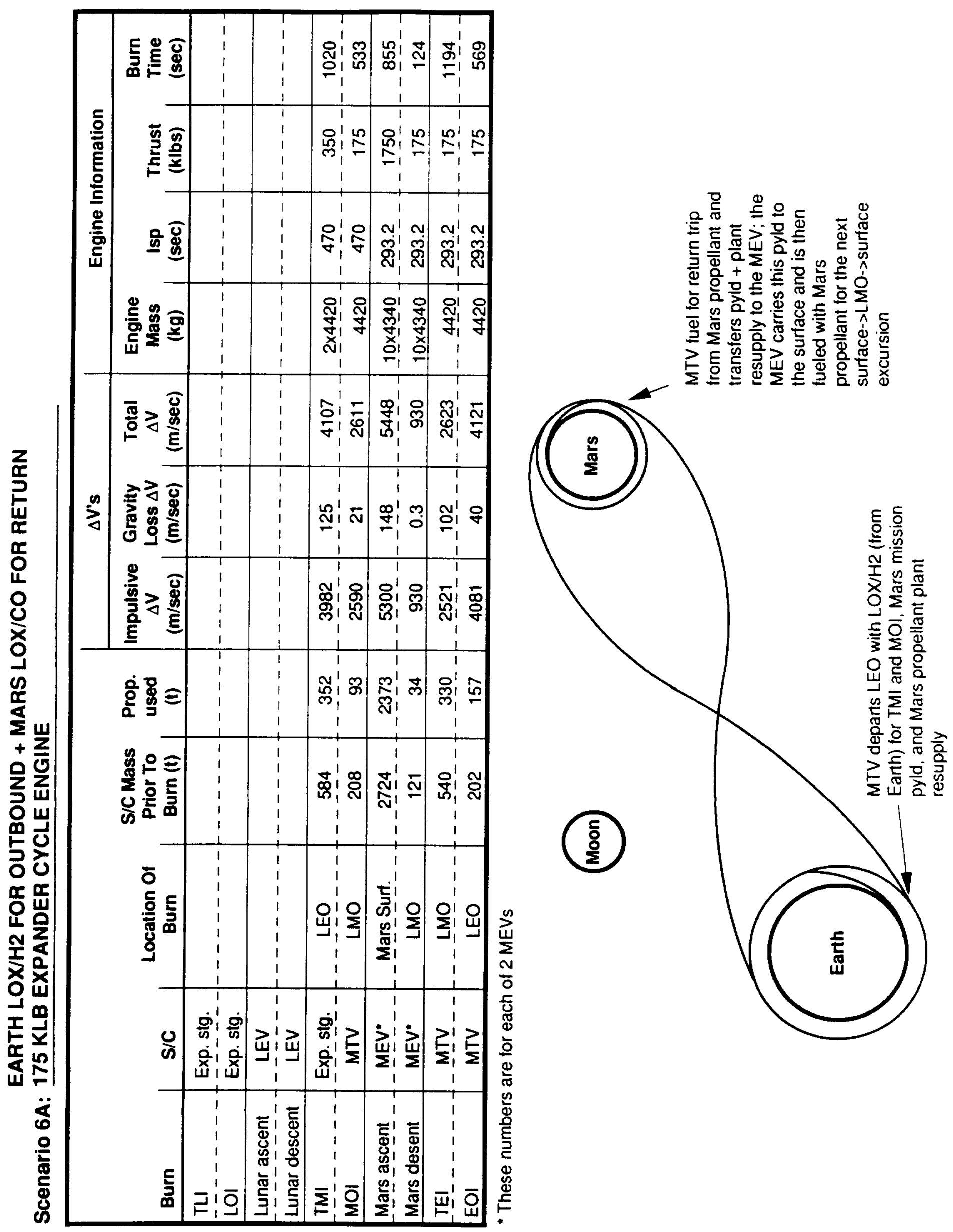





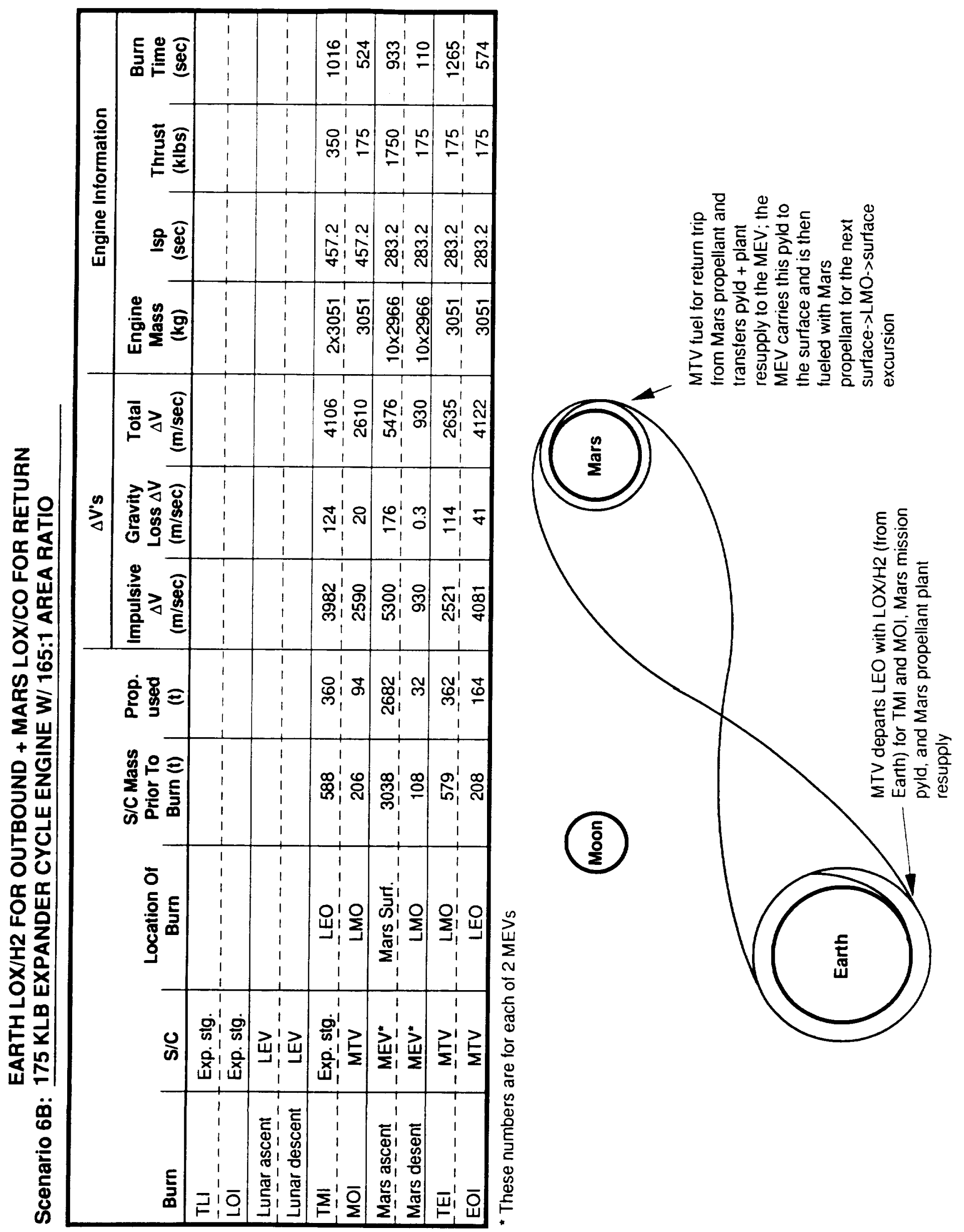




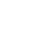




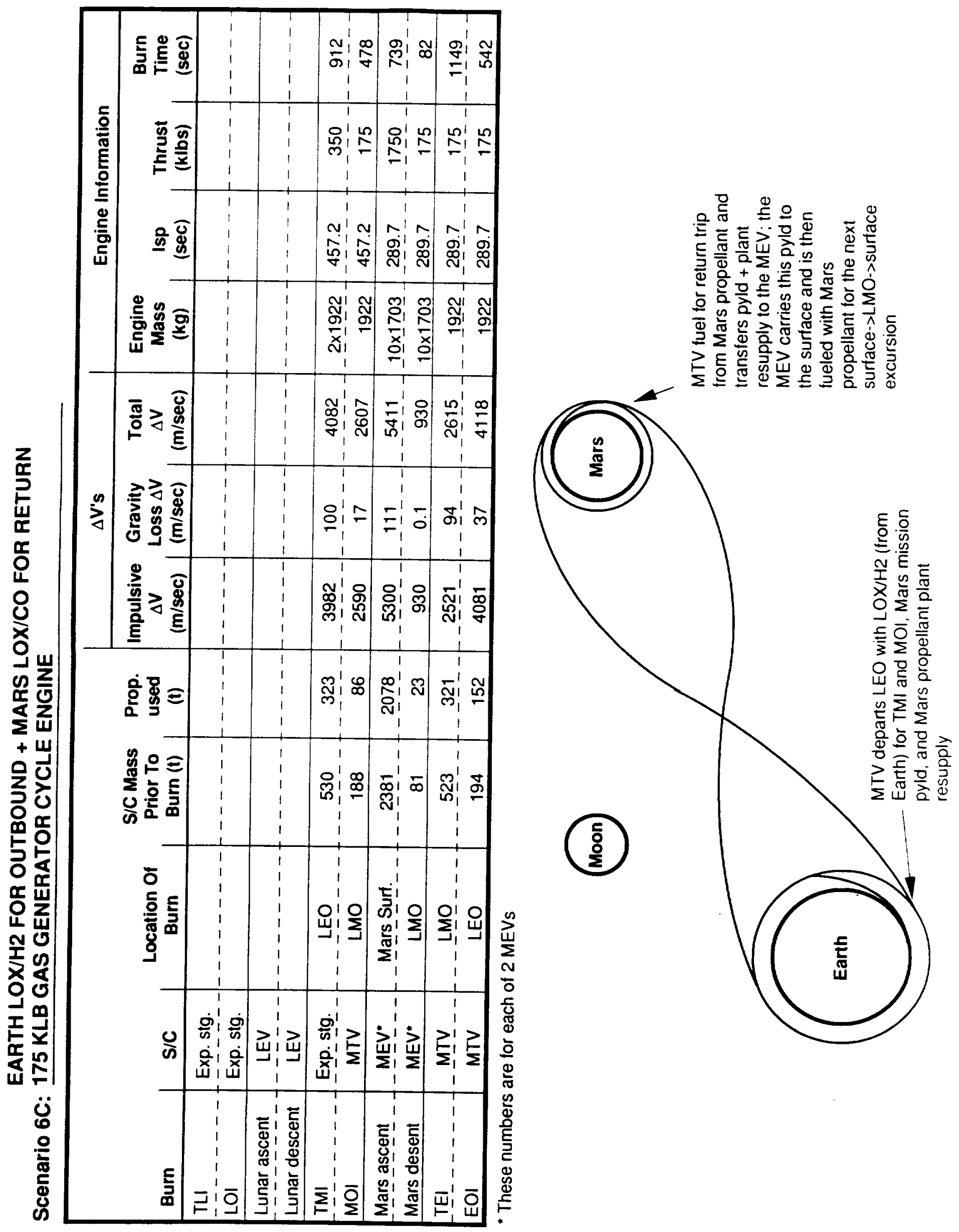





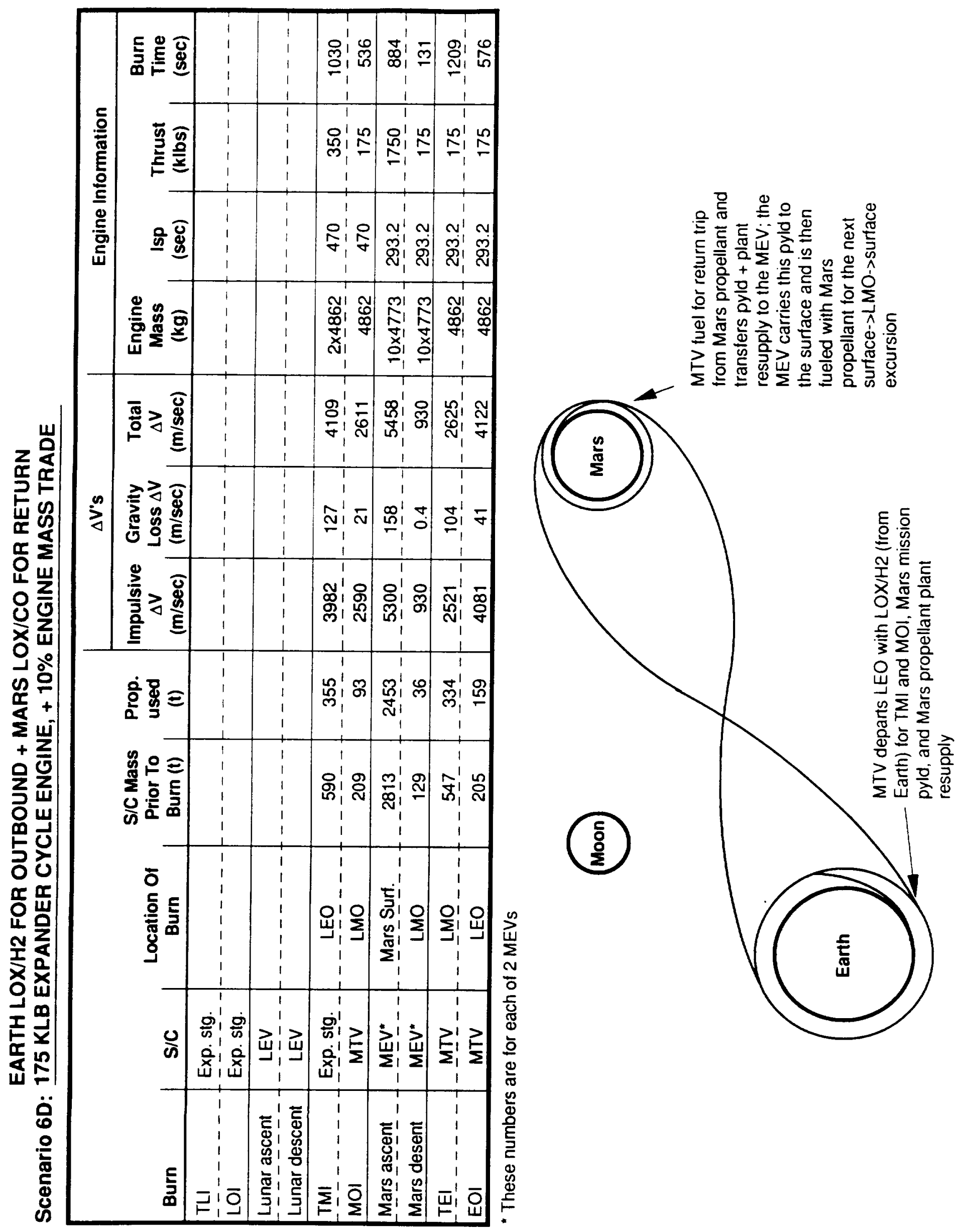





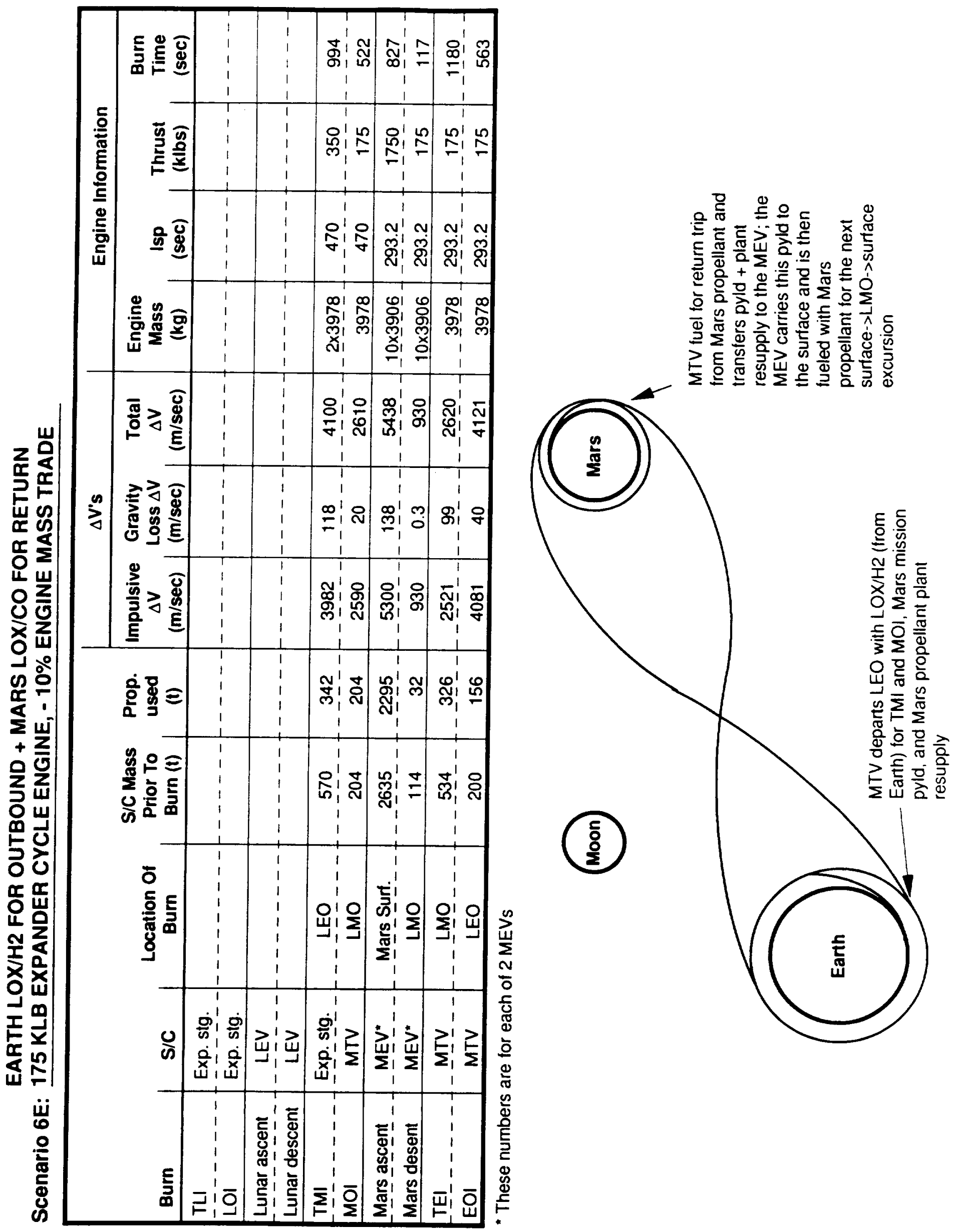





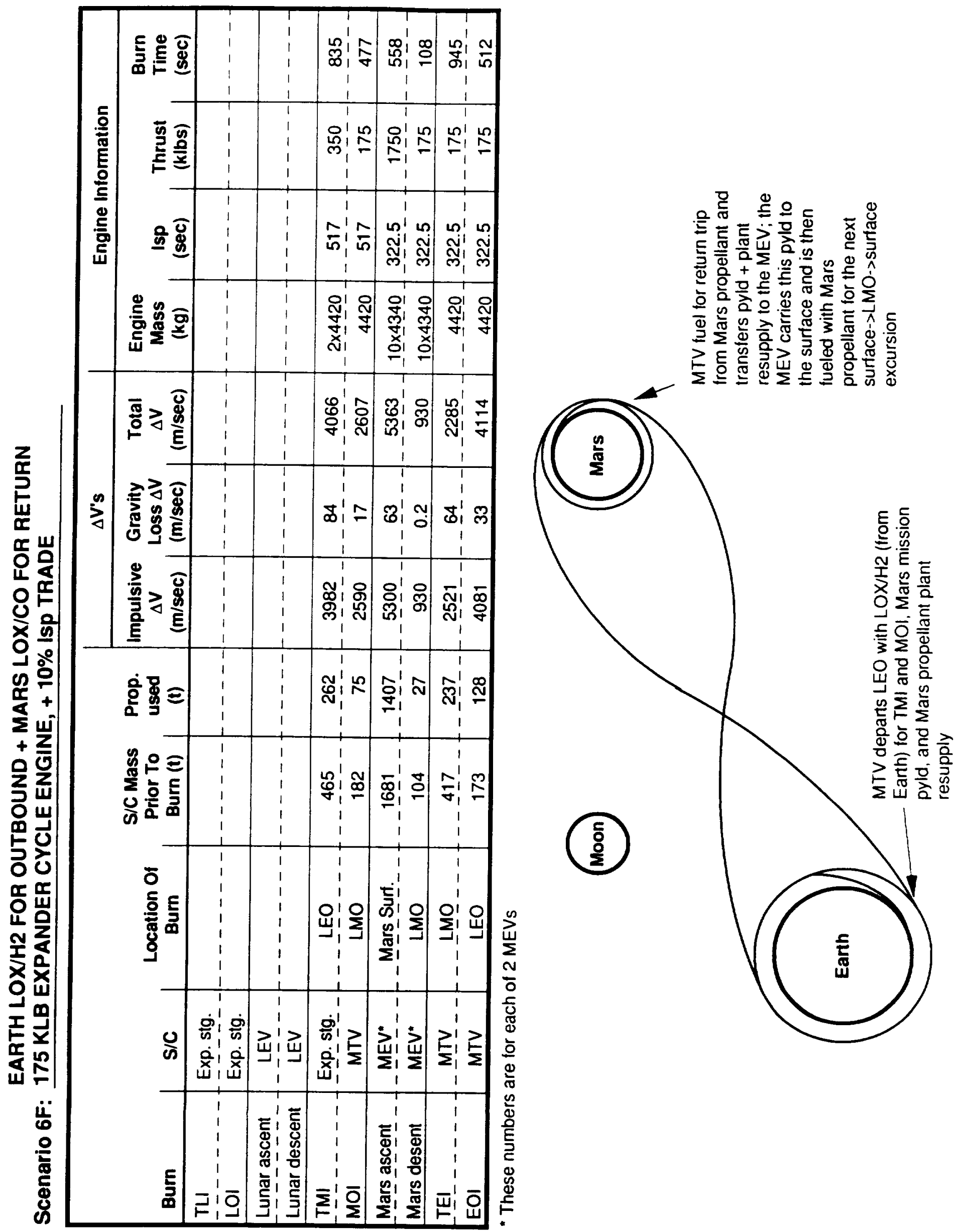





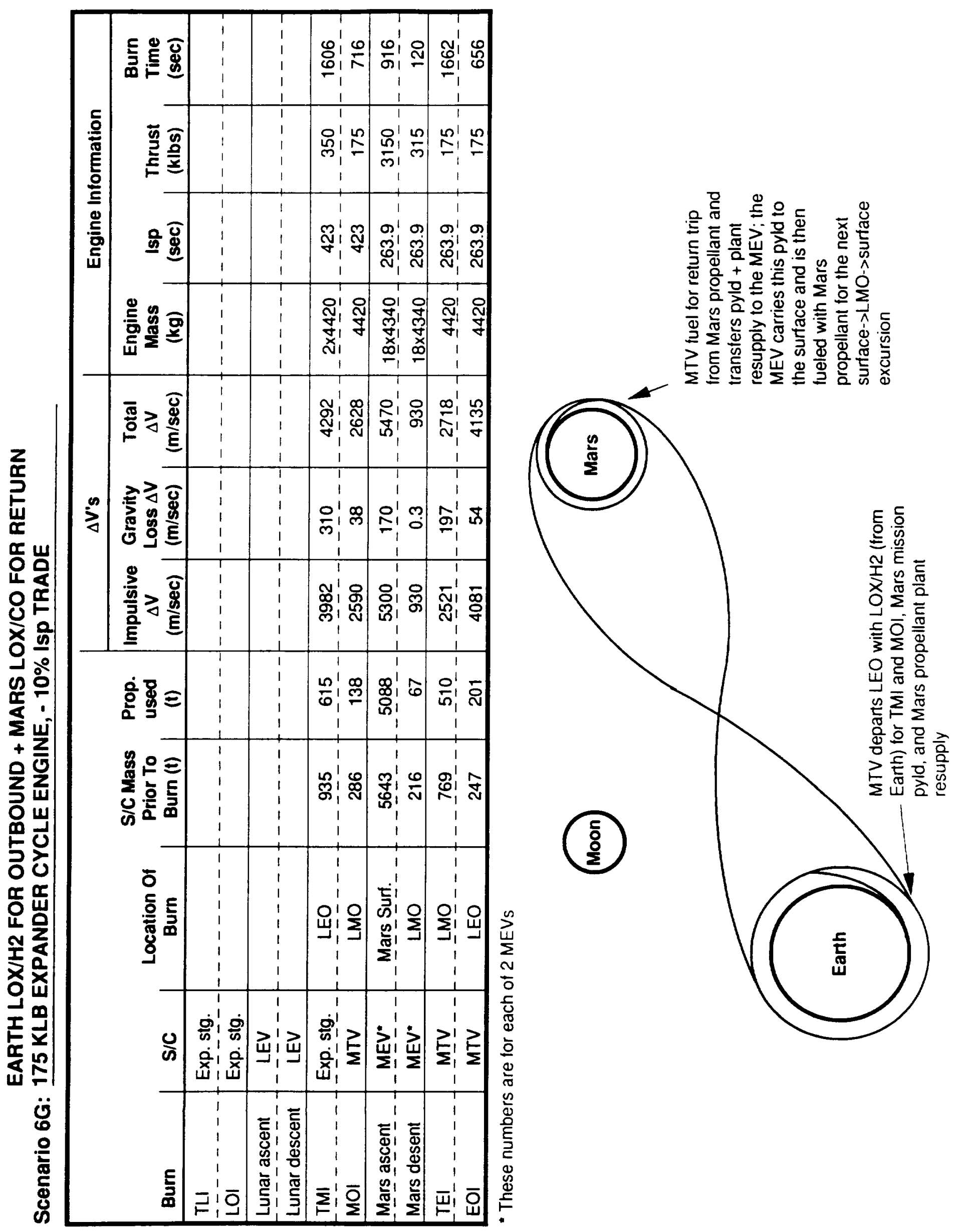





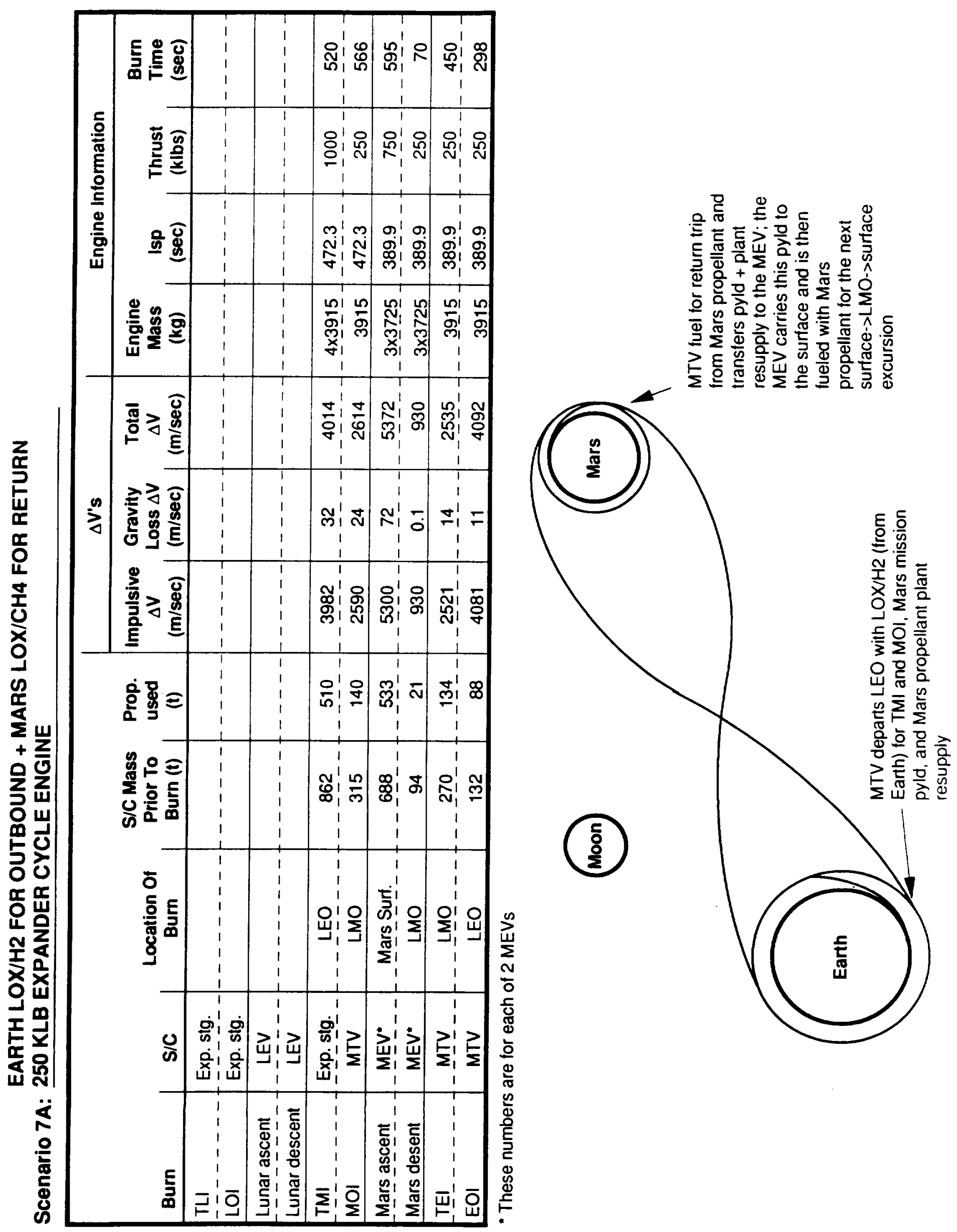





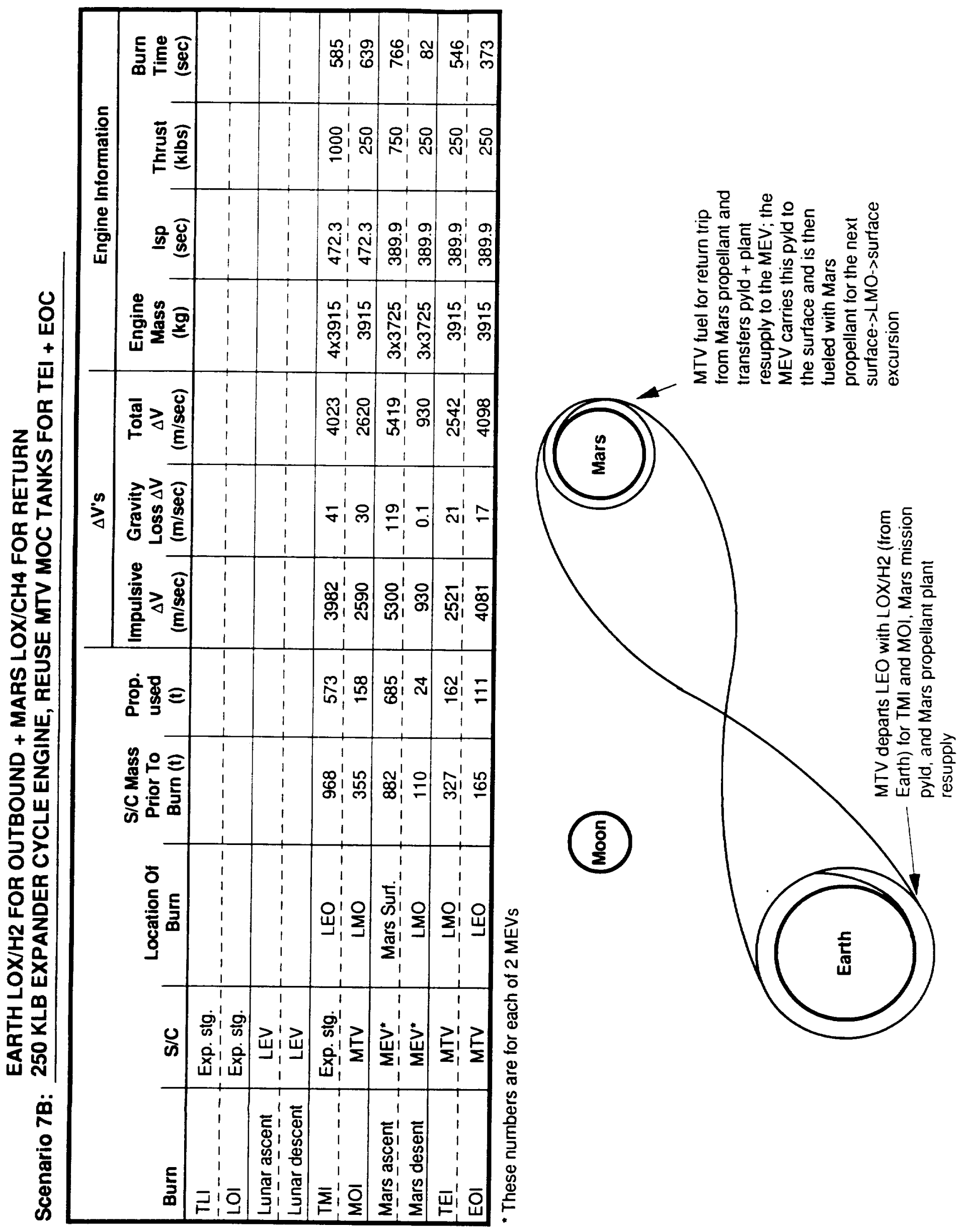





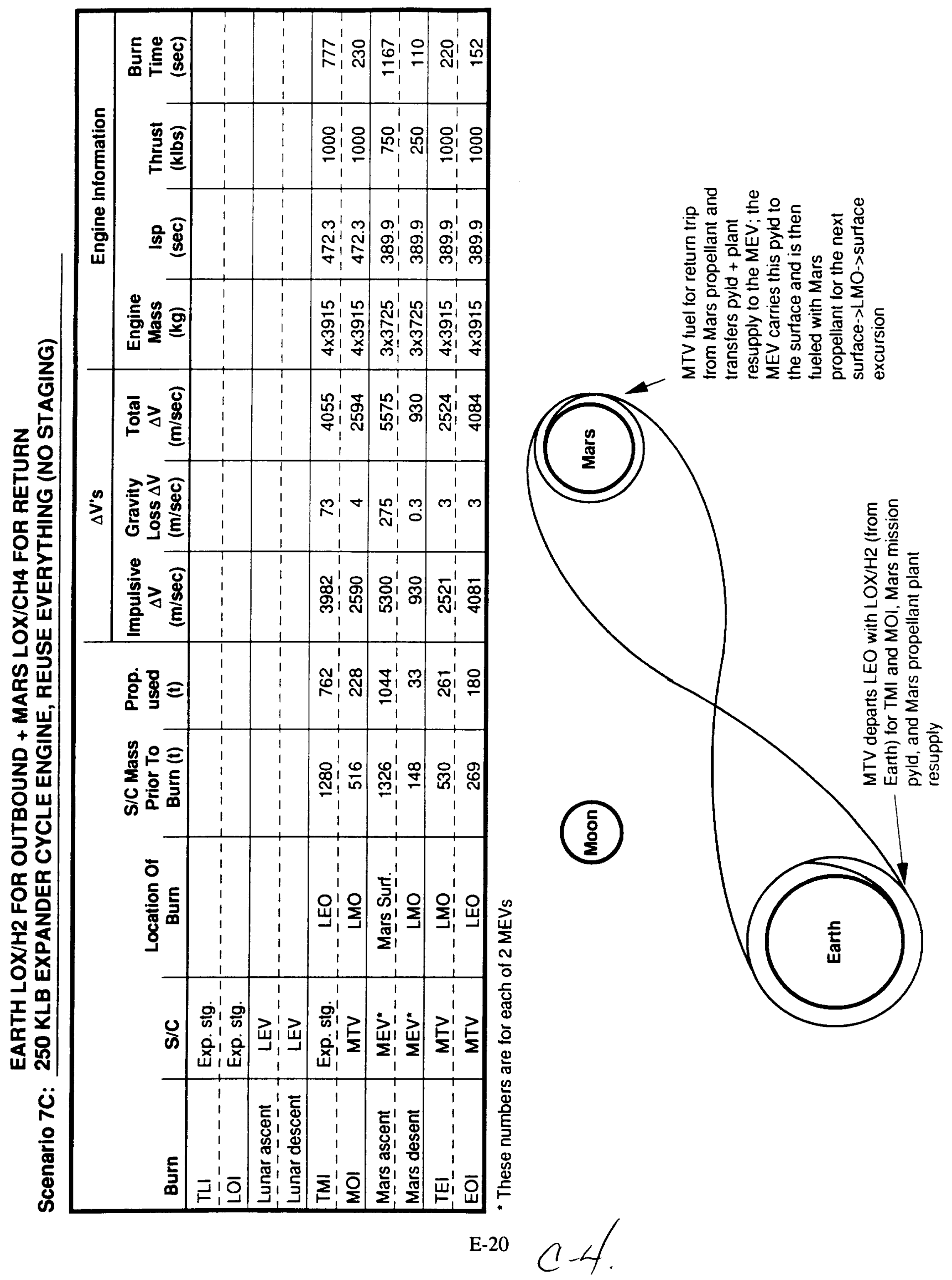





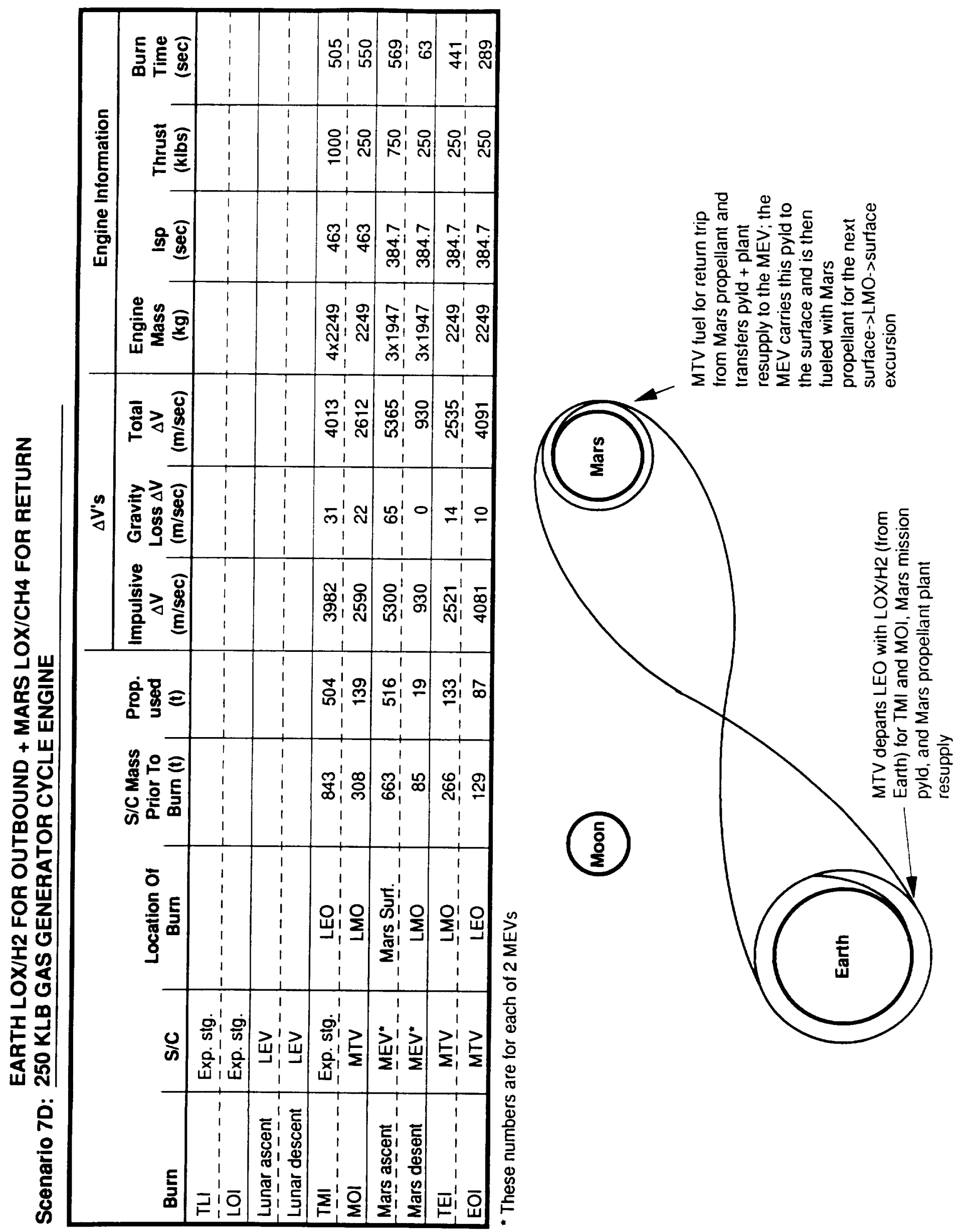





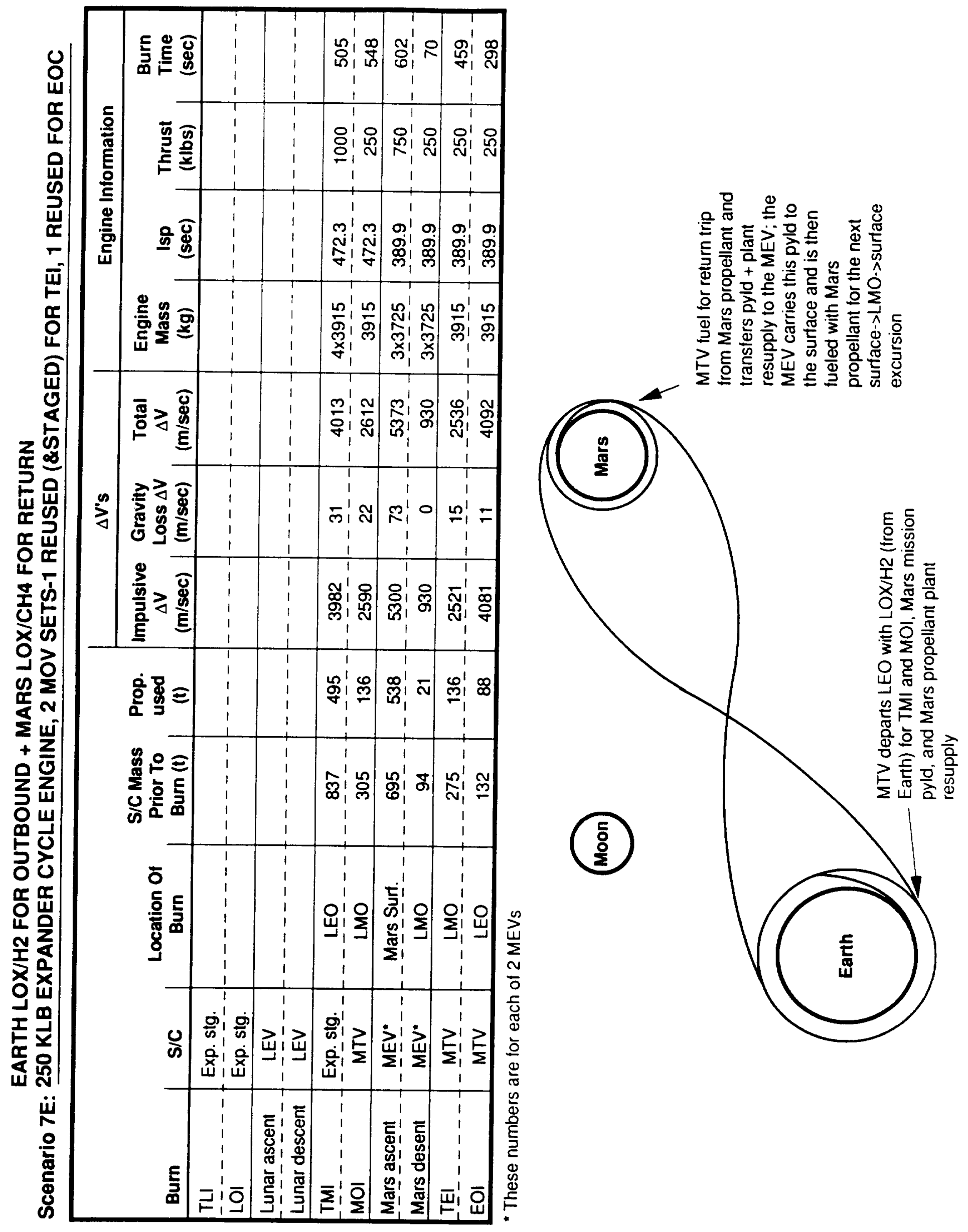





\section{APPENDIX F}

TANKAGE SYSTEM DESIGN DATA

F-1 



\section{APPENDIX $F$ TANKAGE SYSTEM DESIGN DATA}

This appendix presents the detailed tankage system design analysis data for propellant tank systems evaluated in Section 4.3. 



\section{TANKAGE SYSTEM DATA SUMMARY*}

Design No.: 1

Mission Scenario No. : 1-Baseline Earth $\mathrm{LOX} / \mathrm{H}_{2}$

Mission Segment: TMI

Vehicle Application: MTV

Engine Type (Cycle/No.): Expander/No. 2-A

Propellant Combination: $\mathrm{LOX} / \mathrm{H}_{2}$

Thrust Level (lbf): 250,000

Number of Engines: 2

Mixture Ratio: 6.0

Average Orbit Distance from the Sun (A.U.): 1.0

Space Hold Time (days): 5

Total Exposure Time (days): 7

Tank Material: Weldalite

Insulation: Superfloc

Propellants Carried (lbm): 1,099,183

Propellants Burned (lbm): 1,090,409

Oxidizer Tank Pressure (psia): 22.8

Fuel Tank Pressure (psia): 35.0

Oxidizer Tank Inside Diameter (cm): 843.3

Fuel Tank Inside Diameter (cm): 1,183.6 X 1,334.5

Oxidizer Tank Wall Thickness (cm): .109

Fuel Tank Wall Thickness (cm): 234

Oxidizer Tank Surface Area $\left(\mathrm{m}^{2}\right)^{* *}: 233.6$

Fuel Tank Surface Area $\left(\mathrm{m}^{2}\right)^{* *}: 384.1$

Oxidizer Tank Weight (lbm):

-Tank Structure: 2629.4

-Insulation: 930.6

-Acquisition System: 13.7

-Meteoroid Protection System: 1,030.2

Total: 4,603.9

Fuel Tank Weight (lbm):

-Tank Structure: 12812.6

-Insulation: 2112.8

-Acquisition System: 15.6

-Meteoroid Protection System: 1,693.8

Total: $16,634.8$

Other Tankage System Weight (lbm):

-Lines: 646.7

-Tank Mounts: 4431.3

-Pressurants Control System: 108.3

Total: $5,186.3$

Total Tankage System Weight $(\mathrm{lbm})^{*}: 26,425.0$

Total Tankage System Mass Fraction: .024

* Based on a single propellant tank set (fuel and oxidizer)

** Includes the thickness of insulation, but not the meteoroid protection system 



\section{TANKAGE SYSTEM DATA SUMMARY*}

Design No.: 2

Mission Scenario No. : 1-Baseline Earth LOX/ $\mathrm{H}_{2}$

Mission Segment: MOC

Vehicle Application: MTV

Engine Type (Cycle/No.): Expander/No. 2-A

Propellant Combination: $\mathrm{LOX} / \mathrm{H}_{2}$

Thrust Level (lbf): 250,000

Number of Engines: 2

Mixture Ratio: 6.0

Average Orbit Distance from the Sun (A.U.): 1.3

Space Hold Time (days): 300

Total Exposure Time (days): 300

Tank Material: Weldalite

Insulation: Superfloc

Propellants Carried (lbm): 605,699

Propellants Burned (lbm): 592,314

Oxidizer Tank Pressure (psia): 22.8

Fuel Tank Pressure (psia): 35.0

Oxidizer Tank Inside Diameter $(\mathrm{cm}): 700.0$

Fuel Tank Inside Diameter $(\mathrm{cm}): 1,088.1$

Oxidizer Tank Wall Thickness (cm): .076

Fuel Tank Wall Thickness $(\mathrm{cm}): .076$

Oxidizer Tank Surface Area $\left(\mathrm{m}^{2}\right)^{* *}: 162.7$

Fuel Tank Surface Area $\left(\mathrm{m}^{2}\right)^{* *}: 366.4$

Oxidizer Tank Weight (lbm):

-Tank Structure: $1,512.7$

-Insulation: 619.6

-Acquisition System: 12.8

-Meteoroid Protection System: 717.5

Total: $2,862.6$

Fuel Tank Weight (lbm):

-Tank Structure: 3653.8

-Insulation: 1431.9

-Acquisition System: 14.8

-Meteoroid Protection System: 1,615.8

Total: $6,716.3$

Other Tankage System Weight (lbm):

-Lines: 414.8

-Tank Mounts: 2398.6

-Pressurants Control System: 56.1

Total: $2,869.5$

Total Tankage System Weight $(\mathrm{lbm})^{*}: 12,448.4$

Total Tankage System Mass Fraction: .020

* Based on a single propellant tank set (fuel and oxidizer)

** Includes the thickness of insulation, but not the meteoroid protection system 
TANKAGE SYSTEM DATA SUMMARY*

Design No.: 3

Mission Scenario No. : 1-Baseline Earth LOX/ $/ \mathrm{H}_{2}$

Mission Segment: TEI

Vehicle Application: MTV

Engine Type (Cycle/No.): Expander/No. 2-A

Propellant Combination: $\mathrm{LOX} / \mathrm{H}_{2}$

Thrust Level (lbf): 250,000

Number of Engines: 2

Mixture Ratio: 6.0

Average Orbit Distance from the Sun (A.U.): 1.3

Space Hold Time (days): 340

Total Exposure Time (days): 340

Tank Material: Weldalite

Insulation: Superfloc

Propellants Carried (lbm): 202,832

Propellants Burned (lbm): 195,850

Oxidizer Tank Pressure (psia): 22.8

Fuel Tank Pressure (psia): 35.0

Oxidizer Tank Inside Diameter (cm): 484.6

Fuel Tank Inside Diameter (cm): 767.1

Oxidizer Tank Wall Thickness (cm): .076

Fuel Tank Wall Thickness (cm): .076

Oxidizer Tank Surface Area $\left(\mathrm{m}^{2}\right)^{* *}: 80.0$

Fuel Tank Surface Area $\left(\mathrm{m}^{2}\right)^{* *}: 194.6$

Oxidizer Tank Weight (lbm):

-Tank Structure: 726.3

-Insulation: 296.3

-Acquisition System: 11.2

-Meteoroid Protection System: 352.8

Total: $1,386.6$

Fuel Tank Weight (lbm):

-Tank Structure: 1817.2

-Insulation: 685.1

-Acquisition System: 13.3

-Meteoroid Protection System: 858.2

Total: $3,373.8$

Other Tankage System Weight (lbm):

-Lines: 297.7

-Tank Mounts: 795.0

-Pressurants Control System: 54.7

Total: $1,147.4$

Total Tankage System Weight $(\mathrm{lbm})^{*}: 5,907.8$

Total Tankage System Mass Fraction: .028

* Based on a single propellant tank set (fuel and oxidizer)

** Includes the thickness of insulation, but not the meteoroid protection system 



\section{TANKAGE SYSTEM DATA SUMMARY*}

Design No.: 4

Mission Scenario No. : 2-Lunar (Earth $\mathrm{H}_{2}$ ) for Outbound and Mars LOX/CO for Return

Mission Segment: TMI

Vehicle Application: MTV

Engine Type (Cycle/No.): Expander/No. 1-A

Propellant Combination: $\mathrm{LOX} / \mathrm{H}_{2}$

Thrust Level (lbf): 175,000

Number of Engines: 1

Mixture Ratio: 6.0

Average Orbit Distance from the Sun (A.U.): 1.0

Space Hold Time (days): 14

Total Exposure Time (days): 14

Tank Material: 14

Insulation: Superfloc

Propellants Carried (lbm): 273,022

Propellants Burned (lbm): 270,691

Oxidizer Tank Pressure (psia): 22.8

Fuel Tank Pressure (psia): 35.0

Oxidizer Tank Inside Diameter (cm): 536.9

Fuel Tank Inside Diameter (cm): 828.5

Oxidizer Tank Wall Thickness (cm): .076

Fuel Tank Wall Thickness (cm): .076

Oxidizer Tank Surface Area $\left(\mathrm{m}^{2}\right)^{* *}: 97.4$

Fuel Tank Surface Area $\left(\mathrm{m}^{2}\right)^{* *}: 226.2$

Oxidizer Tank Weight (lbm):

-Tank Structure: 891.3

-Insulation: 366.0

-Acquisition System: 11.2

-Meteoroid Protection System: 429.5

Total: $1,698.0$

Fuel Tank Weight (lbm):

-Tank Structure: 2118.5

-Insulation: 868.8

-Acquisition System: 13.3

-Meteoroid Protection System: 997.5

Total: $3,998.1$

Other Tankage System Weight (lbm):

-Lines: 260.3

-Tank Mounts: 1096.9

-Pressurants Control System: 36.1

Total: $1,393.3$

Total Tankage System Weight $(\mathrm{lbm})^{*}: 7,089.4$

Total Tankage System Mass Fraction: .025

* Based on a single propellant tank set (fuel and oxidizer)

** Includes the thickness of insulation, but not the meteoroid protection system 



\section{TANKAGE SYSTEM DATA SUMMARY*}

\section{Design No.: 5}

Mission Scenario No. : 2-Lunar LOX (Earth $\mathrm{H}_{2}$ ) for Outbound and Mars LOX/CO for Return Mission Segment: TEI

Vehicle Application: MTV

Engine Type (Cycle/No.): Expander/No. 1-B

Propellant Combination: LOX/CO

Thrust Level (lbf): 175,000

Number of Engines: 1

Mixture Ratio: 0.55

Average Orbit Distance from the Sun (A.U.): 1.3

Space Hold Time (days): 14

Total Exposure Time (days): 14

Tank Material: 14

Insulation: Superfloc

Propellants Carried (lbm): 325,607

Propellants Burned (lbm): 321,709

Oxidizer Tank Pressure (psia): 22.8

Fuel Tank Pressure (psia): 22.3

Oxidizer Tank Inside Diameter (cm): 421.1

Fuel Tank Inside Diameter (cm): 605.1

Oxidizer Tank Wall Thickness (cm): .076

Fuel Tank Wall Thickness $(\mathrm{cm}): .076$

Oxidizer Tank Surface Area $\left(\mathrm{m}^{2}\right)^{* *}: 61.1$

Fuel Tank Surface Area $\left(\mathrm{m}^{2}\right)^{* *}: 122.7$

Oxidizer Tank Weight (lbm):

-Tank Structure: 548.9

-Insulation: 224.9

-Acquisition System: 10.6

-Meteoroid Protection System: 269.5

Total: $1,053.9$

Fuel Tank Weight (lbm):

-Tank Structure: 1130.7

-Insulation: 464.5

-Acquisition System: 12.2

-Meteoroid Protection System: 541.1

Total: $2,148.5$

Other Tankage System Weight (lbm):

-Lines: 219.4

-Tank Mounts: 1299.5

-Pressurants Control System: 51.7

Total: $1,570.6$

Total Tankage System Weight $(\mathrm{lbm})^{*}: 4,773.0$

Total Tankage System Mass Fraction: .014

* Based on a single propellant tank set (fuel and oxidizer)

* Includes the thickness of insulation, but not the meteoroid protection system 



\section{TANKAGE SYSTEM DATA SUMMARY*}

Design No.: 6

Mission Scenario No. : 4- $\mathrm{LOX} / \mathrm{CH}_{4}$ for Outbound and Mars LOX/CH $\mathrm{CH}_{4}$ Return

Mission Segment: TMI

Vehicle Application: MTV

Engine Type (Cycle/No.): Expander/No. 3-A

Propellant Combination: $\mathrm{LOX}_{\mathrm{CH}}$

Thrust Level (lbf): 175,000

Number of Engines: 1

Mixture Ratio: 3.6

Average Orbit Distance from the Sun (A.U.): 1.0

Space Hold Time (days): 14

Total Exposure Time (days): 14

Tank Material: 14

Insulation: Superfloc

Propellants Carried (lbm): 384,128

Propellants Burned (lbm): 381,711

Oxidizer Tank Pressure (psia): 22.8

Fuel Tank Pressure (psia): 12.5

Oxidizer Tank Inside Diameter (cm): 582.2

Fuel Tank Inside Diameter (cm): 567.9

Oxidizer Tank Wall Thickness (cm): .076

Fuel Tank Wall Thickness (cm): .076

Oxidizer Tank Surface Area $\left(\mathrm{m}^{2}\right)^{* *}: 113.9$

Fuel Tank Surface Area $\left(\mathrm{m}^{2}\right)^{* *}: 108.6$

Oxidizer Tank Weight (lbm):

-Tank Structure: 1047.3

-Insulation: 430.2

-Acquisition System: 12.0

-Meteoroid Protection System: 502.3

Total: 1991.8

Fuel Tank Weight (lbm):

-Tank Structure: 996.7

-Insulation: 409.3

-Acquisition System: 11.9

-Meteoroid Protection System: 478.9

Total: $1,896.8$

Other Tankage System Weight (lbm):

-Lines: 108.6

-Tank Mounts: 1542.0

-Pressurants Control System: 30.3

Total: $1,680.9$

Total Tankage System Weight $(\mathrm{lbm})^{*}: 5,569.5$

Total Tankage System Mass Fraction: .014

* Based on a single propellant tank set (fuel and oxidizer)

** Includes the thickness of insulation, but not the meteoroid protection system 



\section{TANKAGE SYSTEM DATA SUMMARY*}

\section{Design No.: 7}

Mission Scenario No. : 4-Lunar $\mathrm{LOX} / \mathrm{CH}_{4}$ for Outbound and Mars $\mathrm{LOX} / \mathrm{CH}_{4}$ Return

Mission Segment: MOC

Vehicle Application: MTV

Engine Type (Cycle/No.): Expander/No. 3-A

Propellant Combination: $\mathrm{LOX} / \mathrm{CH}_{4}$

Thrust Level (lbf): 175,000

Number of Engines: 1

Mixture Ratio: 3.6

Average Orbit Distance from the Sun (A.U.): 1.3

Space Hold Time (days): 300

Total Exposure Time (days): 300

Tank Material: 300

Insulation: Superfloc

Propellants Carried (lbm): 261,979

Propellants Burned (lbm): 257,938

Oxidizer Tank Pressure (psia): 22.8

Fuel Tank Pressure (psia): 12.5

Oxidizer Tank Inside Diameter (cm): 512.1

Fuel Tank Inside Diameter (cm): 500.9

Oxidizer Tank Wall Thickness (cm): .076

Fuel Tank Wall Thickness (cm): 076

Oxidizer Tank Surface Area $\left(\mathrm{m}^{2}\right)^{* *}: 88.9$

Fuel Tank Surface Area $\left(\mathrm{m}^{2}\right)^{* *}: 85.2$

Oxidizer Tank Weight (lbm):

-Tank Structure: 811.0

-Insulation: 331.3

-Acquisition System: 11.5

-Meteoroid Protection System: 392.2

Total: $1,546.0$

Fuel Tank Weight (lbm):

-Tank Structure: 775.3

-Insulation: 315.2

-Acquisition System: 11.4

-Meteoroid Protection System: 375.7

Total: $1,477.6$

Other Tankage System Weight (lbm):

-Lines: 157.5

-Tank Mounts: 1042.4

-Pressurants Control System: 30.0

Total: $1,229.9$

Total Tankage System Weight $(\mathrm{lbm})^{*}: 4,253.5$

Total Tankage System Mass Fraction: .016

* Based on a single propellant tank set (fuel and oxidizer)

** Includes the thickness of insulation, but not the meteoroid protection system 



\section{TANKAGE SYSTEM DATA SUMMARY*}

Design No.: 8

Mission Scenario No. : 4-Lunar $\mathrm{LOX} / \mathrm{CH}_{4}$ for Outbound and Mars $\mathrm{LOX} / \mathrm{CH}_{4}$ Return

Mission Segment: TEI

Vehicle Application: MTV

Engine Type (Cycle/No.): Expander/No. 3-B

Propellant Combination: LOX/CO

Thrust Level (lbf): 175,000

Number of Engines: 1

Mixture Ratio: 0.55

Average Orbit Distance from the Sun (A.U.): 1.3

Space Hold Time (days): 14

Total Exposure Time (days): 14

Tank Material: Weldalite

Insulation: Superfloc

Propellants Carried (lbm): 731,017

Propellants Burned (lbm): 722,800

Oxidizer Tank Pressure (psia): 22.8

Fuel Tank Pressure (psia): 22.3

Oxidizer Tank Inside Diameter (cm): 551.2

Fuel Tank Inside Diameter (cm): 792.5

Oxidizer Tank Wall Thickness (cm): .076

Fuel Tank Wall Thickness (cm): .076

Oxidizer Tank Surface Area $\left(\mathrm{m}^{2}\right)^{* *}: 102.5$

Fuel Tank Surface Area $\left(\mathrm{m}^{2}\right)^{* *}: 207.4$

Oxidizer Tank Weight (lbm):

-Tank Structure: 939.4

-Insulation: 385.8

-Acquisition System: 11.8

-Meteoroid Protection System: 452.0

Total: $1,789.0$

Fuel Tank Weight (lbm):

-Tank Structure: 1937.6

-Insulation: 385.8

-Acquisition System: 13.4

-Meteoroid Protection System: 914.6

Total: $3,251.4$

Other Tankage System Weight (lbm):

-Lines: 287.8

-Tank Mounts: 2917.6

-Pressurants Control System: $\mathbf{5 2 . 7}$

Total: $3,258.1$

Total Tankage System Weight $(\mathrm{lbm})^{*}: 8,298.5$

Total Tankage System Mass Fraction: .011

* Based on a single propellant tank set (fuel and oxidizer)

** Includes the thickness of insulation, but not the meteoroid protection system 



\section{TANKAGE SYSTEM DATA SUMMARY*}

Design No.: 9

Mission Scenario No. : 1-Baseline Earth $\mathrm{LOX} / \mathrm{H}_{2}$

Mission Segment: TMI

Vehicle Application: MTV

Engine Type (Cycle/No.): Expander/No. 2-A

Propellant Combination: $\mathrm{LOX} / \mathrm{H}_{2}$

Thrust Level (lbf): 250,000

Number of Engines: 2

Mixture Ratio: 6.0

Average Orbit Distance from the Sun (A.U.): 1.0

Space Hold Time (days): 5

Total Exposure Time (days): 7

Tank Material: A1 2219-T87 Alloy

Insulation: Superfloc

Propellants Carried (lbm): 1,099,189

Propellants Burned (lbm): 1,099,409

Oxidizer Tank Pressure (psia): 22.8

Fuel Tank Pressure (psia): 35.0

Oxidizer Tank Inside Diameter $(\mathrm{cm}): 856.0$

Fuel Tank Inside Diameter $(\mathrm{cm}): 1,132.8 \times 1,334.5$

Oxidizer Tank Wall Thickness (cm): . 183

Fuel Tank Wall Thickness (cm): .358

Oxidizer Tank Surface Area $\left(\mathrm{m}^{2}\right)^{* *}: 241.1$

Fuel Tank Surface Area $\left(\mathrm{m}^{2}\right)^{* *}: 383.7$

Oxidizer Tank Weight $(\mathrm{lbm})$ :

-Tank Structure: 4574.6

-Insulation: 930.6

-Acquisition System: 13.7

-Meteoroid Protection System: 1,063.3

Total: $6,582.2$

Fuel Tank Weight (lbm):

-Tank Structure: $20,738.3$

-Insulation: 2112.7

-Acquisition System: 15.6

-Meteoroid Protection System: 1,692.3

Total: $24,558.8$

Other Tankage System Weight (lbm):

-Lines: 646.7

-Tank Mounts: 4,454.7

-Pressurants Control System: 108.3

Total: $5,209.7$

Total Tankage System Weight $(\mathrm{lbm})^{*}: 36,350.7$

Total Tankage System Mass Fraction: .032

* Based on a single propellant tank set (fuel and oxidizer)

** Includes the thickness of insulation, but not the meteoroid protection system 



\section{TANKAGE SYSTEM DATA SUMMARY*}

Design No.: 10

Mission Scenario No. : 4-Lunar $\mathrm{LOX} / \mathrm{CH}_{4}$ for Outbound and Mars $\mathrm{LOX} / \mathrm{CH}_{4}$ Return

Mission Segment: TEI

Vehicle Application: MTV

Engine Type (Cycle/No.): Expander/No. 3-B

Propellant Combination: LOX/CO

Thrust Level (lbf): 175,000

Number of Engines: 1

Mixture Ratio: 0.55

Average Orbit Distance from the Sun (A.U.): 1.3

Space Hold Time (days): 14

Tank Material: Al2219-T87 Alloy

Insulation: Superfloc

Propellants Carried (lbm): 731,012

Propellants Burned (lbm): 722,800

Oxidizer Tank Pressure (psia): 22.8

Fuel Tank Pressure (psia): 22.8

Oxidizer Tank Inside Diameter (cm): 551.2

Fuel Tank Inside Diameter (cm): 792.0

Oxidizer Tank Wall Thickness (cm): .076

Fuel Tank Wall Thickness (cm): .081

Oxidizer Tank Surface Area $\left(\mathrm{m}^{2}\right)^{* *}: 102.5$

Fuel Tank Surface Area $\left(\mathrm{m}^{2}\right)^{* *}: 207.1$

Oxidizer Tank Weight (lbm):

-Tank Structure: 982.6

-Insulation: 385.8

-Acquisition System: 11.8

-Meteoroid Protection System: 452.0

Total: $1,832.2$

Fuel Tank Weight (lbm):

-Tank Structure: 2166.8

-Insulation: 796.7

-Acquisition System: 13.4

-Meteoroid Protection System: 913.3

Total: $3,890.2$

Other Tankage System Weight (lbm):

-Lines: 287.8

-Tank Mounts: 2917.2

-Pressurants Control System: 52.7

Total: $3,257.7$

Total Tankage System Weight $(\mathrm{lbm})^{*}: \mathbf{8 , 9 8 0 . 1}$

Total Tankage System Mass Fraction: .012

* Based on a single propellant tank set (fuel and oxidizer)

** Includes the thickness of insulation, but not the meteoroid protection system 



\section{TANKAGE SYSTEM DATA SUMMARY*}

Design No.: 11

Mission Scenario No. : 1-Baseline Earth LOX/ $/ \mathrm{H}_{2}$

Mission Segment: MOC

Vehicle Application: MTV

Engine Type (Cycle/No.): Expander/No. 2-A

Propellant Combination: $\mathrm{LOX} / \mathrm{H}_{2}$

Thrust Level (lbf): 250,000

Number of Engines: 2

Mixture Ratio: 6.0

Average Orbit Distance from the Sun (A.U.): 1.3

Space Hold Time (days): 300

Total Exposure Time: 300

Tank Material: Weldalite

Insulation: MLI

Propellants Carried (lbm): 611,696

Propellants Burned (lbm): 592,314

Oxidizer Tank Pressure (psia): 22.8

Fuel Tank Pressure (psia): 35.0

Oxidizer Tank Inside Diameter (cm): 700.5

Fuel Tank Inside Diameter (cm): $1,105.4$

Oxidizer Tank Wall Thickness (cm): .076

Fuel Tank Wall Thickness (cm): .076

Oxidizer Tank Surface Area $\left(\mathrm{m}^{2}\right)^{* *}: 158.6$

Fuel Tank Surface Area $\left(\mathrm{m}^{2}\right)^{* *}: 390.9$

Oxidizer Tank Weight (lbm):

-Tank Structure: 1516.6

-Insulation: 922.9

-Acquisition System: 12.9

-Meteoroid Protection System: 699.4

Total: $3,151.8$

Fuel Tank Weight (lbm):

-Tank Structure: 3770.0

-Insulation: 2118.0

-Acquisition System: 14.9

-Meteoroid Protection System: 1,723.9

Total: $7,626.8$

Other Tankage System Weight (lbm):

-Lines: 412.7

-Tank Mounts: 2398.9

-Pressurants Control System: 56.1

Total: $2,867.7$

Total Tankage System Weight $(\mathrm{lbm})^{*}: 13,646.3$

Total Tankage System Mass Fraction: .022

* Based on a single propellant tank set (fuel and oxidizer)

** Includes the thickness of insulation, but not the meteoroid protection system 



\section{TANKAGE SYSTEM DATA SUMMARY*}

Design No.: 12

Mission Scenario No. : 4-Lunar $\mathrm{LOX} / \mathrm{CH}_{4}$ for Outbound and Mars $\mathrm{LOX} / \mathrm{CH}_{4}$ Return

Mission Segment: MOC

Vehicle Application: MTV

Engine Type (Cycle/No.): Expander/No. 3-A

Propellant Combination: $\mathrm{LOX} / \mathrm{CH}_{4}$

Thrust Level (lbf): 175,000

Number of Engines: 1

Mixture Ratio: 3.6

Average Orbit Distance from the Sun (A.U.): 1.3

Space Hold Time (days): 300

Total Exposure Time: 300

Tank Material: Weldalite

Insulation: MLI

Propellants Carried (lbm): 263,764

Propellants Burned (lbm): 257,938

Oxidizer Tank Pressure (psia): 22.8

Fuel Tank Pressure (psia): 12.5

Oxidizer Tank Inside Diameter (cm): 513.1

Fuel Tank Inside Diameter $(\mathrm{cm}): 502.9$

Oxidizer Tank Wall Thickness (cm): .076

Fuel Tank Wall Thickness (cm): .076

Oxidizer Tank Surface Area $\left(\mathrm{m}^{2}\right)^{* *}: 86.0$

Fuel Tank Surface Area $\left(\mathrm{m}^{2}\right)^{* *}: 82.7$

Oxidizer Tank Weight (lbm):

-Tank Structure: 814.0

-Insulation: 489.8

-Acquisition System: 11.5

-Meteoroid Protection System: 379.2

Total: $1,694.5$

Fuel Tank Weight (lbm):

-Tank Structure: 781.4

-Insulation: 466.0

-Acquisition System: 11.4

-Meteoroid Protection System: 364.8

Total: $1,623.6$

Other Tankage System Weight (lbm):

-Lines: 155.5

-Tank Mounts: 1042.4

-Pressurants Control System: 30.0

Total: $1,227.9$

Total Tankage System Weight $(\mathrm{lbm})^{*}: 4,546.0$

Total Tankage System Mass Fraction: .017

* Based on a single propellant tank set (fuel and oxidizer)

** Includes the thickness of insulation, but not the meteoroid protection system 



\section{TANKAGE SYSTEM DATA SUMMARY*}

Design No.: 13

Mission Scenario No. : 4-LOX/CH $\mathrm{CH}_{4}$ for Outbound and Mars $\mathrm{LOX} / \mathrm{CH}_{4}$ Return

Mission Segment: TMI

Vehicle Application: MTV

Engine Type (Cycle/No.): Expander/No. 3-A

Propellant Combination: $\mathrm{LOX}_{\mathrm{CH}} \mathrm{CH}_{4}$

Thrust Level (lbf): 175,000

Number of Engines: 1

Mixture Ratio: 3.6

Average Orbit Distance from the Sun (A.U.): 1.0

Space Hold Time (days): 14

Total Exposure Time: 14

Tank Material: Weldalite

Insulation: Superfloc

Propellants Carried (lbm): 386,289

Propellants Burned (lbm): 381,711

Oxidizer Tank Pressure (psia): 42.8

Fuel Tank Pressure (psia): 32.5

Oxidizer Tank Inside Diameter (cm): 582.2

Fuel Tank Inside Diameter (cm): 569.0

Oxidizer Tank Wall Thickness (cm): .076

Fuel Tank Wall Thickness (cm): .076

Oxidizer Tank Surface Area $\left(\mathrm{m}^{2}\right)^{* *}: 113.9$

Fuel Tank Surface Area $\left(\mathrm{m}^{2}\right)^{* *}: 108.9$

Oxidizer Tank Weight (lbm):

-Tank Structure: 1047.5

-Insulation: 430.3

-Acquisition System: 12.0

-Meteoroid Protection System: 502.3

Total: $1,992.1$

Fuel Tank Weight (lbm):

-Tank Structure: 1001.0

-Insulation: 411.1

-Acquisition System: 11.9

-Meteoroid Protection System: 480.3

Total: $1,904.3$

Other Tankage System Weight (lbm):

-Lines: 181.0

-Tank Mounts: 1542.0

-Pressurants Control System: 30.3

Total: $1,753.3$

Total Tankage System Weight $(\mathrm{lbm})^{*}: 5,649.7$

Total Tankage System Mass Fraction: .014

* Based on a single propellant tank set (fuel and oxidizer)

** Includes the thickness of insulation, but not the meteoroid protection system 



\section{TANKAGE SYSTEM DATA SUMMARY*}

Design No.: 14

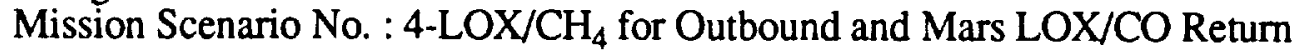

Vehicle Application: MTV Mission Segment: TMI

Engine Type (Cycle/No.): Expander/No. 3-A

Propellant Combination: $\mathrm{LOX} / \mathrm{CH}_{4}$

Thrust Level (lbf): 175,000

Number of Engines: 1

Mixture Ratio: 3.6

Average Orbit Distance from the Sun (A.U.): 1.0

Space Hold Time (days): 14

Total Exposure Time: 14

Tank Material: Weldalite

Insulation: Superfloc

Propellants Carried (lbm): 388,476

Propellants Burned (lbm): 381,711

Oxidizer Tank Pressure (psia): 62.8

Fuel Tank Pressure (psia): 52.5

Oxidizer Tank Inside Diameter $(\mathrm{cm}): 582.7$

Fuel Tank Inside Diameter $(\mathrm{cm}): 571.0$

Oxidizer Tank Wall Thickness $(\mathrm{cm}): .076$

Fuel Tank Wall Thickness (cm): .076

Oxidizer Tank Surface Area $\left(\mathrm{m}^{2}\right)^{* *}: 114.1$

Fuel Tank Surface Area $\left(\mathrm{m}^{2}\right)^{* *}: 109.7$

Oxidizer Tank Weight (lbm):

-Tank Structure: 1049.1

-Insulation: 430.9

-Acquisition System: 12.0

-Meteoroid Protection System: 503.2

Total: $1,995.2$

Fuel Tank Weight (lbm):

-Tank Structure: 1008.2

-Insulation: 414.0

-Acquisition System: 12.0

-Meteoroid Protection System: 483.8

Total: $1,918.0$

Other Tankage System Weight (lbm):

-Lines: 182.1

-Tank Mounts: 1542.0

-Pressurants Control System: 30.3

Total: $1,754.4$

Total Tankage System Weight $(\mathrm{lbm})^{*}:$ 5,667.6

Total Tankage System Mass Fraction: .014

* Based on a single propellant tank set (fuel and oxidizer)

** Includes the thickness of insulation, but not the meteoroid protection system 



\section{APPENDIX G}

TECHNOLOGY DEVELOPMENT PLAN PROGRAM

ELEMENT PLAN DESCRIPTIONS

G-1 



\section{APPENDIX G \\ TECHNOLOGY DEVELOPMENT PLAN PROGRAM ELEMENT PLAN DESCRIPTIONS}

Detailed descriptions of the program elements that make up the overall technology development plan associated with establishing the feasibility of Mars in situ-based propellant propulsion systems are presented in this appendix. Section 6.0 discussed in detail the rationale and interrelationship of these technology development plan program elements. 



\section{TECHNOLOGY DEVELOPMENT PLAN ELEMENT}

PROGRAM No.: 1

ISSUE: Materials Compatibility

DEVELOPMENT PHASE: Fundamental Research

TITLE: Mars In Situ Propellant Materials Compatibility Research

OBJECTIVE: Identify propulsion system material candidates that are compatible with potential Mars in situ propellants and/or propellant combinations. Propellants and/or propellant combinations for which material compatibility should be investigated include: $\mathrm{CO}, \mathrm{LOX}, \mathrm{CO} / \mathrm{H}_{2}, \mathrm{H}_{2} / \mathrm{CH}_{4}, \mathrm{CO} / \mathrm{CH}_{4}$.

MISSION IMPACT: Results will have a major impact on propulsion system weight, performance and vehicle tankage design approaches. These propulsion system parameters have a major impact on overall mission mass and ISPP requirements.

\section{APPROACH:}

1. Conduct screening task to identify candidate materials for the study.

2. Experimentally expose material specimens to propellant and/or propellant combinations to conditions typical of propellants tankage, thrust chamber, turbine drive, gas generator portions of an engine system (where appropriate) for corresponding exposure times.

3. Inspect specimens for chemical compatibility effects.

OUTPUTS/RESULTS: Listing of candidate propulsion materials that are compatible with potential propellants of interest.

\section{SPECIAL FACILITIES/COMMENTS:}

- Facility capabilities to expose material specimens to a variety of propellant(s) over a wide range of pressure and temperature conditions.

- Advanced material inspection instrumentation. 

Title: 1. Mars In Situ Propellant Propulsion System

Materials Compatibility Research

- SCHEDULE/COST -

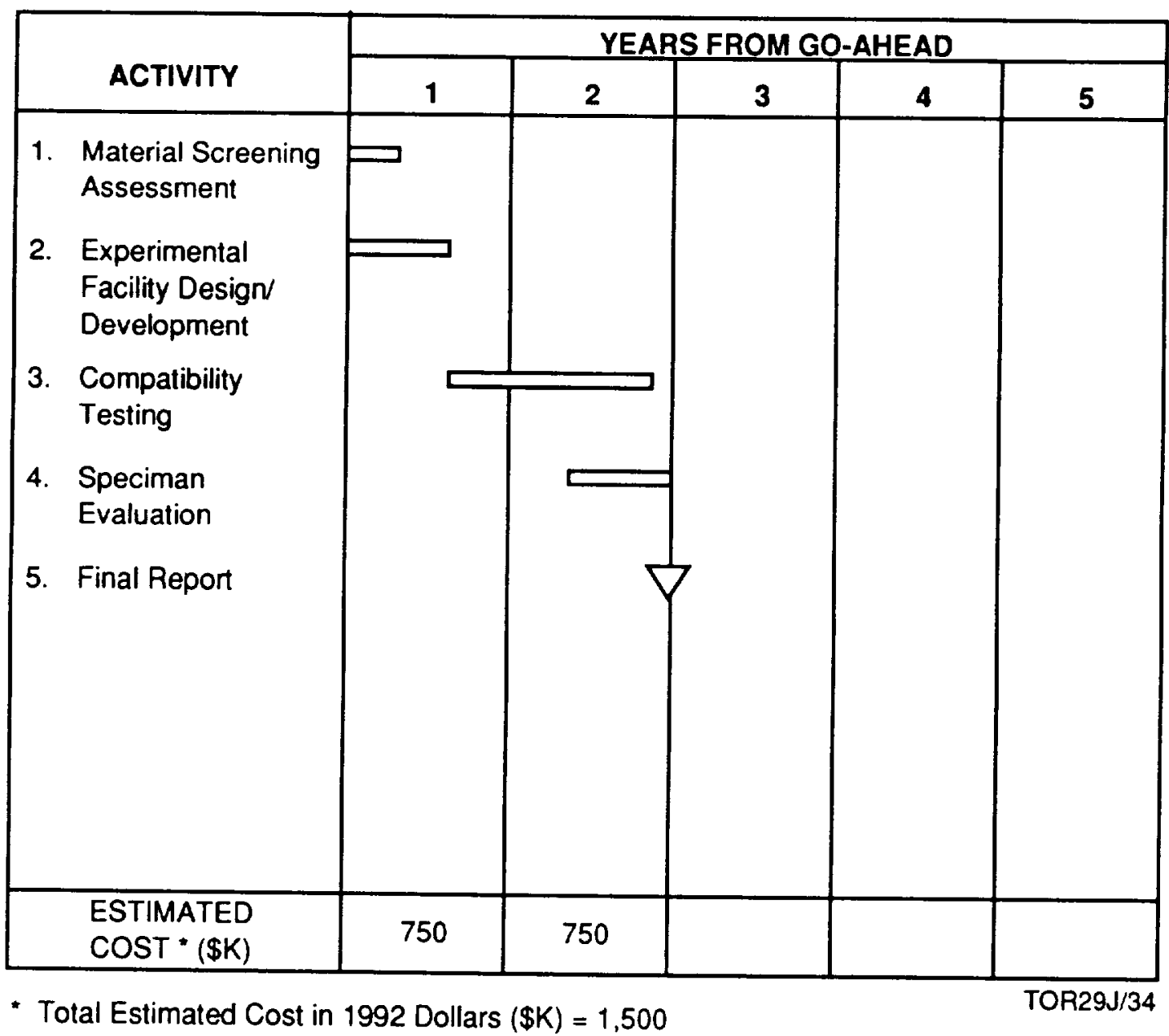





\section{TECHNOLOGY DEVELOPMENT PLAN ELEMENT}

PROGRAM No.: 2

ISSUE: CO Cooling Data

DEVELOPMENT PHASE: Fundamental Research

TITLE: Fundamental CO Cooling Data Study

OBJECTIVE: Establish a fundamental database associated with $\mathrm{CO}$ cooling for conditions which are typical of thrust chambers and turbopumps.

MISSION IMPACT: Establishes operating limitations of LOX/CO engine options which greatly influences engine mass. This impacts overall mission mass and ISPP requirements.

APPROACH:

1. Define experimental facility requirements (heated tube and calorimetric thrust chamber).

2. Conduct tests at appropriate conditions.

3. Review results and establish CO cooling correlations and limitations.

4. Upgrade engine design analysis models with new data.

OUTPUTS/RESULTS: Accurate fundamental CO cooling database for the range of conditions to support the design of $\mathrm{LOX} / \mathrm{CO}$ engines.

SPECIAL FACILITIES/COMMENTS:

- Heat tube and calorimetric thrust chamber facilities. 

Title: 2. Fundamental CO Cooling Data Study

- SCHEDULE/COST -

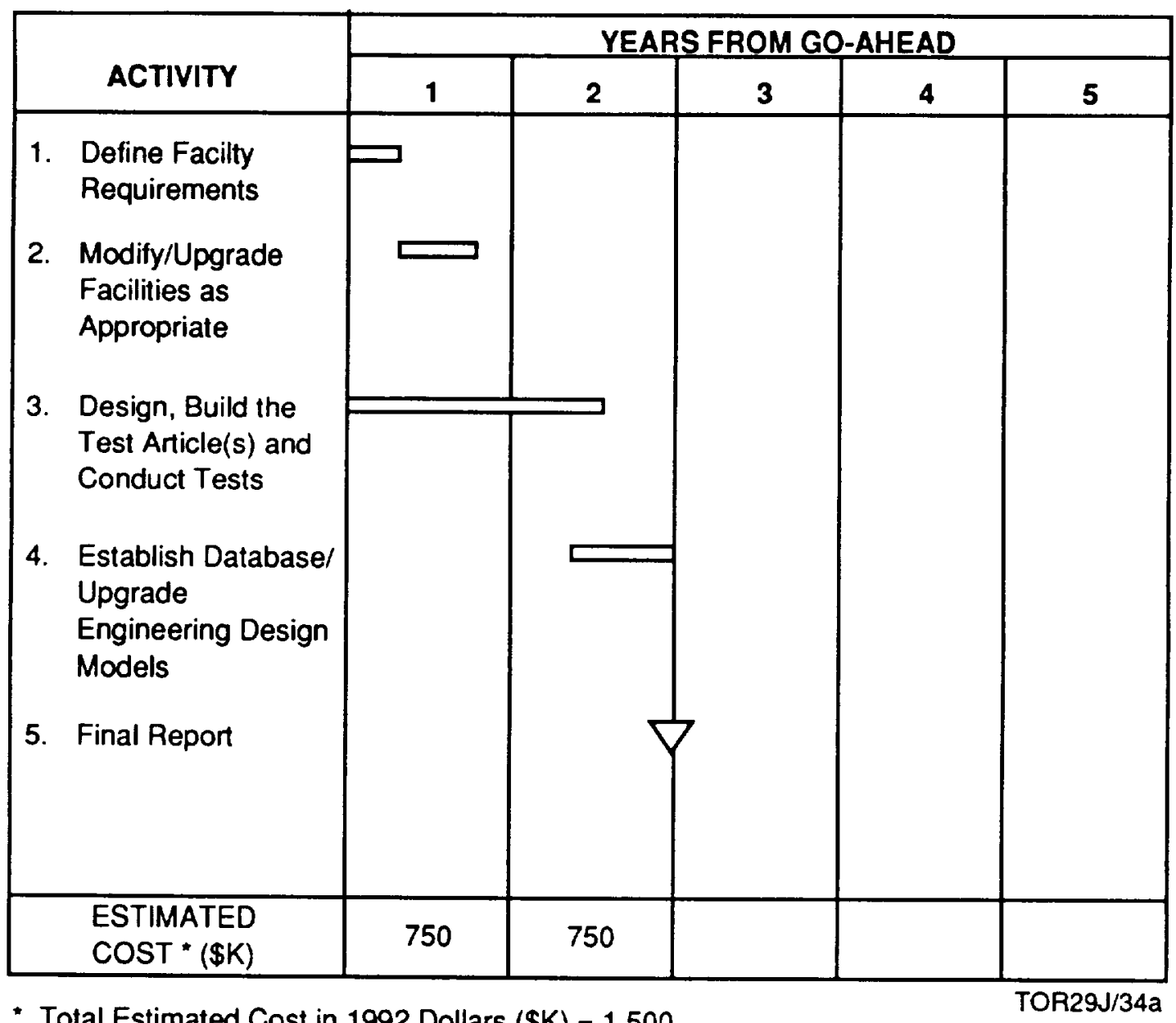

G-6 



\section{TECHNOLOGY DEVELOPMENT PLAN ELEMENT}

PROGRAM No.: 3

ISSUE: LOX/CO Ignition/Combustion

DEVELOPMENT PHASE: Fundamental Research

TITLE: LOX/CO Ignition/Combustion Research

OBJECTIVE: Establish a fundamental database associated with LOX/CO ignition and combustion for conditions typical of an engine system.

MISSION IMPACT: Establishes LOX/CO engine performance and operating conditions that directly influence overall mission mass and ISPP requirements.

APPROACH: Experimentally measure LOX/CO ignition and combustion characteristics for conditions typical of engine systems; gas generator and main combustion chamber conditions. Establish ignition and stability limitations as well as measure performance for a host of injector/chamber design options. Results will then be included in an appropriate engineering design model.

OUTPUTS/RESULTS: Fundamental LOX/CO ignition and combustion database for the range of conditions of interest. Updated design correlation and models.

\section{SPECIAL FACILITIES/COMMENTS:}

- Breadboard combustor facility with advanced instrumentation capabilities. 

Title: 3. LOX/CO Ignition/Combination Research

- SCHEDULE/COST -

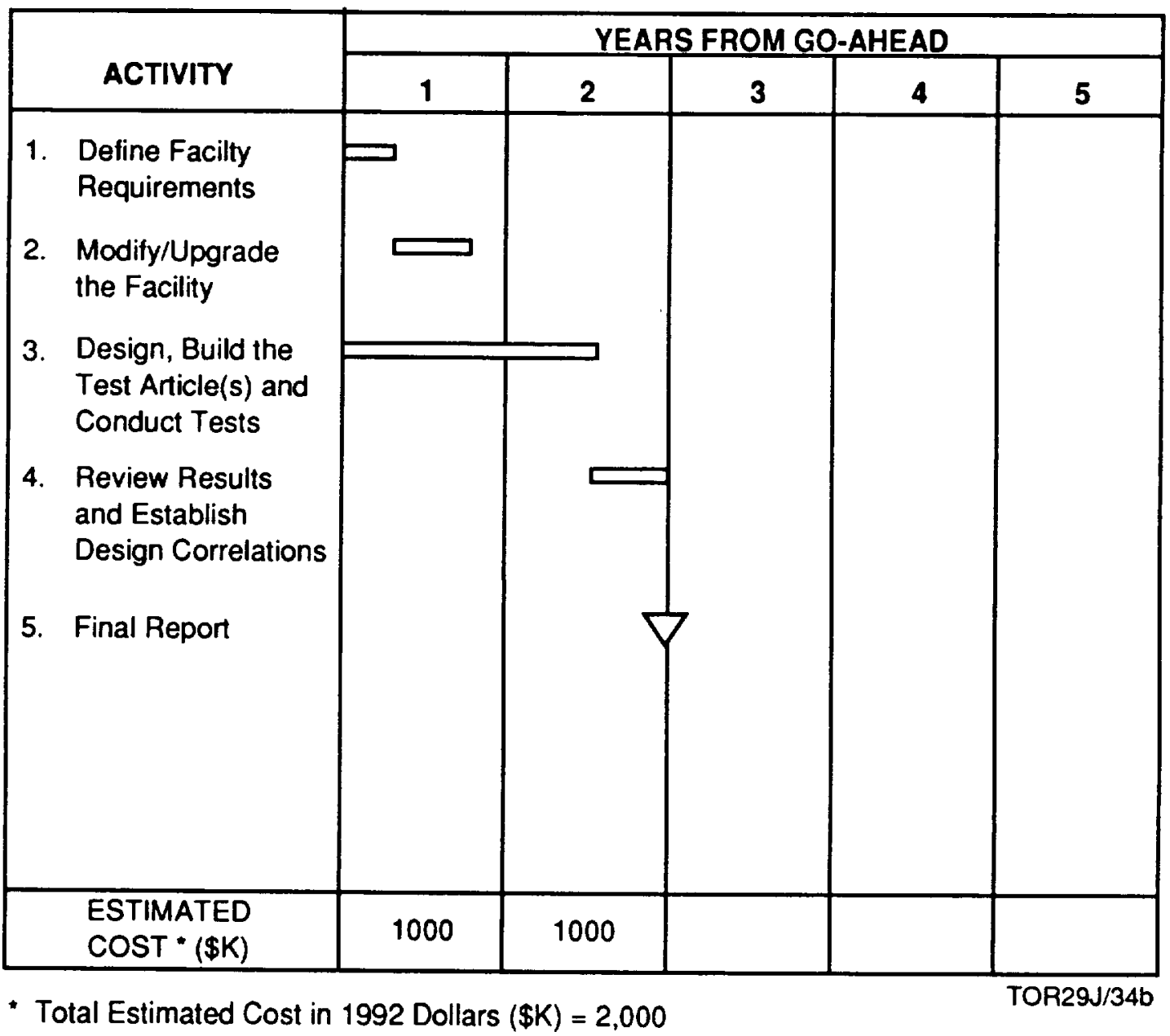





\section{TECHNOLOGY DEVELOPMENT PLAN ELEMENT}

PROGRAM No.: 4

ISSUE: CO Pumping

DEVELOPMENT PHASE: Fundamental Research

TTTLE: Fundamental CO Pumping Database

OBJECTIVE: Establish CO pumping database for the range of conditions typical of a LOX/CO engine.

MISSION IMPACT: Support in establishing the design limitations of a LOX/CO engine, such as chamber pressure. This influences overall mission mass and ISPP requirements.

\section{APPROACH:}

1. Review CO pumping data from ruated areas such as the petrochemical industry.

2. Define an experiment and upgrade a facility to measure key parameters associated with the pumping of $\mathrm{CO}$.

3. Review results and establish engineering correlations and limitations.

4. Upgrade engineering design models.

OUTPUTS/RESULTS: Fundamental CO pumping database for the range of conditions of interest. Updated design correlations and models.

SPECIAL FACILITIES/COMMENTS:

- Highly instrumented pumping facility which can operate over the conditions of interest. 

Title: 4. Fundamental CO Pumping Database

- SCHEDULE/COST -

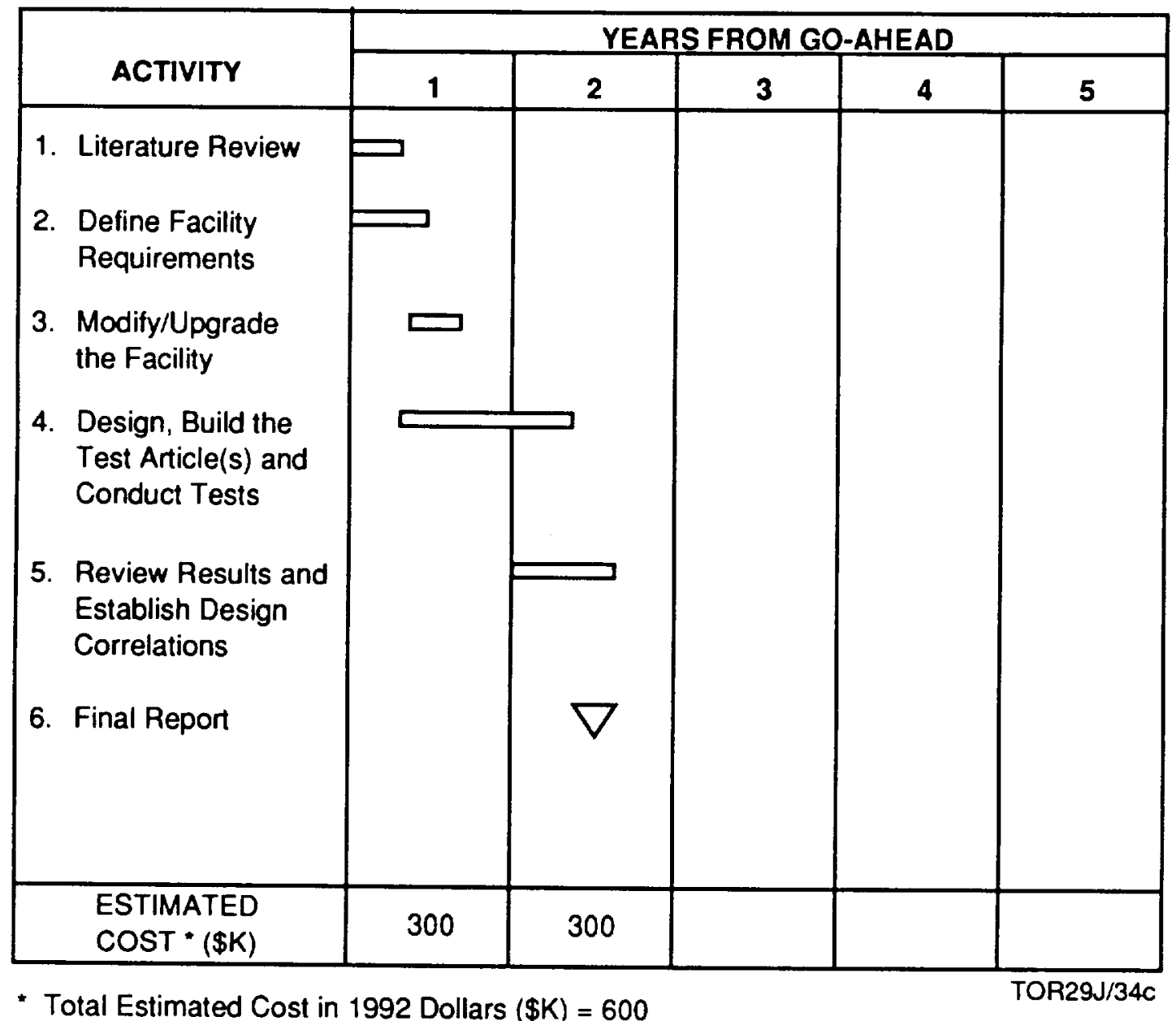





\section{TECHNOLOGY DEVELOPMENT PLAN ELEMENT}

PROGRAM No.: 5

ISSUE: Injector Design

DEVELOPMENT PHASE: Exploratory Development

TITLE: Common Multipropellant Injector Design Feasibility Study

OBJECTIVE: Establish feasibility and identify promising injector design(s) that can operate with more than one Mars in situ-based propellant combination over a wide operating range. Main injector and gas generator injector designs are to be investigated.

MISSION IMPACT: Addresses a critical Mars tripropellant engine design issue. This study can impact the Mars propellant options that can be used as well as the limits of operation conditions of such engines. Mission options, mass, and ISPP requirements can be greatly affected.

APPROACH: Design and experimental demonstration tasks that investigates the performance and limitation of injector designs for the conditions of interest.

1. Design concept screening study.

2. Select promising injector concepts for further study.

3. Modify/upgrade test facility.

4. Fabricate and test injector concepts.

5. Recommend most promising injector designs.

OUTPUTS/RESULTS: Recommendation of most promising common injector design(s) with supporting engineering data.

SPECIAL FACILITIES/COMMENTS:

- Breadboard combustor facility with supporting instrumentation capability required. 

Title: 5. Common Multipropellant Injection Design

Feasibility Study

- SCHEDULE/COST -

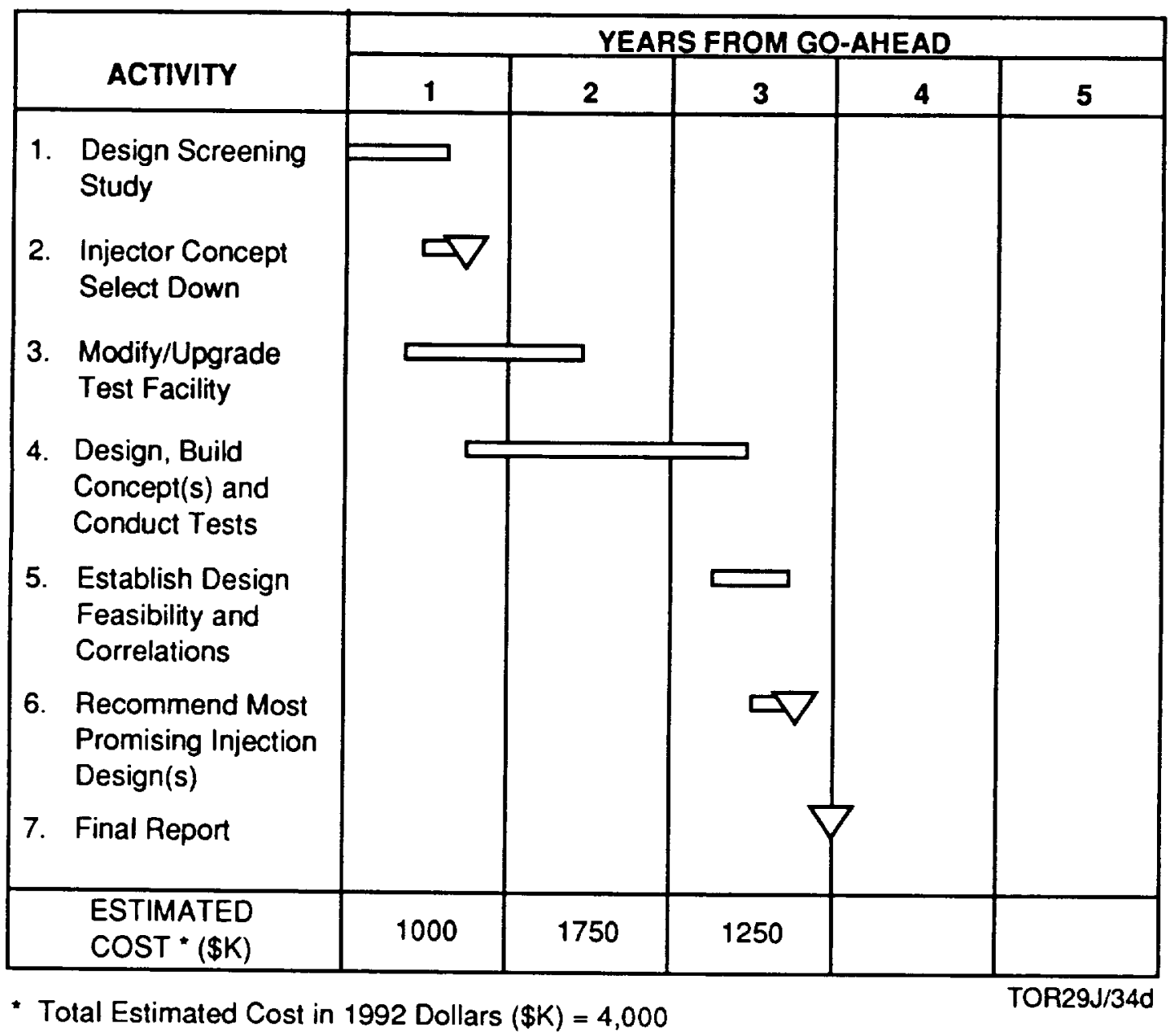





\section{TECHNOLOGY DEVELOPMENT PLAN ELEMENT}

PROGRAM No.: 6

ISSUE: Feed System/Turbopump Design

DEVELOPMENT PHASE: Exploratory Development

TITLE: Common Multipropellant Feed System/Turbopump Design Feasibility Study

OBJECTIVE: Establish feasibility and identify promising feed system/turbopump design(s) that can operate efficiently with more than one Mars in situ-based fuels over a wide operating range.

MISSION IMPACT: Can influence the engine thrust-to-weight ratio that affects overall mission mass and ISPP requirements.

APPROACH: Design and experimental demonstration tasks which investigates feed system/ turbopumps designs that efficiently supply (pump) more than one fuel of interest over a wide operating range.

1. Design screening study.

2. Select promising feed system/turbopump design concepts for further study.

3. Modify/upgrade test facility.

4. Build and test candidate feed system design concept(s).

5. Establish feasibility of common feed system/turbopump design(s) and recommend most promising design concept(s), if possible.

OUTPUTS/RESULTS: Establish the feasibility of common feed system/turbopump design options. Recommendations, if possible, of the most promising design with supporting engineering data.

\section{SPECIAL FACILITIES/COMMENTS:}

- Highly flexible feed system/turbopump development test facility with extensive instrumentation required. 

Title: 6. Common Multipropellant Feed System Turbopump Design Feasibility Study

- SCHEDULE/COST -

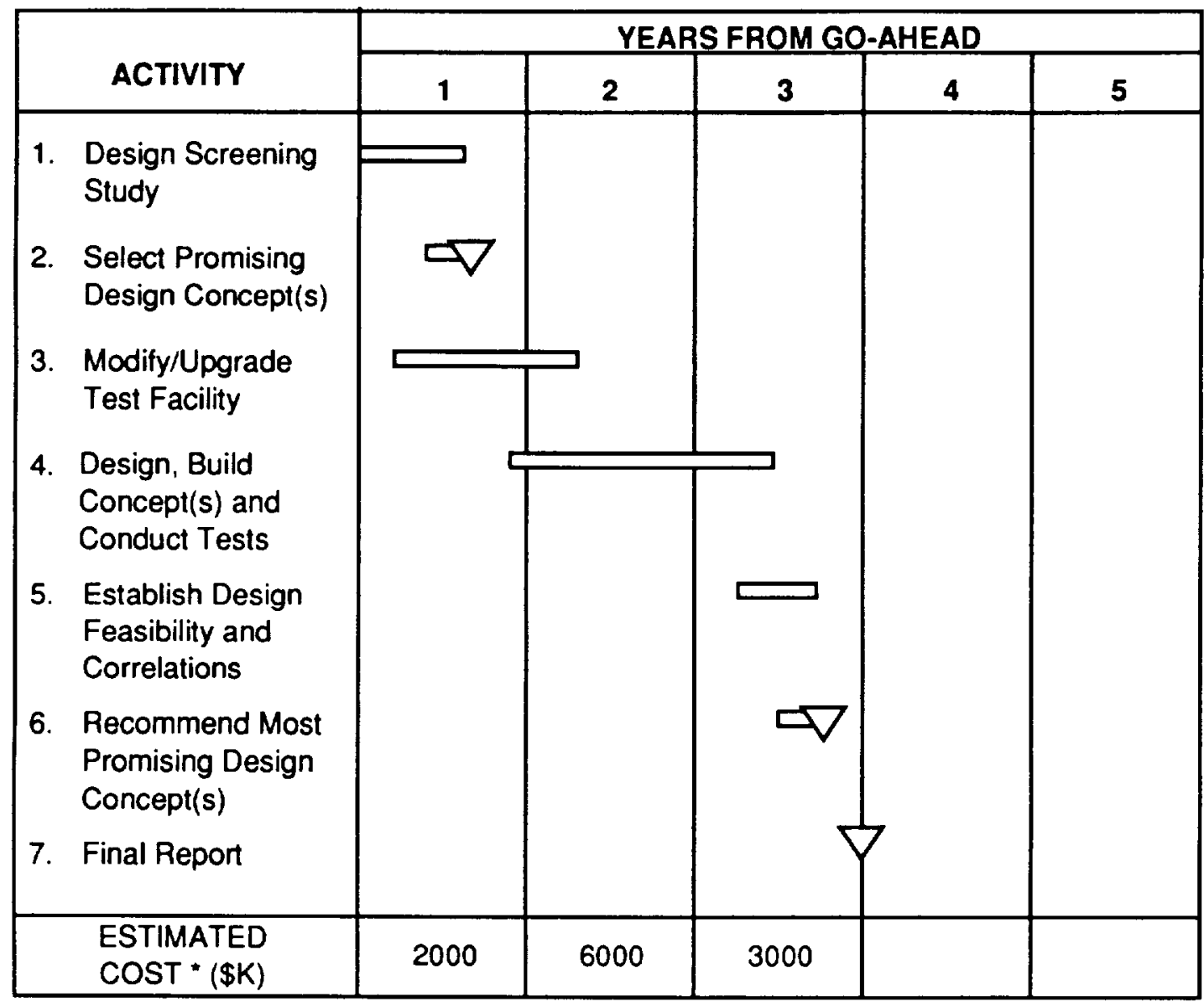

- Total Estimated Cost in 1992 Dollars $(\$ K)=11,000$ 



\section{TECHNOLOGY DEVELOPMENT PLAN ELEMENT}

PROGRAM No.: 7

ISSUE: Thrust Chamber Design

DEVELOPMENT PHASE: Exploratory Development

TITLE: Common Thrust Chamber Design Feasibility Study

OBJECTIVE: Establish feasibility and identify promising thrust chamber design(s) that can operate with more than one Mars in situ-based propellant combination over a wide operating range.

MISSION IMPACT: Addresses a critical Mars tripropellant engine design issue. This study can impact the engine systems thrust-to-weight ratio and performance that affects overall mission mass and ISPP requirements.

APPROACH: Design and experimental demonstration tasks that investigate common thrust chamber design option(s) that can use more than one in situ propellant over a wide operating range.

1. Design screening study.

2. Select promising thrust chamber design concept(s) for further study.

3. Modify/upgrade test facility.

4. Build and test candidate thrust chamber design concept(s).

5. Establish feasibility of thrust chamber design(s) and recommend most promising concepts, if possible.

OUTPUTS/RESULTS: Establish the feasibility of common propellant cooled thrust chamber design option(s), if possible. Recommendations, if possible, of the most promising design concept(s) with supporting engineering data.

\section{SPECIAL FACILITIES/COMMENTS:}

- Flexible breadboard subscale engine test facility with supporting instrumentation is required. 

Title: 7. Common Thrust Chamber Design Feasibility Study

- SCHEDULE/COST -

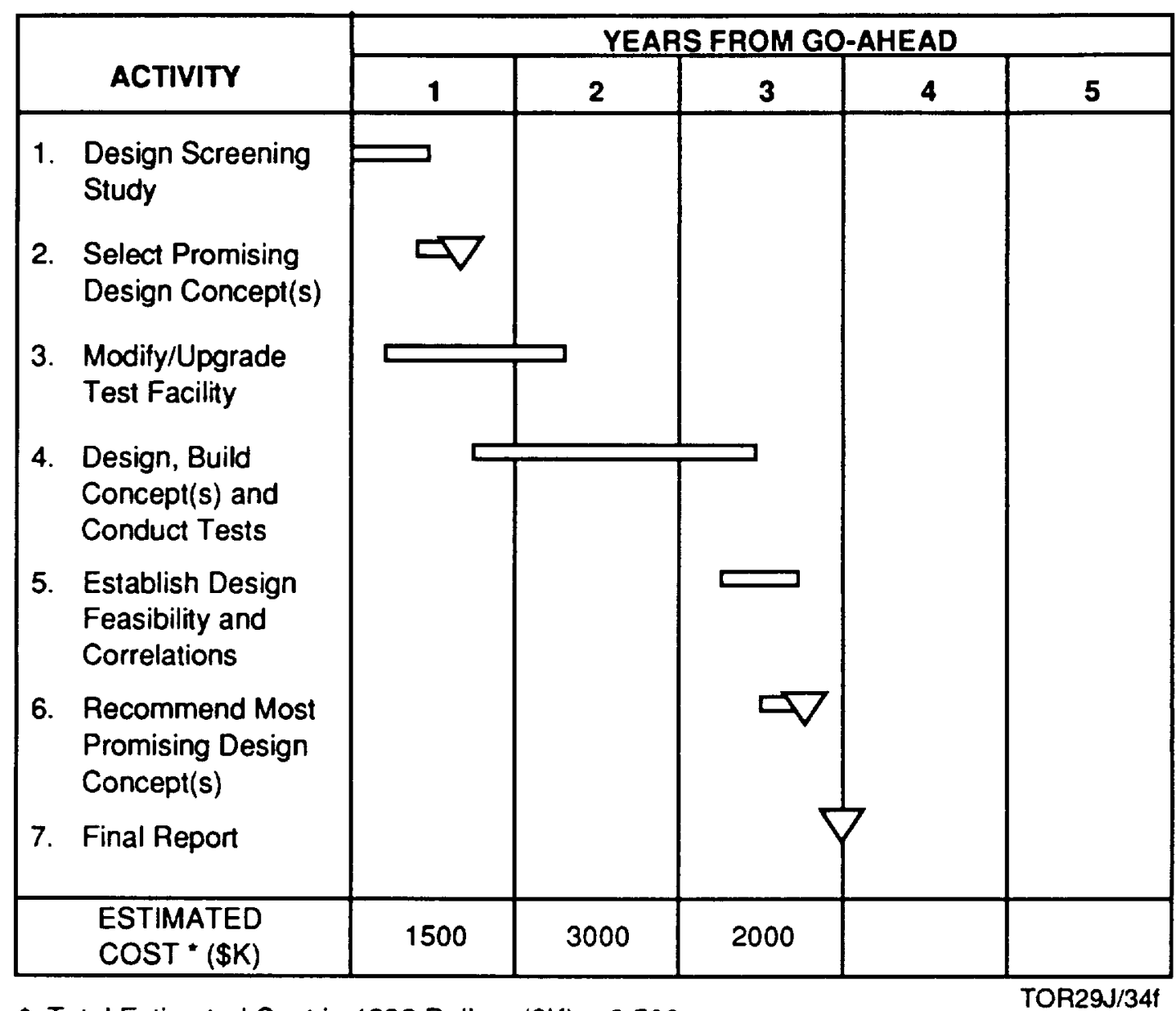

- Total Estimated Cost in 1992 Dollars $(\$ K)=6,500$ 



\section{TECHNOLOGY DEVELOPMENT PLAN ELEMENT}

PROGRAM No.: 8

ISSUE: Gas Generator Design

DEVELOPMENT PHASE: Exploratory Development

TITLE: LOX/CO Gas Generator Design Feasibility Study

OBJECTIVE: Establish feasibility and identify LOX/CO gas generator design(s) that can operate over a wide range of operating conditions.

MISSION IMPACT: Addresses a critical LOX/CO gas generator (GG) cycle engine design. If feasible, such engine systems may be possible with high thrust-to-weight characteristics that impact overall mission mass and ISPP requirements.

APPROACH: Design and experimental investigation tasks that examine LOX/CO gas generator design concept, such as a - stoichmotric gas generator design, which can operate over a wide range.

1. Design concept screening study.

2. Select promising GG design concept(s).

3. Modify/upgrade test facility.

4. Build and test candidate GG design concept(s).

5. Establish feasibility of such design(s) and recommend most promising concept(s), if possible.

OUTPUTS/RESULTS: Establish the feasibility of LOX/CO GG design option(s), if possible. Recommendations, if possible, of the most promising design concept(s) with supporting engineering data.

SPECIAL FACILITIES/COMMENTS:

- Burner/chamber test facility with support instrumentation is required. 

Title: 8. LOX/CO Gas Generator Design Feasibility Study

- SCHEDULE/COST -

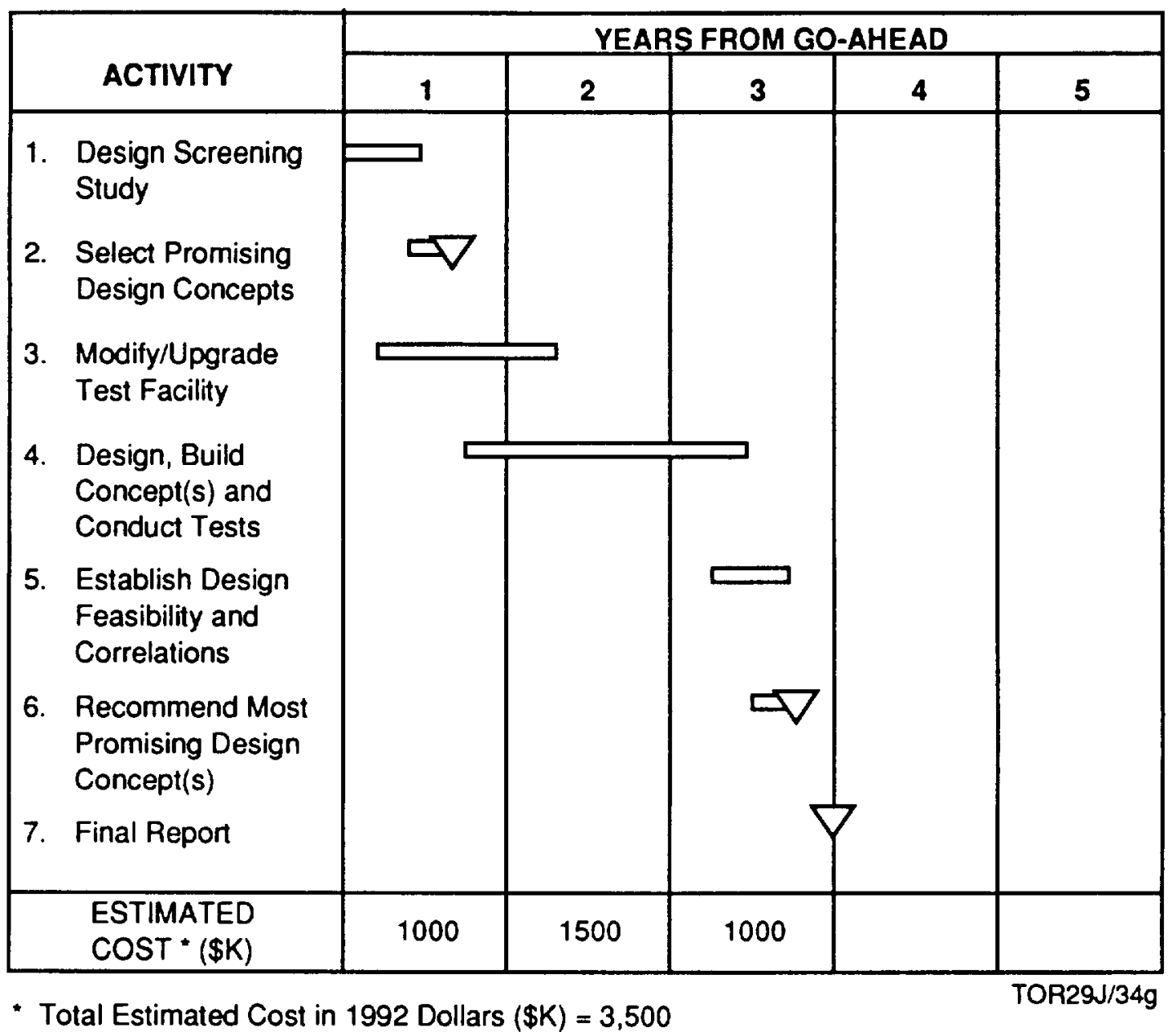





\section{TECHNOLOGY DEVELOPMENT PLAN ELEMENT}

PROGRAM No.: 9

ISSUE: System Control/Health Monitoring

DEVELOPMENT PHASE: Exploratory Development

TITLE: Common Control/Health Monitoring System Design Feasibility Study

OBJECTIVE: Establish feasibility and identify promising common control/health monitoring system(s) that can operate with numerous in situ Mars propellant combinations for various engine system operating modes.

MISSION IMPACT: Addresses a critical Mars tripropellant engine design issue. Can impact engine propellant combination options and mission options.

APPROACH: Identify common control/health monitoring system design issues. Identify promising system architecture option(s) and candidate system design(s) through real-time simulation.

OUTPUTS/RESULTS: Establish the feasibility and identify promising design approaches, if possible. Provide support engineering data and development plans of promising design concept option(s).

SPECIAL FACILITIES/COMMENTS:

- Real time engine control simulation facility is required. 

Title: 9. Common Control/Health Monitor System

Design Feasibility Study

- SCHEDULE/COST -

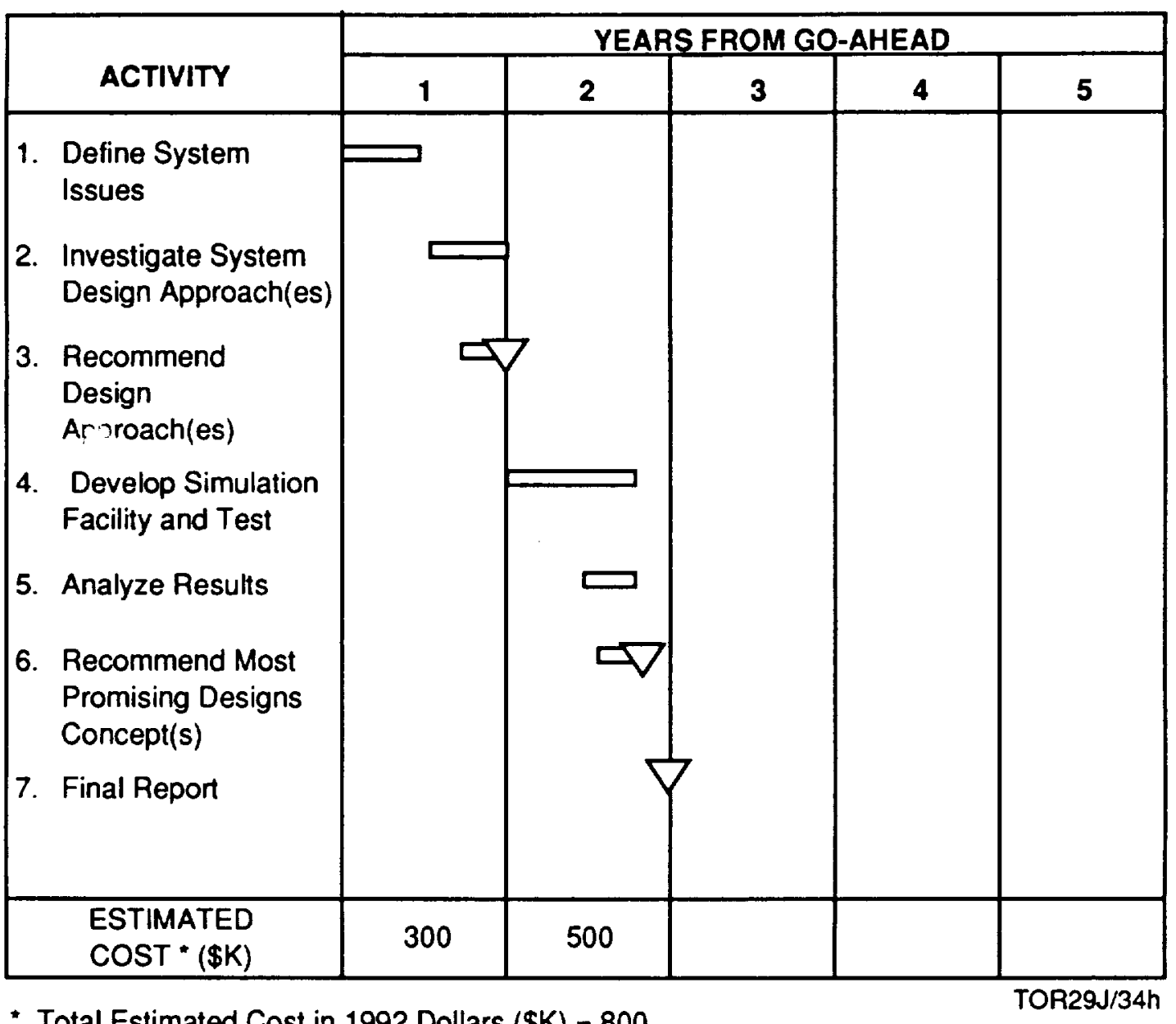

- Total Estimated Cost in 1992 Dollars $(\$ K)=800$ 



\section{TECHNOLOGY DEVELOPMENT PLAN ELEMENT}

PROGRAM No.: 10

ISSUE: Propellant Tank Design

DEVELOPMENT PHASE: Exploratory Development

TITLE: Common Propellant Tank Design and Supporting Operations Study

OBJECTIVE: Establish feasibility and identify common propellant tank design(s) and supporting operation requirements and design approaches, such as for resupply. Identification of high payoff alternative tank designs will also be investigated.

MISSION IMPACT: Can have a major impact on MTV designs, overall mission mass and ISPP requirements.

APPROACH: System analysis design and experimental study which:

1. Establishes in situ tank requirements and issues.

2. Screens design options and their supporting operations requirements.

3. Demonstrates subscale tank design options and supporting operations under simulated environmental conditions.

OUTPUTS/RESULTS: Recommendation of the most promising tank design(s) and supporting operational approach(s) with supporting engineering data.

SPECIAL FACILITIES/COMMENTS:

- Propellant storage/handling and an adequate long-term space simulation facility is required. 

Title: 10. Common Propellant Tank Design and Supporting Operations Study

- SCHEDULE/COST -

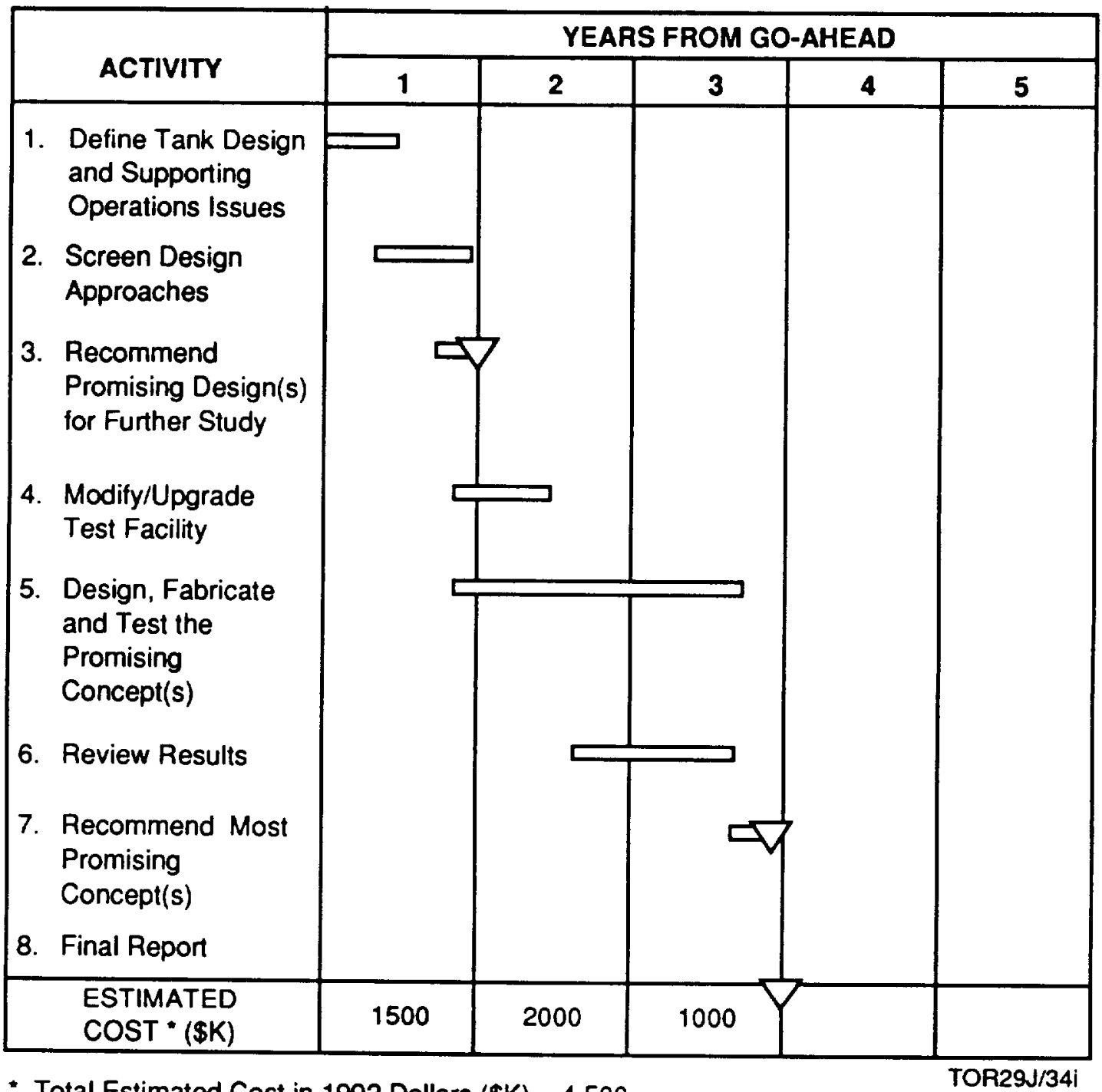

- Total Estimated Cost in 1992 Dollars $(\$ K)=4,500$ 



\section{TECHNOLOGY DEVELOPMENT PLAN ELEMENT}

PROGRAM No.: 11

ISSUE: Nozzle Design

DEVELOPMENT PHASE: Exploratory Development

TTTLE: Lightweight, Compact High Area Ratio Nozzle Design Study

OBJECTIVE: Identify lightweight compact high area ratio nozzle designs for Mars in situ tripropellant engine systems employing LOX/CO as one of its two propellant combinations.

MISSION IMPACT: Addresses a critical design issue of Mars in situ tripropellant engine systems that employ LOX/CO. Such advanced nozzle designs are required to reduce engine system mass and stowed volume requirements. This impacts overall mission mass and LEO vehicle support options and ISPP requirements.

APPROACH: Systems analysis, design and experimental demonstration of promising lightweight, compact (while stowed) nozzle design(s) will be undertaken. High area ratio nozzle design option(s) for such engine systems including translated and alternate nozzle concepts will be examined. Promising design option(s) will be demonstrated by subscale high pressure gas and breadboard engine testing, respectively.

OUTPUTS/RESULTS: Identification of promising nozzle design concept(s) with supporting engineering data.

SPECIAL FACILITIES/COMMENTS:

- A hot high pressure gas facility as well as a subscale breadboard engine system/test facility are required. 

Title: 11. Lightweight, Compact High Area Ratio

Nozzle Design Study

- SCHEDULE/COST -

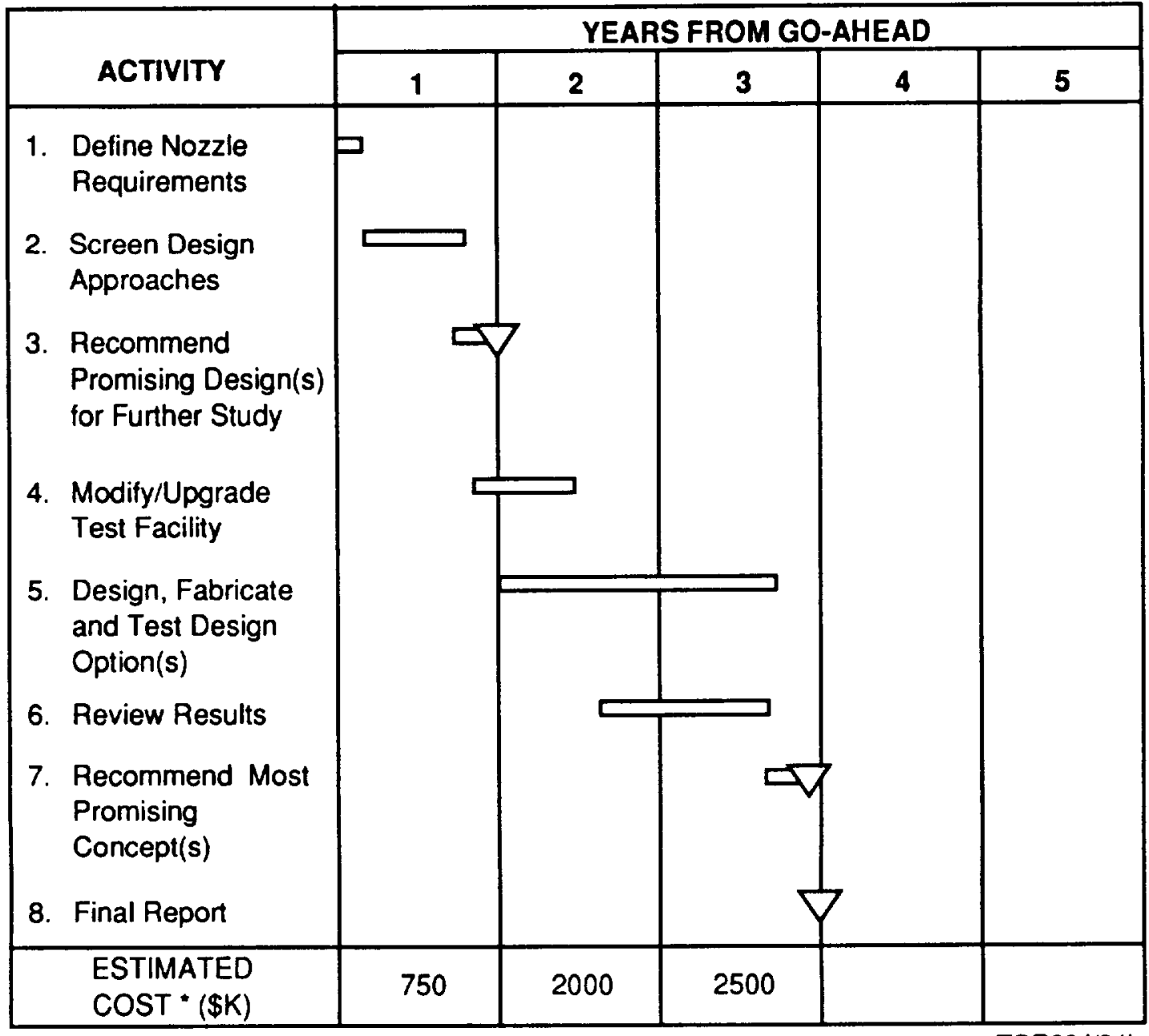

* Total Estimated Cost in 1992 Dollars $(\$ K)=5,250$ 



\section{TECHNOLOGY DEVELOPMENT PLAN ELEMENT}

PROGRAM No.: 12

ISSUE: Engine System Demonstration

DEVELOPMENT PHASE: Prototype Demonstration

TTTLE: Mars Tripropellant Subscale Engine System Demonstration Program

OBJECTIVE: Successfully demonstrate and establish feasibility of a subscale $(15,000-60,000 \mathrm{lbf}$ thrust) candidate Mars in situ propellant-based tripropellant engine system design concept.

MISSION IMPACT: Will verify feasibility and characterize a Mars tripropellant engine design concept. This will lead to more accurate assessment of Mars in situ propellantbased propulsion system and mission options.

APPROACH: Design, fabricate, and ground test a subscale candidate Mars in situ propellantbased tripropellant engine system design concept. Verify both design and offdesign performance and reliability for such an engine system for its various operating modes.

OUTPUTS/RESULTS: Engineering data characterizing the engine system that can support a flight system development decision.

SPECIAL FACILITIES/COMMENTS:

- Subscale engine test facility. 

Title: 12. Mars Tripropellant Subscale Engine System

Demonstration Program

- SCHEDULE/COST -

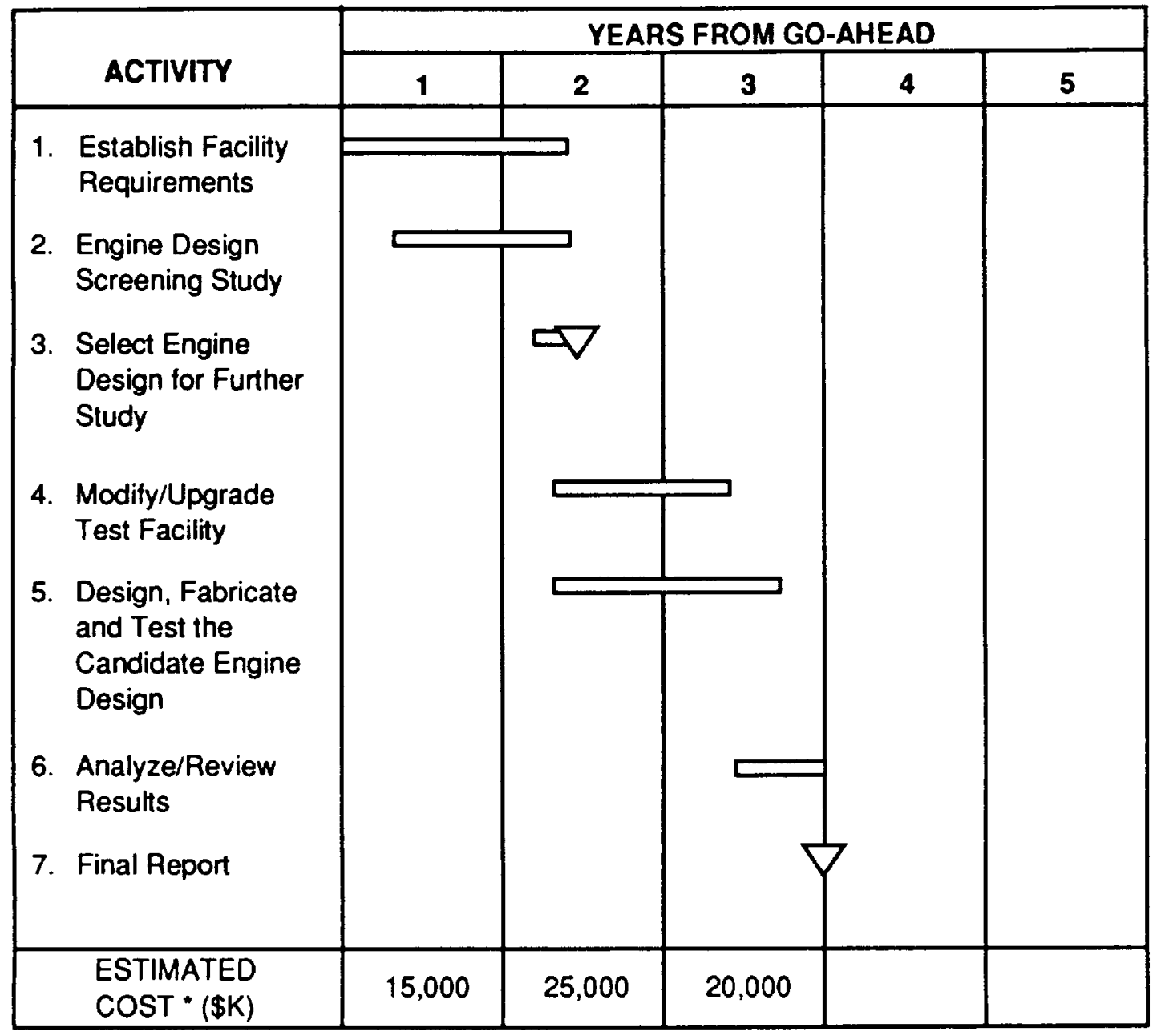

- Total Estimated Cost in 1992 Dollars $(\$ K)=60,000$ 



\section{TECHNOLOGY DEVELOPMENT PLAN ELEMENT}

PROGRAM No.: 13

ISSUE: Preliminary Design/System Integration

DEVELOPMENT PHASE: System Engineering

TITLE: Preliminary Mars In situ Propellant Mission/Vehicle/Engine System Design Studies

OBJECTIVE: Assesses the impact of engine technology data as it becomes available, on evolving Mars in situ propellant-based mission, vehicle and engine system designs.

MISSION IMPACT: Will allow for more accurate assessment of Mars in situ propellant-based mission options as engine technology data becomes available.

APPROACH: An ongoing preliminary system design study, during the fundamental research and exploratory development engine development phases, which assesses mission options, vehicle and engine systems design concepts as engine technology data becomes available.

OUTPUTS/RESULTS: Mission, vehicle and engine system preliminary design (engineering and cost) data as Mars tripropellant engine technology matures.

\section{SPECIAL FACILITIES/COMMENTS:}

- None. 


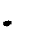


Title: 13. Preliminary Mars In Situ Propellant Mission/Vehicle/Engine System Design Studies

- SCHEDULE/COST -

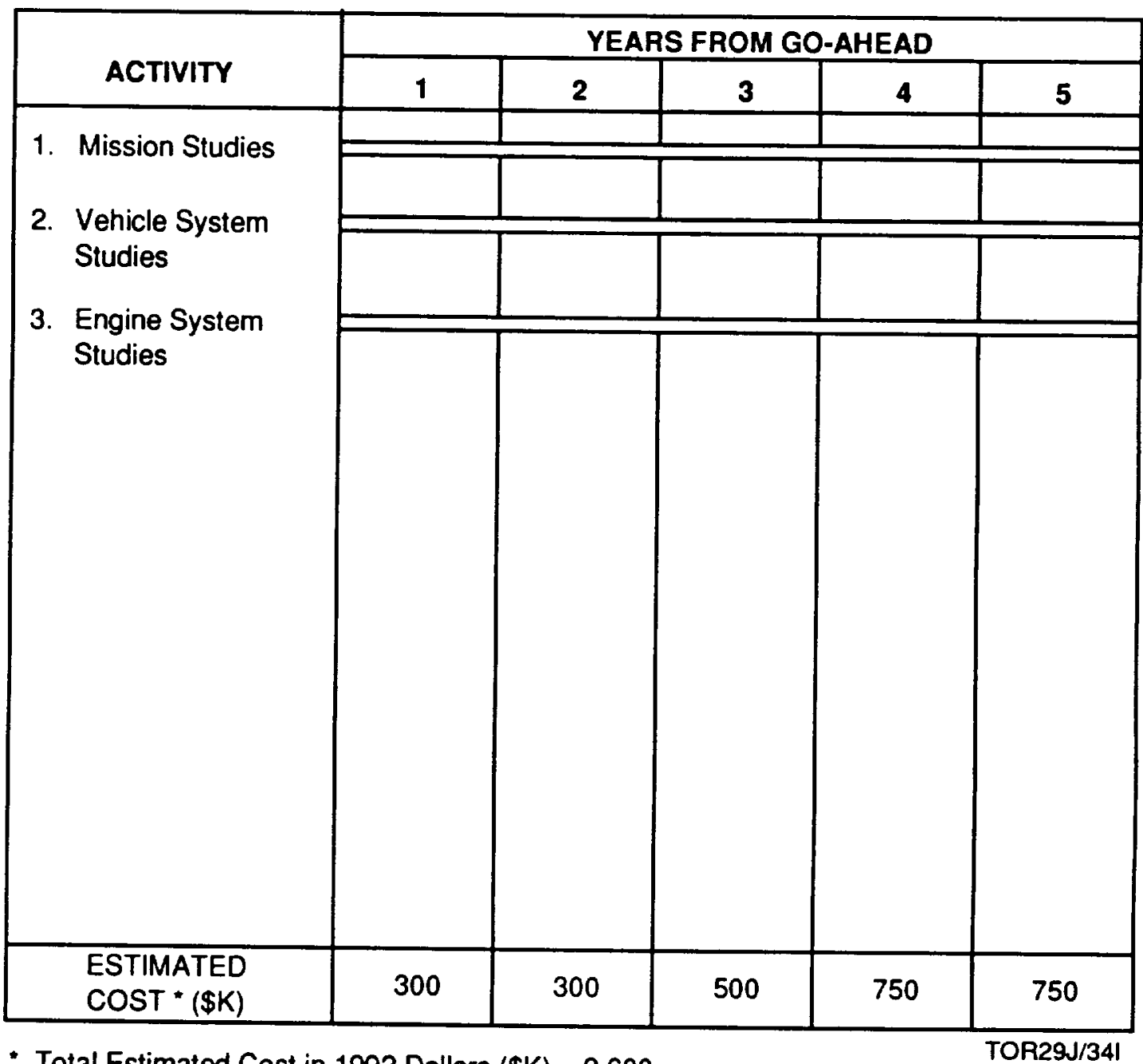

- Total Estimated Cost in 1992 Dollars $(\$ K)=2,600$ 


\section{REPORT DOCUMENTATION PAGE}

Public reporting burden for this collection of intormation is estimated to averege $t$ hour per responee, inclucing the time lor revienmin instructons. searching existing data sources. gathenng and maintaining the dasa needed, and completing and reviewing the collection of informevion. Send comments regarding this burden extimate or any ather aspect of this

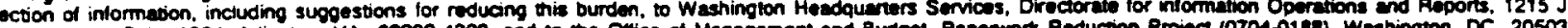

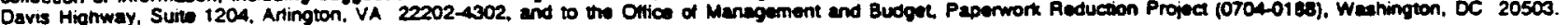

\begin{tabular}{|l|c|c|}
\hline 1. AGENCY USE ONLY (Leave blank) & $\begin{array}{r}\text { 2. AEPOAT DATE } \\
\text { June, 1992 }\end{array}$ & $\begin{array}{r}\text { 3. REPORT TYPE AND DATES COVEAED } \\
\text { Final Contractor Report }\end{array}$ \\
\hline
\end{tabular}

4. TITLE ANQ SUBTTILE

Engine System Assessment Study Using Martian Propellants - Final Report

6. AUTHOR(S)

D. Pelaccio, M. Jacobs, J. Collins, and C. Scheil

7. PERFOAMING ORgANIZATION NAME(S) AND ADORESS(ES)

Science Applications International Corporation

21151 Western Avenue

Torrance California 90501

9. SPONSORING/MONITORING AGENCY NAMES(S) AND ADDRESS(ES)

National Aeronautics and Space Administration

Lewis Research Center

Cleveland, Ohio 44135-3191

11. SUPPLEMENTARY NOTES

Project Manager, Michael L. Meyer, Space Propulsion Technology Division, NASA Lewis Research Center

12b. DISTRIBUTION CODE

Unclassified - Unlimited

Subject Category

13. ABSTRACT (Maximum 200 words)

Recent studies have shown that there can be substantial advantages in using in situ propellants for fast transfers to, and explorations of, Mars when compared to chemical systems that use Earth-based propellants. Using vehicles that are powered by systems that use Martian resources has the potential to reduce low-earth-orbit mass requirements as well as increase mobility on the surface of Mars. A single propulsion system that can use two or more candidate propellant combinations, such as $\mathrm{LOX} / \mathrm{H}_{2}, \mathrm{LOX} / \mathrm{CH}_{4}$ and $\mathrm{LOX} / \mathrm{CO}$, could best leverage this exploration option. Design of such a propulsion system is challenging due to its requirements that it be inherently compatible with numerous candidate propellants, as well as operate efficiently over a large range of conditions.

A study was undertaken that identified and characterized promising chemical propulsion system designs that use two or more of the following propellant combinations: $\mathrm{LOX} / \mathrm{H}_{2}, \mathrm{LOX} / \mathrm{CH}_{4}$ and LOX/CO. Propulsion system requirements were established and expander and gas generator cycle tripropellant LOX-cooled engine systems were defined that used as much common hardware as possible. Overall mission impacts were quantified and Mars transfer vehicle propellant tank design strategies were evaluated. Critical propulsion system technologies and corresponding maturation plans are identified that are required to support development of such systems.

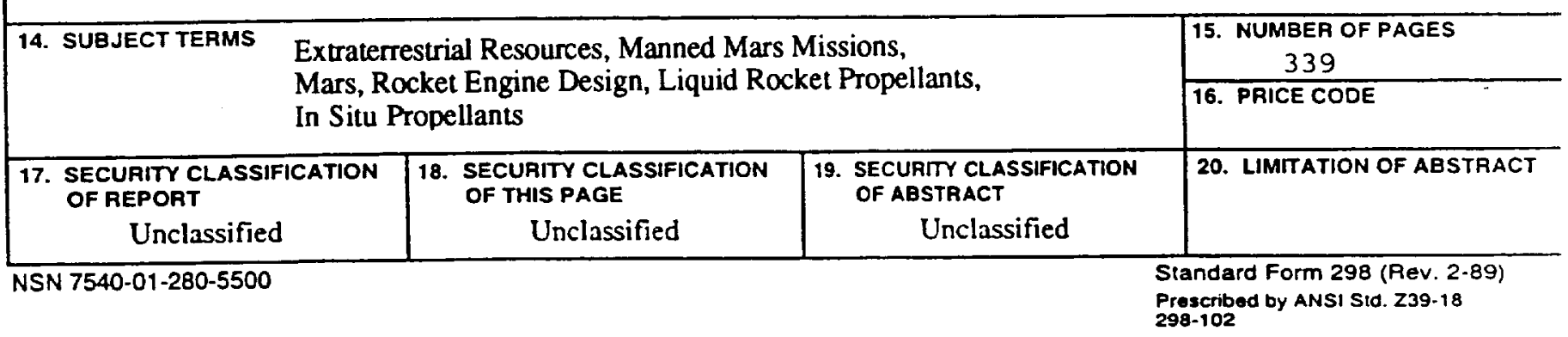



